NUREG-0980

Vol. 1, No. 3

\title{
Nuclear Regulatory
}

Legislation

103d Congress

RECEIVED

\section{U.S. Nuclear Regulatory Commission}

\section{Office of the General Counsel}

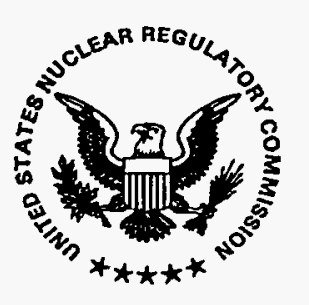

DISTRIBUTION OF THIS DOCUMENT IS UNLMITED 


\section{AVAILABILITY NOTICE}

Availability of Reference Materials Cited in NRC Publications

Most documents cited in NRC publications will be available from one of the following sources:

1. The NRC Public Document Rioom, 2120 L Street, NW., Lower Level, Washington, DC 20555-0001

2. The Superintendent of Documents, U.S. Government Printing Office, P. O. Box 37082, Washington, DC 20402-93213

3. The National Technical Information Service, Springfield, VA 22161-0002

Although the listing that follows represents the majority of documents cited in NRC publications, it is not intended to be exhaustive.

Referenced documents available for inspection and copying for a fee from the NRC Public Document Room include NRC correspondence and internal NRC memcranda; NRC bulletins, circulars, information notices, ins,pection and investigation notices; licensee event reports; vendor reports and correspondence; Commission papers; and applicant and licensee documents and correspondence.

The following documents in the NUIREG series are available for purchase from the Government Printing Office: formal NRC staff and contractor reports, NRC-sponsored conference proceedings, international agreemerit reports, grantee reports, and NRC booklets and brochures. Also available are regulatory guides, NRC regulations in the Ccide of Federal Regulations, and Nuclear Regulatory Commission Issuances.

Documents available from the National Technical Information Service include NUREG-series reports and technical reports prepared by other Federal agencies and reports prepared by the Atomic Energy Commission, forerunner agency to the Nuclear Regulatory Commission.

Documents available from public and special technical libraries include all open literature items, such as books, journal articles, and transactions. Federal Register notices, Federal and State legislation, and congressional reports can usually be obtained from these libraries.

Documents such as theses, disserlations, foreign reports and translations, and non-NRC conference proceedings are available for purchase from the organization sponsoring the publication cited.

Single copies of NRC draft report:s are available free, to the extent of supply, upon written request to the Office of Administriation, Distribution and Mail Services Section, U.S. Nuclear Regulatory Commission. Washington DC 20555-0001.

Copies of industry codes and stardards used in a substantive manner in the NRC regulatory process are maintained at the NRC; Library, Two White Flint North, 11545 Rockville Pike, Rockville, MD 20852-2738, for use by the public. Codes and standards are usually copyrighted and may be purchased from the originating organization or, if they are American National Standards, from the American Netional Standards Institute, 1430 Broadway, New York, NY 10018-3308. 
NUREG-0980

Vol. 1, No. 3

\title{
Nuclear Regulatory Legislation
}

\author{
103d Congress
}

Date Published: August 1995

Office of the General Counsel

U.S. Nuclear Regulatory Commission

Washington, DC 20555-000I

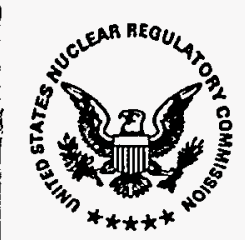

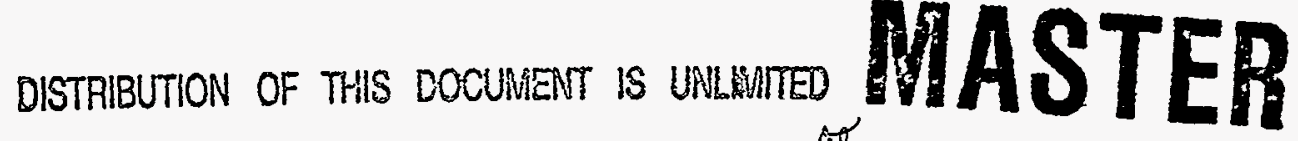


For the U.S. Government Printing Office

- Superintendent of Documents, Mail Stop: SSOP, Washington, DC 20402-9328

$3 . .+2 \%:$ ISBN $0-16-048397-2$ 


\section{DISCLAIMER}

This report was prepared as an account of work sponsored by an agency of the United States Government. Neither the United States Government nor any agency thereof, nor any of their employees, make any warranty, express or implied, or assumes any legal liability or responsibility for the accuracy, completeness, or usefulness of any information, apparatus, product, or process disclosed, or represents that its use would not infringe privately owned rights. Reference herein to any specific commercial product, process, or service by trade name, trademark, manufacturer, or otherwise does not necessarily constitute or imply its endorsement, recommendation, or favoring by the United States Government or any agency thereof. The views and opinions of authors expressed herein do not necessarily state or reflect those of the United States Government or any agency thereof. 


\section{DISCLAIMER}

Portions of this document may be illegible in electronic image products. Images are produced from the best available original document. 


\section{FOREWORD}

This compilation of statutes and material pertaining to nuclear regulatory legislation through the 103d Congress, 2nd Session, has been prepared by the Office of the General Counsel, U.S. Nuclear Regulatory Commission, with the assistance of staff, for use as an internal resource document. Persons using this document are placed on notice that it may not be used as an authoritative citation in lieu of the primary legislative sources. Furthermore, while every effort has been made to ensure the completeness and accuracy of this material, neither the United States Government, the Nuclear Regulatory Commission, nor any of their employees makes any expressed or implied warranty or assumes liability for the accuracy or completeness of the material presented in this compilation.

If you have any questions concerning this compilation, please contact Christine Pierpoint, Legislative Specialist, Office of the General Counsel, U.S. Nuclear Regulatory Commission, Washington, DC 20555-0001. 


\section{TABLE OF CONTENTS}

\section{VOLUME 1}

1. Atomic Energy Act of 1954

2. Energy Reorganization Act of 1974

- Reorganization Plan No. 3 of 1970 (EPA)

- Reorganization Plan No. 1 of 1980 (NRC)

- Executive Order No. 11834, Activation of the NRC

3. Low-Level Radioactive Waste Policy Amendments Act of 1985 (Title I)

(Title II-Compacts: SEE Volume II)

4. Nuclear Waste Policy Act of 1982, as Amended

5. Uranium Mill Tailings

6. NRC User Fees

7. NRC Authorizations

8. Inspector General Act of 1978, as Amended

9. Administrative Procedure Act

- Subchapter II - Administrative Procedure

- Subchapter III - Negotiated Rulemaking Procedure

- Subchapter IV - Alternative Means to Dispute Resolution in the Administrative Process

- Chapter 6-The Analysis of Regulatory Functions

- Chapter 7-Judicial Review

Federal Advisory Committee Act

\section{VOLUME 2}

1. Commissioner Tenure

- Tenure of AEC Commissioners

- Tenure of NRC Commissioners

2. NRC Appropriations

- Tabulation of NRC Appropriations by Fiscal Year

3. Chief Financial Officers Act of 1990

4. Low-Level Radioactive Waste Policy Amendments Act of 1985 (Title II-Compacts)

- Northwest Interstate Compact on Low-Level Radioactive Waste Management Compact

- Southeast Interstate Low-Level Radioactive Waste Management Compact

- Central Midwest Interstate Low-Level Radioactive Waste Compact 
- $\quad$ Midwest Interstate Low-Level Radioactive Waste Management Compact

- Rocky Mountain Low-Level Radioactive Waste Management Compact

- Northeast Interstate Low-Level Radioactive Waste Management Compact

5. Appalachian States Low-Level Radioactive Waste Compact Consent Act (P.L. 100-319)

6. Southwestern Low-Level Radioactive Waste Disposal Compact Consent Act (P.L. 100-712)

7. Clean Air Act of 1977, as Amended (Selected Sections)

8. Federal Water Pollution Control Act of 1972 (Sect. 511)

9. National Environmental Policy Act of $\mathbf{1 9 6 9}$

10. Hazardous Materials Transportation Act, as amended

11. West Valley Demonstration Project Act

12. Nuclear Non-Proliferation and Export Licensing Statutes:

- Nuclear Non-Proliferation Act of 1978 (P.L. 95-242)

- Nuclear Non-Proliferation Act of 1978-Exports of Low-Enriched Uranium (P.L. 96-280)

- Atomic Weapons and Special Nuclear Materials Rewards Act (P.L. 84-165)

- International Atomic Energy Agency Participation Act of 1957 and the Statute of the International Atomic Energy Agency (P.L. 85-177)

- $\quad$ EURATOM Cooperation of 1958 and Concurrent Resolution (P.L. 85-846)

- $\quad$ EURATOM Cooperation Act of 1958, Amendment (P.L. 93-88)

- International Security Assistance and Arms Export Control Act of 1976 (P.L. 94-329)

- International Security and Development Cooperation Act of 1980 (P.L. 96-533)

- International Security and Development Cooperation Act of 1981 (P.L. 97-113)

- Convention on the Physical Protection of Nuclear Material Implementation (P.L. 97-351)

- U.S.-Canada Free Trade Implementation Act of 1988 (P.L. 100-449); Title III; Sect. 305

13. Miscellaneous:

- Nuclear Non-Proliferation Treaty

- Convention on the Physical Protection of Nuclear Material

- Convention on Early Notification of a Nuclear Accident

- Convention on Assistance in the Case of a Nuclear Accident or Radiological Emergency

- Additional Protocol to the Treaty for the Prohibition of Nuclear Weapons in Latin America

- United States List of Agreements for Peaceful Nuclear Cooperation

- Agreements for Cooperation in the Use of Atomic Energy

- IAEA Supply Agreements

- Agreement between the United States and the International Atomic Energy Agency for the Application of Safeguards in the United States 
- Convention of the Prevention of Marine Pollution by Dumping of Wastes and Other Matters

- Executive Order 10841 (re: International Atomic Energy Cooperation)

- Executive Order 10956 (re: Amndt. to E.O. 10841)

- Executive Order 12058 (re: Functions Relating to Nuclear Non-Proliferation)

- Executive Order 12658 (re: President's Commission on Catastrophic Nuclear Accidents)

- Executive order 12730 (re: Continuation of Export Control Regulations) 
1 


\section{TITLE I-ATOMIC ENERGY \\ CHAPTER 1 \\ DECLARATION, FINDINGS, AND PURPOSE}

PAGE USC

42 USC

Sec.

Sec. 1. Declaration. ............................. 2011

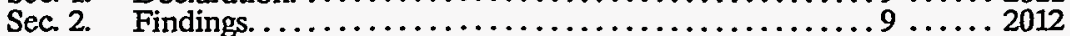

Sec. 3. Purpose. ................................. 2013

\section{CHAPTER 2 \\ DEFINITIONS}

Sec. 11. Definitions.

11

2014

\section{CHAPTER 3 \\ ORGANIZATION}

Sec. 23. Office.............................. $17 \ldots 2033$

Sec. 24. General Manager, Deputy and ........................... 17 .... 2034

Assistant General Managers.

Sec. 25. Divisions, Offices, and Positions ................. 18 .... 2035

Sec. 26. Repealed. ................................ 19

Sec. 27. Repealed. ..............................19

Sec. 28. Appointment of Army, Navy, or Air Force Officers .. $19 \ldots 2038$

Sec. 29. Advisory Committee on Reactor Safeguards ........2 20.... 2039

\section{CHAPTER 4}

RESEARCH

Sec. 31. Research Assistance ......................... 20 ..... 2051

Sec. 32. Research by the Commission .....................22 ..... 2052

Sec. 33. Research for Others .............................22 $\ldots \ldots \ldots 2053$

\section{CHAPTER 5 \\ PRODUCTION OF SPECIAL NUCLEAR MATERIAL}

Sec. 41. Ownership and Operation of Production Facilities ...22 ..... 2061

Sec. 42. Irradiation of Materials .....................23 .... 2062

Sec. 43. Acquisition of Production Facilities ....................23 $\ldots \ldots \ldots 2063$

Sec. 44. Disposition of Energy .....................23 ..... 2064 
Sec. 51. Special Nuclear Material ......................24 ..... 2071

Sec. 53. Domestic Distribution of Special Nuclear Material. ... $24 \ldots \ldots 2073$

Sec. 54. Foreign Distribution of Special

Nuclear Material ..............................2 27 ..... 2074

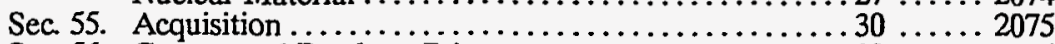

Sec. 56. Guaranteed Purchase Prices ..................... 30 ..... 2076

Sec. 57. Prohibition ..................................... 2077

Sec. 58. Review ...................................... 2078

\section{CHAPTER 7 \\ SOURCE MATERIAL}

Sec. 61. Source Material ............................ 33 ..... 2091

Sec. 62. License for Transfers Required .............................. 2092

Sec. 63. Domestic Distribution of Source Material ............ 34 ...... 2093

Sec. 64. Foreign Distribution of Source Material .................... 2094

Sec. 65. Reporting .............................. $35 \ldots \ldots .2095$

Sec. 66. Acquisition .................................... 2096

Sec. 67. Operations on Lands Belonging to the United ...... 35 ..... 2097 States.

Sec. 68. Public and Acquired Lands ...................... 2098

Sec. 69. Prohibition ........................................ 2099

CHAPTER 8

\section{BYPRODUCT MATERIAL}

Sec. 81. Domestic Distribution ........................ 2111

Sec. 82. Foreign Distribution of Byproduct Material ................. 38 .... 2112

Sec. 83. Ownership and Custody of Certain Byproduct $\ldots \ldots 38 \ldots \ldots 2113$

Sec. 84. $\begin{aligned} & \text { Auterial and Disposal Sites. } \\ & \text { Byproduct Material. }\end{aligned}$

\section{CHAPTER 9 \\ MILITARY APPLICATION OF ATOMIC ENERGY}

Sec. 91. Authority ............................. $42 \ldots \ldots .2121$

Sec. 92. Prohibition $\ldots \ldots \ldots \ldots \ldots \ldots \ldots \ldots \ldots \ldots \ldots \ldots \ldots \ldots, 43 \ldots \ldots .2122$ 


\section{CHAPTER 10 ATOMIC ENERGY LICENSES}

PAGE USC

42 USC

Sec.

Sec.101. License Required .....................43 .... 2131

Sec.102. Utilization and Production Facilities ....................... 43132

for Industrial or Commercial Purposes.

Sec.103. Commercial Licenses ...................... $44 \ldots \ldots 2133$

Sec.104. Medical Therapy and Research and Development ...45 ..... 2134

Sec.105. Antitrust Provisions ...........................46 ..... 2135

Sec.106. Classes of Facilities .......................... 48 ..... 2136

Sec.107. Operators' Licenses .................................. 2138

Sec.108. War or National Emergency ................... 49 ..... 2138

Sec.109. Component and other Parts of Facilities ..........49 ..... 2139

Sec.110. Exclusions .................................5 ..... 2140

Sec.111. Distribution by the Department of Energy ...........50 ..... 2141

\section{CHAPTER 11 \\ INTERNATIONAL ACTIVTIES}

Sec.121. Effect of International Arrangements $\ldots . \ldots \ldots \ldots . . .51 \ldots . .2151$

Sec.122. Policies Contained in International

Sec.123. Cooperation With Öther Nations ........................... 2152

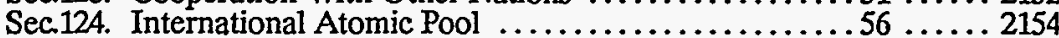

Sec.125. Cooperation With Berlin ......................... $56 \ldots \ldots .2153$

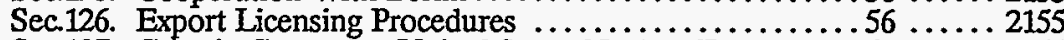

Sec.127. Criteria Governing United States Nuclear Exports ...61 ..... 2156

Sec.128. Additional Export Criterion and Procedures ........62 ..... 2157

Sec.129. Conduct Resulting in Termination of Nuclear Exports 63 ..... 2158

Sec.130. Congressional review Procedures .................64 ..... 2159

Sec.131. Subsequent Arrangements ......................... 2160

Sec.132. Authority to Suspend Nuclear Cooperation.............73 $\ldots \ldots .2160 \mathrm{~b}$

Sec.133. Consultation with DOD $\ldots \ldots \ldots \ldots \ldots \ldots \ldots \ldots \ldots .73 \ldots \ldots .2160$

Sec.134. Further restrictions on exports ........................... 2160d

\section{CHAPTER 12 \\ CONTROL OF INFORMATION}

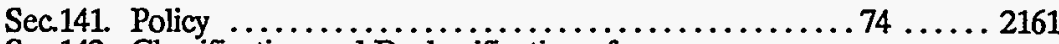

Sec.142. Classification and Declassification of

Restricted Data .......................... 75 ..... 2162

Sec.143. Department of Defense Participation .......................... 2163

Sec.144. International Cooperation ......................76 ...... 2164

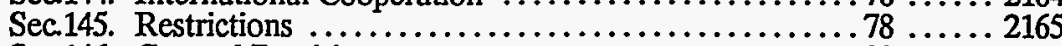

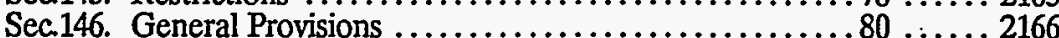

Sec.147. Safeguards Information ............................ 2167

Sec.148. Prohibition Against the Dissemination of

Certain Unclassified Information .............. $82 \ldots \ldots 2168$

Sec.149. Fingerprinting For Criminal History Record Checks .. 84 ...... 2169 


\section{CHAPTER 13 \\ PATENTS AND INVENTIONS}

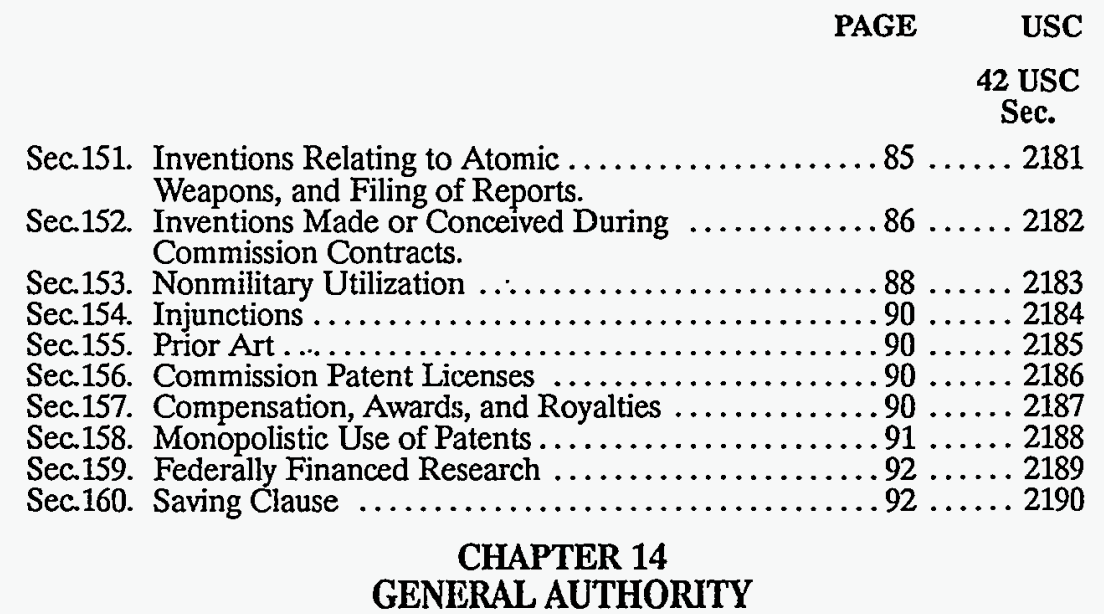

Sec.161. General Provisions ............................. 92 ..... 2201

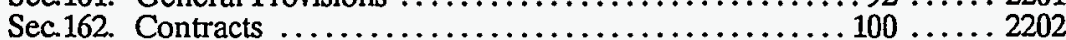

Sec.163. Advisory Committees .......................... $100 \ldots \ldots .2203$

Sec.164. Electric Utility Contracts..................... $101 \ldots \ldots .2204$

Sec.165. Contract Practices ................................. $101 \ldots \ldots .2205$

Sec.166. Comptroller General Audit .................. $101 \ldots \ldots .2206$

Sec.167. Claims Settlements .............................. 102 ...... 2207

Sec.168. Payments in Lieu of Taxes .................. 102 ..... 2208

Sec.169. No Subsidy ........................................ 102209

Sec.170. Indemnification and Limitation of. ................ 103 ...... 2210 Liability.

Sec.170A.Conflicts of Interest Relating to .............. 121 ... 2210a Contracts and other Arrangements

Sec.170B.Uranium Supply .......................... $121 \ldots . .2210 \mathrm{~b}$

\section{CHAPTER 15 \\ COMPENSATION FOR PRIVATE PROPERTY ACQUIRED}

Sec.171. Just Compensation ....................... $123 \ldots \ldots .2221$

Sec.172. Condemnation of Real Property ................. $123 \ldots \ldots .2222$

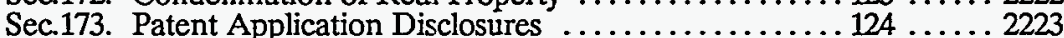

Sec.174. Attorney General Approval of Title ...................... 2224

\section{JUDICIAL REVIEW AND ADMINISTRATIVE PROCEDURE}

Sec.181. General .................................... 124 ...... 2231

Sec.182. License Applications .......................... 124 ...... 2232

Sec.183. Terms of Licenses ......................... $126 \ldots \ldots 2233$

Sec.184. Inalienability of Licenses ...................... $126 \ldots \ldots 2234$

Sec.185. Construction Permits and Operating Licenses ...... $127 \ldots \ldots .2235$

Sec.186 Revocation .............................. $127 \ldots \ldots .2236$

Sec.187. Modification of License............................ $128 \ldots \ldots .2237$

Sec.188. Continued Operation of Facilities ............... $128 \ldots \ldots .2238$

Sec.189. Hearings and Judicial Review ..................... $128 \ldots \ldots .2239$

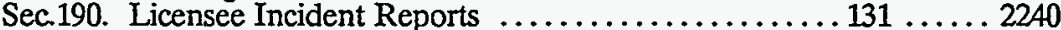

Sec.191. Atomic Safety and Licensing Board ............... $131 \ldots \ldots .2241$

Sec.192. Temporary Operating License ................ $131 \ldots \ldots .2242$

Sec.193. Licensing of Uranium Enrichment 


\section{CHAPTER 17 \\ JOINT COMMITTEE ON ATOMIC ENERGY}

PAGE

USC

135

42 USC

Sec.

\section{CHAPTER 18 \\ ENFORCEMENT}

Sec. 221. General Provisions .......................... 136 ..... 2271

Sec. 222 Violation of Specific Sections ................. $137 \ldots \ldots .2272$

Sec. 223 . Violation of Sections Generally ................... $137 \ldots \ldots \ldots 2273$

Sec. 224. Communication of Restricted Data. .............. 138 ...... 2274

Sec. 225. Receipt of Restricted Data. ...................... 139 ....... 2275

Sec. 226. Tampering with Restricted Data ............... 139 ..... 2276

Sec. 227. Disclosure of Restricted Data .................... 139 ..... 2277

Sec. 228. Statute of Limitations ............................ 1392278

Sec. 229. Trespass Upon Commission............................ 139 2278a Installations.

Sec. 230. Photographing, etc., of Commission ............ $140 \ldots 2278 \mathrm{~b}$ Installations.

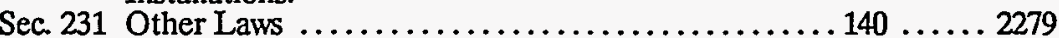

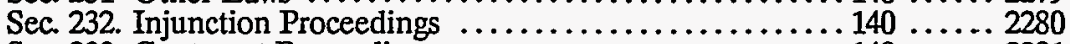

Sec. 233 Contempt Proceedings .......................... $140 \ldots \ldots 2281$

Sec. 234 Civil Monetary Penalties for Violations of $\ldots \ldots \ldots 141 \ldots \ldots .2282$ Licensing Requirements

Sec. 234ACivil Monetary Penalties for

Violations of DOE Regulations ................. $141 \ldots .2282$ a.

Sec. 235. Protection of Nuclear Inspectors ................. $143 \ldots \ldots .2283$

Sec. 236. Sabotage of Nuclear Facilities or Fuel .............. $144 \ldots \ldots .2284$

\section{CHAPTER 19 MISCELLANEOUS}

Sec. 241. Transfer of Property .......................... 144 ..... 2015

Sec. 251. Report to Congress ......................... 144 ...... 2016

Sec. 261. Appropriations ........................................ 145 ..... 2017

Sec. 271. Agency Jurisdiction ......................... $146 \ldots \ldots 2018$

Sec. 272. Applicability of Federal Power Act ............... 146 ...... 2019

Sec. 273. Licensing of Government Agencies ............ $146 \ldots \ldots 2020$

Sec. 274. Cooperation with States ......................... 2021

Sec. 275. Health and Environmental Standards

for Uranium Mill Tailings .................. $152 \ldots \ldots 2022$

Sec. 276. State authority to regulate radiation below

level of regulatory concern of Nuclear

Regulatory Commission

$155 \ldots . .2023^{*}$

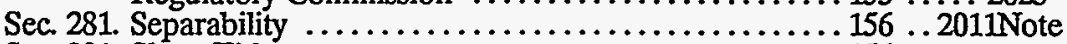

Sec. 291. Short Title .......................... 156

*P.L. 102-486 (106 Stat. 3122) 


\section{CHAPTER 20 \\ JOINT COMMITTEE ON ATOMIC ENERGY ABOLISHED: FUNCTIONS AND RESPONSIBILITIES REASSIGNED}

PAGE

USC

42 USC

Sec.

Sec. 301. Joint Committee on Atomic Energy

Abolished.

Sec. 302. Transfer of Certain Functions of the Joint

Committee on Atomic Energy and

Conforming Amendments to

Certain Other Laws.

Sec. 303. Information and Assistance to

Congressional Committees.

\section{DEFENSE NUCLEAR FACILITIES SAFETY BOARD}

Sec. 311. Establishment ............................. $158 \ldots \ldots 2286$

Sec. 312. Functions of the Board ...................... 159 .... 2286a

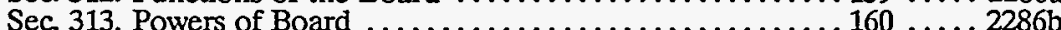

Sec. 314. Responsibilities of the Secretary of ........... 162 ... 2286c Energy.

Sec. 315. Board Recommendations ............. $162 \ldots \ldots 6$

Sec. 316. Reports ...................................... 22856

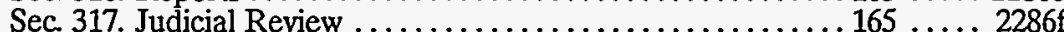

Sec. 318. Definition ............................. $165 \ldots 2286 \mathrm{~g}$

Sec. 319. Contract authority subject to $\ldots \ldots \ldots \ldots \ldots \ldots \ldots 166 \ldots 2286 \mathrm{~h}$ appropriations

Sec. 320 Transmittal of Certain Information to Congress .... 166 . . 2286h-1

Sec. 321 Annual authorization of Appropriations ......... $166 \ldots \ldots 2286 \mathrm{i}$

\section{TITLE II-UNITED STATES ENRICHMENT CORPORATION}

CHAPTER 22 GENIERAL PROVISIONS

Sec. 1201. Definitions. ............................... 169 .... 2297*

Sec. 1202. Purposes ............................. $169 \ldots \ldots$ 2297a

*Added by P.L. 102-486 (106 Stat. 2924) 


\section{CHAPTER 23* \\ ESTABLISHMENT, POWERS, AND ORGANIZATION OF CORPORATION}

PAGE USC

42 USC

Sec.

Sec. 1301. Establishment of the Corporation ............ $170 \ldots \ldots 2297 \mathrm{~b}$

Sec. 1302. Corporate Offices ......................... 170 ... 2297b-1

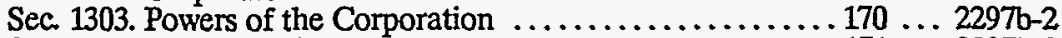

Sec. 1304. Board of Directors ....................... 171 ... 2297b-3

Sec. 1305. Employees of the Corporation ..............172 ... 2297b-4

Sec. 1306. Audits .................................. $174 \ldots . .2297 b-5$

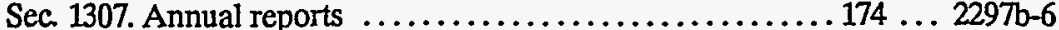

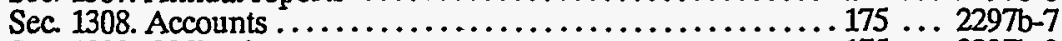

Sec. 1309. Obligations ......................... 175 ... 2297b-8

Sec. 1310. Exemption from taxation and payments

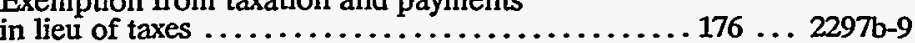

Sec 1311 Cooperation with other agencies $\ldots \ldots \ldots \ldots \ldots 17 \ldots 2297 \mathrm{~b}-10$

Sec. 1312. Applicability of certain Federal laws ........... 177 .. 2297b-11

Sec. 1313. Security ................................ 178 .. 2297b-12

Sec. 1314 Control of information ................. 178 .. 2297b-13

Sec. 1315. Transition ............................... $178 \ldots 2297 \mathrm{~b}-14$

Sec. 1316. Working Capital Account $\ldots \ldots \ldots \ldots \ldots \ldots \ldots \ldots \ldots$.. 2297b-15

\section{CHAPTER 24* \\ RIGHTS, PRIVILEGES, AND ASSETS OF THE CORPORATION}

Sec. 1401. Marketing and contracting authority ........... $179 \ldots . .2297 \mathrm{c}$

Sec. 1402. Pricing ..................................... $180 \ldots 2297 \mathrm{c}-1$

Sec. 1403. Leasing of gaseous diffusion facilities

of department ........................ 2297c-2

Sec. 1404. Capital structure of Corporation .............. 181 ... 2297c-3

Sec. 1405. Patents and inventions ................... 182 ... 2297c-4

Sec. 1406. Liabilities .......................... 182 ... 2297c-5

Sec. 1407. Transfer of uranium inventories $\ldots \ldots \ldots \ldots \ldots \ldots .182 \ldots 2297 c-6$

Sec. 1408. Purchase of highly enriched uranium

from former Soviet Union .............. 182 .. 2297c-7

\section{CHAPTER 25* \\ PRIVATIZATION OF THE CORPORATION}

Sec. 1501. Strategic plan for privatization ............... 183 .... 2297d

Sec. 1502. Privatization .................................. $184 \ldots 2297 \mathrm{~d}-1$

*Added by P.L. 102-486; 106 Stat. 2925; 106 Stat. 2934; and 106 Stat. 2937 


\section{CHAPTER 26* \\ AVLIS AND ALTERNATIVE TECHNOLOGIES FOR \\ URANIUM ENRICHMENT}

PAGE USC

42 USC

Sec.

Sec. 1601. Assessment by United States Enrichment

Corporation ........................ $184 \ldots 2297 \mathrm{e}$

Sec. 1602. Transfer of rights and property to

United States Enrichment Corporation ........ 185 . . 2297e-1

Sec. 1603. Predeployment activities by

United States Enrichment Corporation ........ 186 ... 2297e-2

Sec. 1604. United States Enrichment Corporation sponsorship of private for-profit corporation to construct AVLIS and alternative technologies for uranium enrichment .......... 186 ... 2297e-3

Sec. 1605. AVLIS Commercialization Fund within United States Enrichment Corporation ......... 188 .. 2297e-4

Sec. 1606. Department research and development assistance ............................ 188 .. 2297e-5

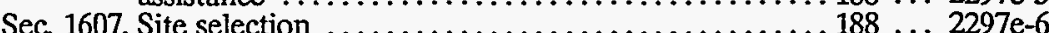

Sec. 1608. Exclusion from Price-Anderson coverage . . . . . . . 189 ... 2297e-7

\section{CHAPTER 27* \\ LICENSING AND REGULATION OF URANIUM ENRICHMENT FACILITIES}

Sec. 1701. Gaseous diffusion facilities ................. $189 \ldots \ldots 2297 \mathrm{f}$

Sec. 1702. Licensing of other technologies ............... $190 \ldots \ldots 2297 \mathrm{f}-1$

Sec. 1703. Regulation of restricted data................. $190 \ldots 2297 \mathrm{f}-2$

\section{CHAPTER 28* DECONTAMINATION AND DECOMMISSIONING}

Sec. 1801. Uranium Enrichment Decontamination and Decommissioning Fund . . . . . . . . . . . $190 \ldots \ldots 2297 \mathrm{~g}$

Sec. 1802. Deposits ................................. $191 \ldots .2297 \mathrm{~g}-1$

Sec. 1803. Department facilities $\ldots \ldots \ldots \ldots \ldots \ldots \ldots \ldots \ldots 192 \ldots 2297 \mathrm{~g}-2$

Sec. 1804. Employee provisions ..................... 192 ... 2297g-3

Sec. 1805. Reports to Congress ..................... $193 \ldots 2297 \mathrm{~g}-4^{*}$

*Added by P.L. 102-486 (106 Stat. 2939) 


\section{THE ATOMIC ENERGY ACT OF 1954}

\section{TITLE I-ATOMIC ENERGY*}

Declaration.

42 USC sec. 2011

Findings.

42 USC sec. 2012

\section{CHAPTER 1 - DECLARATION, FINDINGS, AND PURPOSE}

Sec. 1. Declaration-Atomic energy is capable of application for peaceful as well as military purposes. It is therefore declared to be the policy of the United States that-

"a. the development, use, and control of atomic energy shall be directed so as to make the maximum contribution to the general welfare, subject at all times to the paramount objective of making the maximum contribution to the common defense and security; and

"b. the development, use, and control of atomic energy shall be directed so as to promote world peace, improve the general welfare, increase the standard of living, and strengthen free competition in private enterprise.

Sec. 2. Findings. ${ }^{2}-$ The Congress of the United States hereby makes the following findings concerning the development, use and control of atomic energy:

"a. The development, utilization, and control of atomic energy for military and for all other purposes are vital to the common defense and security.

"c. ${ }^{3}$ The processing and utilization of source, byproduct, and special nuclear material affect interstate and foreign commerce and must be regulated in the national interest.

"d. The processing and utilization of source, byproduct, and special nuclear material must be regulated in the national interest and in order to provide for the common defense and security and to protect the health and safety of the public.

"e. Source and special nuclear material, production facilities, and utilization facilities are affected with the public interest, and regulation by the United States of the production and utilization of atomic energy and of the facilities used in connection therewith is necessary in the national interest to assure the common defense and security and to protect the health and safety of the public.

"f. The necessity for protection against possible interstate damage occurring from the operation of facilities for production or utilization of source or special nuclear material places the operation of those facilities in interstate commerce for the purposes of this Act.

\footnotetext{
-Added by P.L. 102-486 (106 Stat. 2943); Oct. 24, 1992
}

${ }^{2}$ Sec. 20 Public Law 88-489 (78 Stat.602)(1964), the Privale Ownership of Special Nuclear Materials Act reads as follows:

"Nothing in this Act shall be deemed to diminish existing authority of the United States, or of the Atomic Energy Commission under the Atomic Energy Act of 1954, as amended to regulate source, byproduct, and special nuclear material and production and utilization facilities or to control such materials and facilities exported from the United States by imposition of governmental guarantees and security safeguards with respect thereto, in order to assure the common defense and searrity and to protect the health and safety of the public, or to reduce the resporsibility of the common defense and seasrity and toprotect the health and

Atomic Energy Commission to achieve such objectives."

3Public Law 88-489 (78 Stat. 602)(1964), sec. 1, deleted subsec. 2b. Subsec. $2 b$ read as follows:

"b. In permitting the property of the United States to beused by others such sue must be regulated in the national interest and in order to provide for the common defense and security and to protect the health and safety of the pub- 
Purpose

42 USC Sec. 2013 "g. Funds of the United Sates may be provided for the development and use of atomic energy under conditions which will provide for the common defense and security and promote the general welfare.

"i.4 In order to protect the public and to encourage the development of the atomic energy industry, in the interest of the general welfare and of the common defense and security, the United States may make funds available for a portion of the damages suffered by the public from nuclear incidents, and may limit the liability of those persons liable for such losses. 5

"Sec. 3. Purpose. - It is the purpose of this Act to effectuate the policies set forth above by providing for-

"a. a program of conducting, assisting, and fostering research and development in order to encourage maximum scientific and industrial progress;

"b. a program for the dissemination of unclassified scientific and technical information and for the control, dissemination, and declassification of Restricted Data, subject to appropriate safeguards, so as to encourage scientific and industrial progress;

"c. a program for Government control of the possession, use, and production of atomic energy and special nuclear material, whether owned by the Government or others, so directed as to make the maximum contribution to the common defense and security and the national welfare, and to provide continued assurance of the Government's ability to enter into and enforce agreements with nations or groups of nations for the control of special nuclear materials and atomic weapons. ${ }^{6}$

"d. a program to encourage widespread participation in the development and utilization of atomic energy for peaceful purposes to the maximum extent consistent with the common defense and security and with the health and safety of the public;

"e. a program of international cooperation to promote the common defense and security and to make available to cooperating nations the benefits of peaceful applications of atomic energy as widely as expanding technology and considerations of the common defense and security will permit; and

"f. a program of administration which will be consistent with the foregoing policies and programs, with international arrangements, and with agreements for cooperation, which will enable the Congress to be currently informed so as to take further legislative action as may be appropriate.

\footnotetext{
${ }^{4}$ Public Law 88-489 (78Stat. 602) (1964), sec. 2, deleted subsec. 2 h. Subsec. 2 h, read as follows:

"h. It is essential to the common defense and security that title to all special nuclear material be in the United States while such special nuclear material is within the United States."

5Public Law 85-256 (71 Stat. 576), (1957) sec. 1, added subsec. i.

Bpublic Law 88-489 (78 Stnt. 602) (1964), sec. 3, amended this subsection. Before amendment it read:

"c. A program for Government control of the possession, use, and production of atomic energy and special nuclear material so directed as to make the maximum contribution to the common defenseand security and the national welfare;"
} 
Definitions.

42 USC sec. 2014

Agency of the

U.S.

Agreement for cooperation.

Atomic energy.

Atomic weapon.

Byproduct material.

Commission.

Common defense and security.

Defense

information.

Design.

Extraordinary nuclear occurrence.

\section{"CHAPTER 2-DEFINITIONS}

"Sec. 11. Definitions.-The intent of Congress in the definitions as given in this section should be construed from the words or phrases used in the definitions. As used in this Act:

"a. The term 'agency of the United States' means the executive branch of the United States, or any Government agency, or the legislative branch of the United States, or any agency, committee, commission, office, or other -establishment in the legislative branch, or the judicial branch of the United States, or any office, agency, committee, commission, or other establishment in the judicial branch.

'b. The term 'agreement for cooperation' means any agreement with another nation or regional defense organization authorized or permitted by sections $54,57,64,82,91$ c., 103,104 , or 144 , and made pursuant to section 123.7

“c. The term 'atomic energy' means all forms of energy released in the course of nuclear fission or nuclear transformation.

“d. The term 'atomic weapon' means any device utilizing atomic energy, exclusive of the means for transporting or propelling the device (where such means is a separable and divisible part of the device), the principal purpose of which is for use as, or for development of, a weapon prototype, or a weapon test device.

"e. The term 'byproduct material' means (1) any radioactive material (except special nuclear material) yielded in or made radioactive by exposure to the radiation incident to the process of producing or utilizing special nuclear material, and (2) the tailings or wastes produced by the extraction or concentration of uranium or thorium from any ore processed primarily for its source material content. 8

"f. The term 'Commission' means the Atomic Energy Commission.

"g. The term 'common defense and security' means the common defense and security of the United States.

"h. The term 'defense information' means any information in any category determined by any Government agency authorized to classify information, as being information respecting, relating to, or affecting the national defense.

"i. The term 'design' means (1) specifications, plans drawings, blueprints, and other items of like nature; (2) the information contained therein; or (3) the research and development data pertinent to the information contained therein.

“j. The term 'extraordinary nuclear occurrence' means any event causing a discharge or dispersal of source, special nuclear, or byproduct material from its intended place of confinement in amounts off-site, or causing radiation levels off-site, which the

\footnotetext{
7Public Law 87-206 (75 Stat. 475) (1961), sec. 2, amended this subsection by adding sec $91 \mathrm{c}$

${ }^{8}$ Public Law 95-604 (92 Stat. 3033) (1978), sec. 201, amended sec. 11(c) by substituting a complete new subsec. 11(e). Before amendment, subsec. 11(e) read as follows: "The term "byproduct material' means any radioactive material (except special nuclear material) yielded in or made radioactive by exposureto theradiation incident to theprocess of producing or utilizing special nuclear material.
} 
Financial protection.

Government agency.

Indemnitor.

International arrangement.

Joint Committee.

Licensed activity.

Nuclear incident.

Nuclear Regulatory Commission or the Secretary of Energy, as appropriate, determines to be substantial, and which the Nuclear Regulatory Commission or the Secretary of Energy, as appropriate determines has resulted or will probably result in substantial damages to persons off-site or property off-site. Any determination by the Nuclear Regulatory Commission or the Secretary of Energy, as appropriate, that such an event has, or has not, occurred shall be final and conclusive, and no other official or any court shall have power or jurisdiction to review any such determination. The Nuclear Regulatory Commission or the Secretary of Energy, as appropriate, shall establish criteria in writing setting forth the basis upon which such determination shall be made. As used in this subsection, 'off-site' means away from 'the location' or 'the contract location' as defined in the applicable Nuclear Regulatory Commission or the Secretary of Energy, as appropriate, indemnity agreement, entered into pursuant to section $170 .^{9}$

"k. The term 'financial protection' means the ability to respond in damages for public liability and to meet the costs of investigating and defending claims and settling suits for such damages. ${ }^{10}$

"I. The term 'Government agency' means any executive department, commission, independent establishment, corporation, wholly or partly owned by the United States of America which is an instrumentality of the United States, or any board, bureau, division, service, office, officer, authority, administration, or other establishment in the executive branch of the Government.

" $\mathrm{m}$. The term 'indemnitor' means (1) any insurer with respect to his obligations under a policy of insurance furnished as proof of financial protection; (2) any licensee, contractor or other person who is obligated under any other form of financial protection, with respect to such obligations; and (3) the Nuclear Regulatory Commission or the Secretary of Energy, as appropriate, with respect to any obligation undertaken by it in an indemnity agreement entered into pursuant to section 170.11

" $\mathrm{n}$. The term 'international arrangiement' means any international agreement hereafter approved by the Congress or any treaty during the time such agreement or treaty is in full force and effect, but does not include any agreement for cooperation.

“o. The term 'Joint Committee' means the Joint Committee on Atomic Energy.

" $p$. The term 'licensed activity' means an activity licensed pursuant to this Act and covered by the provisions of section 170a.12

" $\mathrm{q}$. The term 'nuclear incident' means any occurrence, including an extraordinary nuclear occurrence, ${ }^{13}$ within the United States causing, within or outside the United States, bodily injury, sickness, disease, or death, or loss of or damage to property, or loss of use of property, arising out of or resulting from the radioactive, toxic, ex-

\footnotetext{
9Public Law 89-645 (80 Stat. 891) (1966), sec. 1, added subsec. j.

10.Public Law 85-256 (71 Stat. 576) (1957), sec. 3, added subsec. $k$.

11 Public I aw 89-645 (80 Stat. 891) (1966), sec. 1, added subsec. m

12Public Law 85-256 (71 Stat. 576) (1957), sec. 3, added subsec. p.

${ }^{13}$ Public Law 89-645 (80 Stat. 891) (1966), sec. 1, amended this subsection by inserting the phase "including an extraordinary nuclear occurrence."
} 
42 USC 2091, 2111, 2121,2151

Operator.

Person.

Person idemnified. plosive, or other hazardous properties of source, special nuclear, or byproduct material: Provided, however, That as the term is used in section 170 1., it shall include any such occurrence outside of the United States: And provided further, That as the term is used in section $170 \mathrm{~d}$., it shall include any such occurrence outside the United States if such occurrence involves source, special nuclear, or byproduct material owned by, and used by or under contract with, the United States: And provided further, That as the

term is used in section $170 \mathrm{c}$., it shall include any such occurrence outside both the United States and any other nation if such occurrence arises out of or results from the radioactive, toxic, explosive, or other hazardous properties of source, special nuclear, or byproduct material licensed pursuant to chapters $6,7,8$, and 10 of this Act, which is used in connection with the operation of a licensed stationary production utilization facility or which moves outside the territorial limits of the United States in transit from one person licensed by the Nuclear Regulatory Commission to another person licensed by the Nuclear Regulatory Commission. ${ }^{14}$

" $r$. The term 'operator' means any individual who manipulates the controls of a utilization or production facility.

"s. The term 'person' means (1) any individual, corporation, partnership, firm, association, trust, estate, public or private institution, group, Government agency other than the Commission, any State or any political subdivision of, or any political entity within a State, any foreign government or nation or any political subdivision of any such government or nation, or other entity; and (2) any legal successor, representative, agent, or agency of the foregoing.

" $t$. The term 'person indemnified' means (1) with respect to a nuclear incident occurring within the United States or outside the United States as the term is used in section $170 \mathrm{c}$., and with respect to any nuclear incident in connection with the design, development, construction, operation, repair, maintenance, or use of the nuclear ship Savannah, the person with whom an indemnity agreement is executed or who is required to maintain financial protection, and any other person who may be liable for public liability or (2) with respect to any other nuclear incident occurring outside the United States, the person with whom an indemnity agreement is executed and any other person who may be liable for publicliability by reason of his activities under any contract with the Secretary of Energy or any project to which indemnification under the provisions of section $170 \mathrm{~d}$. has been extended or under any subcontract,

\footnotetext{
${ }_{14}^{14}$ Public Law 85-256 (71 Stat. 576)(1957), sec. 3 added subsec. q. Prior to amendment by Public Law 89-645(see footnote9, above) the subsection had been amended by Public Law 87-615 (76 Stat. 409) (1962), sec. 4. Before amendment it read: "o. The term 'nuclear incident' means any occurrence within the United States causing bodily injury, sickness, disease, or death, or loss of or damage to property, or for loss of use of property, arising out of or resulting from the radioactive, toxic, explosive, or other hazardous properties of source, special nuclear, or byproduct material Provided however, That as the term is used in subsection 170.1., it shall meanany suchoccurrenceoutside of the United States rather than within the United States." Public Law 84-197 (89 Stat. I111) (1975), sec. 1, amended the second proviso in subsection 11a. Prior to amendment, the proviso read as follows: "And provided furher, That as the term is used in section $170 \mathrm{~d}$, it shall inchude any such occurrence outside of the United States if such occurrence involves a facility or device owned by, and used by or under contrat with, the United States."
} 
Production facility.

purchase order or other agreement, of any tier, under any such contract or project. 15

" $u$. The term 'produce', when used in relation to special nuclear material, means (1) to manufacture, make, produce, or refine special nuclear material; (2) to separate special nuclear material from other substances in which such material may be contained; or (3) to make or to produce new special nuclear material.

"v. The term 'production facility' means (1) any equipment or device determined by rule of the Commission to be capable of the production of special nuclear material in such quantity as to be of significance to the common defense and security, or in such manner as to affect the health and safety of the public; or (2) any important component part especially designed for such equipment or device as determined by the Commission. Except with respect to the export of a uranium enrichment production facility, 16 a or the construction and operation of a uranium enrichment production facility using Atomic Vapor Laser Isotope Separation technology, such term as used in chapters 10 and 16 shall not include any equipment or device (or important component part especially designed for such equipment or device) capable of separating the isotopes of uranium or enriching uranium in the isotope 235."16

Public liability.

"w. The term 'public liability' 17 means any legal liability arising out of or resulting from a nuclear incident or precautionary evacuation (including all reasonable additional costs incurred by a State, or political subdivision of a State, in the course of responding to a nuclear incident or precautionary evacuation) except: (i) claims under State or Federal workmen's compensation acts of employees or persons indemnified who are employed at the site of and in connection with the activity where the nuclear incident occurs; (ii) claims arising out of an act of war; and (iii) whenever used in subsections a., c., and k., of section 170 , claims for loss of, or damage to property which is located at the site of and used in connection with licenses activity where the nuclear incident occurs. 'Public liability; also includes damage to property of persons indemnified: Provided, That such property is covered under the terms of the financial protection required, except property which is located at the site of and

${ }^{15}$ Public Law 85-256(71 Stal.576) (1957), sec. 3, added subsection t. Public Law 87-615 (76 Stat. 409)(1962), sec. 5, amended the subsection. Before amendment, it read: "r. The term 'person indemnified' means the person with whom an indemnity agreement is executed and any other person who may be liable for public liability." Public Law 94-197 (89 Stat. 1111) (1975), sec. 1, amended subsection 11 t. by adding the phrases "or outside the United States as theterm is used in subsection $170 \mathrm{c}$." and "or who is required to maintain financial protection." to the definition of the term person "indemnified".

${ }^{16}$ Public Law 101-575 (104 Stat. 2834) (1990) Sec. 5(a) added new sentence to Section 11v.

162 Public Law 102-486 (106 Stat. 2955) amended the last sentence of " $\checkmark$ ". Before amendment the last sentence read: "Ercept with respect to the export or a uranium enrichment production facility, such term as used in chapters 10 and 16 shall not include any equipment or device (or important component part especially designed for such equipment or device) capable of separating the isotopes of uranium or enriching uranium in the isotope 235."

${ }_{17}$ Public Law 85-256 (71 Stat. 576)(1957), sec. 3, added subsectionw. PublicLaw 87-206(75 Stat.475)(1961), sec. 3, amended the subsection. Before amendment it read:

"u. The term "public liability" means any legal tiability arising out of or resulting from a muclear incident, except claims under State or Federal Workmen's Compensation Acts of employes of persons indemnified who are employed at the site of and in connection with the activity where the nuclear incident occurs, and except for claims arising out of an act of war. 'Public liability' also included damage to property of persons indemnified: Provided, That such property is covered under the terms of the financial protection required, except property which is located at thesite of and used in connection with the activity where the nuclear incident ocaurs." 
Research and development.

Restricted Data.

Source material.

Special nuclear material.

United States.

Utilization facility.

used in connection with the activity where the nuclear incident occurs.

" $x$. The term 'research and development' means (1) theoretical analysis, exploration, or experimentation; or (2) the extension of investigative findings and theories of a scientific or technical nature into practical application for experimental and demonstration purposes, including the experimental production and testing of models, devices, equipment, materials, and processes.

"y. The term 'Restricted Data' means all data concerning (1) design, manufacture, or utilization of atomic weapons; (2) the production of special nuclear material; or (3) the use of special nuclear material in the production of energy, but shall not include data declassified or removed from the Restricted Data category pursuant to section 142 .

" $z$. The term 'source material' means (1) uranium, thorium, or any other material which is determined by the Commission pursuant to the provisions of section 61 to be source material; or (2) ores containing one or more of the foregoing materials, in such concentration as the Commission may by regulation determine from time to time.

"aa. The term 'special nuclear material' means (1) plutonium, uranium enriched in the isotope 233 or in the isotope 235 , and any other material which the Commission, pursuant to the provisions of section 51, determines to be special nuclear material, but does not include source material; or (2) any material artificially enriched by any of the foregoing, but does not include source material.

' $\mathrm{bb}$. The term 'United States' when used in a geographical sense includes all Territories and possessions of the United States, the Canal Zone and Puerto Rico. ${ }^{18}$

"cc. The term 'utilization facility' means (1) any equipment or device, except an atomic weapon, determined by rule of the Commission to be capable of making use of special nuclear material in such quantity as to be of significance to the common defense and security, or in such manner as to affect the health and safety of the public, or peculiarly adapted for making use of atomic energy in such quantity as to be of significance to the common defense and security, or in such manner as to affect the health and safety of the public; or (2) any important component part especially designed for such equipment or device as determined by the Commission.

"dd.18aThe terms "high-level radioactive waste" and "spent nuclear fuel" have the meanings given such terms in section 2 of the Nuclear Waste Policy Act of 1982 (42 U.S.C. 10101).

"ee. The term "transuranic waste" means material contaminated with elements that have an atomic number greater than 92, including neptunium, plutonium, americium, and curium, and that are in concentrations greater than 10 nano-curies per gram, or in such

\footnotetext{
${ }^{18}$ Public Law 84-1006 (70 Stat. 1069) (1956), sec. 1, amended this definition. Before amendment it read:

"u. The term 'United States' when used in a geographical sense, inchudes all Territories and possessions of the United States, and the Canal Zone."

${ }^{18}$ a Public Law 100-408 (102 Stat. 1066) (1988) added subsections dd-ji.
} 
other concentrations as the Nuclear Regulatory Commission may prescribe to protect the public health and safety.

"ff. The term "nuclear waste activities", as used in section 170, means activities subject to an agreement of indemnification under subsection d. of such section, that the Secretary of Energy is authorized to undertake, under this Act or any other law, involving the storage, handling, transportation, treatment, or disposal of, or research and development on, spent nuclear fuel, high-level radioactive waste, or transuranic waste, including (but not limited to) activities authorized to be carried out under the Waste Isolation Pilot Project under section 213 of Public Law 96-164 (93 Stat. 1265).

"gg. The term "precautionary evacuation" means an evacuation of the public within a specified area near a nuclear facility, or the transportation route in the case of an accident involving transportation of source material, special nuclear material, byproduct material, high-level radioactive waste, spent nuclear fuel, or transuranic waste to or from a production or utilization facility, if the evacuation is-

(1) the result of any event that is not classified as a nuclear incident but that poses imminent danger of bodily injury or property damage from the radiological properties of source material, special nuclear material, byproduct material, high-level radioactive waste, spent nuclear fuel, or transuranic waste, and causes an evacuation; and

(2) initiated by an official of a State or a political subdivision of a State, who is authorized by State law to initiate such an evacuation and who reasonably determined that such an evacuation was necessary to protect the public health and safety.

$\mathrm{hh}$. The term "public liability action", as used in section 170 , means any suit asserting public liability. A public liability action shall be deemed to be an action arising under section 170, and the substantive rules for decision in such action shall be derived from the law of the State in which the nuclear incident involved occurs, unless such law is inconsistent with the provisions of such section. jj. Legal Costs.-As used in section 170, the term "legal costs" means the costs incurred by a plaintiff or a defendant in initiating, prosecuting, investigating, settling, or defending claims or suits for damages arising under such section. 
Office.

42 USC

sec. 2033

General Manager,

Deputy and Assistant General Managers.

42 USC sec. 2034

CHAPTER 3-ORGANIZATION

"Sec. 23.19 Office.-The principal office of the Commission shall be in or near the District of Columbia, but the Commission or any duly authorized representative may exercise any or all of its powers in any place; however, the Commission shall maintain an office for the service of process and papers within the District of Columbia.

"Sec. 24.20 General Manager, Deputy and Assistant General Managers. - There is hereby established within the Commission-

"a. a General Manager, who shall be the chief executive officer of the Commission, and who shall discharge such of the administrative and executive functions of the Commission as the Commission may direct. The General Manager shall be appointed by the Commission, shall serve at the pleasure of the Commission, and shall be removable by the Commission. ${ }^{21}$

"b. a Deputy General Manager, who shall act in the stead of the General Manager during his absence when so directed by the General Manager, and who shall perform such other administrative and executive functions as the General Manager shall direct.

${ }^{10}$ P.L. 93-438, Sec. 104(a)(88 Stat. 1233)(1974), repealed sections 21 and 22 . Prior to repeal, section 21 read as follows.

"Sec. 21. Atomic Energy Commission. - There is hereby established an AtomicEnergy Commission, which shall be composed of five members, each of whom shall be a citizen of the United States. The President shall designate one member of the Commission as Chairman thercoto membro the Co time may stead of the Chair shall preside at all meetings of the Commission and a quonmm for the transaction of business shall consist of at least and anthority in all decisions and actions of the Commission, shall have full access to all information relating to the

Action of the Commission shall be determined by a majority vote of the members present. The Chairman (or Acting Chairman in the absence of the Chairman) shall be the official spokesman of the Commission in its relations with the Congress. Government agencies, persons or the public, and on behalf of the Commission, shall see to the faithful execution of the policies and decisions of the Commission, and shall report thereon to the Commission from time to time or as the Commission may direct. The Commission shall have an official seal which shall be judicially noticed."

Public Law 84-337 (69 Stat. 630) (1955). sec. 3 had previously amended the fifth sentence of sec. 21 . Before amendment this sentence read:

"Each member of the Commission, including the Chairman, shall have equal responsibility and authority in all decisions and actions of the Commission and shall have one vote."

Prior to repeal, sec. 22 read as follows:

"Sec. 22. Members. -

a. Members of the Commission shall be appointed by the President, by and with the advice and consent of the Senate. In submitting any nomination to the Senate, the President shall set forth the experience and qualifications of the nominee. The term of office of each member of the Commission taking office after June 30, 1950, shall be five years, except that (1) the terms of office of the members first taking office after June 30 , 1950, shall erpire as designated by the President at the time of the appointment, oneat the end of oneyear, one at the end of two o years, aneat the nated ore end of hree years, one at the end ol four years, and one al thecnd or shall be appointed for the remainder of such term. Any member of the Commission may be removed by the President for inefficiency, neglect of duty, or malfeasance in office.

"b. No member of the Commission shall engage in any business, vocation, or emiployment other than that of serving as a member of the Commission."

Public Law 88-426 (78 Stat. 400) (1964), sec. 305(10)(A) previousty amended sec. 22 a. by repealing the last sentence, which read: "Each member, except the Chairman, shall receive compensation at the rate of $\$ 22,000$ peranmum; and the member designated as Chairman shall receive compensation at the rate of $\$ 22,500$ per annum.

Public Law 85-287 (71 Stat. 612) (1957), sec. 1, had amended that senterce by substituting $\$ 22,000$ for $\$ 18,000$, and by substituting $\$ 22,500$ for $\$ 20,000$.

20 Public Law 85-287 (71 Stat. 612) (1957), sec. 2. amended sec. 24 and replaced it in its entirety. Before amendment sec. 24 read:

"Sec. 24. General Manager. -There is hereby established within the Commission a General Manager, whoshall discharge such of the administrative and executive functions of the Commission as the Commission may direct. The General Manager shall be appointed by the Commission, shall serve at the pleasure of the Commission, shall be romovable by the Commission, and shall receive compensation at a rate determined by the Commission, but not in excess of $\$ 20,000$ per annum."

${ }^{21}$ Public Law 88-426 (78 Stat. 400) (1964), sec. 306(0), amended the last sentence of sec. 24c. by inserting "and" immediately before "shall be removable by the Gezeral Manager" and by deleting the last part of the sentence which Iead: ", and shall receive compensation at a rate determined by the General Manager, but not in excess of $\$ 20,500$ per reanis" 
Divisions and offices.

42 USC sec. 2035.

Assistant General Manager for

Military

Application.

Program divisions.

General Counsel.
The Deputy General Manager shall be appointed by the General Manager with the approval of the Commission, shall serve at the pleasure of the General Manager, and shall be removable by the General Manager.22

"c. Assistant General Managers, or their equivalents (not to exceed a total of three positions), who shall perform such administrative and executive functions as the General Manager shall direct. They shall be appointed by the General Manager with the approval of the Commission, shall serve at the pleasure of the General Manager, and shall be removable by the General Manager.23

"Sec. 25. Divisions, Offices, And Positions. ${ }^{24}$-There is hereby established within the Commission-

"a. A Division of Military Application and such other program divisions (not to exceed ten in number) as the Commission may determine to be necessary to the discharge of its responsibilities, including a division or divisions the primary responsibilities of which include the development and application of civilian uses of atomic energy. The Division of Military Application shall be under the direction of an Assistant General Manager for Military Application, who shall be appointed by the Commission and shall be an active commissioned officer of the Armed Forces serving in general or flag officer rank or grade, as appropriate. Each other program division shall be under the direction of a Director who shall be appointed by the Commission. The Commission shall require each such division to exercise such of the Commission's administrative and executive powers as the Commission may determine;25

"b. an Office of the General Counsel under the direction of the General Counsel who shall be appointed by the Commission;26 and

22Public Law 88-426 (78 Stat. 400) (1964), sec. 306(f), amended the last sentence of sec. 24 b. by inserting "and" immediately before "shall be removable by the General Manager" and by deleting the last part of the sentence which read: ", and shall receive compensation at a rate determined by the General Manager, but not in excess of $\$ 20,500$ per annum".

${ }^{23}$ Public Law 88-426 (78 Stat. 400)(1964), sec 306(f), amended the last sentence of sec. 24 c. by inserting "and" immediately before "shall be rernovable by the General Manager" and by deleting the last part of the sentence with read: “, and shall receive compensation at a rate determined by the General Manager, but not in excess of $\$ 20,000$ per annum"

${ }^{24}$ Public Law 85-287 (71 Stat. 612) (1957), sec. 3, amended thetitle of sec. 25. Before amendment the title of this section was: "Divisions and Offices." lows:

25 Public Law 90-190 (81 Stat. 575) (1967), sec. 5, amended sec. 25 a. Before amendment, sec. 25 a. read as fol-

4a. a Division of Military Application and such other program divisions (not to exceed ten in number) as the Commission may determine to be necessary to the discharge of its responsibilities, including a division or divisions the primary responsibilities of which inchude the development and application of civilian uses of atomic energy. Each such division shall be under the direction of a Director who shall be appointed by the Commission. The Director o the Division of Military Application shall be an active member of the Armed Forces. The Commission shall require each such division to exercise such of the Commission's administrative añd executive powers as the Commission may etermine".

Public Law 88-426 (78 Stat. 400) (1964), sec. 306(f), earlier had amended the second sentence of sec. 25 a. by deleting the last part which read: " and shall receive compensation at a rate determined by the Commission, but not in excess of $\$ 19,000$ per annum". Public Law 85-287 (71 Stat. 612) (1957), sec. 3, had amended that sentence by substituting $\$ 19,000$ for $\$ 16,000$

${ }_{26}$ Public Law 88-426 (78 Stat. 400) (1964), sec. 306(f), amended sec. 25 b. by deleting the last part which read: and shall receive compensation at a rate determined by the Commission, but not in excess of $\$ 19500$ per annum. Public Law 85-287 (71 Stat. 612) (1957), sec. 3, had amended sec. 25 b. by substituting $\$ 19,500$ for $\$ 16,000$. 
Inspection Division.

"c. an Inspection Division under the direction of a Director who shall be appointed by the Commission. 27 The Inspection Division shall be responsible for gathering information to show whether or not the contractors, licensees, and officers and employees of the Commission are complying with the provisions of this Act (except those provisions for which the Federal Bureau of Investigation is responsible) and the appropriate rules and regulations of the Commission.

“d. such other executive management positions (not to exceed six in number) as the Commission may determine to be necessary to the discharge of its responsibilities. Such positions shall be established by the General Manager with the approval of the Commission. They shall be appointed by the General Manager with the approval of the Commission, shall serve at the pleasure of the General Manager, and shall be removable by the General Manager.28

“Sec. 26.29

"Sec. 27.30

Appointment of Army, Navy or Air. Force Officers. 42 USC

"Sec. 28. Appointment Of Army, Navy, Or Air Force Officers. - Notwithstanding the provisions of any other law, the officer of the Army, Navy, or Air Force serving as Assistant General Manager for Military Application shall serve without prejudice to his commissioned status as such officer. Any such officer serving as Assistant General Manager for

${ }^{27}$ Public Law 88-426 (78 Stat. 400) (1964), sec. 306(0), amended the first sentence of sec. $25 \mathrm{c}$. by deleting the last part which read: "and shall receive compensation at a rate determined by the Commission, but not inexcess of $\$ 19,000$ per annum".

Public Law 85-287 (71 Stat. 612) (1957), sec. 3, had amended that sentence by substituting $\$ 19,000$ for $\$ 16,000$.

${ }^{28}$ Public Law 85-287 (71 Stat. 612) (1957), sec. 3, added subsec. d. Public Law 88-426 (78 Stat. 400) (1964), sec. 306(D). amended the last sentence of this subsection by inserting "and" immediately before 'shall be removable by the General Manager and by deleting the last part of the sentence which read: ", and shall receive compensation at a rate determined by the General Manager, but not in excess of $\$ 19,000$ per annum".

${ }^{29}$ Public Law 95-91 (91 Stat. 608) (1977) sec. 709(c)(1). repealed sec. 26 which read:

"General Advisory Committee - Thereshall be a General Advisory Committee to advise the Commission on scicatific and technical matters relating to materials, production, and research and development, to becomposed of nine members, who shall be appointed from civilian life by the President. Each member shall bold office for a term of six years, except that (a) any member appointed to fill a vacancy occurring prior to the expiration of the term for which his predecessor was appointed, shall be appointed for the remainder of such term; and (b) the terms of office of themembers first taking office after August 1, 1946, shall expire, as designated by the President at the time of appointment, three at the end of two years, three at the end of four years, and three at the end of sixyears, after August 1, 1946. The Committee shall designate one of its own members as Chairman. The Committee shall meet at least four times in every calendar year. The members of the Committee shall receive a per diem compensation for cach day spent in meetings or conferences, and all members shall receive their necessary traveling or other expenses while engaged in the work of the Committee"

30 Public Law 99-661 (100 Stat. 4066) (1986) Div C, Title I, Part C, sec 3137(c) repealed sec. 27, which read: "Military Liaison Committee. -There is hereby established a Military Liaison Committee consisting of a. a Chairman, who shall be the head thereof and who skall be appointed by the President, by and with the advice and consent of the Senate, who shall serve at the pleasure of the President; and

b. a representative or representatives from each of the Departments of the Army, Navy, and Air Force, in equal numbers, as determined by the Secretary of Defense, to be assigned fromeach Department by the Secretary thereof, and who will serve without additional compensation.

The Chairman of the Committee may designate one of the members of the Committee as Acting Chairman to act during his absence. The Commission shall advise and consult with the Department of Defense, through the Committee, on all atomic energy matters which the Department of Defense deems to relate to military applications of atomic weapons or atomic energy including the development, manufacture, use, and storage of atomic weapons, the allocation of special nuclear material for military research, and the control of information relating to the mamufacture or informed of all such matters before the Commission The Department of Defense through the Committee shall keep the Commission fully and arrently informed on all matters within the Department of Defensewhich the Comxeepthe Commission fulty and carrently informed on all matters within the Department of Defense which the Commission deems to relate to the development or application of atomic energy. The Department of Defense, throughthe Committee, shall have the authority to make written recommendations to the Commission from time to time on matters relating to military applications of atomic energy as the Department of Defense may deem appropriate. If the Department of Defenseat any time coneludesthat any request, action, proposed action, or failure toact on the part of the matter to the President whose decision shall be final. 
Military Application shall receive in addition to his pay and allowances, including special and incentive pays, for which pay and allowances the

Chairman, Military Liaison Committee.

Committee on Reactor Safeguards. 42 USC sec. 2039

Research assistance. 42 USC sec. 2051
Commission shall reimburse his service, an amount equal to the difference between such pay and allowances, including special and incentive pays, and the compensation established for this position ${ }^{31}$. Notwithstanding the provisions of any other law, any active or retired officer of the Army, Navy, or Air Force may serve as Chairman of the Military Liaison Committee without prejudice to his active or retired status as such officer. Any such officer serving as Chairman of the Military Liaison Committee shall receive, in addition to his pay and allowances, including special and incentive pays, or in addition to his retired pay, an amount equal to the difference between such pay and allowances, including special and incentive pays, or between his retired pay, and the compensation prescribed for the Chairman of the Military Liaison Committee.

"Sec. 29. Advisory Committee On Reactor Safeguards.-There is hereby established an Advisory Committee on Reactor Safeguards consisting of a maximum of fifteen members appointed by the Commission for terms of four years each. The Committee shall review safety studies and facility license applications referred to it and shall make reports thereon, shall advise the Commission with regard to the hazards of proposed or existing reactor facilities and the adequacy of proposed reactor safety standards, and shall perform such other duties as the Commission may request. One member shall be designated by the Committee as its Chairman. The members of the Committee shall receive a per diem compensation for each day spent in meetings or conferences, or other work of the Committee, and all members shall receive their necessary traveling or other expenses while engaged in the work of the Committee. The provisions of section 163 shall be applicable to the Committee.32 In addition to its other duties under this section, the Committee, making use of all available sources, shall undertake a study of reactor safety research and prepare and submit annually to the Congress a report containing the results of such study. The first such report shall be subrnitted to the Congress not later than December 31, 1977.33

\section{"CHAPTER 4-RESEARCH}

"Sec. 31. Research Assistance.-

"a. The Commission is directed to exercise its powers in such manner as to insure the continued conduct of research and devel-

\footnotetext{
${ }^{31}$ Public Law 90-190 (81-Stat. 575) (1967), sec.6, amended the first two sentences of sec. 28. Prior to this amendment, these sentences read as follows:

"Notwithstanding theprovisions of any other law, any active officer of the Army, Navy, or Air Force may serveas Director of the Division of Military Application without prejudice to his commissioned status as such officer. Any such officer serving as Director of the division of Military Application shall receive in addition to his pay and allowances, including special and incentive pus a ances, including special and incentive pays, an amount equal to the difference between such pay and allowances, including special and incentive pays, and the compensation

309 of the Federal Executive Salary Act of $1964 . "$
Public Law $88-426$ ( 73 Stat. 400 ), sec. 306, had earlier amended the second sentence of sec. 28 by substituting the last phrase for the phrase "and the compensation prescribed in section 25 ".

${ }^{32}$ Public Law 85-256 (71 Stat. 576) (1957), sec. 5, added sec. 29.

${ }^{30}$ Public Law 95-209 (91 Stat. 1483) (1977), sec. 5, amended sec. 29 by adding the last two sentences.
} 
Grants for construction of reactors, etc.

41 USC 252(c). (See 41 USC 260b).)

opment and training 34 activities in the fields specified below, by private or public institutions or persons, and to assist in the acquisition of an ever-expanding fund of theoretical and practical knowledge in such fields. To this end the Commission is authorized and directed to make arrangements (including contracts, agreements, and loans) for the conduct of research and development activities relating to-

"(1) nuclear processes;

"(2) the theory and production of atomic energy, including processes, materials, and devices related to such production;

"(3) utilization of special nuclear material and radioactive material for medical, biological, agricultural, health, or military purposes;

"(4) utilization of special nuclear material, atomic energy, and radioactive material and processes entailed in the utilization or production of atomic energy or such material for all other purposes, including industrial or commercial uses, the generation of usable energy, and the demonstration of advances in the commercial or industrial application of atomic energy; 35

"(5) the protection of health and the promotion of safety during research and production activities; and

"(6) the preservation and enhancement of a viable environment by developing more efficient methods to meet the Nation's energy needs. 36

"b. The Commission is further authorized to make grants and contributions to the cost of construction and operation of reactors and other facilities and other equipment to colleges, universities, hospitals, and eleemosynary or charitable institutions for the conduct of educational and training activities relating to the fields in subsection $a^{37}$

"c. The Commission may (1) make arrangements pursuant to this section, without regard to the provisions of section 3709 of the Revised Statutes, as amended, upon certification by the Commission that such action is necessary in the interest of the common defense and security, or upon a showing by the Commission that advertising is not reasonably practicable; (2) make partial and advance payments under such arrangements; and (3) make available for use in connection therewith such of its equipment and facilities as it may deem desirable.

"d. The arrangements made pursuant to this section shall contain such provisions (1) to protect health, (2) to minimize danger to life or property, and (3) to require the reporting and to permit the inspection of work performed thereunder, as the Commission may

\footnotetext{
${ }^{34}$ Publie Law 84-1006 (70 Stat. 1069) (1956), sec. 2. added the words "and training"

${ }^{35}$ Public Law 91-560 (84 Stat. 1472) (1970), sec. 1, amended paragraph 31 a. (4) which read as follows: "Utilization of special nuclear material, atomic energy, and radioactive material and processes entailed in the utilization or production atomic energy or such material for all other purposes, including industrial use, the generation of usable energy, and the demonstration of the practical value of utilization or productionfacilities for industrial or commercial purposes; and".

${ }^{36}$ Public Law $92-84$ (85 Stat. 304) (1971), sec. 201(a). added paragraph (6).

${ }^{37}$ Public Law 84-1006 (70 Stat. 1069)(1956), see. 3, added subsec. 31b. and redesignated former subsecs. 31b. and c. as subsecs. 31 c. and d., respectively.
} 
Research by the Commission.

42 USC

$\sec 2052$

Research for others.

42 USC

sec. 2053

Ownership and operation of production facilities. 42 USC sec. 2061

Operation of the Commission's production facilities.

determine. No such arrangement shall contain any provisions or conditions which prevent the dissemination of scientific or technical information, except to the extent such dissemination is prohibited by law.

"Sec. 32. Research by the Commission.-The Commission is authorized and directed to conduct, through its own facilities, activities and studies of the types specified in section 31 .

"Sec. 33. Research For Others. - Where the Commission finds private facilities or laboratories are inadequate for the purpose, it is authorized to conduct for other persons, through its own facilities, such of those activities and studies of the types specified in section 31 as it deems appropriate to the development of energy. ${ }^{38}$ To the extent the Commission determines that private facilities or laboratories are inadequate to the purpose, and that the Commission's facilities, or scientific or technical resources have the potential of lending significant assistance to other persons in the fields of protection of public health and safety, the Commission may also assist other persons in these fields by conducting for such persons, through the Commission's own facilities, research and development or training activities and studies. The Commission is authorized to determine and make such charges as in its discretion may be desirable for the conduct of the activities and studies referred to in this section. ${ }^{39}$

\section{"CHAPTER 5-PRODUCTION OF SPECIAL NUCLEAR MATERIAL}

"Sec. 41. Ownership and Operation of Production Facilities."a. OWNERSHIP OF PRODUCTION FACILITIES. - The Commission, as agent of and on behalf of the United States, shall be the exclusive owner of all production facilities other than facilities which (1) are useful in the conduct of research and development activities in the fields specified in section 31, and do not, in the opinion of the Commission, have a potential production rate adequate to enable the user of such facilities to produce within a reasonable period of time a sufficient quantity of special nuclear material to produce an atomic weapon; (2) are licensed by the Commission pursuant under this title; or (3) are owned by the United States Enrichment Corporation. $39 \mathrm{a}$

"b. OPERATION OF THE COMMISSION'S PRODUCTION FACILITIES. - The Commission is authorized and directed to produce or to provide for the production of special nuclear material in its own production facilities. To the extent deemed necessary, the Commission is authorized to make, or to continue in ef-

\footnotetext{
${ }^{38}$ Public Law 92-84 (85 Stat. 304) (1971), sec. 201(b), amended this sentence. Prior to amendment it read as fol lows: "Where the Commission finds private facilities or laboratories are inadequate to the purpose, it is authorized to conduct for other persons, through its own facilities, such of those activities and studies of the types specified in section 31 as it deems appropriate to the development of atomic energy."

${ }^{39}$ Public Law 90-190 (81 Stat. 575) (1967), sec. 7, amended sec. 33. Prior to amendment, the section read as follows:

"Sec 33. RESEARCH FOR OTHERS. - Where the Commission finds private facilities or laboratories are in adequate to the purpose, it is authorized to conduct for other persons, through its own facilities, such of those activities and studies of the types specified in section 31 as it deems appropriate to the derelopment of atomicenergy. The Commission is authorized to determine and make such charges as in its discretion may be desirable for the conduct of such activities and studies."

${ }^{39 a}$ Public Law 102-486 (106 Stat. 2943) Oat. 24, 1992 added new section (3).
} 
41 USC 252(c)

(See 41 USC 260(b).)

Operation of other production facilities.

Irradiation of materials. 42 USC sec. 2062

Acquisition of production facilities. 42 USC sec. 2063

44 USC 252(c) (See 41 USC 260(b).)

Disposition of energy. 42 USC sec. 2064 fect, contracts with persons obligating them to produce special nuclear material in facilities owned by the Commission. The Commission is also authorized to enter into research and development contracts authorizing the contractor to produce special nuclear material in facilities owned by the Commission to the extent that the production of such special nuclear material may be incident to the conduct of research and development activities under such contracts. Any contract entered into under this section shall contain provisions (1) prohibiting the contractor from subcontracting any part of the work he is obligated to perform under the contract, except as authorized by the Commission; and (2) obligating the contractor (A) to make such reports pertaining to activities under the contract to the Commission as the Commission may require (B) to submit to inspection by employees of the Commission of all such activities, and (C) to comply with all safety and security regulations which may be prescribed by the Commission. Any contract made under the provisions of this paragraph may be made without regard to the provisions of section 3079 of the Revised Statues, as amended, upon certification by the Commission that such action is necessary in the interest of the common defense and security, or upon a showing by the Commission that advertising is not reasonable practicable. Partial and advance payments may be made under such contracts. 40

"c. OPERATION OF OTHER PRODUCTION FACILITIES. - Special nuclear material may be produced in the facilities which under this section are not required to be owned by the Commission.

"Sec. 42. Irradiation of Materials.-The Commission and persons lawfully producing or utilizing special nuclear material are authorized to expose materials of any kind to the radiation incident to the processes of producing or utilizing special nuclear material.

"Sec. 43. Acquisition of Production Facilities.-The Commission is authorized to purchase any interest in facilities for the production of special nuclear materials, or in real property on which such facilities are located, without regard to the provisions of section 3709 of the Revised Statutes, as amended, upon certification by the Commission that such action is necessary in the interest of the common defense and security, or upon a showing by the Commission that advertising is not reasonably practicable. Partial and advance payments may be made under contracts for such purposes. The Commission is further authorized to requisition, condemn, or otherwise acquire any interest in such production facilities, or to condemn or otherwise acquire such real property, and just compensation shall be made therefor.

"Sec. 44. Disposition Of Energy. - If energy is produced at production facilities of the Commission or is produced in experimental utilization facilities of the Commission, such energy may be used by the Commission, or transferred to other Government agencies, or sold to publicly, cooperatively, or privately owned utilities or users at reasonable and

40public Law 90-190 (81 Stat. 575) (1967), sec. 8, deleted the last sentence of sec. 41b. which read as follows: "The President shall determine in writing at least once each year the quantities of special nuclear material to be produced under this section and shall specify in such determination the quantities of special nuclear material to be available for distribution by the Commission pursuant to section 53 or $54 . .^{n}$ 
Special nuclear material.

42 USC sec. 2071

Nuclear material licenses

42 USC sec. 2073 nondiscriminatory prices. If the energy produced is electric energy, the price shall be subject to regulation by the appropriate agency having jurisdiction. In contracting for the disposal of such energy, the Commission shall give preference and priority to public bodies and cooperatives or to privately owned utilities providing electric utility services to high cost areas not being served by public bodies or cooperatives. Nothing in this Act shall be construed to authorize the Commission to engage in the sale or distribution of energy for commercial use except such energy as may be produced by the Commission incident to the operation of research and development facilities of the Commission, or of production facilities of the Commission.

\section{"CHAPTER 6-SPECIAL NUCLEAR MATERIAL}

"Sec. 51. Special Nuclear Material.-The Commission may determine from time to time that other material is special nuclear material in addition to that specified in the definition as special nuclear material. Before making any such determination, the Commission must find that such material is capable of releasing substantial quantities of atomic energy and must find that the determination that such material is special nuclear material is in the interest of the common defense and security, and the President must have expressly assented in writing to the determination. The Commission's determination, together with the assent of the President, shall be submitted to the Joint Committee* and a period of thirty days shall elapse while Congress is in session (in computing such thirty days, there shall be excluded the days on which either House is not in session because of an adjournment for more than three days) before the determination of the Commission may become effective: Provided, however, That the Joint Committee, after having received such determination, may by resolution in writing, waive the conditions of or all or any portion of such thirty-day period.

"Sec. 53,41 Domestic Distribution of Special Nuclear Material-

"a. The Commission is authorized (i) to issued licenses to transfer or receive in interstate commerce, transfer, deliver, acquire, possess, own, receive possession of or title to, import, or export under the terms of an agreement for cooperation arranged pursuant to section 123, special nuclear material, (ii) to make special nuclear material available for the period of the license, and, (iii) to distrib-

\footnotetext{
- See Public Law 95-110, sec. $301 \mathrm{~b}$.

${ }^{41}$ Public Law 88-489 (78 Stat. 602) (1964), sec. 4, reads as follows:

"Section 52 of the Atomic Energy Act of 1954, as amended, is repealed. All rights, title, and interest in and to any special nuclear material vested in the United States solely by virtue of the provisions of the first sentence of such section 52, and not by any other transaction authorized by the Atomic Energy Aet of 1954, as amended, or other applicable law, are hereby extinguishexl."

Section 52 read as follows:

"Sec. 52. Government Ownership Of All Special Nuclear Material.-All rights, title, and interest in or to any special muclear material within or under the jurisdiction of the United States, now or hereafter produced, shall be the property of the United States andshall be administered and controlled by the Commission as agent of and on behalfor property of the United States and shall be administered and controlled by he Commission as agent of and on behalfo the United States by virtue of this Act. Any person owning any interest in any special nuclear material at the timewhen such material is hereafter determined to be a special nuclear material shall be paid just compensation therefor. Any person who lawfully produces any special nuclear material, except pursuant to a contract with the Commission unde the provisions of section 31 or 41 , shall be paid a fair price, determined pursuant to section 56 , for producing such material."
} 
ute special nuclear material within the United States to qualified applicants requesting such material-42

"(1) for the conduct of research and development activities of the types specified in section 31 ;

"(2) for use in the conduct of research and development activities or in medical therapy under a license issued pursuant to section 104;

"(3) for use under a license issued pursuant to section 103;

"(4) for such other uses as the Commission determines to be appropriate to carry out the purposes of this Act. 43

"b. The Commission shall establish, by rule, minimum criteria for the issuance of specific or general licenses for the distribution of special nuclear material depending upon the degree of importance to the common defense and security or to the health and safety of the public of -

"(1) the physical characteristics of the special nuclear material to be distributed;

"(2) the quantities of special nuclear material to be distributed; and

"(3) the intended use of the special nuclear material to be distributed.

"c. (1) The Commission may distribute special nuclear material licensed under this section by sale, lease, lease with option to buy, or grant.44 Provided however, That unless otherwise authorized by

Distribution.

Agreements. law, the Commission shall not after December 31, 1970, distribute special nuclear material except by sale ${ }^{44^{2}}$ to any person who possesses or operates a utilization facility under a license pursuant to section 103 or $104 \mathrm{~b}$. for use in the course of activities under such license; nor shall the Commission permit any such person after June 30,1973, to continue leasing for use in the course of such activities special nuclear material previously leased to such person by the Commission.

"(2) The Commission shall establish reasonable sales prices for the special nuclear material licensed and distributed by sale under this section. Such sales prices shall be established on a nondiscriminatory basis which, in the opinion of the Commission, will provide reasonable compensation to the Government for such special nuclear material.

"(3) The Commission is authorized to enter into agreements with licensees for such period of time as the Commission may deem necessary or desirable to distribute to such licensees such quantities of special nuclear material as may be necessary for the conduct of the licensed activity. In such agreements, the

\footnotetext{
${ }^{42}$ Public Law 88-489 (78 Stat. 602) (1964), sec. 5, amended this subsection. Before amendment, this subsection read:

The Commission is authorized to issue licenses for the possession of, to make available for the period of the license, and to distribute special nuclear material within the United States to qualified applicants requesting such material-

${ }^{43}$ Public Law 85-681 (72 Stat. 632) (1958), sec. 1, added clause (4).

${ }^{44}$ Public Law 90-190 (81 Stat. 575) (1967), sec. 10, added the phrase "or through the provision of production or enrichment services".

44aSect. (c)(1) amended by P.L. 102-486, (106 Stat. 2943) Oct. 24, 1992.
} 
Commission may agree to repurchase any special nuclear material licensed and distributed by sale which is not consumed in the course of the licensed activity, or any uranium remaining after irradiation of such special nuclear material, at a repurchase price not to exceed the Commission's sale price for comparable special nuclear material or uranium in effect at the time of delivery of such material to the Commission.

"(4) The Commission may make a reasonable charge, determined pursuant to this section, for the use of special nuclear material licensed and distributed by lease under subsection 53 a.(1), (2) or (4) ${ }^{45}$ and shall make a reasonable charge determined pursuant to this section for the use of special nuclear material licensed and distributed by lease under subsection 53 a. (3). The Commission shall establish criteria in writing for the determination of whether special nuclear material will be distributed by grant and for the determination of whether a charge will be made for the use of special nuclear material licensed and distributed by lease under subsection 53 a. (1), (2) or (4), considering, among other things, whether the licensee is a nonprofit or eleemosynary institution and the purposes for which the special nuclear material will be used. 46

"d. In determining the reasonable charge to be made by the Commission for the use of special nuclear material distributed by lease $\mathrm{A}^{47}$ to licensees of utilization or production facilities licensed pursuant to section 103 or 104 , in addition to consideration of the cost thereof, the Commission shall take into consideration-

"(1) the use to be made of the special nuclear material;

"(2) the extent to which the use of the special nuclear material will advance the development of the peaceful uses of atomic energy;

"(3) the energy value of the special nuclear material in the particular use for which the license is issued;

"(4) whether the special nuclear material is to be used in facilities licensed pursuant to section 103 or 104. In this respect, the Commission shall, insofar as practicable, make uniform, nondiscriminatory charges for the use of special nuclear material distributed to facilities licensed pursuant to section 103 ; and

"(5) with respect to special nuclear material consumed in a facility licensed pursuant to section 103 , the Commission shall make a further charge equivalent to the sale price for similar special nuclear material established by the Commission in accordance with subsection $53 \mathrm{c}$. (2), and the Commission may

\footnotetext{
${ }^{45}$ Public Law 85-681 (72 Stat. 632) (1958), sec. 2, amended subsec. c. of sec. 53 . Before amendment this phraseand the same phrase in the net sentence read "subsection 53 a. (1) or subsection 53 a. (2)". See footnote 45 .

${ }^{46}$ Public Law 88-489 (78 Stat. 602) (1964), sec. 6, amended subsec. 53c. Before amendment, this subsection read:

"c. The Commission may make a reasonable charge, determined pursuant to this section, for the use of special nuclear material licensed and distributed under subsection $53 \mathrm{a}$.(1), (2) or (4) and shall make a reasonable chargedetermined pursuant to this section for theuse of special nuclear material licensed and distributed under subsection 53 a (3). The Commission shall establish criteria in writing for the determination of whet her a charge will be made for the use of special nuclear mariallicensed and distributed special nclear materialliced ans will be used."

47 Public Law 88-489 (78 Stat. 602) (1964), sec. 7, added the words "by lease.
} 
License conditions.

Distribution for independent research, etc.

Foreign distribution of special nuclear material, 42 USC sec. 2074.

make such a charge with respect to such material consumed in a facility licensed pursuant to section 104.48

"e. Each license issued pursuant to this section shall contain and be subject to the following conditions-

" $(2)^{49}$ no right to the special nuclear material shall be conferred by the license except as defined by the license;

"(3) neither the license nor any right under the license shall be assigned or otherwise transferred in violation of the provisions of this Act;

“(4) all special nuclear material shall be subject to the right of recapture or control reserved by section 108 and to all other provisions of this Act;

"(5) no special nuclear material may be used in any utilization or production facility except in accordance with the provisions of this Act;

"(6) special nuclear material shall be distributed only on terms, as may be established by rule of the Commission, such that no user will be permitted to construct an atomic weapon;

"(7) special nuclear material shall be distributed only pursuant to such safety standards as may be established by rule of the Commission to protect health and to minimize danger to life or property; and

(8) except to the extent that the indemnification and limitation of liability provisions of section $170 \mathrm{apply}$, the license will hold the United States and the Commission harmless from any damages resulting from the use or possession of special nuclear material by the licensee. 50

"f. The Commission is directed to distribute within the United States sufficient special nuclear material to permit the conduct of widespread independent research and development activities to the maximum extent practicable. 51 In the event that applications for special nuclear material exceed the amount available for distribution, preference shall be given to those activities which are most likely, in the opinion of the Commission, to contribute to basic research, to the development of peacetime uses of atomic energy, or to the economic and military strength of the Nation.

"Sec. 54. Foreign Distribution Of Special Nuclear Material.-a. The Commission is authorized to cooperate with any nation or group of nations by distributing special nuclear material and to distribute such special nuclear material, pursuant to the terms of an agreement for cooperation to which such nation or group of nations is a party and which is made in accordance with section 123. Unless hereafter otherwise

\footnotetext{
${ }^{48}$ Public Law 88-489 (78 Stat. 602) (1964), sec. 7, amended this paragraph. Before amendment this paragraph read:

"(5) with respect to special nuclear material consumed in a facility licensed pursuant to section 103 , the Commissionshall makea further charge based on the cost to the Commission, as estimated by the Commission, or the average fair price paid for the production of such special nuclear material as determined by section 56 , whichever is lower."

${ }^{49}$ Public Law 88-489 (78 Stat. 602) (1964), sec 8, deleted, subsec. 53 c. (1). Subsec. 53 e. (1) read:

"(1) title to all special nuclear material shall at all times be in the United States:"

50 Public Law 85-256 (71 Stat. 576), Sec 2 amended Sec. 53e.(8). Before amendment this Subsection read:

(8) the licensee will hold the United States and the Commission harmless from any damages resulting from the use or possession of special nuclear material by the licensee."

${ }^{51}$ Public Law 90-190 (81 Stat. 575)(1967), sec. 9, deleted the following phrase which appeared at the end of this sentence: "and within the limitations set by the President pursuant to section 41."
} 
Purchase of special nuclear material. authorized by law the Commission shall be compensated for special nuclear material so distributed at not less than the Commission's published charges applicable to the domestic distribution of such material, except that the Commission to assist and encourage research on peaceful uses or for medical therapy may so distribute without charge during any calendar year only a quantity of such material which at the time of transfer does not exceed in value $\$ 10,000$ in the case of one nation or $\$ 50,000$ in the case of any group of nations. The Commission may distribute to the International Atomic Energy Agency, or to any group of nations, only such amounts of special nuclear materials and for such period of time as are authorized by Congress: Provided, however, That, (i) notwithstanding this provision, the Commission is hereby authorized, subject to the provisions of section 123, to distribute to the Agency, five thousand kilograms of contained uranium 235, five hundred grams of uranium-233, and three kilograms of plutonium, together with the amounts of special nuclear material which will match in amount the sum of all quantities of special nuclear materials made available by all other members of the Agency to June 1, 1960; and (ii) notwithstanding the foregoing provisions of this subsection, the Commission may distribute to the International Atomic Energy Agency, or to any group of nations, such other amounts of special nuclear materials and for such other periods of time as are established in writing by the Commission: Provided, however, That before they are established by the Commission pursuant to this subdivision (ii), such proposed amounts and periods shall be submitted to the Congress and referred to the Joint Committee ${ }^{52}$ and a period of sixty days shall elapse while Congress is in session (in computing such sixty days, there shall be excluded the days on which either House is not in session because of adjournment of more than three days): And provided further, That any such proposed amounts and periods shall not become effective if during such sixty-day period the Congress passes a concurrent resolution stating in substance that it does not favor the proposed action: And provided further, That prior to the elapse of the first thirty days of any such sixty-day period the Joint Committee shall submit a report to the Congress of its views and recommendations respecting the proposed amounts and periods and an accompanying proposed concurrent resolution stating in substance that the Congress

favors, or does not favor, as the case may be, the proposed amounts or periods. The Commission may agree to repurchase any special nuclear material distributed under a sale arrangement pursuant to this subsection which is not consumed in the course of activities conducted in accordance with the agreement for cooperation, or any uranium remaining after irradiation of such special nuclear material, at a repurchase price not to exceed the Commission's sale price for comparable special nuclear material or uranium in effect at the time of delivery of such material to the Commission: The Commission may also agree to purchase, consistent with and within the period of the agreement for cooperation, special nuclear material produced in a nuclear reactor located outside the United States through the use of special nuclear material which was leased or sold pursuant to this subsection. Under any such agreement

${ }^{62}$ See Public Law 95-110, sec. 301b. 
Foreign distribution of certain materials.

the Commission shall purchase only such material as is delivered to the Commission during any period when there is in effect a guaranteed purchase price for the same material produced in a nuclear reactor by a person licensed under section 104, established by the Commission pursuant to section 56 , and the price to be paid shall be the price so established by the Commission and in effect for the same material delivered to the Commission.

"b. Notwithstanding the provisions of sections 123,124 , and 125, the Commission is authorized to distribute to any person outside the United States (1) plutonium containing 80 percent centum or more by weight of plutonium-238, and (2) other special nuclear material when it has, in accordance with subsection $57 \mathrm{~d}$., exempted certain classes or quantities of such other special nuclear material or kinds of uses or users thereof from the requirements for a license set forth in this chapter. Unless hereafter otherwise authorized by law, the Commission shall be compensated for special nuclear material so distributed at not less than the Commission's published charges applicable to the domestic distribution of such material. The Commission shall not distribute any plutonium containing 80 per centum or more by weight of plutonium-238 to any person under this subsection if, in its opinion, such distribution would be inimical to the common defense and security. The Commission may require such reports regarding the use of material distributed pursuant to the provisions of this subsection as it deems necessary.

"c. The Commission is authorized to license or otherwise permit others to distribute special nuclear material to any person outside the United States under the same conditions, except as to charges, as would be applicable if the material were distributed by the Commission. .33

63 Section 2 of Public Law 93-377 (88 Stat. 473) (1974), amended section 54. Previously section 54 read as follows: «Sec.54. Foreign Distribution Of Special NuclearMaterial - The Commission is authorized to cooperate with any nation by distributing special nuclear material and to distribute such special nuclear material, pursuant to the terms of an agreement for cooperation to which such nation is a party and which is made in accordance with section 123. Unless hereafter otherwiseauthorized by law the Commission shall be compensated for special nuclear material so distributed at not less than the Commission's published charges applicable to the domestic distribution of such material, except that the Commission to assist and encourage research on peaceful uses or for medical therapy may so distribute without charge during any calendar year only a quantity of such material which at the time of transfer does not exceed in value $\$ 10,000$ in the case of one nation or $\$ 50,000$ in the case of any group of nations. The Commission may distribute to the International Atomic Energy Agency, or to any group of nations, only such amounts of special nuclear materials and for such periods of time as are authorized by Congress; Provided, however, That notwithstanding this provision, the Commission is hereby authorized subject to the provisions of section 123, to distribute to the Agency five thousand kilograms of contained uranium-235, five hund red grams of uranium 233 and three kilograms of plutonium together with the amounts of special nucicar material which will match in amount the sum of all quantities of special nuclearmaterials madeavilable by all other members of the Agency to July1, 1960. The Commission may agree to repurchaseany special puclear material distributed under a sale Arrangement pursuant to this section which is not consumed in the course of nuclear material distributed under a sale arrangement pursuant to this section which is not consumed in the course of the activities conducted in accordance with the agreement for cooperation, or any uranium remaining after irradiation of such special nuclear material, at a repurchase price not to exceed the Commission's sale price for comparable special auclear material or uranium in effect at thetime of delivery of such material to the Commission. The Commission may also agree to purchase, consistent with and within the period of the agreement for cooperation, special nuclearmaterial produced in a muclear reactor located outside the United States through the use of special nuclear material which was leased or sold pursuant to this section. Under any such agreement, the Commissionshall purchase only suchmaterial as is delivered to the Commission during any period when there is in effect a guaranteed purchase price for the same matorial produced in a nuclear reactor by a person licensed under section 104, established by the Commission pursuant to section 56, and the price to be paid shall be the priceso established by the Commission and in effect for the samematerial delivered to the Commission.

Public Law 88-487 (78 Stat. 602)(1964) has added the last three sentences to section 54, Publa Law 87-206 (75 Staf 475)(1961) sec. 4, had added the words "five hundred grams of uranium 233 and three kilograms of phutonium" to the proviso in this section. Public Law 85-177(71 Stat. 453)(1957), sec. 7, had added the second and third nentences, including the proviso, to sec. 54 . 
Acquisition. 42 USC $\sec .2075$.

41 USC 252(c) (see 41 USC 260(b).)

Guaranteed purchase prices. 42 U.S.C. Sec. 2076. "d. The authority to distribute special nuclear material under this section other than under an export license granted by the Nuclear Regulatory Commission shall extend only to the following small quantities of special nuclear material (in no event more than five hundred grams per year of the uranium isotope 233 , the uranium isotope 235 , or plutonium contained in special nuclear material to any recipient):

"(l) which are contained in laboratory samples, medical devices, or monitoring or other instruments; or

"(2) the distribution of which is needed to deal with an emergency situation in which time is of the essence.

"e. The authority in this section to commit United States funds for any activities pursuant to any subsequent arrangement under section 131 a. (2)(E) shall be subject to the requirements of section 131.54

"Sec. 55. Acquisition.-The Commission is authorized, to the extent it deems necessary to effectuate the provisions of this Act, to purchase without regard to the limitations in section 54 or any guaranteed purchase prices established pursuant to section 56 , and to take, requisition, condemn, or otherwise acquire any special nuclear material or any interest therein. Any contract of purchase made under this section may be made without regard to the provisions of section 3709 of the Revised Statutes, as amended, upon certification by the Commission that such action is necessary in the interest of the common defense and security, or upon a showing by the Commission that advertising is not reasonably practical. Partial and advance payments may be made under contracts for such purposes. Just compensation shall be made for any right, property, or interest in property taken, requisitioned, or con condemned under this section. ${ }^{55}$ Providing, That the authority in this section to commit United States funds for any activities pursuant to any subsequent arrangement under section 131 a.(2)(E) shall be subject to the requirements of section 131.56

"Sec. 56. Guaranteed Purchase Prices. - The Commission shall establish guaranteed purchase prices for plutonium produced in a nuclear reactor by a person licensed under section 104 and delivered to the Commission before January 1, 1971. The Commission shall also establish for such periods of time as it may deem necessary but not to exceed ten years as to any such period, guaranteed purchase prices for uranium enriched in the isotope 233 produced in a nuclear reactor by a person licensed under section 103 or section 104 and delivered to the Commission within the period of the guarantee. 57 Guaranteed purchase prices established under the authority of this section shall not exceed the Com-

\footnotetext{
${ }^{54}$ Public Law 95-242 (92 Stat. 125)(1978), sec. 301(a) and sec. 303(b)(1) added subsec. 54(d) and subsec. 54(c), re spectively.

65 Public Law 88-489 (78 Stat. 602)(1964), sec. 10, amended sec. 55 by substituting a complete new sec. 55 . Before amendment sec. 55 read as follows:

Sec. 55 Acquisition. - The Commission is authorized to purchase or otherwise acquire any special muclear material or any inlerest therein outside the United States without regard to the provisions of section 3709 of the Revised Statutes, as amended, upon certification by the Commission that such action is necessary in the interest of the common defense and security, or upon a showing by the Commission that advertising is not reasonably practicable. Partial and advance payments may be made under contracts for such purposes."

${ }^{66}$ Public Law $95-242$ (92 Stat. 131) (1978), sec. 303(b)(2), added the proviso at the end of sec. 55.

${ }^{66}$ Public Law 91-560 (84 Stat. 1472) (1970), sec. 2, added "section 103 or" to this sentence.
} 
Unauthorized handling. 42 U.S.C. sec. 2077.

Special nuclear material production. Technology transfers. 42 U.S.C. 2077. Post, p. 142.

Post, p. 127.

Authorization requests, procedures. mission's determination of the estimated value of plutonium or uranium enriched in the isotope 233 as fuel in nuclear reactors, and such prices shall be established on a non-discriminatory basis: Provided, That the Commission is authorized to establish such guaranteed purchase prices only for such plutonium or uranium enriched in the isotope 233 as the Commission shall determine is produced through the use of special nuclear material which was leased or sold by the Commission pursuant to section 53.58

"Sec. 57. Prohibition.-

"a. Unless authorized by a general or specific license issued by the Commission, which the Commission is authorized to issue pursuant to section 53, no person may transfer or receive in interstate commerce, transfer, deliver, acquire, own, possess, receive possession of or title to, or import into or export from the United States any special nuclear material.

¿b. It shall be unlawful for any person to directly or indirectly engage in the production of any special nuclear material outside of the United States except (1) as specifically authorized under an agreement for cooperation made pursuant to section 123 , including a specific authorization in a subsequent arrangement under section 131 of this Act, or (2) upon authorization by the Secretary of Energy after a determination that such activity will not be inimical to the interest of the United States: Provided, That any such determination by the Secretary of Energy shall be made only with the concurrence of the Department of State and after consultation with the Arms Control and Disarmament Agency, the Nuclear Regulatory Commission, the Department of Commerce, and the Department of Defense. The Secretary of Energy shall, within ninety days after the enactment of the Nuclear Non-Proliferation Act of 1978, establish orderly and expeditious procedures, including provision for necessary administrative actions and inter-agency memoranda of understanding, which are mutually agreeable to the Secretaries of State, Defense, and Commerce, the Director of the Arms Control and Disarmament Agency, and the Nuclear Regulatory Commission for the consideration of requests for authorization under this subsection. Such procedures shall include, at a minimum, explicit direction on the handling of such requests, express deadlines for the solicitation and collection of the views of the consulted agencies (with identified officials responsible for meeting such deadlines), an inter-agency coordinating authority to monitor the processing of such requests, predetermined procedures for the expeditious handling of intra-agency and inter-agency

${ }^{60}$ Public Law 88-489 (78 Stat. 602)(1964), sec. 11 amended sec. 56, by substituting a new sec. 56. Before amendment sec. 56 read as follows:

sec. 56. Fair Price.-In determining the fair price to be paid by the Commission pursuant to section 52 for the production of any special nuclear material, the Commission shall take into consideration the value of the special nuclear material for its intended use by the United States and may give such weight to the actual cost of producing that material as the Commission finds to be equitable. The fair price, as may be determined by the Commission, shall apply to all licensed producers of the same material: Provided, however, That the Commission may establish guaranteed fair to all licensed producers of the same material: Frovided, however, That the Commission may establish guaranteed fair not to exceed seven years." 
Standards and criteria.

Trade secrets, protection.

42 U.S.C. 2014.

Post, pp. 131, 141.

42 U.S.C. 7172

42 U.S.C. 2074, 2094.

Ante, p. 125.

Certain exemptions. disagreements and appeals to higher authorities, frequent meetings of inter-agency administrative coordinators to review the status of all pending requests, and similar administrative mechanisms. To the extent practicable, an applicant should be advised of all the information required of the applicant for the entire process for every agency's needs at the beginning of the process. Potentially controversial requests should be identified as quickly as possible so that any required policy decisions or diplomatic consultations can be initiated in a timely manner. An immediate effort should be undertaken to establish quickly any necessary standards and criteria, including the nature of only required assurances or evidentiary showings, for the decision required under this subsection. The processing of any requests proposed and filed as of the date of enactment of the Nuclear Non-Proliferation Act of 1978 shall not be delayed pending the development and establishment of procedures to implement the requirements of this subsection. Any trade secrets or proprietary information submitted by any person seeking an authorization under this subsection shall be afforded the maximum degree of protection allowable by law: Provided further, That the export of component parts as defined in subsection $11 \mathrm{v}$. (2) or $11 \mathrm{cc}$. (2) shall be governed by sections 109 and 126 of this Act: Provided further, That notwithstanding subsection 402(d) of the Department of Energy Organization Act (Public Law 95-91), the Secretary of Energy and not the Federal Energy Regulatory Commission, shall have sole jurisdiction within the Department of Energy over any matter arising from any function of the Secretary of Energy in this section, section 54 d., section 64 , or section 111 b.59

"c. The Commission shall not-

“(1) distribute any special nuclear material to any person for a use which is not under the jurisdiction of the United States except pursuant to the provisions of section 54; or

"(2) distribute any special nuclear material or issue a license pursuant to section 53 to any person within the United States if the Commission finds that the distribution of such special nuclear material or the issuance of such license would be inimical to the common defense and security or would constitute an unreasonable risk to the health and safety of the public.

"d. The Commission is authorized to establish classes of special nuclear material and to exempt certain classes or quantities of special nuclear material or kinds of uses or users from the requirements for a license set forth in this section when it makes a finding that the exemption of such classes or quantities of special nuclear material or such kinds of uses or users would not be inimical to the

68 Public Law 95-242 (92 Stat. 126) (1978), sec. 302, amended sec. 57 by substituting a complete new subsec. 57(b). Before amendment, subsec. 57(b) read as follows: "b. It shall be unlawful for any person to directly or indirectly engage in the production of any special nuclear material outside of the United States except (1) under an agreement for cooperation made pursuant to section 123, or (2) upon authorization by the Commission after a determination that such activity will not be inimical to the interest of the United States." 
Review

42 USC sec. 2078

Source material. 42 USC sec. 2091 common defense and security and would not constitute unreasonable risk to the health and safety of the public. ${ }^{60}$

"e. Special nuclear material, as defined in section 11, produced in facilities licensed under section 103 or 104 may not be transferred, reprocessed, used, or otherwise made available by any instrumentality of the United States or any other person for nuclear explosive purposes." 61

"Sec. 58. Review.-Before the Commission establishes any guaranteed purchase price or guaranteed purchase price period in accordance with the provisions of section 56, or establishes any criteria for the waiver of any charge for the use of special nuclear material licensed and distributed under section 53, the proposed guaranteed purchase price, guaranteed purchase price period, or criteria for the waiver of such charge shall be submitted to the Joint Committee and a period of forty-five days shall elapse while Congress is in session (in computing such forty-five days there shall be excluded the days in which either House is not in session because of adjournment for more than three days): Provided, however, That the Joint Committee, after having received the proposed guaranteed purchase price, guaranteed purchase price period, or criteria for the waiver of such charge, may by resolution in writing waive the conditions of, or all or any portion of, such forty-five day period. 62,63

\section{"CHAPTER 7-SOURCE MATERIAL}

"Sec. 61. Source Material.-The Commission may determine from time to time that other material is source material in addition to those specified in the definition of source material. Before making such determination, the Commission must find that such material is essential to the production of special nuclear material and must find that the determination that such material is source material is in the interest of the common defense and security, and the President must have expressly

${ }^{60}$ Section 3 of Public Law 93-377 (88 Stat. 475)(1974) added new subsec. d to sec. 57. Previously Public Law 88-459 (78 Stat. 602) (1964), sec. 12, amended sec. 57 by substituting a complete new sec. 57 . Before amendment sec. 57 read as follows:

"Sec. 57. Prohibition -

a. It shall be unlawful for any person to-

"(1) possess or transfer any special nuclear material which is the property of the United States except as authorized by the Commission pursuant to subsection 53 a.;

"(2) transfer or receive any special nuclear material in interstate commerce except as authorized by the Commission pursuant to subsection $53 \mathrm{a}$, or export from or import into the United States any special nuclear material; and "(3) directly or indirectly engage in the production of any special nuelear material outside of the United States except (A) under an agreement for cooperation made pursuant to section 123, or (B) upon authorization by the Commisafter a determination that such activity will not be inimical to the interest of the United States.

"b. The Commission shall not distribute any special nuclear material-

"(D) to anypersan for a use which is not under the jurisdiction of the United States except pursuant to the provisions of section 54; or

"(2) to any person within the Untied States, if the Commission finds that the distribution of such special nuclear material to such person would be inimical to the common defense and security."

${ }^{61}$ Section 14 of Public Law 97-415 (96 Stat. 2067) (1983) added new subsec. e to sec. 57.

62 Public Law 85-79 (71 Stat. 274) (1957), added sec. 58. See footnote 63.

63 Public Law 88-469 (78 Stat. 602) (1964), sec. 13, amended sec. 58 by substituting a completenew sec. 58. Before amendment sec. 58 read as follows:

"Sec. 58. Review. - Before the Commission establishes any fair priceor guaranteed fair priceperiod in accordance with the provisions of section 56, or establishes any criteria for the waiver of any charge for the use of special nuclear material licensed or distributed under section 53 the proposed fair price, guaranteed fair priceperiod, or criteria for the waiver of such chargeshall be submitted to the Joint Committee, and a period of forty-fivedays shall elapse while Congress is in session (in computing such forty-five days there shall be excluded the days in which either House is not in session because of adjournment for more than three days): Provided, however, That the Joint Committec, after having received the proposed fair price, guaranteed fair prices period, or criteria for the waiver of such charge, may by resolution waive the conditions of or all or any portion of such forty-five day period." 
Submittal of determination to Joint Committee.

License for transfers required 42 USC sec. 2092.

Domestic distribution of source material. 42 USC sec. 2093

Charges. assented in writing to the determination. The Commission's determination, together with the assent of the President, shall be submitted to the Joint Committee* and a period of thirty days shall elapse while Congress is in session (in computing such thirty days, there shall be excluded the days on which either House is not in session because of an adjournment of more than three days) before the determination of the Commission may become effective: Provided, however, That the Joint Committee, after having received such determination, may by resolution in writing waive the conditions of or all or any portion of such thirty-day period.

"Sec. 62. License For Transfers Required.-Unless authorized by a general or specific license issued by the Commission, which the Commission is hereby authorized to issue, no person may transfer or receive in interstate commerce, transfer, deliver, receive possession of or title to, or import into or export from the United States any source material after removal from its place of deposit in nature, except that licenses shall not be required for quantities of source material which, in the opinion of the Commission, are unimportant.

"Sec. 63. Domestic Distribution Of Source Material.-

"a. The Commission is authorized to issue licenses for and to distribute source material within the United States to qualified applicants requesting such material-

"(I) for the conduct of research and development activities of the types specified in section 31 ;

"(2) for use in the conduct of research and development activities or in medical therapy under a license issued pursuant to section 104;

"(3) for use under a license issued pursuant to section 103; or

"(4) for any other use approved by the Commission as an aid to science or industry.

"b. The Commission shall establish, by rule, minimum criteria for the issuance of specific or general licenses for the distribution of source material depending upon the degree of importance to the common defense and security or to the health and safety of the public of-

"(l) the physical characteristics of the source material to be distributed;

"(2) the quantities of source material to be distributed; and

"(3) the intended use of the source material to be distributed.

"c. The Commission may make a reasonable charge determined pursuant to subsection $161 \mathrm{~m}$. for the source material licensed and distributed under subsection 63 a. (1), subsection 63 a. (2), or subsection 63 a. (4), and shall make a reasonable charge determined pursuant to subsection $161 \mathrm{~m}$., for the source material licensed and distributed under subsection 63 a. (3). The Commission shall establish criteria in writing for the determination of whether a charge will be made for the source material licensed and distributed under subsection 63a. (1), subsection 63 a. (2), or subsection 63 a. (4), considering, among other things, whether the license is 
Foreign

distribution of

material.

42 USC sec. 2094.

42 USC 2094.

Reporting.

42 USC sec. 2095.

Acquisitions.

42 USC sec. 2096.

41 USC 252(c):

(See 41 USC

260(b).

Operations on lands belonging to the United

States.

42 USC sec. 2097 nonprofit or eleemosynary institution and the purposes for which the source material will be used.

Sec. 64. Foreign Distribution Of Source Material.-The Commission is authorized to cooperate with any nation by distributing source material and to distribute source material pursuant to the terms of an agreement for cooperation to which such nation is a party and which is made in accordance with section 123 . The Commission is alsoauthorized to distribute source material outside of the United States upon a determination by the Commission that such activity will not be inimical to the interests of the United. States. The authority to distribute source material under this section other than under an export license granted by the Nuclear Regulatory Commission shall in no case extend to quantities of source material in excess of three metric tons per year per recipient. 64

Sec. 65. Reporting.--The Commission is authorized to issue such rules, regulations, or orders requiring reports of ownership, possession, extraction, refining, shipment, or other handling of source material as it may deem necessary, except that such reports shall not be required with respect to (a) any source material prior to removal from its place of deposit in nature, or (b) quantities of source material which in the opinion of the Commission are unimportant or the reporting of which will discourage independent prospecting for new deposits.

Sec. 66. Acquisition.-The Commission is authorized and directed, to the extent it deems necessary to effectuate the provisions of this Acta. to purchase, take, requisition, condemn, or otherwise acquire supplies of source material;

b. to purchase, condemn, or otherwise acquire any interest in real property containing deposits of source material; and

c. to purchase, condemn, or otherwise acquire rights to enter upon any real property deemed by the Commission to have possibilities of containing deposits of source material in order to conduct prospecting and exploratory operations for such deposits. Any purchase made under this section may be made without regard to the provisions of section 3709 of the Revised Statutes, as amended, upon certification by the Commission that such action is necessary in the interest of the common defense and security, or upon a showing by the Commission that advertising is not reasonably practicable. Partial and advanced payments may be made under contracts for such purposes. The Commission may establish guaranteed prices for all source material delivered to it within a specified time. Just compensation shall be made for any right, property, or interest in property taken, requisitioned, condemned, or otherwise acquired under this section.

"Sec. 67. Operations On Lands Belonging To The United States.The Commission is authorized, to the extent it deems necessary to effectuate the provisions of this Act, to issue leases or permits for prospecting for, exploration for, mining of, or removal of deposits of source material in lands belonging to the United States: Provided, however, That notwithstanding any other provisions of law, such leases or permits may be issued for lands administered for national park, monu-

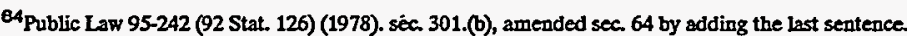


Public and acquired lands. 42 USC sec. 2098.

Release of reservation.

60 STAT 775.

ment, and wildlife purposes only when the President by Executive Order declares that the requirements of the common defense and security make such action necessary.

"Sec. 68. Public And Acquired Lands._-65

"a. No individual, corporation, partnership, or association, which had any part, directly or indirectly, in the development of the atomic energy program, may benefit by any location, entry, or settlement upon the public domain made after such individual, corporation, partnership, or association took part in such project, if such individual, corporation, partnership, or association, by reason of having had such part in the development of the atomic energy program, acquired confidential official information as to the existence of deposits of such uranium, thorium, or other materials in the specific lands upon which such location, entry, or settlement is made, and subsequent to the date of the enactment of this Act made such location, entry, or settlement or caused the same to be made for his, or its, or their benefit.

"b. Any reservation of radioactive mineral substances, fissionable materials, or source material, together with the right to enter upon the land and prospect for, mine, and remove the same, inserted pursuant to Executive Order 9613 of September 13, 1945, Executive Order 9701 of March 4, 1946, the Atomic Energy Act of 1946, or Executive Order 9908 of December 5, 1947, in any patent, conveyance, lease, permit, or other authorization or instrument disposing of any interest in public or acquired lands of the United States, is hereby released, remised, and quitclaimed to the person or persons entitled upon the date of this Act under the grant from the United States or successive grants to the ownership, occupancy, or use of the land under applicable Federal or State laws: Provided, however, That in cases where any such reservation on acquired lands of the United States has been heretofore released, remised, or quitclaimed subsequent to August 12,1954, in reliance upon authority deemed to have been contained in the Atomic Energy Act of 1946, as amended, or the Atomic Energy Act of 1954, as heretofore amended, the same shall be valid and effective in all respects to the same extent as if public lands and not acquired lands had been involved. The foregoing release shall be subject to any rights which may have been granted by the United States pursuant to any such reservation, but the releases shall be subrogated to the rights of the United States. ${ }^{66}$

"c. Notwithstanding the provisions of the Atomic Energy Act of 1946 , as amended, and particularly section $5(\mathrm{~b})(7)$ thereof, 67 or the

\footnotetext{
${ }^{65}$ Public Law 85-681 (72 Stat. 623) (1958), sec. 3, amended the title to sec. 68. Before amendment it read "PUBLIC LANDS"

${ }^{66}$ Public Law 85-681 (72Stat. 632)(1958), sec. 3 amended sec. 68 by substinting a new subsec .b. Before amendment subsec. b. read as follows:

"b. In cases where any patent, conveyance, lease, permit, or other authorization has been issued, which reserved to the United States source materials and the right to enter upon the land and prospect for, mine, and remove the same, the head of the Government agency which issued the patent, conveyance, lease, permit, or other authorization shall, on application of the holder thereof, issue a new or supplemental patent, conveyance, lease, permit, or other authorization without such reservation. If any rights have been granted by the United States pursuant to any such reservation then such patent shall be made subject to those rights, but thepatenteeshall be subrogated to the rights of the United States."

${ }^{67}$ See Atomic Energy Act of 1946, appendix B, infra, sec. 5(b)(7).
} 
provisions of the Act of August 12, 1953 (67 Stat. 539), and particularly section 3 thereof, any mining claim, heretofore located under the mining laws of the United States, for or based upon a discovery of a mineral deposit which is a source material and which, except for the possible contrary construction of said Atomic Energy Act, would have been locatable under such mining laws, shall, insofar as adversely affected by such possible contrary construction, be valid and effective, in all respects to the same extent as if said mineral deposit were a locatable mineral deposit other than a source material.

Prohibition.

"Sec. 69. Prohibition.-The Commission shall not license any person 42 USC sec. 2099. to transfer or deliver, receive possession of or title to, or import into or export from the United States any source material if, in the opinion of the Commission, the issuance of a license to such person for such purpose would be inimical to the common defense and security or the health and safety of the public.

\section{"CHAPTER 8-BYPRODUCT MATERIAL}

Domestic distribution. 42 USC sec. 2111.

"Sec. 81. Domestic Distribution.-No person may transfer or receive in interstate commerce, manufacture, produce, transfer, acquire, own, possess, import, or export any byproduct material, except to the extent authorized by this section, section 82 or section $84 .{ }^{\circ 8}$ The Commission is authorized to issue general or specific licenses to applicants seeking to use byproduct material for research or development purposes, for medical therapy, industrial uses, agricultural uses, or such other useful applications as may be developed. The Commission may distribute, sell, loan, or lease such byproduct material as it owns to qualified applicants ${ }^{69}$ with or without charge: Provided, however, That, for byproduct material to be distributed by the Commission for a charge, the Commission shall establish prices on such equitable basis as, in the opinion of the Commission, (a) will provide reasonable compensation to the Government for such material, (b) will not discourage the use of such material or the development of sources of supply of such material independent of the Commission, and (c) will encourage research and development. In distributing such material, the Commission shall give preference to applicants proposing to use such material either in the conduct of research and development or in medical therapy. The Commission shall not permit the distribution of any byproduct material to any licensee, and shall recall or order the recall of any distributed material from any licensee, who is not equipped to observe or who fails to observe such safety standards to protect health as may be established by the Commission or who uses such material in violation of law or regulation of the Commission or in a manner other than as disclosed in the application therefor or approved by the Commission. The Commission is authorized to establish classes of

\footnotetext{
68 Public Law 95-604 (92 Stat. 3039)(1978), sec. 205(b), amended the first sentence of sec 81. Before amendment it read as follows: "No person may transfer or receive in interstate commerce, mamufacture, produce transfer, acquire, read as follows: "No persess, import, or export any byproduct material, except to the entent authorized by this section or by section 82 ."

69 Sec. 4 of Public Law 93-377 (88 Stat. 475) (1974) changed the word "licensees" to "qualified applicants" and deleted the following sentence, which was previously the fifth sentence of sec. 81:

"Licensees of the Commission may distribute byproduct material only to applicants therefor who are licensed by the Commission to receive such byproduct material.
} 
Foreign distribution of byproduct material. 42 USC sec. 2112.

42 USC sec. 2113.

42 USC 2002, 2111. 42 USC 2014.

42 U.S.C. 2014 byproduct material and to exempt certain classes or quantities of material or kinds of uses or users from the requirements for a license set forth in this section when it makes a finding that the exemption of such classes or quantities of such material or such kinds of uses or users will not constitute an unreasonable risk to the common defense and security and to the health and safety of the public.

"Sec. 82. Foreign Distribution Of Byproduct Material.

"a. The Commission is authorized to cooperate with any nation by distributing byproduct material, and to distribute byproduct material, pursuant to the terms of an agreement for cooperation to which such nation is party and which is made in accordance with section 123.

"b. The Commission is also authorized to distribute byproduct material to any person outside the United States upon application therefor by such person and demand such charge for such material as would be charged for the material if it were distributed within the United States: Provided, however, That the Commission shall not distribute any such material to any person under this section if, in its opinion, such distribution would be inimical to the common defense and security: And provided further, That the Commission may require such reports regarding the use of material distributed pursuant to the provisions of this section as it deems necessary.

"c. The Commission is authorized to license others to distribute byproduct material to any person outside the United States under the same conditions, except as to charges, as would be applicable if the material were distributed by the Commission.

"Sec. 83. Ownership And Custody Of Certain Byproduct Material And Disposable Sites.-

"a. Any license issued or renewed after the effective date of this section under section 62 or section 81 of any activity which results in the production of any byproduct material, as defined in section 11e.(2), shall contain terms and conditions as the Commission determines to be necessary to assure that, prior to termination of such license-

"(1) the licensee will comply with decontamination, decommissioning, and reclamation standards prescribed by the Commission for sites (A) at which ores were processed primarily for their source material content and (B) at which such byproduct material is deposited, and

"(2) ownership of any byproduct material, as defined in section $11 \mathrm{e}$. (2), which resulted from such licensed activity shall be transferred to (A) the United States or (B) in the State in which such activity occurred if such State exercises the option under subsection b. (1) to acquire land used for the disposal of byproduct material. 
Rule, regulation of order.

"Any license which is in effect on the effective date of this section and which is subsequently terminated without renewal shall comply with paragraphs (1) and (2) upon termination."70

"(b)(1)(A) The Commission shall require by rule, regulation, or order that prior to the termination of any license which is issued after the effective date of this section, title to the land, including any interest therein (other than land owned by the United States or by a State) which is used for the disposal of any byproduct material, as defined by section 11 e. (2), pursuant to such license shall be transferred to-

"(i) the United States or-

"(ii) the State in which such land is located, at the option of such State.

unless ${ }^{71}$ the Commission determines prior to such termination that transfer of title to such land and such byproduct material is not necessary or desirable to protect the public health, safety, or welfare or to minimize or eliminate danger to life or property. Such determination shall be made in accordance with section 181 of this Act. Notwithstanding any other provision of law or any such determination, such property and materials shall be maintained pursuant to a license issued by the Commission pursuant to section 81 of this Act ${ }^{72}$ in such manner as will protect the public health, safety, and the environment.

"(B) If the Commission determines by order that use of the surface or subsurface estates, or both, of the land transferred to the United States or to a State under sub-paragraph (A) would not endanger the public health, safety, welfare, or environment, the Commission, pursuant to such regulations as it may prescribe, shall permit the use of the surface or subsurface estates, or both, of such land in a manner consistent with the provisions of this section. If the Commission permits such use of such land, it shall provide the person who transferred such land with the right of first refusal with respect to such use of such land.

"(2) If transfer to the United States of title to such byproduct material and such land is required under this section, the Secretary of Energy or any Federal agency designated by the President shall, following the Commission's determination of compliance under subsection c., assume title and custody of such byproduct material and land transferred as provided in this subsection Such Secretary or Federal agency shall maintain such material and land in such manner as will protect the public health and safety and the environ-

\footnotetext{
70Public Law 96-106 (93 Stat. 800) (1979) sec. 22(c) amended last sentence of sec. 83a. Before amendment this sentence read as follows:

Any license in effect on the date of the enactment of this section shall either contain such terms and conditions on renewal thereof after the effective date of this section, or comply with paragraphs (1) and (2) upon the termination of such license, whichever first ocaurs.

71 Public Law 96-106 (93 Stat. 800) (1979) sec. 22(e)(1) amended sec. 83(b)(1)(A) by striking out all that follows "transferred to." through "Unless". Before amendment this part read as follows:

(A) the United States, or

"(B) the State in which such land is located, at the option of such State.

(2) Unless

${ }^{71}$ Public Law 96-106 (93 Stat. 800) (1979) sec. 22(e)(2) amended sec. 83(b)(1)(A) by inserting "section 81 of this Act" in liew of "section $84 \mathrm{~b}$ ".
} 
42 USC 2092

Post, p. 3039.

42 USC 2014.

ment. Such custody may be transferred to another officer or instrumentality of the United States only upon approval of the President.

"(3) If transfer to a State of title to such byproduct material is required in accordance with this subsection, such State shall, following the Cornmission's determination of compliance under subsection d., assume title and custody of such byproduct material and land transferred as provided in this subsection. Such State shall maintain such material and land in such manner as will protect the public health, safety, and the environment.

"(4) In the case of any such license under section 62 , which was in effect on the effective date of this section, the Commission may require, before the termination of such license, such transfer of land and interest therein (as described in paragraph (1) of this subsection) to the United States or a State in which land is located, at the option of such State, as may be necessary to protect the public health, welfare, and the environment from any effects associated with such byproduct material. In exercising the authority of this paragraph, the Commission shall take into consideration the status of the ownership of such land and interest therein and the ability of the licensee to transfer title and custody thereof to the United States or a State.

"(5) The Commission may, pursuant to a license, or by rule or order, require the Secretary or other Federal agency or State having custody of such property and materials to undertake such monitoring, maintenance, and emergency measures as are necessary to protect the public health and safety and such other actions as the Commission deems necessary to comply with the standards promulgated pursuant to section 84 of this Act. The Secretary or such other Federal agency is authorized to carry out maintenance, monitoring, and emergency measures, but shall take no other action pursuant to such license, rule or order, with respect to such property and materials unless expressly authorized by Congress after the date of enactment of this Act.

"(6) The transfer of title to land or byproduct materials, as defined in section 11 e. (2), to a State or the United States pursuant to this subsection shall not relieve any licensee of liability for any fraudulent or negligent acts done prior to such transfer.

"(7) Material and land transferred to the United States or a State in accordance with this subsection shall be transferred without cost to the United States or a State (other than administrative and legal costs incurred in carrying out such transfer). Subject to the provisions of paragraph (1)(B) of this subsection, the United States or a State shall not transfer title to material or property acquired under this subsection to any person, unless such transfer is in the same manner as provided under section 104(h) of the Uranium Mill Tailings Radiation Control Act of 1978.

"(8) The provisions of this subsection respecting transfer of title and custody to land shall not apply in the case of lands held in trust by the United States for any Indian tribe or lands owned by such Indian tribe subject to a restriction against alienation imposed by the United States. In the case of such lands which are used for the 
42 USC 2114.

42 USC 2014.

Infra.

42 USC 6901.

note.

Rule, regulation

of order.

42 USC 2112.

Civil penalty.

Ante, p. 3033.

42 USC 2282.

disposal of byproduct material, as defined in section 11 e. (2), the licensee shall be required to enter into such arrangements with the Commission as may be appropriate to assure the long-term maintenance and monitoring of such lands by the United States.

"c. Upon termination on any license to which this section applies, the Commission shall determine whether or not the licensee has complied with all applicable standards and requirements under such license.73

"Sec. 84. Authorities of Commission Respecting Certain Byproduct Material.-

"a. The Commission shall insure that the management of any byproduct material, as defined in section $11 \mathrm{e.}$ (2), is carried out in such manner as-

"(1) the Commission deems appropriate to protect the public health and safety and the environment from radiological and nonradiological hazards associated with the processing and with the possession and transfer of such material taking into account the risk to the public health, safety, and the environment, with due consideration of the economic costs and such other factors as the Commission determines to be appropriate,"74

"(2) conforms with applicable general standards promulgated by the Administration of the Environmental Protection Agency under section 275 , and

“(3) conforms to general requirements established by the Commission, with the concurrence of the Administrator, which are, to the maximum extent practicable, at lease comparable to requirements applicable to the possession, transfer, and disposal of similar hazardous material regulated by the Administrator under the Solid Waste Disposal Act, as amended.

"b. In carrying out its authority under this section, the Commission is authorized to-

“(1) by rule, regulation, or order require persons, officers, or instrumentalities, exempted from licensing under section 81 of this Act to conduct monitoring, perform remedial work, and to comply with such other measures as it may deem necessary or desirable to protect health or to minimize danger to life or property, and in connection with the disposal or storage of such byproduct material; and

"(2) make such studies and inspections and to conduct such monitoring as may be necessary.

Any violation by any person other than the United States or any officer or employee of the United States or a State of any rule, regulation, or order or licensing provision, of the Commission established under this section or section 83 shall be subject to a civil penalty in the same manner and in the same amount as violations subject to a civil penalty under section 234 . Nothing in this section affects any authority of the Commission under any other provisions of this Act. 75

${ }^{73}$ Public Law 95-604 (92 Stat. 3033) (1978, sec. 202(a), added sec. 83.

${ }^{74}$ Public Law 97-415 (96 Stat. 2067) (1983) sec. 22 added the language after "malerial".

75 Public Law 95-604 (92 Stat. 3039) (1978), sec. 205(a), added sec. 84. 

source material content or which are used for the disposal of byproduct material as defined in section 11e. (2), a licensee may propose alternatives to specific requirements adopted and enforced by the Commission under this Act. Such alternative proposals may take into account local or regional conditions, including geology, topography, hydrology and meteorology. The Commission may treat such alternatives as satisfying Commission requirements if the Commission determines that such alternatives will achieve a level of stabilization and containment of the sites concerned, and a level of protection for public health, safety, and the environment from radiological and nonradiological hazards associated with such sites, which is equivalent to, to the extent practicable, or more strigent than the level which would be achieved by standards and requirements adopted and enforced by the Commission for the same purpose and any final standards promulgated by the Administrator of the Environmental Protection Agency in accordance with section 275."76

Authority.

\section{"CHAPTER 9-MILITARY APPLICATION OF ATOMIC ENERGY}

"Sec. 91. Authority.-

42 USC sec. 2121. "a. The Commission is authorized to-

"(1) conduct experiments and do research and development work in the military application of atomic energy; and

"(2) engage in the production of atomic weapons, or atomic weapon parts, except that such activities shall be carried on only to the extent that the express consent and direction of the President of the United States has been obtained, which consent and direction shall be obtained at least once each year.

"b. The President from time to time may direct the Commission (1) to deliver such quantities of special nuclear material or atomic weapons to the Department of Defense for such use as he deems necessary in the interest of national defense, or (2) to authorize the Department of Defense to manufacture, produce, or acquire any atomic weapon or utilization facility for military purposes: Provided, however, That such authorization shall not extend to the production of special nuclear material other than that incidental to the operation of such utilization facilities.

"c. The President may authorize the Commission or the Department of Defense, with the assistance of the other, to cooperate with another nation and, notwithstanding the provisions of section 57,62 , or 81 , to transfer by sale, lease, or loan to that nation, in accordance with terms and conditions of a program approved by the President-

"(1) nonnuclear parts of atomic weapons provided that such nation has made substantial progress in the development of atomic weapons, and other nonnuclear parts of atomic weapons systems involving Restricted Data provided that such transfer will not contribute significantly to that nation's atomic weapon design, development or fabrication capability; for the purpose of improving that nation's state of training and operational readiness;

"(2) utilization facilities for military applications; and

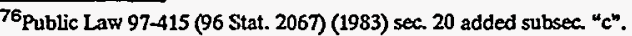


Prohibition. 42 USC sec. 2122.

License required. 42 USC sec. 2131.

42 USC sec. 2132.

"(3) source, byproduct, or special nuclear material for research on, development of, production of, or use in utilization facilities for military applications; and

"(4) source, byproduct, or special nuclear material for research on, development of, or use in atomic weapons: Provided, however, That the transfer of such material to that nation is necessary to improve its atomic weapon design, development, or fabrication capability: And provided further, That such nation has made substantial progress in the development of atomic weapons,

whenever the President determines that the proposed cooperation and each proposed transfer arrangement for the nonnuclear parts of atomic weapons and atomic weapons systems, utilization facilities or source, byproduct, or special nuclear material will promote and will not constitute an unreasonable risk to the common defense and security, while such other nation is participating with the United States pursuant to an international arrangement by substantial and material contributions to the mutual defense and security: Provided, however, That the cooperation is undertaken pursuant to an agreement entered into in accordance with section 123: And provided further, That if an agreement for cooperation arranged pursuant to this subsection provides for transfer of utilization facilities for military applications the Commission, or the Department of Defense with respect to cooperation it has been authorized to undertake, may authorize any person to transfer such utilization facilities for military applications in accordance with the terms and conditions of this subsection and of the agreement for cooperation 77 .

"Sec. 92. Prohibition.-It shall be unlawful, except as provided in section 91 , for any person to transfer or receive in interstate or foreign commerce, manufacture, produce, transfer, acquire, possess, import, or export any atomic weapon. Nothing in this section shall be deemed to modify the provisions of subsection $31 \mathrm{a}$. or section 101.78

\section{"CHAPTER 10-ATOMIC ENERGY LICENSES}

"Sec. 101. License Required.-It shall be unlawful, except as provided in section 91, for any person within the United States to transfer or receive in interstate commerce, manufacture, produce, transfer, acquire, possess, use, 79 import, or export any utilization or production facility except under and in accordance with a license issued by the Commission pursuant to section 103 or 104 .

"Sec. 102. Utilization And Production Facilities For Industrial Or Commercial Purposes.-

"a. Except as provided in subsections b. and c., or otherwise specifically authorized by law, any license hereafter issued for a utilization or production facility for industrial or commercial purposes shall be issued pursuant to section 103.

\footnotetext{
77 Public Law 85-479 (72 Stat. 276) (1958), sec. 1, added subsec. c to sec. 91.

78. Public Law 85-479 (72 Stat. 276)(1958), sec.2, amended sec. 92 by substituting a complete new sec. 92 . Before amendment sec. 92 read as follows:

"Sec.92. Prohibition -It shall be unlawful for any person to transfer or receive in interstatecommerce, manufacture, produce, transfer, acquire, possess, import, or export any atomic weapon, except as may be authorized by the Commission pursuant to the provisions of section 91 . Nothing inthis sectionshall bedeemed to modify theprovisions of subsection 31 a. or section 101 ."

70Public Law 84-1006 (70 Stat. 1069) (1956), sec. 11, added the word "use".
} 
Commercial licenses.

42 USC. sec. 2133

"b. Any license hereafter issued for a utilization or production facility for industrial or commercial purposes, the construction or operation of which was licensed pursuant to subsection $104 \mathrm{~b}$. prior to enactment into law of this subsection, shall be issued under subsection $104 \mathrm{~b}$.

"c. Any license for a utilization or production facility for industrial or commercial purposes constructed or operated under an arrangement with the Commission entered into under the Cooperative Power Reactor Demonstration Program shall, except as otherwise specifically required by applicable law, be issued under subsection 104 b.80

"Sec. 103. Commercial Licenses.-

"a. The Commission is authorized to issue licenses to persons applying therefor to transfer or receive in interstate commerce, manufacture, produce, transfer, acquire, possess, use ${ }^{81}$ import, or export under the terms of an agreement for cooperation arranged pursuant to section 123, utilization or production facilities for industrial or commercial purposes. ${ }^{82}$ Such licenses shall be issued in accordance with the provisions of chapter 16 and subject to such conditions as the Commission may by rule or regulation establish to effectuate the purposes and provisions of this Act.

"b. The Conmission shall issue such licenses on a nonexclusive basis to persons applying therefor (1) whose proposed activities will serve a useful purpose proportionate to the quantities of special nuclear material or source material to be utilized; (2) who are equipped to observe and who agree to observe such safety standards to protect health and to minimize danger to life or property as the Commission may by rule establish; and (3) who agree to make available to the Commission such technical information and data concerning activities under such licenses as the Commission may determine necessary to promote the common defense and security and to protect the health and safety of the public. All such information may be used by the Commission only for the purposes of the common defense and security and to protect the health and safety of the public.

"c. Each such license shall be issued for a specified period, as determined by the Commission, depending on the type of activity to be licensed, but not exceeding forty years, and may be renewed upon the expiration of such period.

"d. No license under this section may be given to any person for activities which are not under or within the jurisdiction of the United States, except for the export of production or utilization facilities under terms of an agreement for cooperation arranged

\footnotetext{
${ }^{80}$ Public Law 91-560 (84 Stat. 1472) (1970), sec. 3, amended sec. 102, prior to amendment it read as follows: "Sec. 102. Finding Of Practical Value-Whenever the Commission has made a finding in writing that any type of utilization or production facility has been sufficiently developed to be of practical value for industrial or commercial purposes, the Commission may thereafter issue licenses for such type of facility pursuant to section 103."

81 Public Law 84-1006 (70 Stat. 1069) (1956), sec. 12, added the word "use".

${ }^{82}$ Public Law $91-560$ (84 Stat. 1472)(1970), sec. 4, amended the first sentence of sec. 103 a. Before amendment it read as follows:

"Subsequent to a finding by the Commission as required in section 102, the Commission may issue licenses to transfer or receive in interstate commerce, manufacture, produce, transfer, accuire, possess, use, import, or export under the terms of an agreement for cooperation arranged pursuant to section 123, such type of utilization or production facility."
} 
42 USC 2133.

pursuant to section 123, or except under the provisions of section 109. No license may be issued to an alien or any ${ }^{83}$ corporation or other entity if the Commission knows or has reason to believe it is owned, controlled, or dominated by an alien, a foreign corporation, or a foreign government. In any event, no license may be issued to any person within the United States if, in the opinion of the Commission, the issuance of a license to such person would be inimical to the common defense and security or to the health and safety of the public.

"f. Each license issued for a utilization facility under this section or section $104 \mathrm{~b}$. shall require as a condition there of that in case of any accident which could result in an unplanned release of quantities of fission products in excess of allowable limits for normal operation established by the Commission, the licensee shall immediately so notify the Commission. Violation of the condition prescribed by this subsection may, in the Commission's discretion, constitute grounds for license revocation. In accordance with sec-

42 USC 2237. tion 187 of this Act, the Commission shall promptly amend each license for a utilization facility issued under this section or section $104 \mathrm{~b}$. which is in effect on the date of enactment of this subsection to include the provisions required under this subsection." 84

Medical therapy and research and development. 42 USC sec. 2134.
"Sec. 104. Medical Therapy And Research And Development.-

"a. The Commission is authorized to issue licenses to persons applying therefore for utilization facilities for use in medical therapy. In issuing such licenses the Commission is directed to permit the widest amount of effective medical therapy possible with the amount of special nuclear material available for such purposes and to impose the minimum amount of regulation consistent with its obligations under this Act topromote the common defense and security and to protect the health and safety of the public.

"b. As provided for in subsection $102 \mathrm{~b}$., or $102 \mathrm{c}$., or where specifically authorized by law, the Commission is authorized to issue licenses under this subsection to persons applying therefor for utilization and production facilities for industrial and commercial purposes. In issuing licenses under this subsection, the Commission shall impose the minimum amount of such regulations and terms of license as will permit the Commission to fulfill its obligations under this Act. 85

"c. The Commission is authorized to issue licenses to persons applying therefor for utilization and production facilities useful in the conduct of research and development activities of the types

\footnotetext{
${ }^{83}$ Public Law 84-1006 (70 Stat. 1069) (1956), sec. 13, added the words "an alien or any" between the words "to" and "any" in the second sentence of subsec. $103 \mathrm{~d}$. Addition of the word "any" was, of course, unnecessary.

94 Public Law 96-295 (94 Stat. 786) (1980) sec. 201, added subser ( $($ without prior enactment of subsec. (e).

${ }^{85}$ Public Law 91-560 (84 Stat. 1472) (1970), sec. 5, amezded subsec. 104 b. Before amendment it read as follows: $\mathrm{cb}$. The Commission is authorized to issue licenses to persons applying therefor for utilization and production facilities involved in the conduct of research and development activities leading to the demonstration of the practical value of such facilities for industrial or commercial purposes. In issuing licenses under this subsection, the Commission shall impose the minimum amount of such regulations and terms of license as will permit the Commission to fulfill its obligations under this Act to promote the common defense and security and to protect the health and safety of the public and will be compatible with the regulations and terms of license which would apply in the event that a commercial license were later to be issued pursuant to section 103 for that type of facility. In issuing such licenses, priority shatl be given to those activities which will, in the opinion of the Commission, lead to major advances in the application of atomic energy for industrial or commercial purposes."
} 
Antitrust provisions.

42 USC sec. 2135

specified in section 31 and which are not facilities of the type specified in subsection 104b. The Commission is directed to impose only such minimum amount of regulation of the licensee as the Commission finds will permit the Commission to fulfill its obligations under this Act to promote the common defense and security and to protect the health and safety of the public and will permit the conduct of widespread and diverse research and development.

"d. No license under this section may be given to any person for activities which are not under or within the jurisdiction of the United States, except for the export of production or utilization facilities under terms of an agreement for cooperation arranged pursuant to section 123 or except under the provisions of section 109. No license may be issued to any corporation or other entity if the Commission knows or has reason to believe it is owned, controlled, or dominated by an alien, a foreign corporation, or a foreign government. In any event, no license may be issued to any person within the United States if, in the opinion of the Commission, the issuance of a license to such person would be inimical to the common defense and security or to the health and safety of the public.

"Sec. 105. Antitrust Provisions.-

"a. Nothing contained in this Act ${ }^{86}$ shall relieve any person from the operation of the following Acts, as amended, An Act to protect trade and commerce against unlawful restraints and monopolies, approved July second, eighteen hundred and ninety: sections seventy-three to seventy-seven inclusive, of an Act entitled 'An Act to reduce taxation, to provide revenue for the Government, and for other purposes approved August twenty-seven, eighteen hundred and ninety-four; 'An Act to supplement existing laws against unlawful restraints and monopolies, and for other purposes, approved October fifteen, nineteen hundred and fourteen; and 'An Act to create a Federal Trade Commission, to define its powers and duties, and for other purposes, approved September twenty-six, nineteen hundred and fourteen. In the event a licensee is found by a court of competent jurisdiction, either in an original action in that court or in a proceeding to enforce or review the findings or orders of any Government agency having jurisdiction under the laws cited above, to have violated any of the provisions of such laws in the conduct of the licensed activity, the Commission may suspend, revoke, or take such other action as it may deem necessary with respect to any license issued by the Commission under the provisions of this Act.

"b. The Commission shall report promptly to the Attorney General any information it may have with respect to any utilization of special nuclear material or atomic energy which appears to violate or to tend toward the violation of any of the foregoing Acts, or to restrict free competition in private enterprise.

${ }^{66}$ Public Law 88-489 (78 Stat.602) (1964), sec. 14, deleted the phase ", inchuding the provisions which vest titleto all special nuclear material in the United States," which appeared after the word "Act". 
"c. (1) The Commission shall promptly transmit to the Attorney General a copy of any license application provided for in paragraph (2) of this subsection, and a copy of any written request provided for in paragraph (3) of this subsection; and the Attorney General shall, within a reasonable time, but in no event to exceed 180 days after receiving a copy of such application or written request, render such advice to the Commission as he determines to be appropriate in regard to the finding to be made by the Commission pursuant to paragraph (5) of this subsection. Such advice shall include an explanatory statement as to the reasons or basis therefor.

"2. Paragraph (1) of this subsection shall apply to an application for a license to construct or operate a utilization or production facility under section 103: Provided, however, That paragraph (1) shall not apply to an application for a license to operate a utilization or production facility for which a construction permit was issued under section 103 unless the Commission determines such review is advisable on the ground that significant changes in the licensee's activities or proposed activities have occurred subsequent to the previous review by the Attorney General and the Commission under this subsection in connection with the construction permit for the facility.

"(3) With respect to any Commission permit for the construction of a utilization or production facility issued pursuant to subsection $104 \mathrm{~b}$. prior to the enactment into law of this subsection, any person who intervened or who sought by timely written notice to the Commission to intervene in the construction permit proceeding for the facility to obtain a determination of antitrust considerations or to advance a jurisdiction basis for such determination shall have the right, upon a written request to the Commission, to obtain an antitrust review under this section of the application for an operating license. Such written request shall be made within 25 days after the date of initial Commission publication in the Federal Register of notice of the filing of an application for an operating license for the facility or the date of enactment into law of this subsection, whichever is later.

"(4) Upon the request of the Attorney General, the Commission shall furnish or cause to be furnished such information as the Attorney General determines to be appropriate for the advice called for in paragraph (1) of this subsection.

"(5) Promptly upon receipt of the Attorney General's advice, the Commission shall publish the advice in the Federal Register. Where the Attorney General advises that there may be adverse antitrust aspects and recommends that there be a hearing, the Attorney General or his designee may participate as a party in the proceedings thereafter held by the Commission on such licensing matter in connection with the subject matter of his advice. The Commission shall give due consideration to the advice received from the Attorney General and to such evidence as may be provided during the proceedings in connection with such subject matter, and shall make a finding as to whether the activities under the 
Classes of facilities.

42 USC sec. 2136. license would create or maintain a situation inconsistent with the antitrust laws as specified in subsection 105a.

"(6) In the event the Commission's finding under paragraph (5) is in the affirmative, the Commission shall also consider, in determining whether the license should be issued or continued, such other factors, including the need for power in the affected area, as the Commission in its judgment deems necessary to protect the public interest. On the basis of its findings, the Commission shall have the authority to issue or continue a license as applied for, to refuse to issue a license, to rescind a license or amend it, and to issue a license with such conditions as it deems appropriate.

"(7) The commission, with the approval of the Attorney General, may except from any of the requirements of this subsection such classes or types of licenses as the Commission may determine would not significantly affect the applicant's activities under the antitrust laws as specified in subsection 105a.

"(8) With respect to any application for a construction permit on file at the time of enactment into law of this subsection, which permit would be for issuance under section 103, and with respect to any application for an operating license in connection with which a written request for an antitrust review is made as provided for in paragraph (3), the Commission, after consultation with the Attorney General, may, upon determination that such action is necessary in the public interest to avoid unnecessary delay, establish by rule or order periods for Commission notification and receipt of advice differing from those set forth above and may issue a construction permit or operating license in advance of consideration of and findings with respect to the matters covered in this subsection: Provided, That any construction permit or operating license so issued shall contain such conditions as the Commission deems appropriate to assure that any subsequent findings and orders of the Commission with respect to such matters will be given full force and effect. 87

"Sec. 106. Classes Of Facilities. - The Commission may-

"a. group the facilities licensed either under section 103 or under section 104 into classes which may include either production or utilization facilities or both, upon the basis of the similarity of operating and technical characteristics of the facilities;

"b. define the various activities to be carried on at each such class of facility; and

"c. designate the amounts of special nuclear material available for use by each such facility.

Operators'

\footnotetext{
87Public Law 91-560 (84 Stat. 1472)(1970), sec. 6, amended subsec. 105c. Before amendment it read as follows: "c. Whenever the Commission proposes to issue any license to any persons under section 103 , it shall notify the Attorney General of the proposed license and the proposed terms and conditions thereof, except such classes or type of licenses, as the Commission, with the approval of the Attorney General, may determine would not significantly affect the licensee's activities under the antitnist laws as specified in subsection $150 \mathrm{a}$. Within a reasonabletime, in no event to exceed 90 days after receiving such notification, the Attorney General shall advise the Commission whether, insofar as he can determine, the proposed license would tend to create or maintain a situation inconsistent with the insofar as he can determine, the proposed license would tend to create or maintain a situation inconsistent with the antitrust taws, and such advice shall be published in the Federal Register. Upon the request of the Attorney General, appropriate or necessary to enable him to give the advice called for by this section."
} 
licenses.

42 USC sec. 2137.

War or

national

emergency.

42 USC sec. 2138.

Domestic

activities

licenses,

issuance,

authorization.

42 USC 2139.

Export licenses.

Ante, p. 131.

“a. prescribe uniform conditions for licensing individuals as operators of any of the various classes of production and utilization facilities licensed in this Act;

"b. determine the qualifications of such individuals;

"c. issue licenses to such individuals in such form as the commission may prescribe; and

"d. suspend such licenses for violations of any provision of this Act or any rule or regulation issued thereunder whenever the Commission deems such action desirable.

"Sec. 108. War Or National Emergency.-Whenever the Congress declares that a state of war or national emergency exists, the Commission is authorized to suspend any licenses granted under this Act if in its judgment such action is necessary to the common defense and security. The Commission is authorized during such period, if the Commission finds it necessary to the common defense and security, to order the recapture of any special nuclear material 88 or to order the operation of any facility licensed under section 103 or 104, and is authorized to order the entry into any plant or facility in order to recapture such material, or to operate such facility. Just compensation shall be paid for any damages caused by the recapture of any special nuclear material or by the operation of any such facility.

"Sec. 109. Component And Other Parts Of Facilities.

"a. With respect to those utilization and production facilities which are so determined by the Commission pursuant to subsection $11 \mathrm{v}$. (2) or $11 \mathrm{cc}$. (2) the Commission may issue general licenses for domestic activities required to be licensed under section 101, if the Commission determines in writing that such general licensing will not constitute an unreasonable risk to the common defense and security.

"b. After consulting with the Secretaries of State, Energy, and Commerce and the Director, the Commission is authorized and directed to determine which component parts as defined in subsection $11 \mathrm{v}$. (2) or $11 \mathrm{cc}$. (2) and which other items or substances are especially relevant from the standpoint of export control because of their significance for nuclear explosive purposes. Except as provided in section $126 \mathrm{~b}$. (2), no such component, substance, or item which is so determined by the Commission shall be exported unless the Commission issues a general or specific license for its export after finding, based on a reasonable judgment of the assurances provided and other information available to the Federal Government, including the Commission, that the following criteria or their equivalent are met: (1) IAEA safeguards as required by Article III (2) of the Treaty will be applied with respect to such component, substance, or item; (2) no such component, substance, or item will be used for any nuclear explosive device or for research on or development of any nuclear explosive device; and (3) no such component, substance, or item will be retransferred to the jurisdiction of any nation or group of nations unless the prior consent of the United States is obtained for such retransfer; and after determin-

\footnotetext{
${ }^{80}$ Public Law 86-373 (73 Stat. 685)(1959), sec. 2, amended sec. 108 by deleting the phrase "distributed under the provisions of subsection 53 a.," after the words "special nuclear material" in the second sentence.
} 
Exclusions.

42 USC sec. 2140.

42 USC 2141

Supra.

42 USC 2112 ing in writing that the issuance of each such general or specific license or category of licenses will not be inimical to the common defense and security; Provided, That a specific license shall not be required for an export pursuant to this section if the component, item or substance is covered by a facility license issued pursuant to section 126 of this Act.

"c. The Commission shall not issue an export license under the authority of subsection $b$. if it is advised by the executive branch, in accordance with the procedures established under subsection 126 a., that the export would be inimical to the common defense and security of the United States. 89

"Sec. 110. Exclusions.-Nothing in this chapter shall be deemed

"a. to require a license for (1) the processing, fabricating, or refining of special nuclear material, or the separation of special nuclear material, or the separation of special nuclear material from other substances, under contract with and for the account of the Commission; or (2) the construction or operation of facilities under contract with and for the account of the Commission; or

'b. to require a license for the manufacture, production, or acquisition by the Department of Defense of any utilization facility authorized pursuant to section 91 , or for the use of such facility by the Department of Defense or a contractor thereof.

"Sec. 111. Distribution By The Department Of Energy.-

"a. The Nuclear Regulatory Commission is authorized to license the distribution of special nuclear material, source material, and byproduct material by the Department of Energy, pursuant to section 54, 64, and 82 of this Act, respectively, in accordance with the same procedures established by law for the export licensing of such material by any person: Provided, That nothing in this section shall require the licensing of the distribution of byproduct material by the Department of Energy under section 82 of this Act.

"b. The Department of Energy shall not distribute any special nuclear material or source material under section 54 or 64 of this Act other than under an export license issued by the Nuclear Regulatory Commission until (1) the Department has obtained the concurrence of the Department of State and has consulted with the Arms Control and Disarmament Agency, the Nuclear Regulatory Commission, and the Department of Defense under mutually agreed procedures which shall be established within not more than ninety days after the date of enactment of this provision and (2) the Department finds based on a reasonable judgment of the assur-

${ }^{89}$ Public Law 95-242 (92 Stat. 141)(1978), sec. 309(a), amended sec. 109 by substituting a complete new sec. 109. Before amendment, sec. 109 read as follows, "Sec. 109 . Component Parts of Facilities-With respect to thoseutilization and production facilities which are so determined by this Commission pursuant to subsection $11 \mathrm{v}$. (2) $)^{2}$ or $11 \propto$. (2) the Commission may (a) issue general licenses for activities required to be licensed under section 101, if the Commission determines in writing that such general licensing will not constitute an unreasonable risk to the common de. fense and security, and (b) issue licenses for the export of such facilities, if the Commission determines in writing that each export will not constitute an unreasonable risk to the common defense and security.".

HAmended by Public Law 89-645 (80 Stat. 891)(1966), sec. 1. Prior to amendment, reference was to "11 t. (2) Amended by Public Law 89-645 (80 Stat. 891)(1966), sec. 1. Prior to amendment, reference was to 11 aa (2) ${ }^{n}$. Earlier, Public Law 87-615(76 Stat. 409)(1962), sec.9, had amended the reference. Prior to this amendment the reference was to " 11 y. (2)". 
Post, p. 136.

Post, p. 137.

Effect of international arrangements. 42 USC sec. 2151.

Policies contained in international arrangements. 42 USC sec. 2152.

42 USC 2073, 2074, 2077, 2094, 2112, 2121,2133 , 2134, 2164. Cooperative agreements, submittal to President. Contents. ances provided and the information available to the United States Government, that the criteria in section 127 of this Act or their equivalent and any applicable criteria in subsection 128 are met, and that the proposed distribution would not be inimical to the common defense and security. 90

\section{"CHAPTER 11 - INTERNATIONAL ACTIVITTES}

"Sec. 121. Effect Of International Arrangements.-Any provision of this Act or any action of the Commission to the extent and during the time that it conflicts with the provisions of any international arrangements made after the date of enactment of this Act shall be deemed to be of no force or effect.

"Sec. 122. Policies Contained In International Arrangements. - In the performance of its functions under this Act, the Commission shall give maximum effect to the policies contained in any international arrangement made after the date of enactment of this Act.

"Sec. 123. Cooperation With Other Nations.-"No cooperation with any nation, group of nations or regional defense organization pursuant to section 53,54 a., $57,64,82,91,103,104$, or 144 shall be undertaken until-

"a. the proposed agreement for cooperation has been submitted to the President, which proposed agreement shall include the terms, conditions, duration, nature, and scope of the cooperation; and shall include the following requirements:

"(1) a guaranty by the cooperating party that safeguards as set forth in the agreement for cooperation will be maintained with respect to all nuclear materials and equipment transferred pursuant thereto, and with respect to all special nuclear material used in or produced through the use of such nuclear materials and equipment, so long as the material or equipment remains under the jurisdiction or control of the cooperating party, irrespective of the duration of other provisions in the agreement or whether the agreement is terminated or suspended for any reason;

"(2) in the case of non-nuclear-weapon states, a requirement, as a condition of continued United States nuclear supply under the agreement for cooperation, that IAEA safeguards be maintained with respect to all nuclear materials in all peaceful nuclear activities within the territory of such state, under its jurisdiction, or carried out under its control anywhere;

"(3) except in the case of those agreements for cooperation arranged pursuant to subsection $91 \mathrm{c}$., a guaranty by the cooperating party that no nuclear materials and equipment or sensitive nuclear technology to be transferred pursuant to such agreement, and no special nuclear material produced through the use of any nuclear materials and equipment or sensitive nuclear technology transferred pursuant to such agreement, will be used for any nuclear explosive device, or for research on or development of any nuclear explosive device, or for any other military purpose;

${ }^{90}$ Public Law 95-242 (92 Stat. 125)(1978), sec. 301(c), added sec. 111. 
42 USC 2121, 2164
“(4) except in the case of those agreements for cooperation arranged pursuant to subsection $91 \mathrm{c}$. and agreements for cooperation with nuclear-weapon states, a stipulation that the United States shall have the right to require the return of any nuclear materials and equipment transferred pursuant thereto and any special nuclear material produced through the use thereof if the cooperating party detonates a nuclear explosive device or terminates or abrogates an agreement providing for IAEA safeguards;

"(5) a guaranty by the cooperating party that any material or any Restricted Data transferred pursuant to the agreement for cooperation and, except in the case of agreements arranged pursuant to subsection 91 c., 144 b., 144 c., or 144 d.,* any production or utilization "facility transferred pursuant to the agreement for cooperation or any special nuclear material produced through the use of any such facility or through the use of any material transferred pursuant to the agreement, will not be transferred to unauthorized persons or beyond the jurisdiction or control of the cooperating party without the consent of the United States;

"(6) a guaranty by the cooperating party that adequate physical security will be maintained with respect to any nuclear material transferred pursuant to such agreement and with respect to any special nuclear material used in or produced through the use of any material, production facility, or utilization facility transferred pursuant to such agreement;

"(7) except in the case of agreements for cooperation arranged pursuant to subsection 91 c., 144 b., 144 c., or 144 d., * a guaranty by the cooperating party that no material transferred pursuant to the agreement for cooperation and no material used in or produced through the use of any material, production facility, or utilization facility transferred pursuant to the agreement for cooperation will be reprocessed, enriched or (in the case of plutonium, uranium 233, or uranium enriched to greater than twenty percent in the isotope 235 , or other nuclear materials which have been irradiated) otherwise altered in form or content without the prior approval of the United States;

"(8) except in the case of agreements for cooperation arranged pursuant to subsection $91 \mathrm{c}$., $144 \mathrm{~b}$., $144 \mathrm{c}$., or $144 \mathrm{~d} .{ }^{*}$ a guaranty by the cooperating party that no plutonium, no uranium 233 , and no uranium enriched to greater than twenty percent in the isotope 235 , transferred pursuant to the agreement for cooperation, or recovered from any source or special nuclear material so transferred or from any source or special nuclear material used in any production facility or utilization facility transferred pursuant to the agreement for cooperation, will be stored in any facility that has not been approved in advance by the United States; and 
Agreement requirements Presidential exemptions.

Proposed cooperation agreements submittal to President. Nuclear Proliferation Assessment Statement, submitted to President. 42 USC 2121 2164.
"(9) except in the case of agreements for cooperation arranged pursuant to subsection 91 c., 144 b., 144 c., or $144 \mathrm{~d} .{ }^{*}$ a guaranty by the cooperating party that any special nuclear material, production facility, or utilization facility produced or constructed under the jurisdiction of the cooperating party by or through the use of any sensitive nuclear technology transferred pursuant to such agreement for cooperation will be subject to all the requirements specified in this subsection.

The President may exempt a proposed agreement for cooperation (except an agreement arranged pursuant to subsection $91 \mathrm{c} ., 144 \mathrm{~b}$., $144 \mathrm{c.}$, or $144 \mathrm{d.}^{*}$ ) from any of the requirements of the foregoing sentence if he determines that inclusion of any such requirement would be seriously prejudicial to the achievement of United States nonproliferation objectives or otherwise jeopardize the common defense and security. Except in the case of those agreements for cooperation arranged pursuant to subsection $91 \mathrm{c.}, 144 \mathrm{~b}$., $144 \mathrm{c}$, or $144 \mathrm{~d}$. $^{*}$ any proposed agreement for cooperation shall be negotiated by the Secretary of State, with the technical assistance and concurrence of the Secretary of Energy and in consultation with the Director of the Arms Control and Disarmament Agency ('the Director'); and after consultation with the Commission shall be submitted to the President jointly by the Secretary of State and the Secretary of Energy accompanied by the views and recommendations of the Secretary of State, the Secretary of Energy, the Nuclear Regulatory Commission, and the Director, who shall also provide to the president an unclassified Nuclear Proliferation Assessment Statement (A) which shall analyze the consistency of the text of the proposed agreement for cooperation with all the requirements of this Act, with specific attention to whether the proposed agreement is consistent with each of the criteria set forth in this subsection, and $(B)^{90^{a}}$ regarding the adequacy of the safeguards and other control mechanisms and the peaceful use assurances contained in the agreement for cooperation to ensure that any assistance furnished thereunder will not be used to further any military or nuclear explosive purpose. In the case of those agreements for cooperation arranged pursuant to subsection $91 \mathrm{c}$., $144 \mathrm{~b}$., $144 \mathrm{c}$., or $144 \mathrm{~d} .{ }^{*}$ any proposed agreement for cooperation shall be submitted to the President by the Secretary of Energy or, in the case of those agreements for cooperation arranged pursuant to subsection $91 \mathrm{c}$., or $144 \mathrm{~b}$., which are to be implemented by the Department of Defense, by the Secretary of Defense:

"b. the President has submitted text of the proposed agreement for cooperation, except an agreement arranged pursuant to section 91c., 144 b., 144 c., or 144 d. of section $144,{ }^{*}$ together with the accompanying unclassified Nuclear Proliferation Assessment Statement, to the Committee on Foreign Relations of the Senate and the Committee on Foreign Affairs of the House of Representatives, the President has consulted with such Committees for a period of not less than thirty days of continuous session (as defined in section $130 \mathrm{~g}$. of this Act) concerning the consistency of the terms

-As amended by Public Law 103-227 (108 Stat. 2092), October 5, 1994

${ }^{80 \mathrm{a}}$ As amended by Public Law 99.64, sec. 301 (a)(1). 
Submittal to congressional committees.

Ante, p. 139.

42 USC 2073, $2074,2133,2134$

Ante, p. 142.

Ante, p. 139. of the proposed agreement with all the requirements of this Act, and ${ }^{90}$ the President has approved and authorized the execution of the proposed agreement for cooperation and has made a determination in writing that the performance of the proposed agreement will promote and will not constitute an unreasonable risk to, the common defense and security;;

"c. the proposed agreement for cooperation (if not an agreement subject to subsection d.), together with the approval and determination of the President, has been submitted to the Committee on International Relations of the House of Representatives and the Committee on Foreign Relations of the Senate for a period of thirty days of continuous session (as defined in subsection $130 \mathrm{~g}$.): Provided, however, That these committees, after having received such agreement for cooperation, may by resolution in writing waive the conditions of all or any portion of such thirty-day period; and

"d. the proposed agreement for cooperation (if arranged pursuant to subsection $91 \mathrm{co,} 144 \mathrm{~b}$., $144 \mathrm{c}$., or $144 \mathrm{~d}$., or if entailing implementation of section 53,54 a., 103 , or 104 in relation to a reactor that may be capable of producing more than five thermal megawatts or special nuclear material for use in connection therewith) has been submitted to the Congress, together with the approval and determination of the President, for a period of sixty days of continuous session (as defined in subsection $130 \mathrm{~g}$. of this Act) and referred to the Committee on International Relations of the House of Representatives and the Committee on Foreign Relations of the Senate, and in addition, in the case of a proposed agreement for cooperation arranged pursuant to subsection $91 \mathrm{c}$., 144b., $144 \mathrm{c}$, or $144 \mathrm{~d}$., the Committee on Armed Services of the House of Representatives and the Committee on Armed Services of the Senate, but such proposed agreement for cooperation shall not become effective if during such sixty-day period the Congress adopts, and there is enacted, a joint resolution ${ }^{90 c}$ stating in substance that the Congress does not favor the proposed agreement for cooperation: Provided, That the sixty-day period shall not begin until a Nuclear Proliferation Assessment Statement prepared by the Director of the Arms control and Disarmament Agency, when required by subsection $123 \mathrm{a}$., has been submitted to the Congress: Provided further, That an agreement for cooperation exempted by the President pursuant to subsection a. from any requirement contained in that subsection shall not become effective unless the Congress adopts, and there is enacted, a joint resolution stating that the Congress does favor such agreement. ${ }^{90^{d}}$ During the sixty-day period the Committee on Foreign Affairs of the House of Representatives and the Committee on Foreign Relations of the Senate shall each hold hearings on the proposed agreement for cooperation and submit a report to their respective bodies recommending whether it 
Agency views to Congressional Committees 42 USC 2121, 2164.

Ante, p. 137.

Ante, p. 131.

should be approved or disapproved. ${ }^{90}{ }^{e}$ Any such proposed agreement for cooperation shall be considered pursuant to the procedures set forth in section $130 \mathrm{i}$. of this Act. ${ }^{90^{\mathrm{f}}}$

"Following submission of a proposed agreement for cooperation (except an agreement for cooperation arranged pursuant to subsection 91 c., 144 b., 144 c., or 144 d.) to the Committee on International Relations of the House of Representatives and the Committee on Foreign Relations of the Senate, the Nuclear Regulatory Commission, the Department of State, the Department of Energy, the Arms control and Disarmament Agency, and the Department of Defense shall, upon the request of either of those committees, promptly furnish to those committees their views as to whether the safeguards and other controls contained therein provide an adequate framework to ensure that any export as contemplated by such agreement will not be inimical to or constitute an unreasonable risk to the common defense and security.

"If, after the date of enactment of the Nuclear Non-Proliferation Act of 1978, the Congress fails to disapprove a proposed agreement for cooperation which exempts the recipient nation from the requirement set forth in subsection $123 \mathrm{a}$. (2), such failure to act shall constitute a failure to adopt a resolution of disapproval pursuant to subsection $128 \mathrm{~b}$. (3) for purposes of the Commission's consideration of applications and requests under section 126a. (2) and there shall be no congressional review pursuant to section 128 of any subsequent license or authorization with respect to that state until the first such license or authorization which is issued after twelve months from the elapse of the sixty-day period in which the agreement for cooperation in question is reviewed by the Congress.91

\footnotetext{
${ }^{\circ}{ }^{\circ}$ As ameaded by Public Law 99-64, sec. 301 (a)(3).

90f As amended by Public Law 99-64, sec. 301 (b)(3).
}

${ }^{91}$ Public Law 95-242 (92 Stat. 142) (1978), sec. 401, amended sec. 123 by substituting a complete new see. 123. Before amendment, sec. 123 read as follows: "Sec 123. Cooperation With Other Nations-No cooperation with any nation or regional defense organization pursuant to sections $53,54 a, 57,64,82,91,103,104$, or 144 shall beundertaken until-

"a. the Commission or, in the case of those agreements for cooperation arranged pursuant to subsection $91 \mathrm{c}$ or $144 \mathrm{~b}$. which are to be implemented by the Department of Defense, the Department of Defense has submitted to the President the proposed agreement for cooperation, together with its recommendations thereon, which proposed agreement shall include (1) the terms, conditions, duration, nature, and scope of the cooperation; (2) a guaranty by the cooperating party that security safeguards and standards as set forth in the agreement for cooperation will be maintained; (3) except in the case of those agreements for cooperation arranged pursuant to subsection $91 \mathrm{c}$. a guaranty by the cooperating party that any material to be transferred pursuant to such agreement will not be used for atomic weapons, or for ing party that any research on or development of atomic weapons or for any other milltary puspose; and (4) a guaranly by the cooperaling transferred to unauthorized persons or beyond the jurisdiction of the cooperating party, except as specified in the agreement for cooperation;

"b. the President has approved and authorized the execution of the proposed agreement for cooperation, and has made a determination in writing that the performance of the proposed agreement will promote and will not constitute an unreasonable risk to the common defense and security;

"c. the proposed agreement for cooperation, together with the spproval and thedetermination of the President, has been submitted to the Joint committee and a period of thirty days has elapsed while congress is in session (in computing such thirty days, there shall be exchuded the days on which either House is not in session because of an adjournment of more than threedays): Provided, however, That the Joint Committee, after having received such agreement for cooperation, may by resolution in writing waive the conditions of all or any portion of such thirty-day period; and

(Continued) 
International atomic pool. 42 USC sec. 2154 .

Cooperation with Berlin. 42 USC $\sec 2153(\mathrm{Nt})$.

42 USC 2155 Exemption.
"Sec. 124. International Atomic Pool.-The President is authorized to enter into an international arrangement with a group of nations providing for international cooperation in the nonmilitary applications of atomic energy and he may thereafter cooperate with that group of nations pursuant to sections 54a, 57, 64, 82, 103, 104, or 144 a.: Provided, however, That the cooperation is undertaken pursuant to an agreement for cooperation entered into in accordance with section 123.

"Sec. 125. Cooperation With Berlin.-The President may authorize the Commission to enter into agreements for cooperation with the Federal Republic of Germany in accordance with section 123 , on behalf of Berlin, which for the purposes of this Act comprises those areas over which the Berlin Senate exercises jurisdiction (the United States, and French sectors) and the Commission may thereafter cooperate with Berlin pursuant to sections 54a, 92 57, 64, 82, 103, or 104; Provided, That the guaranties required by section 123 shall be made by Berlin with the approval of the allied commandants. ${ }^{93}$

"Sec. 126. Export Licensing Procedures.-

"a. No license may be issued by the Nuclear Regulatory Commission (the 'Commission') for the export of any production or utiliza-

(Continued)

"d. The proposed agreement for cooperation together with the approval and determination of the President, if arranged pursuant to subsection $91 \mathrm{c} ; 144 \mathrm{~b}$., or $144 \mathrm{c}$, or if entailing implementation of sections $53,54 \mathrm{a}, 103$ or 104 in relation to a reactor that may be capable of producing more than five thermal megawatts or special nuclear material for use in connection therewith, has been submitted to the Congress and referred to the Joint Committee and a period of sixty days has elapsed while congress is in session (in computing such sixty days, there shall be excluded the days on which either House is not in session because of an adjournment of more than three days), but any such proposed agree ment for cooperation shall not become effective if during such sixty-day period the congress passes a concurrent resolution stating in substance that it does not favor the proposed agreement for cooperation: Provided, That prior to the elapse of the first thirty days of any such sixty-day period the Joint committeeshall submit a report to the Congress of its views and recommendations respecting the proposed agreement and an accompanying proposed concurrent resolution stating in substance that the Congress favors, or does not favor, as the case may be, the proposed agreement for cooperation. Any such concurrent resolution so reported shall become the pending business of the House in question (in the case of the Senate the time for debate shall be equally divided between the proponents and the opponents) within twenty-five days and shall be voled on within five calendar days thereafter, unless such House shall otherwise determine"

"Public Law 88-489 (78 Stat. 602) (1964), sec. 15, added "53.".

Sec. 5 of Public Law 93-377 (88 Stat. 475) (1974) changed the term "54" to "54a".

Tublic Law 85-479 (72. Stat. 276) (1958), sec. 3 amended sec. 123 by inserting "91," and substituting a nep

subsec. a. Before amendment subsec. a. read as follows:

"a. the Commission or, in the case of those agreements for cooperation arranged pursuant to subsection 144 b., the Department of Defense has submitted to the President the proposed agreement for cooperation, together with its recommendation thereon, which proposed agreement shall include (1) the terms conditions, duration, nature, and scope of the cooperation; (2) a guaranty by the cooperating party that security safeguards and standards as set forth in theagreement for cooperation will be maintained; (3) a guaranty by the cooperating party that any material to be transferred pursuant to such agreement will not be used for atomic weapons, or for research on or development of atomic weapons, or for any other military purpose; and (4) a guaranty by the cooperating party that any matorial or any Restricted Data to be transferred pursuant to the agreement for cooperation will not be transferred to unauthorized persons or beyond the jurisdiction of the cooperating party, except as specified in the agreement for cooperation;"

Public Law 85-681 (72 Stat. 632) (1958), sec. 4, added the proviso to subsec. 123 c. The semicolon $85-479$.

Subsec. 123d was amended by Public Law 93-485 (88 stat. 1460) (1974). Prior to amendment, subsec. 123d read as follows:

"d. the proposed agreement for cooperation, together with the approval and determination of the President, if arranged pursuant to subsection $91 \mathrm{c}, 144 \mathrm{~b}$, or $144 \mathrm{c}$, has been submitted to the Congress and referred to the Joint Committee and a period of sixty days has elapsed while Congress is in gress and referred to the Joint Committee and a period of sixty days has elapsed while Congress is in session, but any such proposed agreement for cooperation shall not become effective if during such sixty-day period the Congress passes a concurzent resolution stating in substance that it does not favor the proposed agreement for cooperation: Provided, however, That during the Eighty-fifth Congress such period shall be thirty days (in computing such sixty days, or thirty days, as the case may be, there shall be excluded the days on which either House is not in session because of an adjourament of more

Public Law 85-479 (72 Stat. 276) (1958), sec. 4 added new subsec. 123d.

${ }^{83} \mathrm{Sec} .5$ of Public Law 93-377 (88 stat. 475) (1974) amended secs. 124 and 125 by substituting theterms " $54 a^{\text {" for }}$ the term " 54 ".

${ }^{00}$ Public Law 85-14 (71 St2t. 11) (1957), added sec. 125. 
Ante, p. 125.

Supra.

42 USC 2112

Executive

branch judgment

notice to

commission.

Procedures.

Contents.

Standards and criteria. tion facility, or any source material or special nuclear material, including distributions of any material by the Department of Energy under section 54,64 , or 82 , for which a license is required or or requested, no. exemption from any requirement for such an export license may be granted by the Commission, as the case may be, until-

"(1) the Commission has been notified by the Secretary of State that it is the judgment of the executive branch that the proposed export or exemption will not be inimical to the common defense and security, or that any export in the category to which the proposed export belongs would not be inimical to the common defense and security because it lacks significance for nuclear explosive purposes. The Secretary of State shall, within ninety days after the enactment of this section, establish orderly and expeditious procedures, including provision for necessary administrative actions and inter-agency memoranda of understanding, which are mutually agreeable to the Secretaries of Energy, Defense, and Commerce, the Director of the Arms Control and Disarmament Agency, and the Nuclear Regulatory Commission for the preparation of the executive branch judgment on export applications under this section. Such procedures shall include, at a minimum, explicit direction on the handling of such applications, express deadlines for the solicitation and collection of the views of the consulted agencies (with identified officials responsible for meeting such deadlines), an inter-agency coordinating authority to monitor the processing of such applications, predetermined procedures for the expeditious handling of intra-agency and inter-agency disagreements and appeals to higher authorities, frequent meetings of interagency administrative coordinators to review the status of all pending applications, and similar administrative mechanisms. To the extent practicable, an applicant should be advised of all the information required of the applicant for the entire process for every agency's needs at the beginning of the process. Potentially controversial applications should be identified as quickly as possible so that any required policy decisions or diplomatic consultations can be initiated in a timely manner. An immediate effort should be undertaken to establish quickly any necessary standards and criteria, including the nature of any required assurances or evidentiary showing, for the decisions required under this section. The processing of any export application proposed and filed as of the date of enactment of this section shall not be delayed pending the development and establishment of procedures to implement the requirements of this section. The executive branch judgment shall be completed in not more than sixty days from receipt of the application or request, unless the Secretary of State in his discretion specifically authorizes additional time for consideration of the application or request because it is in the national interest to allow such additional time. The Secretary shall notify the Committee on Foreign Relations of the Senate and the Committee on 
Notice to congressional committees.

Post, p. 136.

Data and recommendations.

Post, p. 136.

42 USC 2154.

Extension, notice to

Congress.
International Relations of the House of Representatives of any such authorization. In submitting any such judgment, the Secretary of State shall specifically address the extent to which the export criteria then in effect are met and the extent to which the cooperating party has adhered to the provisions of the applicable agreement for cooperation. In the event he considers it warranted, the Secrètary may also address the following additional factors, among others:

"(A) whether issuing the license or granting the exemption will materially advance the non-proliferation policy of the United States by encouraging the recipient nation to adhere to the Treaty, or to participate in the undertakings contemplated by section 403 or 404(a) of the Nuclear Non-Proliferation Act of 1978;

"(B) whether failure to issue the license or grant the exemption would otherwise be seriously prejudicial to the non-proliferation objectives of the United States; and

"(C) whether the recipient nation or group of nations has agreed that conditions substantially identical to the export criteria set forth in section 127 of this Act will be applied by another nuclear supplier nation or group of nations to the proposed United States export, and whether in the Secretary's judgment those conditions will be implemented in a manner acceptable to the United States.

The Secretary of State shall provide appropriate data and recommendations, subject to requests for additional data and recommendations, as required by the Commission or the Secretary of Energy, as the case may be; and

"(2) the Commission finds, based on a reasonable judgment of the assurances provided and other information available to the Federal Government, including the Commission, that the criteria in section 127 of this Act or their equivalent, and any other applicable statutory requirements, are met: Provided, That continued cooperation under an agreement for cooperation as authorized in accordance with section 124 of this Act shall not be prevented by failure to meet the provisions of paragraph (4) or (5) of section 127 for a period of thirty days after enactment of this section, and for a period of twenty-three months thereafter if the Secretary of State notifies the commission that the nation or group of nations bound by the relevant agreement has agreed to negotiations as called for in section 404(a) of the Nuclear Non-Proliferation act of 1978; however, nothing in this subsection shall be deemed to relinquish any rights which the United States may have under agreements for cooperation in force on the date of enactment of this section: Provided further, That if, upon the expiration of such twenty four month period, the President determines that failure to continue cooperation with any group of nations which has been exempted pursuant to the above proviso from the provisions of paragraph (4) or (5) of section 127 of this Act, but which has not 
Post, p. 139. Findings.

Judicial review, exception.

Presidential review. yet agreed to comply with those provisions would be seriously prejudicial to the achievement of United States non-proliferation objectives or otherwise jeopardize the common defense and security, he may, after notifying the Congress of his determination, extend by Executive order the duration of the above proviso for a period of twelve months, and may further extend the duration of such proviso by one year increments annually thereafter if he again makes such determination and so notifies the Congress. In the event that the Committee on International Relations of the House of Representatives or the Committee on Foreign Relations of the Senate reports a joint resolution to take any action with respect to any such extension, such joint resolution will be considered in the House or Senate, as the case may be, under procedures identical to those provided for the consideration of resolutions pursuant to section 120 of this Act: And additionally provided, That the Commission is authorized to (A) make a single finding under this subsection for more than a single application or request, where the applications or requests involve exports to the same country, in the same general time frame, of similar significance for nuclear explosive purposes and under reasonably similar circumstances and $(\mathrm{B})$ make a finding under this subsection that there is no material changed circumstance associated with a new application or request from those existing at the time of the last application or request for an export to the same country, where the prior application or request was approved by the Commission using all applicable procedures of this section, and such finding of no material changed circumstance shall be deemed to satisfy the requirement of this paragraph for findings of the Commission. The decision not to make any such finding in lieu of the findings which would otherwise be required to be made under this paragraph shall not be subject to judicial review: And provided further, That nothing contained in this section is intended to require the Commission independently to conduct or prohibit the Commission from independently conducting country or site specific visitations in the Commission's consideration of the application of IAEA safeguards.

"b. (1) Timely consideration shall be given by the Commission to requests for export license and exemptions and such requests shall be granted upon a determination that all applicable statutory requirements have been met.

"(2) If, after receiving the executive branch judgment that the issuance of a proposed export license will not be inimical to the common defense and security, the Commission does not issue the proposed license on a timely basis because it is unable to make the statutory determinations required under this Act, the Commission shall publicly issue its decision to that effect, and shall submit the license application to the President. The Commission's decision shall include an explanation of the basis for the decision and any dissenting or separate views. If, after receiving the proposed license application and reviewing the 
Report to

Congress and congressional committees.

Post, p. 139.

Review.

Concerns and requests, transmittal to executive branch.
Commission's decision, the President determines that withholding the proposed export would be seriously prejudicial to the achievement of United States non-proliferation objectives, or would otherwise jeopardize the common defense and security, the proposed export may be authorized by Executive order: Provided, That prior to any such export, the President shall submit the Executive order, together with his explanation of why, in light of the Commission's decision, the export should nonetheless be made, to the Congress for a period of sixty days of continuous session (as defined in subsection $130 \mathrm{~g}$.) and shall be referred to the Committee on International Relations of the House of Representatives and the Committee on Foreign Relations of the Senate, but any such proposed export shall not occur if during such sixty-day period the Congress adopt a concurrent resolution stating in substance that it does not favor the proposed export. Any such Executive order shall be considered pursuant to the procedures set forth in section 130 of this Act for the consideration of Presidential submissions: And provided further, That the procedures established pursuant to subsection (b) of section 304 of the Nuclear Non-Proliferation Act of 1978 shall provide that the Commission shall immediately initiate review of any application for a license under this section and to the maximum extent feasible shall expeditiously process the application concurrently with the executive branch review while awaiting the final executive branch judgment. In initiating its review the Commission may identify a set of concerns and requests for information associated with the projected issuance of such license and shall transmit such concerns and requests to the executive branch which shall address such concerns and requests in its written communications with the Commission. Such procedures shall also provide that if the Commission has not completed action on the application within sixty days after the receipt of an executive branch judgment that the proposed export or exemption is not inimical to the common defense and security or that any export in the category to which the proposed export belongs would not be inimical to the common defense and security because it lacks significance for nuclear explosive purposes, the Commission shall inform the applicant in writing of the reason for delay and provide followup reports as appropriate. If the Commission has not completed action by the end of an additional sixty days (a total of one hundred and twenty days from receipt of the executive branch judgment), the President may authorize the proposed export by Executive order, upon a finding that further delay would be excessive and upon making the findings required for such Presidential authorizations under this subsection, and subject to the Congressional review procedures set forth herein. However, if the Commission has commenced procedures for public participation regarding the proposed export under regulations promulgated pursuant to subsection (b) of section 304 of the Nuclear Non-Proliferation Act of 1978, or-within sixty days after re- 
Referral to congressional committees.

42 USC 2156

ceipt of the executive branch judgment on the proposed export-the Commission has identified and transmitted to the executive branch a set of additional concerns or requests for information, the President may not authorize the proposed export until sixty days after public proceedings are completed or sixty days after a full executive branch response to the Commis-. sion's additional concerns or requests has been made consistent with subsection a. (1) of this section: Provided further, That nothing in this section shall affect the right of the Commission to obtain data and recommendations from the Secretary of State at any time as provided in subsection a. (1) of this section.

"c. In the event that the House of Representatives or the Senate passes a joint resolution which would adopt one or more additional export criteria, or would modify any existing export criteria under this Act, any such joint resolution shall be referred in the other House to the Committee on Foreign Relations of the Senate or the Committee on International Relations of the House of Representatives, as the case may be, and shall be considered by the other House under applicable procedures provided for the consideration of resolutions pursuant to section 130 of this Act.94

"Sec. 127. Criteria Governing United States Nuclear Exports.-

"The United States adopts the following criteria which, in addition to other requirements of law, will govern exports for peaceful nuclear uses from the United States of source material, special nuclear material, production or utilization facilities, and any sensitive nuclear technology:

"(1) IAEA safeguards as required by Article III (2) of the Treaty will be applied with respect to any such material or facilities proposed to be exported, to any such material or facilities previously exported and subject to the applicable agreement for cooperation, and to any special nuclear material used in or produced through the use thereof.

"(2) No such material, facilities, or sensitive nuclear technology proposed to be exported or previously exported and subject to the applicable agreement for cooperation, and no special nuclear material produced through the use of such materials, facilities, or sensitive nuclear technology, will be used for any nuclear explosive device or for research on or development of any nuclear explosive device.

"(3) Adequate physical security measures will be maintained with respect to such material or facilities proposed to be exported and to any special nuclear material used in or produced through the use thereof. Following the effective date of any regulations promulgated by the Commission pursuant to section 304 (d) of the Nuclear Non-Proliferation Act of 1978, physical security measures shall be deemed adequate if such measures provide a level of protection equivalent to that required by the applicable regulations.

"(4) No such materials, facilities, or sensitive nuclear technology proposed to be exported, and no special nuclear material produced

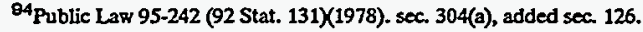


42 USC 2157.

Export applications, criterion enforcement. through the use of such material, will be retransferred to the jurisdiction of any other nation or group of nations unless the prior approval of the United States is obtained for such retransfer. In addition to other requirements of law, the United States may approve such retransfer only if the nation or group of nations designated to receive such retransfer agrees that it shall be subject to the conditions required by this section.

"(5) No such material proposed to be exported and no special nuclear material produced through the use of such material will be reprocessed, and no irradiated fuel elements containing such material removed from a reactor shall be altered in form or content, unless the prior approval of the United states is obtained for such reprocessing or alteration.

"(6) No such sensitive nuclear technology shall be exported unless the foregoing conditions shall be applied to any nuclear material or equipment which is produced or constructed under the jurisdiction of the recipient nation or group of nations by or through the use of any exported sensitive nuclear technology. 95

"Sec. 128. Additional Export Criterion And Procedures. -

"a. (1) As a condition of continued United States export of source material, special nuclear material, production or utilization facilities, and any sensitive nuclear technology to non-nuclear-weapon states, no such export shall be made unless IAEA safeguards are maintained with respect to all peaceful nuclear activities in, under the jurisdiction of, or carried out under the control of such state at the time of the export.

"(2) The President shall seek to achieve adherence to the foregoing criterion by recipient non-nuclear weapon states.

"b. The criterion set forth in subsection a. shall be applied as an export criterion with respect to any application for the export of materials, facilities, or technology specified in subsection a. which is filed after eighteen months from the date of enactment of this section, or for any such application under which the first export would occur at least twenty-four months after the date of enactment of this section, except as provided in the following paragraphs:

"(1) If the Commission or the Department of Energy, as the case may be, is notified that the President has determined that failure to approve an export to which this subsection applies because such criterion has not yet been met would be seriously prejudicial to the achievement of United States non-proliferation objectives or otherwise jeopardize the common defense and security, the license or authorization may be issued subject to other applicable requirements of law: Provided, That no such export of any production or utilization facility or of any source or special nuclear material (intended for use as fuel in any production or utilization facility) which has been licensed or authorized pursuant to this subsection shall be made to any non-nuclear-weapon state which has failed to meet such criterion until the first such license or authorization with respect to such state is submitted to the Congress (together with a

${ }^{95}$ Public Law 95-242 (92 Stat. 136)(1978), sec. 305, added sec. 127. 
Ante, p. 131.

Post, p. 139.

Congressional disapproval, resolution.

Export authorizations, congressional review.

Export terminations, criterion. 42 USC 2158. detailed assessment of the reasons underlying the President's determination, the judgement of the executive branch required under section 126 of this Act, and any Commission opinion and views) for a period of sixty days of continuous session (as defined in subsection $130 \mathrm{~g}$. of this Act) and referred to the Committee on International Relations of the House of Representatives and the Committee on Foreign Relations of the Senate, but such export shall not occur if during such sixty-day period the Congress adopts a concurrent resolution stating in substance that the Congress does not favor the proposed export. Any such license or authorization shall be considered pursuant to the procedures set forth in section 130 of this Act for the consideration of Presidential submissions.

"(2) If the Congress adopts a resolution of disapproval pursuant to paragraph (1), no further export of materials, facilities, or technology specified in subsection a. shall be permitted for the remainder of that Congress, unless such state meets the criterion or the President notifies the Congress that he has determined that significant progress has been made in achieving adherence to such criterion by such state or that United States foreign policy interests dictate reconsideration and the Congress, pursuant to the procedure of paragraph (1), does not adopt a concurrent resolution stating in substance that it disagrees with the President's determination.

"(3) If the Congress does not adopt a resolution of disapproval with respect to a license or authorization submitted pursuant to paragraph (1), the criterion set forth in subsection a. shall not be applied as an export criterion with respect to exports of materials, facilities and technology specified in subsection a. to that state: Provided, That the first license or authorization with respect to that state which is issued pursuant to this paragraph after twelve months from the elapse of the sixty-day period specified in paragraph (1), and the first such license or authorization which is issued after each twelve-month period thereafter, shall be submitted to the Congress for review pursuant to the procedures specified in paragraph (1): Provided further, That if the Congress adopts a resolution of disapproval during any review period provided for by this paragraph, the provisions of paragraph (2) shall apply with respect to further exports to such state. ${ }^{96}$

"Sec. 129. Conduct Resulting In Termination Of Nuclear Exports."No nuclear materials and equipment or sensitive nuclear technology shall be exported to-

"(1) any non-nuclear-weapon state that is found by the President to have, at any time after the effective date of this section,

"(A) detonated a nuclear explosive device; or

“(B) terminated or abrogated IAEA safeguards; or

"(C) materially violated an IAEA safeguards agreement; or

${ }^{80}$ Public Law 95-242 (92 Stat. 137), Sec. 306, added sec. 128. 
Report to. Congress.

Infra.

42 USC 2159

Congressional committee reports.

Post. p. 142
"(D) engaged in activities involving source or special nuclear material and having direct significance for the manufacture or acquisition of nuclear explosive devices, and has failed to take steps which, in the President's judgment, represent sufficient progress toward terminating such activities; or

"(2) any nation or group of nations that is found by the President to have, at any time after the effective date of this section,

"(A) materially violated an agreement for cooperation with the United States, or, with respect to material or equipment not supplied under an agreement for cooperation, materially violated the terms under which such material or equipment was supplied or the terms of any commitments obtained with respect thereto pursuant to section 402(a) of the Nuclear NonProliferation Act of 1978; or

"(B) assisted, encouraged, or induced any non-nuclearweapon state to engage in activities involving source or special nuclear material and having direct significance for the manufacture or acquisition of nuclear explosive devices, and has failed to take steps which, in the President's judgment, represent sufficient progress toward terminating such assistance, encouragement, or inducement; or

"(C) entered into an agreement after the date of enactment of this section for the transfer of reprocessing equipment, materials, or technology to the sovereign control of a non-nuclearweapon state except in connection with an intentional fuel cycle evaluation in which the United States is a participant or pursuant to a subsequent international agreement or understanding to which the United States subscribes;

unless the President determines that cessation of such exports would be seriously prejudicial to the achievement of United States non-proliferation objectives or otherwise jeopardize the common defense and security: Provided, That prior to the effective date of any such determination, the President's determination, together with a report containing the reasons for his determination, shall be submitted to the Congress and referred to the Committee on International Relations of the House of Representatives and the Committee on Foreign Relations of the Senate for a period of sixty days of continuous session (as defined in subsection $130 \mathrm{~g}$. of this act), but any such determination shall not become effective if during such sixty-day period the Congress adopts a concurrent resolution stating in substance that it does not favor the determination. Any such determination shall be considered pursuant to the procedures set forth in section $\mathbf{1 3 0}$ of this Act for the consideration of Presidential submissions. ${ }^{97}$

"Sec. 130. Congressional Review Procedures. -

"a. Not later than forty-five days of continuous session of Congress after the date of transmittal to the Congress of any submission of the President required by subsection ${ }^{97} 126$ a. (2), 126 b. (2), 128 b., 129, 131 a. (3), or $131 \mathrm{f}$. (1)(A) of this Act, the

\footnotetext{
97 Public Law 95-242 (92 Stat. 138)(1978), sec. 307, added sec. 129

$87{ }^{\text {a }}$ P.L. 99-64, sec 301 (c)(1)(A)(i)
} 
Ante. pp. 131, 137, 138, 127.

42 USC 2121 , 2164.

Committee on Foreign Relations of the Senate and the Committee on Foreign Affairs of the House of Representatives. ${ }^{97}$ shall each submit a report to its respective House on its views and recommendations respecting such Presidential submission together with a resolution, as defined in subsection $f$., stating in substance that the Congress approves or disapproves such submission, as the case may be: Provided, That if any such committee has not reported such a resolution at the end of such forty-five day period, such committee shall be deemed to be discharged from further consideration of such submission. ${ }^{97^{c}}$ If no such resolution has been reported at the end of such period, the first resolution, as defined in subsection $\mathrm{f}$., which is introduced within five days thereafter within such House shall be placed on the appropriate calendar of such House.

"b. When the relevant committee or committees have reported such a resolution (or have been discharged from further consideration of such a resolution pursuant to subsection a.) or when a resolution has been introduced and placed on the appropriate calendar pursuant to subsection a., as the case may be, it is at any time thereafter in order (even though a previous motion to the same effect has been disagreed to) for any Member of the respective House to move to proceed to the consideration of the resolution. The motion is highly privileged and is not debatable. The motion shall not be subject to amendment, or to a motion to postpone, or to a motion to proceed to the consideration of other business. A motion to reconsider the vote by which the motion is agreed to or disagreed to shall not be in order. If a motion to proceed to the consideration of the resolution is agreed to, the resolution shall remain the unfinished business of the respective House until disposed of.

"c. Debate on the resolution, and on all debatable motions and appeals in connection therewith, shall be limited to not more than ten hours, which shall be divided equally between individuals favoring and individuals opposing the resolution. A motion further to limit debate is in order and not debatable. An amendment to a motion to postpone, or a motion to recommit the resolution, or a motion to proceed to the consideration of other business is not in order. A motion to reconsider the vote by which the resolution is agreed to or disagreed to shall not be in order. No amendment to any concurrent resolution pursuant to the procedures of this section is in order except as provided in subsection d.

"d. Immediately following (1) the conclusion of the debate on such concurrent resolution, (2) a single quorum call at the conclusion of debate if requested in accordance with the rules of the appropriate House, and (3) the consideration of an amendment introduced by the Majority Leader or his designee to insert the phrase, 'does not' in lieu of the word 'does' if the resolution under

97b P.L. 99-64, sec 301 (c)(1)(A)(ii)

$97 \mathrm{C}$ P.L. 99.64, sec 301 (C)(1)(B) 
"Resolution."

Continuous sessions of Congress. Computation. consideration is a concurrent resolution of approval, the vote on final approval of the resolution shall occur.

"e. Appeals from the decisions of the Chair relating to the application of the rules of the Senate or the House of Representatives, as the case may be, to the procedure relating to such a resolution shall be decided without debate.

"f. For the purposes of subsections a. through e. of this section, the term 'resolution' means a concurrent resolution of the Congress, the matter after the resolving clause of which is as follows: 'That the Congress (does or does not) favor the transmitted to the Congress by the President on $\quad$, , the blank spaces therein to be appropriately filled, and the affirmative or negative phrase within the parenthetical to be appropriately selected.

"g. (1) Except as provided in paragraph (2), for the purposes of this section-

"(A) continuity of session is broken only by an adjournment of Congress sine die; and

"(B) the days on which either House is not in session because of an adjournment of more than three days to a day certain are excluded in the computation of any period of time in which Congress is in continuous session.

"(2) For purposes of this section insofar as it applies to section $123-$

"(A) continuity of session is broken only by an adjournment of congress sine die at the end of a Congress; and

"(B) the days on which either House is not in session because of an adjournment of more than three days are excluded in the computation of any period of time in which Congress is in continuous session.

"h. This section is enacted by Congress-

"(1) as an exercise of the rulemaking power of the Senate and the House of Representatives, respectively, and as such they are deemed a part of the rules of each House, respectively, but applicable only with respect to the procedure to be followed in that House in the case of resolutions described by subsection $f$. of this section; and they supersede other rules only to the extent that they are inconsistent therewith; and

"(2) With full recognition of the constitutional right of either House to change the rules (so far as relating to the procedure of that House) at any time, in the same manner and to the same extent as in the case of any other rule of that House. 98

"i. (1) For the purposes of this subsection, the term 'joint resolution' means a joint resolution, the matter after the resolving clause of which is as follows: 'That the Congress (does or does not) favor the proposed agreement for cooperation transmitted to the Congress by the President on with the date of the transmission of the proposed agreement for cooperation inserted in the blank, and the affirmative or negative phrase within the parenthetical appropriately selected.

${ }^{80}$ Public Law 95-242 (92 Stat. 138)(1978), sec. 308, added sec. 130. 
"(2) On the day on which a proposed agreement for cooperation is submitted to the House of Representatives and the Senate under section $123 \mathrm{~d}$., a joint resolution with respect to such agreement for cooperation shall be introduced (by request) in the House by the chairman of the Committee on Foreign Affairs, for himself and the ranking minority member of the Committee, or by Members of the House designated by the chairman and ranking minority member; and shall be introduced (by request) in the Senate by the majority leader of the Senate, for himself and the minority leader of the Senate, or by Members of the Senate designated by the majority leader and minority leader of the Senate. If either House is not in session on the day on which such an agreement for cooperation is submitted, the joint resolution shall be introduced in that House, as provided in the preceding sentence, on the first day thereafter on which that House is in session.

"(3) All joint resolutions introduced in the House of Representatives shall be referred to the appropriate committee or committees, and all joint resolutions introduced in the Senate shall be referred to the Committee on Foreign Relations and in addition, in the case of a proposed agreement for cooperation arranged pursuant to section $91 \mathrm{c}$., $144 \mathrm{~b}$., or $144 \mathrm{c}$., the Committee on Armed Services.

"(4) If the committee of either House to which a joint resolution has been referred has not reported it at the end of 45 days after its introduction, the committee shall be discharged from further consideration of the joint resolution or of any other joint resolution introduced with respect to the same matter; except that, in the case of a joint resolution which has been referred to more than one committee, if before the end of that 45-day period one such committee has reported the joint resolution, any committee to which the joint resolution was referred shall be discharged from further consideration of the joint resolution or of any other joint resolution introduced with respect to the same matter.

(5) A joint resolution under this subsection shall be considered in the Senate in accordance with the provisions of section 601(b)(4) of the International Security Assistance and Arms Export Control Act of 1976. For the purpose of expediting the consideration and passage of joint resolutions reported or discharged pursuant to the provisions of this subsection, it shall be in order for the committee on Rules of the House of Representatives to present for consideration a resolution of the House of Representatives providing procedures for the immediate consideration of a joint resolution under this subsection which may be similar, if applicable, to the procedures set forth in section 601(b)(4) of the International Security Assistance and Arms Export Control Act of 1976.

(6) In the case of a joint resolution described in paragraph (1), if prior to the passage by one House of a joint resolution of that 
42 USC 2160.

Consultation

42 USC 2121, 2164.

Notice publication in the Federal

Register.

Nuclear Proliferation Assessment Statement.

"Subsequent arrangements."

Contracts.
House, that House receives a joint resolution with respect to the same matter from the other House, then-

(A) the procedure in that House shall be the same as if no joint resolution had been received from the other House; but

(B) the vote on final passage shall be on the joint resolution of the other House".

Sec. 131. Subsequent Arrangements.-

a (1) Prior to entering into any proposed subsequent arrangement under an agreement for cooperation (other than an agreement for cooperation arranged pursuant to subsection $91 \mathrm{c}$., $144 \mathrm{~b}$., or $144 \mathrm{c}$. of this Act), the Secretary of Energy shall obtain the concurrence of the Secretary of State and shall consult with the Director, the Commission, and the Secretary of Defense: Provided, That the Secretary of State shall have the leading role in any negotiations of a policy nature pertaining to any proposed subsequent arrangement regarding arrangements for the storage or disposition of irradiated fuel elements or approvals for the transfer, for which prior approval is required under an agreement for cooperation, by a recipient of source or special nuclear material, production or utilization facilities, or nuclear technology. Notice of any proposed subsequent arrangement shall be published in the Federal Register, together with the written determination of the Secretary of Energy that such arrangement will not be inimical to the common defense and security, and such proposed subsequent arrangement shall not take effect before fifteen days after publication. Whenever the Director declares that he intends to prepare a Nuclear Proliferation Assessment Statement pursuant to paragraph (2) of this subsection, notice of the proposed subsequent arrangement which is the subject of the Director's declaration shall not be published until after the receipt by the Secretary of Energy of such Statement or the expiration of the time authorized by subsection $c$. for the preparation of such Statement, whichever occurs first.

(2) If in the Director's view a proposed subsequent arrangement might significantly contribute to proliferation, he may prepare an unclassified Nuclear Proliferation Assessment Statement with regard to such proposed subsequent arrangement regarding the adequacy of the safeguards and other control mechanisms and the application of the peaceful use assurances of the relevant agreement to ensure that assistance to be furnished pursuant to the subsequent arrangement will not be used to further any military or nuclear explosive purpose. For the purposes of this section, the term 'subsequent arrangements' means arrangements entered into by any agency or department of the United States Government with respect to cooperation with any nation or group of nations (but not purely private or domestic arrangements) involving-

(A) contracts for the furnishing of nuclear materials and equipment;

(B) approvals for the transfer, for which prior approval is required under an agreement for cooperation, by a recipient of 
Ante, p. 125.

Post, pp. 131, 141.

Post, p. 142.

Report to congressional committees.

Post, p. 139.

any source or special nuclear material, production or utilization facility, or nuclear technology;

"(C) authorization for the distribution of nuclear materials and equipment pursuant to this Act which is not subject to the procedures set forth in section $111 \mathrm{~b}$., section 126, or section 109b.;

"(D) arrangements for physical security;

(E) arrangements for the storage or disposition of irradiated fuel elements;

"(F) arrangements for the application of safeguards with respect to nuclear materials and equipment; or

"(G) any other arrangement which the President finds to be important from the standpoint of preventing proliferation.

“(3) The United States will give timely consideration to all requests for prior approval, when required by this Act, for the reprocessing of material proposed to be exported, previously exported and subject to the applicable agreement for cooperation, or special nuclear material produced through the use of such material or a production or utilization facility transferred pursuant to such agreement for cooperation, or to the altering of irradiated fuel elements containing such material, and additionally, to the maximum extent feasible, will attempt to expedite such consideration when the terms and conditions for such actions set forth in such agreement for cooperation or in some other international agreement executed by the United States and subject to congressional review procedures comparable to those set forth in section 123 of this Act.

"(4) All other statutory requirements under other sections of this Act for the approval or conduct of any arrangement subject to this subsection shall continue to apply and any other such requirements for prior approval or conditions for entering such arrangements shall also be satisfied before the arrangement takes effect pursuant to subsection a. (1).

"b. With regard to any special nuclear material exported by the United States or produced through the use of any nuclear materials and equipment or sensitive nuclear technology exported by the United States-

"(1) the Secretary of Energy may not enter into any subsequent arrangement for the retransfer of any such material to a third country for reprocessing, for the reprocessing of any such material, or for the subsequent retransfer of any plutonium in quantities greater than 500 grams resulting from the reprocessing of any such material, until he has provided the Committee on International Relations of the House of Representatives and the Committee on Foreign Relations of the Senate with a report containing his reasons for entering into such arrangement and a period of 15 days of continuous session (as defined in subsection $130 \mathrm{~g}$. of this Act) has elapsed: Provided, however, That if in the view of the President an emergency exists due to unforeseen circumstances requiring immedi- 
Nuclear

materials, reprocessing or transfer procedures. ate entry into a subsequent arrangement, such period shall consist of fifteen calendar days;

“(2) the Secretary of Energy may not enter into any subsequent arrangement for the reprocessing of any such material in a facility which has not processed power reactor fuel assemblies or been the subject of a subsequent arrangement therefor prior to the date of enactment of the Nuclear Non-Proliferation Act of 1978 or for subsequent retransfer to a non-nuclear-weapon state of any plutonium in quantities greater than 500 grams resulting from such reprocessing, unless in his judgment, and that of the Secretary of State, such reprocessing or retransfer will not result in a significant increase of the risk of proliferation beyond that which exists at the time that approval is requested. Among all the factors in making this judgment, foremost consideration will be given to whether or not the reprocessing or retransfer will take place under conditions that will ensure timely warning to the United States of any diversion well in advance of the time at which the non-nuclear-weapon state could transform the diverted material into a nuclear explosive device and

"(3) the Secretary of Energy shall attempt to ensure, in entering into any subsequent arrangement for the reprocessing of any such material in any facility that has processed power reactor fuel assemblies or been the subject of a subsequent arrangement therefor prior to the date of enactment of the Nuclear Non-Proliferation Act of 1978, or for the subsequent retransfer to any non-nuclearweapon state of any plutonium in quantities greater than $500 \mathrm{grams}$ resulting from such reprocessing, that such reprocessing or retransfer shall take place under conditions comparable to those which in his view, and that of the Secretary of State, satisfy the standards set forth in paragraph (2).

"c. The Secretary of Energy shall, within ninety days after the enactment of this section, establish orderly and expeditious procedures, including provision for necessary administrative actions and inter-agency memoranda of understanding, which are mutually agreeable to the Secretaries of State, Defense, and Commerce, the Director of the Arms Control and Disarmament Agency, and the Nuclear Regulatory Commission for the consideration of requests for subsequent arrangements under this section. Such procedures shall include, at a minimum, explicit direction on the handling of such requests, express deadlines for the solicitation and collection of the views of the consulted agencies (with identified officials responsible for meeting such deadlines), an inter-agency coordinating authority to monitor the processing of such requests, predetermined procedures for the expeditious handling of intra-agency and inter-agency disagreements and appeals to higher authorities, frequent meetings of inter-agency administrative coordinators to review the status of all pending requests, and similar administrative mechanisms. To the extent practicable, an applicant should be advised of all the information required of the applicant for the entire process for every agency's needs at the 
Controversial requests, identification. Standards and criteria. Nuclear Proliferation Assessment Statement. Presidential waiver.

Notice to congressional committees.

42 USC 7172.

Presidential plan, submittal to Congress.

beginning of the process. Potentially controversial request should be identified as quickly as possible so that any required policy decisions or diplomatic consultations can be initiated in a timely manner. An immediate effort should be undertaken to establish quickly any necessary standards and criteria, including the nature of any required assurance or evidentiary showings, for the decisions required under this section. Further, such procedures shall specify that if he intends to prepare a Nuclear Proliferation Assessment Statement, the Director shall so declare in his response to the Department of Energy. If the Director declares that he intends to prepare such a Statement, he shall do so within sixty days of his receipt of a copy of the proposed subsequent arrangement (during which time the Secretary of Energy may not enter into the subsequent arrangement), unless pursuant to the Directors request, the President waives the sixty-day requirement and notifies the Committee on International Relations of the House of Representatives and the Committee on Foreign Relations of the Senate of such waiver and the justification therefor. The processing of any subsequent arrangement proposed and filed as of the date of enactment of this section shall not be delayed pending the development and establishment of procedures to implement the requirements of this section.

"d. Nothing in this section is intended to prohibit, permanently or unconditionally, the reprocessing of spent fuel owned by a foreign nation which fuel has been supplied by the United States, to preclude the United States from full participation in the International Nuclear Fuel cycle Evaluation provided for in section 105 of the Nuclear Non-Proliferation Act of 1978; to in any way limit the presentation or consideration in that evaluation of any nuclear fuel cycle by the United States or any other participation; nor to prejudice open and objective consideration of the results of the evaluation.

"e. Notwithstanding subsection 402(d) of the Department of Energy Organization Act (Public Law 95-91), the Secretary of Energy, and not the Federal Energy Regulatory Commission, shall have sole jurisdiction within the Department of Energy over any matter arising from any function of the Secretary of energy in this section.

" $f$. (1) With regard to any subsequent arrangement under subsection a.(2)(E) (for the storage or disposition of irradiated fuel elements), where such arrangement involves a direct or indirect commitment of the United States for the storage or other disposition, interim or permanent, of any foreign spent nuclear fuel in the United States, the Secretary of Energy may not enter into any such subsequent arrangement, unless:

"(A)(i) Such commitment of the United States has been submitted to the Congress for a period of sixty days of continuous session (as defined in subsection $130 \mathrm{~g}$. of this act) and has been referred to the Committee on International relations of the House of representatives and the 
Ante, p. 125.

Post, p. 131.

Notice to congressional committees.

Plan, contents.

"Foreign spent nuclear fuel"
Committee on Foreign Relations of the Senate, but any such commitment shall not become effective if during such sixty-day period the Congress adopts a concurrent resolution stating in substance that it does not favor the commitment, any such commitment to be considered pursuant to the procedures set forth in section 130 of this act for the consideration of Presidential submission; or (ii) if the President has submitted a detailed generic plan for such disposition or storage in the United States to the Congress for a period of sixty days of continuous session (as defined in subsection $130 \mathrm{~g}$. of this Act), which plan has been referred to the Committee on International Relations of the House of Representatives and the Committee on Foreign Relations of the Senate and has not been adoption of a concurrent resolution stating in substance that Congress does not favor the plan; and the commitment is subject to the terms of an effective plan. any such plan shall be considered pursuant to the procedures set forth in section 130 of this act for the consideration of Presidential submissions:

"(B) The Secretary of Energy has complied with subsection a.; and

"(C) The Secretary of Energy has complied, or in the arrangement will comply with all other statutory requirements of this Act, under sections 54 and 55 and any other applicable sections, and any other requirements of law.

"(2) Subsection (1) shall not apply to the storage or other disposition in the United States of limited quantities of foreign spent nuclear fuel if the President determines that (A) a commitment under section 54 or 55 of this Act of the United States for storage or other disposition of such limited quantities in the United States is required by an emergency situation, (B) it is in the national interest to take such immediate action, and $(C)$ he notifies the Committees on International Relations and Science and Technology of the House of Representatives and the Committees on Foreign Relations and Energy and Natural Resources of the Senate of the determination and action, with a detailed explanation and justification thereof, as soon as possible.

"(3) Any plan submitted by the President under subsection f. (1) shall include a detailed discussion, with detailed information, and any supporting documentation thereof, relating to policy objectives, technical description, geographic information, cost data and justifications, legal and regulatory considerations, environmental impact information and any related international agreements, arrangements for understandings.

“(4) For the purposes of this subsection, the term 'foreign spent nuclear fuel' shall include any nuclear fuel irradiated in any nuclear power reactor located outside of the United States and operated by any foreign legal entity, government or nongovernment, regardless of the legal ownership or other control of the fuel or the 
42 USC $2160 \mathrm{~b}$.

reactor and regardless of the origin or licensing of the fuel or reactor, but not including fuel irradiated in a research reactor. 99

"Sec. 132. Authority To Suspend Nuclear Cooperation With Nations Which Have Not Ratified The Convention On The Physical Security Of Nuclear Material.-

President of U.S. "The President may suspend nuclear cooperation under this Act with any nation or group of nations which has not ratified the Convention on the Physical Security of Nuclear Material." $99^{\mathrm{a}}$

42 USC $2160 \mathrm{c}$

"Sec. 133. Consultation With The Department OfDefense Concerning Certain Exports And Subsequent Arrangements.-

"a. In addition to other applicable requirements-

"(1) a license may be issued by the Nuclear Regulatory Commission under this Act for the export of special nuclear material described in subsection b.; and

"(2) approval may be granted by the Secretary of Energy

42 USC 2160 under section 131 of this Act for the transfer of special nuclear material described in subsection $b$;

only after the Secretary of Defense has been consulted on whether the physical protection of that material during the export or transfer will be adequate to deter theft, sabotage, and other acts of international terrorism which would result in the diversion of that material. If, in the view of the Secretary of Defense based on all available intelligence information, the export or transfer might be subject to a genuine terrorist threat, the Secretary shall provide to the Nuclear Regulatory commission or the Secretary of Energy, as appropriate, his written assessment of the risk and a description of the actions the Secretary of Defense considers necessary to upgrade physical protection measures.

"b. Subsection a. applies to the export or transfer of more than 2 kilograms of plutonium or more than $5^{99 b}$ kilograms of uranium enriched to more than 20 percent in the isotope 233 or the isotope $235.9^{99}$

"Sec 134. Further Restrictions on Exports.-

"a. The Commission may issue a license for the export of highly enriched uranium to be used as a fuel or target in a nuclear research or test reactor only if, in addition to any other requirement of this Act, the Commission determines that-

"(1) there is no alternative nuclear reactor fuel or target enriched in the isotope 235 to a lesser percent that the proposed export, that can be used in that reactor;

"(2) the proposed recipient of that uranium has provided assurances that, whenever an alternative nuclear reactor fuel or target can be used in that reactor, it will use that alternative in lieu of highly enriched uranium; and

"(3) the United States Government is actively developing an alternative nuclear reactor fuel or target than can be used in that reactor.

"b. As used in this section-

${ }^{80}$ Public Law 95-242 (92 Stat. 127)(1978), sec. 303(a), added sec. 131

89. Public Law 99-399 (100 Stat 853)(1986), sec. 602 added sec. 132.

690 Public Law 103-236 (108 Stat. 521) (1994), changed 20 kilograms to 5 kilograms.

92 Public Law 99-399 (100 Stat 853)(1986), sec. 602 added sec. 133. 
Policy

42 USC $\sec .2161$.

"(1) the term 'alternative nuclear reactor fuel or target' means a nuclear reactor fuel or target which is enriched to less than 20 percent in the isotope U-235;

"(2) the term 'highly enriched uranium' means uranium enriched to 20 percent or more in the isotope U-235; and

“(3) a fuel or target 'can be used' in a nuclear research or test reactor if-

"(A) the fuel or target has been qualified by the Reduced Enrichment Research and Test Reactor Program of the Department of Energy, and

"(B) use of the fuel or target will permit the large majority of ongoing and planned experiments and isotope production to be conducted in the reactor without a large percentage increase in the total cost of operating the reactor." $99 \mathrm{~d}$

"c. Report to Congress.

"(1) IN GENERAL. - Not later than 90 days after the date of the enactment of this Act, the Chairman of the Nuclear Regulatory Commission, after consulting with other relevant agencies, shall submit to the Congress a report detailing the current disposition of previous United States exports of highly enriched uranium, including -

"(A) their location;

"(B) whether they are irradiated;

"(C) whether they have been used for the purpose stated in their export license; and

"(D) whether they have been used for an alternative purpose and, if so, whether such alternative purpose has been explicitly approved by the Commission.

"(2) EXPORTS TO EURATOM.-To the maximum extent possible, the export required by paragraph (1) shall include"(A) exports of highly enriched uranium to EURATOM; and

"(B) subsequent retransfers of such material within EURATOM, without regard to the extent of United States control over such retransfers. $99 \mathrm{e}$

"CHAPTER 12-CONTROL OF INFORMATION

"Sec. 141. Policy.-It shall be the policy of the Commission to control the dissemination and declassification of Restricted Data in such a manner as to assure the common defense and security. Consistent with such policy, the Commission shall be guided by the following principles:

"a. Until effective and enforceable international safeguards against the use of atomic energy for destructive purposes have been established by an international arrangement, there shall be no exchange of Restricted Data with other nations except as authorized by section 144; and

"b. The dissemination of scientific and technical information relating to atomic energy should be permitted and encouraged so

\footnotetext{
990Public Law 102-486 (106 Stat 2945) added new sec. 134.

89.public Law 103-160, Div c., Title XXXII, § 3202(a)(2), Nov. 30, 1993 (107 Stat 1959) added.
} 
Classification

and declassi-

fication of restricted data. 42 USC

sec. 2162.

61 STAT. 498 , 50 USC 403(d).

Department of Defense participation. 42 USC sec. 2163. as to provide that free interchange of ideas and criticism which is essential to scientific and industrial progress and public understanding and to enlarge the fund of technical information.

"Sec. 142. Classification And Declassification Of Restricted Data."a. The Commission shall from time to time determine the data, within the definition of Restricted Data, which can be published without undue risk to the common defense and security and shall thereupon cause such data to be declassified and removed from the category of Restricted Data.

"b. The commission shall maintain a continuous review of Restricted Data and of any Classification guides issued for the guidance of those in the atomic energy program with respect to the areas of Restricted Data which have been declassified in order to determine which information may be declassified and removed from the category of Restricted Data without undue risk to the common defense and security.

"c. In the case of Restricted Data which the Commission and the Department of Defense jointly determine to relate primarily to the military utilization of a tomic weapons, the determination that such data may be published without constituting an unreasonable risk to the common defense and security shall be made by the Commission and the Department of Defense jointly, and if the Commission and the Department of Defense do not agree, the determination shall be made by the President.

"d. The Commission shall remove from the Restricted Data category such data as the Commission and the Department of Defense jointly determine relates primarily to the military utilization of atomic weapons and which the Commission and Department of Defense jointly determine can be adequately safeguarded as defense information: Provided, however, That no such data so removed from the Restricted Data category shall be transmitted or otherwise made available to any nation or regional defense organization, while such data remains defense information, except pursuant to an agreement for cooperation entered into in accordance with subsection $b$. or d. of section 144 .

"e. The Commission shall remove from the Restricted Data category such information concerning the atomic energy programs of other nations as the Commission and the Director of Central Intelligence jointly determine to be necessary to carry out the provisions of section 102(d) of the National Security Act of 1947, as amended, and can be adequately safeguarded as defense information.

"Sec. 143. Department Of Defense Participation.-The Commission may authorize any of its employees, or employees of any contractor, prospective contractor, licensee or prospective licensee of the Commission or any other person authorized access to Restricted Data by the

${ }^{100}$ Public Law 103-337 (108 Stat. 3092) (1994) 
International cooperation. 42 USC sec. 2164.

Cooperation by Defense Department

Commission under subsections 145 b. ${ }^{101}$ and 145 c. ${ }^{102}$ to permit any employee of an agency of the Department of Defense or of its contractors, or any member of the Armed Forces to have access to Restricted Data required in the performance of his duties and so certified by the head of the appropriate agency of the Department of Defense or his designee: Provided, however, That the head of the appropriate agency of the Department of: Defense or his designee has determined, in accordance with the established personnel security procedures and standards of such agency, that permitting the member or employee to have access to such Restricted Data will not endanger the common defense and security: And provided further, That the Secretary of Defense finds that the established personnel and other security procedures and standards of such agency are adequate and in reasonable conformity to the standards established by the Commission under section 145 .

"Sec. 144. International Cooperation.-

"a. The President may authorize the Commission to cooperate with another nation and to communicate to that nation Restricted Data on-

"(1) refining, purification, and subsequent treatment of source material;

"(2) civilian reactor development;

"(3) production of special nuclear material;

"(4) health and safety;

"(5) industrial and other applications of atomic energy for peaceful purposes; and

"(6) research and development relating to the foregoing:

Provided, however, That no such cooperation shall involve the communication of Restricted Data relating to the design or fabrication of atomic weapons: And provided further, That the cooperation is undertaken pursuant to an agreement for cooperation entered into in accordance with section 123 , or is undertaken pursuant to an agreement existing on the effective date of this Act. ${ }^{102 a}$

"b. The President may authorize the Department of Defense, with the assistance of the Commission, to cooperate with another nation or with a regional defense organization to which the United States is a party, and to communicate to that nation or organization such Restricted Data (including design information) as is necessary to-

"(1) the development of defense plans;

"(2) the training of personnel in the employment of and defense against atomic weapons and other military applications of atomic energy;

"(3) the evaluation of the capabilities of potential enemies in the employment of atomic weapons and other military applications of atomic energy; and

\footnotetext{
${ }^{101}$ Public Law 84-1006 (70 Stat. 1069)(1956), sec. 14, added the words: "or any other person authorized access to Restricted Data by the Commission under subsection 145b."

${ }^{102}$ Public Law 87-206 (75 Stat. 475)(1961), sec. 5, deleted the words subsection $145 \mathrm{~b}$." and substituted in liew thereof the words, "subsections $145 \mathrm{~b}$. and $145 \mathrm{c}$."

${ }^{1023}$ Public Law 85-479 (725tat. 276)(1958), sec. 5 amended subsec. a. of sea. 144 by inserting the word "civilian" before the words "reactor development" in clause (2) thereof.
} 
"(4) the development of compatible delivery systems for atomic weapons;

whenever the President determines that the proposed cooperation and the proposed communication of the Restricted Data will promote and will not constitute an unreasonable risk to the common defense and security, while such other nation or organization is participating with the United States pursuant to an international arrangement by substantial and material contributions to the mutual defense and security: Provided, however, That the cooperation is undertaken pursuant to an agreement entered into accordance with section $123 .{ }^{103}$

"c. In addition to the cooperation authorized in subsections 144 a. and $144 \mathrm{~b}$., the President may authorize the Commission, with the assistance of the Department of Defense, to cooperate with another nation and-

"(1) to exchange with that nation Restricted Data concerning atomic weapons: Provided, That communication of such Restricted Data to that nation is necessary to improve its atomic weapon design, development, or fabrication capability and provided that nation has made substantial progress in the development of atomic weapons; and

"(2) to communicate or exchange with that nation Restricted Data concerning research, development, or design, of military reactors,

whenever the President determines that the proposed cooperation and the communication of the proposed Restricted Data will promote and will not constitute an unreasonable risk to the common defense and security, while such other nation is participating with the United States pursuant to an international arrangement by substantial and material contributions to the mutual defense and security: Provided, however, That the cooperation is undertaken pursuant to an agreement entered into in accordance with section $123 .{ }^{103^{a}}$

"d. (1) In addition to the cooperation authorized in subsections a., b., and c., the President may, upon making a determination described in paragraph (2), authorize the Department of Energy, with the assistance of the Department of Defense, to cooperate with another nation to communicate to that nation such Restricted Data, and the President may, upon making such determination, authorize the Department of Defense, with the assistance of the Department of Energy, to cooperate with another nation to com-

\footnotetext{
${ }^{103}$ Public Law $85-479$ (72 Stat. 276)(1958), sec. 6, amended sec. 144 by substituting a new subsec. b. Before amendment subsec. b. read as follows:

" $b$. The President may authorize the Department of Defense, with the assistance of the Commission, to cooperate with another nation or with a regional defense organization to which the United States is a party, and to communicate

(1) the development of defense plans;

"(2) the training of personnel in the employment of and defense against atomic weapons; and

"(3) the evaluation of the capabilities of potential enemies in the employment of atomic weapons.

while such other nation or organization is participating with the United States pursuant to an international arrangement by substantial and material contributions to the mutual defense and security: Provided, however, That no such cooperation shall involve communication of Restricted Data relating to the design or fabrication of atomic weapons except with regard to external characteristics, including size, weight, and shape, yields and effects, and systems employed in thedelivery oruse thereof but not including any data in thesecategories unless in the the joint judgment of the Commission and the Department of Defense such data will not revealimportant information coneening the design or fabrication of the nuclear components of an atomic weapon: And provided further, That the cooperation is undertaken pursuant to an agreement entered into in accordance with section 123 ."

${ }^{103}$ Public Law 103-337 (108 Stat. 3091), October 5, 1994 added new subsection "d".
} 
Restrictions.

42 USC

sec. 2165 .

Investigations by CSC. municate to that nation such data removed from the Restricted Data category under section 142, as is necessary for-

(A) the support of a program for the control of and accounting for fissile material and other weapons material;

(B) the support of the control of and accounting for atomic weapons;

(C) the verification of a treaty; and

(D) the establishment of international standards for the classification of data on atomic weapons, data on fissile material, and related data.

(2) A determination referred to in paragraph (1) is a determination that the proposed cooperation and proposed communication referred to in that paragraph-

(A) will promote the common defense and security interests of the United States and the nation concerned; and

(B) will not constitute an unreasonable risk to such common defense and security interests.

(3) Cooperation under this subsection shall be undertaken pursuant to an agreement for cooperation entered into in accordance with section 123 .

"e. The President may authorize any agency of the United States to communicate in accordance with the terms and conditions of an agreement for cooperation arranged pursuant to subsection $144 \mathrm{a}$., b., c., or d., such Restricted Data as is determined to be transmissable under the agreement for cooperation involved.104

"Sec. 145. Restrictions.-

"a. No arrangement shall be made under section 31 , no contract shall be made or continued in effect under section 41, and no license shall be issued under section 103 or 104, unless the person with whom such arrangement is made, the contractor or prospective contractor, or the prospective licensee agrees in writing not to permit any individual to have access to Restricted Data until the Civil Service Commission shall have made an investigation and report to the Commission on the character, associations, and loyalty of such individual, and the Commission shall have determined that permitting such person to have access to Restricted Data will not endanger the common defense and security.

"b. Except as authorized by the Commission or the General Manager upon a determination by the Commission or General Manager that such action is clearly consistent with the national interest, no individual shall be employed by the Commission nor shall the Commission permit any individual to have access to Restricted Data until the Civil Service Commission shall have made an investigation and report to the Commission on the character, associations, and loyalty of such individual, and the Commission shall have determined that permitting such person to have access to Restricted Data will not endanger the common defense and security.

${ }^{104}$ Public Law 103-337 (103 Stat. 3092) amended Public Law 85-479 (92 Stat. 276) (1958) by redesignating subsection " $d^{n}$ to " $e$ ". [Note: see footnote 103a for explanation of new subsection " $d$ ".] 
Investigations by FBI.

"c. In lieu of the investigation and report to be made by the Civil Service Commission pursuant to subsection $b$. of this section, the Commission may accept an investigation and report on the character, associations, and loyalty of an individual made by another Government agency which conducts personnel security investigations, provided that a security clearance has been granted to such individual by another Government agency based on such investigation and report.

"d. In the event an investigation made pursuant to subsections a. and $b$. of this section develops any data reflecting that the individual who is the subject of the investigation is of questionable loyalty, the Civil Service Commission shall refer the matter to the Federal Bureau of Investigation for the conduct of a full field investigation, the results of which shall be furnished to the Civil Service commission for its information and appropriate action.

"e. If the President deems it to be in the national interest he may from time to time determine that investigations of any group or class which are required by subsections $a .$, b., and c. of this section be made by the Federal Bureau of Investigation.

"f. Notwithstanding the provisions of subsections a., b., and c. of this section, a majority of the members of the Commission shall certify those specific positions which are of a high degree of importance or sensitivity, and upon such certification, the investigation ${ }^{105}$ and reports required by such provisions shall be made by the Federal Bureau of Investigation.

"g. The commission shall establish standards and specifications in writing as to the scope and extent of investigations, the reports of which will be utilized by the Commission in making the determination, pursuant to subsections a., b., and c. of this section, that permitting a person access to restricted data will not endanger the common defense and security. Such standards and specifications shall be based on the location and class or kind of work to be done, and shall, among other considerations, take into account the degree of importance to the common defense and security of the Restricted Data to which access will be permitted.

" $h$. Whenever the Congress declares that a state of war exists, or in the event of a national disaster due to enemy attack, the Commission is authorized during the state of war or period of national disaster due to enemy attack to employ individuals and to permit individuals access to Restricted Data pending the investigation report, and determination required by section $145 \mathrm{~b}$., to the extent that and so long as the Commission finds that such action is re-

${ }^{105}$ Public Law 87-615 (76 Stat. 409)(1962), sec. 10, amended subsec. 145 f. by striking outa commaafter the word "investigation". 
General provisions. 42 USC sec. 2166 .

42 USC 2167. Regulations. quired to prevent impairment of its activities in furtherance of the common defense and security. ${ }^{106}$

"Sec. 146. General Provisions.-

"a. Sections 141 to 145 , inclusive, shall not exclude the applicable provisions of any other laws, except that no Government agency shall take any action under such other laws inconsistent with the provisions of those sections.

"b. The Commission shall have no power to control or restrict the dissemination of information other than as granted by this or any other law.

"Sec. 147. Safeguards Information.-

"a. In addition to any other authority or requirement regarding protection from disclosure of information, and subject to subsection (b)(3) of section 552 of title 5 of the United States Code, the Commission shall prescribe such regulations, after notice and opportunity for public comment, or issue such orders, as necessary to prohibit the unauthorized disclosure of safeguards information which specifically identifies a licensee's or applicant's detailed-

"(1) control and accounting procedures or security measures (including security plans, procedures, and equipment) for the physical protection of special nuclear material, by whomever possessed, whether in transit or at fixed sites, in quantities determined by the Commission to be significant to the public health and safety or the common defense and security;

"(2) security measures (including security plans, procedures, and equipment) for the physical protection of source material or byproduct material, by whomever possessed, whether in transit or at fixed sites, in quantities determined by the Com-

\footnotetext{
${ }^{106}$ Public Law $87-206$ (75 Stat. 475) (1961), sec. 6, amended sec. 145 by redesignating subsec. c. as subsec. $d$ and subsec. g. as subsec. h. This arnendment also added new subsecs. " $\mathrm{c}$ ", " $\mathrm{e}$ ", " $\mathrm{f}$ ", and " $\mathrm{g}$ ". Before amendment, the subsec. g. as subsec. h.

"Sec. 145. Restrictions. a. No arrangement shalibe madeunder section 31 , no contract shall be made or continued in effect under section the contractor or prospective contractor, or the prospective licensee agrees in writing not to permit any individual to have access to Restricted Data until the Civil Service Commission shall have made an investigation and report to the Commission on the character, associations, and loyalty of such individual and the Commission shall have determincd that permitting such person to have access to Restricted Data will not endanger the common defense security.

b. Except as authorized by the Commission or the General Manager upon a determination by the Commission or General Manager that such action is clearly consistent with the national interest, no individual shall be employed by the Commission nor shall the Commission permit any individual to have access to Restricted Data until the Civil Service Commissionshall have made an investigation and report to the Commission on the character, associations, and loyally of such individual, and the Commission shall have determined that permitting such person to have access to Restricted Data will not endanger the common defense and security.

"c. In the event an investigation made pursuant to subsections a. and b. of this section develops any data reflecting that the individual who is the subject of the investigation is of questionable loyalty, the Civil Service Commissionshall refer the matter to the Federal Bureau of Investigation of the conduct of a ful field investigation, the results of which hall be furnished to the Civil Service Commission for its information and appropriate action.

d. If the President deems it to be in the national interest, he may from time to time cause investigations of any made by the Federal bureau of Investiga.

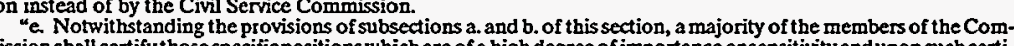
missionshall certify those specific positions which are of a high degree of importance or sensitivity and upon such certification the investigation and reports required by such provisions shall be made by the Federai Burean of Investigation instead of by the Civil Service Commission.

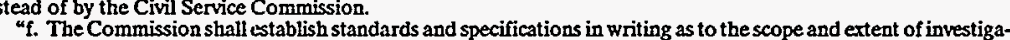
tions to be made by the Civil Service Commission pursuant to subsections a and b. of this section. Sueh standards and tions to be made by the Civil Service Commission pursuant to subsections a and b. Of this section. Such standards and specifications shall be based on the location and class or kind of work to be done, and shall, among other consideraaccess will be permitted.

" g. Whenever the Congress declares that a state of war exists, or in the event of a national disaster due to enemy attack, the Commission is authorized during the state of war or period of national disaster due to enemy attack to employ individuals and to permit individual access to Restricted Data pending the investigation report, and determination required by section $145 \mathrm{~b}$., to the extent that and so long as the Commission finds that such action is required to prevent impairment of its activities in furtherance of the common defense and security."
} 
mission to be significant to the public health and safety or the common defense and security; or

"(3) security measures (including security plans, procedures, and equipment) for the physical protection of and the location of certain plant equipment vital to the safety of production or utilization facilities involving nuclear materials covered by paragraphs (1) and (2) if the unauthorized disclosure of such information could reasonably be expected to have a significant adverse effect on the health and safety of the public or the common defense and security by significantly increasing the likelihood of theft, diversion, or sabotage of such material or such facility. The Commission shall exercise the authority of this subsection-

"(A) so as to apply the minimum restrictions needed to protect the health and safety of the public or the common defense and security, and

"(B) upon a determination that the unauthorized disclosure of such information could reasonably be expected to have a significant adverse effect on the health and safety of the public or the common defense and security by significantly increasing the likelihood of theft, diversion, or sabotage of such material or such facility.

Nothing in this Act shall authorize the Commission to prohibit the public disclosure of information pertaining to the routes and quantities of shipments of source material, by-product material, high level nuclear waste, or irradiated nuclear reactor fuel. Any person, whether or not a licensee of the Commission, who violates any regulations adopted under this section shall be subject to the civil monetary penalties of section 42 USC 2282. 234 of this Act. Nothing in this section shall be construed to authorize the withholding of information from the duly authorized committees of the Congress.

42 USC $2273 . \quad$ "b. For the purpose of section 223 of this Act, any regulations or orders prescribed or issued by the Commission under this section shall also be deemed to be prescribed or issued under section $161 \mathrm{~b}$. of this Act.

"c. Any determination by the Commission concerning the applicability of this section shall be subject to judicial review pursuant to subsection (a)(4)(B) of section 552 of title 5 of the United States Code.

"d. Upon prescribing or issuing any regulation or order under subsection a. of this section, the Commission shall submit to Congress a report that:

"(1) specifically identifies the type of information the Commission intends to protect from disclosure under the regulation or order;

"(2) specifically states the Commission's justification for determining that unauthorized disclosure of the information to be protected from disclosure under the regulation or order could reasonably be expected to have a significant adverse effect on the health and safety of the public or the common defense and security by significantly increasing the likelihood of theft, diver- 
42 USC 2168.

Regulations. sion, or sabotage of such material or such facility, as specified under subsection (a) of this section; and

"(3) provides justification, including proposed alternative regulations or orders, that the regulation or order applies only the minimum restrictions needed to protect the health and safety of the public or the common defense and security.

"e. In addition to the reports required under subsection d. of this section, the Commission shall submit to Congress on a quarterly basis a report detailing the Commission's application during that period of every regulation or order prescribed or issued under this section. In particular, the report shall:

"(1) identify any information protected from disclosure pursuant to such regulation or order;

“(2) specifically state the Commission's justification for determining that unauthorized disclosure of the information protected from disclosure under such regulation or order could reasonably be expected to have a significant adverse effect on the health and safety of the public or the common defense and security by significantly increasing the likelihood of theft, diversion or sabotage of such material or such facility, a specified under subsection a. of this section; and

"(3) provide justification that the Commission has applied such regulation or order so as to protect from disclosure only the minimum amount of information necessary to protect the health and safety of the public or the common defense and security. 107

"Sec. 148. Prohibition Against The Dissemination Of Certain Unclassified Information. - 108

"a. (1) In addition to any authority or requirement regarding protection from dissemination of information, and subject to section 552(b)(3) of title 5, United States Code, the Secretary of Energy (hereinafter in this section referred to as the 'Secretary' with respect to atomic energy defense programs, ${ }^{109}$ ) shall prescribe such regulations, after notice and opportunity for public comment thereon, or issue such orders as may be necessary to prohibit the unauthorized dissemination of unclassified information pertaining to-

"(A) the design of production facilities or utilization facilities;

"(B) security measures (including security plans, procedures, and equipment) for the physical protection of (i) production or utilization facilities, (ii) nuclear material contained in such facilities, or (iii) nuclear material in transit; or

"(C) the design, manufacture, or utilization of any atomic weapon or component if the design, manufacture, or utilization of such weapon or component was contained

\footnotetext{
${ }^{107}$ Public Law 96-295 (94 Stat. 788)(1980) sec. 207(a)(1), added new sec. 147.

${ }^{108}$ Public Law $97-90$ (95 Stat. 1163)(1981) Sec. 210(a)(1), added new sec. 148.

${ }^{109}$ Public Law 97-415 (96 Stat. 2067)(1983) sec. 17 inserted in sec. 148a.(1) after "Secretary" the words ",with respect to atomic energy defense programs,".
} 
42 USC 2162.

Penalties.

42 USC 2282.

42 USC 2273. in any information declassified or removed from the Restricted Data category by the Secretary (or the head of the predecessor agency of the Department of Energy) pursuant to section 142 .

"(2) The Secretary may prescribe regulations or issue orders under paragraph (1) to prohibit the dissemination of any information described in such paragraph only if and to the extent that the Secretary determines that the unauthorized dissemination of such information could reasonably be expected to have a significant adverse effect on the health and safety of the public or the common defense and security by significantly increasing the likelihood of (A) illegal production of nuclear weapons, or (B) theft, diversion, or sabotage of nuclear materials, equipment, or facilities.

"(3) In making a determination under paragraph (2), the Secretary may consider what the likelihood of an illegal production, theft, diversion, or sabotage referred to in such paragraph would be if the information proposed to be prohibited from dissemination under this section were at no time available for dissemination.

"(4) The Secretary shall exercise his authority under this subsection to prohibit the dissemination of any information described in subsection a. (1)-

"(A) so as to apply the minimum restrictions needed to protect the health and safety of the public or the common defense and security; and

"(B) upon a determination that the unauthorized dissemination of such information could reasonably be expected to result in a significant adverse effect on the health and safety of the public or the common defense and security by significantly increasing the likelihood of (i) illegal production of nuclear weapons, or (ii) theft, diversion, or sabotage of nuclear materials, equipment, or facilities.

"(5) Nothing in this section shall be construed to authorize the Secretary to authorize the withholding of information from the appropriate committees of the Congress.

"b. (1) Any person who violates any regulation or order of the Secretary issued under this section with respect to the unauthorized dissemination of information shall be subject to a civil penalty, to be imposed by the Secretary, of not to exceed $\$ 100,000$ for each such violation. The Secretary may compromise, mitigate, or remit any penalty imposed under this subsection.

"(2) The provisions of subsections b. and c. of section 234 of this Act shall be applicable with respect to the imposition of civil penalties by the Secretary under this section in the same manner that such provisions are applicable to the imposition of civil penalties by the Commission under subsection a. of such section.

"c. For the purposes of section 223 of this Act, any regulation prescribed or order issued by the Secretary under this section shall also 
Judicial review.

Quarterly report.

42 USC 2169.

42 USC 2133, 2134.

42 USC 2168.

Health and medical care. Safety. be deemed to be prescribed or issued under section $161 \mathrm{~b}$. of this Act."

"d. Any determination by the Secretary concerning the applicability of this section shall be subject to judicial review pursuant to section $552(\mathrm{a})(4)(\mathrm{B})$ of title 5 , United States Code.

"e. The Secretary shall prepare on a quarterly basis a report to be made available upon the request of any interested person, detailing the Secretary's application during that period of each regulation or order prescribed or issued under this section. In particular, such report shall-

"(1) identify any information protected from disclosure pursuant to such regulation or order;

"(2) specifically state the Secretary's justification for determining that unauthorized dissemination of the information protected from disclosure under such regulation or order could reasonably be expected to have a significant adverse effect on the health and safety of the public or the common defense and security by significantly increasing the likelihood of illegal production of nuclear weapons, or theft, diversion, or sabotage of nuclear materials, equipment, or facilities, as specified under subsection a.; and

"(3) provide justification that the Secretary has applied such regulation or order so as to protect from disclosure only the minimum amount of information necessary to protect the health and safety of the public or the common defense and security."110

Sec. 149. Fingerprinting For Criminal History Record Checks.-

"a. The Nuclear Regulatory Commission (in this section referred to as the 'Commission') shall require each licensee or applicant for a license to operate a utilization facility under section 103 or $104 \mathrm{~b}$. to fingerprint each individual who is permitted unescorted access to the facility or is permitted access to safeguards information under section 147. All fingerprints obtained by a licensee or applicant as required in the preceding sentence shall be submitted to the Attorney General of the United States through the Commission for identification and a criminal history records check. The costs of any identification and records check conducted pursuant to the preceding sentence shall be paid by the licensee or applicant. Notwithstanding any other provision of law, the Attorney General may provide all the results of the search to the Commission, and, in accordance with regulations prescribed under this section, the Commission may provide such results to licensee or applicant submitting such fingerprints.

"b. The Commission, by rule, may relieve persons from the obligations imposed by this section, under specified terms, conditions, and periods, if the Commission finds that such action is consistent with its obligations to promote the common defense and security and to protect the health and safety of the public.

${ }^{110}$ Public Law 97-415 (96 Stat. 2067)(1983) sec. 17 added new subsec. “d” and “e” to sec. 148. 
Regulations.

42 USC 2168.

Inventions relating to atomic weapons. 42 USC

"c. For purposes of administering this section, the Commission shall prescribe, subject to public notice and comment, regulations-

"(1) to implement procedures for the taking of fingerprints; "(2) to establish the conditions for use of information received from the Attorney General, in order-

"(A) to limit the redissemination of such information;

"(B) to ensure that such information is used solely for the purpose of determining whether an individual shall be permitted unescorted access to the facility of a licensee or applicant or shall be permitted access to safeguards information under section 147 ;

"(C) to ensure that no final determination may be made solely on the basis of information provided under this section involving-

"(i) an arrest more than 1 year old for which there is no information of the disposition of the case; or

"(ii) an arrest that resulted in dismissal of the charge or an acquittal; and

“(D) to protect individuals subject to fingerprinting under this section from misuse of the criminal history records; and

"(3) to provide each individual subject to fingerprinting under this section with the right to complete, correct, and explain information contained in the criminal history records prior to any final adverse determination.

"d. (1) The Commission may establish and collect fees to process fingerprints and criminal history records under this section.

(2) Notwithstanding section 3302(b) of title 31, United States Code, and to the extent approved in appropriation Acts-

"(A) a portion of the amounts collected under this subsection in any fiscal year may be retained and used by the Commission to carry out this section; and

"(B) the remaining portion of the amounts collected under this subsection in such fiscal year may be transferred periodically to the Attorney General and used by the Attorney General to carry out this section.

“(3) Any amount made available for use under paragraph (2) shall remain available until expended.". ${ }^{110^{2}}$

\section{"CHAPTER 13. - PATENTS AND INVENTIONS}

\section{"Sec. 151. Inventions Relating To Atomic Weapons, And Filing Of} Reports.-111

"a. No patent shall hereafter be granted for any invention or discovery which is useful solely in the utilization of special nuclear material or atomic energy in an atomic weapon. Any patent

\footnotetext{
${ }^{1103}$ Public Law 99-399 (100 Stat. 853) (1986) sec. 606 added sec. 149.

${ }^{11}$ 'Public Law 87-206 (75 Stat. 475) (1961), sec. 7, changed the title of this section. The title prior to amendment was "Military Utilization."
} 
$\sec 2181$

Inventions reports.

Invention conceived during Commission contracts. 42 USC $\sec 2182$. granted for any such invention or discovery is hereby revoked, and just compensation shall be made therefor.

"b. No patent hereafter granted shall confer any rights with respect to any invention or discovery to the extent that such invention or discovery is used in the utilization of special nuclear material or atomic energy in atomic weapons. Any rights conferred by any patent heretofore granted for any invention or discovery are hereby revoked to the extent that such invention or discovery is so used, and just compensation shall be made therefor.

"c. Any person who has made or hereafter makes any invention or discovery useful in the production or utilization of special nuclear material or atomic energy, shall file with the Commission a report containing a complete description thereof unless such invention or discovery is described in an application for a patent filed with the Commissioner of Patents by such person within the time required for the filing of such report. The report covering any such invention or discovery shall be filed on or before the one hundred and eightieth day after such person first discovers or first has reason to believe that such invention or discovery is useful in such production or utilization. ${ }^{112}$

"d. The Commissioner of Patents shall notify the Commission of all applications for patents heretofore or hereafter filed which, in his opinion, disclose inventions or discoveries required to be reported under subsection 151c., and shall provide the Commission access to all such applications.

"e. Reports filed pursuant to subsection c. of this section, and application to which access is provided under subsection d. of this section, shall be kept in confidence by the Commission, and no information concerning the same given without authority of the inventor or owner unless necessary to carry out the provisions of any Act of Congress or in such special circumstances as may be determined by the Commission. ${ }^{113}$

"Sec. 152. Inventions Made Or Conceived During Commission Contracts.-Any invention or discovery, useful in the production or utilization of special nuclear material or atomic energy, made or conceived in the course of or under any contract, subcontract, or arrangement entered into with or for the benefit of the Commission, regardless of whether the contract, subcontract, or arrangement involved the expenditure of funds by the Commission, shall be vested in, and be the property of, the Commission, except that the Commission may waive its claim to any such invention or discovery under such circumstances as the Commission may deem appropriate, consistent with the policy of this section. No patent for any invention or discovery,

${ }^{112}$ Public Law 87-206 (75 Stat. 475) (1961), sec. 8, amended sec. 151c. Before amendment section 151c, read as follows:

"c. Any person who has made or bereafter makes any invention or discovery useful (1) in the production or utilization of special nuclear material or atomic energy; (2) in the utilization of special nuclear material in an atomic weapon; or (3) in the utilization of atomic energy in an atomic weapon, shall file with the Commission a report containing a complete description thereof unless such invention or discovery is described in an application for a patent filed with the Commission of Patents by such person within the time required for the filing of such report. The report covering any such invention or discovery shall be filed on or before whichever of the following is the later either the ninetieth day

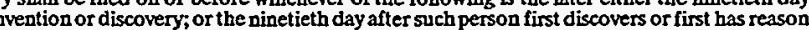
to believe that such invention or discovery is useful in such production or utilization."

${ }^{113}$ Public Law 87-206 (75 Stat. 475) (1961) sec. 9, added subsec. e. 
useful in the production or utilization of special nuclear material or atomic energy, shall be issued unless the applicant files with the application, or within thirty days after request therefor by the Commissioner of Patents (unless the Commission advises the Commissioner of Patents that its rights have been determined and that accordingly no statement is necessary) a statement under oath setting forth the full facts surrounding the making or conception of the invention or discovery described in the application and whether the invention or discovery was made or conceived in the course of or under any contract, subcontract, or arrangement entered into with or for the benefit of the Commission, regardless of whether the contract, subcontract, or arrangement involved the expenditure of funds by the Commission. The Commissioner of Patents shall as soon as the application is otherwise in condition for allowance ${ }^{114}$ forward copies of the application and the statement to the Commission.

The Commissioner of Patents may proceed with the application and issue the patent to the applicant (if the invention or discovery is otherwise patentable) unless the Commission, within 90 days after receipt of copies of the application and statement, directs the Commissioner of Patents to issue the patents to the Commission (if the invention or discovery is otherwise patentable) to be held by the Commission as the agent of and on behalf of the United States.

If the Commission files such a direction with the Commissioner of Patents, and if the applicant's statement claims, and the applicant still believes, that the invention or discovery was not made or conceived in the course of or under any contract, subcontract or arrangement entered into with or for the benefit of the Commission entitling the Commission to the title to the applicant or the patent the applicant may, within 30 days after notification of the filing of such a direction, requesta hearing before the Board of Patents Appeals and Interferences. The Board shall have the power to hear and determine whether the Commission was entitled to the direction filed with the Commissioner of Patents. The Board shall follow the rules and procedures established for interference cases and an appeal may be taken by either the applicant or the Commission from the final order of the Board to the United States Court of Appeals for the Federal Circuit in accordance with the procedures governing the appeals from the Board of Patent Appeals an Interferences.

If the statement filed by the applicant should thereafter be found to contain false material statements any notification by the Commission that it has no objections to the issuance of a patent to the applicant shall not be deemed in any respect to constitute a waiver of the provisions of this section or of any applicable civil or criminal statute, and the Commission may have the title to the patent transferred to the Commission on the records of the Commissioner of Patents in accordance with the provisions of this section. A determination of rights by the Commission pursuant to a contractual provision or other arrangement prior to the request of the Commissioner of Patents for the statement, shall be final

${ }^{114}$ Amended by Public Law 87-615 (76 Stat. 409) (1962), sec. 11. Prior to amendment word was "allowances". 
Nonmilitary utilization.

42 USC

sec. 2183.

in the absence of false material statements or nondisclosure of material facts by the applicant. 115

Sec. 153. Nonmilitary Utilization.-

a. The Commission may, after giving the patent owner an opportunity for a hearing, declare any patent to be affected with the public interest if (1) the invention or discovery covered by the patent is of primary importance in the production or utilization of special nuclear material or atomic energy; and (2) the licensing of such invention or discovery under this section is of primary importance to effectuate the policies and purposes of this Act.

b. Whenever any patent has been declared affected with the public interest, pursuant to subsection 153 a.-

(1) the Commission is hereby licensed to use the invention or discovery covered by such patent in performing any of its powers under this Act;

(2) any person may apply to the Commission for a nonexclusive patent license to use the intervention or discovery covered by such patent, and the Commission shall grant such patent license to the extent that it finds that the use of the invention or discovery is of primary importance to the conduct of an activity by such person authorized under this Act.

c. Any person-

(1) who has made application to the Commission for a license under sections $53,62,63,81,103$, or 104 , or a permit or lease under section 67 ;

(2) to whom such license, permit, or lease has been issued by the Commission;

(3) who is authorized to conduct such activities as such applicant is conducting or proposed to conduct under a general license issued by the Commission under section 62 or 81 ; or

\footnotetext{
${ }^{115}$ Public Law 87-206 (75 Stat. 475) (1961), sec 10, amended sec 152. Before amendment this section read as follows:

"Sec. 152. Inventions Conceived During Commission Contracts-Any invention or discovery, useful in the production or utilization of special nuclear material or atomic energy, made or conceived under any contract, subcontract, arrangement, or other relationship with the Commission, regardless of whether the contract or arrangement inwolved the expenditure of funds by the Commission, shall be deemed to have been made or conceived by the Commission, except the Commission may waive its claim to any such invention or discovery if made or conceived by any person at or in connection with any laboratory under the jurisdiction of the Commission as provided in section 33, or useful in theproduction orutilization of special nuclear deem appropriate. No patent for any invention or discovery, files with the application, or within 30 days after request therefor by the Commissioner of Patents, a statement under oath setting forth the full facts surrounding the making or conception of the invention or discovery described in the application and whether the invention or discovery was made or conceived in the course of, in connection with or under the terms of any contract, subcontract, arrangemen, or other relationshipwith the Commission, regardless of whether the contract or agreenent involved the expenditure of funds by the Commission. The Commissioner of Patents shall forthwith forward copies of the application and the statement to the Commission.

"The Commissioner of Patents may proceed with the application and issue thepatent tothe applicant (if the invention or discovery is otherwise patentable) unless the Commission, within 90 days after receipt of copies of theapplication and statement, directs the Commissioner of Patents to issue the patent to the Commission (if the invention or discovery is otherwise patentable) to be held by the Commission as the agent of and on behalf of the United States. "If the Commission files such a direction with the Commissioner of Patents, and if the applicant's statement claims, and the applicant still believes, that the invention or discovery was not made or conceived in the course of, in connection with, or under the terms of any contract, subcontract, arrangement, or other relationship with the Commission entitling the Commission to take title to the application or the patent the applicant may, within 30 days after notification of the filing of such a direction, request a hearing before a Board of Patents interferences. The Boards shall havethe power to hear and determine whelher he Commission was entilled thedirection flled with the Comdures established an appeal may betaken by either theapplicant or the Commission from the final order of the Board to the Court of Customs and Patent Appeals in accordance with the procedures governing the appeals from the Board to the Court of Customs and Patent Appeals in accordance with the procedures governing the appeals from the Board
of Patent Interferences (amended by P.L. 97-164 and P.L. 98-622).

"If the statement filed by the applicant should thereafter be found to contain false material statements any notification by the Commission that it has no objections to the issuance of a patent to the applicant shall not be deemed in any respect to constitute a waiver of the provisions of this section or of any applicable civil or criminal statute, and the Commission may have the title to the patent transferred to the Commission on the records of the Commissioner of Patents in accordance with the rovisions of this section."
} 
(4) whose activities or proposed activities are authorized under section 31,

may at any time make application to the Commission for a patent license for the use of an invention or discovery useful in the production or utilization of special nuclear material or atomic energy covered by a patent. Each such application shall set forth the nature and purpose of the use which the applicant intends to make of the patent license, the steps taken by the applicant to obtain a patent license from the owner of the patent, and a statement of the effects, as estimated by the applicant, on the authorized activities which will result from failure to obtain such patent license and which will result from the granting of such patent license.

"d. Whenever any person has made an application to the Commission for a patent license pursuant to subsection $153 \mathrm{c}$.-

"(1) the Commission, within 30 days after the filing of such application, shall make available to the owner of the patent all of the information contained in such application, and shall notify the owner of the patent of the time and place at which a hearing will be held by the Commission;

"(2) the Commission shall hold a hearing within 60 days after the filing of such application at a time and place designated by the Commission; and

"(3) in the event an applicant applies for two or more patent licenses, the Commission may, in it discretion, order the consolidation of such applications, and if the patents are owned by more than one owner, such owners may be made parties to one hearing.

"e. If, after any hearing conducted pursuant to subsection $153 \mathrm{~d}$, the Commission finds that-

"(1) the invention or discovery covered by the patent is of primary importance in the production or utilization of special nuclear material atomic energy;

"(2) the licensing of such invention or discovery is of primary importance to the conduct of the activities of the applicant;

"(3) the activities to which the patent license are proposed to be applied by such applicant are of primary importance to the furtherance of policies and purposes of this Act; and

"(4) such applicant cannot otherwise obtain a patent license from the owner of the patent on terms which the Commission deems to be reasonable for the intended use of the patent to be made by such applicant, the Commission shall license the applicant to use the invention or discovery covered by the patent for the purposes stated in such application on terms deemed equitable by the Commission and generally not less fair than those granted by the patents or by the Commission to similar licensees for comparable use.

"f. The Commission shall not grant any patent license pursuant to subsection $153 \mathrm{e}$. for any other purpose than that stated in the application. Nor shall the Commission grant any patent license to any other applicant for a patent license on the same patent without an application being made by such applicant pursuant to subsection 
Injunctions. 42 USC sec. 2184

Prior art. 42 USC sec. 2185 .

Commission patent licenses. 42 USC sec. 2186.

Compensation, awards, and royalties. 42 USC sec. 2187.

62 STAT 697.
$153 \mathrm{c}$., and without separate notification and hearing as provided in subsection $153 \mathrm{~d}$., and without a separate finding as provided in subsection $153 \mathrm{e}$.

" $\mathrm{g}$. The owner of the patent affected by a declaration or a finding made by the Commission pursuant to subsection $153 \mathrm{~b}$. or $153 \mathrm{e}$. shall be entitled to a reasonable royalty fee from the licensee for any use of an invention or discovery licensed by the section. Such royalty fee may be agreed upon by such owner and the patent licensee, or in the absence of such agreement shall be determined for each patent license by the Commission pursuant to subsection $157 \mathrm{c}$.

"h. The provisions of this section shall apply to any patent the application for which shall have been filed before September 1, 1979.116

"Sec. 154. Injunctions.-No court shall have jurisdiction or power to stay, restrain, or otherwise enjoin the use of any invention or discovery by a patent licensee, to the extent that such use is licensed by subsection $153 \mathrm{~b}$. or $153 \mathrm{e}$. If, in any action against such patent licensee, the court shall determine that the defendant is exercising such license, the measure of damages shall be the royalty fee determined pursuant to subsection $157 \mathrm{c}$. If any such patent licensee shall fail to pay such royalty fee, the patentee may bring an action in any court of competent jurisdiction for such royalty fee, together with such costs, interest, and reasonable attorney's fees as may be fixed by the court.

"Sec.155. Prior Art.-In connection with applications for patents covered by this Chapter, the fact that the invention or discovery was known or used before shall be a bar to the patenting of such invention or discovery even though such prior knowledge or use was under secrecy within the atomic energy program of the United States.

"Sec. 156. Commission Patent Licenses.-The Commission shall establish standards specifications upon which it may grant a patent license to use any patent 117 declared to be affected with the public interest pursuant to subsection $153 \mathrm{a}$. Such a patent license shall not waive any of the other provisions of this Act.

"Sec. 157. Compensation, Awards, And Royalties.-

“a. Patent Compensation Board.-The Commission shall designate a patent Compensation Board to consider applications under this section. The members of the Board shall receive a per diem compensation for each day spent in meetings or conferences, and all members shall receive their necessary traveling or other expenses while engaged in the work of the Board. The members of the Board may serve as such without regard to the provisions of sections 281,283 , or 284 of Title 18 of the United States Code, except in so far as such sections may prohibit any such member from receiving compensation in respect of any particular matter which

${ }^{116}$ Public Law 86-50 (73 Stat. 81)(1959), sec. 114, amended subsec. $153 \mathrm{~h}$. by changing the date from Sept. 1, 1959, to Sept. 1, 1964. Public Law 88-394 (78 Stat. 376)(1964), sec. 1, amended subsec. 153h. by changing the date from Sept. 1, 1964, to Sept. 1, 1969. Public Law 91-161 (83 Stat. 444)(1969), sec. 1, amended subsec. 153 h. by changing the date from Sept. 1, 1969, to Sept. 1, 1974. Public Law93-377, sec.6 (88 Stat. 475)(1974), amended subsec. 153 h. by changing the date from Sept. 1, 1974 to Sept. 1, 1979.

117Public Law 96-517 (94 5tat. 3027) (1980), sec. 7(a), amended sec. 156 by deleting the words "held by the Commission or". 
Eligibility.

Standards.

Monopolistic use of patents. 42 USC

directly involves the Commission or in which the Commission is directly interested.

"b. Eligibility.-

"(1) Any owner of a patent licensed under section 158 or subsection $153 \mathrm{~b}$. or $153 \mathrm{e}$., or any patent licensed thereunder may make application to the Commission for the determination of a reasonable royalty fee in accordance with such procedures as the Commission by regulation may establish.

"(2) Any person seeking to obtain the just compensation provided in section 151 shall make application therefor to the Commission in accordance with such procedures as the Commission may by regulation establish.

"(3) Any person making any invention or discovery useful in the production or utilization of special nuclear material or atomic energy, who is not entitled to compensation or a royalty therefor under this Act and who has complied with the provisions of section $151 \mathrm{c}$. hereof may make application to the Commission for, and the Commission may grant, an award. The Commission may also, after consultation with ${ }^{118}$ the General Advisory Committee, and with the approval of the President, grant an award for any especially meritorious contribution to the development, use, or control of atomic energy.

"c. Standards.-

"(1) In determining a reasonable royalty fee as provided for in subsection 153 b., or 153 e., the Commission shall take into consideration (A) the advice of the Patent Compensation Board; (B) any defense, general or special, that might be pleaded by a defendant in an action for infringement; (C) the extent to which, if any, such patent was developed through federally financed research; and (D) the degree of utility, novelty, and importance of the invention or discovery, and, may consider the cost to the owner of the patent of developing such invention or discovery or acquiring such patent.

"(2) In determining what constitutes just compensation as provided for in section 151, or in determining the amount of any award under subsection 157b.(3), the Commission shall take into account the considerations set forth in subsection $157 \mathrm{c} .(1)$ and the actual use of such invention or discovery. Such compensation may be paid by the Commission in periodic payments or in a lump sum.

"d. Period Of Limitations. - Every application under this section shall be barred unless filed within six years after the date on which first accrues the right of such reasonable royalty fee, just compensation, or award for which such application is filed..$^{119}$

"Sec. 158. Monopolistic Use Of Patents.-Whenever the owner of any patenet hereafter granter for any invention or discovery or primary use in the utilization or production of special nuclear material or atomic

\footnotetext{
${ }^{110}$ Public Law 93-276 (88 Stat. 115) (1974), sec. 201, amended this section by substituting thewords "after consultation with" for the words "upon the recommendation of"

${ }^{119}$ Public Law 87-206 (75 Stat. 475) (1961), sec. 11, added subsec. 4.
} 
sec. 2188.

Federally financed research. 42 USC sec. 2189.

Saving clause. 42 USC sec. 2190.

General provisions. 42 USC sec. 2201. energy is found by a court of competent jurisdiction to have intentionally used such patent in a manner so as to violate any of the antitrust laws specified in subsection 105a., there may be included in the judgement of the court, in its discretion and in addition to any other lawful sanction, a requirement that such owner license such patent to any other licensee of the Commission who demonstrates a need therefor. If the court, at its discretion, deems that such licensee shall pay a reasonable royalty to the owner of the patent, the reasonable royalty shall be determined in accordance with section 157.120

"Sec. 159. Federally Financed Research.-Nothing in this Act shall affect the right of the Commission to require the patents granted on inventions made or conceived during the course of federally financed research or operations, be assigned to the United States.

"Sec. 160. Saving Clause. - Any patent application on which a patent was denied by the United States Patent Office under section 11 (a) (1), 11 (a) (2), or 11 (b) of the Atomic Energy Act of 1946,121 and which is not prohibited by section 151 or section 155 of this Act may be reinstated upon application to the Commissioner of Patents within one year after enactment of this Act and shall then be deemed to have been continuously pencling since its original filing date: Provided, however, That no patent issued upon any patent application so reinstated shall in any way furnish a basis of claim against the Government of the United States.

\section{CHAPTER 14-GENERAL AUTHORITY}

"Sec. 161. General Provisions. - In the performance of its functions the Commission is authorized to-

"a. establish advisory boards to advise with and make recommendations to the Commission on legislation, policies, administration, research, and other matters, provided that the Commission issues regulations setting forth the scope, procedure, and limitation of the authority of each such board;

"b. establish by rule, regulation, or order, such standards and instructions to govern the possession and use of special nuclear material, source material, and byproduct material as the Commission may deem necessary or desirable to promote the common defense and security or to protect health or to minimize danger to life or property; in addition, the Commission shall prescribe such regulations or orders as may be necessary or desirable to promote the Nation's common defense and security with regard to control, ownership, or possession of any equipment or device, or important component part especially designed for such equipment or device, capable of separating the isotopes of uranium or enriching uranium in the isotope $235 ; 122$

"c. make such studies and investigations, obtain such information, and hold such meetings or hearings as the Commission may deem necessary or proper to assist it in exercising any authority

${ }^{120}$ The second sentence of sec. 158 was amended by Public Law 87-206 (75 stat. 475) (1961), sec. 12. Prior to amendment, it read: "Such licensee shall pay a reasonable royalty fee to be determined in accordance with section 157. to the owner of the patent.

${ }^{121}$ See Atomic Energy Act of 1946, appendix 4, infra, sec. 11

${ }^{122}$ Public Law 101-575 (104 Stat. 2835) (1990), Amended Sec. 161 b. 
27 STAT 443. 49 USC 46.

80 STAT 443. 5 USC 5101.

provided in this Act, or in the administration or enforcement of this Act, or any regulations or orders issued thereunder. For such purposes the Commission is authorized to administer oaths and affirmations, and by subpena to require any person to appear and testify or appear and produce documents, or both, at any designated place. Witnesses subpenaed under this subsection shall be paid the same fees and mileage as are paid witnesses in th district courts of the United States; ${ }^{123}$

"d. appoint and fix the compensation of such officers and employees as may be necessary to carry out the functions of the Commission. Such officers and employees shall be appointed in accordance with the civil-service laws and their compensation fixed in accordance with the Classification Act of 1949, as amended, except that, to the extent the Commission deems such action necessary to the discharge of its responsibilities, personnel may be employed and their compensation fixed without regard to such laws: Provided, however, That no officer or employee (except such officers and employees whose compensation is fixed by law, and scientific and technical personnel up to a limit of the highest rate of grade 18 of the General Schedule of the Classification Act of 1949, as amended) ${ }^{124}$ whose position would be subject to the Classification Act of 1949, as amended, if such Act were applicable to such position, shall be paid a salary at a rate in excess of the rate payable under such Act for positions of equivalent difficulty or responsibility. Such rates of compensation may be adopted by the Commission as may be authorized by the Classification Act of 1949, as amended, as of the same date such rates are authorized for positions subject to such Act. 125 The Commission shall make adequate provision for administrative review of any determination to dismiss any employee;

"e. acquire such material, property, equipment, and facilities, establish or construct such buildings and facilities, and modify such buildings and facilities from time to time, as it may deem necessary, and construct, acquire, provide, or arrange for such facilities and services (at project sites where such facilities and services are not available) for the housing, health, safety, welfare, and recreation of personnel employed by the Commission as it may deem necessary, subject to the provisions of section 174: Provided, however, That in the communities owned by the Commission, the Commission is authorized to grant privileges, leases and permits upon adjusted terms which (at the time of the initial grant of any privilege, grant, lease, or permit, or renewal thereof, or in order to avoid inequities or undue hardship prior to the sale by the United States of property

\footnotetext{
123 Public Law 91-452 (84Stat.922)(1970) sec. 237, The Organized Crime Control Act of 1970, deleted the following sentence form subsec. $161 \mathrm{c}$, "No person shall be excused from complying with any requirements under this paragraph because of his privilege against self-incrimination, but the immunity provisions of the Compulsory Testimony Act of February 11, 1893, shall apply with respect to any individual who specifically claims such privilege."

${ }^{124}$ Public Law 87-793 (76 Stat. 832) (1962), sec. 1001(g), added the words "up to a limit of the highest rate of grade 18 of the General Schedule of the Classification Act of 1949, as amended." Prior to this amendment a limitation of $\$ 19,000$ had been imposed by Public Law 85-287 (71 Stat. 612) (1957), sec. 4.

125 Public Law 85-681 (72 Stat. 633) (1968), see. - amended subsec. 161 d. by inserting this sentence.
} 
affected by such grant) ${ }^{126}$ are fair and reasonable to responsible persons to operate commercial businesses without advertising and without advertising (sic) and without securing competitive bids, but taking into consideration, in addition to the price, and among other things (1) the quality and type of services required by the residents of the community, (2) the experience of each concession applicant in the community and its surrounding area, (3) the ability of the concession applicant to meet the needs of the community, and (4) the contribution the concession applicant has made or will make to the other activities and general welfare of the community; 127

f. with the consent of the agency concerned, utilize or employ the services or personnel of any Government agency or any State or local government, or voluntary or uncompensated personnel, to perform such functions on its behalf as may appear desirable;

g. acquire, purchase, lease, and hold real and personal property, including patents, as agent of and on behalf of the United States, 128 subject to the provisions of section 174, and to sell, lease, grant, and dispose of such real and personal property as provided in this Act;

$h$. consider in a single application one or more of the activities for which a license is required by this Act, combine in a single license one or more of such activities, and permit the applicant or licensee to incorporate by reference pertinent information already filed with the Commission;

i. prescribe such regulations or order as it may deem necessary (1) to protect Restricted Data received by any person in connection with any activity authorized pursuant to this Act, (2) to guard against the loss or diversion of any special nuclear material acquired by any person pursuant to section 53 or produced by any person in connection with any activity authorized pursuant to this Act, to prevent any use or disposition thereof which the Commission may determine to be inimical to the common defense and security, including regulations or orders designating activities, involving quantities of special nuclear material which in the opinion of the Commission are important to the common defense and security, that may be conducted only by persons whose character, associations, and loyalty shall have been investigated under standards and specifications established by the Commission and as to whom the Commission shall have determined that permitting each such person to conduct the activity will not be inimical to the common defense and security, ${ }^{129}$ and (3) to govern any activity authorized pursuant to this Act, including standards and restrictions governing the design, location, and operation of facilities used in the conduct of such activity, in order to protect health and to minimize danger to life or property;".

\footnotetext{
${ }^{126}$ Public Lar 85-162 (71 Stat. 403) (1957), sec. 201, added the clause "(at the time of the initial grant of any privilege grant, lease, or permit, or renewal thereof, or in order to avoid inequalities or undue hardship prior to the sale by the United States of property affected by such grant."

${ }^{127}$ Public Law 84-722 (70 Stat. 553) (1956), amended sec. 161 e. by adding the proviso clause.

${ }^{120}$ The tert of Executive Order 9816 , providing for the transfer of properties and personnel of the Manhattan Engineer District to the Atomic Energy Commission on January 1, 1947, will be found in appendix 8, infra.

${ }^{129} \mathrm{Sec} .7$ of Public Law $93-377$ ( 88 Stat. 475) (1974), amended subsec. $161 \mathrm{i}$. by adding the phrase beginning with the word "including" and ending with the word "security" the second time it appears thereafter.
} 
63 STAT 377. 40 USC 471 note, 488 .

42 USC sec. 2201(K)

j. without regard to the provisions of the Federal Property and Administrative Services Act of 1949, as amended, except section 207 of that Act, or any other law, make such disposition as it may deem desirable of (1) radioactive materials, and (2) any other property, the special disposition of which is, in the opinion of the Commission, in the interest of the national security: Provided, however, That the property furnished to licensees in accordance with the provisions of subsection $161 \mathrm{~m}$. shall not be deemed to be properly disposed of by the commission pursuant to this subsection;

k. authorize such of its members, officers, and employees as it deems necessary in the interest of the common defense and security to carry firearms while in the discharge of their official duties. The Commission may also authorize such of those employees of its contractors and subcontractors (at any tier) engaged in the protection of property under the jurisdiction of the United States located at facilities owned by or contracted to the United States or being transported to or from such facilities as it deems necessary in the interests of the common defense and security to carry firearms while in the discharge of their official duties. A person authorized to carry firearms under this subsection may, while in the performance of, and in connection with, official duties, make arrests without warrant for any offense against the United States committed in that person's presence or for any felony cognizable under the laws of the United States if that person has reasonable grounds to believe that the individual to be arrested has committed or is committing such felony. An employee of a contractor or subcontractor authorized to carry firearms under this subsection may make such arrests only when the individual to be arrested is within, or in direct flight from, the area of such offense. A person granted authority to make arrests by this subsection may exercise that authority only in the enforcement of (1) laws regarding the property of the United States in the custody of the Department of Energy, the Nuclear Regulatory Commission, or a contractor of the Department of Energy or Nuclear Regulatory Commission, or (2) any provision of this Act that may subject an offender to a fine, imprisonment, or both. The arrest authority conferred by this subsection is in addition to any arrest authority under other laws. The Secretary, with the approval of the Attorney General, shall issue guidelines to implement this subsection; ${ }^{130}$

" $\mathrm{m}$. ${ }^{131}$ enter into agreements with persons licensed under Section 103, 104, 53 a. (4), or 63 a. (4) ${ }^{132}$ for such periods of time as the Commission may deem necessary or desirable (1) to provide for the

\footnotetext{
${ }^{130}$ Public Law 99-661 (100 Stat. 4064)(1986)amended subsec. $161 \mathrm{~K}$. Public Law 97-90 (95Stat. 1163)(1981)sec. 211 amended sec. 161k (42U.S.C. 2201k) by striking out the semicolon after "duties" and inserting in lien thereof a period and the new language giving arrest authority for persons authorized to carry firearms.

${ }^{131}$ Public Law 87-456 (76 Stat. 72) (1962), sec. 303(c), the Tariff Classification Act of 1962, repealed sec, 161 L, effective on the 10 day following a Presidential proclamation concerning tariff schedules, import restrictions and ro lated matters. This proclamation was issued on August 21, 1963 (3 C.F.R., Proclamation 3548).

Sec. 1611 , read as follows:

iL Secure the admittance free of duty into the United States of purchases madeabroad of source materials, upon certification to the Security of the Treasury that such entry is necessary in the interest of the common defense and security;".

${ }^{132}$ Public Law 86-300 (73Stat. 574)(1959), sec. 1, amended subsec. 161 m. to authorize agreements with persons licensed under sees. 53 a. (4) or 63 a. (4) as well as under secs. 103 or 104.
} 
Easements for rights-of-way.

processing, fabricating, separating, or refining in facilities owned by the Commission of source, byproduct, or other material or special nuclear material owned by or made available to such licensees and which is utilized or produced in the conduct of the licensed activity, and (2) to sell, lease, or otherwise make available to such licensees such quantities of source or byproduct material, and other material not defined as special nuclear material pursuant to this Act, as may be necessary for the conduct of the licensed activities; Provided, however, That any such agreement may be canceled by the licensee at any time upon payment of such reasonable cancellation charges as may be agreed upon by the licensee and the Commission: And provided, further, That the Commission shall establish prices to be paid by licensees for material or services to be furnished by the Commission pursuant to this subsection, which prices shall be established on such a nondiscriminatory basis as, in the opinion of the Commission, will provide reasonable compensation to the Government for such material or services and will not discourage the development of sources of supply independent of the Commission;

"n. ${ }^{133}$ delegate to the General Manager or other officers of the Commission any of those functions assigned to it under this Act except those specified in section $51,57 \mathrm{~b} .{ }^{134} 61,{ }^{135} 108,123,145 \mathrm{~b}$. (with respect to the determination of those persons to whom the Commission may reveal Restricted Data in the national interest), $145 f .,{ }^{136}$ and 161 a.;

"o. require by rule, regulation, or order, such reports, and the keeping of such records with respect to, and to provide for such inspections of, activities and studies of types specified in section 31 and of activities under licenses issued pursuant to sections 53,63 , 81,103 , and 104 , as may be necessary to effectuate the purposes of this Act, including section 105; and

"p. make, promulgate, issue, rescind, and amend such rules and regulations as may be necessary to carry out the purposes of this Act.

"q. The Commission is empowered, under such terms and conditions as are deemed advisable by it, to grant easements for rights-of-way over, across, in, and upon acquired lands under its jurisdiction and control, and public lands permanently withdrawn or reserved for the use of the Commission, to any State, political subdivision thereof, or municipality, or to any individual, partnership,

\footnotetext{
${ }^{133}$ Public Law 85-507 (72 Stat. 327) (1958). sec. 21, repealed former subsec. $161 \mathrm{n}$., and relettered subsequent subsections accordingly.

Subsec. $161 \mathrm{n}$. read as follows: " $n$. assign scientific, technical, professional, and administrative employees for instruction, education, or training by public or private agencies, institutions of learning, laboratories, or industrial or commercial organizations and to pay the whole or any part of the salaries of such employees, costs of their transportation and per dicm in to their assignments (including tuition and other related fees): Provided, howrever, That (1) not morethan one per centum of the eligible employees shall be so assigned during any fiscal year, and (2) any such assignment shall be approved in advance by the Commission or shall be in accordance with a training program previously approved by the Commission: And provided further, That appropriations or oth

${ }^{134}$ Public Law 90-190 (81 Stat. 575) (1967), sec. 11, amended sec. 161 n. by striking out " $57 \mathrm{a} .(3)$ " and inserting in lieu thereof " $57 \mathrm{~b}$."

${ }^{135}$ Public Law 91-560 (84 Stat. 1472)(1970), sec. 7, amended subsec. $161 \mathrm{n}$. by striking out at this point the following: "102 (with respect to the finding of practical value)."

${ }^{136}$ Amended by Public Law 87-615 (76 Stat. 409) (1962), sec. 12. Prior to amendment reference was to «145 e.".
} 
or corporation of any State, Territory, or possession of the United States, for (a) railroad tracks; (b) oil pipe lines; (c) substations for electric power transmission lines, telephone lines, and telegraph lines, and pumping stations for gas, water, sewer, and oil pipe lines; (d) canals; (e) ditches; (f) flumes; (g) tunnels; (h) dams and reservoirs in connection with fish and wildlife programs, fish hatcheries, and other fish-cultural improvements; (i) roads and street; and (j) for any other purpose or purposes deemed advisable by the Commission: Provided, That such rights-of-way shall be granted only upon a finding by the Commission that the same will not be incompatible with the public interest: Provided further, That such rightsof-way shall not include any more land than is reasonably necessary for the purpose for which granted: And provided further, That all or any part of such right-of-way may be annulled and forfeited by the Commission for failure to comply with the terms and conditions of any grant hereunder or for nonuse for a period of two consecutive years or abandonment of rights granted under authority hereof. Copies of all instruments granting easements over public lands pursuant to this section shall be furnished to the Secretary of the Interior. ${ }^{137}$

"r. Under such regulations and for such periods and at such prices the Commission may prescribe, the Commission may sell or contract to sell to purchasers within Commission-owned communities or in the immediate vicinity of the Commission community, as the case may be, any of the following utilities and related services, if it is determined that they are not available from another local source and that the sale is in the interest of the national defense or in the public interest:

"(1) Electric power.

"(2) Steam.

“(3) Compressed air.

“(4) Water.

“(5) Sewage and garbage disposal.

"(6) Natural, manufactured, or mixed gas.

"(7) Ice.

“(8) Mechanical refrigeration.

“(9) Telephone service.

"Proceeds of sales under this subsection shall be credited to the appropriation currently available for the supply of that utility or service. To meet local needs the Commission may make minor expansions and extensions of any distributing system or facility within or in the immediate vicinity of a Commission-owned community through which a utility or service is furnished under this subsection. 138

Succession of authority.

"s. establish a plan for a succession of authority which will assure the community of direction of the Commission's operations in the event of a national disaster due to enemy activity. Notwithstanding any other provision of this Act, the person or persons succeeding to

\footnotetext{
${ }^{137}$ Public Law 84-1006 (70 Stat. 1069), sec. 4, added subsec. q. (originally subsec. r.).

${ }^{138}$ Public Law 85-162 (71 Stat. 403)(1957), sec. 204, added subsec. 4. (originally subsec s.).
} 
Processing contracts.

Long term contract authority.

command in the event of disaster in accordance with the plan established pursuant to this subsection shall be vested with all of the authority of the Commission:Provided, That any such succession to authority, and vesting of authority shall be effective only in the event and as long as a quorum of three or more members of the Commission is unable to convene and exercise direction during the disaster period: Provided further, That the disaster period includes the period when attack on the United States is imminent and the post-attack period necessary to reestablish normal lines of command; 139

"t. enter into contracts for the processing, fabricating, separating, or refining in facilities owned by the Commission of source, byproduct or other material, or special nuclear material, in accordance with and within the period of an agreement for cooperation while comparable services are available to persons licensed under section 103 or 104: Provided, That the prices for services under such contracts shall be no less than the prices currently charged by the Commission pursuant to section $161 \mathrm{~m}$.;

"u. (1) enter into contracts for such periods of time as the Commission may deem necessary or desirable, but not to exceed five years from the date of execution of the contract, for the purchase or acquisition of reactor services or services related to or required by the operation of reactors;

"(2) (A) enter into contracts for such periods of time as the Commission may deem necessary or desirable for the purchase or acquisition of any supplies, equipment, materials, or services required by the Commission whenever the Commission determines that: (i) it is advantageous to the Government to make such purchase or acquisition from commercial sources; (ii) the furnishing of such supplies, equipment, materials, or services will require the construction or acquisition of special facilities by the vendors or supplies thereof; (iii) the amortization chargeable to the Commission constitutes an appreciable portion of the cost of contract performance, excluding cost of materials; and (iv) the contract for such period is more advantageous to the Government than a similar contract not executed under the authority of this subsection. Such contracts shall be entered into for periods not to exceed five years each from the date of initial delivery of such supplies, equipment, materials, or services or ten years from the date of execution of the contracts excluding periods of renewal under option.

"(B) In entering into such contracts the Commission shall be guided by the following principles: (i) the percentage of the total cost of special facilities devoted to contract performance and chargeable to the Commission should not exceed the ratio between the period of contract deliveries and the anticipated useful life of such special facilities; (ii) the desirability of obtaining options to renew the contract for reasonable periods at

\footnotetext{
${ }^{139}$ Public Law 85-681 (72 Stat 632) (1958) sec 7 amended sec 161 by adding new subsecs t $u$ and $v$ Public Law 87-206 (75 Stat. 475) (1961), sec. 13, changed the designation of subsecs. t., u., and v. to subsecs. s., t., and $u$. respectively.
} 
Contract authority.

42 USC 2231.

prices not to include charges for special facilities already amortized; and (iii) the desirability of reserving in the Commission the right to take title to the special facilities under appropriate circumstances; and

"(3)include in contracts made under this subsection provisions which limit the obligation of funds to estimated annual deliveries and services and the unamortized balance of such amounts due for special facilities as the parties shall agree is chargeable to the performance of the contract. Any appropriation available at the time of termination or thereafter made available to the Commission for operating expenses shall be available for payment of such costs which may arise from termination as the contract may provide. The term "special facilities" as used in this subsection means any land and any depreciable buildings, structures, utilities, machinery, equipment, and fixtures necessary for the production or furnishing of such supplies, equipment, materials, and services and not available to the vendors or suppliers for the performance of the contract. ${ }^{140}$

"v. provide services in support of the United States Enrichment Corporation, except that the Secretary of Energy shall annually collect payments and other charges from the Corporation sufficeint to ensure recovery of the costs (excluding depreciation and imputed interest on original plant investments in the Department's gaseous diffusion plants and costs under section 1403(d)) incurred by the Department of Energy after the date of the enactment of the Energy Policy Act of 1992 in performing such services;". $142+142^{a}$

"w. prescribe and collect from any other Government agency, which applies for or is issued a license for a utilization facility designed to produce electrical or heat energy pursuant to section 103 or 104b, or which operates any facility regulated or certified under section 1701 or 1702,"; and any fee, charge, or price which it may require, in accordance with the provisions of section 483a of title 31 of the United States Code or any other law, of applicants for, or holders of, such licenses or certificates. ${ }^{143+143 a}$

" $x$. Establish by rule, regulation, or order, after public notice, and in accordance with the requirements of section 181 of this Act, such standards and instructions as the Commission may deem necessary or desirable to ensure-

"(1) that an adequate bond, surety, or other financial arrangement (as determined by the Commission) will be provided, before termination of any license for byproduct materials as defined in section 11e. (2), by a licensee to permit the completion of all

\footnotetext{
${ }^{140}$ See footnote 137, stpra.

142 Public Law 88-459 (78 Stat. 602)(1964), sec. 16, added subsec. v.

142 P.L. 102-486 (106 Stat. 2944) Oct. 24, 1992 changed sec. "v."

${ }^{143}$ Public Law $92-314$ (86 Stat. 222) (1972), sec. 301, added subsec. w.

${ }^{143}$ P.L. 102-486 (106 Stat. 2944) Oct. 24, 1992 amended sect. "
} 

tion, decommissioning, and reclamation of sites, structures, and equipment used in conjunction with byproduct material as so defined, and

"(2) that-

"(A) in the case of any such license issued or renewed after the date of the enactment of this subsection, the need for long-term maintenance and monitoring of such sites, structures and equipment after termination of such license will be minimized and, to the maximum extent practicable, eliminated; and

"(B) in the case of each license for such material (whether in effect on the date of the enactment of this section or issued or renewed thereafter), if the Commission determines that any such long-term maintenance and monitoring is necessary, the licensee, before termination of any license for byproduct material as defined in section 11 e. (2), will make available such bonding, surety, or other financial arrangements as may be necessary to assure such long-term maintenance and monitoring.

Such standards and instructions promulgated by the Commission pursuant to this subsection shall take into account, as determined by the Commission, so as to avoid unnecessary duplication and expense, performance bonds or other financial arrangements which are required by other Federal agencies or State agencies and/or other local governing bodies for such decommissioning, decontamination, and reclamation and long-term maintenance and monitoring except that nothing in this paragraph shall be constructed to require that the Commission accept such bonds or arrangements if the Commission determines that such bonds or arrangements are not adequate to carry out subparagraphs (1) and (2) of this subsection. 144

Contracts.

"Sec. 162. Contracts.--The President may, in advance,exempt any

42 USC sec. 2202. specific action of the Commission in a particular matter from the provisions of law relating to contracts whenever he determines that such action is essential in the interest of the common defense and security.

Advisory committees. 42 USC sec. 2203.

62 STAT. 697.
"Sec. 163. Advisory Committees.-The members of the General Advisory Committee established pursuant to section 26 and the members of advisory boards established pursuant to section 161 a. may serve as such without regard to the provisions of sections 281,283 , or 284 of Title 18 of the United States Code, except insofar as such sections may prohibit any such member from receiving compensation from a source other than a nonprofit educational institution ${ }^{145}$ in respect of any particular matter which directly involves the Commission or in which the Commission is directly interested. ${ }^{146}$

\footnotetext{
${ }^{144}$ Public Law 95-604 (92 Stat. 3036) (1978), sec. 203, added a new subsection. 161(x).

${ }^{145}$ Public Law 86-300 (73 Stat. 574)(1959), sec. 2, amended sec. 163 by inserting after the words "from receiving compensation" the words "from a source other than a nonprofit educational institution."

${ }^{146}$ Public Law $87-849$ (76 Stat. 1119) (1962), Sec. 2, revised the existing conflict of interest laws. All exemptions from the provisions of secs. 281,283 and 284 of Title 18 of the U.S. Code are deemed to be exemptions from the corresponding sections of the new conflict of interest law "except to the extent that they affect officers or employeeso the exeative branch oftheUnited states Governme whom they are no longer applicable."
} 
Electric utility contracts.

42 USC sec. 2204.

31 USC 665.

Contract practices. 42 USC sec. 2205.

60 STAT 755.

Comptroller General audit.

42 USC sec. 2206.
"Sec 164. Electric Utility Contracts.-The Commission is authorized in connection with the construction or operations of the Oak Ridge, Paducah, and Portsmouth installations of the Commission, without regard to section 3679 of the Revised Statutes, as amended, to enter into new contracts or modify or confirm existing contracts to provide for electric utility serves for periods not exceeding twenty-five years, and such contracts shall be subject to termination by the Commission upon payment of cancellation costs as provided in such contracts, and any appropriation presently or hereafter made available to the Commission shall be available for the payment of such cancellation costs. Any such cancellation payments shall be taken into consideration in determination of the rate to be charged in the event the Commission or any other agency of the Federal Government shall purchase electric utility services from the contractors subsequent to the cancellation and during the life of the original contract. The authority of the Commission under this section to enter into new contracts or modify or confirm existing contracts to provide for electric utility services includes, in case such electric utility services are to be furnished to the Commission by the Tennessee Valley Authority, authority to contract with any person to furnish electric utility services to the Tennessee Valley Authority in replacement thereof. Any contract hereafter entered into by the Commission pursuant to this section shall be submitted to the Joint Committee and a period of thirty days shall elapse while Congress is in session (in computing such thirty days, there shall be excluded the days on which either House is not in session because of adjournment for more than three days) before the contract of the Commission shall become effective: Provided, however, That the Joint Committee, after having received the proposed contract, may by resolution in writing, waive the conditions of or all or any portion of such thirty-day period.

"Sec. 165. Contract Practices.-

"a. In carrying out the purposes of this Act the Commission shall not use the cost-plus-percentage-of-cost system of contracting.

"b. No contract entered into under the authority of this Act shall provide, and no contract entered into under the authority of the Atomic Energy Act of 1946, as amended, shall be modified or amended after the date of enactment of this Act to provide, for direct payment or direct reimbursement by the Commission of any Federal income taxes on behalf of any contractor performing such contract for profit.

"Sec. 166. Comptroller General Audit.-No moneys appropriated for the purposes of this Act shall be available for payments under any contract with the Commission, negotiated without advertising, except contracts with any foreign government or any agency thereof and contracts with foreign producers, unless such contract includes a clause to the effect that the Comptroller General of the United States or any of his duly authorized representatives shall, until the expiration of three years after final payment, have access to and the right to examine any directly pertinent books, documents, papers, and records of the contractor or any of his subcontractors engaged in the performance of, and involving transactions related to such contracts or subcontracts: Provided, however, That no moneys so appropriated shall be available for 
42 USC sec. 2207. "Sec. 167. Claims Settlements.-The Commission, acting on behalf of the United States, is authorized to consider, ascertain, adjust, determine, settle, and pay, any claim for money damage of $\$ 5,000$ or less against the United States for bodily injury, death, or damage to or loss of real or personal property resulting from any detonation, explosion, or radiation produced in the conduct of any program undertaken by the Commission involving the detonation of an explosive device, where such claim is presented to the Commission in writing within one year after the accident or incident out of which the claim arises: Provided, however, That the damage to or loss of property, or bodily injury or death, shall not have been caused in whole or in part by any negligence or wrongful act on the part of the claimant, his agents, or employees. Any such settlement under the authority of this section shall be final and conclusive for all purposes, notwithstanding any other provision of law to the contrary. If the Commission considers that a claim in excess of $\$ 5,000$ is meritorious and would otherwise be covered by this section, the Commission may report the facts and circumstances thereof to the Congress for its consideration. 148

Payments in

Lieu of taxes.

42 USC

sec. 2208.

No subsidy.

42 USC

Sec. 168. Payments In Lieu Of Taxes.-In order to render financial assistance to those States and localities in which the activities of the Commission are carried on, and in which the Commission has acquired property previously subject to State and local taxation, the Commission is authorized to make payments to State and local governments in lieu of property taxes. Such payments may be in the amounts, at times, and upon the terms the Commission deems appropriate, but the Commission shall be guided by the policy of not making payments in excess of the taxes which would have been payable for such property in the condition in which it was acquired, except in cases where special burdens have been cast upon the State or local government by activities of the Commission, the Manhattan Engineer District or their agents. In any such case, any benefit accruing to the State or local government by reason of such activities shall be considered in determining the amount of the payment.

Sec. 169. No Subsidy.-No funds of the Commission shall be employed in the construction or operation of facilities licensed under

\footnotetext{
${ }^{147}$ Public Law $85-681$ (72 Stat. 632) (1958), sec. 8, amended sec. 166 by adding the second proviso clause. ${ }^{148}$ Public Law 87-206 (75 Stat. 474) (1961), sec 14, amended sec. 167. Prior to amendment this section read as follows:

"Sec. 167. Claim Settlements-The Commission, acting on behalf of the United States, is authorized to consider, ascertain, adjust, determine, settle, and pay, any claim for money damage of $\$ 5,000$ or less against the United States for bodily injury, death, or damage to or loss of real or personal property resulting from any detonation, explosion, or radiationproduced in the conduct of the Commission's program for testing atomic weapons, where such claim is preradiationproduced in the condud of the Commission's program for testing atomic weapons, where such claim is pre-
sented to the Commission in writing within one year after the accident or incident out of which the claim arises: Pro-
vided, however, That the damage to or loss of property, or bodily injury or death, shall not have been caused in whole or vided, however, That the damage to or loss of property, or bodily injury or death, shall not have been caused in whole or
in part by any negligence or wrongful act on the part of the claimant, his agents, or cmployees. Any such settlement
under the authority of this sections shall be final and conclusive for all purposes, notwithstanding any other provision of law to the contrary."
} 
sec. 2209.

42 USC sec. 2210

Indemnification agreement.

Waiver.

Liability

insurance.

section 103 or 104 except under contract or other arrangement entered into pursuant to section 31 .

Sec. 170. Indemnification And Limitation Of Liability. - 149

a. Each license issued under section 103 or 104 and each construction permit issued under section 185 shall, and each license issued under section 53,63, or 81 may, for the public purposes cited in section 2i., have as a condition of the license a requirement that the licensee have and maintain financial protection of such type and in such amounts as the Nuclear Regulatory Commission (in this section referred to as the "Commission") in the exercise of its licensing and regulatory authority and responsibility shall require in accordance with subsection $b$. to cover public liability claims. Whenever such financial protection is required, it may be a further condition of the license that the licensee execute and maintain an indemnification agreement in accordance with subsection $c$. The Commission may require, as a further condition of issuing a license, that an applicant waive any immunity from public liability conferred by Federal or State law. ${ }^{150}$

b. (1) The amount of primary financial protection required shall be the amount of liability insurance available from private sources, except that the Commission may establish a lesser amount on the basis of criteria set forth in writing, which it may revise from time to time, taking into consideration such factors as the following: (A) the cost and terms of private insurance, (B) the type, size, and location of the licensed activity and other factors pertaining to the hazard, and (C) the nature and purpose of the licensed activity: Provided, That for facilities designed for producing substantial amounts of electricity and having a rated capacity of 100,000 electrical kilowatts or more, the amount of primary financial protection required shall be the maximum amount available at reasonable cost and on reasonable terms from private sources (excluding the amount of private liability insurance available under the industry retrospective rating plan required in this subsection). Such primary financial protection may include private insurance, private contractual indemnities, self insurance, other proof of financial responsibility, or a combination of such measures and shall be subject to such terms and conditions as the Commission may, be rule, regulation, or order, prescribe. The Commission shall require licensees that are required to have and maintain primary financial protection equal to the maximum amount of liability insurance available from private sources to maintain, in addition to such primary financial protection, private liability insurance available under an industry retrospective rating plan providing for premium charges deferred in whole of major part until public liability from a nuclear incident

\footnotetext{
${ }^{149}$ Public Law 85-256 (72 Stat. 576) (1957), sec. 4, added sec. 170.

150 PublicLaw 94-197 (89 Stat. 1111)(1975), sec. 2, amended subsection 170a. Prior toamendment subsection 170 a. read as follows:

"a. Each license issued under section 103 or 104 and each construction permit issued under section 185 shall, and each license issued under section 53, 63, or 81 may, have as a condition of the license a requirement that the licensee haveand maintain finarcial protection of such type and insuch amounts as the Commission shall require in accordance with subsection $170 \mathrm{~b}$. to cover public liability claims. Whenever such financial protection is required, it shall be a fursubsection $170 \mathrm{c}$. The Commission may require, as a further condition of issuing a license, that an applicant waive any immunity from public liability conferred hy Federal or State law."
} 
exceeds or appears likely to exceed the level of the primary financial protection required of the licensee involved in the nuclear incident: Provided, That such insurance is available to, and required of, all of the licensees of such facilities without regard to the manner in which they obtain other types or amounts of such primary financial protection: And provided further, That the maximum amount of the standard deferred premium that may be charged a licensee following any nuclear incident under such a plan shall not be more than $\$ 63,000,000$ (subject to adjustment for inflation under subsection t.) but not more than $\$ 10,000,000$ in any 1 year, for each facility for which licensee is required to maintain the maximum amount of primary financial protection: And provided further, That the amount which may be charged a licensee following any nuclear incident shall not exceed the licensee's pro rata share of the aggregate public liability claims and costs (excluding legal costs subject to subsection o.(1)(D), payment of which has not been authorized under such subsection) arising out of the nuclear incident. Payment of any State premium taxes which may be applicable to any deferred premium provided for in this Act shall be the responsibility of the licensee and shall not be included in the retrospective premium established by the Commission.

(2)(A) The Commission may, on a case by case basis, assess annual deferred premium amounts less than the standard annual deferred premium amount assessed under paragraph (1) -

(i) for any facility, if more than one nuclear incident occurs in any one calendar year; or

(ii) for any licensee licensed to operate more than one facility, if the Commission determines that the financial impact of assessing the standard annual deferred premium amount under paragraph (1) would result in undue financial hardship to such licensee or the ratepayers of such licensee.

(B) In the event that the Commission assesses a lesser annual deferred premium amount under subparagraph (A), the Commission shall require payment of the difference between the standard annual deferred premium assessment under paragraph (1) and any such lesser annual deferred premium assessment within a reasonable period of time, with interest at a rate determined by the Secretary of Treasury on the basis of the current average market yield on outstanding marketable obligations of the United States of comparable maturities during the month preceding the date that the standard annual deferred premium assessment under paragraph (1) would become due.

(3) The Commission shall establish such requirements as are necessary to assure availability of funds to meet any assessment of deferred premiums within a reasonable time when due, and may provide reinsurance or shall otherwise guarantee the payment of such premiums in the event it appears that the amount of such premiums will not be available on a timely basis through the resources of private industry and insurance. Any agreement by the Commission with a licensee or indemnitor to guarantee the payment of deferred premiums may contain such terms as 
the Commission deems appropriate to carry out the purposes of this section and to assure reimbursement to the Commission for its payments made due to the failure of such licensee or indemnitor to meet any of its obligations arising under or in connection with financial protection required under this subsection including without limitation terms creating liens upon the licensed facility and the revenues derived therefrom or any other property or revenues of such licensee to secure such reimbursement and consent to the automatic revocation of any license. ${ }^{151}$

(4)(A) In the event that the funds available to pay valid claims in any year are insufficient as a result of the limitation on the amount of deferred premiums that maybe required of a licensee in any year under paragraph (1) or (2), or the Commission is required to make reinsurance or guaranteed payments under paragraph (3), the Commission shall, in order to advance the necessary funds-

(i) request the Congress to appropriate sufficient funds to satisfy such payments; or

(ii) to the extent approved in appropriation Acts, issue to the Secretary of the Treasury obligations in such forms and denominations, bearing such maturities, and subject to such terms and conditions as may be agreed to by the Commission and the Secretary of the Treasury.

(B) Except for funds appropriated for purposes of making reinsurance or guaranteed payments under paragraph (3), any funds appropriated under subparagraph (A)(i) shall be repaid to the general fund of the United States Treasury from amounts made available by standard deferred premium assessments, with interest at a rate determined by the Secretary of Treasury on the basis of the current average market yield on outstanding marketable obligations of the United States of comparable maturities during the month preceding the date that the funds appropriated under such subparagraph are made available.

(C) Except for funds appropriate for purposes of making reinsurance or guaranteed payments under paragraph (3), redemption of obligations issued under subparagraph (A)(ii) shall be made by the Commission from amounts made available by standard deferred premium assessments. Such obligations shall bear interest at a rate determined by the Secretary of Treasury by taking into consideration the average market yield on outstanding marketable obligations to the United States of comparable maturities during the month preceding the issuance of the obligations under this para-

${ }^{161}$ Publie Law 94-197 (\$9 Stat. 1111) (1975), sec. 3, ameaded subsection 170 b. Prior to amendment, subsection $170 \mathrm{~b}$. read as follows:

"b. The amount of financial protection required shall be in the amount of liability insurance available from private sources, except that the Commission may establish a lesser amount on the basis of criteria set forth in writing which it may revise from time to time, taking into consideration such factors as the following: (1) the cost and termso private insurance, (2) the type, size and location of the licensed activity and other factors pertaining to the hazard, and (3) the nature and purpose of the licensed activity: Provided, That for facilities designed for producing substantial amounts of electricity and having a rated capacity of 100,000 electrical kilowatts or more, the amount of financial protection required shall be the maximum amount available from private sources. Such financial protection may include private insurance, private contractual indemnities, self insurance, other proof of financial responsibility, or a combination of such measures." 
graph. The Secretary of the Treasury shall purchase any issued obligations, and for such purpose the Secretary of the Treasury may use as a public debt transaction the proceeds from the sale of any securities issued under chapter 31 of title 31, United States Code, and the purposes for which securities may be issued under such chapter are extended to include any purchase of such obligations. The Secretary of the Treasury may at any time sell any of the obligations acquired by the Secretary of the Treasury under this paragraph. All redemptions, purchases, and sales by the Secretary of the Treasury of obligations under this paragraph shall be treated as public debt transactions of the United States.

c. The Commission shall, with respect to licenses issued between August 30, 1954, and August 1, 2002, for which it requires financial protection of less than $\$ 560,000,000$, agree to indemnify and hold harmless the licensee and other persons indemnified, as their interest may appear, from public liability arising from nuclear incidents which is in excess of the level of financial protection required of the licensee. The aggregate indemnity for all persons indemnified in connection with each nuclear incident shall not exceed $\$ 500,000,000$ excluding costs of investigating and settling claims and defending suits for damage: Provided, however, That this amount of indemnity shall be reduced by the amount that the financial protection required shall exceed $\$ 60,000,000$. Such a contract of indemnification shall cover public liability arising out of or in connection with the licensed activity. With respect to any production or utilization facility for which a construction permit is issued between August 30, 1954, and August 1, 2002,152 the requirements of this subsection shall apply to any license issued for such facility subsequent to August 1, 2002.

d.(1)(A) In addition to any other authority the Secretary of Energy (in this section referred to as the "Secretary") may have, the Secretary shall, until August 1, 2002, enter into agreements of indemnification under this subsection with any person who may conduct activities under a contract with the Department of Energy that involve the risk of public liability and that are not subject to

${ }^{152}$ PublicLaw 94-197( 89 Stat. 1111)(1975), sec. 5(a) and (b) amended subsection $170 \mathrm{c}$. by adding the phrase "of less than $\$ 560,000,000$." by substituting the work "excluding" for the words "including the reasonable," and by substituting the date "August 1,1987" for the date "August 1, 1977" wherever it appeared.

Public Law 89-210 (79 Stat. 355) (1965), sec. 1. had previously amended subsec. $170 \mathrm{C}$. Prior to amendment this subsection read as follows:

"c. The Commission shall, with respect to licenses issued between August 30, 1954 , and August 1, 1967, for which it requires financial protection, agree to indemnify and hold harmless the licensee and other persons indemnified, as their interest may appear, from public liability arising form nuclear incidents which is in excess of the level of financial protection required of the license. The aggregate indemnity for all persons indemnified in connection with each nuclearincident shall not exceed $\$ 500,000,000$ including the reasonable costs of investigating and settling claims and defending suits for damage. Such a contract of indemnification shall cover public liability arising out of or in connection with the licensed activity. With respect to any production or utilization facility for which a construction permit is issued between August 30,1954, and August 1, 1967, the requirements of this subsection shall apply to any cense issued for such facility subsequent to August 1, 1967.

Public Law 88-394 (78 Stat. 376) (1964), sec. 2, had previously amended subsec. $170 \mathrm{c}$. by adding the last sentence. 
Claims.

financial protection requirements under subsection $b$. or agreements of indemnification under subsection c. or k. ${ }^{153}$

"(B)(i)(I) Beginning 60 days after the date of enactment of the Price-Anderson Amendments Act of 1988, agreements of indemnification under subparagraph (A) shall be the exclusive means of indemnification for public liability arising from activities described in such subparagraph, including activities conducted under a contract that contains an indemnification clause under Public Law 85-804 entered into between August 1, 1987, and the date of enactment of the Price-Anderson Amendments Act of 1988.

"(II) The Secretary may incorporate in agreements of indemnification under subparagraph $(A)$ the provisions relating to the waiver of any issue or defense as to charitable or governmental immunity authorized in subsection $n$. (1) to be incorporated in agreements of indemnification. Any such provisions incorporated under this subclause shall apply to any nuclear incident arising out of nuclear waste activities subject to an agreement of indemnification under subparagraph (A).

"(ii) Public liability arising out of nuclear waste activities subject to an agreement of indemnification under subparagraph (A) that are funded by the Nuclear Waste Fund established in section 302 of the Nuclear Waste Policy Act of 1982 (42 U.S.C. 10222) shall be compensated from the Nuclear Waste Fund in an amount not to exceed the maximum amount of financial protection required of licensees under subsection $b$.

(2) In agreements of indemnification entered into under paragraph (1), the Secretary may require the contractor to provide and maintain financial protection of such a type and in such amounts as the Secretary shall determine to be appropriate to cover public liability arising out of or in connection with the contractual activity, and shall indemnify the persons indemnified against such claims above the amount of the financial protection required, to the full extent of the aggregate public liability of the persons indemnified for each nuclear incident, including such legal costs of the contractor as are approved by the Secretary.

(3) (A) Notwithstanding paragraph (2), if the maximum amount of financial protection required of licensees under subsection $b$. is increased by the Commission, the amount of indemnity, together

\footnotetext{
${ }^{153}$ Public Law 100-408 (102 Stat. 1066) amended subsection 170d.

Public Law 94-197 (89 Stat 1111) (1975), sec. 5 (a) and (b), amended subsection $170 \mathrm{~d}$. by substituting the date "August 1, 1987" for the date "August 1, 1977", and by substituting the word "excluding" for the words "including the reasonablen.

PublicLiw 89-210 (79 Stat 855 (1965), sec. 2 had previously amended the first two sentences of subsection $170 \mathrm{~d}$. Prior to amendment these sentences read as follows:

"d. In addition to any other authority the Commission may have, the Commission is autborized until August 1 , 1967, to enter into agreements of indemnification with its contractors for the construction or operation of production or utilization facilities or other activities under cont racts for the benefit of the United States inwolving activities under the risk of public liability for a substantial nuclear incident. In such agreements of indemnification the Commission may require its contractor to provide and maintain financial protection of such a type and in such amounts as the com mission shall determine to be appropriate to cover public liability arising out of or in connection with the contractual activity, and shall indemnify the persons indemnified against such claims above the amount of the financial protection required, in the amount of $\$ 500,000,000$ including the reasonable costs of investigating and settling claims and defending suits for damage in theaggregate for all persons indemnified in connection with such contract and for each nuclear incident: Provided: That in the case of nuclear incidents occurring outside the United States, the amount of the indemnity provided by the Commission shall not exceed $\$ 100,000,000 . "$

Public Law 87-615 (76 Stat. 409) (1962), sec. 6 had previously amended the second sentence of subsec. $170 \mathrm{~d}$. by adding the proviso providing that in the case of incidents occurring outside the United States, the amount of indemnity provided by the Comimission shall not exceed $\$ 100$ million.
} 
with any financial protection required of the contractor, shall at all times remain equal to or greater than the maximum amount of financial protection required of licensees under subsection $b$.

(B) The amount of indemnity provided contractors under this subsection shall not, at any time, be reduced in the event that the maximum amount of financial protection required of licensees is reduced.

(C) All agreements of indemnification under which the Department of Energy (or its predecessor agencies) may be required to indemnify any person, shall be deemed to be amended, on the date of the enactment of the Price-Anderson Amendments Act of 1988, to reflect the amount of indemnity for public liability and any applicable financial protection required of the contractor under this subsection on such date.

(4) Financial protection under paragraph (2) and indemnification under paragraph (1) shall be the exclusive means of financial protection and indemnification under this section for any Department of Energy demonstration reactor licensed by the Commission under section 202 of the Energy Reorganization Act of 1974 (42 U.S.C. 5842).

(5) In the case of nuclear incidents occurring outside the United States, the amount of the indemnity provided by the Secretary under this subsection shall not exceed $\$ 100,000,000$.

(6) The provisions of this subsection may be applicable to lump sum as well as cost type contracts and to contracts and projects financed in whole or in part by the Secretary.

(7) A contractor with whom an agreement of indemnification has been executed under paragraph (1)(A) and who is engaged in activities connected with the underground detonation of a nuclear explosive device shall be liable, to the extent so indemnified under this subsection, for injuries or damage sustained as a result of such detonation in the same manner and to the same extent as would a private person acting as principal, and no immunity or defense founded in the Federal, State, or municipal character of the contractor or of the work to be performed under the contract shall be effective to bar such liability. ${ }^{154}$

e. Limitation On Aggregate Public Liability.-(1)155 The aggregate public liability for a single nuclear incident of persons indemnified, including such legal costs as are authorized to be paid under subsection o.(1)(D), shall not exceed-

(A) in the case of facilities designed for producing substantial amounts of electricity and having a rated capacity of 100,000 elec-

\footnotetext{
${ }^{164}$ Public Law 87-206 (75 Stat. 475) (1961), sec. 15, added the last sentence of subsec. $170 \mathrm{~d}$.

${ }^{165}$ Public Law 100-408 (102 Stat. 1066) (1988), amended subsec. 170e. Subsectione. originally read as follows: "e. The aggregate liability for a single nuclear incident of persons indemnified, including the reasonable costs of investiamount of financial protection required of the licensee or contractor. The Commission or any person indemnified

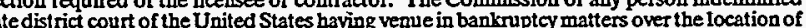
twill probably exceed the limit of liability imposed by this section, shall be entitled to such orders as may be appropriate for enforcement of the ersons indemnified, orders staying the payment of claims and the execution of court judgments, orders apportioning the payments to be made to claimants, orders permitting partial payments to be made before final determination of the total claims, and an order setting aside $a$ part of the funds available for possible latent injuries not discovered until a later time."
}

(Contimued) 
Contracts

Claims.

trical kilowatts or more, the maximum amount of financial protection required of such facilities under subsection $b$. (plus any surcharge assessed under subsection $0 .(1)(E))$;

$(B)$ in the case of contractors with whom the Secretary has entered into an agreement of indemnification under subsection $d$., the maximum amount of financial protection and required under subsection $b$. or the amount of indemnity and financial protection that may be required under paragraph (3) of subsection d., whichever amount is more; and

(C) in the case of all other licensees of the Commission required to maintain financial protection under this section-

(i) $\$ 500,000,000$, together with the amount of financial protection required of the licensee; or

(ii) if the amount of financial protection required of the licensee exceeds $\$ 60,000,000, \$ 560,000,000$ or the amount of financial protection required of the licensee, whichever amount is more.

(2) In the event of a nuclear incident involving damages in excess of the amount of aggregate public liability under paragraph (1), the Congress will thoroughly review the particular incident in accordance with the procedures set forth in section $170 \mathrm{i}$, and will in accordance with; such procedures, take whatever action is determined to be necessary (including approval of appropriate compensation plans and appropriation of funds) to provide full and

(Continued)

Public Law 85-602 (72 Stat. 525)(1958), sec. 2, deleted the second sentence in the original subsection and substituted the following: "The Commission or any person indemnified may apply to the appropriate district court of the venue in bankruptcy matters over the location of the nuclear incicent, except that in the case of nuclear incidents caused by ships of the United States outside of the United States, the Commission or any person indemniffed may apply to the appropriate district court of the United States' having venue in banknuptcy matters over the location of the priscipal place of business of the shipping company owning or operating and ship, and upon a showing that the public liability from a single nuclear incident will probably exceed the limit of liability imposed by this action, shall be entitled to such orders as may be appropriate for enforcement of the provisions of this section, including an order limiting the liability of the persons indemnified, orders staying the payment of claims and the crecution of court judgments, orders apportioning the payments to be made to claimants, orders permitting partial payments to be latent injuries not discovered until a later time"

Public Law 87-615 (76 Stat. 409) (1962), sec. 7, amended the subsection to read:

ce. The aggregate liability for a single nuclear incident of persons indemnified, including the reasonable costs of investigating and settling claims and defending suits for damage, shall not exceed the sum of $\$ 500,000,000$ together with the amount of financial protection required of the licensee or contractor. Provided, hovever. That with respect to any muclear incident occurring outside of the United States to which an agreement of indemnification entered into under the provisions of subsection $170 \mathrm{~d}$. is applicable, such aggregate liability shall not exceed tbe amount of $\$ 100,000,000$ together with the amount of financial protection required of the contractor. The Commission or any person indemnified may apply to the appropriate district court of the United States having venue in bankruptcy matters over the location of the nuclear incident, except that in the case of nuclear incidents occurring outside the United States, the Commission or any person indemnified may apply to the United States District Coust for the District of Columbia, and upon a showing that the public liability from a single nuclear incident will probably exceed the limit of liability imposed by this section, shall beentitled to such orders as may be appropriate for enforcement of the provision of this section, including an order limiting the liability of persons indemnified, orders staying the payments of claims and the execution of court judgments, orders apportioning the payments to be made before final determination of the total claims, and an order setting aside a part of the funds available for possible latent injuries not discovered until a

Public Law 89.210 (79 Stat 855) (1965), sec. 3, amended, the first sentence by adding the first proviso relating to the mitation of aggregate liability.

Public Law $89-645$ ( 80 Stat. 891 ) (1960 sec. 2 amended the subsection by deleting the last sentence thereof. Public Law 94-197 (89 Stat. 1111) (1975), Sec. 6, amended subsection $170 \mathrm{e}$. Prior to this amendment, subsection $170 \mathrm{e}$. read as follows:

"e. The aggregate liability for a single nuclear incident of persons indemnified, including the reasonable costs of investigating and settling claims and defending suits for damage, shall not exceed the sum of $\$ 500,000,000$ together with the amount of financial protection required of the licensec or contractor. Provided, howeves, That such aggregate liability shall in no event erceed the sum of $\$ 560,000,000 \cdot$ Provided further $T$. occurring outside of the United States to which an occurring outside of the United States to which an agreement of indemnification entered into under the provisions of amount of financial protection required of the contractor." 
Contracts.

prompt compensation to the public for all public liability claims resulting from a disaster of such magnitude.

(3) No provision of paragraph (1) may be construed to preclude the Congress from enacting a revenue measure, applicable to licensees of the Commission required to maintain financial protection pursuant to subsection $b$., to fund any action undertaken pursuant to paragraph (2).

(4) With respect to any nuclear incident occurring outside of the United States to which an agreement of indemnification entered into under the provisions of subsection d. is applicable, such aggregate public liability shall not exceed the amount of $\$ 100,000,000$, together with the amount of financial protection required of the contractor.

f. The Commission or the Secretary, as appropriate, is authorized to collect a fee from all persons with whom an indemnification agreement is executed under this section. This fee shall be $\$ 30$ per year per thousand kilowatts of thermal energy capacity for facilities licensed under section 103: Provided, That the Commission or the Secretary, as appropriate, is authorized to reduce the fee for such facilities in reasonable relation to increases in financial protection required above a level of $\$ 60,000,000$. For facilities licensed under section 104 , and for construction permits under section 185 , the Commission is authorized to reduce the fee set forth above. The Commission shall establish criteria in writing for determination of the fee for facilities licensed under section 104, taking into consideration such factors as (1) the type, size, and location of facility involved, and other factors pertaining to the hazard, and (2) the nature and purpose of the facility. For other licenses, the Commission shall collect such nominal fees as it deems appropriate. No fee under this subsection shall be less than $\$ 100$ per year. ${ }^{156}$

Private insurance organizations. Use of services.

42 USC 252

(c) See 41) USC 260 (b)). Terms of settlement. g. In administering the provisions of this section, the Commission or the Secretary, as appropriate, shall use, to the maximum extent practicable, the facilities and services of private insurance organizations, and the Commission or the Secretary, as appropriate, may contract to pay a reasonable compensation for such services. Any contract made under the provisions of this subsection may be made without regard to the provisions of section 3709 of the Revised Statutes (41 U.S.C. 5), as amended, upon a showing by the Commission or the Secretary, as appropriate, that advertising is not reasonable practicable and advance payments may be made.

h. The agreement of indemnification may contain such terms as the Commission or the Secretary, as appropriate, deems appropriate to carry out the purposes of this section. Such agreement shall provide that, when the Commission or the Secretary, as appropriate, makes a determination that the United States will probably be required to make indemnity payments under this section, the Commission or the Secretary, as appropriate, shall collaborate with any person indemnified and may approve the payment of any claim under the agreement of indemnification, appear through the Attorney General on behalf of the

${ }^{156}$ Public Law 100-408 (102Stat. 1066) (1988), amended subsection $170 \mathrm{f}$. by adding, "or the Secretary, as appropriate".

Public Law 94-197 (89 Stat. 1111) (1975), sec. 7, amended subsection 170 f. by adding the proviso to the second sentence. 
Reports,

Defense and national security.

President of U.S

Claims.

Claims.

person indemnified, take charge of such action, and settle or defend any such action. The Commission or the Secretary, as appropriate, shall have final authority on behalf of the United States to settle or approve the settlement of any such claim on a fair and reasonable basis with due regard for the purposes of this Act. Such settlement shall not include expenses in connection with the claim incurred by the person indemnified. 157

i. Compensation Plans. - (1) After any nuclear incident involving damages that are likely to exceed the applicable amount of aggregate public liability under subparagraph (A), (B), or (C) of subsection e. (1), the Secretary or the Commission, as appropriate, shall-

(A) make a survey of the causes and extent of damage; and (B) expeditiously submit a report setting forth the results of such survey to the Congress, to the Representatives of the affected districts, to the Senators of the affected States, and (except for information that will cause serious damage to the national defense of the United States) to the public, to the parties involved, and to the courts.

(2) Not later than 90 days after any determination by a court, pursuant to subsection 0 , that the public liability from a single nuclear incident may exceed the applicable amount of aggregate public liability under subparagraph (A), (B), or (C) of subsection e. (1) the President shall submit to the Congress-

(A) an estimate of the aggregate dollar value of personal injuries and property damage that arises from the nuclear incident and exceeds the amount of aggregate public liability under subsection e. (1);

(B) recommendations for additional sources of funds to pay claims exceeding the applicable amount of aggregate public liability under subparagraph (A), (B), or (C) of subsection e. (1), which recommendations shall consider a broad range of possible sources of funds (including possible revenue measures on the sector of the economy, or on any other class, to which such revenue measures might be applied);

(C) 1 or more compensation plans, that either individually or collectively shall provide for full and prompt compensation for all valid claims and contain a recommendation or recommendations as to the relief to be provided, including any recommendations that funds be allocated or set aside for the payment of claims that may arise as a result of latent injuries that may not be discovered until a later date; and

(D) any additional legislative authorities necessary to implement such compensation plan or plans.

(3)(A) Any compensation plan transmitted to the Congress pursuant to paragraph (2) shall bear an identification number and shall be transmitted to both Houses of Congress on the same day and to each House while it is in session.

${ }^{157}$ Public Law 94-197 ( 89 Stat. 1111) (1975), sec. 8, amended subsection 170 h. by substituting the words "shall not include ${ }^{n}$ for the words "may include reasonable" in the last sentence of the subsection. 
(B) The provisions of paragraphs (4) through (6) shall apply with respect to consideration in the Senate of any compensation plan transmitted to the Senate pursuant to paragraph (2).

(4) No such compensation plan may be considered approved for purposes of subsection $170 \mathrm{e}$. (2) unless between the date of transmittal and the end of the first period of sixty calendar days of continuous session of Congress after the date on which such action is transmitted to the Senate, the Senate passes a resolution described in paragraph 6 of this subsection.

(5) For the purpose of paragraph (4) of this subsection-

(A) continuity of session is broken only by an adjournment of Congress sine die; and

(B) the days on which either House is not in session because of an adjournment of more than three days to a day certain are excluded in the computation of the sixty-day calendar period.

(6)(A) This paragraph is enacted-

(i) as an exercise of the rulemaking power of the Senate and as such it is deemed a part of the rules of the Senate, but applicable only with respect to the procedure to be followed in the Senate in the case of resolutions described by subparagraph (B) and it supersedes other rules only to the extent that it is inconsistent therewith; and

(ii) with full recognition of the constitutional right of the Senate to change the rules at any time, in the same manner and to the same extent as in the case of any other rule of the Senate.

(B) For purposes of this paragraph, the term 'resolution' means only a joint resolution of the Congress the matter after the resolving clause of which is as follows: "That the plan numbered submitted to the Congress on

, $19 \therefore$, the first blank space therein being filled with the name of the resolving House and the other blank spaces being appropriately filled; but does not include a resolution which specifies more than one compensation plan.

(C) A resolution once introduced with respect to a compensation plan shall immediately be referred to a committee (and all resolutions with respect to the same compensation plan shall be referred to the same committee) by the President of the Senate.

(D)(i) If the committee of the Senate to which a resolution with respect to a compensation plan has been referred has not reported it at the end of twenty calendar days after its referral, it shall be in order to move either to discharge the committee from further consideration of such resolution or to discharge the committee from further consideration with respect to such compensation plan which has been referred to the committee.

(ii) A motion to discharge may be made only by an individual favoring the resolution, shall be highly privileged (except that it may not be made after the committee has reported a resolution with respect to the same compensation plan), and debate thereon shall be limited to not more than one hour, to be divided equally between those favoring and those opposing the resolution. An amendment to the motion shall not be in order, and it shall not be 
Contracts in advance of appropriations 31 USC 665.

Educational activities. in order to move to reconsider the vote by which the motion was agreed to or disagreed to.

(iii) If the motion to discharge is agreed to or disagreed to the motion may not be renewed, nor may another motion to discharge the committee be made with respect to any other resolution with respect to the same compensation plan.

(E)(i) When the committee has reported, or has been discharged from further consideration of, a resolution, it shall be at any time thereafter in order (even though a previous motion to the same effect has been disagreed to ) to move to proceed to the consideration of the resolution. The motion shall be highly privileged and shall not be debatable. An amendment to the motion shall not be in order, and it shall not be in order to move to reconsider the vote by which the motion was agreed to or disagreed to.

(ii) Debate on the resolution referred to in clause (i) of this subparagraph shall be limited to not more than ten hours, which shall be divided equally between those favoring and those opposing such resolution. A motion further to limit debate shall not be debatable. An amendment to, or motion to recommit, the resolution shall not be in order, and it shall not be in order to move to reconsider the vote by which such resolution was agreed to or disagreed to.

(F)(i) Motions to postpone, made with respect to the discharge from committee, or the consideration of a resolution or motions to proceed to the consideration of other business, shall be decided without debate.

(ii) Appeals from the decision of the Chair relating to the application of the rules of the Senate to the procedures relating to a resolution shall be decided without debate. ${ }^{158}$

j. In administering the provisions of this section, the Commission or the Secretary, as appropriate, may make contracts in advance of appropriations and incur obligations without regard to sections 1341, $1342,1349,1350$, and 1351 , and subchapter II of chapter 15 , of title 31 , United States Code.

k. With respect to any license issued pursuant to section $53,63,81$, $104 \mathrm{a}$., or 104c. for the conduct of educational activities to a person found by the Commission to be a nonprofit educational institution, the Commission shall exempt such licensee from the financial protection requirement of subsection a. With respect to licenses issued between August 30,1954, and August 1, 2002, for which the Commission grants such exemption:

(1) the Commission shall agree to indemnify and hold harmless the licensee and other persons indemnified, as their interests may appear, from public liability in excess of $\$ 250,000$ arising from nuclear incidents. The aggregate indemnity for all persons indemnified in connection with each nuclear incident shall not exceed

${ }^{168}$ Public Law 100-408 (102 Stat. 1066) (1988), sec. 7, amended subsection 170 i “Public Law 94-197(89 Stat. 1111) (1975), sec. 9, amended subsection $170 \mathrm{i}$. Prior to amendment, subsection $170 \mathrm{i}$. read as follows:

i After any nuclear incident which will probably require payments by the United States under this section, the Commissionshall make a survey of the causes and extent of damage which shall forthwith be reported to the Joint Com mittec, and, except as forbidden by the provisions of chapter 12 of this Act or any other law or Executive order, all fina findings shall be made available to the public, to the parties invoked and to the courts. The Commissionshall report to
the Joint Committee by April 1, 1958, and every year thereafter on the operations under this section." 
$\$ 500,000,000$, including such legal costs of the licensee as are approved by the Commission;

(2) such contracts of indemnification shall cover public liability arising out of or in connection with the licensed activity; and shall include damage to property of persons indemnified, except property which is located at the site of and used in connection with the activity where the nuclear incident occurs; and

(3) such contracts of indemnification, when entered into with a licensee having immunity from public liability because it is a State agency, shall provide also that the Commission shall make payments under the contract on account of activities of the licensee in the same manner and to the same extent as the Commission would be required to do if the licensee were not such a State agency. Any licensee may waive an exemption to which it is entitled under this subsection. With respect to any production or utilization facility for which a construction permit is issued between August 30, 1954, and August 1,2002, the requirements of this subsection shall apply to any license issued for such facility subsequent to August 1,2002.159

(1) Presidential Commission On Catastrophic Nuclear Accidents.(1) Not later than 90 days after the date of the enactment of the PriceAnderson Amendments Act of 1988, the President shall establish a commission (in this subsection referred to as the 'study commission') in accordance with the Federal Advisory Committee Act (5 U.S.C. App.) to study means of fully compensating victims of a catastrophic nuclear accident that exceeds the amount of aggregate public liability under subsection e. (1).

(2)(A) The study commission shall consist of not less than 7 and not more than 11 members, who-

(i) shall be appointed by the President; and

(ii) shall be representative of a broad range of views and interests.

(B) The members of the study commission shall be appointed in a manner that ensures that not more than a mere majority of the members are of the same political party.

(C) Each member of the study commission shall hold office until the termination of the study commission, but may be removed by the President for inefficiency, neglect of duty, or malfeasance in office.

(D) Any vacancy in the study commission shall be filled in the manner in which the original appointment was made.

(E) The President shall designate one of the members of the study commission as chairperson, to serve at the pleasure of the President.

Reports.

(3) The study commission shall conduct a comprehensive study of appropriate means of fully compensating victims of a catastrophic nuclear accident that exceeds the amount of aggregate public liability

${ }^{159}$ Public Law $85-744$ (72 Stat. 837) (1958) amended sec. 170 by adding new subsec. k.

Public Law 88-394 (78 Stat. 376) (1964), sec. 3, amended subsec. $170 \mathrm{k}$, by adding the last sentence.

Public Law 89-210 (79 Stat. 855) (1965), sec. 4, amended subsec. $170 \mathrm{k}$. by amending the date "August 1, 1967" wherever it appeared to "August 1, 1977"

Public Lar 94-197 ( $\$ 9$ Stat. 1111) (1975), Sec. 10, amended subsection $170 \mathrm{k}$. by substituting the date "August 1 $1987^{n}$ for the date "August 1, 1977" wherever it appeared and by substituting the word "exchuding" for the words "including the reasonable". 
under subsection e. (1), and shall submit to the Congress a final report setting forth-

(A) recommendations for any changes in the laws and rules governing the liability or civil procedures that are necessary for the equitable, prompt, and efficient resolution and payment of all valid damage claims, including the advisability of adjudicating public liability claims through an administrative agency instead of the judicial system;

(B) recommendations for any standards or procedures that are necessary to establish priorities for the hearing, resolution, and payment of claims when awards are likely to exceed the amount of funds available within a specific time period; and

(C) recommendation for any special standards or procedures necessary to decide and pay claims for latent injuries caused by the nuclear incident.

(4)(A) The chairperson of the study commission may appoint and fix the compensation of a staff of such persons as may be necessary to discharge the responsibilities of the study commission, subject to the applicable provisions of the Federal Advisory Committee Act (5 U.S.C. App.) and title 5, United States Code.

(B) To the extent permitted by law and requested by the chairperson of the study commission, the Administrator of General Services shall provide the study commission with necessary administrative services, facilities, and support on a reimbursable basis.

(C) The Attorney General, the Secretary of Health and Human Services, and the Director of the Federal Emergency Management Agency shall, to the extent permitted by law and subject to the availability of funds, provide the study commission with such facilities, support, funds and services, including staff, as may be necessary for the effective performance of the functions of the study commission.

(D) The study commission may request any Executive agency to furnish such information, advice, or assistance as it determines to be necessary to carry out its functions. Each such agency is directed, to the extent permitted by law, to furnish such information, advice or assistance upon request by the chairperson of the study commission.

(E) Each member of the study commission may receive compensation at the maximum rate prescribed by the Federal Advisory Committee Act (5 U.S.C. App.) for each day such member is engaged in the work of the study commission. Each member may also receive travel expenses, including per diem in lieu of subsistence under sections 5702 and 5703 of title 5, United States Code.

(F) The functions of the President under the Federal Advisory Committee Act (5 U.S.C. App.) that are applicable to the study commission, except the function of reporting annually to the Congress, shall be performed by the Administrator of General Services.

Reports.

(5) The final report required in paragraph (3) shall be submitted to the Congress not later than the expiration of the 2 -year period beginning on 
Termination date.

Emergency assistance payments.

Waiver of defenses. the date of the enactment of the Price-Anderson Amendments Act of 1988.

(6) The study commission shall terminate upon the expiration of the 2-month period beginning on the date on which the final report required in paragraph (3) is submitted. 160

$\mathrm{m}$. The Commission or the Secretary, as appropriate, is authorized to enter into agreements with other indemnitors to establish coordinated procedures for the prompt handling, investigation, and settlement of claims for public liability. The Commission or the Secretary, as appropriate, and other indemnitors may make payments to, or for the aid of, claimants for the purpose of providing immediate assistance following a nuclear incident. Any funds appropriate to the Commission or the Secretary, as appropriate, shall be available for such payments. Such payments may be made without securing releases, shall not constitute an admission of the liability of any person indemnified or of any indemnitor, and shall operate as a satisfaction to the extent there of of any final settlement or judgment. ${ }^{161}$

n. (1) With respect to any extraordinary nuclear occurrence to which an insurance policy or contract furnished as proof of financial protection or an indemnity agreement applies and which-

(A) arises out of or results from or occurs in the course of the construction, possession, or operation of a production or utilization facility,

(B) arises out of or results from or occurs in the course of transportation of source material, by-product material, or special nuclear material to or from a production of utilization facility,

(C) during the course of the contract activity arises out of or results from the possession, operation, or use by a Department of Energy contractor or subcontractor of a device utilizing special nuclear material or by-product material,

(D) arises out of, results from, or occurs in the course of, the construction, possession, or operation of any facility licensed under sections 53,63 , or 81 , for which the Commission has imposed as a condition of the license a requirement that the licensee have and maintain financial protection under subsection a.,

(E) arises out of, results from, or occurs in the course of, transportation of source material, byproduct material, or special nuclear material to or from any facility licensed under section 53,63 , or 81 , for which the Commission has imposed as a condition of the license

${ }^{160}$ Public Law 100-408 (102 Stat. 1066) (1988) deleted the provisions of subsections $170 \mathrm{f}$. and replaced with the Presidential Commission.

Public Law 85-602 (72 Stat. 525) (1958), sec. 2, amended see 170 by adding new subsection 1 Public Law 89-210 (79 Stet. 855) (1965), sec.5, amended subsec. 1701 . Prior to amendment this subsection read as

"1. The Commission is authorized until August 1, 1967, to enter into an agreement of indemnification with any person engaged in the design, development, construction, operation, repair, and maintenance or use of the nuclearpowered ship authorized by section 716 of the Merchant Marine Act, 1936, and designated the 'nuclear ship Savannah. In any such agreement of indemnification the Commission may require such person to provide and maintain financial protection of such a type and in such amounts as the Commission shall determine to be appropriate to cover public liability arising from a nuclear incident in connection with such design, development, construction, operation, repair, maintenance or use and shall indemnify the person indemnified against such claims above the amount of the investigating and settling claims and defending suits for damage.

Public Law 94197 (89 State. 1111) (1975), Sec. 11, amended subsection 170.1. by substituting the word "exclud. ing" for the words "including the reasonable".

${ }^{161}$ Public Law 89-645 (80 Stat. 891) (1966), sec. 3, amended sec. 170 by adding new subsection m. 
a requirement that the licensee have and maintain financial protection under subsection a., or

(F) arises out of, results from, or occurs in the course of nuclear waste activities.

the Commission or the Secretary, as appropriate, may incorporate provisions in indemnity agreements with licensees and contractors under this section, and may require provisions to be incorporated in insurance policies or contracts furnished as proof of financial protection, which waive (i) any issue or defense as to conduct of the claimant or fault of persons indemnified, (ii) any issue or defense as to charitable or governmental immunity, and (iii) any issue or defense based on any statute of limitations if suit is instituted within three years from the date on which the claimant first knew, or reasonable could have know, of his injury or damage and the cause thereof. The waiver of any such issue or defense shall be effective regardless of whether such issue or defense may otherwise be deemed jurisdictional or relating to an element in the cause of action. When so incorporated, such waivers shall be judicially enforceable in accordance with their terms by the claimant against the person indemnified. Such waivers shall not preclude a defense based upon a failure to take reasonable steps to mitigate damages, nor shall such waivers apply to injury or damage to a claimant or to claimants property which is intentionally sustained by the claimant or which results from a nuclear incident intentionally and wrongfully caused by the claimant. The waivers authorized in this subsection shall, as to indemnitors, be effective only with respect to those obligations set forth in the insurance policies or the contracts furnished as proof of financial protection and in the indemnity agreements. Such waivers shall not apply to, or prejudice the prosecution or defense of, any claim or portion of claim which is not within the protection afforded under (i) the terms of insurance policies or contracts furnished as proof of financial protection, or indemnity agreements, and

76 STAT 410 42 USC 2210 .

Courts, U.S. (ii) the limit of liability provisions of subsection $\mathrm{e}$.

(2) With respect to any public liability action arising out of or resulting from a nuclear incident, the United States district court in the district where the nuclear incident takes place, or in the case of a nuclear incident taking place outside the United States, the United States District Court for the District of Columbia, shall have original jurisdiction without regard to the citizenship of any party or the amount in controversy. Upon motion of the defendant or of the Commission or the Secretary, as appropriate, any such action pending in any State court (including any such action pending on the date of the enactment of the Price-Anderson Amendments Act of 1988) or United States district court shall be removed or transferred to the United States district court having venue under this subsection. Process of such district court shall be effective throughout the United States. In any action that is or becomes removable pursuant to his paragraph, a petition for removal shall be filed within the period provided in section 1446 of title 28, United States Code, or within the 30-day period beginning on the date of the enactment of the Price Anderson Amendments Act of 1988, whichever occurs later.

(3) (A) Following any nuclear incident, the chief judge of the United States district court having jurisdiction under paragraph (2) with respect 
Allocation of funds.

to public liability actions (or the judicial council of the judicial circuit in which the nuclear incident occurs) may appoint a special caseload management panel (in this paragraph referred to as the 'management panel') to coordinate and assign (but not necessarily hear themselves) cases arising out of the nuclear incident, if-

(i) a court, acting pursuant to subsection 0 . determines that the aggregate amount of public liability is likely to exceed the amount of primary financial protection available under subsection $b$. (or an equivalant amount in the case of a contractor indemnified under subsection d.); or

(ii) the chief judge of the United States district court (or the judicial council of the judicial circuit) determines that cases arising out of the nuclear incident will have an unusual impact on the work of the court.

(B)(i) Each management panel shall consist only of members who are United States district judges or circuit judges.

(ii) Members of a management panel may include any United States district judge or circuit judge of another district court or court of appeals, if the chief judge of such other district court or court of appeals consents to such assignment.

(C) It shall be the function of each management panel-

(i) to consolidate related or similar claims for hearing or trial;

(ii) to establish priorities for the handling of different classes of cases;

(iii) to assign cases to a particular judge or special master;

(iv) to appoint special masters to hear particular types of cases, or particular elements or procedural steps of cases;

(v) to promulgate special rules of court, not inconsistent with the Federal Rules of Civil Procedure, to expedite cases or allow more equitable consideration of claims;

(vi) to implement such other measures, consistent with existing law and the Federal Rules of Civil Procedure, as will encourage the equitable, prompt, and efficient resolution of cases arising out of the nuclear incident; and

(vii) to assemble and submit to the President such data, available to the court, as may be useful in estimating the aggregate damages from the nuclear incident. 162

o. Plan For Distribution Of Funds.-(1) Whenever the United States district court in the district where a nuclear incident occurs, or the United States District Court for the District of Columbia in case of a nuclear incident occurring outside the United States, determines upon the petition of any indemnitor or other interested person that public liability from a single nuclear incident may exceed the limit of liability under the applicable limit of liability under subparagraph (A), (B), or (C) of subsection e. (1):

${ }^{162}$ Public Law 100-408 (102 Stat. 1066) (1988), sec. 11, added subsection 170 n.3.D, E, F, substantially amended subsection n.2, and added subsec. n.3. The amendments made by sec. 11 apply to nuclear incidents occurring before, on , or after the date of the enactment of Public Law 100-408.

Public Law 89-645 (80 Stat. 891) (1966), sec. 3, amended sec. 170 by adding new subsection $n$
Public Law 94-197 (89 Stat. 1111) (1975), sec. 12, amended subsection 170 n (1)(iii) by substituting the word "twenty" for the word "ten." 
(A) Total payments made by or for all indemnitors as a result of such nuclear incident shall not exceed 15 per centum of such limit of liability without the prior approval of such court;

(B) The court shall not authorize payments in excess of 15 percentum of such limit of liability unless the court determines that such payments are or will be in accordance with a plan of distribution which has been approved by the court of such payments are not likely to prejudice the subsequent adoption and implementation by the court of a plan of distribution pursuant to subparagraph (C); and

(C) The Commission or the Secretary, as appropriated, shall, and any other indemnitor or other interested person may, submit to such district court a plan for the disposition of pending claims and for the distribution of remaining funds available. Such a plan shall include an allocation of appropriate amounts for personal injury claims, property damage claims, and possible latent injury claims which may not be discovered until a later time and shall include establishment of priorities between claimants and classes of claims, as necessary to insure the most equitable allocation of available funds. Such court shall have all power necessary to approve, disapprove, or modify plans proposed, or to adopt another plan; and to determine the proportionate share of funds available for each claimant. The Commission or the Secretary, as appropriate, any other indemnitor, and any person indemnified shall be entitled to such orders as may be appropriate to implement and enforce the provisions of this section, including orders limiting the liability of the persons indemnified, orders approving or modifying the plan, orders staying the payment of claims and the execution of court judgments, orders apportioning the payments to be made to claimants, and orders permitting partial payments to be made before final determination of the total claims. The orders of such court shall be effective throughout the United States.

(D) A court may authorize payment of only such legal costs as are permitted under paragraph (2) from the amount of financial protection required by subsection $b$.

(E) If the sum of public liability claims and legal costs authorized under paragraph (2) arising from any nuclear incident exceeds the maximum amount of financial protection required under subsection b., any licensee required to pay a standard deferred premium under subsection b.(1) shall, in addition to such deferred premium, be charged such an amount as is necessary to pay a pro rata share of such claims and costs, but in no case more than 5 percent of the maximum amount of such standard deferred premium described in such subsection.

(2) A court may authorize the payment of legal costs under paragraph (1) (D) only if the person requesting such payment has-

(A) submitted to the court the amount of such payment requested; and

(B) demonstrated to the court-

(i) that such costs are reasonable and equitable; and

(ii) that such person has- 
(I) litigated in good faith;

(II) avoided unnecessary duplication of effort with that of other parties similarly situated;

(III) not made frivolous claims or defenses; and

(IV) not attempted to unreasonably delay the prompt settlement or adjudication of such claims. ${ }^{163}$

p. Reports To Congress. - (1) The Commission and the Secretary shall submit to the Congress by August 1, 1998, detailed reports concerning the need for continuation or modification of the provisions of this section, taking into account the condition of the nuclear industry, availability of private, insurance, and the state of knowledge concerning nuclear safety at that time, among other relevant factors, and shall include recommendations as to the repeal or modification of any of the provisions of this section.

(2) Not later than April 1 of each year, the Commission and the Secretary shall each submit an annual report to the Congress setting forth the activities under this section during the preceeding calendar year.

q. Limitation On Awarding Of Precautionary Evacuation Costs. - No court may award costs of a precautionary evacuation unless such costs constitute a public liability.

r. Limitation Of Liability Of Lessors. - No person under a bona fide lease of any utilization or production facility (or part thereof or undivided interest therein) shall be liable by reason of an interest as lessor of such production or utilization facility, for any legal liability arising out of or resulting from a nuclear incidents resulting from such facility, unless such facility is in the actual possession and control of such person at the time of the nuclear incident giving rise to such legal liability.,

s. Limitation On Punitive Damages.-No court may award punitive damages in any action with respect to a nuclear incident or precautionary evacuation against a person on behalf of whom the United States is obligated to make payments under an agreement of indemnification covering such incident or evacuation.

t. Inflation Adjustment. - (1) The Commission shall adjust the amount of the maximum standard deferred premium under subsection b.(1) not less than once during each 5-year period following the date of the enactment of the Price-Anderson Amendments Act of 1988 in accordance with the aggregate percentage change in the Consumer Price Index since-

(A) such date of enactment, in the case of the first adjustment under this subsection; or

(B) the previous adjustment under this subsection.

(2) For purposes of this subsection, the term "Consumer Price Index" means the Consumer Price Index for all urban consumers published by the Secretary of Labor. ${ }^{164}$

${ }^{163}$ Public Law 100-408 (102 Stat. 1066) (1988), added 170 subsection 0.1.D and E and subsection 0.2 Public Law 89-645 (80 Stat. 891) (1966), sec. 3, amended sec. 170 by adding new subsection 0 .

Public Law 94-197 ( 89 Stat. 1111) (1975), sec. 13, amended subsection $170 \mathrm{o}$. by adding new subparagraph (4) and by adding the following language to the second sentence of subparagraph (3): "and shallichudeestablishment of pribet claimants and classes of chaims, as necessary to insurethe most equitableallocation of available funds."

${ }^{164}$ Public Law 100-408 (102 Stat. 1066) (1988), amended 170 subsection p and added subsections q-t.

Public Law 94-197 (89 Stat. 1111) (1975), sec. 14, added a new subsection 170 p. 
Conflict of interest. 42 USC sec. 2210 a.

Publication.

Report to Congress and President. 42 USC $2210 \mathrm{~b}$.

42 USC 2231.
"Sec. 170A. Conflicts Of Interest Relating To Contracts And Other Arrangements.-

"a. The Commission shall, by rule, require any person proposing to enter into a contract, agreement, or other arrangement, whether by competitive bid or negotiation, under this Act or any other law administered by it for the conduct of research, development, evaluation activities, or for technical and management support services, to provide the Commission, prior to entering into any such contract, agreement, or arrangement, with all relevant information, as determined by the Commission, bearing on whether that person has a possible conflict of interest with respect to-

(1) being able to render impartial, technically sound, or objective assistance or advice in light of other activities or relationships with other persons, or

(2) being given an unfair competitive advantage. Such person shall insure, in accordance with regulations prescribed by the Commission, compliance with this section by any subcontractor (other than a supply subcontractor) or such person in the case of any subcontract for more than $\$ 10,000$.

"b. The Commission shall not enter into any such contract agreement or arrangement unless it finds, after evaluating all information provided under subsection a. and any other information otherwise available to the Commission that-

(1) it is unlikely that a conflict of interest would exist, or

(2) such conflict has been avoided after appropriate conditions have been included in such contract, agreement, or arrangement; except that if the Commission determines that such conflict of interest exists and that such conflict of interest cannot be avoided by including appropriate conditions therein, the Commission may enter into such contract, agreement, or arrangement, if the Commission determines that it is in the best interests of the United States to do so and includes appropriate conditions in such contract, agreement, or arrangement to mitigate such conflict.

"c. The Commission shall publish rules for the implementation of this section, in accordance with section 553 of Title 5, United States Code (without regard to subsection (a)(2) thereof) as soon as practicable after the date of the enactment of this section, but in no event later than 120 days after such date. ${ }^{165}$

"Sec. 170B. Uranium Supply.-

"a. The Secretary of Energy shall monitor and for the years 1983 to 1992 report annually to the Congress and to the President a determination of the viability of the domestic uranium mining and milling industry and shall establish by rule, after public notice and in accordance with the requirements of section 181 of this Act, within 9 months of enactment of this section, specific criteria which shall be assessed in the annual reports on the domestic uranium

${ }^{165}$ Public Law 95-601 (92 Stat. 2950) (1978), Sec. 8(a) added to a new Sec. 170A. 
Regulations.

Proprietary information, disclosure.

Criteria.

Imported material, impact on domestic industry and national security. industry's viability. The Secretary of Energy is authorized to issue regulations providing for the collection of such information as the Secretary of Energy deems necessary to carry out the monitoring and reporting requirements of this section.

"b. Upon a satisfactory showing to the Secretary of Energy by any person that any information, or portion thereof obtained under this section, would, if made public, divulge proprietary information of such person, the Secretary shall not disclose such information and disclosure thereof shall be punishable under section 1905 of title 18, United States Code.

"c. The criteria referred to in subsection a. shall also include, but not be limited to-

"(1) an assessment of whether executed contracts or options for source material or special nuclear material will result in greater than $371 / 2$ percent of actual or projected domestic uranium requirements for any two-consecutive-year period being supplied by source material or special nuclear material from foreign sources;

"(2) projections of uranium requirements and inventories of domestic utilities for a 10 year period;

"(3) present and probable future use of the domestic market by foreign imports;

"(4) whether domestic economic reserves can supply all future needs for a future 10 year period;

"(5) present and projected domestic uranium exploration expenditures and plans;

"(6) present and projected employment and capital investment in the uranium industry;

"(7) the level of domestic uranium production capacity sufficient to meet projected domestic nuclear power needs for a 10 year period; and

"(8) a projection of domestic uranium production and uranium price levels which will be in effect under various assumptions with respect to imports.

"d. The Secretary or Energy, at any time, may determine on the basis of the monitoring and annual reports required under this section that source material or special nuclear material from foreign sources is being imported in such increased quantities as to be a substantial cause of serious injury, or threat thereof, to the United States uranium mining and milling industry. Based on that determination, the United States Trade Representative shall request that the United States International Trade Commission initiate an investigation under section 201 of the Trade Act of 1974 (19 U.S.C. 2251).

"e. (1) If, during the period 1982 to 1992, the Secretary of Energy determines that executed contracts or options for source material or special nuclear material from foreign sources for use in utilization facilities within or under the jurisdiction of the United States represent greater than $371 / 2$ percent of actual or projected domestic uranium requirements for any two-consecutive-year period, or if the Secretary of Energy determines the level of contracts or 
Investigations.

options involving source material and special nuclear material from foreign sources may threaten to impair the national security, the Secretary of Energy shall request the Secretary of Commerce to initiate under section 232 of the Trade Expansion Act of 1962(19 U.S.C. 1862) an investigation to determine the effects on the national security of imports of source material and special nuclear material. The Secretary of Energy shall cooperate fully with the Secretary of Commerce in carrying out such an investigation and shall make available to the Secretary of Commerce the findings that lead to this request and such other information that will assist the Secretary of Commerce in the conduct of the investigation.

"(2) The Secretary of Commerce shall, in the conduct of any investigation requested by the Secretary of Energy pursuant to this section, take into account any information made available by the Secretary of Energy, including information regarding the impact on national security of projected or executed contracts or options for source material or special nuclear material from foreign sources or whether domestic production capacity is sufficient to supply projected national security requirements.

"(3) No sooner than 3 years following completion of any investigation by the Secretary of Commerce under paragraph (1), if no recommendation has been made pursuant to such study for trade adjustments to assist or protect domestic uranium production, the Secretary of Energy may initiate a request for another such investigation by the Secretary of Commerce." $165^{2}$

\section{"CHAPTER 15-COMPENSATION FOR PRIVATE PROPERTY ACQUIRED}

Just

compensation.

42 USC sec. 2221

62 STAT. 933.

Condemnation

of real property.

42 USC sec. 2222 ,

62 STAT. 937,

"Sec. 171. Just Compensation.-The United States shall make just compensation for any property or interests therein taken or requisitioned pursuant to sections $43,16655,16766$, and 108. Except in case of real property or any interest therein, the Commission shall determine and pay such just compensation. If the compensation so determined is unsatisfactory to the person entitled thereto, such person shall be paid 75 per centum of the amount so determined, and shall be entitled to sue the United States Court of Federal Claims, ${ }^{*}$ or in any district court of the United States for the district in which such claimant is a resident in the manner provided by section 1346 of Title 28 of the United States Code to recover such further sum as added to said 75 per centum will constitute just compensation.

"Sec. 172. Condemnation of Real Property.-Proceedings for condemnation shall be instituted pursuant to the provisions of the Act approved August 1, 1888, as amended and section 1403 of Title 28 of the United States Code. The Act approved February 26, 1931, as amended,

165 P.L. 97-415, sec. 23(b)(1), amended Chapter 14 to inclioude a new sec. 170B.

${ }^{166}$ Public Law 88-489 (78 Stat. 602)(1964), sec. 17 deleted the phrase " 52 (with respect to the material for which the United States is required to pay just compensation)," after "43."

${ }^{167}$ Public Law 88-489 (78 Stat. 602)(1964), sec. 17 added "55."

-Public Law 102-572 (105 Stat. 4516), \$902(b)(1) states: "Reference to 'United States Claims Court' shall be deemed to refer to the 'United States Court of Federal Claims." 
986; 46 STAT. 1421.

40 USC 257 , $258 \mathrm{a}-258 \mathrm{e}$.

Patent application disclosures. 42 USC. sec. 2223.

62 STAT. 933. Attorney General approval of title. 42 USC sec. 2224.

40 USC 255

General.

80 STAT. $382-$

388, 5 USC

551-559

42 USC

sec. 2231

License applications 42 USC shall be applicable to any such proceedings.

"Sec. 173. Patent Application Disclosures.-In the event that the Commission communicates to any nation any Restricted Data based on any patent application not belonging to the United States, just compensation shall be paid by the United States to the owner of the patent application. The Commission shall determine such compensation. If the compensation so determined is unsatisfactory to the person entitled thereto, such person shall be paid 75 per centum of the amount so determined, and shall be entitled to sue the United States Court of Federal Claims* or in any district court of the United States for the district in which such claimant is a resident in a manner provided by section 1346 of Title 28 of the United States Code to recover such further sum asadded to such 75 per centum will constitute just compensation.

"Sec. 174. Attorney General Approval of Title.-All real property acquired under this Act shall be subject to the provisions of section 355 of the Revised Statutes, as amended: Provided, however, That real property acquired by purchase or donation, or other means of transfer may also be occupied, used, and improved for the purposes of this Act prior to approval of title by the Attorney General in those cases where the President determines that such action is required in the interest of the common defense and security.

\section{"CHAIPTER 16-JUDICIAL REVIEW AND} ADMINISTRATIVE PROCEDURE

"Sec. 181. General.-The provisions of the Administrative Procedure Act (Public Law 404, Seventy-ninth Congress, approved June 11, 1946) shall apply to all agency action taken under this Act, and the terms 'agency' and 'agency action' shall have the meaning specified in the Administrative Procedure Act: Provided, however, That in the case of agency proceedings or actions which involve Restricted Data, defense information, safeguards information protected from disclosure under the authority of section 147168 or information protected from dissemination under authority of section $148^{169}$ the Commission shall provide by regulation for such parallel procedures as will effectively safeguard and prevent disclosure of Restricted Data, defense information, or such safeguards information 170 to unauthorized persons with minimum impairment of the procedural rights which would be available if Restricted Data, defense information, or such safeguards information, ${ }^{170}$ were not involved.

"Sec. 182. License Applications.-

"a. Each application for a license hereunder shall be in writing and shall specifically state such information as the Commission, by

-Public Law 102-572 (106 Stat. 4516), § 902(0)(1) states: "Reference to 'United States Claims Court' shall be deemed to refer to the "United States Court of Federal Claims."'

${ }^{169}$ Public Law 97-90 (95 Slat. 1163)(1981) sec. 210(b) amended sec. 181 (42 U.S.C. 2231) as follows:

(1) by striking out "or" before "safeguards information protected",

(2) by inserting "or information protected from dissemination under the authority of section 148 " after "section 147"; and

(3) by striking out ", defense information, or such safeguards inforamtion, " eachplace it appears and inserting in lieu thereof ", defense information, such safeguards information, or information protected from dissemination under the authority of section 148 ." $^{n}$

170 Public Law96-295 (94 Stat. 789)(1980) sec. 207(b)(2), deleted the words ", or defense information" and substituted the words ", defense information, or such safeguards information.". 
$\sec .2232$

ACRS Report.

Commercial power.

rule or regulation, may determine to be necessary to decide such of the technical and financial qualifications of the applicant, the character of the applicant, the citizenship of the applicant, or any other qualifications of the applicant as the Commission may deem appropriate for the license. In connection with applications for licenses to operate production or utilization facilities, the applicant shall state such technical specifications, including information of the amount, kind, and source of special nuclear material required, the place of the use, the specific characteristics of the facility, and such other information as the Commission may, by rule or regulation, deem necessary in order to enable it to find that the utilization or production of special nuclear material will be in accord with the common defense and security and will provide adequate protection to the health and safety of the public. Such technical specifications shall be a part of any license issued. The Commission may at any time after the filing of the original application, and before the expiration of the license, require further written statements in order to enable the Commission to determine whether the application should be granted or denied or whether a license should be modified or revoked. All applications and statements shall be signed by the applicant or licensee. Applications for, and statements made in connection with, licenses under sections 103 and 104 shall be made under oath or affirmation. The Commission may require any other applications or statements to be made under oath or affirmation. 171

"b. The Advisory Committee on Reactor Safeguards shall review each application under section 103 or section 104 b. for a construction permit or an operating license for a facility, any application under section $104 \mathrm{c}$. for a construction permit or an operating license for a testing facility, any application under section $104 \mathrm{a}$. or c. specifically referred to it by the Commission, and any application for an amendment to a construction permit or ar amendment to an operating license under section 103 or 104 a., b., or c. specifically referred to it by the Commission, and shall submit a report thereon which shall be made part of the record of the application and available to the public except to the extent that security classification prevents disclosure 172

"c. The Commission shall not issue any license under section 103 for a utilization or production facility for the generation of commercial power until it has given notice in writing to such regulatory agency as may have jurisdiction over the rates and services incident to the proposed activity; until it has published notice of the application in such trade or news publications as the Commission deems

\footnotetext{
171 Public Law 84-1006 (70 Stat. 1069), sec. 5, amended the third from last sentence of subsec. 182a. and added the present last two sentences. Beforeamendment the third from last sentence read: "All applications and statements shall be signed by the applicant or licensee under oath or affirmation."

${ }^{172}$ Public Law 85-256 (71 Stat. 576) (1957), sec. 6, added subsec. b. and relettered former subsecs. b. and $c$. as subsecs, c. and d. Public Law 87-615 (76 Stat. 409)(1962), sec. 3, amended subsec. b. Before amendment, it read: "b. The Advisory Committee on Reactor Safeguards shall review each application under section 103 or 104 b. for a license for a facility, any application under section $104 \mathrm{c}$. for a testing facility, any application under section $104 \mathrm{a}$. or c. specifically referred to it by the Commission, and shall submit a report thereon, which shall be madepart of the record of the application and available to the public, except to the extent that security classification prevents disclosure."
} 
Terms of licenses. 42 USC sec. 2233.

Inalienability of licenses. 42 USC sec. 2234 .

appropriate to give reasonable notice to municipalities, private utilities, public bodies, and cooperatives which might have a potential interest in such utilization or production facility; and until it has published notice of such application once each week for four consecutive weeks in the Federal Register, and until four weeks after the last notice. 173

"d. The Commission, in issuing any license for a utilization or production facility for the generation of commercial power under section 103, shall give preferred consideration to applications for such facilities which will be located in high cost power areas in the United States if there are conflicting applications for a limited opportunity for such license. Where such conflicting applications resulting from limited opportunity for such license include those submitted by public or cooperative bodies such applications shall be given preferred consideration.

"Sec. 183. Terms of Licenses. - Each license shall be in such form and contain such terms and conditions as the Commission may, by rule or regulation, prescribe to effectuate the provisions of this Act, including the following provisions:

"b. ${ }^{174}$ No right to the special nuclear material shall be conferred by the license except as defined by the license.

"c. Neither the license nor any right under the license shall be assigned or otherwise transferred in violation of the provisions of this Act.

"d. Every license issued under this Act shall be subject to the right of recapture or control reserved by section 108 , and to all of the other provisions of this Act, now or hereafter in effect and to all valid rules and regulations of the Commission.

"Sec. 184. Inalienability of Licenses. - No license granted hereunder and no right to utilize or produce special nuclear material granted hereby shall be transferred, assigned or in any manner disposed of, either voluntarily or involuntarily, directly or indirectly, through transfer of control of any license to any person, unless the Commission shall, after securing full information, find that the transfer is in accordance with the provisions of this Act, and shall give its consent in writing. The Commission may give such consent to the creation of a mortgage, pledge, or other lien upon any facility or special nuclear material, 175 owned or thereafter acquired by a licensee, or upon any leasehold or other interest in such facility, ${ }^{176}$ and the rights of the creditors so secured may thereafter be enforced by any court subject to rules and regulations established by the Commission to protect public health and safety and promote the common defense and security.

\footnotetext{
${ }^{173}$ Public Law 91-560 (84 Stat. 1472)(1970), sec. 9, amended subsec. $182 \mathrm{c}$. Before amendment it read as follows: "c. the Commission shall not issue any license for a utilization or production facility for the generation of commercial power under section 103, until it has given notice in writing to stch regulatory agency as may have jurisdiction over the rates and services of the proposed activity, to municipalities, private utilities, public bodies, and cooperatives within transmission distance authorized to engage in the distribution of electric energy and until it has published notice of such application once each week for four consecutive weeks in the Federal Register, and until four weeks after the last notice."

${ }^{174}$ Public Law 88-489 (78 Stat. 602)(1964), sec. 18, deleted subsec. 183a. Subsec. a. read as follows:

“a. Title to all special nuclear material utilized or produced by facilities pursuant to the license, shall at all times be in the United States."

175 Public Law 88-489 (78 Stat. 602)(1964), sec. 19, added "or special muclear material."

${ }^{176}$ Public Law 88-489 (78 Stat. 602)(1964), sec. 19, substituted the word "facility" for the word "property".
} 
Construction

permits

42 USC

sec. 2235.

Revocation. 42 USC sec. 2236 .
"Sec. 185. Construction Permits and Operating Licenses.-

"a. All applicants for licenses to construct or modify production or utilization facilities shall, if the application is otherwise acceptable to the Commission, be initially granted a construction permit. The construction permit shall state the earliest and latest dates for the completion of the construction or modification. Unless the construction or modification of the facility is completed by the completion date, the construction permit shall expire, and all rights thereunder be forfeited, unless upon good cause shown, the Commission extends the completion date. Upon the completion of the construction or modification of the facility, upon the filing of any additional information needed to bring the original application up to date, and upon finding that the facility authorized has been constructed and will operate in conformity with the application as amended and in conformity with the provisions of this Act and of the rules and regulations of the Commission, and in the absence of any good cause being shown to the Commission why the granting of a license would not be in accordance with the provisions of this Act, the Commission shall thereupon issue a license to the applicant. For all other purposes of this Act, a construction permit is deemed to be a 'license'.

"b. After holding a public hearing under section 189 a. (1)(A), the Commission shall issue to the applicant a combined construction and operating license if the application contains sufficient information to support the issuance of a combined license and the Commission determines that there is reasonable assurance that the facility will be constructed and will operate in conformity with the license, the provisions of this Act, and the Commission's rules and regulations. The Commission shall identify within the combined license the inspections, tests, and analyses, including those applicable to emergency planning, that the licensee shall perform, and the acceptance criteria that, if met, are necessary and sufficient to provide reasonable assurance that the facility has been constructed and will be operated in conformity with the license, the provisions of this Act, and the Commission's rules and regulations. Following issuance of the combined license, the Commission shall ensure that the prescribed inspections, tests, and analyses are performed and, prior to operation of the facility, shall find that the prescribed acceptance criteria are met. Any finding made under this subsection shall not require a hearing except as provided in section 189 a. (1)(B)."176a and NOTE.

"Sec. 186. Revocation.-

“a. Any license may be revoked for any material false statement in the application or any statement of fact required under section 182 , or because of conditions revealed by such application or statement of fact or any report, record, or inspection or other means which would warrant the Commission to refuse to grant a

178a PublicLaw 102-486(106 Stat. 3120), Oct. 24, 1992 added new headirg and (a) to Sec. 185 and new (b) at end of Sect. 185 (a).

NOTE: Sections $185 \mathrm{~b}$ and $189 \mathrm{a}$ (1)(b) of the Atomic Energy Act of 1954, as added by sections 2801 and 2802 of this Act, shall apply to all proceedings imvolving a combined license for which an application was flled after May 8, 1991, under such sections. 
80 STAT. 388, 5 USC 558(b).

5 USC 551.

Modification

of license.

42 USC sec. 2237.

Continued operation of facilities.

42 USC sec. 2238.

Hearings and judicial review. 42 USC sec. 2239.

Federal

Register.

Publication license on an original application, or for failure to construct or operate a facility in accordance with the terms of the construction permit or license or the technical specifications in the application, or for violation of, or failure to observe any of the terms and provisions of this Act or of any regulation of the Commission.

"b. The Commission shall follow the provisions of section 9(b) of the Administrative Procedure Act in revoking any license.

"c. Upon revocation of the license, the Commission may immediately retake possession of all special nuclear material held by the licensee. In cases found by the Commission to be of extreme importance to the national defense and security or to the health and safety of the public, the Commission may recapture any special nuclear material held by the licensee or may enter upon and operate the facility prior to any of the procedures provided under the Administrative Procedures Act. Just compensation shall be paid for the use of the facility.

"Sec. 187. Modification of License.-The terms and conditions of all licenses shall be subject to amendment, revision, or modification, by reason of amendments of this Act, or by reason of rules and regulations issued in accordance with the terms of this Act.

"Sec. 188. Continued Operation of Facilities.-Whenever the Commission finds that the public convenience and necessity or the production program of the Commission requires continued operation of a production facility or utilization facility the license for which has been revoked pursuant to section 186 , the Commission may, after consultation with the appropriate regulatory agency, State or Federal, having jurisdiction, order that possession be taken of and such facility be operated for such period of time as the public convenience and necessity or the production program of the Commission may, in the judgment of the Commission, require, or until a license for the operation of the facility shall become effective. Just compensation shall be paid for the use of the facility.

"Sec. 189. Hearings and Judicial Review.-

"a. (1)(A) In any proceeding under this Act, for the granting, suspending, revoking, or amending of any license or construction permit, or application to transfer control, and in any proceeding for the issuance or modification of rules and regulations dealing with the activities of licensees, and in any proceeding for the payment of compensation, an award, or royalties under sections 153, 157, 186 c., or 188, the Commission shall grant a hearing upon the request of any person whose interest may be affected by the proceeding, and shall admit any such person as a party to such proceeding. The Commission shall hold a hearing after thirty days' notice and publication once in the Federal Register, on each application under section 103 or $104 \mathrm{~b}$. for a construction permit for a facility, and on any application under section $104 \mathrm{c}$. for a construction permit for a testing facility. In cases where such a construction permit has been issued following the holding of such a hearing, the Commission may, in the absence of a request therefor by any person whose interest may be affected, issue an operating license or an amendment to a construction permit or an amendment to an operating license 
without a hearing, but upon thirty days' notice and publication once in the Federal Register of its intent to do so. The Commission may dispense with such thirty days' notice and publication with respect to any application for an amendment to a construction permit or an amendment to an operating license upon a determination by the Commission that the amendment involves no significant hazards consideration. $177+177 \mathrm{a}$;

"(B)(i) Not less than 180 days before the date schedules for initial loading of fuel into a plant by a licensee that has been issued a combined construction permit and operating license under section $185 \mathrm{~b}$., the Commission shall publish in the Federal Register notice of intended operation. That notice shall provide that any person whose interest may be affected by operation of the plant, may within 60 days request the Commission to hold a hearing on whether the facility as constructed complies, or on completion will comply, with the acceptance criteria of the license.

"(ii) A request for hearing under clause (i) shall show, prima facie, that one or more of the acceptance criteria in the combined license have not been, or will not be met, and the specific operational consequences of nonconformance that would be contrary to providing reasonable assurance of adequate protection of the public health and safety.

"(iii) After receiving a request for a hearing under clause (i), the Commission expeditiously shall either deny or grant the request. If the request is granted, the Commission shall determine, after considering petitioners' prima facie showing and any answers thereto, whether during a period of interim operation, there will be reasonable assurance of adequate protection of the public health and safety. If the Commission determines that there is such reasonable assurance, it shall allow operation during an interim period under the combined license.

"(iv) The Commission, in its discretion, shall determine appropriate hearing procedures, whether informal or formal adjudicatory, for any hearing under clause (i), and shall state its reasons therefor.

"(v) The Commission shall, to the maximum possible extent, render a decision on issues raised by the hearing request within 180 days of the publication of the notice

\footnotetext{
177 Public Law 87-615 (76 Stat. 409)(1962), sec. 2, amended this section. Before amendment it read: "SEC. 189. HEARINGS AND JUDICIAL REVIEW.-

"a. In any proceeding under this Act, for the granting, suspending, revoking, or amending of any license or construction permit, or application to transfer control, and in any proceeding for the issuance or modification of construction permit, or application to transfer control, and in any proceeding for the issuance or modification of
rules and regulations dealing with the activities of licensees, and in any proceeding for the payment of compensation, an award or rayalties under sections 153,157, $186 \mathrm{c}$, or 188, the Commission shall grant a hearing upon the request of any person whose interest may be affected by the proceeding, and shall admit any such person as a party o such proceeding. The Commission shall hold a hearing after thirty days notice and publication once in the Fedcral Register on each application under section 103 or

Public Law 85-256 (71 Stat. 576)(1957), sec. 7, had previously amended sec. 189a. by adding the last sentence

thereof.
177apublic subsection (B)(i).
} 
Notice publication.

Regulations establishing staandards, criteria, and procedures.

5 USC 701706, 28 USC provided by clause (i) or the anticipated date for initial loading of fuel into the reactor, whichever is later. Commencement of operation under a combined license is not subject to subparagraph (A).".177b

"(2)(A) The Commission may issue and make immediately effective any amendment to an operating license or any amendment to a combined construction and operating license, upon a determination by the Commission that such amendment involves no significant hazards consideration, notwithstanding the pendency before the Commission of a request for a hearing from any person. Such amendment may be issued and made immediately effective in advance of the holding and completion of any required hearing. In determining under this section whether such amendment involves no significant hazards consideration, the Commission shall consult with the State in which the facility involved is located. In all other respects such amendment shall meet the requirements of this Act.

“(B) The Commission shall periodically (but not less frequently than once every thirty days) publish notice of any amendments issued, or proposed to be issued, as provided in subparagraph (A). Each such notice shall include all amendments issued, or proposed to be issued, since the date of publication of the last such periodic notice. Such notice shall, with respect to each amendment or proposed amendment (i) identify the facility involved; and (ii) provide a brief description of such amendment. Nothing in this subsection shall be construed to delay the effective date of any amendment.

"(C) The Commission shall, during the ninety-day period following the effective date of this paragraph, promulgate regulations establishing (i) standards for determining whether any amendment to an operating license involves no significant hazards consideration; (ii) criteria for providing or, in emergency situations, dispensing with prior notice and reasonable opportunity for public comment on any such determination, which criteria shall take into account the exigency of the need for the amendment involved; and (iii) procedures for consultation on any such determination with the State in which the facility involved is located."178

"b. Any final order entered in any proceeding of the kind specified in subsection a. above or any final order allowing or prohibiting a facility to begin operating under a combined construction and operating license shall be subject to judicial review in the manner prescribed in the Act of December 29, 1950, as amended (ch. 1189, 64 Stat. 1129),

$177 \mathrm{~b}$ Public Law 102-486 (106 Stat. 3121), Oct. 24, 1992 amends Sec. 189a(2) of the Atomic Energy Act of 1954 (42 U.S.C. 2239 (a)(2)) is amended by inserting "or any amendment to a combined constructionand operating license" after "any amendment to an operating license" each time it occurs.

- Note: Sections 185b. and 189a.(1)(b) of the Atomic Energy Act of 1954, as added by sections 2801 and 2802 of this Act, shall apply to all procedings involving a combined license for which an application was filed after May 8 , 1991, under such sections.

${ }^{178}$ Public Law 97-415 (96 Stat. 2067)(1983), sec. 12 amended sec. 189 by inserting (1) after subsec. (a)designation and by adding at end thereof new paragraph (2)(A)(B)(C). 
42 USC sec. 2240 .

"Sec. 190. Licensee Incident Reports. - No report by any licensee of any incident arising out of or in connection with a licensed activity made pursuant to any requirement of the Commission shall be admitted as evidence in any suit or action for damages growing out of any matter mentioned in such report. ${ }^{179}$

Atomic Safety and Licensing

Board 80 STAT. 386, 387,5 USC

$556,557$.

42 USC

sec. 2241

Temporary licensing authority. 42 USC sec. 2242 .

42 USC 2133, 2134.

Post. p. 2073.

"Sec. 191. Atomic Safety and Licensing Board.-

"a. Notwithstanding the provisions of sections 7(a) and 8(a) of the Administrative Procedure Act, the Commission is authorized to establish one or more atomic safety and licensing boards, each comprised of three members, one of whom shall be qualified in the conduct of administrative proceedings and two of whom shall have such technical or other qualifications as the Commission deems appropriate to the issues to be decided, to conduct such hearings as the Commission may direct and make such intermediate or final decisions as the Commission may authorize with respect to the granting, suspending, revoking or amending of any license or authorization under the provisions of this Act, any other provision of law, or any regulation of the Commission issued thereunder. ${ }^{180}$ The Commission may delegate to a board such other regulatory functions as the Commission deems appropriate. The Commission may appoint a panel of qualified persons from which board members may be selected.

"b. Board members may be appointed by the Commission from private life, or designated from the staff of the Commission or other Federal agency. Board members appointed from private life shall receive a per diem compensation for each day spent in meetings or conferences, and all members shall receive their necessary traveling or other expenses while engaged in the work of a board. The provisions of section 163 shall be applicable to board members appointed from private life. ${ }^{181}$

"Sec. 192. Temporary Operating License.-

"a. In any proceeding upon an application for an operating license for a utilization facility required to be licensed under section 103 or $104 \mathrm{~b}$. of this Act, in which a hearing is otherwise required pursuant to section $189 \mathrm{a}$, the applicant may petition the Commission for a temporary operating license for such facility authorizing fuel loading, testing, and operation at a specific power level to be determined by the Commission, pending final action by the Commission on the application. The initial petition for a temporary operating license for each such facility, and any temporary

\footnotetext{
${ }^{179}$ Sec. 190 was added by Public Law 87-206 (75 Stat. 475)(1961), sec. 16.

${ }^{100}$ Public Law 91.560 (84 Stat. 1472)(1970), sec. 10, amended the first sentence of subsec. $191 \mathrm{a}$. Before amend-

ment it read as follows:
"Notwithstanding the provisions of sections 7(a) and $8(a)$ of the Administrative Procedure Act, the Commission is authorized to establish one or more atomic safety and licensing boards, cach composed of three members, two of whom shall be technically qualified and one of whom shall be qualfied in the conduct of administrative proceedings, to conduct such hearings as the Commission may direct and make such intermediate or final decisions as the Commission may authorize with respect to the granting, suspending, revoking or amending of any license or authorization under the provisions of this Act, amy of her provision of law, or any regulation of the Commission issued hereunder."

${ }^{181}$ Sec. 191 was added by Public Law 87-615 (76 Stat. 409) (1962), sec. 1.
} 
Initial petition.

Affidavits.

Publication in Federal Register. operating license issued for such facility based upon the initial petition, shall be limited to power levels not to exceed 5 percent of rated full thermal power. Following issuance by the Commission of the temporary operating license for each such facility, the licensee may file petitions with the Commission to amend the license to allow facility operation in staged increases at specific power levels, to be determined by the Commission, exceeding 5 percent of rated full thermal power. The initial petition for a temporary operating license for each such facility may be filed at any time after the filing of: (1) the report of the Advisory Committee on Reactor Safeguards required by section $182 \mathrm{~b} . ;$ (2) the filing of the initial Safety Evaluation Report by the Nuclear Regulatory Commission staff and the Nuclear Regulatory Commission staff's first supplement to the report prepared in response to the report of the Advisory Committee on Reactor Safeguards for the facility; (3) the Nuclear Regulatory Commission staff's final detailed statement on the environmental impact of the facility prepared pursuant to section 102(2)(C) of the National Environmental Policy Act of 1969 (42 U.S.C. 4332(2)(C)); and (4) a State, local, or utility emergency preparedness plan for the facility. Petitions for the issuance of a temporary operating license, or for an amendment to such a license allowing operation at a specific power level greater than that authorized in the initial temporary operating license, shall be accompanied by an affidavit or affidavits setting forth the specific fact upon which the petitioner relies to justify issuance of the temporary operating license or the amendment thereto. The Commission shall publish notice of each such petition in the Federal Register and in such trade or news publications as the Commission deems appropriate to give reasonable notice to persons who might have a potential interest in the grant of such temporary operating license or amendment thereto. Any person may file affidavits or statements in support of, or in opposition to, the petition within thirty days after the publication of such notice in the Federal Register.

"b. With respect to any petition filed pursuant to subsection a. of this section, the Commission may issue a temporary operating license, or amend the license to authorize temporary operation at each specific power level greater than that authorized in the initial temporary operating license, as determined by the Commission, upon finding that-

"(1) in all respects other than the conduct or completion of any required hearing, the requirements of law are met;

"(2) in accordance with such requirements, there is reasonable assurance that operation of the facility during the period of the temporary operating license in accordance with its terms and conditions will provide adequate protection to the public health and safety and the environment during the period of temporary operation; and

"(3) denial of such temporary operating license will result in delay between the date on which construction of the facility is sufficiently completed, in the judgment of the Commission, to permit issuance of the temporary operating license, and the 
Final order, transmittal to congressional committees.

Judicial review.

28 USC 2341

et seq.

Post, p. 2073.

Hearing.

Infra.

date when such facility would otherwise receive a final operating license pursuant to this Act.

The temporary operating license shall become effective upon issuance and shall contain such terms and conditions as the Commission may deem necessary, including the duration of the license and any provision for the extension thereof. Any final order authorizing the issuance or amendment of any temporary operating license pursuant to this section shall recite with specificity the facts and reasons justifying the findings under this subsection, and shall be transmitted upon such issuance to the Committee on Interior and Insular Affairs and Energy and Commerce of the House of Representatives and the Committee on Environment and Public Works of the Senate. The final order of the Commission with respect to the issuance or amendment of a temporary operating license shall be subject to judicial review pursuant to chapter 158 of title 28 , United States Code. The requirements of section $189 \mathrm{a}$. of this Act with respect to the issuance or amendment of facility licenses shall not apply to the issuance or amendment of a temporary operating license under this section.

"c. Any hearing on the application for the final operating license for a facility required pursuant to section 189 a. shall be concluded as promptly as practicable. The Commission shall suspend the temporary operating license if it finds that the applicant is not prosecuting the application for the final operating license with due diligence. Issuance of a temporary operating license under subsection b. of this section shall be without prejudice to the right of any party to raise any issue in a hearing required pursuant to section $189 \mathrm{a}$.; and failure to assert any ground for denial or limitation of a temporary operating license shall not bar the assertion of such ground in connection with the issuance of a subsequent final operating license. Any party to a hearing required pursuant to section $189 \mathrm{a}$. on the final operating license for a facility for which a temporary operating license has been issued under subsection b., and any member of the Atomic Safety and Licensing Board conducting such hearing, shall promptly notify the Commission of any information indicating that the terms and conditions of the temporary operating license are not being met, or that such terms and conditions are not sufficient to comply with the provisions of paragraph (2) of subsection b.

"d. The Commission is authorized and directed to adopt such administrative remedies as the Commission deems appropriate to minimize the need for issuance of temporary operating licenses pursuant to this section. 
Expriation date.

42 USC 2243

Federal

Register, publication. Nuclear materials. "e. The authority to issue new temporary operating licenses under this section shall expire on December 31, 1983."182

"Sec. 193. Licensing of Uranium Enrichment Facilities.

"(a) Environmental Impact Statement.-

"(1) Major Federal Action. - The issuance of a license under sections 53 and 63 for the construction and operation of any uranium enrichment facility shall be considered a major Federal action significantly affecting the quality of the human environment for purposes of the National Environmental Policy Act of 1969 (42 U.S.C. 4321 et seq.).

"(2) Timing.-An environmental impact statement prepared under paragraph (1) shall be prepared before the hearing on the issuance of a license for the construction and operation of a uranium enrichment facility is completed.

"(b) Adjudicatory Hearing.-

"(1) In General. - The Commission shall conduct a single adjudicatory hearing on the record with regard to the licensing of the construction and operation of a uranium enrichment facility under sections 53 and 63 .

"(2) Timing. - Such hearing shall be completed and a decision issued before the issuance of a license for such construction and operation.

"(3) Single Proceeding.-No further Commission licensing action shall be required to authorize operation.

"(c) Inspection and Operation.-Prior to commencement of operation of a uranium enrichment facility licensed hereunder, the Commission shall verify through inspection that the facility has been constructed in accordance with the requirements of the license for construction and operation. The Commission shall publish notice of the inspection results in the Federal Register.

"(d) Insurance and Decommissioning.-

"(1) The Commission shall require, as a condition of the issuance of a license under sections 53 and 63 for a uranium enrich-

$102 \mathrm{Sec} .192$ was added by Public Law 92-307 (86 Stat. 191)(1972) and amended by Public Law 97-415 (96 Stat. 2067 (1983) prior to which sec. 192 read as follows:

"Sec. 192 Temporary Operating Licenses. -

a. In an proceeding upon an application for an operating license for a nuclear power reactor, in which a hearing is otherwise required pursuant to section 189 a., the applicant may petition the Commission fora temporary operating license authorizing operation of the facility pending final action by the Commission on the application. Such petition may be filed at any time after filing of: (1) the report of the Advisory Committee on Reactor Safeguards required by subsection $182 \mathrm{~b}$.; (2) the safety evaluation of the application by the Commission's regulatory staff; and (3) the regulatory staff's final detailed statement on the environmental impact of the facility prepared pursuant to section 102 (2) (C) of the National Environmental Policy Act of 1969 (83 Stat. 853) or, in the case of an application for operating license filed on or before September 9,1971 , if the regulatory staff's final detailed statement required under section 102(2)(C) is not completed, the Commission must satisfy the applicable requirements of the National Environmental Policy Act prior to issuing any temporary operating license under this section 192. The petition shall be accompanied by an affidavit or affidavits setting forth the facts upon which the petitioner relies to justify issuance of the temporary operating license. Any party to the proceeding may file affidavits in support of, or opposition to, the petition within fourteen days subject to judicial review pursuant to the Act of December 29, 1950, as amended (ch. 1189, 64 Stat. 1129).

"c. The hearing on the application for the final operating licenseotherwise required pursuant to section $189 \mathrm{a}$ shall be concluded as promptly as practicable. The Commission shall vacate the temporary operating license if it finds that the applicant is not prosecuting the application for the final operating license with due diligence. Issuance of a temporary operating license pursuant to subsection b. of this section shall be without prejudice to the position of amy party to the proceeding in which a hearing is otherwise required pursuant to section 189 a, and failure to assert any ground for denial or limitation of a temporary operating license shall not bar the assertion of such ground in connection with the issuance of a subsequent final operating license.

“d. The authority under this section shall expire on October 30, 1973. 
ment facility, that the licensee have and maintain liability insurance of such type and in such amounts as the Commission judges appropriate to cover liability claims arising out of any occurrence within the United States, causing, within or outside the United States, bodily injury, sickness, disease, or death, or loss of or damage to property, or loss of use of property, arising out of or resulting from the radioactive, toxic, explosive, or other hazardous properties of chemical compounds containing source or special nuclear material.

"(2) The Commission shall require, as a condition for the issuance of a license under sections 53 and 63 for a uranium enrichment facility, that the licensee provide adequate assurance of the availability of funds for the decommissioning (including decontamination) of such facility using funding mechanisms that may include, but are not necessarily limited to, the following:

"(A) Prepayment (in the form of a trust, escrow account, government fund, certificate of deposit, or deposit of government securities).

"(B) Surety (in the form of a surety or performance bond, letter of credit, or line of credit), insurance, or other guarantee (including parent company guarantee) method.

"(C) External sinking fund in which deposits are made at least annually.

"(e) No Price-Anderson Coverage.-Section 170 of this Act shall not apply to any license under section 53 or 63 for a uranium enrichment facility constructed after the date of enactment of this section."183

\section{"CHAPTER 17-184}

${ }^{183}$ Public Law 101-575 (104 Stat. 2835) (1990), added new Sec. 193.

${ }^{164}$ Public Law 95-110 (91 Stat. 884)(1977), which added Chapter 20, repealed Chapter 17, which read as follows: "JOINT COMMITTEE ON ATOMIC ENERGY

"Sec. 201. Membership. - There is hereby established a Joint Committee on Atomic Energy to be composed of ine Members of the Senate to be appointed by the President of the Senate, and nine Members of the House of Representatives to be appointed by the Speaker of the House of Representatives. In each instance not morethan five Members sentatives to beappointed by the Speaker of the

"Sec. 202 . Authority and Duty.-
.

"a. The Joint Committeeshall makecontinuing studies of the activities or the Atomic Energy Commission and of problems relating to the development, use, and control of atomic energy. During the first ninety days of each Con conduct hearings in either open or executive session for the purpose of receiving information concerning the development, growth, and state of the atomic energy industryb The Commission shall kep the Joint Committee fully and currently informed with respect to allof the Commission's adivities. TheDepartmeat of Defense shall keep the Joint Committee futly and currently informed with respect to all matters within the Department of Defense relating to the development, utilization, or application of atomic energy. Any Government a gency shall furmish any information requested by the Joint Committee with respect to the activities or responsibilities of that agency in the field of atomic energy. All bills, resolutions, and other matters in the Serate or the House of Representatives relating primarily to the Commission or to the development, use, or control of atomic energy shall be referred to the Joint Committee. The members of the Joint Committee who are Members of the Senate shall from time to time report to the Senate, and the members of the Joint Committee who are Members of the House of Representatives shall from time to time report to the House, by bill or otherwise, their recommendations with respect to matters within the jurisdiction of their respective Houses which are referred to the Joint Committee or otherwise within the jurisdiction of the Joint Committee.

"b. The members of the Joint Committee who are Members of the Senate and the Members of the Joint Committee who are Members of the Fiouse of Representatives shall, on or before June 30 of each year, report to thei respective Houses on the development, use, and control of muclear energy for the common defenseand security and for peaceful purposes. Each report shall provide facts and information availableto the Joint Committee concerning 
General provisions. 42 USC sec. 2271.

\section{"CHAPTER 18-ENFORCEMENT}

"Sec. 221. General Provisions.-

"a. To protect against the unlawful dissemination of Restricted Data and to safeguard facilities, equipment, materials, and other property of the Commission, the President shall have authority to utilize the services of any Government agency to the extent he may deem necessary or desirable.

"b. The Federal Bureau of Investigation of the Department of Justice shall investigate all alleged or suspected criminal violations of this Act.

"c. No action shall be brought against any individual or person for any violation under this Act unless and until the Attorney General of the United States has advised the Commission with respect to such action and no such action shall be commenced except by the Attorney General of the United States: Provided, however, That

(Continued)

nuclear energy which will assist the appropriate committees of the Congress and individual members in the exercise of informed judgment on matters of weaponry; foreign policy; defense; international trade; and in respect to the expenditure and appropriation of Government revenues. Each report shall be presented formally under circumexpenditure and appropriation of Government revenues. Each report shall be presented formally under circumtion of the need for public unclerstanding, presentations of the reports shall be made to the maximum extent possible in open session and by means of unclassified written materials

bec in open session and by means of unclassified written materials "Sec. 203. Chairman. - Vacancies in the membership of the Joint Committee shall not affect the power of the reof the original selection. The Joint Committeeshall select a Chairman and a Vice Chairman from among its membersat the beginning of each Congress. The Vice Chairman shall act in the place and stead of the Chairman in the absence of the Chairman. The Chairmanship shall alternate between the Senate and the House of Representatives with each Congress, and the Chairman shall be selected by the Members from that House entitled to the Chairmanship. The Vice Chairman shall be chosen from the House other than that of the Chairman by the Members from that House.

"Sec. 204 Powers. - In carrying out its duties under this Act, the Joint Committee, or any duly authorized subcom"Sec. 204 Powers. - In carrying out its duties underthis Act, the Joint Committee, or any duly authorized subcom-
mittee thereof, is authorized to hold such hearings or investigations, to sit and act at such places and times to require, by mittee thereof, is authorized to hold such hearings or investigations, to sit and act at such places and times to require, by
subpena or otherwise, the attendance of such witnesses and the production of such books, papers, and documents, to administer such oaths, to take such testimony, to procure such printing and binding, and to make such expenditures as it deems advisable. The Joint Committee may make such rules respecting its organization and procedures as it deems necessary: Provided, however, That no measure or recommendation shall bereported from the Joint Committeeunless a majority of the committee assent. Subpoenas may be issued over the signature of the Chairman of the Joint Committee or by any member designated by him or by the Joint Committee, and may be served by such person or persons as may be designated by such Chairman or member. The Chairman of the Joint Committee or any member thereof may administer oaths to witnesses. The Joint Committee may use a committee seal. The provisions of Sections 102 to 104, inclusive, of the Revised Statutes, as amended, shall apply in case of any failure of any witness to comply with a subpoena orto testify when summoned under authority of this section. The expenses of the Joint Committee shall be paid from the contingent fund of the Senate from funds appropriated for the Joint Committee upon vouchers approved by the Chairman. The cost of stenographic service to report public hearings shall not be in excess of the amounts prescribed by law for reporting the hearings of standing committees of the Senate. The cost of stenographic service to report executive hearings shall be fixed at an equitable rate by the Joint Committee. Members of the Joint Committee, and its employees and consultants, whiletraveling on official business for the Joint Committee, may receive either the per diem allowance authorized to be paid to Members of Congress or its employees, or their actual and necessary expenses provided an itemized statement of such expenties is attached to the voucher.

"Sec. 205. Staff and Assistance. - The Joint Committee is empowered to appoint and fix the compensation of such experts, consultants, technicians, and staff employees as it deems necessary and advisable. The Joint Committee is authorized to utilize the services, information, facilities, and personnel of the departments and establishments of the Government. The Joint Committee is authorized to permit such of its members, employees, and consultants as it deems necessary in the interest of common defense and security to carry firearms while in the discharge of their official duties for the committee.

"Sec. 206. Classification of Information. - The Joint Committee may classify information originating within the committee in accordance with standards used generally by the exeautive branch for classifying Restricted Data or defense information.

"Sec 207. Records. - The Joint Committee shall keep a complete record of all committee actions, including a record of the votes on any question on which a record vote is demanded. All committee records, data, charts, and files shall be theproperty of the Joint Committee and shall be kept in theoffices of the Joint Committee or other places as the Joint Committeemay direct under such security safeguards as the Joint Committee shall determine in the interest of the Joint Committec may direct unders

"Public Law 87-206 (75 Stat. 475) (1961), sec. 17, substituted the word "ninety" for the word "sixty".

"Public Law 88-294 (78 Stat. 172) (1964), amended the second sentence of sec. 202. Before amendment this sentence read: "During the first ninety days of each session of the Congress, the Joint Committee shall conduct hearings in either open or executive session for the purpose of receiving information concerning the development, growth, and state of the atomic energy industry."

"Subsection 202b, was added by Public Law 93-514 (88 Stat. 1611) (1974), 
Violation of specific sections. 42 USC $\sec .2272$.

Violation of sections generally. 42 USC sec. 2273.

nothing in this subsection shall be construed as applying to administrative action taken by the Commission. 185

"Sec.222. Violations of Specific Sections. - Whoever willfully violates, attempts to violate, or conspires to violate, any provisions of sections 57, 92 , or 101 , or whoever unlawfully interferes, attempts to interfere, or conspires to interfere with any recapture or entry under section 108 , shall, upon conviction thereof, be punished by a fine of not more than $\$ 10,000$ or by imprisonment for not more than ten ${ }^{186}$ years, or both, except that whoever commits such an offense with intent to injure the United States or with intent to secure an advantage to any foreign nation shall, upon conviction thereof, be punished by imprisonment for life, or by imprisonment for any term of years or a fine of not more than $\$ 20,000$ or both. 187

Sec. 223. Violation of Sections Generally.-a. Whoever 188 willfully violates, attempts to violate, or conspires to violate, any provision of this Act for which no criminal ${ }^{189}$ penalty is specifically provided or of any regulation or order prescribed or issued under section 65 or subsections $161 \mathrm{~b} ., \mathrm{i} .$, or $0,{ }^{190}$ shall, upon conviction thereof, be punished by a fine of not more than $\$ 5,000$ or by imprisonment for not more than two years, or both, except that whoever commits such as offense with intent to injure the United States or with intent to secure an advantage to any foreign nation, shall, upon conviction thereof, be punished by a fine of not more than $\$ 20,000$ or by imprisonment for not more than twenty years, or both.

b. Any individual director, officer, or employee of a firm constructing, or supplying the components of any utilization facility required to be licensed under section 103 or $104 \mathrm{~b}$. of this Act who by act or omission, in connection with such construction or supply, knowingly and willfully violates or causes to be violated, any section of this Act, any rule, regulation, or order issued thereunder, or any license condition, which violation results, or if undetected could have resulted, in a significant impairment of a basic component of such a facility shall, upon conviction, be subject to a fine of not more than $\$ 25,000$ for each day of violation, or to imprisonment not to exceed two years, or both. If the conviction is for a violation committed after a first conviction under this subsection, punishment shall be a fine of not more than $\$ 50,000$ per day of violation, or imprisonment for not more than two years, or both.

185 upublic Law 101-647(104 Stat. 4789), sec. 1211, deleted "That no action shall be brought under section 222, 223, 224, 225 or 226 except by the express direction of the Attorney General: and provided further,."

186 upulic 201 161 (83 Stat 444)(1969) sec 2 amended sec 222 by substituting the word "ten" for the rord "five". Sec. 7 provided that the amendment apply only to offenses committed on or after December 24, 1969.

187 upublic Law 91-161 (83 Stat. 444) (1969), sec. 3(a), amended sec. 222 by substituting the words "imprisonment for life, or by imprisonment for any term of yearsor a fine of not more than $\$ 20,000$ or both" in lieu of "death or imprisonment for life (but the penalty of death or imprisonment for life may be imposed only upon recommendation of the jury), or by a fine of not more than $\$ 20,000$ or by imprisonment for not more than 20 years,

${ }^{108}$ Public Law 96-295 (94 Stat. 786)(1980), see. 203, designated the existing paragraph as subsec. "a".

${ }^{180}$ PublicLaw $91-161$ (83 Stat. 444)(1969), sec. 6, amended sec. 223 by adding theword "criminal" before theword "penalty".

${ }^{100}$ Public Law 90-190 (81 Stat. 575)(1967), sec. 12 amended sec. 223 by striking out the letter "p." appearing after the word "or", and inserting in lieu therof the letter " $o$." 
"Basic component."

42 USC 2133.

2134.

Contracts.

Communication of restricted data.

42 USC sec. 2274
For the purposes of this subsection, the term 'basic component' means a facility structure, system, component or part thereof necessary to assure-

(1) the integrity of the reactor coolant pressure boundary,

(2) the capability to shut-down the facility and maintain it in a safe shut-down condition, or

(3) the capability to prevent or mitigate the consequences of accidents which could result in an unplanned offsite release of quantities of fission products in excess of the limits established by the Commission.

The provisions of this subsection shall be prominently posted at each site where a utilization facility required to be licensed under section 103 or $104 \mathrm{~b}$. of the Act is under construction and on the premises of each plant where components for such a facility are fabricated.

c. Any individual director, officer or employee of a person indemnified under an agreement of indemnification under section $170 \mathrm{~d}$. (or of a subcontractor or supplier thereto) who, by act or omission, knowingly and willfully violates or causes to be violated any section of this Act or any applicable nuclear safety-related rule, regulation or order issued thereunder by the Secretary of Energy (or expressly incorporated by reference by the Secretary for purposes of nuclear safety, except any rule, regulation, or order issued by the Secretary of Transportation), which violation results in or, if undetected, would have resulted in a nuclear incident as defined in subsection 11 q. shall, upon conviction, notwithstanding section 3571 of title 18, United States Code, be subject to a fine of not more than $\$ 25,000$, or to imprisonment not to exceed two years, or both. If the conviction is for a violation committed after the first conviction under this subsection, notwithstanding section 3571 of title 18, United States Code, punishment shall be a fine of not more than $\$ 50,000$, or imprisonment for not more than five years, or both. ${ }^{191}$

Sec. 224. Communication of Restricted Data. - Whoever, lawfully or unlawfully, having possession of, access to, control over, or being entrusted with any document, writing, sketch, photograph, plan, model, instrument, appliance, note, or information involving or incorporating Restricted Data-

"a. communicates, transmits, or discloses the same to any individual or person, or attempts or conspires to do any of the foregoing, with intent to injure the United States or with intent to secure an advantage to any foreign nation, upon conviction thereof, shall be punished by imprisonment for life, or by imprisonment for any term of years or a fine of not more than $\$ 20,000$ or both; 192

${ }^{191}$ Public Law 100-408 (102 Stat. 1066)(1988), sec. 18 amended sec. 223 by adding a subsec. c. Public Law96-295 (94 Stat. 786)(1980), sec. 203 added a new subsec. b.

${ }^{192}$ P;ublic Law 91-161 (83 Stat. 444)(1969), sec. 3(b), amended secs. 224a, 225, and 226 by substituting in each section, the words "imprisonment for life, or by imprisonment for any term of years or a fine of not more than $\$ 20,000$ or both" in lieu of "death or imprisonment for life (but the penalty of death or imprisonment forlife may be imposed only both" in lieu of "death or imprisonment for life (but the penalty of death or imprisonment for life may be imposed only upon recommendation of the juiry), or by a fine of not more than $\$ 20,000$ or imprisonment for sot more than twenty
years, or both". Sec. 7 of the amendment provided that the amendment apply only to of fenses committed on or after years, or both". Sec.
Decernber 24, 1969. 
"b. communicates, transmits, or discloses the same to any individual or person, or attempts or conspires to do any of the foregoing, with reason to believe such data will be utilized to injure the United States or to secure an advantage to any foreign nation, shall, upon conviction, be punished by a fine of not more than $\$ 10,000$ or imprisonment for not more than ten years, or both.

"Sec. 225. Receipt of Restricted Data.-Whoever, with intent to injure

Receipt of restricted data. 42 USC sec. 2275.

Tampering with restricted data. 42 USC sec. 2276.

Disclosure of restricted data. 42 USC sec. 2277.

Statute of limitations. 42 USC 2278.

Trespass on Commission installations. 42 USC the United States or with intent to secure an advantage to any foreign nation, acquires, or attempts or conspires to acquire any document, writing, sketch, photograph, plan, model, instrument, appliance, note, or information involving or incorporating Restricted Data shall, upon conviction thereof, be punished by imprisonment for life, or by imprisonment for any term of years or a fine of not more than $\$ 20,000$ or both. 192

"Sec. 226. Tampering with Restricted Data.-Whoever, with intent to injure the United States or with intent to secure an advantage to any foreign nation, removes, conceals, tampers with, alters, mutilates, or destroys any document, writing, sketch, photograph, plan, model, instrument, appliance, or note involving or incorporating Restricted Data and used by any individual or person in connection with the production of special nuclear material, or-research or development relating to atomic energy, conducted by the United States, or financed in whole or in part by Federal funds, or conducted with the aid of special nuclear material, shall be punished by imprisonment for life, or by imprisonment for any term of years or a fine of not more than $\$ 20,000$ or both. ${ }^{193}$

"Sec. 227. Disclosure of Restricted Data.-Whoever, being or having been an employee or member of the Commission, a member of the Armed Forces, an employee of any agency of the United States, or being or having been a contractor of the Commission or of an agency of the United States, or being or having been an employee of a contractor of the Commission or of an agency of the United States, or being or having been a licensee of the Commission, or being or having been an employee of a licensee of the Commission, knowingly communicates, or whoever conspires to communicate or to receive, any Restricted Data, knowing or having reason to believe that such data is Restricted Data, to any person not authorized to receive Restricted Data pursuant to the provisions of this Act or under rule or regulation of the Commission issued pursuant thereto, knowing or having reason to believe such person is not so authorized to receive Restricted Data shall, upon conviction thereof, be punishable by a fine of not more than $\$ 2,500$.

"Sec. 228. Statute of Limitations.-Except for a capital offense, no individual or person shall be prosecuted, tried, or punished for any offense prescribed or defined in sections 224 to 226 , inclusive, of this Act, unless the indictment is found or the information is instituted within ten years next after such offense shall have been committed.

"Sec. 229. Trespass Upon Commission Installations. ${ }^{193}$

"a. The Commission is authorized to issue regulations relating to the entry upon or carrying, transporting, or otherwise introducing or causing to be introduced any dangerous weapon, explosive, or

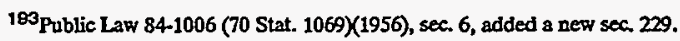


sec. $2278 \mathrm{a}$.

Photographing of Commission installations. 42 USC sec. $2278 \mathrm{~b}$.

Other laws. 42 USC sec. 2279. Injunction proceedings. 42 USC sec. 2280.

Contempt other dangerous instrument or material likely to produce substantial injury or damage to persons or property, into or upon any facility, installation, or real property subject to the jurisdiction, administration, or in the custody of the Commission. Every such regulation of the Commission shall be posted conspicuously at the location involved.

"b. Whoever shall willfully violate any regulation of the Commission issued pursuant to subsection a. shall, upon conviction thereof, be punishable by a fine of not more than $\$ 1,000$.

"c. Whoever shall willfully violate any regulation of the Commission issued pursuant to subsection a. with respect to any installation or other property which is enclosed by a fence, wall, floor, roof, or other structural barrier shall be guilty of a misdemeanor and upon conviction thereof shall be punished by a fine of not to exceed $\$ 5,000$ or to imprisonment for not more than one year, or both.

"Sec. 230. Photographing, etc., of Commission Installations. 194 - It shall be an offense, punishable by a fine of not more than $\$ 1,000$ or imprisonment for not more than one year, or both-

“(1) to make any photograph, sketch, picture, drawing, map or graphical representation, while present on property subject to the jurisdiction, administration or in the custody of the Commission, of any installations or equipment designated by the President as requiring protection against the general dissemination of information relative thereto, in the interest of the common defense and security, without first obtaining the permission of the Commission, and promptly submitting the product obtained to the Commission for inspection or such other action as may be deemed necessary; or

(2) to use or permit the use of an aircraft or any contrivance used, or designed for navigation or flight in air, for the purpose of making a photograph, sketch, picture, drawing, map or graphical representation of any installation or equipment designated by the President as provided in the preceding paragraph, unless authorized by the Commission.

Sec. 231. Other Laws. ${ }^{195}$-Sections 224 to 230 shall not exclude the applicable provisions of any other laws.

Sec. 232. ${ }^{196}$-Injunction Proceedings-Whenever in the judgment of the Commission any person has engaged or is about to engage in any acts or practices which constitute or will constitute a violation of any provision of this Act, or any regulation or order issued thereunder, the Attorney General on behalf of the United States may make application to the appropriate court for an order enjoining such acts or practices, or for an order enforcing compliance with such provision, and upon a showing by the Commission that such person has engaged or is about to engage in any such acts or practices, a permanent or temporary injunction, restraining order, or other order may be granted.

Sec. 233. ${ }^{196}$ Contempt Proceedings.-In case of failure or refusal to

${ }^{184}$ Public Law 84-1006 (70 Stat. 1069)(1956), sec. 6, added a new sec. 230.

${ }^{185}$ Public Law 84-1006 (70 Stat 1069)(1956), sec. 7, amended former sec. 229 and redesignated it as sec. 231. Before amendment, sec. 229 read:

"Sec. 229. Other Lays.-Sections 224 to 228 shall not exchude the applicable provisions of any other laws."

${ }^{106}$ Public Law 84-1006 (70 Stat. 1069)(1956), sec. 6, renumbered former secs. 230 and 231 to secs. 232 and 233 , respectively. 
proceedings.

42 USC sec. 2281

Civil penalties.

42 USC sec. 2282.

68 STAT. 930.

42 USC 2073 ,

$2077,2092,2093$,

$2111,2112,2131$

$2133,2134,2137$,

2139.

42 USC 2236.

83 STAT. 445.

Written

notification.

42 USC 2282a

Contracts.

obey a subpoena served upon any person pursuant to subsection $161 \mathrm{c}$, the district court for any district in which such person is found or resides or transacts business, upon application by the Attorney General on behalf of the United States, shall have jurisdiction to issue an order requiring such person to appear and give testimony or to appear and produce documents, or both, in accordance with the subpoena; and any failure to obey such order of the court may be punished by such court as a contempt thereof.

Sec. 234.197 Civil Monetary Penalties for Violations of Licensing Requirements.-

a. Any person who (1) violates any licensing provision of section $53,57,62,63,81,82,101,103,104,107$, or 109 of any rule, regulation, or order issued thereunder, or any term, condition, or limitation of any license issued thereunder, or (2) commits any violation for which a license may be revoked under section 186, shall be subject to a civil penalty, to be imposed by the Commission, of not to exceed $\$ 100,000$ for each such violation. ${ }^{198}$ If any violation is a continuing one, each day of such violation shall constitute a separate violation for the purpose of computing the applicable civil penalty. The Commission shall have the power to compromise, mitigate, or remit such penalties.

b. Whenever the Commission has reason to believe that a person has become subject to the imposition of a civil penalty under the provisions of this section, it shall notify such person in writing (1) setting forth the date, facts, and nature of each act or omission with which the person is charged, (2) specifically identifying the particular provision or provisions of the section, rule, regulation, order, or license involved in the violation, and (3) advising of each penalty which the Commission proposes to impose and its amount. Such written notice shall be sent by registered or certified mail by the Commission to the last known address of such person. The person so notified shall be granted an opportunity to show in writing, within such reasonable period as the Commission shall by regulation prescribe, why such penalty should not be imposed. The notice shall also advise such person that upon failure to pay the civil penalty subsequently determined by the Commission, if any, the penalty may be collected by civil action.

c. On the request of the Commission, the Attorney General is authorized to institute a civil action to collect a penalty imposed pursuant to this section. The Attorney General shall have the exclusive power to compromise, mitigate, or remit such civil penalties as are referred to him for collection.

Sec. 234A. Civil Monetary Penalties For Violations Of Department Of Energy Regulations.-

a. Any person who has entered into an agreement of indemnification under subsection $170 \mathrm{~d}$. (or any subcontractor or supplier

\footnotetext{
197 Public Law 100-408 (102 Stat. 1066)(1988), sec 17 added sec. 234A.

Public Law 91-161 (83 Stat. 444)(1069), sec. 4, added Sec. 234.

180 public Law 96-295 (94 Stat. 787)(1980), sec. 206, amended sec. (a) by striking all that followed "exceed" and inserted "\$100,000 for each violation.". Prior to amendment, the portion deleted read as follows: $\$ 5,000$ for each inserted " $\$ 100,000$ for each violation." Prior to amendment, the portion deleted read as follows: $\$ 5,000$ for each such person occurring within any period of thirty consective days."
} 
Courts, U.S.

thereto) who violates (or whose employee violates) any applicable rule, regulation or order related to nuclear safety prescribed or issued by the Secretary of Energy pursuant to this Act (or expressly incorporated by reference by the Secretary for purposes of nuclear safety, except any rule, regulation, or order issued by the Secretary of Transportation) shall be subject to a civil penalty of not to exceed $\$ 100,000$ for each such violation. If any violation under this subsection is a continuing one, each day of such violation shall constitutea separate violation for the purpose of computing the applicable civil penalty.

b. (1) The Secretary shall have the power to compromise, modify or remit, with or without conditions, such civil penalties and to prescribe regulations as he may deem necessary to implement this section.

(2) In determining the amount of any civil penalty under this subsection, the Secretary shall take into account the nature, circumstances, extent, and gravity of the violation or violations and, with respect to the violator, ability to pay, effect on ability to continue to do business, any history of prior such violations, the degree of culpability, and such other matters as justice may require. In implementing this section, the Secretary shall determine by rule whether nonprofit educational institutions should receive automatic remission of any penalty under this section.

c. (1) Before issuing an order assessing a civil penalty against any person under this section, the Secretary shall provide to such person notice of the proposed penalty. Such notice shall inform such person of his opportunity to elect in writing within thirty days after the date of receipt of such notice to have the procedures of paragraph (3) (in lieu of those paragraph (2)) apply with respect to such assessment.

(2) (A) Unless an election is made within thirty calendar days after receipt of notice under paragraph (1) to have paragraph (3) apply with respect to such penalty, the Secretary shall assess the penalty, by order, after a determination of violation has been made on the record after an opportunity for an agency hearing pursuant to section 554 of title 5, United States Code, before an administrative law judge appointed under section 3105 of such title 5. Such assessment order shall include the administrative law judge's findings and the basis for such assessment.

(B) Any person against whom a penalty is assessed under this paragraph may, within sixty calendar days after the date of the order of the Secretary assessing such penalty, institute an action in the United States court of appeals for the appropriate judicial circuit for judicial review of such order in accordance with chapter 7 of title 5, United States Code. The court shall have jurisdiction to enter a final judgment affirming, modifying or setting aside in whole or in part, the order of the Secretary, or the court may remand the proceeding to the Secretary for such further action as the court may direct.

(3) (A) In the case of any civil penalty with respect to which the procedures of this paragraph have been elected, the Secretary shall 
Courts, U.S.

promptly assess such penalty, by order, after the date of the election under paragraph (1).

Courts, U.S.

Schools and colleges.

Corporations.

(B) If the civil penalty has not been paid within sixty calendar days after the assessment order has been made under subparagraph $(A)$, the Secretary shall institute an action in the appropriate district court of the United States for an order affirming the assessment of the civil penalty. The court shall have authority to review de novo the law and facts involved, and shall have jurisdiction to enter a judgment enforcing, modifying, and enforcing as so modified, or setting aside in whole or in part, such assessment.

(C) Any election to have this paragraph apply may not be revoked except with consent of the Secretary.

(4) If any person fails to pay an assessment of a civil penalty after it has become a final and unappealable order under paragraph (2), or after the appropriate district court has entered final judgment in favor of the Secretary under paragraph (3), the Secretary shall institute an action to recover the amount of such penalty in any appropriate district court of the Untied States. In such action, the validity and appropriateness of such final assessment order or judgment shall not be subject to review.

d. The provisions of this section shall not apply to:

(1) The University of Chicago (and any subcontractors or suppliers thereto) for activities associated with Argonne National Laboratory;

(2) The University of California (and any subcontractors or suppliers thereto) for activities associated with Los Alamos National Laboratory, Lawrence Livermore National Laboratory, and Lawrence Berkeley National Laboratory;

(3) American Telephone and Telegraph Company and its subsidiaries (and any subcontractors or suppliers thereto) for activities associated with Sandia National Laboratories;

(4) Universities Research Association, Inc. (and any subcontractors or suppliers thereto) for activities associated with FERMI National Laboratory;

(5) Princeton University (and any subcontractors or suppliers thereto) for activities associated with Princeton Plasma Physics Laboratory;

(6) The Associated Universities, Inc. (and any subcontractors or suppliers thereto) for activities associated with the Brookhaven National Laboratory; and

(7) Battelle Memorial Institute (and any subcontractors or suppliers thereto) for activities associated with Pacific Northwest Laboratory.

42 USC 2283.

\section{Sec. 235. Protection Of Nuclear Inspectors.-}

a. Whoever kills any person who performs any inspections which-

"(1) are related to any activity or facility licensed by the Commission, and

"(2) are carried out to satisfy requirements under this Act or under any other Federal law governing the safety of utilization facilities required to be licensed under section 103 or $104 \mathrm{~b}$, or 
42 USC sec. 2284.

Penalties.

Transfer of property.

42 USC sec. 2015.

Report to

Congress.

42 USC sec. 2016. the safety of radioactive materials, shall be punished as provided under sections 1111 and 1112 of title 18, United States Code. The preceding sentence shall be applicable only if such person is killed while engaged in the performance of such inspection duties or on account of the performance of such duties.

b. Whoever forcibly assaults, resists, opposes, impedes, intimidates, or interferes with any person who performs inspections a described under subsection a. of this section, while such person is engaged in such inspection duties or on account of the performance of such duties, shall be punished as provided under section 111 of title 18, United States Code. ${ }^{199}$

"Sec. 236. Sabotage Of Nucleaer Facilities Or Fuel.-

a. Any person who intentionally and willfully destroys or causes physical damage to, or who intentionally and willfully attempts to destroy or cause physical damage to-

"(1) any production facility or utilization facility licensed under this Act;

"(2) any nuclear waste storage facility licensed under this Act;

"(3) any nuclear fuel for such a utilization facility, or any spent nucleaer fuel from such a facility; or

"(4) any uranium enrichment facility licensed by the Nuclear Regulatory Commission."200

"b. Any person who intentionally and willfully causes or attempts to cause an interruption of normal operation of any such facility thorugh the unauthorized use of or tampering with the machinery, components, or controls of any such facility, shall be fined not more than $\$ 10,000$ or imprisoned for not more than ten years, or both."201

\section{"CHAPTER 19-MISCELLANEOUS}

"Sec. 241. Transfer of Property.-Nothing in this Act shall be deemed to repeal, modify, amend, or alter the provisions of section 9(a) of the Atomic Energy Act of 1946, as heretofore amended.202

"Sec. 251. Report'To Congress.-The Commission shall submit to the Congress, in January ${ }^{203}$ of each year, a report concerning the activities of the Commission. The Commission shall include in such report, and shall at such other times as it deems desirable submit to the Congress, such recommendations for additional legislation as the Commission deems necessary or desirable.

\footnotetext{
${ }^{199}$ Public Law 96-295 (94 Stat. 786) (1980), sec. 202, added new sec. 235.

200 Public Law 101-575 (104 Stat. 2835) (1990), added new paragraph (4).

${ }^{201}$ Puublic Law $97-415$ (96 Stat. 2067) (1983) sec. 16 amended sec. 236 by adding subsec. b.

${ }^{202}$ See appendix 4, sec $9($ a).

${ }^{203}$ Public Law 86-43 (73 Stat. 73) (1959), amended sec. 251 by deleting the words "and July" after the word "Janu*
} ary". 
"a. No appropriation" 205 shall be made to the Commission, nor shall the Commission waive charges for the use of materials under the Cooperative Power Reactor Demonstration Program, unless previously authorized by legislation enacted by the Congress. ${ }^{206}$

"b. Any Act appropriating funds to the Commission may appropriate specified portions thereof to be accounted for upon the certification of the Commission only.

"c. Notwithstanding the provisions of subsection a., funds are hereby authorized to be appropriated for the restoration or replacement of any plant or facility destroyed or otherwise seriously damaged, and the Commission is authorized to use available funds for such purposes.

"d. Funds authorized to be appropriated for any construction project to be used in connection with the development or production of special nuclear material or atomic weapons may be used to start another construction project not otherwise authorized if the substituted construction project is within the limit of cost of the construction project for which substitution is to be made, and the Commission certifies that-

"(1) the substituted project is essential to the common defense and security;

"(2) the substituted project is required by changes in weapon characteristics or weapon logistics operations; and

" $(3)$ the Commission is unable to enter into a contract with any person on terms satisfactory to it to furnish from a privately owned plant or facility the product or services to be provided by the new project.

204 Public Law 88-72 (77 Stat. 84) (1963). sec. 107, the AEC Fiscal Year 1964 Autborization Act, amended section 261. Before amendment this section read as follows:

"Sec. 261. APPROPRIATIONS-

"a. There are hereby authorized to be appropriated such sums as may benecessary and appropriate to carry out the provisions and purposes of this Act, except-

(1) Such as may be necessary for acquisition or condemnation of any real property or any facility or for plant or facility acquisition, construction or expansion: Provided, That for the purposes of this subsection a, any nonmilitary esperimental reactor $w$ hich is designed to produce more than 10,000 thermal kilowatts of heat (except for intermittent $x$ aursions) or which is designed to be used in the production of electric power shall be deemed to be a facility.

(2) Such as may be necessary to carry out cooperative programs with persons for the development and construction of reactors for the demonstration of their use, in whole or in part, in the production of electric power or process heat, or for propulsion, or solely or principally for the commercial provision of byproduct material, irradiation, or other special for propulsion, or solely or principally for the commercial provision of byproduct materia, irradiation, or other special services, for civilian use, by arrangements (including contracts, agreements, and loans) or amendments thereto, providing for the payment of funds, the rendering of services, and the undertaking of research and development without full reimbursement, the waiver of charges accompanying such arrangement, or the provision by the Commission of any other financial assistance pursuant to such arrangement, or whichinvolves the acquisition or condemnation of any real property or any facility or for plant or facility acquisition, construction or expansion undertaken by the Commission as a part of such arrangements.

"b. The acts appropriating such sums may appropriate specified portions thereof to be accounted for upon the certification of the Commission only.

"c. Funds are hereby authorized to be appropriated for advance planning, construction design, and architecturalservices in connection with any plant or facility not otherwise authorized, and for the restoration or replacement of any plant or facility destroyed or otherwise seriously damaged, and the Commission is authorized to use available funds for such purposes.

"d. Funds hereafter authorized to be sppropriated for any project to be used in connection with the development or proctuction of special muclear material or atomic weapons may be used to start another project not otherwiseanthorized. If the substituted project is within the limit of cost of the project for which substitution is to be made, and the Commission certifies that-

(1) the substituted project is essential to the common defense and security;

(2) the substituted project is required by changes in weapon characteristics or weapon logistic operations; and (3) the sibstived project is required be con pris Public Law 87-615 (76 Stat. 409), sec. 8. For previous amendments of this section see "Atomic Energy Legislation Through 87th Congress, 2nd Session," p. 79.

${ }^{205}$ Excerpts from legishtion appropriating funds to the Atomic Energy Commission are set forth in appendix 5 .

${ }^{206}$ Legislation authorizing appropriations to the Commission is sel forth in Part II, Infra. 
Agency

jurisdiction.

42 USC sec. 2018.

Applicability

of Federal

Power Act.

42 USC sec. 2019.

Licensing of

Government agencies.

42 USC sec. 2020.

Cooperation with States.

42 USC sec. 2021.

Agreements
"Sec. 271. Agency Jurisdiction.-Nothing in this Act shall be construed to affect the authority or regulations of any Federal, State, or Local agency with respect to the generation, sale, or transmission of electric power produced through the use of nuclear facilities licensed by the Commission: Provided, That this section shall not be deemed to confer upon any Federal, State, or local agency any authority to regulate, control, or restrict any activities of the Commission. ${ }^{207}$

"Sec. 272. Applicability Of Federal Power Act.-Every licensee under this Act who holds a license from the Commission for a utilization of production facility for the generation of commercial electric energy under section 103 and who transmits such electric energy in interstate commerce or sells it as wholesale in interstate commerce shall be subject to the regulatory provisions of the Federal Power Act.

"Sec. 273. Licensing Of Government Agencies.-Nothing in this Act shall preclude any Government agency now or hereafter authorized by law to engage in the production, marketing, or distribution of electric energy from obtaining a license under section 103, if qualified under the provisions of section 103, for the construction and operation of production of utilization facilities for the primary purpose of producing electric energy for disposition for ultimate public consumption.

"Sec. 274. Cooperation With States. ${ }^{208}$

"a. It is the purpose of this section-

"(1) to recognize the interests of the States in the peaceful uses of atomic energy, and to clarify the respective responsibilities under this Act of the States and the Commission with respect to the regulation of byproduct, source, and special nuclear materials;

"(2) to recognize the need, and establish programs for cooperation between the States and the Commission with respect to control of radiation hazards associated with use of such materials;

"(3) to promote an orderly regulatory pattern between the Commission and State governments with respect to nuclear development and use and regulation of byproduct, source, and special nuclear materials;

"(4) to establish procedures and criteria for discontinuance of certain of the Commission's regulatory responsibilities with respect to byproduct, source, and special nuclear materials, and the assumption thereof by the States;

"(5) to provide for coordination of the development of radiation standards for the guidance of Federal agencies and cooperation with the States; and

"(6) to recognize that, as the States improve their capabilities to regulate effectively such materials, additional legislation may be desirable.

"b. Except as provided in subsection c., the Commission is

207 Public Law 89-135 (79 Stat. 551) (1965), amended sec. 271. Prior to amendment this section read as follows: "Sec. 271. AGENCY JURISDICTION-Nothing in this Act shall be construed toaffect the aut thority or regulation of any Federal, State, or local agency with respect to the generation, sale, or transmission of electric power."

${ }^{208}$ Public Law 86-373 (73 Stat. 688) (1959), sec. 1, added sec. 274. 
with States.

42 USC 2014.

Conditions.

authorized to enter into agreements with the Governor of any State providing for discontinuance of the regulatory authority of the Commission under chapters 6,7 , and 8 , and section 161 of this Act, with respect to any one or more of the following materials within the State-

"(1) byproduct materials as defined in section 11e. (1);209

"(2) byproduct materials as defined in section 11e. (2); ;10

"(3) source materials;

"(4) special nuclear materials in quantities not sufficient to form a critical mass.

During the duration of such an agreement it is recognized that the State shall have authority to regulate the materials covered by the agreement for the protection of the public health and safety from radiation hazards.

"c. No agreement entered into pursuant to subsection b. shall provide for discontinuance of any authority and the Commission shall retain authority and responsibility with respect to regulation of-

"(1) the construction and operation of any production or utilization facility or any uranium enrichment facility;210a

"(2) the export from or import into the United States of byproduct, source, or special nuclear material, or of any production or utilization facility;

"(3) the disposal into the ocean or sea of byproduct, source, or special nuclear waste materials as defined in regulations or orders of the Commission;

"(4) the disposal of such other byproduct, source, or special nuclear material as the Commission determines by regulation or order should, because of the hazards or potential hazards thereof, not be so disposed of without a license from the Commission. The Commission shall also retain authority under any such agreement to make a determination that all applicable standards and requirements have been met prior to termination of a license for byproduct material, as defined in section 11e. (2). ${ }^{211}$

Notwithstanding any agreement between the Commission and any State pursuant to subsection b., the Commission is authorized by rule, regulation, or order to require that the manufacturer, processor, or producer of any equipment, device, commodity, or other product containing source, byproduct, or special nuclear material shall not transfer possession or control of such product except pursuant to a license issued by the Commission.

"d. The Commission shall enter into an agreement under subsection $b$. of this section with any State if-

\footnotetext{
${ }^{209}$ Public Law 95-604 (92 Stat. 3036) (1978), sec. 204(a), amended sec. 274(b)(1) by adding "as defined in section 11e. (1)" after the words "byproduct materials".

210 Public Law 95-604 (92 Stat. 3037) (1978), sec. 204(a),, renumbered paragraphs (2) and (3) as paragraphs (3) and (4), and added a new paragraph (2).

210a Public Law 102-486 (106 Stat. 2944), Oct. 24, 1992.

211 Public Law 95-604 (92 Stat. 3038) (1978), sec. 204(f), added a new sentence after paragraph (4).
} 
Publication in F.R.

Licensing requirements. Exemptions.

Federal Radiation Council.
"(1) The Governor of that State certifies that the State has a program for the control of radiation hazards adequate to protect the public health and safety with respect to the materials within the State covered by the proposed agreement, and that the State desires to assume regulatory responsibility for such materials; and

"(2) the Commission finds that the State program is in accordance with the requirements of subsection 0 . and in all other respects ${ }^{212}$ compatible with the Commission's program for regulation of such materials, and that the State program is adequate to protect the public health and safety with respect to the materials covered by the proposed agreement.

"e. (1) Before any agreement under subsection $b$. is signed by the Commission, the terms of the proposed agreement and of proposed exemptions pursuant to subsection $\mathrm{f}$. shall be published once each week for four consecutive weeks in the Federal Register; and such opportunity for comment by interested persons on the proposed agreement and exemptions shall be allowed as the Commission determines by regulation or order to be appropriate.

"(2) Each proposed agreement shall include the proposed effective date of such proposed agreement or exemptions. The agreement and exemptions shall be published in the Federal Register within thirty days after signature by the Commission and the Governor.

"f. The Commission is authorized and directed, by regulation or order, to grant such exemptions from the licensing requirements contained in chapters 6,7 , and 8 , and from its regulations applicable to licensees as the Commission finds necessary or appropriate to carry out any agreement entered into pursuant to subsection $b$. of this section.

"g. The Commission is authorized and directed to cooperate with the States in the formulation of standards for protection against hazards of radiation to assure that State and Commission programs for protection against hazards of radiation will be coordinated and compatible.

"h. There is hereby established a Federal Radiation Council, consisting of the Secretary of Health, Education, and Welfare, the Chairman of the Atomic Energy Commission, the Secretary of Defense, the Secretary of Commerce, the Secretary of Labor, or their designees, and such other members as shall be appointed by the President. The Council shall consult qualified scientists and experts in radiation matters, including the President of the National Academy of Sciences, the Chairman of the National Committee on Radiation Protection and Measurement, and qualified experts in the field of biology and medicine and in the field of health physics. The Special Assistant to the President for Science and Technology, or his designee, is authorized to attend meetings, participate in the deliberations of, and to advise the Council. The Chairman of the Council shall be designated by the President, from time to time,

212 Public Law 95-604 (92 Stat. 3037) (1978), sec. 904(b), amended sec. 274(d)(2) by inserting the words "in accor dance with the requirements of subsection 0 , and in all otber respects" before the word "compatible". 
from among the members of the Council. The Council shall advise the President with respect to radiation matters, directly or indirectly affecting health, including guidance for all Federal agencies in the formulation of radiation standards and in the establishment and execution of programs of cooperation with States. The Council shall also perform such other functions as the President may assign to it by Executive order.

Inspections.

Termination of agreement.

"i. The Commission in carrying out its licensing and regulatory responsibilities under this Act is authorized to enter into agreements with any State, or group of States, to perform inspections or other functions on a cooperative basis as the Commission deems appropriate. The Commission is also authorized to provide training, with or without charge, to employees of, and such other assistance to, any such State or political subdivision thereof or group of States as the Commission deems appropriate. Any such provision or assistance by the Commission shall take into account the additional expenses that maybe incurred by a State as a consequence of the State's entering into an agreement with the Commission pursuant to subsection $b$.

"j. (1) ${ }^{213}$ The Commission, upon its own initiative after reasonable notice and opportunity for hearing to the State with which an agreement under subsection $b$. has become effective, or upon request of the Governor of such State, may terminate or suspend all or part of 214 its agreement with the State and reassert the licensing and regulatory authority vested in it under this Act, if the Commission finds that (1) ${ }^{215}$ such termination or suspension is required to protect the public health and safety, or (2) the State has not complied with one or more of the requirements of this section. The Commission shall periodically review such agreements and actions taken by the States under the agreements to insure compliance with the provisions of this section.216

"(2) The Commission, upon its own motion or upon request of the Governor of any State, may, after notifying the Governor, temporarily suspend all or part of its agreement with the State without notice or hearing if, in the judgment of the Commission:

"(A) an emergency situation exists with respect to any material covered by such an agreement creating danger which requires immediate action to protect the health or safety of persons either within or outside of the State, and

"(B) the State has failed to take steps necessary to contain or eliminate the cause of the danger within a reasonable time after the situation arose.

A temporary suspension under this paragraph shall remain in effect only for such time as the emergency situation exists and shall

\footnotetext{
${ }^{213}$ Public Law 96-295 (94 Stat. 787) (1980), sec. 205, inserted "(1)" after "j".

${ }^{214}$ Public Law $95-604$ (92 Stat. 3037) (1978), sec. 204(0)(1), amended sec. 274j by adding the words "all or part of" after "suspend".

210 Public Law 95-604 (92 Stat. 3037) (1978), sec. 204(d)(2), amended sec. 274j by inserting "(1)" after "finds that".

${ }^{216}$ Public Law 95-604 (92 Stat. 3037) (1978), sec. 204(d)(3), amended sec. 274j by adding at the end before the period «, or (2) the State has not complied with one or more of the requirements of this section. The Commission shall periodically review such agreements and actions taken by the States under the agreements to ensure compliance with the provisions of this section".
} 
Notice of filing.

Definition.

“Agreement."

Ante, p. 3033

Post. p. 3039. authorize the Commission to exercise its authority only to the extent necessary to contain or eliminate the danger."217

" $k$. Nothing in this section shall be construed to affect the authority of any State or local agency to regulate activities for purposes other than protection against radiation hazards.

"1. With respect to each application for Commission license authorizing an activity as to which the Commission's authority is continued pursuant to subsection $c$., the Commission shall give prompt notice to the State or States in which the activity will be conducted of the filing of the license application; and shall afford reasonable opportunity for State representatives to offer evidence, interrogate witnesses, and advise the Commission as to the application without requiring such representatives to take a position for or against the granting of the application.

" $m$. No agreement entered into under subsection b., and no exemption granted pursuant to subsection $f$., shall affect the authority of the Commission under subsection $161 \mathrm{~b}$. or i. it issue rules, regulations, or orders to protect the common defense and security, to protect restricted data or to guard against the loss or diversion of special nuclear material. For purposes of subsection 161 i., activities covered by exemptions granted pursuant to subsection $\mathrm{f}$. shall be deemed to constitute activities authorized pursuant to this Act; and special nuclear material acquired by any person pursuant to such an exemption shall be deemed to have been acquired pursuant to section 53 .

"n. As used in this section, the term 'State' means any State, Territory, or possession of the United States, the Canal Zone, Puerto Rico, and the District of Columbia. As used in this section, the term 'agreement' includes any amendment to any agreement. 218

"o. In the licensing and regulation of byproduct material, as defined in section 11 e. (2) of this Act, or of any activity which results in the production of byproduct material as so defined under an agreement entered into pursuant to subsection b., a State shall require-

"(1) compliance with the requirements of subsection b. of section 83 (respecting ownership of byproduct material and land), and

"(2) compliance with standards which shall be adopted by the State for the protection of the public health, safety, and the environment from hazards associated with such material which are equivalent, to the extent practicable, or more stringent than, standards adopted and enforced by the Commission for the same purpose, including requirements and standards promulgated by the Commission and the Administrator of the Environmental Protection Agency pursuant to sections 83, 84, and 275 , and

“(3) procedures which-

217 Public Law 96-295 (94 Stat. 787) (1980), sec. 205 added new subsea "j. (2)".

${ }^{218}$ Public Law 95-604 (92 Stat. 3037) (1978), sec. 204(c), added last sentence to sec. 274n. 
"(A) in the case of licenses, provide procedures under State law which include-

(i) an opportunity, after public notice, for written comments and a public hearing, with a transcript,

"(ii) an opportunity for cross examination, and

"(iii) a written determination which is based upon findings included in such determination and upon the evidence presented during the public comment period and which is subject to judicial review;

"(B) in the case of rulemaking, provide an opportunity for public participation through written comments or a public hearing and provide for judicial review of the rule;

"(C) require for each license which has a significant impact on the human environment a written analysis (which shall be available to the public before the commencement of any such proceedings) of the impact of such license, including any activities conducted pursuant thereto, on the environment, which analysis shall include-

"(i) an assessment of the radiological and nonradiological impacts to the public health of the activities to be conducted pursuant to such license;

"(ii) an assessment of any impact on any waterway and groundwater resulting from such activities;

"(iii) consideration of alternatives, including alternative sites and engineering methods, to the activities to be conducted pursuant to such license; and

"(iv) consideration of the long-term impacts, including decommissioning, decontamination, and reclamation impacts, associated with activities to be conducted pursuant to such license, including the management of any byproduct material, as defined by section 11 e. (2); and

"(D) prohibit any major construction activity with respect to such material prior to complying with the provisions of subparagraph (C).

If any State under such agreement imposes upon any licensee any requirement for the payment of funds to such State for the reclamation or long-term maintenance and monitoring of such material, and if transfer to the United States of such material is required in accordance with section $83 \mathrm{~b}$. of this Act, such agreement shall be amended by the

Ante, p. 3033. Commission to provide that such State shall transfer to the United States upon termination of the license issued to such licensee the total amount collected by such State from such licensee for such purpose. If such payments are required, they must be sufficient to ensure compliance with the standards established by the Commission pursuant 42 USC 2201. to section $161 \mathrm{x}$. of this Act. No State shall be required under paragraph (3) to conduct proceedings concerning any license or regulation which would duplicate proceedings conducted by the Commission.219

${ }^{210}$ Public Law 95-604 (92 Stat. 3037) (1978), sec. 204(e), added a new subsec. o. 
"In adopting requirements pursuant to paragraph (2) of this subsection with respect to sites at which ores are processed primarily for their source material content or which are used for the disposal of byproduct material as defined in section 11 e. (2), the State may adopt alternatives (including, where appropriate, site-specific alternatives) to the requirements adopted and enforced by the Commission for the same purpose if, after notice and opportunity for public hearing, the Commission determines that such alternatives will achieve a level of stabilization and containment of the sites concerned, and a level of protection for public health, safety, and the environment from radiological and nonradiological hazards associated with such sites, which is equivalent to, to the extent practicable, or more stringent than the level which would be achieved by standards and requirements adopted and enforced by the Commission for the same purpose and any final standards promulgated by the Administrator of the Environmental Protection Agency in 42 USC 2022. accordance with section 275. Such alternative State requirements may take into account local or regional conditions, including geology, topography, hydrology and meteorology."220

42 USC 2022.

"Sec. 275. Health And Environmental Standards for Uranium Mill Tailings. -

"a. As soon as practicable, but not later than October 1, 1982, 221 the Administrator of the Environmental Protection Agency (hereinafter referred to in this section as the 'Administrator') shall, by rule, promulgate standards of general application (including standards applicable to licenses under section 104(h) of the Uranium Mill Tailings Radiation Control Act of 1978) for the protection of the public health, safety, and the environment from radiological and nonradiological hazards associated with residual radioactive materials (as defined in section 101 of the Uranium Mill Tailings Radiation Control Act of 1978) located at inactive uranium mill tailings sites and depository sites for such materials selected by the Secretary of Energy, pursuant to title I of the Uranium Mill Tailings Radiation Control Act of 1978. Standards promulgated pursuant to this subsection shall, to the maximum extent practicable, be consistent with the requirements of the Solid Waste Disposal Act, as amended. In establishing such standards, the Administrator shall consider the risk to the public health, safety, and the environment, the environmental and economic costs of applying such standards, and such other factors as the Administrator determines to be appropriate. ${ }^{222}$ The Administrator may periodically revise any standard promulgated pursuant to this subsection.

"After October 1, 1982, if the Administrator has not promulgated standards in final form under this subsection, any action of the Secretary 42 USC 7911. of Energy under title I of the Uranium Mill Tailings Radiation Control Act of 1978 which is required to comply with, or be taken in accordance

\footnotetext{
220Public Law $97-415$ (96 Stat. 2067) (1983), sec. 19 added this paragraph.

221 Public Law $97-415$ (96 Stat. 2067) (1983), sec. 18 substituted "October 1, 1982" for "one year after the date of enactment of this section."

222 Public Law 97-415 (96 Stat. 2067) (1983), sec. 22 added this language to sec. 275a.
} 
42 USC 6901. note.

42 USC 2014.

Promulgation authority.

42 USC 2014.

with, standards of the Administrator shall comply with, or be taken in accordance with, the standards proposed by the Administrator under this subsection until such time as the Administrator promulgates such standards in final form."223

"b. (1) As soon as practicable, but not later than October 31, 1982, the Administrator shall, by rule, propose and within 11 months thereafter promulgate in final form, 224 standards, general application for the protection of the public health, safety, and the environment from radiological and non-radiological hazards associated with processing and with the possession, transfer, and disposal of byproduct material, as defined in section 11 e. (2) of this Act, at sites at which ores are processed primarily for their source material content or which are used for the disposal of such byproduct material.

"If the Administrator fails to promulgate standards in final form under this subsection by October 1, 1983, the authority of the Administrator to promulgate such standards shall terminate, and the Commission may take actions under this Act without regard to any provision of this Act requiring such actions to comply with, or be taken in accordance with, standards promulgated by the Administrator. In any such case, the Commission shall promulgate, and from time to time revise, any such standards of general application which the Commission deems necessary to carry out its responsibilities in the conduct of its licensing activities under this Act. Requirements established by the Commission under this Act with respect to byproduct material as defined in section 11 e. (2) shall confirm to such standards. Any requirements adopted by the Commission respecting such byproduct material before promulgation by the Commission of such standards shall be amended as the Commission deems necessary to conform to such standards in the same manner as provided in subsection $f$. (3). Nothing in this subsection shall be construed to prohibit or suspend the implementation or enforcement by the Commission of any requirement of the Commission respecting byproduct material as defined in section 11 e. (2) pending promulgation by the Commission of any such standard of general application. 225 In establishing such standards, the Administrator shall consider the risk to the public health, safety, and the environment, the environmental and economic costs of applying such standards, and such other factors as the Administrator determines to be appropriate."226

“(2) Such generally applicable standards promulgated pursuant to this subsection for nonradiological hazards shall provide for the protection of human health and the environment consistent with the standards required under subtitle $C$ of the Solid Waste Dis-

${ }^{220}$ Public Law 97-415 (96 Stat. 2067) (1983), sec. 18 substituted this language for "one year after enactment of this section".

224 Public Law 97-415 (96 Stat. 2067) (1983), sec. 22 added this language to sec. 275b(1).

${ }^{225}$ Public Law 97-415(96Stat. 2067)(1983), sec. 18 changed subsec. b from "eighteen months after enactment of this section" to current language.

${ }^{228}$ Public Law 97-415 (96 Stat. 2067) (1983). sec. 22 added this language at end of subsec. b. 
42 USC 2021.

Publication in Federal Register. Notice, hearing opportunity.

Consultation.

Judicial review.

5 USC, et seq.

42 USC 2021.

42 USC 2014 42 USC 7401 posal Act, as amended, which are applicable to such hazards: Provided, however, That no permit issued by the Administrator is required under this Act or the Solid Waste Disposal Act, as amended, for the processing, possession, transfer, or disposal of byproduct material, as defined in section 11 e. (2) of this Act. The Administration may periodically revise any standard promulgated pursuant to this subsection. Within three years after such revision of any such standard, the Commission and any State permitted to exercise authority under section 274 b. (2) shall apply such revised standard in the case of any license for byproduct material as defined in section 11 e. (2) or any revision thereof.

"c. (1) Before the promulgation of any rule pursuant to this section, the Administrator shall publish the proposed rule in the Federal Register, together with a statement of the research, analysis, and other available information in support of such proposed rule, and provide a period of public comment of at least thirty days for written comments thereon and an opportunity, after such comment period and after public notice, for any interested person to present oral data, views, and arguments at a public hearing. There shall be a transcript of any such hearing. The Administrator shall consult with the Commission and the Secretary of Energy before promulgation of any such rule.

"(2) Judicial review of any rule promulgated under this section may be obtained by any interested person only upon such person filing a petition for review within sixty days after such promulgation in the United States court of appeals for the Federal judicial circuit in which such person resides or has his principal place of business. A copy of the petition shall be forthwith transmitted by the clerk of the court to the Administrator. The Administrator thereupon shall file in the court the written submission to, and transcript of, the written or oral proceedings on which such rule was based as provided in section 2112 of title 28, United States Code. The court shall have jurisdiction to review the rule in accordance with chapter 7 of title 5, United States Code, and to grant appropriate relief as provided in such chapter. The judgment of the court affirming, modifying, or setting aside, in whole or in part, any such rule shall be final, subject to judicial review by the Supreme Court of the United States upon certiorari or certification as provided in section 1254 of title 28, United States Code.

"(3) Any rule promulgated under this section shall not take effect earlier than sixty calendar days after such promulgation.

"d. Implementation and enforcement of the standards promulgated pursuant to subsection $b$. of this section shall be the responsibility of the Commission in the conduct of its licensing activities under this Act. States exercising authority pursuant to section $274 \mathrm{~b}$. (2) of this Act shall implement and enforce such standards in accordance with subsection o. of such section.

"e. Nothing in this Act applicable to byproduct material, as defined in section 11 e. (2) of this Act, shall affect the authority of the Admin- 
note.

Uranimum mill licensing requirement regulations.

Implementation and enforcement

Review, public comment, and suspension.

42 USC 2114.

42 USC 2023 istrator under the Clean Air Act of 1970, as amended, or the Federal Water Pollution Control Act, as amended.227

"f.(1) Prior to January 1, 1983, the Commission shall not implement or enforce the provisions of the Uranium Mill Licensing Requirements published as final rules at 45 Federal Register 65521 to 65538 on October 3, 1980 (hereinafter in this subsection referred to as the 'October 3 regulations'). After December 31, 1982, the Commission is authorized to implement and enforce the provisions of such October 3 regulations (and any subsequent modifications or additions to such regulations which may be adopted by the Commission), except as otherwise provided in paragraphs (2) and (3) of this subsection.

"(2) Following the proposal by the Administrator of standards under subsection $b$, the Commission shall review the October 3 regulations, and, not later than 90 days after the date of such proposal, suspend implementation and enforcement of any provision of such regulations which the Commission determines after notice and opportunity for public comment to require a major action or major commitment by licensees which would be unnecessary if-

"(A) the standards proposed by the Administrator are promulgated in final form without modification, and

"(B) the Commission's requirements are modified to conform to such standards.

Such suspension shall terminate on the earlier of April 1, 1984 or the date on which the Commission amends the October 3 regulations to conform to final standards promulgated by the Administrator under subsection $b$. During the period of such suspension, the Commission shall continue to regulate byproduct material (as defined in section 11 e. (2)) under this Act on a licensee-by-licensee basis as the Commission deems necessary to protect public health, safety, and the environment.

"(3) Not later than 6 months after the date on which the Administrator promulgates final standards pursuant to subsection $b$. of this section, the Commission shall, after notice and opportunity for public comment, amend the October 3 regulations, and adopt such modifications, as the Commission deems necessary to conform to such final standards of the Administrator.

"(4) Nothing in this subsection may be construed as affecting the authority or responsibility of the Commission under section 84 to promulgate regulations to protect the public health and safety and the environment."228

"Sec. 276. State Authority to Regulate Radiation Below Level of Regulatory Concern of Nuclear Regulatory Commission.

"(a) IN GENERAL. - No provision of this Act, or of the LowLevel Radioactive Waste Policy Act, may be construed to prohibit or otherwise restrict the authority of any State to regulate, on the basis of radiological hazard, the disposal or off-site incineration of low-level radioactive waste, if the Nuclear Regulatory Commis-

227 Public Law 95-604 (92 Stat. 3039) (1978), sec. 206(a), added sec. 275.

${ }^{228}$ Public Law 97-415 (96 Stat. 2067) (1983), sec. 18 added new subsec. " $"$ ". 
Separability.

Short title.

42 USC 2258

Records, transfer sion, after the date of the enactment of the Energy Policy Act of 1992 exempts such waste from regulation.

"(b) RELATION TO OTHER STATE AUTHORITY.-This section may not be construed to imply preemption of existing State authority. Except as expressly provided in subsection (a), this section may not be construed to confer on any State any additional authority to regulate activities licensed by the Nuclear Regulatory Commission.

"(c) DEFINITIONS.-For purposes of this section:

"(1) The term 'low-level radioactive waste' means radioactive material classified by the Nuclear Regulatory Commission as low-level radioactive waste on the date of the enactment of the Energy Policy Act of 1992.

“(2) The term 'off-site incineration' means any incineration of radioactive materials at a facility that is located off the site where such materials were generated.

"(3) The term 'State' means each of the several States, the District of Columbia, and any commonwealth, territory, or possession of the United States.".

(b) REVOCATION OF RELATED NRC POLICY STATEMENTS. - The policy statements of the Nuclear Regulatory Commission published in the Federal Register on July 3, 1990 (55 Fed. Reg. 27522) and August 29, 1986 (51 Fed. Reg. 30839), relating to radioactive waste below regulatory concern, shall have no effect after the date of the enactment of this Act.228a

"Sec. 281. Separability. - If any provision of this Act or the application of such provision to any person or circumstances, is held invalid, the remainder of this Act or the application of such provision to persons or circumstances other than those as to which it is held invalid, shall not be affected thereby.

"Sec. 291. SHORT TITLE. - This Act may be cited as the "Atomic Energy Act of 1954 '.

\section{"CHAPTER 20-JOINT COMMITTEE ON ATOMIC ENERGY ABOLISHED; FUNCTIONS AND RESPONSIBILITIES REASSIGNED}

"Sec. 301. Joint Committee On Atomic Energy Abolished.-

"a. The Joint Committee on Atomic Energy is abolished.

"b. Any reference in any rule, resolution, or order of the Senate or the House of Representatives or in any law, regulation, or Executive order to the Joint Committee on Atomic Energy shall, on and after the date of enactment of this section, be considered as referring to the committees of the Senate and the House of Representatives which, under the rules of the Senate and the House, have jurisdiction over the subject matter of such reference.

"c. All records, data, charts, and files of the Joint Committee on Atomic Energy are transferred to the committees of the Senate and House of Representatives which, under the rules of the Senate

228a Public Law 102-486 (106 Stat. 3122); Oet. 24, 1992 added new Sec. 276. 
and the House, have jurisdiction over the subject matters to which such records, data, charts, and files relate. In the event that any record, data, chart, or file shall be within the jurisdiction of more than one committee, duplicate copies shall be provided upon request.

Repeal.

42 USC 2251

et seq.

Repeal.

42 USC 2315.

Repeal.

Repeal.

2USC 190j.

42 USC 2259.

"Sec. 302. Transfer Of Certain Functions Of The Joint Committee On Atomic Energy And Conforming Amendments To Certain Other Laws.-

"a. Effective on the date of enactment of this section, chapter 17 of this Act is repealed.

."b. Section 103 of the Atomic Energy Community Act of 1955, as amended, is repealed.

"c. Section 3 of the Congressional Budget and Impoundment Control Act of 1974 is amended by-

"(1) striking the subsection designation '(a)'; and

“(2) repealing subsection (b).

"d. Section 252(a)(3) of the Legislative Reorganization Act of 1970 is repealed.

"Sec. 303. Information And Assistance To Congressional Committees.-

"a. The Secretary of Energy and the Nuclear Regulatory Commission shall keep the committees of the Senate and the House of Representatives which, under the rules of the Senate and the House, have jurisdiction over the functions of the Secretary or the Commission, fully and currently informed with respect to the activities of the Secretary and the Commission.

"b. The Department of Defense and Department of State shall keep the committees of the Senate and the House of Representatives which, under the rules of the Senate and the House, have jurisdiction over national security considerations of nuclear energy, fully and currently informed with respect to such matters within the Department of Defense and Department of State relating to national security considerations of nuclear technology which are within the jurisdiction of such committees.

"c. Any Government agency shall furnish any information requested by the committees of the Senate and the House of Representatives which, under the rules of the Senate and the House, have jurisdiction over the development, utilization, or application of nuclear energy, with respect to the activities or responsibilities of such agency in the field of nuclear energy which are within the jurisdiction of such committees.

" $\mathrm{d}$. The committees of the Senate and the House of Representatives which, under the rules of the Senate and the House, have jurisdiction over the development, utilization or application of nuclear energy, are authorized to utilize the services, information, facilities, and personnel of any Government agency which has activities or responsibilities in the field of nuclear energy which are within the jurisdiction of such committees: Provided, however, That any utilization of personnel by such committees shall be on a reimbursable basis and shall require, with respect to committees of the Senate, the prior written consent of the Committee on Rules and Administration, and with respect to committees of the House 
of Representatives, the prior written consent of the Committee on House Administration.229

Approved August 30, 1954, 9:44 a.m., E.D.T.

\section{CHAPTER 21-DEFENSE NUCLEAR FACILITIES SAFETY} BOARD

42 USC 2286.

President of U.S.

President of U.S.

Reports.

42 USC 2286.

President of U.S.
Sec. 311. Establishment.

(a) Establishment.-There is hereby established an independent establishment in the executive branch, to be known as the 'Defense Nuclear Facilities Safety Board' (hereafter in this chapter referred to as the 'Board').

(b) Membership.-(1) The Board shall be composed of five members appointed from civilian life by the President, by and with the advice and consent of the Senate, from among United States citizens who are respected experts in the field of nuclear safety with a demonstrated competence and knowledge relevant to the independent investigative and oversight functions of the Board. Not more than three members of the Board shall be of the same political party.

(2) Any vacancy in the membership of the Board shall be filled in the same manner in which the original appointment was made.

(3) No member of the Board may be an employee of, or have any significant financial relationship with, the Department of Energy or any contractor of the Department of Energy.

(4) Not later than 180 days after the date of the enactment of this chapter, the President shall submit to the Senate nominations for appointment to the Board. In the event that the President is unable to submit the nominations within such 180-day period, the President shall submit to the Committees on Armed Services and on Appropriations of the Senate and to the Speaker of the House of Representatives a report describing the reasons for such inability and a plan for submitting the nominations within the next 90 days. If the President is unable to submit the nominations within that 90-day period, the President shall again submit to such committees and the Speaker such a report and plan. The President shall continue to submit to such committees and the Speaker such a report and plan every 90 days until the nominations are submitted.

(c) Chairman and Vice Chairman.-(1) The President shall designate a Chairman and Vice Chairman of the board from among members of the Board.

(2) The Chairman shall be the chief executive officer of the Board and, subject to such policies as the Board may establish, shall exercise the functions of the Board with respect to-

(A) the appointment and supervision of employees of the Board;

(B) the organization of any administrative units established by the Board; and

${ }^{229}$ Public Law 95-110 (91 S1at. 884) (1977) added chapter 20. 
(C) the use and expenditure of funds.

(3) The Chairman may delegate any of the functions under this paragraph to any other member or to any appropriate officer of the Board.

(4) The Vice Chairman shall act as Chairman in the event of the absence or incapacity of the Chairman or in case of a vacancy in the office of Chairman.

(d) Terms.-(1) Except as provided under paragraph (2), the members of the Board shall serve for terms of five years. Members of the Board may be reappointed.

(2) Of the members first appointed-

(A) one shall be appointed for a term of one year;

(B) one shall be appointed for a term of two years;

(C) one shall be appointed for a term of three years;

(D) one shall be appointed for a term of four years; and

(E) one shall be appointed for a term of five years, as designated by the President at the time of appointment.

(3) Any member appointed to fill a vacancy occurring before the expiration of the term of office for which such member's predecessor was appointed shall be appointed only for the remainder of such term. A member may serve after the expiration of that member's term until a successor has taken office.

(e) Quorum. - Three members of the Board shall constitute a quorum, but a lesser number may hold hearings.

Sec. 312. Functions Of The Board.

The Board shall perform the following functions:

(1) Review And Evaluation Of Standards. - The Board shall review and evaluate the content and implementation of the standards relating to the design, construction, operation, and decommissioning of defense nuclear facilities of the Department of Energy (including all applicable Department of Energy orders, regulations, and requirements) at each Department of Energy defense nuclear facility. The Board shall recommend to the Secretary of Energy those specific measures that should be adopted to ensure that public health and safety are adequately protected. The Board shall include in its recommendations necessary changes in the content and implementation of such standards, as well as matters on which additional data or additional research is needed.

(2) Investigations. - (A) The Board shall investigate any event or practice at a Department of Energy defense nuclear facility which the Board determines has adversely affected, or may adversely affect, public health and safety.

(B) The purpose of any Böard investigation under subparagraph (A) shall be-

(i) to determine whether the Secretary of Energy is adequately implementing the standards described in paragraph (1) of the Department of Energy (including all applicable Department of Energy orders, regulations, and requirements) at the facility; 
(ii) to ascertain information concerning the circumstances of such event or practice and its implications for such standards;

(iii) to determine whether such event or practice is related to other events or practices at other Department of Energy defense nuclear facilities; and

(iv) to provide to the Secretary of Energy such recommendations for changes in such standards or the implementation of such standards (including Department of Energy orders, regulations, and requirements) and such recommendations relating to data or research needs as may be prudent or necessary.

(3) Analysis Of Design And Operational Data.-The Board shall have access to and may systematically analyze design and operational data, including safety analysis reports, from any Department of Energy defense nuclear facility.

(4) Review Of Facility Design And Construction.-The Board shall review the design of a new Department of Energy defense nuclear facility before construction of such facility begins and shall recommend to the Secretary, within a reasonable time, such modifications of the design as the Board considers necessary to ensure adequate protection of public health and safety. During the construction of any such facility, the Board shall periodically review and monitor the construction and shall submit to the Secretary, within a reasonable time, such recommendations relating to the construction of that facility as the Board considers necessary to ensure adequate protection of public health and safety. An action of the Board, or a failure to act, under this paragraph may not delay or prevent the Secretary of Energy from carrying out the construction of such a facility.

(5) Recommendations. - The Board shall make such recommendations to the Secretary of Energy with respect to Department of Energy defense nuclear facilities, including operations of such facilities, standards, and research needs, as the Board determines are necessary to ensure adequate protection of public health and safety. In making its recommendations the Board shall consider the technical and economic feasibility of implementing the recommended measures.

42 USC $2286 \mathrm{~b}$.

Sec. 313. Powers Of Board

(a) Hearings. - (1) The Board or a member authorized by the Board may, for the purpose of carrying out this chapter, hold such hearings and sit and act at such times and places, and require, by subpoena or otherwise, the attendance and testimony of such witnesses and the production of such evidence as the Board or an authorized member may find advisable.

(2) (A) Subpoenas may be issued only under the signature of the Chairman or any member of the Board designated by him and shall be served by any person designated by the Chairman, any member, or any person as otherwise provided by law. The attendance of witnesses and the production of evidence may be 
required from any place in the Untied States at any designated place of hearing in the United States.

(B) Any member of the Board may administer oaths or affirmations to witnesses appearing before the Board.

(C) If a person issued a subpoena under paragraph (1) refuses to obey such subpoena or is guilty of contumacy, any court of the United States within the judicial district within which the hearing is conducted or within the judicial district within which such person is found or resides or transacts business may (upon application by the Board) order such person to appear before the Board to produce evidence or to give testimony relating to the matter under investigation. Any failure to obey such order of the court may be punished by such court as a contempt of the court.

(D) The subpoenas of the Board shall be served in the manner provided for subpoenas issued by a United States district court under the Federal Rules of Civil Procedure for the United States district courts.

(E) All process of any court to which application may be made under this section may be served in the judicial district in which the person required to be served resides or may be found.

(b) Staff.-The Board may, for the purpose of performing its responsibilities under this chapter-

(1) hire such staff as it considers necessary to perform the functions of the Board, but not more than the equivalent of 100 full-time employees; and

(2) procure the temporary and intermittent services of experts and consultants to the extent authorized by section 3109(b) of title 5, United States Code, at rates the Board determines to be reasonable.

(c) Regulations.-The Board may prescribe regulations to carry out the responsibilities of the Board under this chapter.

Classified information.

42 U USC $2286 \mathrm{~b}$.

(d) Reporting Requirements. - The Board may establish reporting requirements for the Secretary of Energy which shall be binding upon the Secretary. The information which the Board may require the Secretary of Energy to report under this subsection may include any information designated as classified information, or any information designated as safeguards information and protected from disclosure under section 147 or 148 of this Act.

(e) Use Of Government Facilities, Etc.-The Board may, for the purpose of carrying out its responsibilities under this chapter, use any facility, contractor, or employee of any other department or agency of the Federal Government with the consent of and under appropriate support arrangements with the head of such department or agency and, in the case of a contractor, with the consent of the contractor.

(f) Assistance From Certain Agencies Of The Federal Government.-With the consent of and under appropriate support arrangements with the Nuclear Regulatory Commission, the Board may obtain the advice and recommendations of the staff of the Commission on matters relating to the Board's responsibilities and 
42 USC $2286 \mathrm{c}$.

Contracts.

42 USC 2286d.

Federal Register, publication. may obtain the advice and recommendations of the Advisory Committee on Reactor Safeguards on such matters.

(g) Assistance From Organizations Outside The Federal Government-The Board may enter into an agreement with the National Research Council of the National Academy of Sciences or any other appropriate group or organization of experts outside the Federal Government "chosen by the Board to assist the Board in carrying out its responsibilities under this chapter.

(h) Resident Inspectors. - The Board may assign staff to be stationed at any Department of Energy defense nuclear facility to carry out the functions of the Board.

(i) Special Studies. - The Board may conduct special studies pertaining to adequate protection of public health and safety at any Department of Energy defense nuclear facility.

(j) Evaluation Of Information.-The Board may evaluate information received from the scientific and industrial communities, and from the interested public, with respect to-

(1) events or practices at any Department of Energy defense nuclear facility; or

(2) suggestions for specific measures to improve the content of standards described in section 312(1), the implementation of such standards, or research relating to such standards at Department of Energy defense nuclear facilities.

Sec. 314. Responsibilities Of The Secretary Of Energy.

(a) Cooperation.-The Secretary of Energy shall fully cooperate with the Board and provide the Board with ready access to such facilities, personnel, and information as the Board considers necessary to carry out its responsibilities under this chapter. Each contractor operating a Department of Energy defense nuclear facility under a contract awarded by the Secretary shall, to the extent provided in such contract or otherwise with the contractor's consent, fully cooperate with the Board and provide the Board with ready access to such facilities, personnel, and information of the contractor as the Board considers necessary to carry out its responsibilities under this chapter.

(b) Access To Information.-The Secretary of Energy may deny access to information provided to the Board to any person who-

(1) has not been granted an appropriate security clearance or access authorization by the Secretary of Energy; or

(2) does not need such access in connection with the duties of such person.

Sec. 315. Board Recommendations.

(a) Public Availability And Comment.-Subject to subsections (g) and (h) and after receipt by the Secretary of Energy of any recommendations from the Board under section 312, the Board promptly shall make such recommendations available to the public in the Department of Energy's regional public reading rooms and shall publish in the Federal Register such recommendations and a request for the submission to the Board of public comments on such recommendations. Interested persons shall have 30 days after the date of the publication of such notice in which to submit com- 
Federal Register, publication.

Federal Register, publication. Reports.

ments, data, views, or arguments to the Board concerning the recommendations.

(b) Response By Secretary.-(1) The Secretary of Energy shall transmit to the Board, in writing, a statement on whether the Secretary accepts or rejects, in whole or in part, the recommendations submitted to him by the Board under section 312, a description of the actions to be taken in response to the recommendations, and his views on such recommendations. The Secretary of Energy shall transmit his response to the Board within 45 days after the date of the publication, under subsection (a), of the notice with respect to such recommendations or within such additional period, not to exceed 45 days, as the Board may grant.

(2) At the same time as the Secretary of Energy transmits his response to the Board under paragraph (1), the Secretary, subject to subsection $(\mathrm{h})$, shall publish such response, together with a request for public comment on his response, in the Federal Register.

(3) Interested persons shall have 30 days after the date of the publication of the Secretary of Energy's response in which to submit comments, data, views, or arguments to the Board concerning the Secretary's response.

(4) The Board may hold hearings for the purpose of obtaining public comments on its recommendations and the Secretary of Energy's response.

(c) Provision Of Information To Secretary.-The Board shall furnish the Secretary of Energy with copies of all comments, data, views, and arguments submitted to it under subsection (a) or (b).

(d) Final Decision. - If the Secretary of Energy, in a response under subsection (b)(1), rejects (in whole or part) any recommendation made by the Board under section 312 , the Board shall either reaffirm its original recommendation or make a revised recommendation and shall notify the Secretary of its action. Within 30 days after receiving the notice of the Board's action under this subsection, the Secretary shall consider the Board's action and make a final decision on whether to implement all or part of the Board's recommendations. Subject to subsection (h), the Secretary shall publish the final decision and the reasoning for such decision in the Federal Register and shall transmit to the Committees on Armed Services and on Appropriations of the Senate, and to the Speaker of the House of Representatives a written report containing that decision and reasoning.

(e) Implementation Plan.-The Secretary of Energy shall prepare a plan for the implementation of each Board recommendation, or part of a recommendation, that is accepted by the Secretary in his final decision. The Secretary shall transmit the implementation plan to the Board within 90 days after the date of the publication of the Secretary's final decision on such recommendation in the Federal Register. The Secretary may have an additional 45 days to transmit the plan if the Secretary submits to the Board and to the Committees on Armed Services and on Appropriations of the Senate and to the Speaker of the House of Representatives a 
Reports.

Reports.

Public health and safety.

President of U.S.

Public information.

President of U.S. notification setting forth the reasons for the delay and describing the actions the Secretary is taking to prepare an implementation plan under this subsection. The Secretary may implement any such recommendation (or part of any such recommendation) before, on, or after the date on which the Secretary transmits the implementation plan to the Board under this subsection.

(f) Implementation. - (1) Subject to paragraph (2), not later than one year after the date on which the Secretary of Energy transmits an implementation plan with respect to a recommendation (or part thereof) under subsection (e), the Secretary shall carry out and complete the implementation plan. If complete implementation of the plan takes more than 1 year, the Secretary of Energy shall submit a report to the Committees on Armed Services and on Appropriations of the Senate and to the Speaker of the House of Representatives setting forth the reasons for the delay and when implementation will be completed.

(2) If the Secretary of Energy determines that the implementation of a Board recommendation (or part thereof) is impracticable because of budgetary considerations, or that the implementation would affect the Secretary's ability to meet the annual nuclear weapons stockpile requirements established pursuant to section 91 of this Act, the Secretary shall submit to the President, to the Committees on Armed Services and on Appropriations of the Senate, and to the Speaker of the House of Representatives a report containing the recommendation and the Secretary's determination.

(g) Imminent Or Severe Threat.-(1) In any case in which the Board determines that a recommendation submitted to the Secretary of Energy under section 312 relates to an imminent or severe threat to public health and safety, the Board and the Secretary of Energy shall proceed under this subsection in lieu of subsections (a) through (d).

(2) At the same time that the Board transmits a recommendation relating to an imminent or severe threat to the Secretary of Energy, the Board shall also transmit the recommendation to the President and for information purposes to the Secretary of Defense. The Secretary of Energy shall submit his recommendation to the President. The President shall review the Secretary of Energy's recommendation and shall make the decision concerning acceptance or rejection of the Board's recommendation.

(3) After receipt by the President of the recommendation from the Board under this subsection, the Board promptly shall make such recommendation available to the public and shall transmit such recommendation to the Committees on Armed Services and on Appropriations of the Senate and to the Speaker of the House of Representatives. The President shall promptly notify such committees and the Speaker of his decision and the reasons for that decision. 
42 USC $2286 \mathrm{e}$.

42 USC $2286 \mathrm{e}$.

42. USC $2286 f$.

42 USC 2286g.

(h) Limitation.- Notwithstanding any other provision of this section, the requirements to make information available to the public under this section-

(1) shall not apply in the case of information that is classified; and

(2) shall be subject to the orders and regulations issued by the Secretary of Energy under sections 147 and 148 of this Act to prohibit dissemination of certain information.

Sec. 316. Reports

(a) Board Report.-(1) The Board shall submit to the Committees on Armed Services and on Appropriations of the Senate and to the Speaker of the House of Representatives each year, at the same time that the President submits the budget to Congress pursuant to section 1105(a) of title 31 , United States Code, a written report concerning its activities under this chapter, including all recommendations made by the Board, during the year preceding the year in which the report is submitted. The Board may also issue periodic unclassified reports on matters within the Board's responsibilities.

(2) The annual report under paragraph (1) shall include an assessment of-

(A) The improvements in the safety of Department of Energy defense nuclear facilities during the period covered by the report;

(B) the improvements in the safety of Department of Energy defense nuclear facilities resulting from actions taken by the Board or taken on the basis of the activities of the Board; and

(C) the outstanding safety problems, if any, of Department of Energy defense nuclear facilities.

(b) DOE Report.-The Secretary of Energy shall submit to the Committees on Armed Services and on Appropriations of the Senate and to the Speaker of the House of Representatives each year, at the same time that the President submits the budget to Congress pursuant to section 1105(a) of title 31, United State Code, a written report concerning the activities of the Department of Energy under this chapter during the year preceding the year in which the report is submitted.

Sec. 317. Judicial Review.

Chapter 7 of title 5, United States Code, shall apply to the activities of the Board under this chapter.

Sec. 318. Definition.

As used in this chapter, the term 'Department of Energy defense nuclear facility' means any of the following:

(1) A production facility or utilization facility (as defined in section 11 of this Act) that is under the control or jurisdiction of the Secretary of Energy and that is operated for national security purposes, but the term does not include-

(A) any facility or activity covered by Executive Order No. 12344, dated February 1,1982, pertaining to the Naval nuclear propulsion program; 
42 USC 2286h.

42 USC $2286 \mathrm{~h}-1$

42 USC 2286i.

42 USC $2286 e$ note.
(B) any facility or activity involved with the assembly or testing of nuclear explosives or with the transportation of nuclear explosives or nuclear material;

(C) any facility that does not conduct atomic energy defense activities; or

(D) any facility owned by the United States Enrichment Corporation.

(2) A nuclear waste storage facility under the control or jurisdiction of the Secretary of Energy, but the term does not include a facility developed pursuant to the Nuclear Waste Policy Act of 1982 (42 U. S.C. 10101 et seq.) and licensed by the Nuclear Regulatory Commission.

Sec. 319. Contract Authority Subject To Appropriations.

The authority of the Board to enter into contracts under this chapter is effective only to the extent that appropriations (including transfers of appropriations) are provided in advance for such purpose.

Sec. 320. Transmittal Of Certain Information to Congress.

Whenever the Board submits or transmits to the President or the Director of the Office of Management and Budget any legislative recommendation, or any statement or information in preparation of a report to be submitted to the Congress pursuant to section 316(a), the Board shall submit at the same time a copy thereof to the Congress. $229 \mathrm{a}$

Sec. 321. Annual Authorization Of Appropriations.

Authorizations of appropriations for the Board for fiscal years beginning after fiscal year 1989 shall be provided annually in authorizations Acts.

(2) The table of contents at the beginning of the Atomic Energy Act of 1954 is amended by adding at the end the following:

“CHAPTER 21-DEFENSE NUCLEAR FACILITIES SAFETY BOARD

"Sec. 311. Establishment.

"Sec. 312. Functions of the Board.

"Sec. 313. Powers of Board.

"Sec. 314. Responsibilities of the Secretary of Energy.

"Sec. 315. Board recommendations.

"Sec. 316. Reports.

"Sec. 317. Judicial review.

"Sec. 318. Definition.

"Sec. 319. Contract authority subject to appropriations.

"Sec. 320. Annual authorization of appropriations."

(b) Salary For Board Members At Executive Schedule Level III.-Section 5314 of title 5, United States Code, is amended by inserting after "Members, Nuclear Regulatory Commission." the following:

"Members, Defense Nuclear Facilities Safety Board.".

(c) Requirements For First Annual Report.-(1) Before submission of the first annual report by the Defense Nuclear Facilities Safety Board under section 316(a) of the Atomic Energy Act of 1954 (as added by subsection (a)), the Board shall conduct a study on whether nuclear facilities of the Department of Energy that are excluded from the definition of "Department of Energy defense nuclear facility" in section

229aepublic Law 103-160, Div c., Title XXXII, § 3202(a)(2), Nov. 30, 1993107 Stat 1959. 
318(1)(C) of such Act (hereafter in this subsection referred to as "non-defense nuclear facilities") should be subject to independent external oversight. The Board shall include in such first annual report the results of such study and the recommendation of the Board on whether non-defense nuclear facilities should be subject to independent external oversight.

(2) If the Board recommends in the report that non-defense nuclear facilities should be subject to such oversight, the report shall include a discussion of alternative mechanisms for implementing such oversight, including mechanisms such as a separate executive agency and oversight as a part of the Board's responsibilities. The discussion of alternative mechanisms of oversight also shall include considerations of budgetary costs, protection of the security of sensitive nuclear weapons information, and the similarities and differences in the design, construction, operation, and decommissioning of defense and non-defense nuclear facilities of the Department of Energy.

(d) Requirements For Fifth Annual Report.-The fifth annual report submitted by the Defense Nuclear Facilities Safety Board under section 316(a) of the Atomic Energy Act of 1954 (as added by subsection (a)) shall include-

(1) an assessment of the degree to which the overall administration of the Board's activities are believed to meet the objectives of Congress in establishing the Board;

(2) recommendations for continuation, termination, or modification of the Board's functions and programs, including recommendations for transition to some other independent oversight arrangement if it is advisable; and

(3) recommendations for appropriate transition requirements in the event that modifications are recommended.

SEC. 1442. TRANSFER

The Secretary of Energy, to the extent provided in appropriations Acts, shall transfer to the Defense Nuclear Facilities Safety Board established by section 311 of the Atomic Energy Act of 1954 (as added by section 1441) from sums available for obligation for national security programs such sums as may be necessary, as determined by such Board, for the operation of the Board during fiscal year 1989, but in no case may more that $\$ 7,000,000$ transferred for such purpose. Sums transferred shall be available to such Board to carry out its responsibilities under Chapter 21 of the Atomic Energy Act of 1954 (as added by section 1441) and shall remain available until expended.230

42 USC 2210

note.

Contracts.

\section{NEGOTIATED RULEMAKING ON FINANCIAL PROTECTION FOR RADIOPHARMACEUTICAL LICENSEES.}

(A) Rulemaking Proceeding.-

(1) Purpose.-The Nuclear Regulatory Commission (hereafter in this section referred to as the "Commission") shall initiate a proceeding, in accordance with the requirements of this section, to determine whether to enter into indemnity agreements under section 170 of the Atomic Energy Act of 1954 (42 U.S.C. 2210) with persons

${ }^{200}$ Public Law 100-456 (102 Stat. 2076) (1988) added Chapter 21. 
licensed by the Commission under section 81, 104(a), or 104(c) of the Atomic Energy Act of 1954 (42 U.S.C. 2111, 2134(a), and 2134(c)) or by a State under section 274(b) of the Atomic Energy Act of 1954 (42 U.S.C. 2021(b)) for the manufacture, production, possession, or use of radioisotopes or radiopharmaceutical for medical purposes (hereafter in this section referred to as "radiopharmaceutical licensees")

(2) Final Determination.-A final determination with respect to whether radiopharmaceutical licensees, or any class of such licensees, shall be indemnified pursuant to section 170 of the Atomic Energy Act of 1954 (42 U.S.C.2210) and if so, the terms and conditions of such indemnification, shall be rendered by the Commission within 18 months of the date of the enactment of this Act.

(b) Negotiated Rulemaking.-

(1) Administrative Conference Guidelines. - For the purpose of making the determination required under subsection (a), the Commission shall, to the extent consistent with the provisions of this Act, conduct a negotiated rulemaking in accordance with the guidance provided by the Administrative Conference of the United States in Recommendation 82-4, "Procedures for Negotiating Proposed Regulations" (42 Fed. Reg. 30708, July 15, 1982).

(2) Designation Of Convener. - Within 30 days of the date of the enactment of this Act, the Commission shall designate an individual or individuals recommended by the Administrative Conference of the United States to serve as a convener for such negotiations.

(3) Submission Recommendations Of The Convener.-The convener shall, not later than 7 months after the date of the enactment of this Act, submit to the Commission recommendations for a proposed rule regarding whether the Commission should enter into indemnity agreements under section 170 of the Atomic Energy Act of 1954 (42U.S.C. 2210) with radiopharmaceutical licensees and, if so, the terms and conditions of such indemnification. If the convener recommends that such indemnity be provided for radiopharmaceutical licensees, the proposed rule submitted by the convener shall set forth the procedures for the execution if indemnification agreements with radiopharmaceutical licensees.

(4) Publication Of Recommendations And Proposed Rule.-If the convener recommends that such indemnity be provided for radiopharmaceutical licensees, the Commission shall publish the recommendations of the convener submitted under paragraph (3) as a notice of proposed rulemaking within 30 days of the submission of such recommendations under such paragraph.

(5) Administrative Procedures.-To the extent consistent with the provisions of this Act, the Commission shall conduct the proceeding required under subsection (a) in accordance with section 553 of title 5 , United States Code.231

${ }^{231}$ PublicLaw 100-408 (102 Stat. 1066)(1988)Sec. 19 provided for this rulemaking which is not part of the Atomic Energy Ad. 


\section{"CHAPTER 22-GENERAL PROVISIONS}

"SEC. 1201. DEFINITIONS.

"For purposes of this title:

"(1) The term 'alternative technologies for uranium enrichment' means technologies to enrich uranium by methods other than the gaseous diffusion process.

“(2) The term 'AVLIS' means atomic vapor laser isotope separation technology.

"(3) The term 'Board' means the Board of Directors of the Corporation established under section 1304.

“(4) The term 'Corporation' means the United States Enrichment Corporation.

"(5) The term 'corrective actions' has the meaning given such term by the Administrator of the Environmental Protection Agency under section 3004(u) of the Solid Waste Disposal Act (42 U.S.C. 6924(u)).

"(6) The term 'decontamination and decommissioning' means those activities, other than response actions or corrective actions, undertaken to decontaminate and decommission inactive uranium enrichment facilities that have residual radioactive or mixed radioactive and hazardous chemical contamination, including depleted tailings.

“(7) The term 'Department' means the Department of Energy.

“(8) The term 'highly enriched uranium' means uranium enriched to 20 percent or more of the uranium-235 isotope.

“(9) The term 'low-enriched uranium' means uranium enriched to less than 20 percent of the uranium-235 isotope.

"(10) The term 'releases' has the meaning given the term 'release' in section 101(22) of the Comprehensive Environmental response, Compensation, and Liability Act of 1980 (42 U.S.C. 9601(22)).

"(11) The term 'remedial action' has the meaning given such term in section 101(24) of the Comprehensive Environmental Response, Compensation, and Liability Act of 1980 (42 U.S.C. 9601(24)).

"(12) the term 'response actions' has the meaning given the term 'response' in section 101(25) of the Comprehensive Environmental Response, Compensation, and Liability Act of 1980 (42 U.S.C. 9601(25)).

"(13) The term 'Secretary' means the Secretary of Energy.

“(14) The term 'uranium enrichment' means the separation of uranium of a given isotopic content into 2 components, 1 having a higher percentage of a fissile isotope and 1 having a lower percentage.

42 USC 2297a. "SEC. 1202. PURPOSES.

"The Corporation is created for the following purposes:

(1) To operate as a business enterprise on a profitable and efficient basis.

"(2) To maximize the long-term value of the Corporation to the Treasury of the United States. 
ed.

“(3) To lease Department uranium enrichment facilities, as need-

"(4) To acquire uranium for uranium enrichment, low-enriched uranium for resale, and highly enriched uranium for conversion into low-enriched uranium, as needed.

“(5) To market and sell its enriched uranium and uranium enrichment and related services to-

"(A) the Department for governmental purposes; and

"(B) domestic and foreign persons, as provided in section 1303(6).

"(6) To conduct research and development as required to meet business objectives for the purposes of identifying, evaluating, improving, and testing alternative technologies for uranium enrichment.

"(7) To conduct the business as a self-financing corporation and eliminate the need for Federal Government appropriations or sources of Federal financing other than those provided in this title.

"(8) To help maintain a reliable and economical domestic source of uranium enrichment services.

"(9) To comply with laws, and regulations promulgated thereunder, to protect the public health, safety, and the environment.

"(10) To continue at all times to meet the objectives of ensuring the Nation's common defense and security, including abiding by United States laws and policies concerning special nuclear materials and nonproliferation of atomic weapons and other nonpeaceful uses of atomic energy.

"(11) To take all other lawful actions in furtherance of these purposes.

\section{“CHAPTER 23-ESTABLISHMENT, POWERS, AND ORGANIZATION OF CORPORATION}

42 USC 2297b.

42 USC $2297 \mathrm{~b}-1$.

"SEC. 1301. ESTABLISHMENT OF THE CORPORATION.

"(a) IN GENERAL. - There is established a body corporate to be known as the United States Enrichment Corporation.

"(b) GOVERNMENT CORPORATION.-The Corporation shall be established as a wholly owned Government corporation subject to chapter 91 of title 31, United States Code (commonly referred to as the Government Corporation Control Act), except as otherwise provided in this title

"(c) FEDERAL AGENCY.-The Corporation shall be an agency and instrumentality of the United States.

"SEC. 1302. CORPORATE OFFICES.

"The Corporation shall maintain an office for the service of process and papers in the District of Columbia, and shall be deemed, for purposes of venue in civil actions, to be a resident thereof. The Corporation may establish offices in such other place or places as it may deem necessary or appropriate in the conduct of its business.

42 USC 2297b-2. "SEC. 1303. POWERS OF THE CORPORATION.

"In order to accomplish its purposes, the Corporation- 
"(1) shall, except as provided in this title or applicable Federal law, have all the powers of a private corporation incorporated under the District of Columbia Business Corporation Act;

"(2) shall have the priority of the United States with respect to the payment of debts out of bankrupt, insolvent, and decedents' estates;

"(3) may obtain from the Administrator of General Services the services the Administrator is authorized to provide agencies of the United States, on the same basis as those services are provided to other agencies of the United States;

"(4) shall enrich uranium, provide for uranium to be enriched by others, or acquire enriched uranium (including low-enriched uranium derived from highly enriched uranium provided under section 1408);

"(5) may conduct, or provide for conducting, those research and development activities related to uranium enrichment and related processes and activities the Corporation considers necessary or advisable to maintain the Corporation as a commercial enterprise operating on a profitable and efficient basis;

"(6) may enter into transactions regarding uranium, enriched uranium, or depleted uranium with-

"(A) persons licensed under section 53, 63, 103, or 104 in accordance with the licenses held by those persons;

"(B) persons in accordance with, and within the period of, an agreement for cooperation arranged under section 123; or

"(C) persons otherwise authorized by law to enter into such transactions;

“(7) may enter into contracts with persons licensed under section $53,63,103$, or 104 , for as long as the Corporation considers necessary or desirable, to provide uranium or uranium enrichment and related services;

“(8) may enter into contracts to provide uranium or uranium enrichment and related services in accordance with, and within the period of, an agreement for cooperation arranged under section 123 or as otherwise authorized by law; and

"(9) shall sell to the Department as provided in this title, without regard to section $57 \mathrm{e}$., the amounts of uranium enrichment and related services that the Department determinesfrom time to time are required for it to-

"(A) carry out Presidential directions and authorizations under section 91; and

42 USC $2297 \mathrm{~b}-3$.

"(B) conduct other Department programs.

"SEC. 1304. BOARD OF DIRECTORS.

“(a) IN GENERAL.-The powers of the Corporation are vested in the Board of Directors.

"(b) APPOINTMENT.-The Board of Directors shall consist of 5 individuals, to be appointed by the President by and with the advice and consent of the Senate. The President shall designate a Chairman of the Board from among members of the Board.

"(c) QUALIFICATIONS.-Members of the Board shall be citizens of the United States. No member of the Board shall be an employee of the 
Corporation or have any direct financial relationship with the Corporation other than that of being a member of the Board.

"(d) TERMS.-

"(1) IN GENERAL. - Except as provided in paragraph (2), members of the Board shall serve 5-year terms or until the election of a new Board of Directors under section 1704, whichever comes first.

"(2) INITIAL MEMBERS. - Of the members first appointed to the Board-

"(A) 1 shall be appointed for a 1-year term;

"(B) 1 shall be appointed for a 2-year term;

"(C) 1 shall be appointed for a 3-year term; and

"(D) 1 shall be appointed for a 4-year term.

“(3) REAPPOINTMENT. - Members of the Board may be reappointed by the President, by and with the advice and consent of the Senate.

"(e) VACANCIES. - Upon the occurrence of a vacancy on the Board, the President by and with the advice and consent of the Senate shall appoint an individual to fill such vacancy for the remainder of the applicable term.

"(f) MEETINGS AND QUORUM.-The Board shall meet at any time pursuant to the call of the Chairman and as provided by the bylaws of the Corporation, but not less than quarterly. Three voting members of the Board shall constitute a quorum. A majority of the Board shall adopt and from time to time may amend bylaws for the operation of the Board.

"(g) POWERS. - The Board shall be responsible for general management of the Corporation and shall have the same authority, privileges, and responsibilities as the board of directors of a private corporation incorporated under the District of Columbia Business Corporation Act.

"(h) COMPENSATION.-Members of the Board shall serve on a part-time basis and shall receive per diem, when engaged in the actual performance of Corporation duties, plus reimbursement for travel, subsistence, and other necessary expenses incurred in the performance of their duties.

“(i) MEMBERSHIP OF SECRETARY OF TREASURY.-The President may appoint the Secretary of the Treasury or his designee to serve as a member of the Board or as a nonvoting, ex officio member of the Board.

“(j) CONFLICT OF INTEREST REQUIREMENTS.-No director, officer, or other management level employee of the Corporation may have a financial interest in any customer, contractor, or competitor of the Corporation or in any business that may be adversely affected by the success of the Corporation.

42 USC 2297b-4. "SEC. 1305. EMPLOYEES OF THE CORPORATION.

"(a) APPOINTMENT.-The Board shall appoint such officers and employees as are necessary for the transaction of its business.

“(b) COMPENSATION, DUTIES, AND REMOVAL.-The Board shall, without regard to section 5301 of title 6, United States Code, fix the compensation of all officers and employees of the Corporation, define their duties, and provide a system of organization to fix responsi- 
bility and promote efficiency. Any officer or employee of the Corporation may be removed in the discretion of the Board.

"(c) APPLICABLE CRITERIA. - The Board shall ensure that the personnel function and organization is consistent with the principles of section 2301(b) of title 5, United States Code, relating to merit system principles. Officers and employees shall be appointed, promoted, and assigned on the basis of merit and fitness, and other personnel actions shall be consistent with the principles of fairness and due process but without regard to those provisions of title 5 of the United States Code governing appointments and other personnel actions in the competitive service.

"(d) TREATMENT OF PERSONS EMPLOYED PRIOR TO TRANSITION DATE.-Compensation, benefits, and other terms and conditions of employment in effect immediately prior to the transition date, whether provided by statute or by rules of the Department or the executive branch, shall continue to apply to officers and employees who transfer to the Corporation from other Federal employment until changed by the Board.

"(e) PROTECTION OF EXISTING EMPLOYEES.-

"(1) IN GENERAL.-It is the purpose of this subsection to ensure that the establishment of the Corporation pursuant to this chapter shall not result in any adverse effects on the employment rights, wages, or benefits of employees at facilities that are operated, directly or under contract, in the performance of the functions vested in the Corporation.

"(2) APPLICABILITY OF EXISTING COLLECTIVE BARGAINING AGREEMENT.-Any employer (including the Corporation) at a facility described in paragraph (1) shall abide by the terms of a collective bargaining agreement in effect on April 30, 1991, at each individual facility until-

"(A) the earlier of the date on which a new bargaining agreement is signed; or

"(B) the end of the 2-year period beginning on the date of the enactment of this title.

"(3) APPLICABIIITY OF NLRA.-Except as specifically provided in this subsection, the Corporation is subject to the provisions of the National Labor Relations Act (29 U.S.C. 151 et seq.).

“(4) BENEFITS OF TRANSFEREES AND DETAILEES.-At the request of the Board and subject to the approval of the Secretary, an employee of the Department may be transferred or detailed as provided for in section 1315, to the Corporation without any loss in accrued benefits or standing within the Civil Service System. For those employees who accept transfer to the Corporation, it shall be their option as to whether to have any accrued retirement benefits transferred to a retirement system established by the Corporation or to retain their coverage under either the Civil Service Retirement System or the Federal Employees' Retirement System, as applicable, in lieu of coverage by the Corporation's retirement system. For those employees electing to remain with one of the Federal retirement systems, the Corporation shall withhold pay and make such payments as are required under the 
Federal retirement system. For those Department employees detailed, the Department shall offer those employees a position of like grade, compensation, and proximity to their official duty station after their services are no longer required by the Corporation. "SEC. 1306. AUDITS.

"(a) INDEPENDENT AUDITS.-

(1) IN GENERAL.-The financial statements of the Corporation shall be prepared in accordance with generally accepted accounting principles and shall be audited annually by an independent certified public accountant in accordance with auditing standards issued by the Comptroller General. Such auditing standards shall be consistent with the private sector's generally accepted auditing standards.

"(2) REVIEW BY GAO. - The Comptroller General may review any audit of the Corporation's financial statements conducted under paragraph (1). The Comptroller General shall report to the Congress and the Corporation the results of any such review and shall include in such report appropriate recommendations.

"(b) GAO AUDITS.-

(1) IN GENERAL.-The Comptroller General may audit the financial statements of the Corporation for any year in the manner provided in subsection (a)(1).

“(2) REIMBURSEMENT BY CORPORATION.-The Corporation shall reimburse the Comptroller General for the full cost of any audit conducted under this subsection, as determined by the Comptroller General.

"(c) AVAILABILITY OF BOOKS AND RECORDS.-All books, accounts, financial records, reports, files, papers, and other property belonging to or in use by the Corporation and its auditor that the Comptroller General considers necessary to the performance of any audit or review under this section shall be made available to the Comptroller General, subject to section 1314.

(d) TREATMENT OF GAO AUDITS.-Activities the Comptroller General conducts under this section shall be in lieu of any other audit of the financial transactions of the Corporation the Comptroller General is required to make under chapter 91 of title 31, United States Code, or other law.

42 USC 2297b-6. "SEC. 1307. ANNUAL REPORTS.

"(a) IN GENERAI.-The Corporation shall prepare and submit an annual report of its activities to the President and the Congress. This report shall contain-

"(1) a general description of the Corporation's operations;

"(2) a summary of the Corporation's operating and financial performance, including an explanation of the decision to pay or not pay dividends;

“(3) copies of audit reports prepared under section 1305;

"(4) the information required under regulations issued under section 13 of the Securities Exchange Act of 1934 (15 U.S.C. 78m); and

"(5) an identification and assessment of any impairment of capital or ability of the Corporation to comply with this title. 
42 USC 2297b-7. "SEC. 1308. ACCOUNTS.

"(b) DEADLINE.-The report shall be completed not later than 150 days following the close of each of the Corporation's fiscal years and shall accurately reflect the financial position of the Corporation at fiscal year end.

"(a) ESTABLISHMENT OF UNITED STATES ENRICHMENT CORPORATION FUND.-There is established in the Treasury of the United States a revolving fund, to be known as the 'United States Enrichment Corporation Fund', which shall be available to the Corporation, without need for further appropriation and without fiscal year limitation, for carrying out its purposes, functions, and powers, and which shall not be subject to apportionment under subchapter II of chapter 15 of title 31, United States Code.

"(b) TRANSFER OF UNEXPENDED BALANCES. - On the transfer date, the Secretary shall, without need of further appropriation, transfer to the Corporation the unexpended balance of appropriations and other monies available to the Department (inclusive of funds set aside for accounts payable), and accounts receivable which are related to functions and activities acquired by the Corporation from the Department pursuant to this title, including all advance payments.

42 USC 2297b-8. "SEC. 1309. OBLIGATIONS.

"(a) ISSUANCE.-

"(1) IN GENERAL. - The Corporation may issue and sell bonds, notes, and other evidences of indebtedness (collectively referred to in this title as 'bonds'), except that the Corporation may not issue or sell bonds for the purpose of constructing new uranium enrichment facilities or conducting directly related preconstruction activities. Borrowing under this paragraph during any fiscal year ending before October 1, 1996, shall be subject to approval in appropriation Acts.

"(2) USE OF REVENUES. - The Corporation may pledge and use its revenues for payment of the principal of and interest on its bonds, for their purchase or redemption, and for other purposes incidental to these functions, including creation of reserve funds and other funds that may be similarly pledged and used.

“(3) AGREEMENTS WITH HOLDERS AND TRUSTEES.The Corporation may enter into binding covenants with the holders and trustees of its bonds with respect to

"(A) the establishment of reserve and other funds;

"(B) stipulations concerning the subsequent issuance of bonds; and

"(C) other matters not inconsistent with this title; that the Corporation determines necessary or desirable to enhance the marketability of the bonds.

“(b) NOT OBLIGATIONS OF UNITED STATES.-Bonds issued by the Corporation under this section shall not be obligations of, or guaranteed as to principal or interest by, the United States, and the bonds shall so plainly state.

"(c) TERMS AND CONDITIONS.-

"(1) NEGOTIABLE; MATURTTY.-Bonds issued by the Corporation under this section shall be negotiable instruments unless 
otherwise specified in the bond and shall mature not more than 50 years after their date of issuance.

"(2) ROLE OF SECRETARY OF THE TREASURY.-

"(A) RIGHT OF DISAPPROVAL. - The Corporation may set the terms and conditions of bonds issued under this section, subject to disapproval of such terms and conditions by the Secretary of the Treasury within 5 days after the Secretary of the Treasury is notified of the following terms and conditions of the bonds:

"(i) Their forms and denominations.

"(ii) The times, amounts, and prices at which they are sold.

"(iii) Their rates of interest.

"(iv) The terms at which they may be redeemed by the Corporation before maturity.

"(v) The priority of their claims on the Corporation's net revenues with respect to principal and interest payments.

"(vi) Any other terms and conditions.

“(B) INAPPLICABILITY OF RIGHT TO PRESCRIBE TERMS.-Section 9108(a) of title 31, United States Code, shall not apply to the Corporation.

(d) INAPPLICABILITY OF SECURITIES REQUIREMENTS.-

The Corporation shall be considered an executive department of the United States for purposes of section 3(c) of the Securities Exchange Act of 1934 (15 U.S.C. 78c(c)).

"(e) INAPPLICABILITY OF FEE.-The Corporation shall not issue or sell any bonds to the Federal Financing Bank.

42 USC 2297b-9. "SEC. 1310. EXEMPTION FROM TAXATION AND PAYMENTS IN LIEU OF TAXES.

“(a) EXEMPTION FROM TAXATION.-In order to render financial assistance to those States and localities in which the facilities of the Corporation are located, the Corporation shall, beginning in fiscal year 1998, make payments to State and local governments as provided in this section. These payments shall be in lieu of any and all State and local taxes on the real and personal property of the Corporation. All property of the Corporation is expressly exempted from taxation in any manner or form by any State, county, or other local government entity including State, county, or other local government sales tax.

"(b) PAYMENTS IN LIEU OF TAXES.-Beginning in fiscal year 1998, the Corporation shall make annual payments, in amounts determined by the Corporation to be fair and reasonable, to the State and local governmental agencies having tax jurisdiction in any area where facilities of the Corporation are located. In making these determinations, the Corporation shall be guided by the following criteria:

"(1) The Corporation shall take into account the customs and practices prevailing in the area with respect to appraisal, assessment, and classification of industrial property and any special considerations extended to large-scale industrial operations.

“(2) The payment made to any taxing authority for any period shall not be less than the payments that would have been made to the taxing authority for the same period by the Department and its 
cost-type contractors on behalf of the Department with respect to property that has been transferred to the Corporation under section 1404 and that would have been attributable to the ownership, management, operation, and maintenance of the Department's uranium enrichment facilities, applying the laws and policies prevailing immediately prior to the transition date.

“(c) TIME OF PAYMENTS.-Payments shall be made by the Corporation at the time when payments of taxes by taxpayers to each taxing authority are due and payable.

“(d) DETERMINATION OF AMOUNT DUE.-The determination by the Corporation of the amounts due under this section shall be final and conclusive.

\section{USC 2297b-10. "SEC. 1311. COOPERATION WITH OTHER AGENCIES}

"The Corporation may request to use on a reimbursable basis the available services, equipment, personnel, and facilities of agencies of the United States, and on a similar basis may cooperate with such agencies in the establishment and use of services, equipment, and facilities of the Corporation. Further, the Corporation may confer with and avail itself of the cooperation, services, records, and facilities of State, territorial, municipal, or other local agencies.

42 USC 2297b-11. "SEC. 1312. APPLICABILITY OF CERTAIN FEDERAL LAWS.

"(a) ANTITRUST LAWS. - The Corporation shall conduct its activities in a manner consistent with the policies expressed in the following antitrust laws:

"(1) The Sherman Act (15 U.S.C. 1-7).

"(2) The Clayton Act (15 U.S.C. 12-27). 9).

"(3) Sections 73 and 74 of the Wilson Tariff Act (15 U.S.C. 8 and

“(b) ENVIRONMENTAL LAWS.-The Corporation shall be subject to, and comply with, all Federal and State, interstate, and local environmental laws and requirements, both substantive and procedural, in the same manner, and to the same extent, as any person who is subject to such laws and requirements. For purposes of enforcing any such law or substantive or procedural requirements (including any injunctive relief, administrative order, or civil or administrative penalty or fine) against the Corporation, the United States expressly waives any immunity otherwise applicable to the Corporation. For the purposes of this subsection, the term 'person' means an individual, trust, firm, joint stock company, corporation, partnership, association, State, municipality, or political subdivision of a State.

“(c) OSHA REQUIREMENTS.-Notwithstanding sections 3(5), 4(b)(1), and 19 of the Occupational Safety and Health Act of 1970 (29 U.S.C. 652(5), 653(b) (1), and 668)), the Corporation shall be subject to, and comply with, such Act and all regulations and standards promulgated thereunder in the same manner, and to the same extent, as an employer is subject to such Act. For the purposes of enforcing such Act (including any injunctive relief, administrative order, or civil, administrative, or criminal penalty or fine) against the Corporation, the United States expressly waives any immunity otherwise applicable to the Corporation. 
42 USC 2297b-12. "SEC. 1313. SECURITY.

“(d) LABOR STANDARDS. - The Act of March 3, 1931 (known as the Davis-Bacon Act) (40 U.S.C. 276a et seq.) and the Service Contract Act of 1965 (41 U.S.C. 351 et seq.) shall apply to the Corporation. All laborers and mechanics employed on the construction, alteration, or repair of projects funded, in whole or in part, by the Corporation shall be paid wages at rates not less than those prevailing on projects of a similar character in the locality as determined by the Secretary of Labor in accordance with such Act of March 3, 1931. The Secretary of Labor shall have, with respect to the labor standards specified in this subsection, the authority and functions set forth in Reorganization Plan Numbered 14 of 1950 (15 F.R. 3176, 64 Stat. 1267) and the Act of June 13, 1934 (40 U.S.C. $276 \mathrm{c}$ ).

“(e) ENERGY REORGANIZATION ACT REQUIREMENTS.The Corporation is subject to the provisions of section 210 of the Energy Reorganization Act of 1974 (42 U.S.C. 5850) to the same extent as an employer subject to such section, and, with respect to the operation of the facilities leased by the Corporation, section 206 of the Energy Reorganization Act of 1974 (42 U.S.C. 5846) shall apply to the directors and officers of the Corporation.

“(f) EXEMPTIOIN FROM FEDERAL PROPERTY REQUIREMENTS. - The Corporation shall not be subject to the Federal Property and Administrative Services Act of 1949 (41 U.S.C. 471 et seq.).

"Any references to the term 'Commission' or to the Department in sections 161k., 221a., and 230 shall be considered to include the Corporation.

42 USC 2297b-13. "SEC. 1314. CONTIROL OF INFORMATION.

"(a) IN GENERAL. - Except as provided in subsection (b), the Corporation may protect trade secrets and commercial or financial information to the same extent as a privately owned corporation.

"(b) OTHER APPLICABLE LAWS.-Section 552(d) of title 5, United States Code, shall apply to the Corporation, and such information shall be subject to the applicable provisions of law protecting the confidentiality of trade secrets and business and financial information, including section 1905 of title 18, United States Code.

42 USC 2297b-14. "SEC. 1315. TRANSITION.

President

"(a) TRANSITION MANAGER.-Within 30 days after the date of the enactment of this title, the President shall appoint a Transition Manager, who shall serve at the pleasure of the President until a quorum of the Board has been appointed and confirmed in accordance with section 1304.

“(b) POWERS.-

"(1) IN GENERAL.-Until a quorum of the Board has qualified, the Transition Manager shall exercise the powers and duties of the Board and shall be responsible for taking all actions needed to effect the transfer of the uranium enrichment enterprise from the Secretary to the Corporation on the transition date.

“(2) CONTINUATION UNTIL BOARD HAS QUORUM.-In the event that a quorum of the Board has not qualified by the transition date, the Transition Manager'shall continue to exercise the powers and duties of the Board until a quorum has qualified. 
“(c) RATIFICATION OF TRANSITION MANAGER'S ACTIONS. - All actions taken by the Transition Manager before the qualification of a quorum of the Board shall be subject to ratification by the Board.

“(d) RESPONSIBILITIES OF SECRETARY.-Before the transition date, the Secretary shall-

"(1) continue to be responsible for the management and operation of the uranium enrichment plants;

"(2) provide funds, to the extent provided in appropriations Acts, to the Transition Manager to pay salaries and expenses;

"(3) delegate Department employees to assist the Transition Manager in meeting his responsibilities under this section; and

(4) assist and cooperate with the Transition Manager in preparing for the transfer of the uranium enrichment enterprise to the Corporation on the transition date.

“(e)TRANSITION DATE. - The transition date shall be July 1, 1993.

“(f) DETAIL OF PERSONNEL.-For the purpose of continuity of operations, maintenance, and authority, the Department shall detail, for up to 18 months after the date of the enactment of this title, appropriate Department personnel as may be required in an acting capacity, until such time as a Board is confirmed and top officers of the Corporation are hired. The Corporation shall reimburse the Department and its contractors for the detail of such personnel.

42 USC 2297b-15. "SEC. 1316. WORKING CAPITAL ACCOUNT

"There shall be established within the Corporation a Working Capital Account in which the Corporation may retain all revenue necessary for legitimate business expenses, or investments, related to carrying out its purposes.

\section{"CHAPTER 24-RIGHTS, PRIVILEGES, AND ASSETS OF THE CORPORATION}

42 USC 2297c

"SEC. 1401. MARKETING AND CONTRACTING AUTHORITY.

"(a) EXCLUSIVE MARKETING AGENT.-The Corporation shall act as the exclusive marketing agent on behalf of the United States Government for entering into contracts for providing enriched uranium (including low-enriched uranium derived from highly enriched uranium) and uranium enrichment and related services. The Department may not market enriched uranium (including low-enriched uranium derived from highly enriched uranium), or uranium enrichment and related services, after the transition date.

“(b) TRANSFER OF CONTRACTS.-

"(1) IN GENERAL.-Except as provided in paragraph (2), all contracts, agreements, and leases with the Department, including all uranium enrichment contracts and power purchase contracts, that have been executed by the Department before the transition date and that relate to uranium enrichment and related services shall transfer to the Corporation.

"(2) EXCEPTIONS.-

"(A) TVA SETTLEMENT.-The rights and responsibilities of the Department under the settlement agreement with the 
42 USC $2297 \mathrm{c}-1$.

42 USC $2297 \mathrm{c}-2$.
Tennessee Valley Authority, filed on December 18, 1987, with the United States Court of Federal Claims, ${ }^{*}$ shall not transfer to the Corporation.

"(B) NONTRANSFERABLE POWER CONTRACTS. - If the Secretary determines that a power purchase contract executed by the Department prior to the transition date cannot be transferred under its terms, the Secretary may continue to receive power under the contract and resell such power to the Corporation at cost.

"(C) NONPOWER APPLICATIONS.-Contracts for enriched uranium and uranium services in existence as of the date of the enactment of this title for research and development or other nonpower applications shall remain with the Department. At the request of the Department, the Corporation, in consultation with the Department, may enter into such contracts it determines to be appropriate.

"SEC. 1402. PRICING.

"(a) SERVICES PROVIDED TO COMMERCIAL CUSTOMERS. -The Corporation shall establish prices for its products, materials, and services provided to customers other than the Department on a basis that will allow it to attain the normal business objectives of a profitmaking corporation.

"(b) SERVICES PROVIDED TO DOE. - The Corporation shall charge prices to the Department for uranium enrichment services provided under section 1303(9) on a basis that will allow it to recover its costs, on a yearly basis, for providing products, materials, and services, and provide for a reasonable profit.

"SEC. 1403. LEASING OF GASEOUS DIFFUSION FACILITIES OF DEPARTMENT.

"(a) IN GENERAL. - The Corporation shall lease the Paducah Gaseous Diffusion Plant in Paducah, Kentucky, the Portsmouth Gaseous Diffusion Plant in Piketon, Ohio, and related property of the Department, for a period of 6 years from the transition date. Thereafter, the Corporation shall have the exclusive option to lease such facilities and related property for additional periods.

"(b) TERMS OF LEASE. - The Corporation and the Department shall set mutually agreeable terms for a lease under subsection (a), including specifying annual payments to the Department by the Corporation to be made. The amount of annual payments shall be equal to the cost incurred by the Department in administering the lease and providing services related to the lease to the Corporation (excluding depreciation and imputed interest on original plant investments in the Department's gaseous diffusion plants and costs under subsection (d)).

"(c) EXCLUSION OF FACLITIES FOR PRODUCTION OF HIGHIY ENRICHED URANIUM.-Subsection (a) shall not apply to Department facilities necessary for the production of highly enriched uranium. The Secretary may grant to the Corporation access to such facilities for purposes other than the production of highly enriched uranium.

-Public Law 102-572, Títle LX, \$902(b)(1), 106 Stat. 4516; Oct. 29, 1992 struck “United States Claims Court” and inserted "Court of Federal Clains." 
“(d) DOE RESPONSIBILITY FOR PREEXISTING CONDITIONS.-The payment of any costs of decontamination and decommissioning, response actions, or corrective actions with respect to conditions existing before the transition date, in connection with property of the Department leased under subsection (a), shall remain the sole responsibility of the Department.

“(e) ENVIRONMENTAL AUDIT.-The Secretary, in consultation with the Administrator of the Environmental Protection Agency, shall conduct a comprehensive environmental audit identifying environmental conditions that will remain the responsibility of the Department pursuant to subsection (d) after the transition date. Such audit shall be completed no later than the transition date.

"(f) TREATMENT UNDER PRICE-ANDERSON PROVISIONS. - Any lease executed between the Secretary and the Corporation under this section shall be deemed to be a contract for purposes of section 170 d.

"(g) WAIVER OF EIS REQUIREMENT.-The execution of the lease by the Corporation and the Department shall not be considered a major Federal action significantly affecting the quality of the human environment for purposes of section 102 of the National Environmental Policy Act of 1969 (42 U.S.C. 4332).

42 USC 2297c-3. "SEC. 1404. CAPITAL STRUCTURE OF CORPORATION.

"(a) CAPITAL STOCK.-

“(1) ISSUANCE TO SECRETARY OF THE TREASURY.The Corporation shall issue capital stock representing an equity investment equal to the greater of-

"(A) $\$ 3,000,000,000$; or

"(B) the book value of assets transferred to the Corporation, as reported in the Uranium Enrichment Annual Report for fiscal year 1991, modified to reflect continued depreciation and other usual changes that occur up to the transfer date.

The Secretary of the Treasury shall hold such stock for the United States, except that all rights and duties pertaining to management of the Corporation shall remain vested in the Board.

"(2) RESTRICTION ON TRANSFERS OF STOCK BY UNITED STATES.-The capital stock of the Corporation shall not be sold, transferred, or conveyed by the United States, except to carry out the privatization of the Corporation under section 1502.

"(3) ANNUAL ASSESSMENT.-The Secretary of the Treasury shall annually assess the value of the stock held by the Secretary under paragraph (1) and submit to the Congress a report setting forth such value. The annual assessment of the Secretary shall be subject to review by an independent auditor.

“(b) PAYMENT OF DIVIDENDS. - The Corporation shall pay into miscellaneous receipts of the Treasury of the United States or such other fund as is provided by law, dividends on the capital stock, out of earnings of the Corporation, as a return on the investment represented by such stock. Until privatization occurs under section 1502, the Corporation shall pay as dividends to the Treasury of the United States all net revenues remaining at the end of each fiscal year not required for 
42 USC $2297 c-4$.

operating expenses or for deposit into the Working Capital Account established in section 1316.

"(c) PROHIBITION ON ADDITIONAL FEDERAL ASSISTANCE. -Except as otherwise specifically provided in this title, the Corporation shall receive no appropriations, loans, or other financial assistance from the Federal Government.

"(d) SOLE RECOVERY OF UNRECOVERED COSTS.-Receipt by the United States of the proceeds from the sale of stock issued by the Corporation under subsection (a)(1), and the dividends paid under subsection (b), shall constitute the sole recovery by the United States of previously unrecovered costs (including depreciation and imputed interest on original plant investments in the Department's gaseous diffusion plants) that have been incurred by the United States for uranium enrichment activities prior to the transition date.

"SEC. 1405. PATENTS AND INVENTIONS.

"The Corporation may at any time apply to the Department for a patent license for the use of an invention or discovery useful in the production or utilization of special nuclear material or atomic energy covered by a patent when the patent has not been declared to be affected with the public interest under section $153 \mathrm{a}$. and when use of the patent is within the Corporation's authority. An application shall constitute an application under section $153 \mathrm{c}$. subject to section $153 \mathrm{c}$., d., e., f., g., and h.

42 USC 2297c-5. "SEC. 1406. LIABILITIES.

"(a) LIABILITIES BASED ON OPERATIONS BEFORE TRANSITION. - Except as otherwise provided in this title, all liabilities attributable to operation of the uranium enrichment enterprise before the transition date shall remain direct liabilities of the Department.

"(b) JUDGMENTS BASED ON OPERATIONS BEFORETRANSITION.- Any judgment entered against the Corporation imposing liability arising out of the operation of the uranium enrichment enterprise before the transition date shall be considered a judgment against and shall be payable solely by the Department.

“(c) REPRESENTATION.-With regard to any claim seeking to impose liability under subsection (a) or (b), the United States shall be represented by the Department of Justice.

"(d) JUDGMENTS BASED ON OPERATIONS AFTER TRANSITION.-Any judgment entered against the Corporation arising from operations of the Corporation on or after the transition date shall be payable solely by the Corporation from its own funds. The Corporation shall not be considered a Federal agency for purposes of chapter 171 of title 28, United States Code.

42 USC 2297c-6. "SEC. 1407. TRANSFER OF URANIUM INVENTORIES.

"The Secretary shall transfer to the Corporation without charge all raw and low-enriched uranium inventories of the Department necessary for the fulfillment of contracts transferred under section 1401(b).

42 USC 2297c-7. "SEC. 1408. PURCIHASE OF HIGHLY ENRICHED URANIUM FROM FORMER SOVIET UNION

"(a) IN GENERAL. - The Corporation is authorized to negotiate the purchase of all highly enriched uranium made available by any State of the former Soviet Union under a government-to-government agree- 
ment or shall assume the obligations of the Department under any contractual agreement that has been reached with any such State or any private entity before the transition date. The Corporation may only purchase this material so long as the quality of the material can be made suitable for use in commercial reactors.

“(b) ASSESSMENT OF POTENTIAL USE. - The Corporation shall prepare an assessment of the potential use of highly enriched uranium in the business operations of the Corporation.

“(c) PLAN FOR BLENDING AND CONVERSION.-In the event that the agreement under subsection (a) provides for the Corporation to provide for the blending and conversion the assessment shall include a plan for such blending and conversion. The plan shall determine the least-cost approach to providing blending and conversion services, compatible with environmental, safety, security, and nonproliferation requirements. The plan shall include a competitive process that the Corporation shall use for selecting a provider of such services, including the public solicitation of proposals from the private sector to allow a determination of the least-cost approach.

"(d) MINIMIZATION OF IMPACT ON DOMESTIC INDUSTRIES.-The Corporation shall seek to minimize the impact on domestic industries (including uranium mining) of the sale of low-enriched uranium derived from highly enriched uranium.

42 USC $2297 d$.

\section{"CHAPTER 25-PRIVATIZATION OF THE CORPORATION} "SEC. 1501. STRATEGIC PLAN FOR PRIVATIZATION.

"(a) IN GENERAL. - Within 2 years after the transition date, the Corporation shall prepare a strategic plan for transferring ownership of the Corporation to private investors. The Corporation shall revise the plan as needed.

"(b) CONSIDERATION OF ALTERNATIVE MEANS OFTRANSFERRING OWNERSHIP.-The plan shall include consideration of alternative means for transferring ownership of the Corporation to private investors, including public stock offering, private placement, or merger or acquisition. The plan may call for the phased transfer of ownership or for complete transfer at a single point of time. If the plan calls for phased transfer of ownership, then-

"(1) privatization shall be deemed to occur when 100 percent of ownership has been transferred to private investors;"

"(2) prior to privatization, such stock shall be nonvoting stock; and

"(3) at the time of privatization, such stock shall convert to voting stock.

“(c) EVALUATION AND RECOMMENDATION.-The plan shall evaluate the relative merits of the alternatives considered and the estimated return on the Government's investment in the Corporation achievable through each alternative. The plan shall include the Corporation's recommendation on its preferred means of privatization.

"(d) TRANSMTTTAL. - The Corporation shall transmit copies of the strategic plan for privatization to the President and Congress upon completion. 
"SEC. 1502. PRIVATIZATION.

“(a) IMPLEMENTATION.-Subsequent to transmitting a plan for privatization pursuant to section 1501 , and subject to subsections (b) and (c), the Corporation may implement the privatization plan if the Corporation determines, in consultation with appropriate agencies of the United States, that privatization will-

"(1) result in a return to the United States at least equal to the net present value of the Corporation;

"(2) not result in the Corporation being owned, controlled, or dominated by an alien, a foreign corporation, or a foreign government;

"(3) not be inimical to the health and safety of the public or the common defense and security; and

"(4) provide reasonable assurance that adequate enrichment capacity will remain available to meet the domestic electric utility industry.

(b) REQUIREMENT OF PRESIDENTIAL APPROVAL.-The Corporation may not implement the privatization plan without the approval of the President.

"(c) NOTIFICATION OF CONGRESS AND GAO EVALUATION.-The Corporation shall notify the Congress of its intent to implement the privatization plan. Within 30 days of notification, the Comptroller General shall submit a report to Congress evaluating the extent to which-

"(1) the privatization plan would result in any ongoing obligation or undue cost to the Federal Government; and

(2) the revenues gained by the Federal Government under the privatization plan would represent at least the net present value of the Corporation.

“(d) PERIOD FOR CONGRESSIONAL REVIEW.-The Corporation may not implement the privatization plan less than 60 days after notification of the Congress.

"(e) DEPOSIT OF PROCEEDS.-Proceeds from the sale of capital stock of the Corporation under this section shall be deposited in the general fund of the Treasury.

\section{"CHAPTER 26-AVLIS AND ALTERNATIVE TECHNOLOGIES FOR URANIUM ENRICHMENT}

\section{USC 2297e. \\ "SEC. 1601. ASSESSMENT BY UNITED STATES ENRICHMENT CORPORATION.}

“(a) IN GENERAL. - The Corporation shall prepare an assessment of the economic viability of proceeding with the commercialization of AVLIS and alternative technologies for uranium enrichment in accordance with this chapter. The assessment shall include-

"(1) an evaluation of market conditions together with a marketing strategy;

"(2) an analysis of the economic viability of competing enrichment technologies; 
"(3) an identification of predeployment and capital requirements for the commercialization of AVLIS and alternative technologies for uranium enrichment;

"(4) an estimate of potential earnings from the licensing of AVLIS and alternative technologies for uranium enrichment to a private government sponsored corporation;

"(5) an analysis of outstanding and potential patent and related claims with respect to AVLIS and alternative technologies for uranium enrichment, and a plan for resolving such claims; and

"(6) a contingency plan for providing enriched uranium and related services in the event that deployment of AVLIS and alternative technologies for uranium enrichment is determined not to be economically viable.

“(b) DETERMINATION BY CORPORATION TO PROCEED WITH COMMERCIALIZATION OF AVLIS OR ALTERNATIVE TECHNOLOGIES FOR URANIUM ENRICHMENT.-The succeeding sections of this chapter shall apply only to the extent the Corporation determines in its business judgment, on the basis of the assessment prepared under subsection (a), to proceed with the commercialization of AVLIS or alternative technologies for uranium enrichment.

42 USC 2297e-1. "SEC. 1602. TRANSFER OF RIGHTS AND PROPERTY TO UNITED STATES ENRICHMENT CORPORATION

"(a) EXCLUSIVE RIGHTTO COMMERCIALIZE.-The Corporation shall have the exclusive commercial right to deploy and use any AVLIS patents, processes, and technical information owned or controlled by the Government, upon completion of a royalty agreement with the Department.

“(b) TRANSFER OF RELATED PROPERTY TO CORPORATION.-

"(1) IN GENERAL. - TO the extent requested by the Corporation, the President shall transfer without charge to the Corporation all of the Department's right, title, or interest in and to property owned by the Department, or by the United States but under control or custody of the Department, that is directly related to and materially useful in the performance of the Corporation's purposes regarding AVLIS and alternative technologies for uranium enrichment, including-

"(A) facilities, equipment, and materials for research, development, and demonstration activities; and

"(B) all other facilities, equipment, materials, processes, pat-

ents, technical information of any kind, contracts, agreements, and leases.

“(2) EXCEPTION.-Facilities, real estate, improvements, and equipment related to the gaseous diffusion, and gas centrifuge, uranium enrichment programs of the Department shall not transfer under paragraph (1)(B).

"(3) EXPIRATION OF TRANSFER AUTHORITY.-The President's authority to transfer property under this subsection shall expire upon privatization under section 1502. 

respect to any right, title, or interest provided to the Corporation under subsection (a) or (b), the Corporation shall have sole liability for any payments made or awards under section $157 \mathrm{~b}$. (3), or any settlements or judgments involving claims for alleged patent infringement. Any royalty agreement under subsection (a) shall provide for a reduction of royalty payments to the Department to offset any payments, awards, settlements, or judgments under this subsection.

"SEC. 1603. PREDEPLOYMENT ACTIVTTES BY UNITED STATES ENRICHMENT CORPORATION-

"The Corporation may begin activities necessary to prepare AVLIS or alternative technologies for uranium enrichment for commercialization including-

"(1) completion of preapplication activities with the Nuclear Regulatory Commission;

“(2) preparation of a transition plan to move AVLIS or alternative technologies for uranium enrichment from the laboratory to the marketplace;

"(3) confirmation of technical performance;

“(4) validation of economic projections;

“(5) completion of feasibility and risk studies;

“(6) initiation of preliminary plant design and engineering; and

"(7) site selection, site characterization, and environmental documentation activities on the basis of site evaluations and recommendations prepared for the Department by the Argonne National Laboratory.

42 USC 2297e-3. "SEC. 1604. UNITED STATES ENRICHMENT CORPORATION SPONSORSHIP OF PRIVATE FOR-PROFIT CORPORATION TO CONSTRUCT AVLIS AND ALTERNATIVE TECHNOLOGIES FOR URANIUM ENRICHMENT.

“(a) ESTABLISHMENT.-

"(1) IN GENERAL. - If the Corporation determines to proceed with the commercialization of AVLIS or alternative technologies for uranium enrichment under this chapter, the Corporation may provide for the establishment of a private for-profit corporation, which shall have as its initial purpose the construction of a uranium enrichment facility using AVLIS technology or alternative technologies for uranium enrichment.

"(2) PROCESS OF ORGANIZATION.-For purposes of the establishment of the private corporation under paragraph (1), the Corporation shall appoint not less than 3 persons to be incorporators. The incorporators so appointed shall each sign the articles of incorporation and shall serve as the initial board of directors until the members of the 1st regular board of directors shall have been appointed and elected. Such incorporators shall take whatever actions are necessary or appropriate to establish the private corporation, including the filing of articles of incorporation in such jurisdiction as the incorporators determine to be appropriate. The incorporators shall also develop a plan for the issuance by the private corporation of voting common stock to the public, which 
plan shall be subject to the approval of the Secretary of the Treasury.

“(b) LEGAL STATUS OF PRIVATE CORPORATION.-

"(1) NOT FEDERAL AGENCY.-The private corporation established under subsection (a) shall not be an agency, instrumentality, or establishment of the United States Government and shall not be a Government corporation or Government controlled corporation.

“(2) NO RECOURSE AGAINST UNITED STATES.-Obligations of the private corporation established under subsection (a) shall not be obligations of, or guaranteed as to principal or interest by, the Corporation or the United States, and the obligations shall so plainly state.

"(3) NO CLAIMS COURT JURISDICTION.-NO action under section 1491 of title 28, United States Code, shall be allowable against the United States based on the actions of the private corporation established under subsection (a).

“(c) TRANSACTIONS BETWEEN UNITED STATES ENRICHMENT CORPORATION AND PRIVATE CORPORATION;-

"(1) GRANTS FROM USEC.-The Corporation may make grants to the private corporation established under subsection (a) from amounts available in the AVLIS Commercialization Fund. Such grants shall be used by the private corporation to carry out any remaining predeployment activity assigned to the private corporation by the Corporation. Such grants may not be used for the costs of constructing an AVLIS, or alternative technologies for uranium enrichment, production facility or engaging in directly related preconstruction activities (other than such assigned predeployment activities). The aggregate amount of such grants shall not exceed $\$ 364,000,000$.

"(2) LICENSING AGREEMENT.-The Corporation shall license to the private corporation established under subsection (a) the rights, titles, and interests provided to the Corporation under section 1602 . The licensing agreement shall require the private corporation to make periodic payments to the Corporation in an amount that is not less than the aggregate amounts paid by the Corporation during the period involved under subsections (a) and (c) of section 1602 .

"(3) PURCHASE AGREEMENT.-The Corporation may enter into a commitment to purchase all enriched uranium produced at an AVLIS, or alternative technologies for uranium enrichment, facility of the private corporation established under subsection (a) at a price negotiated by the 2 corporations that-

"(A) provides the private corporation with a reasonable return on its investment; and

"(B) is less costly than enriched uranium available from other sources.

“(4) ADDITIONAL ASSISTANCE.-The Corporation may provide to the private corporation established under subsection (a), on a reimbursable basis, such additional personnel, services, 
and equipment as the 2 corporations may determine to be appropriate.

"SEC. 1605. AVLIS COMMERCIALIZATION FUND WITHIN UNITED STATES ENRICHMENT CORPORATION.

"(a) ESTABLISFIMENT.-The Corporation may establish within the Corporation an AVLIS Commercialization Fund, which shall consist of not more than $\$ 364,000,000$ paid into the Fund by the Corporation from amounts provided in appropriation Acts for such purposes and from the retained earnings of the Corporation.

"(b) EXPENDITURES FROM FUND.-Amounts in the AVLIS Commercialization Fund shall be available for-

"(1) expenses of the Corporation in preparing the assessment under section 1601;

(2) expenses of predeployment activities under section 1603; and

"(3) grants to the private corporation under section 1604.

“(c) LIMITATIONS. -

"(1) EXCLUSIVE SOURCE OF FUNDS.-The Corporation may not incur any obligation, or expend any amount, with respect to AVLIS or alternative technologies for uranium enrichment, except from amounts available in the AVLIS Commercialization Fund.

“(2) UNAVAILABLE FOR CONSTRUCTION COSTS.-No amount may be used from the AVLIS Commercialization Fund for the costs of constructing an AVLIS, or alternative technologies for uranium enrichment, production facility or engaging in directly related preconstruction activities (other than activities specified in subsection (b)).

“(d) AUTHORIZATION OF APPROPRIATIONS. - There is authorized to be appropriated $\$ 364,000,000$ from the Uranium Enrichment Special Fund for purposes of this section.

"(e) COST REPORT.-On the basis of the assessment under section 1601(a)(3), the Corporation shall submit to the Congress a report on the capital requirements for commercialization of AVLIS.

42 USC 2297e-5. "SEC. 1606. DEP'ARTMENT RESEARCH AND DEVELOPMENT ASSISTANCE.

"If requested by the Corporation, the Secretary shall provide, on a reimbursable basis, research and development of AVL.IS and alternative technologies for uranium enrichment.

42 USC 2297e-6. "SEC. 1607. SITE SELECTION.

"This chapter shall not prejudice consideration of the site of an existing uranium enrichment facility as a candidate site for future expansion or replacement of uranium enrichment capacity through AVLIS or alternative technologies for uranium enrichment. Selection of a site for the AVLIS, or alternative technologies for uranium enrichment, facility shall be made on a competitive basis, taking into consideration economic performance, environmental compatibility, and use of any existing uranium enrichment facilities. 
"Section 170 shall not apply to any license under section 53, 63, or 103 for a uranium enrichment facility constructed after the date of the enactment of this title.".

42 USC $2297 f$.

\section{"CHAPTER 27-LICENSING AND REGULATION OF URANIUM ENRICHMENT FACILITIES}

\section{"SEC. 1701. GASEOUS DIFFUSION FACILITIES}

"(a) ISSUANCE OF STANDARDS. - Within 2 years after the date of the enactment of this title, the Nuclear Regulatory Commission shall establish by regulation such standards as are necessary to govern the gaseous diffusion uranium enrichment facilities of the Department in order to protect the public health and safety from radiological hazard and provide for the common defense and security. Regulations promulgated pursuant to this subsection shall, among other things, require that adequate safeguards (within the meaning of section 147) are in place.

"(b) ANNUAL REPORT.-

"(1) IN GENERAL. - The Nuclear Regulatory Commission in consultation with the Department and the Environmental Protection Agency, shall report at least annually to the Congress on the status of health, safety, and environmental conditions at the gaseous diffusion uranium enrichment facilities of the Department.

"(2) REQUIRED DETERMINATION.-Such report shall include a determination regarding whether the gaseous diffusion uranium enrichment facilities of the Department are in compliance with the standards established under subsection (a) and all applicable laws.

“(c) CERTIFICATION PROCESS.-

“(1) ESTABLISHMENT.-The Nuclear Regulatory Commission shall establish a certification process to ensure that the Corporation complies with standards established under subsection (a).

"(2) ANNUAL APPLICATION FOR CERTIFICATE OF COMPLIANCE. - The Corporation shall apply at least annually to the Nuclear Regulatory Commission for a certificate of compliance under paragraph (1). The Nuclear Regulatory Commission, in consultation with the Environmental Protection Agency, shall review any such application and any determination made under subsection (b)(2) shall be based on the results of any such review.

"(3) TREATMENT OF CERTIFICATE OF COMPLIANCE.The requirement for a certificate of compliance under paragraph (1) shall be in lieu of any requirement for a license for any gaseous diffusion facility of the Department leased by the Corporation.

\section{"(4) NRC REVIEW.-}

"(A) IN GENERAL. - The Nuclear Regulatory Commission, in consultation with the Environmental Protection Agency, shall review the operations of the Corporation with respect to any gaseous diffusion uranium enrichment facilities of the Department leased by the Corporation to ensure that public health and safety are adequately protected. 
“(B) ACCESS TO FACILITIES AND INFORMATION.-

The Corporation and the Department shall cooperate fully with the Nuclear Regulatory Commission and the Environmental Protection Agency and shall provide the Nuclear Regulatory Commission and the Environmental Protection Agency with the ready access to the facilities, personnel, and information the Nuclear Regulatory Commission and the Environmental Protection Agency consider necessary to carry out their responsibilities under this subsection. A contractor operating a Corporation facility for the Corporation shall provide the Nuclear Regulatory Commission and the Environmental Protection Agency with ready access to the facilities, personnel, and information of the contractor as the Nuclear Regulatory Commission and the Environmental Protection Agency consider necessary to carry out their responsibilities under this subsection.

"(C) LIMITATION.-The Nuclear Regulatory Commission shall limit its finding under subsection (b)(2) to a determination of whether the facilities are in compliance with the standards established under subsection (a).

“(d) REQUIREMENT FOR OPERATION.-The gaseous diffusion uranium enrichment facilities of the Department may not be operated by the Corporation unless the Nuclear Regulatory Commission, in consultation with the Environmental Protection Agency, makes a determination of compliance under subsection (b) or approves a plan prepared by the Department for achieving compliance required under subsection (b).

42 USC 2297f-1. "SEC. 1702. LICENSING OF OTHER TECHNOLOGIES.

“(a) IN GENERAL. - Corporation facilities using alternative technologies for uranium enrichment, other than AVLIS, shall be licensed under sections 53 and 63.

"(b) COSTS FOR DECONTAMINATION AND DECOMMISSIONING. - The Corporation shall provide for the costs of decontamination and decommissioning of any Corporation facilities described in subsection (a) in accordance with the requirements of the amendments made by section 5 of the Solar, Wind, Waste, and Geothermal Power Production Act of 1990.

42 USC 2297f-2. "SEC. 1703. REGULATION OF RESTRICTED DATA.

"The Corporation shall be subject to this Act with respect to the use of, or access to, Restricted Data to the same extent as any private corporation.

\section{"CHAPTER 28-DECONTAMINATION AND DECOMMISSIONING}

42 USC 2297g.

\section{"SEC. 1801. URANIUM ENRICHMENT DECONTAMINATION AND DECOMMISSIONING FUND}

"(a) ESTABLISHMENT. - There is established in the Treasury of the United States an account to be known as the Uranium Enrichment Decontamination and Decommissioning Fund (referred to in this chapter as the 'Fund'). The Fund, and any amounts deposited in it, including 
42 USC $2297 \mathrm{~g}-1$.

any interest earned thereon, shall be available to the Secretary subject to appropriations for the exclusive purpose of carrying out this chapter.

"(b) ADMINISTRATION.-

"(1) IN GENERAL.-The Secretary of the Treasury shall hold the Fund and, after consultation with the Secretary, annually report to the Congress on the financial condition and operations of the Fund during the preceding fiscal year.

"(2) INVESTMENTS.-The Secretary of the Treasury shall invest amounts contained within the Fund in obligations of the United State-

"(A) having maturities determined by the Secretary of the Treasury to be appropriate for what the Department determines to be the needs of the Fund; and

"(B) bearing interest at rates determined to be appropriate by the Secretary of the Treasury, taking into consideration the current average market yield on outstanding marketable obligations of the United States with remaining periods to maturity comparable to these obligations.

"SEC. 1802. DEPOSITS.

"(a) AMOUNT.-The Fund shall consist of deposits in the amount of $\$ 480,000,000$ per fiscal year (to be annually adjusted for inflation using the Consumer Price Index for all-urban consumers published by the Department of Labor) as provided in this section.

"(b) SOURCE.-Deposits described in subsection (a) shall be from the following sources:

"(1) Sums collected pursuant to subsection (c).

"(2) Appropriations made pursuant to subsection (d).

"(c) SPECIAL ASSESSMENT.-The Secretary shall collect a special assessment from domestic utilities. The total amount collected for a fiscal year shall not exceed $\$ 160,000,000$ (to be annually adjusted for inflation using the Consumer Price Index for all-urban consumers published by the Department of Labor). The amount collected from each utility pursuant to this subsection on for a fiscal year shall be in the same ratio to the amount required under subsection (a) to be deposited for such fiscal year as the total amount of separative work units such utility has purchased from the Department of Energy for the purpose of commercial electricity generation, before the date of the enactment of this title, bears to the total amount of separative work units purchased from the Department of Energy for all purposes (including units purchased or produced for defense purposes) before the date of the enactment of this title. For purposes of this subsection-

"(1) a utility shall be considered to have purchased a separative work unit from the Department if such separative work unit was produced by the Department, but purchased by the utility from another source; and

"(2) a utility shall not be considered to have purchased a separative work unit from the Department if such separative work unit was purchased by the utility, but sold to another source.

“(d) AUTHORIZATION OF APPROPRIATIONS.-There are authorized to be appropriated to the Fund, for the period encompassing 15 years after the date of the enactment of this title, such sums as are 
necessary to ensure that the amount required under subsection (a) is deposited for each fiscal year.

"(e) TERMINATION OF ASSESSMENTS.-The collection of amounts under subsection (c) shall cease after the earlier of-

"(1) 16 years after the date of the enactment of this title; or

"(2) the collection of $\$ 2,260,000,000$ (to be annually adjusted for

inflation using the Consumer Price Index for all-urban consumers published by the Department of Labor) under such subsection.

“(f) CONTINUATION OF DEPOSITS. - Except as provided in subsection (e), deposits shall continue to be made into the Fund under subsection (d) for the period specified in such subsection.

“(g) TREATMENT OF ASSESSMENT.-Any special assessment levied under this section on domestic utilities for the decontamination and decommissioning of the Department's gaseous diffusion enrichment facilities shall be deemed a necessary and reasonable current cost of fuel and shall be fully recoverable in rates in all jurisdictions in the same manner as the utility's other fuel cost.

42 USC 2297g-2. "SEC. 1803. DEPARTMENT FACILITIES

"(a) STUDY BY NATIONAL ACADEMY OF SCIENCES.-The National Academy of Sciences shall conduct a study and provide recommendations for reducing costs associated with decontamination and decommissioning, and shall report its findings to the Congress within 3 years after the date of the enactment of this title. Such report shall include a determination of the decontamination and decommissioning required for each facility shall identify alternative methods, using different technologies, shall include sit-specific surveys of the actual contamination, and shall provide estimated costs of those activities.

"(b) PAYMENT OF DECONTAMINATION AND DECOMMISSIONING COSTS. - The costs of all decontamination and decommissioning activities of the Department shall be paid from the Fund until such time as the Secretary certifies and the Congress concurs, by law, that such activities are complete.

"(c) PAYMENT OF REMEDIAL ACTION COSTS.-The annual cost of remedial action at the Department's gaseous diffusion facilities shall be paid from the Fund to the extent the amount available in the Fund is sufficient. To the extent the amount in the Fund is insufficient, the Department shall be responsible for the cost of remedial action. No provision of this title may be construed to relieve in any way the responsibility or liability of the Department for remedial action under applicable Federal and State laws and regulations.

42 USC 2297g-3. "SEC. 1804. EMPLOYEE PROVISIONS.

"All laborers and mechanics employed by contractors or subcontractors in the performance of decontamination or decommissioning of uranium enrichment facilities of the Department shall be paid wages at rates not less than those prevailing on projects of a similar character in the locality as determined by the Secretary of Labor in accordance with the Act of March 3, 1931 (known as the Davis-Bacon Act) (40 U.S.C. 276 a et seq.). The Secretary of Labor shall have, with respect to the labor standards specified in this section, the authority and functions set forth in Reorganization Plan Numbered 14 of 1950 (15F.R. 3176,64 Stat. 1267) and the Act of June 13, 1934 (40 U.S.C. 276c). This section may not be 
construed to require the contracting out of activities associated with the decontamination or decommissioning of uranium enrichment facilities. "SEC. 1805. REPORTS TO CONGRESS.

"Within 3 years after the date of the enactment of this title, and at least once every 3 years thereafter, the Secretary shall report to the Congress on progress under this chapter. The 5th report submitted under this section shall contain recommendations of the Secretary for the reauthorization of the program and Fund under this title. 


\section{ENERGY REORGANIZATION \\ ACT OF 1974}

Public Law 93-438

(88 Stat. 1233)

PAGE USC

42 USC

Sec.

Sec. 1. Short Title .................................... 5801

Sec. 2. Declaration of Purpose ..................... 196 ..... 5801

TITLE I - ENERGY RESEARCH AND DEVELOPMENT ADMINISTRATION

Sec.101. Establishment .......................... 197 ..... 5811

Sec.102. Officers ................................. $197 \ldots \ldots . .5812$

Sec.103. Responsibilities of the Administrator ............ 198 ..... 5813

Sec.104. Abolition and Transfers .............................. 199814

Sec.105. Administrative Provisions .....................201 ..... 5815

Sec.106. Personnel and Services $\ldots \ldots \ldots \ldots \ldots \ldots \ldots \ldots \ldots . \ldots 202 \ldots \ldots .5816$

Sec.107. Powers ............................................ 203817

Sec.108. Repealed

Sec.109. Future Reorganization ........................ 205 ..... 5819

Sec.110. Coordination with Environmental Efforts ........206 ..... 5820

Sec.111. Provisions Applicable to Annual ......................... 206821 Authorization Acts.

\section{TITLE II - NUCLEAR REGULATORY COMMISSION: NUCLEAR WHISTLE BLOWER PROTECTION}

Sec. 201. Establishment and Transfers ....................... 209841

Sec. 202. Licensing and Related Regulatory

Functions Respecting Selected

Administration Facilities .................... $212 \ldots \ldots .5842$

Sec. 203. Office of Nuclear Reactor Regulation $\ldots \ldots \ldots \ldots \ldots 212 \ldots \ldots .5843$

Sec. 204. Office of Nuclear Material Safety and

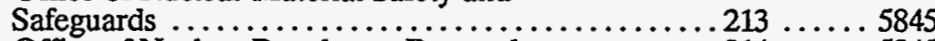

Sec. 205. Office of Nuclear Regulatory Research ............214 ...... 5845

Sec. 206. Noncompliance ........................215 ..... 5846

Sec. 207. Nuclear Energy Center Site Survey ............. 215 ..... 5847

Sec. 208. Abnormal Occurrence Reports ................ 216 ..... 5848

Sec. 209. Other Officers ................................. 216 ..... 5849

Sec. 210. Unresolved Safety Issues Plan ...............217 ..... 5850

Sec. 211. Employee Protection ............................... 5851

\section{TITLE III - MISCELLANEOUS AND TRANSITIONAL PROVISIONS}

Sec. 301. Transitional Provisions .................. $221 \ldots \ldots 5871$

Sec. 302. Transfer of Personnel and

Other Matters .......................... $222 \ldots \ldots .5872$

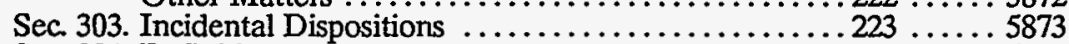

Sec. 304. Definitions ........................ $223 \ldots \ldots .5874$

Sec. 305. Authorization of Appropriations . . . . . . . . . . $223 \ldots \ldots 5875$

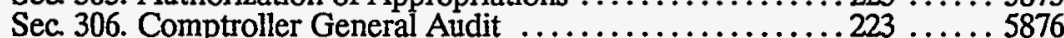

Sec 307. Reports ............................ 5877

•New Title II; P.L. 102-486 (106 Stat. 3124); October 24, 1992. 


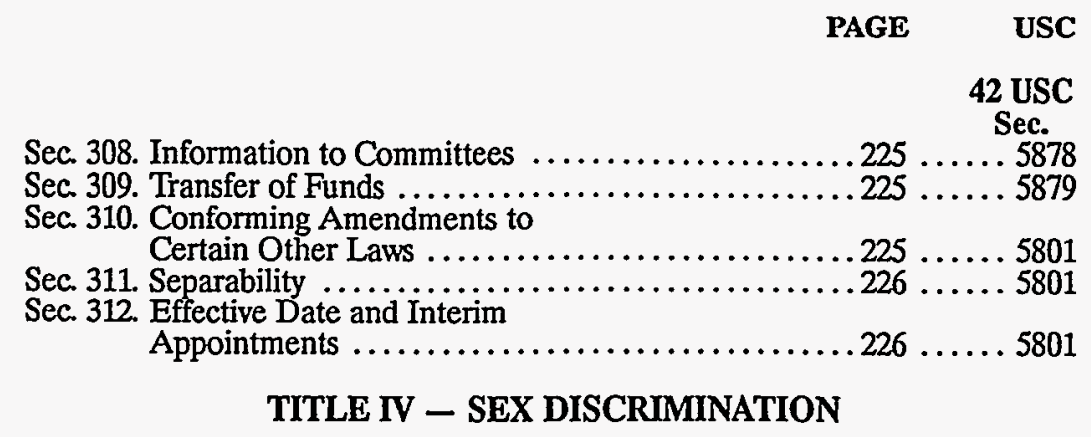

Sec 401. Sex Discrimination Prohibited. .226 5891

Reorganization Plan No. 3-1970 227

Reorganization PIan No. 1-1980. .231

Executive Order No. 11834-Activation of the NRC. 235 
Energy Reorganization Act of 1974.

\section{USC 5801} note.

42 USC 5801.

Energy Research and Development Administration, establishment.

88 Stat. 1233. 88 Stat. 1234.

Separation of AEC licensing and regulatory functions.

Small business participation.

\section{An Act}

To reorganize and consolidate certain functions of the Federal Government in a new Energy Research and Development Administration and in a new Nuclear Regulatory Commission in order to promote more efficient management of such functions.

Be it enacted by the Senate and House of Representatives of the United States of America in Congress assembled,

That the Energy Reorganization Act of 1974, as amended, is amended to read as follows:

\section{"SHORT TITLE}

"Sec. 1. The Act may be cited as the 'Energy Reorganization Act of 1974.'

\section{"DECLARATION OF PURPOSE}

"Sec. 2. (a) The Congress hereby declares that the general welfare and the common defense and security require effective action to develop, and increase the efficiency and reliability of use of, all energy sources to meet the needs of present and future generations, to increase the productivity of the national economy and strengthen its position in regard to international trade, to make the Nation self-sufficient in energy, to advance the goals of restoring, protecting, and enhancing environmental quality, and to assure public health and safety.

"(b) The Congress finds that, to best achieve these objectives, improve Government operations, and assure the coordinated and effective development of all energy sources, it is necessary to establish an Energy Research and Development Administration to bring together and direct Federal activities relating to research and development on the various sources of energy, to increase the efficiency and reliability in the use of energy, and to carry out the performance of other functions, including but not limited to the Atomic Energy Commission's military and production activities and its general basic research activities. In establishing an Energy Research and Development Administration to achieve these objectives, the Congress intends that all possible sources of energy be developed consistent with warranted priorities.

"(c) The Congress finds that it is in the public interest that the licensing and related regulatory functions of the Atomic Energy Commission be separated from the performance of the other functions of the Commission, and that this separation be effected in an orderly manner, pursuant to this Act, assuring adequacy of technical and other resources necessary for the performance of each.

"(d) The Congress declares that it is in the public interest and the policy of Congress that small business concerns be given a reasonable opportunity to participate, insofar as is possible, fairly and 
Priorities.

42 USC 5811.

Administrator, 42 USC 5812.

Deputy

Administrator.

88 Stat. 1234.

88 Stat. 1235.

Assistant

Administrators.

equitably in grants, contracts, purchases, and other Federal activities relating to research, development, and demonstration of sources of energy efficiency, and utilization and conservation of energy. In carrying out this policy, to the extent practicable, the Administrator shall consult with the Administrator of the Small Business Administration.

"(e) Determination of priorities which are warranted should be based on such considerations as power-related values of an energy source, preservation of material resources, reduction of pollutants, export market potential (including reduction of imports), among others. On such a basis, energy sources warranting priority might include, but not be limited to, the various methods of utilizing solar energy.

\section{"TITLE I-ENERGY RESEARCH AND DEVELOPMENT ADMINISTRATION}

\section{"ESTABLISHMENT}

"Sec. 101. There is hereby established an independent executive agency to be known as the Energy Research and Development Administration (hereinafter in this Act referred to as the 'Administration').

\section{"OFFICERS}

"Sec. 102. (a) There shall be at the head of the Administration an Administrator of Energy Research and Development (hereinafter in this Act referred to as the 'Administrator'), who shall be appointed from civilian life by the President by and with the advice and consent of the Senate. A person may not be appointed as Administrator within two years after release from active duty as a commissioned officer of a regular component of an Armed Force. The Administration shall be administered under the supervision and direction of the Administrator, who shall be responsible for the efficient and coordinated management of the Administration.

"(b) There shall be in the Administration a Deputy Administrator, who shall be appointed by the President, by and with the advice and consent of the Senate.

"(c) The President shall appoint the Administrator and Deputy Administrator from among individuals who, by reason of their general background and experience are specially qualified to manage a full range of energy research and development programs.

"(d) There shall be in the Administration six Assistant Administrators, one of whom shall be responsible for fossil energy, another for nuclear energy, another for environment and safety, another for conservation, another for solar, geothermal, and advanced energy systems, and another for national security. The Assistant Administrators shall be appointed by the President, by and with the advice and consent of the Senate. The President shall appoint each Assistant Administrator from among individuals who, by reason of general background and experience, are specially qualified to manage the energy technology area assigned to such Assistant Administrator. 
General Counsel.

Additional officers.

Director of Military

Application.

42 USC 2011

note.

International

cooperation.

Order of

succession.

42 USC 5813.

88 Stat. 1235.

88 Stat. 1236. "(e) There shall be in the Administration a General Counsel who shall be appointed by the Administrator and who shall serve at the please of and be removable by the Administrator.

"(f) There shall be in the Administration not more than eight additional officers appointed by the Administrator. The positions of such officers shall be considered career positions and be subject to subsection $161 \mathrm{~d}$. of the Atomic Energy Act.

"(g) The Division of Military Application transferred to and established in the Administration by section 104 (d) of this Act shall be under the direction of a Director of Military Application, who shall be appointed by the Administrator and who shall serve at the pleasure of and be removable by the Administrator and shall be an active commissioned officer of the Armed Forces serving in general or flag officer rank or grade. The functions, qualifications, and compensation of the Director of Military Application shall be the same as those provided under the Atomic Energy Act of 1954, as amended, for the Assistant General Manager for Military Application.

"(h) Officers appointed pursuant to this section shall perform such functions as the Administrator shall delegate to one such officer the special responsibility for international cooperation in all energy and related environmental research and development.

"(i) The Deputy Administrator (or in the absence or disability of the Deputy Administrator, or in the event of a vacancy in the office of the Deputy Administrator, an Assistant Administrator, the General Counsel or such other official, determined according to such order as the Administrator shall prescribe) shall act for and perform the functions of the Administrator during any absence or disability of the Administrator or in the event of a vacancy in the office of the Administrator.

\section{"RESPONSIBILITIES OF THE ADMINISTRATOR}

"Sec. 103. The responsibilities of the Administrator shall include, but not be limited to-

"(1) exercising central responsibility for policy planning, coord nation, support, and management of research and development programs respecting all energy sources, including assessing the requirements for research and development in regard to various energy sources in relation to near-term and long-range needs, policy planning in regard to meeting those requirements, undertaking programs for the optimal development of the various forms of energy sources, managing such programs, and disseminating information resulting therefrom;

"(2) encouraging and conducting research and development, including demonstration of commercial feasibility and practical applications of the extraction, conversion , storage, transmission, and utilization phases related to the development and use of energy from fossil, nuclear, solar, geothermal, and other energy sources;

"(3) engaging in and supporting environmental, biomedical, physical, and safety research related to the development of energy sources and utilization technologies; 
88 Stat. 1236.

88 Stat. 1237.

Atomic Energy Commission. 42 USC 5814.
“(4) taking into account the existence, progress, and results of other public and private research and development activities, including those activities of the Federal Energy Administration relating to the development of energy resources using currently available technology in promoting increased utilization of energy resources, relevant to the Administration's mission in formulating its own research and development programs;

"(5) participating in and supporting cooperative research and development projects which may involve contributions by public or private persons or agencies, of financial or other resources to the performance of the work;

"(6) developing, collecting, distributing, and making available for distribution, scientific and technical information concerning the manufacture or development of energy and its efficient extraction, conversion, transmission, and utilization;

"(7) establishing, in accordance with the National Energy Extension Service Act, an Energy Extension Service to provide technical assistance, instruction, and practical demonstration on energy conservation measures and alternative energy systems to individuals, businesses, and State and local government officials; ${ }^{1}$

"(8) creating and encouraging the development of general information to the public on all energy conservation technologies and energy sources as they become available for general use, and the Administrator, in conjunction with the Administrator of the Federal Energy Administration shall, to the extent practicable, disseminate such information through the use of mass communications;

"(9) encouraging and conducting research and development in energy conservation, which shall be directed toward the goals of reducing total energy consumption to the maximum extent practicable, and toward maximum possible improvement in the efficiency of energy use. Development of new and improved conservation measures shall be conducted with the goal of the most expeditious possible application of these measures;

"(10) encouraging and participating in international cooperation in energy and related environmental research and development;

"(11) helping to assure an adequate supply of manpower for the accomplishment of energy research and development programs, by sponsoring and assisting in education and training activities in institutions of higher education, vocational schools, and other institutions, and by assuring the collection, analysis, and dissemination of necessary manpower supply and demand data;

"(12) encouraging and conducting research and development in clean and renewable energy sources.

\section{"ABOLITION AND TRANSFERS}

"Sec. 104. (a) The Atomic Energy Commission is hereby abolished. Sections 21 and 22 of the Atomic Energy Act of 1954, as amended (42 U.S.C. 2031 and 2032) are repealed.

'Public Law 95-39 (91 Stat. 200)(1977), sec.510(a), amended sec. 103 by redesignating paragraphs (7) through(11) as paragraphs (8) through (12), respectively, and inserted a new paragraph (7). 
Interior Department functions.

88 Stat. 1238. Helium applications study. 88 Stat. 1238. Report to President and Congress. National Science Foundation functions.

Environmental "(b) All other functions of the Commission, the Chairman and members of the Commission, and the officers and components of the Commission are hereby transferred or allowed to lapse pursuant to the provisions of this Act.

"(c) There are hereby transferred to and vested in the Administrator all functions of the Atomic Energy Commission, the Chairman and members of the Commission, and the officers and components of the Commission, except as otherwise provided in this Act.

"(d) The General Advisory Committee established pursuant to section 26 of the Atomic Energy Act of 1954, as amended (42 U.S.C. 2036), the Patent Compensation Board established pursuant to section 157 of the Atomic Energy Act of 1954, as amended (42 U.S.C. 2187) and the Divisions of Military Application and Naval Research established pursuant to section 25 of the Atomic Energy Act of 1954, as amended (42 U.S.C. 2035), are transferred to the Energy Research and Development Administration and the functions of the Commission with respect thereto, and with respect to relations with the Military Liaison Committee established by section 27 of the Atomic Energy Act of 1954, as amended (42 U.S.C. 2037), are transferred to the Administrator.

"(e) There are hereby transferred to and vested in the Administrator such functions of the Secretary of the Interior, the Department of the Interior, and officers and components of such department-

"(1) as relate to or are utilized by the Office of Coal Research established pursuant to the Act of Jüly 1, 1960 (74 Stat. 336; 30 U.S.C. 661-668);

"(2) as relate to or are utilized in connection with fossil fuel energy research and development programs and related activities conducted by the Bureau of Mines 'energy centers' and synthane plant to provide greater efficiency in the extraction, processing, and utilization of energy resources for the purpose of conserving those resources, developing alternative energy resources such as oil and gas secondary and tertiary recovery, oil shale and synthetic fuels, improving methods of managing energy-related wastes and pollutants, and providing technical guidance needed to establish and administer national energy policies; and

"(3) as relate to or are utilized for underground electric power transmission research.

The Administrator shall conduct a study of the potential energy applications of helium and, within six months from the date of the enactment of this Act, report to the President and Congress his recommendations concerning the management of the Federal helium programs, as they relate to energy.

"(f) There are hereby transferred to and vested in the Administrator such functions of the National Science Foundation as relate to or are utilized in connection with-

"(1) solar heating and cooling development; and

"(2) geothermal power development.

" $(\mathrm{g})$ There are hereby transferred to and vested in the Adminis- 
Protection Agency functions.

Use of other agencies' capabilities.

Regulations. 42 USC 5815.

Policy planning and evalustion.

Delegation of functions.

Organization.

Field offices.

88 Stat. 1239. trator such functions of the Environmental Protection Agency and the officers and components thereof as relate to or are utilized in connection with research, development, and demonstration, but not assessment or monitoring for regulatory purposes, of alternative automotive power systems.

"(h) To the extent necessary or appropriate to perform functions and carry out programs transferred by this Act, the Administrator and Commissions may exercise, in relation to the functions so transferred, any authority or part thereof available by law, including appropriation Acts, to the official or agency from which such functions were transferred.

"(i) In the exercise of his responsibilities under section 103, the Administrator shall utilize, with their consent, to the fullest extent he determines advisable the technical and management capabilities of other executive agencies having facilities, personnel, or other resources which can assist or advantageously be expanded to assist in carrying out such responsibilities. The Administrator shall consult with the head of each agency with respect to such facilities, personnel, or other resources, and may assign, with their consent, specific programs or projects in energy research and development as appropriate. In making such assignments under this subsection, the head of each such agency shall insure that-

"(1) such assignments shall be in addition to and not detract from the basic mission responsibilities of the agency, and

"(2) such assignments shall be carried out under such guidance as the Administrator deems appropriate.

\section{"ADMINISTRATIVE PROVISIONS}

"Sec. 105. (a) The Administrator is authorized to prescribe such policies, standards, criteria, procedures, rules, and regulations as he may deem to be necessary or appropriate to perform functions now or hereafter vested in him.

"(b) The Administrator shall engage in such policy planning, and perform, such program evaluation analyses and other studies, as may be necessary to promote the efficient and coordinated administration of the Administration and properly assess progress toward the achievement of its missions.

"(c) Except as otherwise expressly provided by law, the Administrator may delegate any of his functions to such officers and employees of the Administration as he may designate, and may authorize such successive redelegations of such functions as he may deem to be necessary or appropriate.

"(d) Except as provided in section 102 and in section 104(d), the Administrator may organize the Administration as he may deem to be necessary or appropriate.

"(e)The Administrator is authorized to establish, maintain, alter, or discontinue such State, regional, district, local, or other field offices as he may deem to be necessary or appropriate to perform functions now or hereafter vested in him.

"(f) The Administrator shall cause a seal of office to be made for 
Seal.

Working capital fund.

Information from other agencies.

Appointment and pay.

42 USC 5816.

Experts and consultants. Military personnel. the Administration of such device as he shall approve, and judicial notice shall be taken of such seal.

" $(\mathrm{g})$ The Administrator is authorized to establish a working capital fund, to be available without fiscal year limitation, for expenses necessary for the maintenance and operation of such common administrative services as he shall find to be desirable in the interests of economy and efficiency. There shall be transferred to the fund the stocks of supplies, equipment, assets other than real property, liabilities, and unpaid obligations relating to the services which he determines will be performed through the fund. Appropriations to the fund, in such amounts as may be necessary to provide additional working capital, are authorized. The working capital fund shall recover from the appropriations and funds for which services are performed, either in advance or by way of reimbursement, amounts which will approximate the costs incurred, including the accrual of annual leave and the depreciation of equipment. The fund shall also be credited with receipts from the sale or exchange of its property, and receipts in payment for loss or damage to property owned by the fund.

"( $h)$ Each department, agency, and instrumentality of the executive branch of the Government is authorized to furnish to the Administrator, upon his request, any information or other data which the Administrator deems necessary to carry out his duties under this title.

\section{"PERSONNEL AND SERVICES}

"Sec. 106. (a) The Administrator is authorized to select, appoint, employ, and fix the compensation of such officers and employees, including attorneys, pursuant to section $161 \mathrm{~d}$. of the Atomic Energy Act of 1954, as amended (42 U.S.C. 2201(d)) as are necessary to perform the functions now or hereafter vested in him and to prescribe their functions.

“(b) The Administrator is authorized to obtain services as provided by section 3109 of title 5 of the United States Code.

"(c) The Administrator is authorized to provide for participation of military personnel in the performance of his functions. Members of the Army, the Navy, the Air Force, or the Marine Corps may be detailed for service in the Administration by the appropriate military Secretary, pursuant to cooperative agreements with the Secretary, for service in the Administration in positions other than a position the occupant of which must be approved by and with the advice and consent of the Senate.

"(d) Appointment, detail, or assignment to, acceptance of, and service in, any appointive or other position in the Administration under this section shall in no way affect the status, office, rank, or grade which such officers or enlisted men may occupy or hold, or any emolument, prerequisite, right, privilege, or benefit incident to or arising out of any such status, office, rank, or grade. A member so appointed, detailed, or assigned shall not be subject to direction or control by his Armed Force, or any officer thereof, 
Transportation and per diem.

88 Stat. 1240. Personnel of other agencies.

Advisory boards.

5 USC app. I.

Noncitizens.

Research and development.

42 USC 5817.

Contracts, etc.

42 USC 2011

note.

Facilities and real property. 40 USC 601

note. 5 USC directly or indirectly, with respect to the responsibilities exercised in the position to which appointed, detailed, or assigned.

"(e) The Administrator is authorized to pay transportation expenses, and per diem in lieu of subsistence expenses, in accordance with chapter 57 of title 5 of the United States Code for travel between places of recruitment and duty, and while at places of duty, of persons appointed for emergency, temporary; or seasonal services in the field service of the Administration.

"(f) The Administrator is authorized to utilize, on a reimbursable basis, the services of any personnel made available by any department, agency, or instrumentality, including any independent agency of the Government.

"(g) The Administrator is authorized to establish advisory boards, in accordance with the provisions of the Federal Advisory Committee Act (Public Law 92-463), to advise with and make recommendations to the Administrator on legislation, policies, administration, research, and other matters.

"(h) The Administrator is authorized to employ persons who are not citizens of the United States in expert, scientific, technical, or professional capacities whenever he deems it in the public interest.

\section{"POWERS}

"Sec. 107. (a) The Administrator is authorized to exercise his powers in such manner as to insure the continued conduct of research and development and related activities in areas or fields deemed by the Administrator to be pertinent to the acquisition of an expanded fund of scientific, technical, and practical knowledge in energy matters. To this end, the Administrator is authorized to make arrangements (including contracts, agreements, and loans) for the conduct of research and development activities with private or public institutions or persons, including participation in joint or cooperative projects of a research, development, or experimental nature; to make payments (in lump sum or installments, and in advance or by way of reimbursement, with necessary adjustments on account of overpayments or underpayments); and generally to take such steps as he may deem necessary or appropriate to perform functions now or hereafter vested in him. Such functions of the Administrator under this Act as are applicable to the nuclear activities transferred pursuant to this title shall be subject to the provisions of the Atomic Energy Act of 1954, as amended, and to other authority applicable to such nuclear activities. The non-nuclear responsibilities and functions of the Administrator referred to in sections 103 and 104 of this Act shall be carried out pursuant to the provisions of this Act, applicable authority existing immediately before the effective date of this Act, or in accordance with the provisions of Chapter 4 of the Atomic Energy Act of 1954, as amended (42 U.S.C. 2051-2053).

"(b) Except for public buildings as defined in the Public Buildings Act of 1959, as amended, and with respect to leased space subject to the provisions of Reorganization Plan Numbered 18 of 1950, the Administrator is authorized to acquire (by purchase, lease, condemnation, or otherwise), construct, improve, repair, operate, and maintain facilities 
app. II.

Services for employees at remote locations.

88 Stat. 1241.

Acquisition of copyrights, patents, etc.

Dissemination of information. and real property as the Administrator deems to be necessary in and outside of the District of Columbia. Such authority shall apply only to facilities required for the maintenance and operation of laboratories, research and testing sites and facilities, quarters, and related accommodations for employees and dependents of employees of the Administration, and such other special-purpose real property as the Administrator deems to be necessary in and outside the District of Columbia. Title to any property or interest therein, real, personal, or mixed, acquired pursuant to this section, shall be in the United States.

"(c)(1) The Administrator is authorized to provide, construct, or maintain, as necessary and when not otherwise available, the following for employees and their dependents stationed at remote locations:

"(A) Emergency medical services and supplies.

"(B) Food and other subsistence supplies.

"(C) Messing facilities.

(D) Audiovisual equipment, accessories, and supplies for recreation and training.

"(E) Reimbursement for food, clothing, medicine, and other supplies furnished by such employees in emergencies for the temporary relief of distressed persons.

"(F) Living and working quarters and facilities.

"(G) Transportation for school-age dependents of employees to the nearest appropriate education facilities.

“(2) The furnishing of medical treatment under sub-paragraph (A) of paragraph (1) and the furnishing of services and supplies under paragraphs (B) and (C) of paragraph (1) shall be at prices reflecting reasonable value as determined by the Administrator.

"(3) Proceeds from reimbursements under this section shall be deposited in the Treasury and may be withdrawn by the Administrator to pay directly the cost of such work or services, to repay or make advances to appropriations or funds which do or will bear all or a part of such cost, or to refund excess sums when necessary; except that such payments may be credited to a service or working capital fund otherwise established by law, and used under the law governing such funds, if the fund is available for use by the Administrator for performing the work or services for which payment is received.

"(d) The Administrator is authorized to acquire any of the following described rights if the property acquired thereby is for use in, or is useful to, the performance of functions vested in him;

“(1) Copyrights, patents, and applications for patents, designs, processes, specifications, and data.

"(2) Licenses under copyrights, patents, and applicants for patents.

“(3) Releases, before suit is brought, for past infringement of patents or copyrights.

"(e) Subject to the provisions of chapter 12 of the Atomic Energy Act of 1954, as amended (42 USC 2161-2166), and other applicable law, the Administrator shall disseminate scientific, technical, and practical information acquired pursuant to this title through information programs and other appropriate means, and shall encourage the dissemination of scientific, technical, and practical infor- 
Gifts and bequests.

Report to Congress. 42 USC 5819. mation relating to energy so as to enlarge the fund of such information and to provide that free interchange of ideas and criticism which is essential to scientific and industrial progress and public understanding.

"(f) The Administrator is authorized to accept, hold, administer, and utilize gifts, and bequests of property, both real and personal, for the purpose of aiding or facilitating the work of the Administration. Gifts and bequests of money and proceeds from sales of other property received as gifts or bequests shall be deposited in the Treasury and shall be disbursed upon the order of the Administrator. For the purposes of Federal income, estate, and gift taxes, property accepted under this section shall be considered as a gift or bequest to the United States.

"Sec. 108.2

\section{"FUTURE REORGANIZATION}

"Sec. 109. (a) The President shall transmit to the Congress as promptly as possible, but not later than June 30,1975 , such additional recommendations as he deems advisable for organization of energy and related functions in the Federal Government, including, but not limited to, whether or not there shall be established (1) a Department of Energy and Natural Resources, (2) an Energy Policy Council, and (3) a consolidation in whole or in part of regulatory functions concerning energy.

2Public Law 95-91 (91 Stat. 608) (1977), repealed sec. 108, which read as follows: “(a) There is established in the Executive Office of the President an Energy Resources Council. The Council shall be composed of the Secretary of the Interior, the Administrator of the Federal Energy Administration, the Administrator of the Energy Research and Development Administration, the Secretary of State, theDirector, Office of Management and Budget, and suchother offieials of the Federal Government as the President may designate. The President shall designate one of the members of the Council to serve as Chairman.

"(b) It shall be the duty and function of the Council to-

u(1) insure communication and coordination among the agencies of the Federal Government which have responsibilities for the development and implementation of energy policy or for the management of energy re sources:

"(2) make recommendations to the President and to the Congress for measures to improve the implementation of Federal energy policies or the management of energy resources withparticular emphasis upon policies and activities involving two or more Departments or independent agencies;

"(3) advise the President in the preparation of the reorganization recommendations required by section 110 of this Act; and

"(4) insure that Federal agencies fully discharge their responsibilities under sections 507 and 508 of the $\mathrm{Na}$ tional Energy Extension Service Act for coordinating and planning of their related activities under such Act and any other law, including but not limited to the Energy Policy and Conservation Act.c

"(5) prepare a report on national energy conservation activities which shall be submitted to the President and the Congress annually, beginning on July 1,1977 , and which shall inchude-

(A) a review of all Federal energy conservation expenditures and activities, the purpose of each such activity, the relation of the activity to national conservation targets and plans, and the suecess of the activity and the plans for the activity in future years;

"(B) an analysis of all conservation targets established for industry, residential, transportation, and public sectors of the economy, whether the targets can be achieved or whether they can be further improved, and the progress toward their achievement in the past year,

"(C) a review of the progress made pursuant to the State energy conservation plans under sections 361 through 366 of the Energy Policy and Conservation Act and other similar efforts at the State and local level, and whether further conservation can be carried on by the States or by local governments, and whether further Federal assistance is required;

"(D) a review of the principal conservation efforts in the private sector, the potentialformorewidespread implementation of such efforts and the Federal Government's efforts to promote more widespread use of private energy conservation initiatives; and

(E) an assessment of whether existing conservation targets and goals are sufficient to bridge the gap between domestic energy produetion capacity and domestic energy needs, whether additional incentives or programs are necessary or useful to close that gap further, and a discussion of what mandatory measures might be useful to further bring domestic demand into harmony with domestic supply.

The Chairman of the Energy Resources Council shall coordinate the preparation of the report required under paragraph (5)."

“(c) The President through the Energy Resources Council shall-

"(1) prepare a plan for the reorganization of the Federal Government's activities in energy and natural resources, including, but not limited to, a study of-

(Continued) 

required by section 15(a)(4) of the Federal Energy Administration Act.

\section{"COORDINATION WITH ENVIRONMENTAL EFFORTS}

42 USC 5820.

"Sec. 110. The Administrator is authorized to establish programs to utilize research and development performed by other Federal agencies to minimize the adverse environmental effects of energy projects. The Administrator of the Environmental Protection Agency, as well as other affected agencies and departments, shall cooperate fully with the Administrator in establishing and maintaining such programs, and in establishing appropriate interagency agreements to develop cooperative programs and to avoid unnecessary duplication.

\section{"PROVISIONS APPLICABLE TO ANNUAL \\ AUTHORIZATION ACTS}

42 USC 5821.

"Sec. 111 (a) All appropriations made to the Energy research and Development Administration or the Administrator shall, except as otherwise provided by law, be subject to annual authorization in accord-

42 USC 2017. ance with section 261 of the Atomic Energy Act of 1954, section 16 of the Federal Nonnuclear Energy Research and Development Act of 1974, and section 305 of this Act. The provisions of this section shall apply

42 USC 5915. Post, p.81. with respect to appropriations made pursuant to the Act providing such authorization (hereinafter in this section referred to as 'annual authorization Acts').

"Operating

"(b)(1) Funds appropriated pursuant to an annual authorization Act

(Continued)

States:

the principal laws and directives that constitute the energy and natural resource policy of the United

(B) prospects of developing a consolidated national energy policy;

(C) the major problems and issues of existing energy and natural resource organizations;

(D) the options for Federal energy and natural resource organizations;

(E) an overview of available resources pertinent to energy and natural resource organization;

(F) recent proposals for a national energy and natural resource policy for the United States; and

(G) the relationship between energy policy goals and other national objectives;

"(2) submit to Congress -

"(A) no later than December 31, 1976, the plan prepared pursuant to subsection (c)(1) and a report containing his recommendations for the reorganization of the Federal Government's responsibility for energy and natural resource matters together with such proposed legislation as he deems necessary or appropriate for the implementation of such plans or recommendations; and

(B) not later than April 15, 1977, such revisions to the plan and report described in subparagraph (A) of

this paragraph as he may consider appropriate; and "(3) provide

Government." thereof regarding the duties of the Council or other matters concerning interagency coordination of energy policy and activities.

"(e) There is hereby established an Energy Conservation Subcommittee within the Council which shall be chaired by the Administrator of the Energy Research and Development Administration to discharge the responsibilities specified in subsection (b) (4) of this section and other related functions associated with the coordination and management of Federal efforts in the areas of energy conservation and energy conservation research, development and demonstra(ion."

"(c) This section shall be effective no later than sixty days after the enactment of this Act or such earlier date as the President shall prescribe and publish in the Federal Register, and shall terminate upon enactment of a permanent department responsible for energy and natural resources or not later than September 30, 1977, whichever shall occur first. 8

(a) "P.L. 94-385 (90 Stat. 1140) (1976) sec. 162(a)(1) amended sec. 108(b)(2) by striking out "and" at the end of the paragraph.

(b)"P.L. 94-385(90 Stat. 1140)(1976) sec. 162(a)(2) amended sec. 108(b)(3) by striking out the period at the end

of paragraph and inserting ";and".

(c) "P.L. 95-39 (91 Stat. 200)(1977) sec. 510(b) inadvertently duplicated the paragraph number (4). (See d) [This

$\mathrm{sec}$ also duplicated instructions in a and b].

(d)"P.L 94-385 (90 Stat. 1140)(1976) sec. 162(a)(3) amended sec. 108(b) by adding a new paragraph (4). [There is no paragraph (5) in the original subsection (b)].

(e)"P.L. 94385 (90 Stat. 1141)(1976) sec. 162(b) amended sec. 108 by redesignating subsections (c) and (d) as

subsections (d) and (e), respectively; and added a new subsection (c).

(f) “P.L. 95.39 (91 Stat. 200) (1977) sec. 510(c) inadvertently duplicated the subsection letter (e). (See e)

(g)"P.L 94-385 (90 Stat. 1142)(1976) sec. 163 amended sec. 108 (e) by striking out "two years after such effective date, " and inserting "not later than September 30, 1977." 
expenses", appropriations.

Report to congressional committees.

Expenditure limitations.

Report to congressional committees.

Limitation.

Report, transmittal to congressional committees. for 'Operating expenses' may be used for-

"(A) the construction or acquisition of any facilities, or major items of equipment, which may be required at locations other than installations of the Administration, for the performance of research, development, and demonstration activities, and

“(B) grants to any organization for purchase or construction of research facilities.

No such funds shall be used under this subsection for the acquisition of land. Fee title to all such facilities and items of equipment shall be vested in the United States, unless the Administrator or his designee determines in writing that the research, development, and demonstration authorized by such Act would best be implemented by permitting fee title or any other property interest to be vested in an entity other than the United States; but before approving the vesting of such title or interest in such entity, the Administrator shall (i) transmit such determination, together with all pertinent data, to the Committee on Science and Technology of the House of Representatives and the Committee on Energy and Natural Resources of the Senate and (ii) wait a period of thirty calendar days (not including any day in which either House of Congress is not in session because of adjournment of more than three calendar days to a day certain), unless prior to the expiration of such period each such committee has transmitted to the Administrator written notice to the effect that such committee has no objection to the proposed action.

“(2) No funds shall be used under paragraph (1) for any facility or major item of equipment, including collateral equipment, if the estimated cost to the Federal Government exceeds $\$ 5,000,000$ in the case of such a facility or $\$ 2,000,000$ in the case of such an item of equipment, unless such facility or item has been previously authorized by the appropriate committees of the House of representatives and the Senate, or the Administrator-

"(A) transmit to the appropriate committees of the House of Representatives and the Senate a report on such facility or item showing its nature, purpose, and estimated cost, and

"(B) waits a period of thirty calendar days (not including any day in which either House of Congress is not in session because of adjournment of more than three calendar days to a day certain), unless prior to the expiration of such period each such committee has transmitted to the Administrator written notice to the effect that such committee has no objection to the proposed action.

"(c)(1) Not to exceed 1 per centum of all funds appropriated pursuant to any annual authorization Act for 'Operating expenses' may be used by the Administrator to construct, expand, or modify laboratories and other facilities, including the acquisition of land, at any location under the control of the Administrator, if the Administrator determines that (A) such action would be necessary because of changes in the national programs authorized to be funded by such Act or because the new scientific or engineering developments, and (B) deferral of such action until the enactment of the next authorization Act would be inconsistent with the policies established by Congress for the Administration. 
Notice.

Report, transmittal to congressional committees.

Notice.

Funds merger, limitations.
"(2) No funds may be obligated for expenditure or expended under paragraph (1) for activities described in such paragraph unless-

"(A) a period of thirty calendar days (not including any day in which either House of Congress is not in session because of adjournment of more than three calendar days to a day certain) has passed after the Administrator has transmitted to the appropriate committees of the House of Representatives and the Senate a written report containing a full and complete statement concerning (i) the nature of the construction, expansion, or modification involved, (ii) the cost thereof, including the cost of any real estate action pertaining thereto, and (iii) the reason why such construction, expansion, or modification is necessary and in the national interest, or

"(B) each such committee before the expiration of such period has transmitted to the Administrator a written notice to the effect that such committee has no objection to the proposed action; except that this paragraph shall not apply to any project the estimated total cost of which does not exceed $\$ 50,000$.

"(d)(1) Except as otherwise provided in the authorization Act involved-

"(A) no amount appropriated pursuant to any annual authorization Act may be used for any program in excess of the amount actually authorized for that particular program by such Act, and

"(B) no amount appropriated pursuant to any annual authorization Act may be used for any program which has not been presented to, or requested of the Congress,

unless (i) a period of thirty calendar days (not including any day in which either House of Congress is not in session because of adjournment of more than three calendar days to a day certain) has passed after the receipt by the appropriate committees of the House of Representatives and the Senate of notice given by the Administrator containing a full and complete statement of the action proposed to be taken and the facts and circumstances relied upon in support of such proposed action, or (ii) each such committee before the expiration of such period has transmitted to the Administrator written notice to the effect that such committee has no objection to the proposed action.

"(2) Notwithstanding any other provision of this section or the authorization Act involved, the aggregate amount available for use within the categories of coal, petroleum and natural gas, oil shale, solar, geothermal nuclear energy (non-weapons), environment and safety, and conservation from sums appropriated pursuant to an annual authorization Act may not, as a result of reprogramming, be decreased by more than 10 per centum of the total of the sums appropriated pursuant to such Act for those categories.

"(e) Subject to the applicable requirements and limitations of this section and the authorization Act involved, when so specified in an appropriation Act, amounts appropriated pursuant to any annual authorization Act for 'Operating expenses' or for 'Plant and capital equipment' may be merged with any other amounts appropriated for like purposes pursuant to any other Act authorizing appropriations for the Administration: Provided, That no such 
Construction design services.

Funds transfer.

Members and Chairman. 42 USC 5841.

88 Stat. 1243. amounts appropriated for 'Plant and capital equipment' may be merged with amounts appropriated for 'Operating expenses'.

"(f) When so specified in an appropriation Act, amounts appropriated pursuant to any annual authorization Act for 'Operating expenses' or for 'Plant and capital equipment' may remain available until expended.

"(g) The Administrator is authorized to perform construction design services for any administration construction project whenever (1) such construction project has been included in a proposed authorization bill transmitted to the Congress by the Administration, and (2) the Administration determines that the project is of such urgency in order to meet the needs of national defense or protection of life and property or health and safety that construction of the project should be initiated promptly upon enactment of legislation appropriating funds for its construction.

"(h) When so specified in appropriation Acts, any moneys received by the Administration may be retained and used for operating expenses, and may remain available until expended,notwithstanding the provisions of section 3617 of the Revised Statutes (31 U.S.C. 484); except that-

"(1) this subsection shall not apply with respect to sums received from disposal of property under the Atomic Energy Community Act of 1955 or the Strategic and Critical Materials Stockpiling Act, as amended, or with respect to fees received for tests or investigations under the Act of May 16, 1910, as amended (42 U.S.C. 2301; 50 U.S.C. 98h; 30 U.S.C. 7); and

"(2) revenues received by the Administration from the enrichment of uranium shall (when so specified) be retained and used for the specific purpose of offsetting costs incurred by the Administration in providing uranium enrichment service activities.

"(i) When so specified in an appropriation Act, transfers of sums from the 'Operating expenses' appropriation made pursuant to an annual authorization Act may be made to other agencies of the Government for the performance of the work for which the appropriation is made, and in such cases the sums so transferred may be merged with the appropriations to which they are transferred. ${ }^{3}$

\section{"TITLE II - NUCLEAR REGULATORY COMMISSION: NUCLEAR WHISTLEBLOWER PROTECTION}

\section{"ESTABLISHMENT AND TRANSFERS}

"Sec. 201. (a)(1)4 There is established an independent regulatory commission to be known as the Nuclear Regulatory Commission which shall be composed of five members, each of whom shall be a citizen of the United States. The President shall designate one member of the Commission as Chairman thereof to serve as such during the pleasure of the President. The Chairman may from time to time designate any other member of the Commission as Acting Chairman to act in the place and stead of the Chairman during his absence. The Chairman (or the Acting

${ }^{3}$ Public Law 95-238 (92 Stat. 56)(1978), sec. 201 added sec. 111.

${ }^{4}$ Public Law 94-79 (89 Stat. 413)(1975), sec. 201 added "(1)" immediately after "Sec. 201. (a)." 
Seal.

Commission

Chairman,

functions.

42 USC 5801

note.

Plutonium shipments, restrictions.

42 USC 5841 note.
Chairman in the absence of the Chairman) shall preside at all meetings of the Commission and a quorum for the transaction of business shall consist of at least three members present. Each member of the Commission, including the Chairman, shall have equal responsibility and authority in all decisions and actions of the Commission, shall have full access to all information relating to the performance of his duties or responsibilities, and shall have one vote. Action of the Commission shall be determined by a majority vote of the members present. The Chairman (or Acting Chairman in the absence of the Chairman) shall be the official spokesman of the Commission in its relations with the Congress, Government agencies, persons, or the public, and on behalf of the Commission, shall see to the faithful execution of the policies and decisions of the Commission, and shall report thereon to the Commission from time to time or as the Commission may direct. The Commission shall have an official seal which shall be judicialy noticed.

(2) The Chairman of the Commission shall be the principal executive officer of the Commission, and he shall exercise all of the executive and administrative functions of the Commission, including functions of the commission with respect to (a) the appointment and supervision of personnel employed under the Commission (other than personnel employed regularly and full time in the immediate offices of Commissioners other than the Chairman, and except as otherwise provided in the Energy Reorganization Act of 1974), (b) the distribution of business among such personnel and among administrative units of the Commission, and (c) the use and expenditure of funds.

(3) In carrying out any of his functions under the provisions of this section the Chairman shall be governed by general policies of the Commission and by such regulatory decisions, findings, and determinations as the Commission may by law be authorized to make.

(4) The appointment by the Chairman of the heads of major administrative units under the Commission shall be subject to the approval of the Commission.

(5) There are hereby reserved to the Commission its functions with respect to revising budget estimates and with respect to determining upon the distribution of appropriated funds according to major programs and purposes.

The Nuclear Regulatory Commission shall not license any shipments by air transport of plutonium in any form, whether exports, imports or domestic shipments: Provided, however, That any plutonium in any form contained in a medical device designed for individual human application is not subject to this restriction. This restriction shall be in force until the Nuclear Regulatory Commission has certified to the Joint Committee on Atomic Energy of the Congress that a safe container has been developed and tested which will not rupture under crash and blast-testing equivalent to the crash and explosion of a high-flying aircraft. 5

(b) (1) Members of the Commission shall be appointed by the President, by and with the advice and consent of the Senate.

(5).

SPublic Law 9479 (69 Stat.413)(1975). Sec. 201 amended subsec. 201 (a) by adding new subparagraphs (2) through 
Term of Office. 42 USC 5841

Submission of appointments to Senate.

Transfer of AEC functions and personnel

Additional transfers.

88 Stat. 1244.

(2) Appointments of members pursuant to this subsection shall be made in such a manner that not more than three members of the Commission shall be members of the same political party.

(c) Each member shall serve for a term of five years, each such term to commence on July 1, except that of the five members first appointed to the Commission, one shall serve for one year, one for two years, one for three years, one for four years, and one for five years, to be designated by the President at the time of appointment; and except that any member appointed to fill a vacancy occurring prior to the expiration of the term for which his predecessor was appointed, shall be appointed for the remainder of such term. For the purpose of determining the expiration date of the terms of office of the five members first appointed to the Nuclear Regulatory Commission, each such term "shall" be deemed to have begun July $1,1975.6$

(d) Such initial appointments shall be submitted to the Senate within sixty days of the signing of this Act. Any individual who is serving as a member of the Atomic Energy commission at the time of the enactment of this Act, and who may be appointed by the President to the Commission, shall be appointed for a term designated by the President, but which term shall terminate not later than the end of his present term as a member of the Atomic Energy Commission, without regard to the requirements of subsection (b)(2) of this section. Any subsequent appointment of such individuals shall be subject to the provisions of this section.

(e) Any member of the Commission may be removed by the President for inefficiency, neglect of duty, or malfeasance in office. No member of the Commission shall engage in any business, vocation, or employment other than that of serving as member of the Commission.

(f) There are hereby transferred to the Commission all the licensing and related regulatory functions of the Atomic Energy Commission, the Chairman and member of the Commission, the General Counsel, and other officers and components of the Commission-which functions, officers, components, and personnel are excepted from the transfer to the Administrator by section 104(c) of this Act.

(g) In addition to other functions and personnel transferred to the Commission, there are also transferred to the Commission-

(1) the functions of the Atomic Safety and Licensing Board Panel and the Atomic Safety and Licensing Appeal Board;

(2) such personnel as the Director of the Office of Management and Budget determines are necessary for exercising responsibilities under section 205 , relating to, research, for the purpose of confirmatory assessment relating to licensing and

\footnotetext{
6Public Law 94-79 (89 Stat. 413)(1975), secs. 202 and 203, amended subsec. 201 (c). Prior to amendment this subsection read as follows:

"(c) Each member shall serve for a term of five years, each such term to commence onJuly 1, except that of the five members first appointed to the Commission, one shall serve for oneyear, one for two years, one for threeyears, one for four years, and one for five years, to be designated by the President at the time of appointment."
} 
42 USC 5842.

42 USC

2071-2112,

2131-2140.

Establishment 42 USC 5843.

Director.

Functions.

42 USC 2011. note. other regulation under the provisions of the Atomic Energy Act of 1954, as amended, and of this Act.?

\section{"LICENSING AND RELATED REGULATORY FUNCTIONS} RESPECTING SELECTED ADMINISTRATION FACILITIES

Sec. 202. Notwithstanding the exclusions provided for in section $110 \mathrm{a}$. or any other provisions of the Atomic Energy Act of 1954, as amended (42 U.S.C. 2140(a)), the Nuclear Regulatory Commission shall, except as otherwise specifically provided by section $110 \mathrm{~b}$. of the Atomic Energy Act of 1954, as amended (42 U.S.C. 2140(b)), or other law, have licensing and related regulatory authority pursuant to chapters $6,7,8$, and 10 of the Atomic energy Act of 1954, as amended, as to the following facilities of the Administration:

(1) Demonstration Liquid Metal Fast Breeder reactors when operated as part of the power generation facilities of an electric utility system, or when operated in any other manner for the purpose of demonstrating the suitability for commercial application of such a reactor.

(2) Other demonstration nuclear reactors-except those in existence on the effective date of this Act-when operated as part of the power generation facilities of an electric utility system, or when operated in any other manner for the purpose of demonstrating the suitability for commercial application of such a reactor.

(3) Facilities used primarily for the receipt and storage of highlevel radioactive wastes resulting from activities licensed under such Act.

"(4) Retrievable Surface Storage Facilities and other facilities authorized for the express purpose of subsequent long-term storage of high-level radioactive waste generated by the Administration, which are not used for, or are part of, research and development activities.

\section{"OFFICE OF NUCLEAR REACTOR REGULATION}

"Sec. 203. (a) There is hereby established in the Commission an Office of Nuclear Reactor Regulation under the direction of a Director of Nuclear Reactor Regulation, who shall be appointed by the Commission, who may report directly to the Commission, as provided in section 209 , and who shall serve at the pleasure of and be removable by the Commission.

"(b) Subject to the provisions of this Act, the Director of Nuclear Reactor Regulation shall perform such functions as the Commission shall delegate including:

"(1) Principal licensing and regulation involving all facilities, and materials licensed under the Atomic Energy Act of 1954, as amended, associated with the construction and operation of nuclear reactors licensed under the Atomic Energy Act of 1954, as amended;

"(2) Review the safety and safeguards of all such facilities, materials, and activities, and such review functions shall include, but not be limited to-

7Public Law 95-209 (91 Stat. 1482) (1977), sec. 2, added a new subsec. h, which was subsequently deleted by P.L 99-386 (100 Stat. 822)(1986). 
88 Stat. 1245.

Establishment. 42 USC 5845. Director.

Functions.

42 USC 2011. note.

Report to Congress.
"(A) monitoring, testing and recommending upgrading of systems designed to prevent substantial health or safety hazards; and

"(B) evaluating methods of transporting special nuclear and other nuclear materials and of transporting and storing highlevel radioactive wastes to prevent radiation hazards to employees and the general public.

"(3) Recommend research necessary for the discharge of the functions of the Commission.

"(c) Nothing in this section shall be construed to limit in any way the functions of the Administration relating to the safe operation of all facilities resulting from all activities within the jurisdiction of the Administration pursuant to this Act.

\section{"OFFICE OF NUCLEAR MATERIAL SAFETY AND SAFEGUARDS}

"Sec. 204. (a) There is hereby established in the Commission an Office of Nuclear Material Safety and Safeguards under the direction of a Director of Nuclear Material Safety and Safeguards, who shall be appointed by the Commission, who may report directly to the Commission as provided in section 209, and who shall serve at the pleasure of and be removable by the Commission.

"(b) Subject to the provisions of this Act, the Director of Nuclear Material Safety and Safeguards shall perform such functions as the Commission shall delegate including:

"(1) Principal licensing and regulation involving all facilities and materials, licensed under the Atomic Energy Act of 1954, as amended, associated with the processing, transport, and handling of nuclear materials, including the provision and maintenance of safeguards against threats, thefts, and sabotage of such licensed facilities, and materials.

"(2) Review safety and safeguards of all such facilities and materials licensed under the Atomic Energy Act of 1954, as amended, and such review shall include, but not be limited to-

"(A) monitoring, testing, and recommending upgrading of internal accounting systems for special nuclear and other nuclear materials licensed under the Atomic Energy Act of 1954, as amended:

"(B) developing, in consultation and coordination with the Administration, contingency plans for dealing with threats, thefts, and sabotage relating to special nuclear materials, highlevel radioactive wastes and nuclear facilities resulting from all activities licensed under the Atomic Energy Act of 1954, as amended;

"(C) assessing the need for, and the feasibility of, establishing a security agency within the office for the performance of the safeguards functions, and a report with recommendations on this matter shall be prepared within one year of the effective date of this Act and promptly transmitted to the Congress by the Commission.

"(3) Recommending research to enable the Commission to more effectively perform its functions. 
88 Stat. 1246.

Establishment. 42 USC 5845.

Director.

Functions.

Cooperation of Federal agencies.

Information and research services.

Improved Safety Systems Research Long-term plan development. 42 USC 5845 "(c) Nothing in this section shall be construed to limit in any way the functions of the Administration relating to the safeguarding of special nuclear materials, high-level radioactive wastes and nuclear facilities resulting from all activities within the jurisdiction of the Administration pursuant to this Act.

\section{"OFFICE OF NUCLEAR REGULATORY RESEARCH}

"Sec. 205. (a) There is hereby established in the Commission an Office of Nuclear Regulatory Research under the direction of a Director of Nuclear Regulatory research, who shall be appointed by the Commission, who may report directly to the Commission as provided in section 209 , and who shall serve at the pleasure of and be removable by the Commission.

"(b) Subject to the provisions of this Act, the Director of Nuclear Regulatory Research shall perform such functions as the Commission shall delegate including:

"(1) Developing recommendations for research deemed necessary for performance by the Commission of itslicensing and related regulatory functions.

"(2) Engaging in or contracting for research which the Commission deems necessary for the performance of its licensing and related regulatory functions.

"(c) The Administrator of the Administration and the head of every other Federal agency shall-

“(1) cooperate with respect to the establishment of priorities for the furnishing of such research services as requested by the Commission for the conduct of its functions;

"(2) furnish to the Commission, on a reimbursable basis, through their own facilities or by contract or other arrangement, such research services as the Commission deems necessary and requests for the performance of its functions; and

“(3) consult and cooperate with the Commission on research and development matters of mutual interest and provide such information and physical access to its facilities as will assist the Commission in acquiring the expertise necessary to perform its licensing and related regulatory functions.

"(d) Nothing in subsections (a) and (b) of this section or section 201 of this Act shall be construed to limit in any way the functions of the Administration relating to the safety of activities within the jurisdiction of the Administration.

"(e) Each Federal agency, subject to the provisions of existing law, shall cooperate with the Commission and provide such information and research services, on a reimbursable basis, as it may have or be reasonably able to acquire.

"(f) The Commission shall develop a long-term plan for projects for the development of new or improved safety systems for nuclear powerplants. ${ }^{8}$

${ }^{8}$ Public Law 95-209 (91 Stat. 1482)(1977), sec. 4, added a new subsec. 1. 


\section{"NONCOMPLIANCE}

42 USC 5846.

42 USC 2011

note.

88 Stat. 1247.

Penalty.

42 USC 2282

Posting of requirements. 42 USC 2011 note.

Enforcement.

42 USC 5847.

Federal-Statelocal cooperation.

Solicitation

of views.

Definition.
"Sec. 206. (a) Any individual director, or responsible officer of a firm constructing, owning, operating, or supplying the components of any facility or activity which is licensed or otherwise regulated pursuant to the Atomic Energy Act of 1954 as amended, or pursuant to this Act, who obtains information reasonably indicating that such facility or activity or basic components supplied to such facility or activity-

"(1) fails to comply with the Atomic Energy Act of 1954, as amended, or any applicable rule, regulation, order, or license of the Commission relating to substantial safety hazards, or

"(2) contains a defect which could create a substantial safety hazard, as defined by regulations which the Commission shall promulgate,

shall immediately notify the Commission of such failure to comply, or of such defect, unless such person has actual knowledge that the Commission has been adequately informed of such defect or failure to comply.

"(b) Any person who knowingly and consciously fails to provide the notice required by subsection (a) of this section shall be subject to a civil penalty in an amount equal to the amount provided by section 234 of the Atomic energy Act of 1954, as amended.

"(c) The requirements of this section shall be prominently posted on the premises of any facility licensed or otherwise regulated pursuant to the Atomic Energy Act of 1954, as amended.

"(d) The Commission is authorized to conduct such reasonable inspections and other enforcement activities as needed to insure compliance with the provisions of this section.

\section{"NUCLEAR ENERGY CENTER SITE SURVEY}

"Sec. 207. (a)(1) The Commission is authorized and directed to make or cause to be made under its direction, a national survey, which shall include consideration of each of the existing or future electric reliability regions, or other appropriate regional areas, to locate and identify possible nuclear energy center sites. This survey shall be conducted in cooperation with other interested Federal, State, and local agencies, and the views of interested persons, including electric utilities, citizens' groups, and others, shall be solicited and considered.

"(2) For purposes of this section, the term 'nuclear energy center site' means any site, including a site not restricted to land, large enough to support utility operations or other elements of the total nuclear fuel cycle, or both including, if appropriate, nuclearfuel reprocessing facilities, nuclear fuel fabrication plants, retrievable nuclear waste storage facilities, and uranium enrichment facilities.

“(3) The survey shall include-

"(a) a regional evaluation of natural resources, including land, air, and water resources, available for use in connection with nuclear energy center sites; estimates of future electric power requirements that can be served by each nuclear energy center site; an assessment of the economic impact of each nuclear energy site; and consideration of any other relevant factors, including but not limited to population distribution, proximity to electric load cen- 
Report to Congress and Council on Environmental Quality; public availability.

88 Stat.. 1248

Reports to Congress. 42 USC 5848.

42 USC 2011 note.

Public dissemination of information.

Executive Director. 42 USC 5849. Functions. ters and to other elements of the fuel cycle, transmission line rights-of-way, and the availability of other fuel resources;

"(b) an evaluation of the environmental impact likely to result from construction and operation of such nuclear energy centers, including an evaluation whether such nuclear energy centers will result in greater or lesser environmental impact than separate siting of the reactors and/or fuel cycle facilities; and

"(c) consideration of the use of federally owned property and other property designated for public use, but excluding national parks, national forests, national wilderness areas, and national historic monuments.

"(4) A report of the results of the survey shall be published and transmitted to the Congress and the Council on Environmental Quality not later than one year from the date of the enactment of this Act and shall be made available to the public, and shall be updated from time to time thereafter as the Commission, in its discretion, deems advisable. The report shall include the Commission's evaluation of the results of the survey and any conclusions and recommendations, including recommendations for legislation, which the Commission may have concerning the feasibility and practicality of locating nuclear power reactors and/or other elements of the nuclear fuel cycle or nuclear

energy center sites. The Commission is authorized to adopt policies which will encourage the location of nuclear power reactors and related fuel cycle facilities on nuclear energy center sites insofar as practicable.

\section{"ABNORMAL OCCURRENCE REPORTS}

"Sec. 208. The Commission shall submit to the Congress each quarter a report listing for that period any abnormal occurrences at or associated with any facility which is licensed or otherwise regulated pursuant to the Atomic Energy Act of 1954 as amended, or pursuant to this Act. For the purposes of this section an abnormal occurrence is an unscheduled incident or event which the Commission determines is significant from the standpoint of public health or safety. Nothing in the preceding sentence shall limit the authority of a court to review the determination of the Commission. Each such report shall contain -

"(1) the date and place of each occurrence;

"(2) the nature and probable consequence of each occurrence;

"(3) the cause or causes of each; and

"(4) any action taken to prevent reoccurrence;

the Commission shall also provide as wide dissemination to the public of the information specified in clauses (1) and (2) of this section as reasonably possible within fifteen days of its receiving information of each abnormal occurrence and shall provide as wide dissemination to the public as reasonably possible of the information specified in clauses (3) and (4) as soon as such information becomes available to it.

\section{"OTHER OFFICERS}

"Sec. 209. (a). The Commission shall appoint an Executive Director for Operations, who shall serve at the pleasure of and be removable by the Commission.

"(b) The Executive Director shall perform such functions as the Commission may direct, except that the Executive Director shall not limit the 
Equal employment opportunity, report.

Annual status report.

Report to

Congress.

42 USC 5877.

Other officers.

42 USC 5850

Submittal to

Congress.

Progress

reports.

42 USC 5851 authority of the director of any component organization provided in this Act to communicate with or report directly to the Commission when such director of a component organization deems it necessary to carry out his responsibilities. Not withstanding the preceding sentence, each such director shall keep the Executive Director fully and currently informed concerning the content of all such direct communications with the Commission. ${ }^{9}$

"(c) The Executive Director shall report to the Commission at semiannual public meetings on the problems, progress, and status of the Commission's equal employment opportunity efforts. ${ }^{10}$

"(d) The Executive Director shall prepare and forward to the Commission an annual report (for the fiscal year 1978 and each succeeding fiscal year) on the status of the Commission's programs concerning domestic safeguards matters including an assessment of the effectiveness and adequacy of safeguards at facilities and activities licensed by the Commission. The Commission shall forward to the Congress a report under this section prior to February 1,1979, as a separate document, and prior to February 1 of each succeeding year as a separate chapter of the Commission's annual report (required under section 307(c) of the Energy Reorganization Act of 1974) following the fiscal year to which such report applies. ${ }^{11}$

"(e) $)^{10}$ There shall be in the Commission not more than five additional officers appointedy the Commission. The positions of such officers shall be considered career positions and be subject to subsection $161 \mathrm{~d}$. of the Atomic energy Act.

\section{"UNRESOLVED SAFETY ISSUES PLAN}

"Sec. 210. The Commission shall develop a plan providing for the specification and analysis of unresolved safety issues relating to nuclear reactors and shall take such action as may be necessary to implement corrective measures with respect to such issues. Such plans shall be submitted to the Congress on or before January 1, 1978, and progress reports shall be included in the annual report of the Commission thereafter. ${ }^{12}$

\section{"EMPLOYEE PROTECTION"}

"Sec. 211. (a)(1) No employer may discharge any employee or otherwise discriminate against any employee with respect to his compensation, terms, conditions, or privileges of employment because the employee (or any person acting pursuant to a request of the employee)"(A) notified his employer of an alleged violation of this Act or the Atomic Energy Act of 1954 (42 U.S.C. 2011 et seq.);

"(B) refused to engage in any practice made unlawful by this act or the Atomic Energy Act of 1954, if the employee has identified the alleged illegality to the employer;

\footnotetext{
${ }^{9}$ Public Law 95-601 (92 Stat. 2949) (1978), sec. 4(a) amended subsoc. 209(b) by adding the last sentence.

10Public Law 95-601 (92 Stat. 2949)(1978), sec. 4(b) amended subsec. 209(c) by adding a new subsec. (c) aand redesignated existing subsec. (c) accordingly. Existing subsec. (c) was redesignated as subsec. (e) because this law also added a new subsec.(d)

11 Public Law 95-601 (92 Stat. 2949)(1978), sec.6 added subsec. 209(d).

${ }^{12}$ Public Law 95-209 (91 Stat. 1482)(1977), sec.3, added sec. 210.

- New Sec. 211 added by P.L. 102-486 (106 Stat 3123); October 24, 1992.
} 
42 USC 2011

note.

Complaint, filing and notification.

Investigation and notification.

Order.

Notice and hearing.
“(C) testified before Congress or at any Federal or State proceeding regarding any provision (or proposed provision) of this Act or the Atomic Energy Act of 1954;";

"(D) commenced, caused to be commenced, or is about to commence or cause to be commenced a proceeding under this Act or the Atomic Energy Act of 1954, as amended, or a proceeding for the administration or enforcement of any requirement imposed under this Act or the Atomic Energy Act of 1954, as amended;

"(E) testified or is about to testify in any such proceeding or;

"(F) assisted or participated or is about to assist or participate in any manner in such a proceeding or in any other manner in such a proceeding or in any other action to carry out the purposes of this Act or the Atomic Energy Act of 1954, as amended. "(2) For purposes of this section, the term 'employer' includes-

"(A) a licensee of the Commission or of an Agreement State under section 274 of the Atomic Energy Act of 1954 (42 U.S.C. 2021);

"(B) an applicant for a license from the Commission or such an Agreement State;

“(C) a contractor or subcontractor of such a licensee or applicant; and

"(D) a contractor or subcontractor of the Department of Energy that is indemnified by the Department under section 170 d. of the Atomic Energy Act of 1954 (42 U.S.C. 2210(d)), but such term shall not include any contractor or subcontractor covered by Executive Order No. 12344.".

"(b)(1) Any employee who believes that he has been discharged or otherwise discriminated against by any person in violation of subsection (a) may, within 180 days after such violation occurs, file (or have any person file on his behalf) a complaint with the Secretary of Labor (in this section referred to as the 'Secretary') alleging such discharge or discrimination. Upon receipt of such a complaint, the Secretary shall notify the person named in the complaint of the filing of the complaint, the Commission and the Department of Energy.

“(2)(A) Upon receipt of a complaint filed under paragraph (1), the Secretary shall conduct an investigation of the violation alleged in the complaint. Within thirty days of the receipt of such complaint, the Secretary shall complete such investigation and shall notify in writing the complainant (and any person acting in his behalf) and the person alleged to have committed such violation of the results of the investigation conducted pursuant to this subparagraph. Within ninety days of the receipt of such complaint the Secretary shall, unless the proceeding on the complaint is terminated by the Secretary on the basis of a settlement entered into by the Secretary and the person alleged to have committed such violation, issue an order either providing the relief prescribed by subparagraph (B) or denying the complaint. An order of the Secretary shall be made on the record after notice and opportunity for public hearing. Upon the conclusion of such hearing and the issuance of a recom- 
Settlement.

Relief.

Review.

5 USC 701

et seq. mended decision that the complaint has merit, the Secretary shall issue a preliminary order providing the relief prescribed in subparagraph (B), but may not order compensatory damages pending a final order. The Secretary may not enter into a settlement terminating a proceeding on a complaint without the participation and consent of the complainant.

"(B) If, in response to a complaint filed under paragraph (1), the Secretary determines that a violation of subsection (a) has occurred, the Secretary shall order the person who committed such violation to (i) take affirmative action to abate the violation, and (ii) reinstate the complainant to his former position together with the compensation (including back pay), terms, conditions, and privileges of his employment, and the Secretary may order such person to provide compensatory damages to the complainant. If an order is issued under this paragraph, the Secretary, at the request of the complainant shall assess against the person against whom the order is issued a sum equal to the aggregate amount of all costs and expenses (including attorneys' and expert witness fees) reasonably incurred, as determined by the Secretary, by the complainant for, or in connection with, the bringing of the complaint upon which the order was issued.

"(3)(A) The Secretary shall dismiss a complaint filed under paragraph (1), and shall not conduct the investigation required under paragraph (2), unless the complainant has made a prima facie showing that any behavior described in subparagraphs (A) through ( $F$ ) of subsection (a)(1) was a contributing factor in the unfavorable personnel action alleged in the complaint.

"(B) Notwithstanding a finding by the Secretary that the complainant has made the showing required by subparagraph (A), no investigation required under paragraph (2) shall be conducted if the employer demonstrates, by clear and convincing evidence, that it would have taken the same unfavorable personnel action in the absence of such behavior.

"(C) The Secretary may determine that a violation of subsection (a) has occurred only if the complainant has demonstrated that any behavior described in subparagraphs $(A)$ through $(F)$ of subsection (a)(1) was a contributing factor in the unfavorable personnel action alleged in the complaint.

"(D) Relief may not be ordered under paragraph (2) if the employer demonstrates by clear and convincing evidence that it would have taken the same unfavorable personnel action in the absence of such behavior.".

“(c)(1) Any person adversely affected or aggrieved by an order issued under subsection (b) may obtain review of the order in the United States court of appeals for the circuit in which the violation, with respect to which the order was issued, allegedly occurred. The petition for review must be filed within sixty days from the issuance of the Secretary's order. Review shall conform to chapter 7 of title 5 of the United States Code. The commencement of proceedings under this subparagraph shall not, unless ordered by the court, operate as a stay of the Secretary's order. 
Jurisdiction.

Litigative

costs.

42 USC 2011.
"(2) An order of the Secretary with respect to which review could have been obtained under paragraph (1) shall not be subject to judicial review in any criminal or other civil proceeding.

"(d) Whenever a person has failed to comply with an order issued under subsection (b) (2), the Secretary may file a civil action in the United States district court for the district in which the violation was found to occur to enforce such order. In actions brought under this subsection, the district courts shall have jurisdiction to grant all appropriate relief including, but not limited to, injunctive relief, compensatory, and exemplary damages.

"(e)(1) Any person on whose behalf an order was issued under paragraph (2) of subsection (b) may commence a civil action against the person to whom such order was issued to require compliance with such order. The appropriate United States district court shall have jurisdiction, without regard to the amount in controversy or the citizenship of the parties, to enforce such order.

"(2) The court, in issuing any final order under this subsection, may award costs of litigation (including reasonable attorney and expert witness fees) to any party whenever the court determines such award is appropriate.

"(f) Any nondiscretionary duty imposed by this section shall be enforceable in a mandamus proceeding brought under section 1361 of title 28 of the United States Code.

"(g) Subsection (a) shall not apply with respect to any employee who, acting without direction from his or her employer (or the employer's agent), deliberately causes a violation of any requirement of this Act or of the Atomic Energy Act of 1954, as amended. 13

"(h) This section may not be construed to expand, diminish, or otherwise affect any right otherwise available to an employee under Federal or State law to redress the employee's discharge or other discriminatory action taken by the employer against the employee.".

"(i) The provisions of this section shall be prominently posted in any place of employment to which this section applies.".

“(j)(1) The Commission or the Department of Energy shall not delay taking appropriate action with respect to an allegation of a substantial safety hazard on the basis of-

"(A) the filing of a complaint under subsection (b)(1) arising from such allegation; or

"(B) any investigation by the Secretary, or other action, under this section in response to such complaint.

"(2) A determination by the Secretary under this section that a violation of subsection (a) has not occurred shall not be considered by the Commission or the Department of Energy in its determination of whether a substantial safety hazard exists.".

${ }^{13}$ Public Law 95-601 (92 Stitt. 2951) (1978), sec. 10, duplicated the section number 210. 


\section{"TITLE III-MISCELLANEOUS AND TRANSITIONAL PROVISIONS}

Lapses of agencies and positions. 42 USC 5871

88 Stat. 1249. Savings clauses.

\section{"TRANSITIONAL PROVISIONS}

"Sec. 301. (a) Except as otherwise provided in this Act, whenever all of the functions or programs of an agency, or other body, or any component thereof, affected by this Act, have been transferred from that agency, or other body, or any component thereof by this Act, the agency, or other body, or component thereof shall lapse. If an agency, or other body, or any component thereof, lapses pursuant to the preceding sentence, each position and office therein which was expressly authorized by law, or the incumbent of which was authorized to receive compensation at the rate prescribed for an officer or position at level II, III, IV, or V of the Executive Schedule (5 U.S.C. 5313-5316), shall lapse.

"(b) All orders, determinations, rules, regulations, permits, contracts, certificates, licenses, and privileges-

"(1) which have been issued, made, granted, or allowed to be come effective by the President, any Federal department or agency or official thereof, or by a court of competent jurisdiction, in the performance of functions which are transferred under this Act, and

"(2) which are in effect at the time this Act takes effect, shall continue in effect according to their terms until modified, terminated, superseded, set aside, or revoked by the President, the Administrator, the Commission, or other authorized officials, a court of competent jurisdiction, or by operation of law.

“(c) The provisions of this Act shall not affect any proceeding pending, at the time this section takes effect, before the Atomic Energy Commission or any department or agency (or component thereof) functions of which are transferred by this Act; but such proceedings, to the extent that they relate to functions so transferred, shall be continued. Orders shall be issued in such proceedings, appeals shall be taken therefrom, and payments shall be made pursuant to such orders, as if this Act had not been enacted; and orders issued in any such proceedings shall continue in effect until ;modified, terminated, superseded, or revoked by a duly authorized official, by a court of competent jurisdiction, or by operation of law. Nothing in this subsection shall be deemed to prohibit the discontinuance or modification of any such proceeding under the same terms and conditions and to the same extent that such proceeding could have been disconnected if this Act had not been enacted.

"(d) Except as provided in subsection (f)-

"(1) the provisions of this Act shall not affect suits commenced prior to the date this Act takes effect, and

"(2) in all such suits proceedings shall be had, appeals taken, and judgements rendered, in the same manner and effect as if this Act had not been enacted.

"(e) No suit, action, or other proceeding commenced by or against any officer in his official capacity as an officer of any department or agency, functions of which are transferred by this Act, shall abate by reason of the enactment of this Act. No cause of action by or against any department or agency, functions of which are transferred by this Act, or by or against any officer thereof in his official capacity shall abate by reason of 
88 Stat. 1250

the enactment of this Act. Causes of actions, suits, actions, or other proceedings may be asserted by or against the United States or such official as may be appropriate and, in any litigation pending when this section takes effect, the court may at any time, on its own motion or that of any party, enter any order which will give effect to the provisions of this section.

"(f) If, before the date on which this Act takes effect, any department or agency, or officer there of in his official capacity, is a party toa suit, and under this Act any function of such department, agency, or officer is transferred to the Administrator or Commission, or any other official, then such suit shall be continued as if this Act had not been enacted, with the Administrator of Commission, or other official, as the case may be, substituted.

" $(\mathrm{g})$ Final orders and actions of any official or component in the performance of functions transferred by this Act shall be subject to judicial review to the same extent and in the same manner as if such orders or actions had been make or taken by the officer, department, agency, or instrumentality in the performance of such functions immediately preceding the effective date of the Act. Any statutory requirements relating to notices, hearings, action upon the record, or administrative review that apply to any function transferred by this Act shall apply to the performance of those functions by the Administrator or Commission, or any officer or component.

"(h) With respect to any function transferred by this Act and performed after the effective date of this Act, reference in any other law to any department or agency, or any officer or office, the functions of which are so transferred, shall be deemed to refer to the Administration, the Administrator or Commission, or other office or official in which this Act vests such functions.

"(i) Nothing contained in this Act shall be construed to limit, curtail, abolish, or terminate any function of the President which he had immediately before the effective date of this Act; or to limit, curtail, abolish, or terminate his authority to perform such function; or to limit, curtail, abolish, or terminate his authority to delegate, redelegate, or terminate any delegation of functions.

"(j) Any reference in this Act to any provision if law shall be deemed to include, as appropriate, references thereto as now or hereafter amended or supplemented.

"(k) Except as may be otherwise expressly provided in this Act, all functions exppressly conferred by this Act shall be in addition to and not in substitution for functions existing immediately before the effective date of this Act and transferred by this Act.

\section{“TRANSFER OF PERSONNEL AND OTHER MATTERS}

42 USC 5872

"Sec. 302 (a) Except as provided in the next sentence, the personnel employed in connection with, and the personnel positions, assets, liabilities, contracts, property, records, and unexpended balances of appropriations, authorizations, allocations, and other funds employed, held, used, arising from, available to or to be made available in connection with the functions and programs transferred by this Act, are, subject to section 202 of the Budget and Accounting Procedures Act of 1950 (31 
42 USC 5873

88 Stat. 1251.

42 USC 5874.

42 USC 5875.

42 USC 5876.

42 USC 2206

Ante, pp. 1234,

1242.
U.S.C. 581c), correspondingly transferred for appropriate allocation. Personnel positions expressly created by law, personnel occupying those positions on the effective date of this Act, and personnel authorized to receive compensation at the rate prescribed for offices and positions at levels II, III, IV, or V of the Executive Schedule (5 U.S.C. 5313-5316) on the effective date of this Act shall be subject to the provisions of subsection (c) of this section and section 301 of this Act.

"(b) Except as provided in subsection (c), transfer of nontemporary personnel pursuant to this Act shall not cause any such employee to be separated or reduced in grade or compensation for one year after such transfer.

"(c) Any person who, on the effective date of this Act, held a position compensated in accordance with the Executive Schedule prescribed in chapter 52 of title 5 of the United States Code, and who, without a break in service, is appointed in the Administration to a position having duties comparable to those performed immediately preceding his appointment shall continue to be compensated in his new position at not less than the rate provided for his previous position.

\section{"INCIDENTAL DISPOSITIONS}

"Sec. 303. The Director of the Office of Management and Budget is authorized to make such additional incidental dispositions of personnel, personnel positions, assets, liabilities, contracts, property, records, and unexpended balances of appropriations, authorizations, allocations, and other funds held, used, arising from, available to or to be made available in connection with functions transferred by this Act, as he may deem necessary or appropriate to accomplish the intent and purpose of this Act.

\section{"DEFINITIONS}

"Sec. 304. As used in this Act-

"(1): any reference to "function" or "functions" shall be deemed toinclude references to duty, obligation, power, authority, responsibility, right, privilege, and activity, or the plural thereof, as the case may be; and

"(2) any reference to "perform" or "performance", when used in relation to functions, shall be deemed to include the exercise of power, authority, rights, and privileges.

\section{"AUTHORIZATIONS OF APPROPRIATIONS}

"Sec. 305. (a) Except as otherwise provided by law, appropriations made under this Act shall be subject to an annual authorization.

"(b) Authorization of appropriations to the Commission shall reflect the need for effective licensing and other regulation of the nuclear power industry in relation to the growth of such industry.

\section{"COMPTROLLER GENERAL AUDIT}

"Sec.306. (a) Section 166. "Comptroller General Audit" of the Atomic Energy Act of 1954, as amended, shall be deemed to be applicable, respectively, to the nuclear and nonnuclear activities under title $I$ and to the activities under title II.

"(b) The Comptroller General of the United States shall audit, review, and evaluate the implementation of the provisions of title II of this Act 
Report to Congress.

Reports to the President and Congress.

42 USC 5877.

Administration activities and progress.

Feasibility of transferring military application functions. 88 Stat. 1252.

Commission activities and findings. by the Nuclear Safety and Licensing Commission not later than sixty months after the effective date of this Act, the Comptroller General shall prepare and submit to the Congress a report on his audit, which shall contain, but not be limited to-

"(1) an evaluation of the effectiveness of the licensing and related regulatory activities of the Commission and the operations of the Office of Nuclear Safety Research and the Bureau of Nuclear Materials Security;

"(2) an evaluation of the effect of such Commission activities on the efficiency, effectiveness, and safety with which the activities licensed under the Atomic Energy Act of 1954, as amended, are carried out;

"(3) recommendations concerning any legislation he deems necessary, and the reasons therefor, for improving the implementation of title II.

\section{"REPORTS}

"Sec. 307. (a) The Administrator shall, as soon as practicable after the end of each fiscal year, make a report to the President for submission to the Congress on the activities of the Administration during the preceding fiscal year. Such report shall include a statement of the short-range and long-range goals, priorities, and plans of the Administration together with an assessment of the progress made toward the attainment of objectives and toward the more effective and efficient management of the Administration and the coordination of its functions.

“(b) During the first year of operation of the Administration, the Administrator, in collaboration with the Secretary of Defense, shall conduct a thorough review of the desirability and feasibility of transferring to the Department of Defense or other Federal agencies the functions of the Administrator respecting military application and restricted data, and within one year after the Administrator first takes office, the Administrator shall make a report to the President, for submission to the Congress, setting forth his comprehensive analysis, the principal alternatives, and the specific recommendations of the Administrator and the Secretary of Defense.

“(c) The Commission shall, as soon as practicable after the end of each fiscal year, make a report to the President for submission to the Congress on the activities of the Commission during the preceding fiscal year. Such report shall include a clear statement of the short-range and long-range goals, priorities, and plans of the Commission as they relate to the benefits, costs, and risks of commercial nuclear power. Such report shall also include a clear description of the Commission's activities and findings in the following areas-

“(1) insuring the safe design of nuclear power plants and other licensed facilities;

"(2) investigating abnormal occurrences and defects in nuclear powerplants and other licensed facilities;

"(3) safeguarding special nuclear materials at all stages of the nuclear fuel cycle; 
42 USC 5878.

42 USC 5879.

88 Stat. 1253.

"(4) investigating suspected, attemptect, or actual thefts of special nuclear materials in the licensed sector and developing contingency plans for dealing with such incidents;

"(5) insuring the safe, permanent disposal of high-level radioactive wastes through the licensing of nuclear activities and facilities;

"(6) protecting the public against the hazards of low-level radioactive emissions from licensed nuclear activities and facilities.

\section{"INFORMATION TO COMMITTEES}

"Sec. 308. The Administrator shall keep the appropriate congressional committees fully and currently informed with respect to all of the Administration's activities.

"TRANSFER OF FUNDS

"Sec. 309. The Administrator, when authorized in an appropriation Act, may, in any fiscal year, transfer funds from one appropriation to another within the Administration; except, that no appropriation shall be either increased or decreased pursuant to this section by more than 5 per centum of the appropriation for such fiscal year.

"CONFORMING AMENDMENTS TO CERTAIN OTHER LAWS

"Sec. 310. Subchapter III (relating to Executive Schedule pay rates) of chapter 53 of title 5, United States Code, is amended as follows:

"(1) Section 5313 is amended by striking out '(8) Chairman, Atomic Energy Commission,' and inserting in lieu thereof '(8) Chairman, Nuclear Regulatory Commission,', and by adding at the end thereof the following:

'(22) Administrator of Energy Research and Development Administration.'.

"(2) Section 5314 is amended by striking out '(42) Members, Atomic Energy Commission.' and inserting in lieu thereof '(42) Members, Nuclear Regulatory Commission.', and by adding at the end thereof the following:

'(60) Deputy Administrator, Energy Research and Development Administration.'

“(3) Section 5315 is amended by striking out paragraph (50), and by adding at the end thereof the following:

'(100) Assistant Administrator, Energy Research and Development Administration (6).

(101) Director of Nuclear Reactor Regulation, Nuclear Regulatory Commission.

(102) Director of Nuclear Material Safety and Safeguards, Nuclear Regulatory Commission.

'(103) Director of Nuclear Regulatory Research, Nuclear Regulatory Commission.

'(104) Executive Director for Operations, Nuclear Regulatory Commission.'

'(4) Section 5316 is amended by striking out paragraphs (29), (62), (69), and (102), by striking out '(81), General Counsel of the Atomic Energy Commission,' and inserting in lieu thereof '(81) General Counsel of the Nuclear Regulatory Commission.', and by adding at the end thereof the following: 
'(134) General Counsel, Energy Research and Development Administration.

'(135) Additional officers, Energy Research and Development Administration (8).

'(136) Additional officers, Nuclear Regulatory Commission (5) $\therefore$

42 USC 5801 note.

42 USC 5801

note.

Publication

in Federal

Register.

88 Stat. 1254

42 USC 5891.

42 USC 2000d.

\section{"SEPARABILITY}

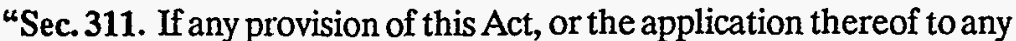
person or circumstance, is held invalid, the remainder of this Act, and the application of such provision to other persons or circumstances, shall not be affected thereby.

\section{"EFFECTIVE DATE AND INTERIM APPOINTMENTS}

"Sec. 312. (a) This Act shall take effect one hundred and twenty days after the date of its enactment, or on such earlier date the President may prescribe and publish in the Federal Register; except that any of the officers provided for in title I of this Act may be nominated and appointed, as provided by this Act, at any time after the date of enactment of this Act. Funds available to any department or agency (or any official or component thereof), any functions of which are transferred to the Administrator and the Commission by this Act, may, with the approval of the President, be used to pay the compensation and expenses of any officer appointed pursuant to this subsection until such time as funds for that purpose are otherwise available.

(b) In the event that any officer required by this Act to be appointed by and with the advice and consent of the Senate shall not have entered upon office on the effective date of this Act, the President may designate any officer, whose appointment was required to be made by and with the advice and consent of the Senate and who was such an officer immediately prior to the effective date of this Act, to act in such office until the office is filled as provided in this Act. While so acting, such persons shall receive compensation at the rates provided by this Act for the respective offices in which they act.

\section{"TITLE IV - SEX DISCRIMINATION}

\section{"SEX DISCRIMINATION PROHIBITED}

"Sec. 401. No person shall on the ground of sex be excluded from participation in, be denied a license under, be denied the benefits of, or be subjected to discrimination under any program or activity carried on or receiving Federal assistance under any title of this Act. This provision will be enforced through agency provisions and rules similar to those already established, with respect to racial and other discrimination, under title VI of the Civil Rights Act of 1964. However, this remrdy is not exclusive and will not prejudice or cut off any other legal remedies available to a discriminatee. 


\section{PRESIDENTIAL DOCUMENTS}

\section{TITLE III - THE PRESIDENT}

\section{REORGANIZATION PLAN N0. 3 OF 1970*}

5 USC, App. I "Prepared by the President and transmitted to the Senateand the House of Representatives in Congress assembled July 9, 1970, pursuant to the provisions of chapter 9 of title 5 of the United States Code. 1

"Environmental Protection Agency

Section 1. Establishment of Agency. "(a) There is hereby established the Environmental Protection Agency, hereinafter referred to as the "Agency."

(b) There shall be at the head of the Agency the Administrator of the Environmental Protection Agency, hereinafter referred to as the "Administrator." The Administrator shall be appointed by the President, by and with the advice and consent of the Senate, and shall be compensated at the rate now or hereafter provided for Level II of the Executive Schedule Pay rates (5 U.S.C. 5313).

(c) There shall be in the Agency a Deputy Administrator of the Environmental Protection Agency who shall be appointed by the President, by and with the advice and consent of the Senate, and shall be compensated at the rate now or hereafter provided for Level III of the Executive Schedule Pay Rates (5 U.S.C. 5314). The Deputy Administrator shall perform such functions as the Administrator shall from time to time assign or delegate, and shall act as Administrator during the absence or disability of the Administrator or in the event of a vacancy in the office of Administrator.

(d) There shall be in the Agency not to exceed five Assistant Administrators of the Environmental Protection Agency who shall be appointed by the President, by and with the advice and consent of the Senate, and shall be compensated at the rate now or hereafter provided for Level IV of the Executive Schedule Pay Rates (5 U.S.C. 5315). Each Assistant Administrator shall perform such functions as the Administrator shall from time to time assign or delegate.

Section 2. Transfers to Environmental Protection Agency. (a) There are hereby transferred to the Administrator:

(1) All functions vested by law in the Secretary of the Interior and the Department of the Interior which are administered through the Federal Water Quality Administration, all functions which were transferred to the Secretary of the Interior by Reorganization Plan No. 2 of 1966 (80 Stat. 1608), and all functions vested in the Secretary of the Interior or the Department of the Interior by the Federal Water Pollution Control Act or by provisions of law amendatory or supplementary thereof.

(2)(i) The functions vested in the Secretary of the Interior by the Act of August 1, 1958, 72 Stat. 479, 16 U.S.C. 742d-1 (being an Act

- this Reorganization Plan was originally approved under special Congressional procedures; the Supreme Court decision in Immignation \& Naturalization Service vs. Chadha (462 U.S. 919 (1983)) called into question the legality of this plan. Congress responded by enating this Reorganization Plan in P.L. 98-614.

${ }^{1}$ Effective December 2, 1970, under the provisions of section 7 of the plan. 
relating to studies on the effects of insecticides, herbicides, fungicides, and pesticides upon the fish and wildlife resources of the United States), and (ii) the functions vested by law in the Secretary of the Interior and the Department of the Interior which are administered by the Gulf Breeze Biological Laboratory of the Bureau of Commercial Fisheries at Gulf Breeze, Florida.

(3) The functions vested by law to the Secretary of Health, Education, and Welfare or in the Department of Health, Education, and Welfare which are administered through the Environmental Health Service, including the functions exercised by the following components thereof:

(i) The National Air Pollution Control Administration,

(ii) The Environmental Control Administration

(A) Bureau of Solid Waste Management,

(B) Bureau of Water Hygiene,

(C) Bureau of Radiological Health,

except that functions carried out by the following components of the Environmental Control Administration of the Environmental Health Service are not transferred: (i) Bureau of Community Environmental Management, (ii) Bureau of Occupational Safety and Health, and (iii) Bureau of Radiological Health, insofar as the functions carried out by the latter Bureau pertain to $(A)$ regulation of radiation from consumer products, including electronic product radiation, (B) radiation as used in the healing arts, (C) occupational exposures to radiation, and (D) research, technical assistance, and training related to clauses (A), (B), and $(\mathrm{C})$.

(4) The functions vested in the Secretary of Health, Education, and Welfare of establishing tolerances for pesticide chemicals under the Federal Food, Drug, and Cosmetic Act as amended, 21 U.S.C. 346, 346a, and 348, together with authority, in connection with the functions transferred, (i) to monitor compliance with the tolerances and the effectiveness of surveillance and enforcement, and (ii) to provide technical assistance to the States and conduct research under the Federal Food, Drug, and Cosmetic Act, as amended, and the Public Health Service Act, as amended.

(5) So much of the functions of the Council on Environmental Quality under section 204(5) of the National Environmental Policy Act of 1969 (Public Law 91-190, approved January 1, 1970, 83 Stat. 855 ), as pertains to ecological systems.

(6) The functions of the Atomic Energy Commission under the Atomic Energy Act of 1954, as amended, administered through its Division of Radiation Protection Standards, to the extent that such functions of the Commission consist of establishing generally applicable environmental standards for the protection of the general environment from radioactive material. As used herein, standards mean limits on radiation exposures or levels, or concentrations or quantities of radioactive material, in the general environment outside the boundaries of locations under the control of persons possessing or using radioactive material.

(7) All functions of the Federal Radiation Council (42 U.S.C. 2021(h)). 
"(8)(i) The functions of the Secretary of Agriculture and the Department of Agriculture under the Federal Insecticide, Fungicide, and the Rodenticide Act, as amended (7U.S.C. 135-135k), (ii) the functions of the Secretary of Agriculture and the Department of Agriculture under section 408 (1) of the Federal Food, Drug, and Cosmetic Act, as amended (21 U.S.C. 346a (1)), and (iii) the functions vested by law in the Secretary of Agriculture and the Department of Agriculture which are administered through the Environmental Quality Branch of the Plant Protection Division of the Agricultural Research Service.

(9) So much of the functions of the transferor officers and agencies referred to in or affected by the foregoing provisions of this section as is incidental to or necessary for the performance by or under the Administrator of the functions transferred by those provisions or relates primarily to those functions. The transfers to the Administrator made by this section shall be deemed to include the transfer of (1) authority, provided by law, to prescribe regulations relating primarily to the transferred functions, and (2) the functions vested in the Secretary of the Interior and the Secretary of Health, Education, and Welfare by section 169(d)(1)(b) and (3) of the Internal Revenue Code of 1954 (as enacted by section 704 of the Tax Reform Act of 1969, 83 Stat. 668); but shall be deemed to exclude the transfer of the functions of the Bureau of Reclamation under section 3(b)(1) of the Water Pollution Control Act (33 U.S.C. $466 \mathrm{a}(\mathrm{b})(1))$.

(b) There are hereby transferred to the Agency:

(1) From the Department of the Interior, (i) the Water Pollution Control Advisory Board (33 U.S.C. 466f), together with its functions, and (ii) the hearing boards provided for in sections 10(c)(4) and $10(\mathrm{f})$ of the Federal Water Pollution Control Act, as amended (33 U.S.C. $466 \mathrm{~g}(\mathrm{c})(4): 466 \mathrm{~g}(\mathrm{f})$ ). The functions of the Secretary of the Interior with respect to being or designating the Chairman of the Water Pollution Control Advisory Board are hereby transferred to the Administrator.

"(2) From the Department of Health, Education, and Welfare, the Air Quality Advisory Board (42U.S.C. 1857e), together with its functions. The functions of the Secretary of Health, Education, and Welfare with respect to being a member and the Chairman of that Board are hereby transferred to the Administrator.

Section 3. Performance of transferred functions. The Administrator may from time to time make such provisions as he shall deem appropriate authorizing the performance of any of the functions transferred to him by the provisions of this reorganization plan by any other officer or by any organizational entity or employee, of the Agency.

Section 4. Incidental transfers. (a) So much of the personnel, property, records, and unexpended balances of appropriations, allocations, and other funds employed, used, held, available, or to be made available in connection with the functions transferred to the Administrator or the Agency by this reorganization plan as the Director of the Office of Management and Budget shall determine shall be transferred to the Agency at such time or times as the Director shall direct. 
(b) Such further measures and dispositions as the Director of Office of Management and Budget shall deem to be necessary in order to effectuate the transfers referred to in subsection (a) of this section shall be carried out in such manner as he shall direct and by such agencies as he shall designate.

Section 5. Interim officers. (a) The President may authorize any person who immediately prior to the effective date of this reorganization plan held a position in the executive branch of the Government to act as Administrator until the office of Administrator is for the first time filled pursuant to the provisions of this reorganization plan or by recess appointment, as the case may be.

"(b) The President may similarly authorize any such person to act as Deputy Administrator, authorize any such person to act as Assistant Administrator, and authorize any such person to act as the head of any principal constituent organizational entity of the Administration.

"(c) The President may authorize any person who serves in an acting capacity under the foregoing provisions of this section to receive the compensation attached to the office in respect of which he so serves. Such compensation, if authorized, shall be in lieu of, but not in addition to, other compensation from the United States to which such person may be entitled.

Section 6. Abolitions. (a) Subject to the provisions of this reorganization plan, the following, exclusive of any functions, are hereby abolished:

(1) The Federal Water Quality Administration in the Department of the Interior (33 U.S.C. 466-1).

(2) The Federal Radiation Council (73 Stat. 690; 42 U.S.C. 2021(h)).

(b) Such provisions as may be necessary with respect to terminating any outstanding affairs shall be made by the Secretary of the Interior in the case of the Federal Water Quality Administration and by the Administrator of General Services in the case of the Federal Radiation Council.

Section 7. Effective date. The provisions of this reorganization plan shall take effect sixty days after the date they would take effect under 5U.S.C. 906(a) in the absence of this section.

(F.R. Doc. 70-13374; Filed, Oct. 5, 1970; 8:45 a.m.) 


\section{REORGANIZATION PLAN NO. 1 OF 1980*}

5 USC, App. I Prepared by the President and submitted to the Senate and the House of Representatives in Congress assembled March 27, 1980, ${ }^{1}$ pursuant to the provisions of Chapter 9 of Title 5 of the United States Code.

\section{Nuclear Regulatory Commission}

Sec. 1. (a) Those functions of the Nuclear Regulatory Commission, hereinafter referred to as the "Commission", concerned with:

(1) policy formulation;

(2) rulemaking, as defined in section 553 of Title 5 of the United

States Code, except that those matters set forth in 553(a)(2) and (b) which do not pertain to policy formulation orders or adjudications shall be reserved to the Chairman of the Commission;

(3) orders and adjudications, as defined in section 551 (6) and (7) of Title 5 of the United States Code;

shall remain vested in the Commission. The Commission may determine by majority vote, in an area of doubt, whether any matter, action, question or area of inquiry pertains to one of these functions. The performance of any portion of these functions may be delegated by the Commission to a member of the Commission, including the Chairman of the Nuclear Regulatory Commission, hereinafter referred to as the "Chairman", and to the staff through the Chairman.

(b)(1) With respect to the following officers or successor officers duly established by statue or by the Commission, the Chairman shall initiate the appointment, subject to the approval of the Commission; and the Chairman or a member of the Commission may initiate an action for removal, subject to the approval of the Commission:

(i) Executive Director for Operations,

(ii) General Counsel,

(iii) Secretary of the Commission,

(iv) Director of the Office of Policy Evaluation,

(v) Director of the Office of Inspector and Auditor,

(vi) Chairman, Vice Chairman, Executive Secretary, and Members of the Atomic Safety and Licensing Board Panel,

(vii) Chairman, Vice Chairman and Members of the Atomic Safety and Licensing Appeal Panel.

(2) With respect to the following officers or successor officers duly established by statute or by the Commission, the Chairman, after consultation with the Executive Director for Operations, shall initiate the appointment, subject to the approval of the Commission, and the Chairman, or a member of the Commission may initiate an action for removal, subject to the approval of the Commission:

(i) Director of Nuclear Reactor Regulation,

(ii) Director of Nuclear Material Safety and Safeguards,

(iii) Director of Nuclear Regulatory Research,

-this Reorganization Plan was originally approved under special Congressional procedures; the Supreme Court decision in Immigration \& Naturalization Service vs. Chadha (462 U.S. 919 (1983)) called into question the legality of this plan. Congress responded by enacting this Reorganization Plan in P.L 98-614.

${ }^{1}$ As amended May 5, 1980 
(iv) Director of Inspection and Enforcement.

(v) Director of Standards Development.

(3) The Chairman or a member of the Commission shall initiate the appointment of the Members of the Advisory Committee on Reactor Safeguards, subject to the approval of the Commission. The provisions for appointment of the Chairman of the Advisory Committee on Reactor Safeguards and the term of the members shall not be affected by the provisions of this Reorganization Plan.

(4) The Commission shall delegate the function of appointing, removing and supervising the staff of the following offices or successor offices to the respective heads of such offices: General Counsel, Secretary of the Commission, Office of Public Evaluation, Office of Inspector and Auditor. The Commission shall delegate the functions of appointing, removing and supervising the staff of the following panels and committee to the respective Chairman thereof: Atomic Safety and Licensing Board Panel, Atomic Safety and Licensing Appeal Panel and Advisory Committee on Reactor Safeguards.

(c) Each member of the Commission shall continue to appoint, remove and supervise the personnel employed in his or her immediate office.

(d) The Commission shall act as provided by subsection 201(a)(1) of the Energy Reorganization Act of 1974, as amended (42 U.S.C. 5841 (a)(1), as amended) in the performance of its functions as described in subsections (a) and (b) of this section.

Sec. 2. (a) All other functions of the Commission, not specified by Section 1 of this Reorganization Plan, are hereby transferred to the Chairman. The Chairman shall be the official spokesman for the Commission, and shall appoint, supervise, and remove, without further action by the Commission, the Directors and staff of the Office of Public Affairs and the Office of Congressional Relations. The Chairman may consult with the Commission as he deems appropriate in exercising this appointment function.

(b) The Chairman shall also be the principal executive officer of the Commission, and shall be responsible to the Commission for developing policy planning and guidance for consideration by the Commission; shall be responsible for the Commission for assuring that the Executive Director for Operations and the staff of the Commission (other than the officers and staff referred to in sections (1)(b)(4), (1)(c) and (2)(a) of this Reorganization Plan) are responsive to the requirements of the Commission in the performance of its functions; shall determine the use and expenditure of funds of the Commission, in accordance with the distribution of appropriated funds according to major programs and purposes approved by the Commission; shall present to the Commission for its consideration the proposals and estimates set forth in subsection (3) of this paragraph; and shall be responsible for the following functions, which he shall delegate, subject to his direction and supervision, to the Executive Director for Operations unless otherwise provided by this Reorganization Plan:

(1) administrative functions of the Commission;

(2) distribution of business among such personnel and among administrative units and offices of the Commission; 
(3) preparation of

(i) proposals for the reorganization of the major offices within

the Commission;

(ii) the budget estimate for the Commission; and

(iii) the proposed distribution of appropriated funds according

to major programs and purposes.

(4) appointing and removing without any further action by the Commission, all officers and employees under the Commission other than those whose appointment and removal are specifically provided for by subsections 1(b), (c) and 2(a) of this Reorganization Plan.

(c) The Chairman as principal executive officer and the Executive Director for Operations shall be governed by the general policies of the Commission and by such regulatory decisions, findings, and determinations, including those for reorganization proposals, budget revisions and distribution of appropriated funds, as the Commission may by law, including this Plan, be authorized to make. The Chairman and the Executive Director for Operations, through the Chairman, shall be responsible for insuring that the Commission is fully and currently informed about matters within its functions.

Sec. 3. (a) Notwithstanding sections 1 and 2 of this Reorganization Plan, there are hereby transferred to the Chairman all the functions vested in the Commission pertaining to an emergency concerning a particular facility or materials licensed or regulated by the Commission, including the functions of declaring, responding, issuing orders, determining specific policies, advising the civil authorities, and the public, directing, and coordinating actions relative to such emergency incident.

(b) The Chairman may delegate the authority to perform such emergency functions, in whole or in part, to any of the other members of the Commission. Such authority may also be delegated or redelegated, in whole or in part to the staff of the Commission.

(c) In acting under this section, the Chairman, or other member of the Commission delegated authority under subsection (b), shall conform to the policy guidelines of the Commission. To the maximum extent possible under the emergency conditions, the Chairman or other member of the Commission delegated authority under subsection (b), shall inform the Commission of actions taken relative to the emergency.

(d) Following the conclusion of the emergency, the Chairman, or the member of the Commission delegated the emergency functions under subsection (b), shall render a complete and timely report to the Commission on the actions taken during the emergency.

Sec. 4. (a) The Chairman may make such delegations and provide for such reporting as the Chairman deems necessary, subject to provisions of law and this Reorganization Plan. Any officer or employee under the Commission may communicate directly to the Commission, or to any member of the Commission, whenever in the view of such officer or employee a critical problem or public health and safety or common defense and security is not being properly addressed.

(b) The Executive Director for Operations shall report for all matters to the Chairman. 
(c) The function of the Director of Nuclear Reactor Regulations, Nuclear Material Safety and Safeguards, and Nuclear Regulatory Research of reporting directly to the Commission is hereby transferred so that such officers report to the Executive Director for Operations. The function of receiving such reports is hereby transferred from the Commission to the Executive Director for Operations.

(d) The heads of the Commission level offices or successor offices, of General Counsel, Secretary to the Commission, Office of Policy Evaluation, Office of Inspector and Auditor, the Atomic Safety and Licensing Board Panel and Appeal Panel, and Advisory Committee on Reactor Safeguards shall continue to report directly to the Commission and the Commission shall continue to receive such reports.

Sec. 5. The provisions of this Reorganization Plan shall take effect October 1, 1980, or at such earlier time or times as the President shall specify, but no sooner than the earliest time allowable under Section 906 of Title 5 of the United States Code. ${ }^{2}$

$2_{45}$ FR 40561 


\section{EXECUTIVE ORDER 11834}

\section{ACTIVATION OF THE ENERGY RESEARCH AND DEVELOPMENT ADMINISTRATION AND THE NUCLEAR REGULATORY COMMISSION}

By virtue of the authority vested in my by the Energy Reorganization Act of 1974 (Public Law 93-438; 88 Stat. 1233), section 301 of title 3 of the United States Code, and as President of the United States of America, it is hereby ordered:

Sec. 1. Pursuant to section 312(a) of the Energy Reorganization Act of 1974 , I hereby prescribe January 19, 1975, as the effective date of that Act. This action shall not impair in any way the activation of the Energy Resources Council by Executive Order No. 11814 of October 11, 1974. Sec 2. The Director of the Office of Management and Budget shall take all steps necessary or appropriate to ensure or effectuate the transfers provided for in the Energy Reorganization Act of 1974, the Solar Heating and Cooling Demonstration Act of 1974 (Public Law 93-409; 88 Stat. 1069), the Geothermal Energy Research, Development, and Demonstration Act of 1974 (Public Law 93-410; 88 Stat. 1079), the Solar Energy Research, Development, and Demonstration Act of 1974 (Public Law 93-473; 88 Stat. 1431), to the extent required or permitted by law, including transfers of funds, personnel and positions, assets liabilities, contracts, property, records, and other items related to the transfer of functions, programs, or authorities.

Sec. 3. As required by the Energy Reorganization Act of 1974, this Order shall be published in the Federal Register.

THE WHITE HOUSE, January 15, 1975.

GERALD R. FORD 


\section{LOW-LEVEL RADIOACTIVE WASTE POLICY AMENDMENTS ACT OF 1985*}

Public Law 99-240

(99 Stat. 1842)

\section{TITLE 1 - LOW-LEVEL RADIOACTIVE WASTE POLICY AMENDMENTS ACT OF 1985}

PAGE - USC

\begin{tabular}{|c|c|c|}
\hline Sec. 101. & Short Title & $\begin{array}{r}42 \text { USC } \\
\text { Sec. } \\
.237 \ldots 2021 \mathrm{~b} \\
.2 .20\end{array}$ \\
\hline Sec. 102. & $\begin{array}{l}\text { Amendment to the Low-Level } \\
\text { Radioactive Waste Policy Act }\end{array}$ & $\begin{array}{l}2021 \mathrm{~b}-\mathrm{d} \\
\text { Note }\end{array}$ \\
\hline $\begin{array}{l}\text { Sec. } 1 . \\
\text { Sec. } 2 . \\
\text { Sec. } 3 .\end{array}$ & $\begin{array}{l}\text { Short title } \ldots \ldots \ldots \ldots \ldots \ldots \ldots \\
\text { Definitions } \ldots \ldots \ldots \ldots \ldots \ldots \ldots \\
\text { Responsibilities for Disposal of }\end{array}$ & $\begin{array}{ll}\cdots 2021 b \\
\cdots 2021 b\end{array}$ \\
\hline Sec. 4. & & $238 \ldots 2021 c$ \\
\hline Sec. 5 . & $\begin{array}{l}\text { Low-Level Radioactive Waste } \ldots \ldots \\
\text { Limited Availability of Certain } \\
\text { Regional Disposal Facilities During } \\
\text { Transition and Licensing Periods }\end{array}$ & 240 . \\
\hline Sec. 6. & 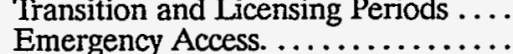 & $\begin{array}{l}2021 \mathrm{c} \\
.2021 \mathrm{f}\end{array}$ \\
\hline Sec. 7. & $\begin{array}{l}\text { Responsibilities of the Department } \\
\text { of Energy. } \ldots \ldots \ldots \ldots \ldots \ldots \ldots \ldots \ldots\end{array}$ & $2021 \mathrm{~g}$ \\
\hline $\begin{array}{l}\text { Sec. } 8 . \\
\text { Sec. } 9 . \\
\text { Sec. } 10 .\end{array}$ & 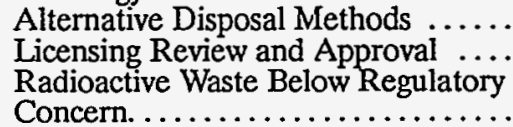 & $\begin{array}{l}.254 \\
.254 \\
.255\end{array}$ \\
\hline
\end{tabular}

*NOTE:

P.L. 96-573, "Low-Level Radionactive Waste Policy Act?"

(94 Stat. 3347); Dec. 22, 1980 was amended by P.I. $99 \div 240$.

The text of P.L. 96-573 is printed at the end of P.L. $99-240$. 


\section{LOW-LEVEL RADIOACTIVE WASTE POLICY AMENDMENTS ACT OF 1985}

Public Law 99-240

99 Stat. 1842

Jan. 15,1986

[H.R. 1083]

State and local governments.

Low-Level

Radioactive

Waste Policy

Amendments

Act of 1985.

42 USC $2021 b$

note.

42 USC

2021b-2021d,

$2021 \mathrm{~b}$ note.

42 USC 2021b

note.

42 USC 2021b

\section{An Act}

To amend the Low-Level Radioactive Waste Policy Act to improve procedures for the implementation of compacts providing for the establishment and operation of regional disposal facilities for lowlevel radioactive waste; to grant the consent of the Congress to certain interstate compacts on low-level radioactive waste; and for other purposes.

Be it enacted by the Senate and House of Representatives of the United States of America in Congress assembled,

\section{TITLE I-LOW-LEVEL RADIOACTIVE WASTE POLICY AMENDMENTS ACT OF 1985}

Sec. 101. Short Title.

This Title may be cited as the "Low-Level Radioactive Waste Policy Amendments Act of 1985".

Sec. 102. Amendment To The Low-level Radioactive Waste Policy Act.

The Low-Level Radioactive Waste Policy Act (42 U.S.C. 2021b et seq.) is amended by striking out sections $1,2,3$, and 4 and inserting in lieu thereof the following:

"Section 1. Short Title.

"This Act may be cited as the 'Low-Level Radioactive Waste Policy Act'.

"Sec. 2. Definitions.

"For purposes of this Act:

"(1) Agreement State.-The term 'agreement State' means a State that-

"(A) has entered into an agreement with the Nuclear Regulatory Commission under section 274 of the Atomic Energy Act of 1954 (42 U.S.C. 2021); and

"(B) has authority to regulate the disposal of low-level radioactive waste under such agreement.

“(2) Allocation. - The term 'allocation' means the assignment of a specific amount of low-level radioactive waste disposal capacity to a commercial nuclear power reactor for which access is required to be provided by sited States subject to the conditions specified under this Act.

"(3) Commercial Nuclear Power Reactor.-The term 'commercial nuclear power reactor' means any unit of a civilian light-water moderated utilization facility required to be licensed under section 103 or 104b. of the Atomic Energy Act of 1954 (42 U.S.C. 2133 or 2134(b)).

"(4) Compact.-The term 'compact' means a compact entered into by two or more States pursuant to this Act. 
South Carolina. Washington.

Nevada.

42 USC 2021c.

Vessels.
“(5) Compact Commission. - The term 'compact commission' means the regional commission, committee, or board established in a compact to administer such compact.

"(6) Compact Region. - The term 'compact region' means the area consisting of all States that are members of a compact.

“(7) Disposal.- The term 'disposal' means the permanent isolation of low-level radioactive waste pursuant to the requirements established by the Nuclear Regulatory Commission under applicable laws, or by an agreement State if such isolation occurs in such agreement State.

"(8) Generate.-The term 'generate', when used in relation to low-level radioactive waste, means to produce low-level radioactive waste.

“(9) Low-level Radioactive Waste. - The term 'low-level radioactive waste' means radioactive material that-

"(A) is not high-level radioactive waste, spent nuclear fuel, or byproduct material (as defined in section 11e.(2) of the Atomic Energy Act of 1954 (42 U.S.C. 2014(e)(2))); and

"(B) the Nuclear Regulatory Commission, consistent with existing law and in accordance with paragraph (A), classifies as low-level radioactive waste.

"(10) Non-sited Compact Region. - The term 'non-sited compact region' means any compact region that is not a sited compact region.

"(11) Regional Disposal Facility.-The term 'regional disposal facility' means a non-Federal low-level radioactive waste disposal facility in operation on January 1, 1985, or subsequently established and operated under a compact.

"(12) Secretary.-The term 'Secretary' means the Secretary of Energy.

"(13) Sited Compact Region. - The term 'sited compact region' means a compact region in which there is located one of the regional disposal faicilities at Barnwell, in the State of South Carolina; Richland, in the State of Washington; or Beatty, in the State of Nevada.

"(14) State.-The term 'State' means any State of the United States, the District of Columbia, and the Commonwealth of Puerto Rico.

Sec. 3. Responsibilities For Disposal Of Low-level Radioactive Waste. "Section 3(a)(1) State Responsibilities.-Each State shall be responsible for providing, either by itself or in cooperation with other States, for the disposal of -

"(A) low-level radioactive waste generated within the State (other than by the Federal Government) that consists of or contains class $\mathrm{A}, \mathrm{B}$, or $\mathrm{C}$ radioactive waste as defined by section 61.55 of title 10, Code of Federal Regulations, as in effect on January 26, 1983;

"(B) low-level radioactive waste described in subparagraph (A) that is generated by the Federal Government except such waste that is-

"(i) owned or generated by the Department of Energy; 
Research and development.

Post, pp. 1846 , 1855.

Vessels.

Research and development

Health

Safety.

42 USC 2011

note.

Report. "(ii) owned or generated by the United States Navy as a result of the decommissioning of vessels of the United States Navy; or

"(iii) owned or generated as a result of any research, development, testing, or production of any atomic weapon; and

"(C) low-level radioactive waste described in subparagraphs (A) and (B) that is generated outside of the State and accepted for disposal in accordance with sections 5 or 6 .

"(2) No regional disposal facility may be required to accept for disposal any material-

"(A) that is not low-level radioactive waste as defined by section 61.55 of title 10, Code of Federal Regulations, as in effect on January 26,1983 , or

"(B) identified under the Formerly Utilized Sites Remedial Action Program.

Nothing in this paragraph shall be deemed to prohibit a State, subject to the provisions of its compact, or a compact region from accepting for disposal any material identified in subparagraph (A) or (B). of-

“(A) low-level radioactive waste owned or generated by the Department of Energy;

"(B) low-level radioactive waste owned or generated by the United States Navy as a result of the decommissioning of vessels of the United States Navy;

"(C) low-level radioactive waste owned or generated by the Federal Government as a result of any research, development, testing, or production of any atomic weapon; and

"(D) any other low-level radioactive waste with concentrations of radionuclides that exceed the limits established by the Commission for class $C$ radioactive waste, as defined by section 61.55 of title 10, Code of Federal Regulations, as in effect on January 26, 1983.

"(2) All radioactive waste designated a Federal responsibility pursuant to subparagraph (b)(1)(D) that results from activities licensed by the Nuclear Regulatory Commission under the Atomic Energy Act of 1954, as amended, shall be disposed of in a facility licensed by the Nuclear Regulatory Commission that the Commission determines is adequate to protect the public health and safety.

"(3) Not later than 12 months after the date of enactment of this Act, the Secretary shall submit to the Congress a comprehensive report setting forth the recommendations of the Secretary for ensuring the safe disposal of all radioactive waste designated a Federal responsibility pursuant to subparagraph (b)(1)(D). Such report shall include-

"(A) an identification of the radioactive waste involved, including the source of such waste, and the volume, concentration, and other relevant characteristics of such waste;

"(B) an identification of the Federal and non-Federal options for disposal of such radioactive waste; 
Prohibition.

Report.

42 USC 2021d.

Ante, p. 1843.

Prohibition.

Prohibition.

Prohibition.
"(C) a description of the actions proposed to ensure the safe disposal of such radioactive waste;

"(D) a description of the projected costs of undertaking such actions;

"(E) an identification of the options for ensuring that the beneficiaries of the activities resulting in the generation of such radioactive wastes bear all reasonable costs of disposing of such wastes; and

"(F) an identification of any statutory authority required for disposal of such waste.

"(4) The Secretary may not dispose of any radioactive waste designated a Federal responsibility pursuant to paragraph (b)(1)(D) that becomes a Federal responsibility for the first time pursuant to such paragraph until ninety days after the report prepared pursuant to paragraph (3) has been submitted to the Congress. Waste.

"Sec. 4. Regional Compacts For Disposal Of Low-level Radioactive

"(a) In General--

"(1) Federal Policy.-It is the policy of the Federal Government that the responsibilities of the States under section 3 for the disposal of low-level radioactive waste can be most safely and effectively managed on a regional basis.

"(2) Interstate Compacts. - To carry out the policy set forth in paragraph (1), the States may enter into such compacts as may be necessary to provide for the establishment and operation of regional disposal facilities for low-level radioactive waste.

“(b) Applicability To Federal Activities. -

"(1) In General.-

"(A) Activities Of The Secretary.-Except as provided in subparagraph (B), no compact or act taken under a compact shall be applicable to the transportation, management, or disposal of any low-level radioactive waste designated in section 3(a)(1)(B) (i)-(iii).

"(B) Federal Low-level Radioactive Waste Disposed Of At Non-federal Facilities. - Low-level radioactive waste owned or generated by the Federal Government that is disposed of at a regional disposal facility or non-Federal disposal facility within a State that is not a member of a compact shall be subject to the same conditions, regulations, requirements, fees, taxes, and surcharges imposed by the compact commission, and by the State in which such facility is located, in the same manner and to the same extent as any low-level radioactive waste not generated by the Federal Government.

“(2) Federal Low-level Radioactive Waste Disposal Facilities. - Any low-level radioactive waste disposal facility established or operated exclusively for the disposal of low-level radioactive waste owned or generated by the Federal Government shall not be subject to any compact or any action taken under a compact.

"(3) Effect Of Compacts On Federal Law.-Nothing contained in this Act or any compact may be construed to confer any new authority on any compact commission or State- 
Trasnportation.

Regulations.

Health.

Safety.

Pollution.

Government organization and employees.

28 USC 2671 et seq.

Prohibition.

Prohibition.

Prohibition.

42 USC 2021e.

"(A) to regulate the packaging, generation, treatment, storage, disposal, or transportation of low-level radioactive waste in a manner incompatible with the regulations of the Nuclear Regulatory Commission or inconsistent with the regulations of the Department of Transportation;

"(B) to regulate health, safety, or environmental hazards from source material, byproduct material, or special nuclear material;

"(C) to inspect the facilities of licensees of the Nuclear Regulatory Commission;

"(D) to inspect security areas or operations at the site of the generation of any low-level radioactive waste by the Federal Government, or to inspect classified information related to such areas or operations; or

"(E) to require indemnification pursuant to the provisions of chapter 171 of title 28 , United States Code (commonly referred to as the Federal Tort Claims Act), or section 170 of the Atomic Energy Act of 1954 (42 U.S.C. 2210) (commonly referred to as the Price-Anderson Act), whichever is applicable.

"(4) Federal Authority.- Except as expressly provided in this Act, nothing contained in this Act or any compact may be construed to limit the applicability of any Federal law or to diminish or otherwise impair the jurisdiction of any Federal agency, or to alter, amend, or otherwise affect any Federal law governing the judicial review of any action taken pursuant to any compact.

"(5) State Authority Preserved.-Except as expressly provided in this Act, nothing contained in this Act expands, diminishes, or otherwise affects State law.

"(c) Restricted Use Of Regional Disposal Facilities.-Any authority in a compact to restrict the use of the regional disposal facilities under the compact to the disposal of low-level radioactive waste generated within the compact region shall not take effect before each of the following occurs:

“(1) January 1, 1986; and

"(2) the Congress by law consents to the compact.

"(d) Congressional Review.-Each compact shall provide that every 5 years after the compact has taken effect the Congress may by law withdraw its consent.

"Sec. 5. Limited Availability Of Certain Regional Disposal Facilities During Transition And Licensing Periods.

"(a) Availability Of Disposal Capacity.-

"(1) Pressurized Water And Boiling Water Reactors.-During the seven-year period beginning January 1, 1986, and ending December 31, 1992, subject to the provisions of subsections (b) through (g), each State in which there is located a regional disposal facility referred to in paragraphs (1) through (3) of subsection (b) shall make disposal capacity available for low-level radioactive waste generated by pressurized water and boiling water commercial nuclear power reactors in accordance with the allocations established in subsection (c). 
Prohibition.

Prohibition.
“(2) Other Sources Of Low-level Radioactive Waste.-During the seven-year period beginning January 1, 1986 and ending December 31, 1992, subject to the provisions of subsections (b) through $(\mathrm{g})$, each State in which there is located a regional disposal facility referred to in paragraphs (1) through (3) of subsection (b) shall make disposal capacity available for low-level radioactive waste generated by any source not referred to in paragraph (1).

"(3) Allocation Of Disposal Capacity.-

“(A) During the seven-year period beginning January 1, 1986 and ending December 31, 1992, low-level radioactive waste generated within a sited compact region shall be accorded priority under this section in the allocation of available disposal capacity at a regional disposal facility referred to in paragraphs (1) through (3) of subsection (b) and located in the sited compact region in which such waste is generated.

"(B) Any State in which a regional disposal facility referred to in paragraphs (1) through (3) of subsection (b) is located may, subject to the provisions of its compact, prohibit the disposal at such facility of low-level radioactive waste generated outside of the compact region if the disposal of such waste in any given calendar year, together with all other low-level radioactive waste would result in that facility disposing of a total annual volume of low-level radioactive waste in excess of 100 per centum of the average annual volume for such facility designated in subsection (b): Provided, however, That in the event that all three States in which regional disposal facilities referred to in paragraphs (1) through (3) of subsection (b) act to prohibit the disposal of low-level radioactive waste pursuant to this subparagraph, each such State shall, in accordance with any applicable procedures of its compact, permit, as necessary, the disposal of additional quantities of such waste in increments of 10 per centum of the average annual volume for each such facility designated in subsection (b).

"(C) Nothing in this paragraph shall require any disposal facility or State referred to in paragraphs (1) through (3) of subsection (b) to accept for disposal low-level radioactive waste in excess of the total amounts designated in subsection (b).

“(4) Cessation Of Operation Of Low-level Radioactive Waste Disposal Facility. - No provision of this section shall be construed to obligate any State referred to in paragraphs (1) through (3) of subsection (b) to accept low-level radioactive waste from any source in the event that the regional disposal facility located in such State ceases operations.

“(b) Limitations. - The availability of disposal capacity for low-level radioactive waste from any source shall be subject to the following limitations:

"(1) Barnwell, South Carolina.-The State of South Carolina, in accordance with the provisions of its compact, may limit the volume of low-level radioactive waste accepted for disposal at the regional disposal facility located in Barnwell, South Carolina to a total of $8,400,000$ cubic feet of low-level radioactive waste during 
the 7-year period beginning January 1, 1986 and ending December 31,1992 (as based on an average annual volume of $1,200,000$ cubic feet of low-level radioactive waste).

"(2) Richland, Washington. - The State of Washington, in accordance with the provisions of its compact, may limit the volume of low-level radioactive waste accepted for disposal at the regional disposal facility located at Richland, Washington to a total of $9,800,000$ cubic feet of low-level radioactive waste during the 7-year period beginning January 1, 1986, and ending December 31, 1992 (as based on an average annual volume of $1,400,000$ cubic feet of low-level radioactive waste).

"(3) Beatty, Nevada. - The State of Nevada, in accordance with the provisions of its compact, may limit the volume of low-level radioactive waste accepted for disposal a the regional disposal facility located at Beatty, Nevada to a total of 1,400,000 cubic feet of low-level radioactive waste during the 7-year period beginning January 1,1986, and ending December 31, 1992 (as based on an average annual volume of 200,000 cubic feet of low-level radioactive waste).

"(c) Commercial Nuclear Power Reactor Allocations. -

"(1) Amount.-Subject to the provisions of subsections (a) through (g) each commercial nuclear power reactor shall upon request receive an allocation of low-level radioactive waste disposal capacity (in cubic feet) at the facilities referred to in subsection (b) during the 4-year transition period beginning January 1, 1986 and ending December 31, 1989, and during the 3-year licensing period beginning January 1, 1990, and ending December 31, 1992 , in an amount calculated by multiplying the appropriate number from the following table by the number of months remaining in the applicable period as determined under paragraph (2).

\begin{tabular}{|c|c|c|c|c|}
\hline \multirow{2}{*}{ "Reactor Type } & \multicolumn{2}{|c|}{ 4-year Transition Period } & \multicolumn{2}{|c|}{ 3-year Licensing Period } \\
\hline & $\begin{array}{l}\text { In Sited } \\
\text { Region }\end{array}$ & $\begin{array}{l}\text { All Other } \\
\text { Locations }\end{array}$ & $\begin{array}{l}\text { In Sited } \\
\text { Region }\end{array}$ & $\begin{array}{l}\text { All Other } \\
\text { Locations }\end{array}$ \\
\hline PWR & 1027 & 871 & 93 & 68 \\
\hline BWR & 2300 & 1951 & 209 & 1533 \\
\hline
\end{tabular}

"(2) Method Of Calculation.-For purposes of calculating the aggregate amount of disposal capacity available to a commercial nuclear power reactor under this subsection, the number of months shall be computed beginning with the first month of the applicable period, or the sixteenth month after receipt of a full power operating license, whichever occurs later.

"(3) Unused Allocations.-Any unused allocation under paragraph (1) received by a reactor during the transition period or the licensing period may be used at any time after such reactor receives its full power license or after the beginning of the pertinent period, whichever is later, but not in any event after December 31, 1992, or after commencement of operation of a regional disposal facility in 
Prohibition.

Prohibition.

Prohibition. the compact region or State in which such reactor is located, whichever occurs first.

"(4) Transferability. - Any commercial nuclear power reactor in a State or compact region that is in compliance with the requirements of subsection (e) may assign any disposal capacity allocated to it under this subsection to any other person in each State or compact region. Such assignment may be for valuable consideration and shall be in writing, copies of which shall be filed at the affected compact commissions and States, along with the assignor's unconditional written waiver of the disposal capacity being assigned.

"(5) Unusual Volumes.-

"(A) The Secretary may, upon petition by the owner or operator of any commercial nuclear power reactor, allocate to such reactor disposal capacity in excess of the amount calculated under paragraph (1) if the Secretary finds and states in writing his reasons for so finding that making additional capacity available for such reactor through this paragraph is required to permit unusual or unexpected operating, maintenance, repair or safety activities.

"(B) The Secretary may not make allocations pursuant to subparagraph $(A)$ that would result in the acceptance for disposal of more than 800,000 cubic feet of low-level radioactive waste or would result in the total of the allocations made pursuant to this subsection exceeding $11,900,000$ cubic feet over the entire seven-year interim access period.

“(6) Limitation.-During the seven-year interim access period referred to in subsection (a), the disposal facilities referred to in subsection (b) shall not be required to accept more than $11,900,000$ cubic feet of low-level radioactive waste generated by commercial nuclear power reactors.

"(d)(1) Surcharges.-The disposal of any low-level radioactive waste under this section (other than low-level radioactive waste generated in a sited compact region) may be charged a surcharge by the State in which the applicable regional disposal facility is located, addition to to the fees and surcharges generally applicable for disposal of low-level radioactive waste in the regional disposal facility involved. Except as provided in subsection (e)(2), such surcharges shall not exceed-

"(A) in 1986 and 1987, \$10 per cubic foot of low-level radioactive waste;

“(B) in 1988 and 1989, \$20 per cubic foot of low-level radioactive waste; and

“(C) in 1990,1991 , and $1992, \$ 40$ per cubic foot of low-level radioactive waste.

"(2) Milestone Incentives. -

"(A) Escrow Account. - Twenty-five per centum of all surcharge fees received by a State pursuant to paragraph (1) during the seven-year period referred to in subsection (a) shall be transferred on a monthly basis to an escrow account held by the Secretary. The Secretary shall deposit all funds received in a special escrow account. The funds so deposited shall not be the property of the United States. The Secretary shall act as trustee 
Ante, p. 1842.

for such funds and shall invest them in interest-bearing United States Government Securities with the highest available yield. Such funds shall be held by the Secretary until-

"(i) paid or repaid in accordance with subparagraph (B) or (C); or

"(ii) paid to the State collecting such fees in accordance with subparagraph $(F)$.

“(B) Payments. -

"(i) July 1, 1986.-The twenty-five per centum of any amount collected by a State under paragraph (1) for lowlevel radioactive waste disposed of under this section during the period beginning on the date of enactment of the Low-Level Radioactive Waste Policy Amendments Act of 1985 and ending June 30,1986, and transferred to the Secretary under subparagraph (A), shall be paid by the Secretary in accordance with subparagraph (D) if the milestone described in subsection (e)(1)(A) is met by the State in which such waste originated.

"(ii) January 1, 1988. - The twenty-five per centum of any amount collected by a State under paragraph (1) for low-level radioactive waste disposed of under this section during the period beginning July 1, 1986 and ending December 31,1987 , and transferred to the Secretary under subparagraph (A), shall be paid by the Secretary in accordance with subparagraph (D) if the milestone described in subsection (e)(1)(B) is met by the state in which such waste originated (or its compact region, where applicable).

“(iii) January 1, 1990.-The twenty-five per centum of any amount collected by a State under paragraph (1) for low-level radioactive waste disposed of under this section during the period beginning January 1, 1988 and ending December 31, 1989, and transferred to the Secretary under subparagraph (A), shall be paid by the Secretary in accordance with subparagraph (D) if the milestone described in subsection (e)(1)(C) is met by the State in which such waste originated (or its compact region, where applicable).

"(iv) The twenty-five per centum of any amount collected by a State under paragraph (1) for low-level radioactive waste disposed of under this section during the period beginning January 1, 1990 and ending December 31,1992 , and transferred to the Secretary under subparagraph (A), shall be paid by the Secretary in accordance with subparagraph (D) if, by January 1, 1993, the State in which such waste originated (or its compact region, where applicable) is able to provide for the disposal of all lowlevel radioactive waste generated within such State or compact region.

“(C) Failure To Meet January 1, 1993 Deadline. - If, by January 1, 1993, a State (or, where applicable, a compact region) in which low-level radioactive waste is generated is unable to 
provide for the disposal of all such waste generated within such State or compact region-

"(i) each State in which such waste is generated, upon the request of the generator or owner of the waste, shall take title to the waste, shall be obligated to take possession of the waste, and shall be liable for all damages directly or indirectly incurred by such generator or owner as a consequence of the failure of the State to take possession of the waste as soon after January 1, 1993 as the generator or owner notifies the State that the waste is available for shipment; or*

"(ii) if such State elects not to take title to, take possession of, and assume liability for such waste, pursuant to clause (i), twenty-five per centum of any amount collected by a State under paragraph (1) for low-level radioactive waste disposed of under this section during the period beginning January 1, 1990 and ending December 31, 1992 shall be repaid, with interest, to each generator from whom such surcharge was collected. Repayments made pursuant to this clause shall be made on a monthly basis, with the first such repayment beginning on February 1 , 1993 , in an amount equal to one thirty-sixth of the total amount required to be repaid pursuant to this clause, and shall continue until the State (or, where applicable, compact region) in which such low-level radioactive waste in generated is able to provide for the disposal of all such waste generated within such State or compact region or until January 1, 1996, whichever is earlier.

If a State in which low-level radioactive waste is generated elects to take title to, take possession of, and assume liability for such waste pursuant to clause (i), such State shall be paid such amounts as are designated in subparagraph (B)(iv). If a State (or, where applicable, a compact region) in which low-level radioactive waste is generated provides for the disposal of such waste at any time after January 1, 1993 and prior to January 1,1996 , such State (or, where applicable, compact region) shall be paid in accordance with subparagraph (D) a lump sum amount equal to twentyfive per centum of any amount collected by a State under paragraph (1): Provided, however, That such payment shall be adjusted to reflect the remaining number of months between January 1, 1993 and January 1, 1996 for which such State (or, where applicable, compact region) provides for the disposal of such waste. If a State (or, where applicable, a compact region) in which low-level radioactive waste is generated is unable to provide for the disposal of all such waste generated within such State or compact region by January 1,1996 , each State in which such waste is generated, upon the request of the generator or owner of the waste shall take title to the waste, be obligated to take possession of the waste, and shall be liable for all damages directly or indirectly incurred by such generator or owner as a consequence of the failure of the State to take pos-

- The United States Supreme Court struck down this provision because it wasunconditional. (N.Y.vs. UnitedStates 112 S. Ct. 2408 (June 19, 1992)). 
session of the waste as soon after January 1,1996 , as the generator or owner notifies the State that the waste is available for shipment.

"(D) Recipients Of Payments.-The payments described in subparagraphs (B) and (C) shall be paid within thirty days after the applicable date-

"(i) if the State in which such waste originated is not a member of a compact region, to such State;

"(ii) if the State in which such waste originated is a member of the compact region, to the compact commission serving such State.

"(E) Uses Of Payments.-

"(i) Limitations.-Any amount paid under subparagraphs (B) or (C) may only be used to-

"(I) establish low-level radioactive waste disposal facilities;

"(II) mitigate the impact of low-level radioactive waste disposal facilities on the host State;

"(III) regulate low-level radioactive waste disposal facilities; or

"(IV) ensure the decommissioning, closure, and care during the period of institutional control of low-level radioactive waste disposal facilities.

"(ii) Reports.-

"(I) Recipient.-Any State or compact commission receiving a payment under subparagraphs (B) or (C) shall, on December 31 of each year in which any such funds are expended, submit a report to the Department of Energy itemizing any such expenditures.

Reports. "(II) Department Of Energy.-Not later than six months after receiving the reports under subclause(I), the Secretary shall submit to the Congress a summary of all such reports that shall include an assessment of the compliance of each such State or compact commission with the requirements of clause (i).

"(F) Payment To States.-Any amount collected by a State under paragraph (1) that is placed in escrow under subparagraph (A) and not paid to a State or compact commission under subparagraphs (B) and (C) or not repaid to a generator under subparagraph (C) shall be paid from such escrow account to such State collecting such payment under paragraph (1). Such payment shall be made not later than 30 days after a determination of ineligibility for a refund is made.

Prohibition.

"(G) Penalty Surcharges. - No rebate shall be made under this subsection of any surcharge or penalty surcharge paid during a period of noncompliance with subsection (e)(1).

“(e) Requirements For Access To Regional Disposal Facilities.-

"(1) Requirements For Non-sited Compact Regions And Nonmember States. - Each non-sited compact region, or State that is not a member of a compact region that does not have an operating disposal facility, shall comply with the following requirements: 
“(A) By July 1, 1986, each such non-member State shall ratify compact legislation or, by the enactment of legislation or the certification of the Governor, indicate its intent to develop a site for the location of a low-level radioactive waste disposal facility within such State.

"(B) By January 1, 1988. -

"(i) each non-sited compact region shall identify the State in which its low-level radioactive waste disposal facility is to be located, or shall have selected the developer for such facility and the site to be developed, and each compact region or the State in which its low-level radioactive waste disposal facility is to be located shall develop a siting plan for such facility providing detailed procedures and a schedule for establishing a facility location and preparing a facility license application and shall delegate authority to implement such plan;

"(ii) each non-member State shall develop a siting plan providing detailed procedures and a schedule for establishing a facility location and preparing a facility license application for a low-level radioactive waste disposal facility and shall delegate authority to implement such plan; and

"(iii) The siting plan required pursuant to this paragraph shall include a description of the optimum way to attain operation of the low-level radioactive waste disposal facility involved, within the time period specified in this Act. Such plan shall include a description of the objectives and a sequence of deadlines for all entities required to take action to implement such plan, including, to the extent practicable, an identification of the activities in which a delay in the start, or completion, of such activities will cause a delay in beginning facility operation. Such plan shall also identify, to the extent practicable, the process for (1) screening for broad siting areas; (2) identifying and evaluating specific candidate sites; and (3) characterizing the preferred site(s), completing all necessary environmental assessments, and preparing a license application for submission to the Nuclear Regulatory Commission or an Agreement State.

"(C) By January 1, 1990.-

"(i) a complete application (as determined by the Nuclear Regulatory Commission or the appropriate agency of an agreement State) shall be filed for a license to operate a low-level radioactive waste disposal facility within each non-sited compact region or within each non-member State; or

"(ii) the Governor (or, for any State without a Governor, the chief executive officer) of any State that is not a member of a compact region in compliance with clause (i), or has not complied with such clause by its own actions, shall provide a written certification to the Nuclear Regulatory 
Federal Register, publication.

Contracts.

Commission, that such State will be capable of providing for, and will provide for, the storage, disposal, or management of any low-level radioactive waste generated within such State and requiring disposal after December 31, 1992, and include a description of the actions that will be taken to ensure that such capacity exists.

“(D) By January 1, 1992, a complete application (as determined by the Nuclear Regulatory Commission or the appropriate agency of an agreement State) shall be filed for a license to operate a low-level radioactive waste disposal facility within each non-sited compact region or within each non-member State.

"(E) The Nuclear Regulatory Commission shall transmit any certification received under subparagraph $(\mathrm{C})$ to the Congress and publish any such certification in the Federal Register.

"(F) Any State may, subject to all applicable provisions, if any, of any applicable compact, enter into an agreement with the compact commission of a region in which a regional disposal facility is located to provide for the disposal of all low-level radioactive waste generated within such State, and, by virtue of such agreement, may, with the approval of the State in which the regional disposal facility is located, be deemed to be in compliance with subparagraphs (A), (B), (C), and (D).

"(2) Penalties For Failure To Comply.-

"(A) By July 1, 1986.-If any State fails to comply with subparagraph (1)(A)-

"(i) any generator of low-level radioactive waste within such region or non-member State shall, for the period beginning July 1,1986 , and ending December 31 , 1986, be charged 2 times the surcharge otherwise applicable under subsection (d); and

"(ii) on or after January 1, 1987, any low-level radioactive waste generated within such region or non-member State may be denied access to the regional disposal facilities referred to in paragraphs (1) through (3) of subsection (b). “(B) By January 1, 1988. - If any non-sited compact region or non-member State fails to comply with paragraph (1)(B)-

"(i) any generator of low-level radioactive waste within such region or non-member State shall-

"(I) for the period beginning January 1, 1988, and ending June 30,1988, be charged 2 times the surcharge otherwise applicable under subsection (d); and

"(II) for the period beginning July 1, 1988, and ending December 31, 1988, be charged 4 times the surcharge otherwise applicable under subsection (d); and

“(ii) on or after January 1,1989, any low-level radioactive waste generated within such region or non-member State may be denied access to the regional disposal facilities referred to in paragraphs (1) through (3) of subsection (b).

“(C) By January 1, 1990.-If any non-sited compact region or non-member State fails to comply with paragraph (1)(C), any 
Prohibition.

Termination

South Carolina. Washington.

Nevada.

South Carolina. Washington.

Nevada. low-level radioactive waste generated within such region or non-member State may be denied access to the regional disposal facilities referred to in paragraphs (1) through (3) of subsection (b).

“(D) By January 1, 1992. - If any non-sited compact region or non-member State fails to comply with paragraph (1)(D), any generator of low-level radioactive waste within such region or non-member State shall, for the period beginning January 1, 1992 and ending upon the filing of the application described in paragraph (1)(D), be charged 3 times the surcharge otherwise applicable under subsection (d).

“(3) Denial Of Access. - No denial or suspension of access to a regional disposal facility under paragraph (2) may be based on the source, class, or type of low-level radioactive waste.

“(4) Restoration Of Suspended Access; Penalties For Failure To Comply.-Any access to a regional disposal facility that is suspended under paragraph (2) shall be restored after the non-sited compact region or non-member State involved complies with such requirement. Any payment of surcharge penalties pursuant to paragraph (2) for failure to comply with the requirements of subsection (e) shall be terminated after the non-sited compact region or non-member State involved complies with such requirements. “(f)(1) Administration. - Each State and compact commission in which a regional disposal facility referred to in paragraphs (1) through (3) of subsection (b) is located shall have authority-

"(A) to monitor compliance with the limitations, allocations, and requirements established in this section; and

"(B) to deny access to any non-Federal low-level radioactive waste disposal facilities within its borders to any low-level radioactive waste that-

"(i) is in excess of the limitations or allocations established in this section; or

"(ii) is not required to be accepted due to the failure of a compact region or State to comply with the requirements of subsection (e)(1).

“(2) Availability Of Information During Interim Access Period.-

"(A) The States of South Carolina, Washington, and Nevada may require information from disposal facility operators, generators, intermediate handlers, and the Department of Energy that is reasonably necessary to monitor the availability of disposal capacity, the use and assignment of allocations and the applicability of surcharges.

"(B) The States of South Carolina, Washington, and Nevada may, after written notice followed by a period of at least 30 days, deny access to disposal capacity to any generator or intermediate handler who fails to provide information under subparagraph (A).

“(C) Proprietary Information.-

"(i) Trade secrets, proprietary and other confidential information shall be made available to a State under this subsection upon request only if such State- 
Prohibition.

Government

organization and

employees.

Commerce and

trade.

42 USC 2021f.

Health.

Safety.

Defence and

national

security.

Health.

Safety.

Defence and national
"(I) consents in writing to restrict the dissemination of the information to those who are directly involved in monitoring under subparagraph (A) and who have a need to know;

"(II) accepts liability for wrongful disclosure; and

"(III) demonstrates that such information is essential to such monitoring.

"(ii) The United States shall not be liable for the wrongful disclosure by any individual or State of any information provided to such individual or State under this subsection.

"(iii) Whenever any individual or State has obtained possession of information under this subsection, the individual shall be subject to the same provisions of law with respect to the disclosure of such information as would apply to an officer or employee of the United States or of any department or agency thereof and the State shall be subject to the same provisions of law with respect to the disclosure of such information as would apply to the United States or any department or agency thereof. No State or State officer or employee who receives trade secrets, proprietary information, or other confidential information under this Act may be required to disclose such information under State law.

"(g) Nondiscrimination.-Except as provided in subsections (b) through (e), low-level radioactive waste disposed of under this section shall be subject without discrimination to all applicable legal requirements of the compact region and State in which the disposal facility is located as if such low-level radioactive waste were generated within such compact region.

"Sec. 6. Emergency Access.

"(a) In General.-The Nuclear Regulatory Commission may grant emergency access to any regional disposal facility or non-Federal disposal facility within a State that is not a member of a compact for specific low-level radioactive waste, if necessary to eliminate an immediate and serious threat to the public health and safety or the common defense and security. The procedure for granting emergency access shall be as provided in this section.

"(b) Request For Emergency Access.-Any generator of low-level radioactive waste, or any Governor (or, for any State without a Governor, the chief executive officer of the State) on behalf of any generator or generators located in his or her State, may request that the Nuclear Regulatory Commission grant emergency access to a regional disposal facility or a non-Federal disposal facility within a State that is not a member of a compact for specific low-level radioactive waste. Any such request shall contain any information and certifications the Nuclear Regulatory Commission may require.

“(c) Determination Of Nuclear Regulatory Commission.-

"(1) Required Determination.-Not later than 45 days after receiving a request under subsection (b), the Nuclear Regulatory Commission shall determine whether- 
security.

Ante, p. 1846.

Prohibition.

Health.

Safety.

Defence and

national

security.

Health.

Safety.

Defence and

national

security.
"(A) emergency access is necessary because of an immediate and serious threat to the public health and safety or the common defense and security; and

"(B) The threat cannot be mitigated by any alternative consistent with the public health and safety, including storage of low-level radioactive waste at the site of generation or in a storage facility obtaining access to a disposal facility by voluntary agreement, purchasing disposal capacity available for assignment pursuant to section 5 (c) or ceasing activities that general low-level radioactive waste.

"(2) Required Notification. - If the Nuclear Regulatory Commission makes the determinations required in paragraph (1) in the affirmative, it shall designate an appropriate non-Federal disposal facility or facilities, and notify the Governor (or chief executive officer) of the State in which such facility is located and the appropriate compact commission that emergency access is required. Such notification shall specifically describe the low-level radioactive waste as to source, physical and radiological characteristics, and the minimum volume and duration, not exceeding 180 days, necessary to alleviate the immediate threat to public health and safety or the common defense and security. The Nuclear Regulatory Commission shall also notify the Governor (or chief executive officer) of the State in which the low-level radioactive waste requiring emergency access was generated that emergency access has been granted and that, pursuant to subsection (e), no extension of emergency access may be granted absent diligent State action during the period of the initial grant.

“(d) Temporary Emergency Access.-Upon determining that emergency access is necessary because of an immediate and serious threat to the public health and safety or the common defense and security, the Nuclear Regulatory Commission may at its discretion grant temporary emergency access, pending its determination whether the threat could be mitigated by any alternative consistent with the public health and safety. In granting access under this subsection, the Nuclear Regulatory Commission shall provide the same notification and information required under subsection (c). Absent a determination that no alternative consistent with the public health and safety would mitigate the threat, access granted under this subsection shall expire 45 days after the granting of temporary emergency access under this subsection.

“(e) Extension Of Emergency Access.-The Nuclear Regulatory Commission may grant one extension of emergency access beyond the period provided in subsection (c), if it determines that emergency access continues to be necessary because of an immediate and serious threat to the public health and safety or the common defense and security that cannot be mitigated by any alternative consistent with the public health and safety, and that the generator of low-level radioactive waste granted emergency access and the State in which such low-level radioactive waste was generated have diligently though unsuccessfully acted during the period of the initial grant to eliminate the need for emergency access. Any extension granted under this subsection shall be for the minimum volume and duration the Nuclear Regulatory Commission 
finds necessary to eliminate the immediate threat to public health and safety or the common defense and security, and shall not in any event exceed 180 days.

"(f) Reciprocal Access. - Any compact region or State not a member of a compact that provides emergency access to non-Federal disposal facilities within its borders shall be entitled to reciprocal access to any subsequently operating non-Federal disposal facility that serves the State or compact region in which low-level radioactive waste granted emergency access was generated. The compact commission or State having authority to approve importation of low-level radioactive waste to the disposal facility to which emergency access was granted shall designate for reciprocal access an equal volume of low-level radioactive waste having similar characteristics to that provided emergency access.

"(g) Approval By Compact Commission. - Any grant of access under this section shall be submitted to the compact commission for the region in which the designated disposal facility is located for such approval as may be required under the terms of its compact. Any such compact commission shall act to approve emergency access not later than 15 days after receiving notification from the Nuclear Regulatory Commission, or reciprocal access not later than 15 days after receiving notification from the appropriate authority under subsection (f).

Prohibitions.

"(h) Limitations. - No State shall be required to provide emergency or reciprocal access to any regional disposal facility within its borders for low-level radioactive waste not meeting criteria established by the license or license agreement of such facility, or in excess of the approved capacity of such facility, or to delay the closing of any such facility pursuant to plans established before receiving a request for emergency or reciprocal access. No State shall, during any 12 -month period, be required to provide emergency or reciprocal access to any regional disposal facility within its borders for more than 20 percent of the total volume of lowlevel radioactive waste accepted for disposal at such facility during the previous calendar year.

"(i) Volume Reduction And Surcharges.-Any low-level radioactive waste delivered for disposal under this section shall be reduced in volume to the maximum extent practicable and shall be subject to surcharges established in this Act.

"(j) Deduction From Allocation.-Any volume of low-level radioactive waste granted emergency or reciprocal access under this section, if generated by any commercial nuclear power reactor, shall be deducted Ante, p. 1846. from the low-level radioactive waste volume allocable under section 5 (c).

Prohibition.

"(k) Agreement States.-Any agreement under section 274 of the Atomic Energy Act of 1954 (42 U.S.C. 2021) shall not be applicable to the determinations of the Nuclear Regulatory Commission under this section.

42 USC 2021g. "Sec. 7. Responsibilities Of The Department Of Energy.

“(a) Financial And Technical Assistance.-The Secretary shall, to the extent provided in appropriations Act, provide to those compact regions, host States, and nonmember States determined by the Secretary to require assistance for purposes of carrying out this Act-

Science and

"(1) continuing technical assistance to assist them in fulfilling 
technology. Transportation. Health.

Safety.

Science and technology. Transportation.

42 USC 2021h. Ante, p. 1842.

42 USC 2021i. their responsibilities under this Act. Such technical assistance shall include, but not be limited to, technical guidelines for site selection, alternative technologies for low-level radioactive waste disposal, volume reduction options, management techniques to reduce low-level waste generation, transportation practices for shipment of low-level wastes, health and safety considerations in the storage, shipment and disposal of low-level radioactive wastes, and establishment of a computerized database to monitor the management of low-level radioactive wastes; and

"(2) through the end of fiscal year 1993, financial assistance to assist them in fulfilling their responsibilities under this Act.

"(b) Reports. - The Secretary shall prepare and submit to the Congress on an annual basis a report which (1) summarizes the progress of low-level waste disposal siting and licensing activities within each compact region, (2) reviews the available volume reduction technologies, their applications, effectiveness, and costs on a per unit volume basis, (3) reviews interim storage facility requirements, costs, and usage, (4) summarizes transportation requirements for such wastes on an inter-and intra-regional basis, (5) summarizes the data on the total amount of low-level waste shipped for disposal on a yearly basis, the proportion of such wastes subjected to volume reduction, the average volume reduction attained, and the proportion of wastes stored on an interim basis, and (6) projects the interim storage and final disposal volume requirements anticipated for the following year, on a regional basis.

"Sec. 8. Alternative Disposal Methods.

"(a) Not later than 12 months after the date of enactment of the Low-Level Radioactive Waste Policy Amendments Act of 1985, the Nuclear Regulatory Commission shall, in consultation with the States and other interested persons, identify methods for the disposal of low-level radioactive waste other than shallow land burial, and establish and publish technical guidance regarding licensing of facilities that use such methods.

"(b) Not later than 24 months after the date of enactment of the Low-Level Radioactive Waste Policy Amendments Act of 1985, the Commission shall, in consultation with the States and other interested persons, identify and publish all relevant technical information regarding the methods identified pursuant to subsection (a) that a State or compact must provide to the Commission in order to pursue such methods, together with the technical requirements that such facilities must meet, in the judgment of the Commission, if pursued as an alternative to shallow land burial. Such technical information and requirements shall include, but need not be limited to, site suitability, site design, facility operation, disposal site closure, and environmental monitoring, as necessary to meet the performance objectives established by the Commission for a licensed low-level radioactive waste disposal facility. The Commission shall specify and publish such requirements in a manner and form deemed appropriate by the Commission.

"Sec. 9. Licensing Review And Approval.

"In order to ensure the timely development of new low-level radioactive waste disposal facilities, the Nuclear Regulatory Commission or, as 
Ante, p. 1842.

appropriate, agreement States, shall consider an application for a disposal facility license in accordance with the laws applicable to such application, except that the Commission and the agreement state shall-

"(1) not later than 12 months after the date of enactment of the Low-Level Radioactive Waste Policy Amendments Act of 1985, establish procedures and develop the technical capability for processing applications for such licenses;

"(2) to the extent practicable, complete all activities associated with the review and processing of any application for such a license (except for public hearings) no later than 15 months after the date of receipt of such application; and

"(3) to the extent practicable, consolidate all required technical and environmental reviews and public hearings.

"Sec. 10. Radioactive Waste Below Regulatory Concern.

"(a) Not later than 6 months after the date of enactment of the Low-Level Radioactive Waste Policy Amendments Act of 1985, the Commission shall establish standards and procedures, pursuant to existing authority, and develop the technical capability for considering and acting upon petitions to exempt specific radioactive waste streams from regulation by the Commission due to the presence of radionuclides in such waste streams in sufficiently low concentrations or quantities as to be below regulatory concern.

"(b) The standards and procedures established by the Commission pursuant to subsection (a) shall set forth all information required to be submitted to the Commission by licensees in support of such petitions, including, but not limited to-

"(1) a detailed description of the waste materials, including their origin, chemical composition, physical state, volume, and mass; and

Health.

Safety.

Regulation.

"(2) The concentration or contamination levels, half-lives, and identities of the radionuclides present.

Such standards and procedures shall provide that, upon receipt of a petition to exempt a specific radioactive waste stream from regulation by the Commission, the Commission shall determine in an expeditious manner whether the concentration or quantity of radionuclides present in such waste stream requires regulation by the Commission in order to protect the public health and safety. Where the Commission determines that regulation of a radioactive waste stream is not necessary to protect the public health and safety, the Commission shall take such steps as may be necessary, in an expeditious manner, to exempt the disposal of such radioactive waste from regulation by the Commission.".

NOTE: TITLE II OF THIS LAW WHICH CONSISTS OF THE TEXT OF SIX COMPACTS IS FOUND IN VOLUME II OF THIS NUREG. 
Dec. 22, 1980

[S. 2189]

Low-Level

Radioactive

Waste Policy Act

42 USC $2021 \mathrm{~b}$

note.

42 USC $2021 \mathrm{~b}$

42 USC 2021c

State compacts

\section{An Act}

To set forth a Federal policy for the disposal of low-level radioactive wastes, and for other purposes.

$B e$ it enacted by the Senate and House of Representatives of the United

States of America in Congress assembled,

\section{"Section 1. Short Title.}

"This Act may be cited as the 'Low-Level Radioactive Waste Policy Act'.

"Sec. 2. Definitions.

"As used in this Act:

"(1) The term 'disposal' means the isolation of low-level radioactive waste pursuant to requirements established by the Nuclear Regulatory Commission under applicable laws.

"(2) The term 'low-level radioactive waste' means radioactive waste not classified as high-level radioactive waste, transuranic waste, spent nuclear fuel, or byproduct material as defined in section 11e.(2) of the Atomic Energy Act of 1954.

"(3) The term 'State' means any State of the United States, the District of Columbia, and, subject to the provisions of Public Law 96-205, the Commonwealth of Puerto Rico, the Virgin Islands, Guam, the Northern Mariana Islands, the Trust Territory of the Pacific Islands, and any other territory or possession of the United States.

"(4) For purposes of this Act the term 'atomic energy defense activities of the Secretary' includes those activities and facilities of the Department of Energy carrying out the function of-

(i) Naval reactors deyelopment and propulsion,

(ii) weapons activities, verification and control technology,

(iii) defense materials production,

(iv) inertial confinement fusion,

(v) defense waste management, and

(vi) defense nuclear materials security and safeguards (all as included in the Department of Energy appropriations account in any fiscal year for atomic energy defense activities).

"Sec. 3. General Provisions. (a) Compacts established under this Act or actions taken under such compacts shall not be applicable to the transportation, management, or disposal of low-level radioactive waste from atomic energy defense activities of the Secretary or Federal research and development activities.

"(b) Any facility established or operated exclusively for the disposal of low-level radioactive waste produced by atomic energy defense activities of the Secretary or Federal research and development activities shall not be subject to compacts established under this Act or actions taken under such compacts.

"Sec. 4. Low-Level Radioactive Waste Disposal. (a)(1) It is the policy of the Federal Government that- 
regarding

regional

facilities.

42 USC 2021d

Congressional consent.

Report to Congress and States
(A) each State is responsible for providing for the availability of capacity either within or outside the State for the disposal of low-level radioactive waste generated within its borders except for waste generated as a result of defense activities of the Secretary or Federal research and development activities; and (B) low-level radioactive waste can be most safely and efficiently managed on a regional basis.

(2)(A) To carry out the policy set forth in paragraph (1), the States may enter into such compacts as may be necessary to provide for the establishment and operation of regional disposal facilities for low-level radioactive waste.

(B) A compact entered into under subparagraph (A) shall not take effect until the Congress has by law consented to the compact. Each such compact shall provide that every 5 years after the compact has taken effect the Congress may by law withdraw its consent. After January 1, 1986, any such compact may restrict the use of the regional disposal facilities under the compact to the disposal of low-level radioactive waste generated within the region.

(b)(1) In order to assist the States in carrying out the policy set forth in subsection (a)(1), the Secretary shall prepare and submit to Congress and to each of the States within 120 days after the date of the enactment of this Act a report which-

(A) defines the disposal capacity needed for present and future low-level radioactive waste on a regional basis;

(B) defines the status of all commercial low-level radioactive waste disposal sites and includes an evaluation of the license status of each such site, the state of operation of each site, including operating history, an analysis of the adequacy of disposal technology employed at each site to contain low-level radioactive wastes for their hazardous lifetimes, and such recommendations as the Secretary considers appropriate to assure protection of the public health and safety from wastes transported to such sites;

(C) evaluates the transportation requirements on a regional basis and in comparison with performance of present transportation practices for the shipment of low-level radioactive wastes, including an inventory of types and quantities of low-level wastes, and evaluation of shipment requirements for each type of waste and an evaluation of the ability of generators, shippers, and carriers to meet such requirements; and

(D) evaluates the capability of the low-level radioactive waste disposal facilities owned and operated by the Department of Energy to provide interim storage for commercially generated low-level waste and estimates the costs associated with such interim storage.

(2) In carrying out this subsection, the Secretary shall consult with the Governors of the States, the Nuclear Regulatory Commission, the Environmental Protection Agency, the United States Geological Survey, and the Secretary of Transportation, and such other agencies and departments as he finds appropriate. 
NUCLEAR WASTE POLICY ACT OF 1982

Public Law 97-425 (96 Stat. 2201)

\section{OMNIBUS BUDGET RECONCILIATION ACT OF 1987}

TITLE V, SUBTITLE A

NUCLEAR WASTE AMENDMENTS

Public Law 100-203

(101 Stat. 1330)

OFFICE OF NUCLEAR WASTE NEGOTIATOR, MRS COMMISSION

Public Law 100-507 (102 Stat. 2541)

\section{SHORT TITLE AND TABLE OF CONTENTS}

Section 1. This Act may be cited as the "Nuclear Waste Policy Act of 1982".

TABLE OF CONTENTS

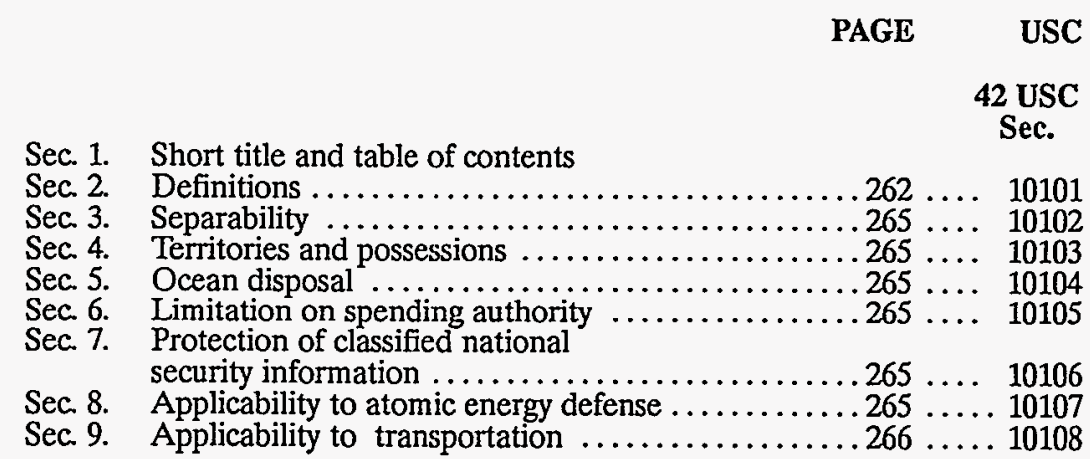

TITLE 1-DISPOSAL AND STORAGE OF HIGH-LEVEL RADIOACTIVE WASTE, SPENT NUCLEAR FUEL, AND LOW-LEVEL RADIOACTIVE WASTE

Sec. 101. State and affected Indian tribe participation in development of proposed repositories for defense waste. 


\section{SUBTITLE A-REPOSITORIES FOR DISPOSAL OF HIGH-LEVEL RADIOACTIVE WASTE AND SPENT NUCLEAR FUEL}

PAGE

USC

42 USC

Sec.

Sec. 111. Findings and purposes .

10131

Sec. 112. Recommendation of candidate sites

for site characterization ......................... 10132

Sec. 113. Site characterization ..................... $270 \ldots \ldots 10133$

Sec. 114. Site approval and construction

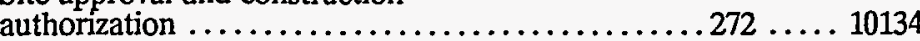

Sec. 115. Review of repository site selection $\ldots \ldots \ldots \ldots \ldots \ldots 276 \ldots \ldots 10135$

Sec. 116. Participation of States. ...................280 . . 10136

Sec. 117. Consultation with States and Indian

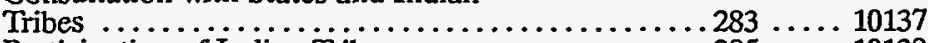

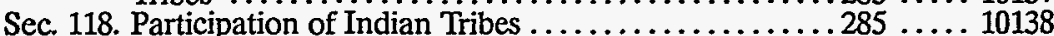

Sec. 119. Judicial review of agency actions . . . . . . . . . $287 \ldots \ldots 10139$

Sec. 120. Expedited authorizations ................... $288 \ldots \ldots 10140$

Sec. 121. Certain standards and criteria ................ $288 \ldots \ldots . . .10141$

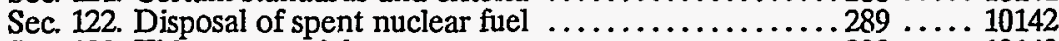

Sec. 123. Title to material .........................290 .... 10143

Sec. 124. Consideration of effect of acquisition

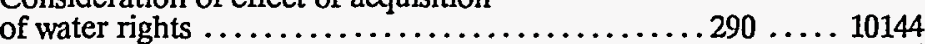

Sec. 125. Termination of certain provisions $\ldots \ldots \ldots \ldots \ldots \ldots 290 \ldots \ldots 10145$

\section{SUBTITLE B-INTERIM STORAGE PROGRAM}

Sec. 131. Findings and purposes .................... 290 .... 10151

Sec. 132. Available capacity for interim storage

of spent nuclear fuel ..................... $291 \ldots \ldots 10152$

Sec. 133. Interim at-reactor storage ..................291 .... 10153

Sec. 134. Licensing of facility expansions and

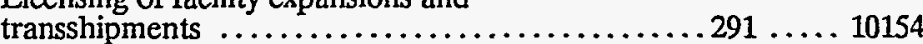

Sec. 135. Storage of spent nuclear fuel ............... 292 .... 10155

Sec. 136. Interim Storage Fund ...................... $299 \ldots \ldots 10156$

Sec. 137. Transportation ......................... $303 \ldots \ldots 10157$

\section{SUBTITLE C-MONITORED RETRIEVABLE STORAGE}

Sec. 141. Monitored retrievable storage ............... 303 ... 10161

Sec. 142. Authorization of monitored

retrievable storage ........................ 306 . 10162

Sec. 143. Monitored Retrievable Storage

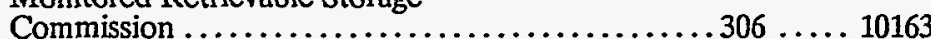

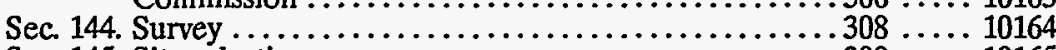

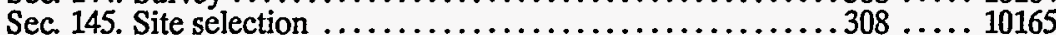

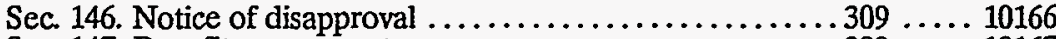

Sec. 147. Benefits agreement ........................... 10167

Sec. 148. Construction authorization ....................... 310108

Sec. 149. Financial assistance ....................... 311 .... 10169

SÜBTITLE D-LOW-LEVEL RADIOACTIVE WASTE

Sec. 151. Financial arrangements for site closure .............. 10171 


\section{SUBTITLE E-REDIRECTION OF THE NUCLEAR WASTE PROGRAM}

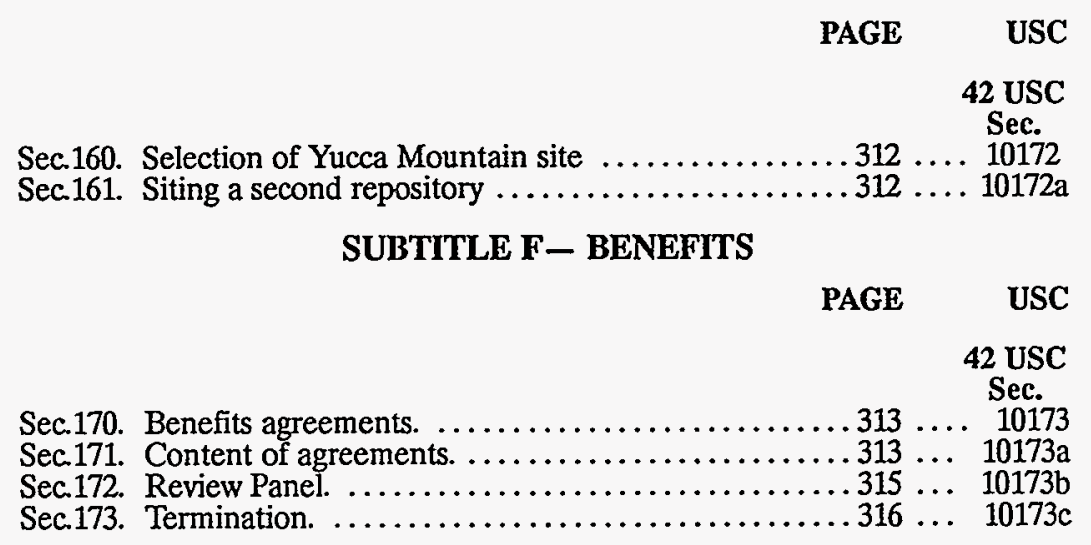

\section{SUBTITLE G- OTHER BENEFITS}

Sec.174. Consideration in siting facilities. ..............316 .... 10174

Sec.175. Report. .............................316 .... 1017a

\section{SUBTITLE H -TRANSPORTATION}

Sec.180. Transportation.

\section{TITLE II-RESEARCH, DEVELOPMENT, AND DEMONSTRATION REGARDING DISPOSAL OF HIGH-LEVEL RADIOACTIVE WASTE AND SPENT NUCLEAR FUEL}

PAGE

USC

42 USC

Sec.

Sec. 211. Purpose. .................................318 ... 10191

Sec. 212. Applicability. .................................... 101918

Sec. 213. Identification of sites............................... 10193

Sec. 214. Siting research and related activities. ................... 10194

Sec. 215. Test and evaluation facility siting

review and reports. ........................ $320 \ldots . . .10195$

Sec. 216. Federal agency actions. .......................... 10196

Sec. 217. Research and development on disposal $\ldots . \ldots . \ldots 322 \ldots . .10197$

Sec. 218. Research and development on spent nuclear fuel. ............................... 325 ... 10198

Sec. 219. Payments to States and

327 .... 10199

Sec. 220. Study of research and development needs for monitored retrievable storage proposal. ............................... 10200

Sec. 221. Judicial review. ................................ 10201

Sec. 222. Research on alternatives for the permanent disposal of high-level radioactive waste. ........................... 327 ... 10202

Sec. 223. Technical assistance to non-nuclear weapon states in the field of spent fuel storage and disposal. .......................... 327 . 10203

Sec. 224. Subseabed disposal. ............................. 10204 


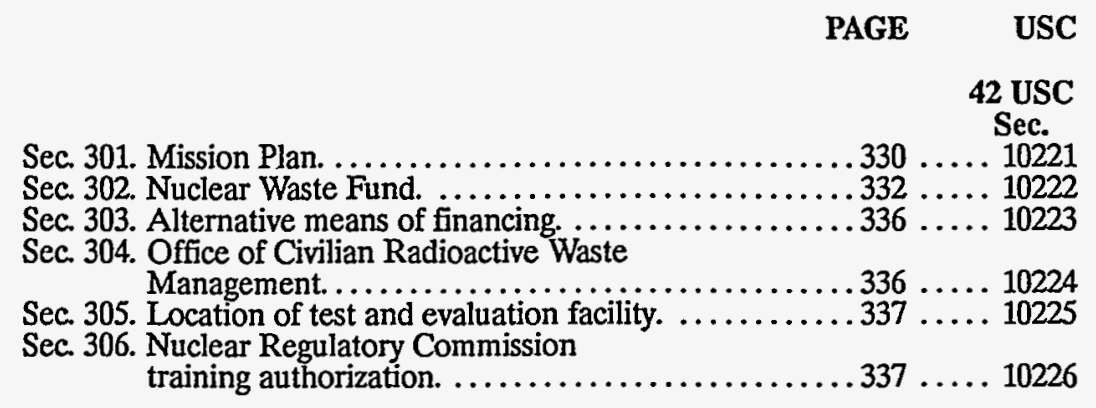

TITLE IV-NUCLEAR WASTE NEGOTIATOR

PAGE USC

Sec.

Sec. 401. Definition. ................................. 338 . 10241

Sec. 402. The Office of Nuclear Waste

Sec. 403. Duties of the Negotiator............................... 102438

Sec. 404. Environmental assessment of sites. ..................... 10244

Sec. 405. Site characterization; Licensing. ...............340 ... 10245

Sec. 406. Monitored retrievable storage. .................. 340 ... 10246

Sec. 407. Environmental impact statement. ................... 3410247

Sec. 408. Administrative powers of the

Negotiator................................... 3410248

Sec. 409. Cooperation of other departments

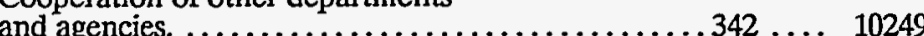

Sec. 410 . Termination of the office. .............................. 10250

Sec. 411. Authorization of Appropriations .................... 10251

TITLE V-NUCLEAR WASTE TECHNICAL REVIEW BOARD

PAGE USC

2 USC

Sec. 501. Definitions ............................ 342 .... 10261

Sec. 502. Nuclear Waste Technical Review Board ................... 10262

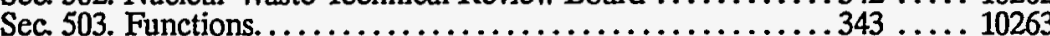

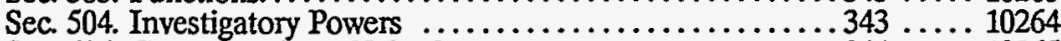

Sec. 505. Compensation of Members ............................ 10265

Sec. 506. Staff .......................................... 10264

Sec. 507. Support Services ............................... 10267

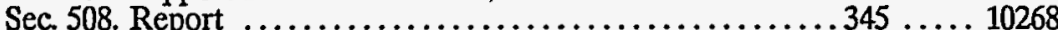

Sec. 509. Authorization of Appropriations ............... 345 ... 10269

Sec 510. Termination of the Board ....................... 10275 
NUCLEAR WASTE POLICY ACT OF 1982, AS AMENDED

Public Law 97-425

96 Stat. 2201

42 USC 10101.

Sec. 2. For purposes of this Act:

(1) The term "Administrator" means the Administrator of the Environmental Protection Agency.

(2) The term "affected Indian tribe" means any Indian tribe(A) within whose reservation boundaries a monitored retrievable storage facility, test and evaluation facility, or a repository for high-level radioactive waste or spent fuel is proposed to be located;

(B) whose federally defined possessory or usage rights to other lands outside of the reservation's boundaries arising out of congressionally ratified treaties may be substantially and adversely affected by the locating of such a facility: Provided, That the Secretary of the Interior finds, upon the petition of the appropriate governmental officials of the tribe, that such effects are both substantial and adverse to the tribe;

(3) the term "atomic energy defense activity" means any activity of the Secretary performed in whole or in part in carrying out any of the following functions:

(A) naval reactors development;

(B) weapons activities including defense inertial confinement fusion;

(C) verification and control technology;

(D) defense nuclear materials production;

(E) defense nuclear waste and materials by-products management;

(F) defense nuclear materials security and safeguards and security investigations; and

$(G)$ defense research and development.

(4) The term "candidate site" means an area, within a geologic and hydrologic system, that is recommended by the Secretary under section 112 for site characterization, approved by the President under section 112 for site characterization, or undergoing site characterization under section 113 .

(5) The term "civilian nuclear activity" means any atomic energy activity other than an atomic energy defense activity.

(6) The term "civilian nuclear power reactor" means a civilian nuclear powerplant required to be licensed under section 103 or 104 b. of the Atomic Energy Act of 1954 (42 U.S.C. 2133, 2134(b)).

(7) The term "Commission" means the Nuclear Regulatory Commission.

(8) The term "Department" means the Department of Energy.

(9) The term "disposal" means the emplacement in a repository of high-level radioactive waste, spent nuclear fuel, or other highly radioactive material with no foreseeable intent of recovery, whether or not such emplacement permits the recovery of such waste. 
(10) The terms "disposal package" and "package"mean the primary container that holds, and is in contact with, solidified highlevel radioactive waste, spent nuclearfuel, or other radioactive materials, and any overpacks that are emplaced at a repository.

(11) The term "engineered barriers" means manmade components of a disposal system designed to prevent the release of radionuclides into the geologic medium involved. Such term includes the high-level radioactive waste form, high-level radioactive waste canisters, and other materials placed over and around such canisters.

(12) The term "high-level radioactive waste" means-

(A) the highly radioactive material resulting from the reprocessing of spent nuclear fuel, including liquid waste produced directly in reprocessing and any solid material derived from such liquid waste that contains fission products in sufficient concentrations; and

(B) other highly radioactive material that the Commission, consistent with existing law, determines by rule requires permanent isolation.

(13) The term "Federal agency" means any Executive agency, as defined in section 105 of title 5, United States Code.

(14) The term "Governor" means the chief executive officer of a State.

(15) The term "Indian tribe" means any Indian tribe, band, nation, or other organized group or community of Indians recognized as eligible for the services provided to Indians by the Secretary of the Interior because of their status as Indians, including any Alaska Native village, as defined in section 3(c) of the Alaska Native Claims Settlement Act (43 U.S.C. 1602(c)).

(16) The term "low-level radioactive waste" means radioactive material that-

(A) is not high-level radioactive waste, spent nuclear fuel, transuranic waste, or by-product material as defined in section 11e(2) of the Atomic Energy Act of 1954 (42 U.S.C. 2014(e)(2)); and

(B) the Commission, consistent with existing law, classifies as low level radioactive waste.

(17) The term "Office" means the Office of Civilian Radioactive Waste Management established in section 305.

(18) The term "repository" means any system licensed by the Commission that is intended to be used for, or may be used for, the permanent deep geologic disposal of high-level radioactive waste and spent nuclear fuel, whether or not, such system is designed to permit the recovery, for a limited period during initial operation, of any materials placed in such system. Such term includes both surface and subsurface areas at which high-level radioactive waste and spent nuclear fuel handling activities are conducted.

(19) The term "reservation" means-

(A) any Indian reservation or dependent Indian community referred to in clause 9 a) or (b) of section 1151 of title 18, United States Code; or 
(B) any land selected by an Alaska Native village or regional corporation under the provisions of the Alaska Native Claims Settlement Act (43 U.S.C. 1601 et seq.).

(20) The term "Secretary" means the Secretary of Energy.

(21) The term "site characterization" means-

(A) siting research activities with respect to a test and evaluation facility at a candidate site; and

(B) activities, whether in the laboratory or in the field, undertaken to establish the geologic condition and the ranges of the parameters of a candidate site relevant to the location of a repository, including borings, surface excavations, excavations of exploratory shafts, limited subsurface lateral excavations and borings, and in situ testing needed to evaluate the suitability of a candidate site for the location of a repository, but not including preliminary borings and geophysical testing needed to assess whether site characterization should be undertaken.

(22) The term "siting research" means activities, including borings, surface excavations, shaft excavations, subsurface lateral excavations and borings, and in situ testing, to determine the suitability of a site for a test and evaluation facility.

(23) The term "spent nuclear fuel" meansfuel that has been withdrawn from a nuclear reactor following irradiation, the constituent elements of which have not been separated by reprocessing.

(24) The term "State" means each of the several States, the District of Columbia, the Commonwealth of Puerto Rico, the Virgin Islands, Guam, American Samoa, the Northern Mariana Islands, the Trust Territory of the Pacific Islands, and any other territory or possession of the United States.

(25) The term "storage" means retention of high-level radioactive waste, spent nuclear fuel, or transuranic waste with the intent to recover such waste or fuel for subsequent use, processing, or disposal.

(26) The term "Storage Fund" means the Interim Storage Fund established in section 137(c).

(27) The term "test and evaluation facility" means an at-depth, prototypic, underground cavity with subsurface lateral excavations extending from a central shaft that is used for research and development purposes, including the development of data and experience for the safe handling and disposal of solidified high-level radioactive waste, transuranic waste, or spent nuclear fuel.

(28) The term "unit of general local government" means any borough, city, county, parish, town, township, village, or other general purpose political subdivision of a State.

(29) The term "Waste Fund" means the Nuclear Waste Fund established in section 302(c).

(30) The term 'Yucca Mountain site' means the candidate site in the State of Nevada recommended by the Secretary to the President under section 112(b)(1)(B) on May 27, 1986.

(31) The term 'affected unit of local government' means the unit of local government with jurisdiction over the site of a repository or a monitored retrievable storage facility. Such term may, at the dis- 
42 USC 10102

cretion of the Secretary, include units of local government that are contiguous with such unit.

(32) The term 'Negotiator' means the Nuclear Waste Negotiator.

(33) As used in title IV, the term 'Office' means the Office of the Nuclear Waste Negotiator established under title IV of this Act.

(34) The term'monitored retrievable storage facility' means the storage facility described in section 141(b)(1)."1

\section{SEPARABILITY}

Sec. 3. If an provision of this Act, or the application of such provision to any person or circumstance, is held invalid, the remainder of this Act, or the application of such provisions to persons or circumstances other than those as to which it is held invalid, shall not be affected thereby.

\section{TERRITORIES AND POSSESSIONS}

42 USC 10103 Sec. 4. Nothing in this Act shall be deemed to repeal, modify, or amend the provisions of section 605 of the Act of March 12, 1980 (48 U.S.C. 1491).

42 USC 10104 Sec.5. Nothing in this Act shall be deemed to affect the Marine Protection, Research, and Sanctuaries Act of 1972 (33 U.S.C. 1401 et seq.).

LIMITATION ON SPENDING AUTHORITY

42 USC 10105 Sec. 6. The authority under this Act to incur indebtedness, or enter into contracts, obligating amounts to be expended by the Federal Government shall be effective for any fiscal year only to such extent or in such amounts as are provided in advance by appropriation Acts.

PROTECTION OF CLASSIFIED NATIONAL SECURITY INFORMATION

42 USC 10106 Sec.7. Nothing in this Act shall require the release or disclosure to any person or to the Commission of any classified national security information.

42 USC $10107 \quad$ Sec. 8. (a) Atomic Energy Defense Activities.-Subject to the provisions of subsection (c), the provisions of this Act shall not apply with respect to any atomic energy defense activity or to any facility used in conjunction with any such activity.

(b) Evaluation By President.-(1) Not later than 2 years after the date of the enactment of this Act, the President shall evaluate the use of disposal capacity at one or more repositories to be developed under subtitle A of title I for the disposal of high-level radioactive waste resulting

Post, p. 2207 from atomic energy defense activities. Such evaluation shall take into consideration factors relating to cost efficiency, health and safety, regulation, transportation, public acceptability, and national security.

(2) Unless the President finds, after conducting the evaluation required in paragraph (1), that the development of a repository for the disposal of high-level radioactive waste resulting from atomic energy defense activities only is required, taking into account all of the factors described in such subsection, the Secretary shall proceed promptly with arrangement for the use of one or more of the

Post, p. 2256 repositories to be developed under subtitle $A$ of title I for the disposal of such waste. Such arrangements shall include the allocation

'Public Law 100-203 (101 Stat. 1330) (1987) sec. 5002, added subsecs. 30-34. 
of costs of developing, constructing, and operating this repository or repositories. The costs resulting from permanent disposal of high-level radioactive waste from atomic energy defense activities shall be paid by the Federal Government, into the special account established under section 302.

(3) Any repository for the disposal of high-level radioactive waste resulting from atomic energy defense activities only shall (A) be subject to licensing under section 202 of the Energy Reorganization Act of 1973 (42 U.S.C. 5842); and (B) comply with all requirements of the Commission for the siting, development, construction, and operation of a repository.

(c) Applicability To Certain Repositories. - The provisions of this Act shall apply with respect to any repository not used exclusively for the disposal of high-level radioactive waste or spent nuclear fuel resulting from atomic energy defense activities, research and development activities of the Secretary, or both.

\section{APPLICABILITY}

42 USC 10108

Sec. 9. Transportation-Nothing in this Act shall be construed to affect Federal, State, or local laws pertaining to the transportation of spent nuclear fuel or high-level radioactive waste.

\section{TITLE I-DISPOSAL AND STORAGE OF HIGH-LEVEL RADIOACTIVE WASTE, SPENT NUCLEAR FUEL, AND LOW-LEVEL RADIOACTIVE WASTE}

\section{STATE AND AFFECTED INDIAN TRIBE PARTICIPATION IN DEVELOPMENT OF PROPOSED REPOSITORIES FOR DEFENSE WASTE}

42 USC 10121

Sec. 101. (a) Notification To States And Affected Indian Tribes.- Notwithstanding the provisions of section 8 , upon any decision by the Secretary or the President to develop a repository for the disposal of highlevel radioactive waste or spent nuclear fuel resulting exclusively from atomic energy defense activities, research and development activities of the Secretary, or both, and before proceeding with any site-specific investigations with respect to such repository, the Secretary shall notify the Governor and legislature of the State in which such repository is proposed to be located, or the governing body of the affected Indian tribe on whose reservation such repository is proposed to be located, as the case may be, of such decision.

(b) Participation Of States And Affected Indian Tribes.-Following the receipt of any notification under subsection (a), the State or Indian tribe involved shall be entitled, with respect to the proposed repository involved, to rights of participation and consultation identical to those provided in section 115 through 118 , except that any financial assistance authorized to be provided to such State or affected Indian tribe under section 116 (c) or 118(b) shall be made from amounts appropriated to the Secretary for purposes of carrying out this section. 


\section{SUBTITLE A-REPOSITORIES FOR DISPOSAL OF HIGH-LEVEL RADIOACTIVE WASTE AND SPENT NUCLEAR FUEL}

\section{FINDINGS AND PURPOSES}

Sec. 111. (a) Findings-The Congress finds that-

(1) radioactive waste creates potential risks and requires safe and environmentally acceptable methods of disposal;

(2) a national problem has been created by the accumulation of (A) spent nuclear fuel from nuclear reactors; and (B) radioactive waste from (i) reprocessing of spent nuclear fuel; (ii) activities related to medical research, diagnosis, and treatment; and (iii) other sources;

(3) Federal efforts during the past 30 years to devise a permanent solution to the problems of civilian radioactive waste disposal have not been adequate;

(4) while the Federal Government has the responsibility to provide for the permanent disposal of high-level radioactive waste and such spent nuclear fuel as may be disposed of in order to protect the public health and safety and the environment, the costs of such disposal should be the responsibility of the generators and owners of such waste and spent fuel;

(5) the generators and owners of high-level radioactive waste and spent nuclear fuel have the primary responsibility to provide for, and the responsibility to pay the costs of, the interim storage of such waste and spent fuel until such waste and spent fuel is accepted by the Secretary of Energy in accordance with the provisions of this Act;

(6) State and public participation in the planning and development of repositories is essential in order to promote public confidence in the safety of disposal of such waste and spent fuel; and

(7) high-level radioactive waste and spent nuclear fuel have become major subjects of public concern, and appropriate precautions may be taken to ensure that such waste and spent fuel do not adversely affect the public health and safety and the environment for this or future generations.

(b) Purposes.-The purposes of this subtitle are-

(1) to establish a schedule for the siting, construction, and operation of repositories that will provide a reasonable assurance that the public and the environment will be adequately protected from the hazards posed by high-level radioactive waste and such spent nuclear fuel as may be disposed of in a repository;

(2) to establish the Federal responsibility, and a definite Federal policy, for the disposal of such waste and spent fuel;

(3) to define the relationship between the Federal Government and the State government with respect to the disposal of such waste and spent fuel; and

(4) to establish a Nuclear Waste Fund, composed of payments made by the generators and owners of such waste and spent fuel, that will ensure that the costs of carrying out activities relating to the disposal of such waste and spent fuel will be borne by the persons responsible for generating such waste and spent fuel. 
Sec. 112. (a) Guidelines. - Not later than 180 days after the date of the enactment of this Act, the Secretary, following consultation with the Council on Environmental Quality, the Administrator of the Environmental Protection Agency, the Director of the Geological Survey, and interested Governors, and the concurrence of the Commission shall issue general guidelines for the recommendation of sites for repositories. Such guidelines shall specify detailed geologic considerations that shall be primary criteria for the selection of sites in various geologic media. Such guidelines shall specify factors that qualify or disqualify any site from development as a repository, including factors pertaining to the location of valuable natural resources, hydrology, geophysics, seismic activity, and atomic energy defense activities, proximity to water supplies, proximity to populations, the effect upon the rights of users of water, and proximity to components of the National Park System, the National Wildlife Refuge System, the National Wild and Scenic Rivers System, the National Wilderness Preservation System, or National Forest Lands. Such guidelines shall take into consideration the proximity to sites where high-level radioactive waste and spent nuclear fuel is generated or temporarily stored and the transportation and safety factors involved in moving such waste to a repository. Such guidelines shall specify population factors that will disqualify any site from development as a repository if any surface facility of such repository would be located (1) in a highly populated area; or (2) adjacent to an area 1 mile by 1 mile having a population of not less than 1,000 individuals. Such guidelines also shall require the Secretary to consider the cost and impact of transporting to the repository site the solidified high-level radioactive waste and spent fuel to be disposed of in the repository and the advantages of regional distribution in the siting of repositories. Such guidelines shall require the Secretary to consider the various geologic media in which sites for repositories may be located and, to the extent practicable, to recommend sites in different geologic media. The Secretary shall use guidelines established under this subsection in considering candidate sites for recommendation under subsection (b). The Secretary may revise such guidelines from time to time, consistent with the provisions of this subsection.

(b) Recommendation By Secretary To The President.-(1)(A)Following the issuance of guidelines under subsection (a) and consultation with the Governors of affected States, the Secretary shall nominate at least 5 sites that he determines suitable for site characterization for selection of the first repository site.

Recommendation date.

Environmental assessment.
(B) Subsequent to such nomination, the Secretary shall recommend to the President 3 of the nominated sites not later than January 1, 1985 for characterization as candidate sites.

(C) Such recommendations under subparagraph (B) shall be consistent with the provisions of section 305.

(D) Each nomination of a site under this subsection shall be accompanied by an environmental assessment, which shall include a detail statement of the basis for such recommendation and of the probable impacts of the site characterization activities planned for such site, and a discussion of alternative activi- 
ties relating to site characterization that may be undertaken to avoid such impacts. Such environmental assessment shall include-

(i) an evaluation by the Secretary as to whether such site is suitable for site characterization under the guidelines established under subsection (a);

(ii) an evaluation by the Secretary as to whether such site is suitable for development as a repository under each such guideline that does not require site characterization as a prerequisite for application of such guidelines;

(iii) an evaluation by the Secretary of the effects of the site characterization activities at such site on the public health and safety and the environment;

(iv) a reasonable comparative evaluation by the Secretary of such site with other sites and locations that have been considered:

(v) a description of the decision process by which such site was recommended; and

(vi) an assessment of the regional and local impacts of locating the proposed repository at such site.

(E)(i) The issuance of any environmental assessment under this paragraph shall be considered to be a final agency action subject to judicial review in accordance with the provisions of chapter 7 of title 5, United States Code, and section 119. Such judicial review shall be limited to the sufficiency of such environmental assessment with respect to the items described in clauses (i) through (vi) of subparagraph (D).

(F) Each environmental assessment prepared under this paragraph shall be made available to the public.

(G) Before nominating a site, the Secretary shall notify the Governor and legislature of the State in which such site is located, or the governing body of the affected Indian tribe where such site is located, as the case may be, of such nomination and the basis for such nomination.

(2) Before nominating any site the Secretary shall hold public hearings in the vicinity of such site to inform the residents of the area in which such site is located of the proposed nomination of such site and to receive their comments. At such hearings, the Secretary shall also solicit and receive any recommendations of such residents with respect to issues that should be addressed in the environmental assessment described in paragraph (1) and the site characterization plan described in section 113(b)(l).

(3) In evaluating the sites nominated under this section prior to any decision to recommend a site as a candidate site, the Secretary shall use available geophysical, geologic, geochemical and hydrologic, and other information and shall not conduct any preliminary borings or excavations at a site unless (i) such preliminary boring or excavation activities were in progress upon the date of enactment of this Act or (ii) the Secretary certifies that such available information from other sources, in the absence of preliminary borings or excavations, will not be adequate to satisfy applicable require- 
Decision transmittal or notification.

42 USC 10133.

ments of this Act or any other law: Provided, That preliminary borings or excavations under this section shall not exceed a diameter of 6 inches.

(c) Presidential Review Of Recommended Candidate Sites.-(1) The President shall review each candidate site recommendation made by the Secretary under subsection (b). Not later than 60 days after the submission by the Secretary of a recommendation of a candidate site, the President, in his discretion, may either approve or disapprove such candidate site, and shall transmit any such decision to the Secretary and to either the Governor and legislature of the State in which such candidate site is located, or the governing body of the affected Indian tribe where such candidate site is located, as the case may be. If, during such 60-day period, the President fails to approve or disapprove such candidate site, or fails to invoke his authority under paragraph (2) to delay his decision, such candidate site shall be considered to be approved, and the Secretary shall notify such Governor and legislature, or governing body of the affected Indian tribe, of the approval of such candidate site by reason of the inaction of the President.

(2) The President may delay for not more than 6 months his decision under paragraph (1) to approve or disapprove a candidate site, upon determining that the information provided with the recommendation of the Secretary is insufficient to permit a decision within the 60-day period referred to in paragraph (1). The President may invoke his authority under this paragraph by submitting written notice to the Congress, within such 60-day period of his intent to invoke such authority. If the President invokes such authority, but fails to approve or disapprove the candidate site involved by the end of such 6-month period, such candidate site shall be considered to be approved, and the Secretary shall notify such Governor and legislature, or governing body of the affected Indian tribe of the approval of such candidate site by reason of the inaction of the President.

(d) Preliminary Activities.-Except as otherwise provided in this section, each activity of the President or the Secretary under this section shall be considered to be a preliminary decision making activity. No such activity shall require the preparation of an environmental impact statement under section 102(2)(C) of the National Environmental Policy Act of 1969 (42 U.S.C. 4332(2)(C)), or to require any environmental review under subparagraph $(\mathrm{E})$ or $(\mathrm{F})$ of section 102(2) of such Act. ${ }^{2}$

\section{SITE CHARACTERIZATION}

Sec. 113. (A) In General.-The Secretary shall carry out, in accordance with the provisions of this section, appropriate site characterization activities at the Yucca Mountain site. The Secretary shall consider fully the comments received under subsection (b)(2) and section 112 (b)(2) and shall, to the maximum extent practicable and in consultation with the Governor of the State of Nevada conduct site characterization activities in a manner that minimizes any significant adverse environmental impacts identified in such comments or in the environmental assessment submitted under subsection (b)(1).

\footnotetext{
${ }^{2}$ Public Law 100-203 (101 Slat. 1330) (1987) sec. 5011, amended Sec. 112.
} 
Plan submittal, review and comment.

Public availability; hearings.

Report. (b) Commission And States.-(1) Before proceeding to sink shafts at the Yucca Mountain site, the Secretary shall submit for such candidate site to the Commission and to the Governor or legislature of the State of Nevada for their review and comment-

(A) a general plan for site characterization activities to be conducted at such candidate site, which plan shall include-

(i) a description of such candidate site;

(ii) a description of such site characterization activities, including the following: the extent of planned excavations, plans for any onsite testing with radioactive or nonradioactive material, plan for any investigation activities that may affect the capabilities of such candidate site to isolate high-level radioactive waste and spent nuclear fuel, and plans to control any adverse, safety-related impacts from such site characterization activities;

(iii) plan for the decontamination and decommissioning of such candidate site, and for the mitigation of any significant adverse environmental impacts caused by the site characterization activities if it is determined unsuitable for application for a construction authorization for a repository;

(iv) criteria to be used to determine the suitability of such candidate site for the location of a repository, developed pursuant to section 112(a); and

(v) any other information required by the Commission; (B) a description of the possible form or packaging for the high-level radioactive waste and spent nuclear fuel to be emplaced in such repository, a description, to the extent practicable, of the relationship between such waste form or packaging and the geologic medium of such site, and a description of the activities being conducted by the Secretary with respect to such possible waste form or packaging or such relationship; and

(C) a conceptual repository design that takes into account likely site-specific requirements.

(2) Before proceeding to sink shafts at the Yucca Mountain site, the Secretary shall (A) make available to the public the site characterization plan described in paragraph (1); and (B) hold public hearings in the vicinity of such candidate site to inform the residents of the area in which such candidate site is located of such plan, and to receive their comments. .

(3) During the conduct of site characterization activities at the Yucca Mountain site, the Secretary shall report not less than once every 6 months to the Commission and to the Governor and legislature of the State of Nevada on the nature and extent of such activities and the information developed from such activities.

(c) Restrictions. - (1) The Secretary may conduct at the Yucca Mountain site only such site characterization activities as the Secretary considers necessary to provide the data required for evaluation of the suitability of such site for an application to be submitted to the Commission for a construction authorization for a repository at such site, and for compli- 
Reports.

42 USC 10134.

ance with the National Environmental Policy Act of 1969 (42 U.S.C. 4321 et seq.).

(2) In conducting site characterization activities-

(A) the Secretary may not use any radioactive material at a site unless the Commission concurs that such use is necessary to provide data for the preparation of the required environmental reports and an application for a construction authorization for a repository at such site; and

(B) if any radioactive material is used at a site-

(i) the Secretary shall use the minimum quantity necessary to determine the suitability of such sites for a repository, but in no event more than the curie equivalent of 10 metric tons of spent nuclear fuel; and

(ii) such radioactive material shall be fully retrievable.

(3) If the Secretary at any time determines the Yucca Mountain site to be unsuitable for development as a repository, the Secretary shall-

(A) terminate all site characterization activities at such site;

(B) notify the Congress, the Governor and legislature of Nevada of such termination and the reasons for such termination;

(C) remove any high-level radioactive waste, spent nuclear fuel, or other radioactive materials at or in such site as promptly as practicable;

(D) take reasonable and necessary steps to reclaim the site and to mitigate any significant adverse environmental impacts caused by site characterization activities at such site;

(E) suspend all future benefits payments under subtitle $F$ with respect to such site; and

(F) report to Congress not later than 6 months after such determination the Secretary's recommendations for further action to assure the safe, permanent disposal of spent nuclear fuel and high-level radioactive waste, including the need for new legislative authority.

(d) Preliminary Activities.-Each activity of the Secretary under this section that is in compliance with the provisions of subsection (c) shall be considered a preliminary decision making activity. No such activity shall require the preparation of an environmental impact statement under section 102(2)(C) of the National Environmental Policy Act of 1969 (42 U.S.C. 4332(2)(C)), or to require any environmental review under subparagraph (E) or (F) of section 102(2) of such Act. ${ }^{3}$

\section{SITE APPROVAL AND CONSTRUCTION AUTHORIZATION}

Sec. 114. (a) Hearings And Presidential Recommendation.-The Secretary shall hold public hearings in the vicinity of the Yucca Mountain site for the purposes of informing the residents of the area of such con-

Notification of decision. sideration and receiving their comments regarding the possible recommendation of such site. If, upon completion of such hearings and completion of site characterization activities at the Yucca Mountain site under section 113, the Secretary decides to recommend approval of such

3public law 100-203 (101 Stat. 1330) (1987) Sec. 5011, amended Sec. 113. 
Public availability.

site to the President, the Secretary shall notify the Governor and legislature of the State of Nevada of such decision. No sooner than the expiration of the 30-day period following such notification, the Secretary shall submit to the President a recommendation that the President approve such site for the development of a repository. Any such recommendation by the Secretary shall be based on the record of information developed by the Secretary under section 113 and this section, including the information described in subparagraph (A) through subparagraph (G). Together with any recommendation of a site under this paragraph, the Secretary shall make available to the public, and submit to the President, a comprehensive statement of the basis of such recommendation, including the following:

(A) a description of the proposed repository, including preliminary engineering specifications for the facility;

(B) a description of the waste form or packaging proposed for use at such repository, and an explanation of the relationship between such waste form or packaging and the geologic medium of such site;

(C) a discussion of data, obtained in site characterization activities, relating to the safety of such site;

(D) a final environmental impact statement prepared for the Yucca Mountain site pursuant to subsection (f) and the National Environmental Policy Act of 1969 (42 U.S.C. 4321 et seq.), together with comments made concerning such environmental impact statement by the Secretary of the Interior, the Council on Environmental Quality; the Administrator, and the Commission, except that the Secretary shall not be required in any such environmental impact statement to consider the need for a repository, the alternatives to geological disposal, or alternative sites to the Yucca Mountain site;

(E) preliminary comments of the Commission concerning the extent to which the at-depth site characterization analysis and the waste form proposal for such site seem to be sufficient for inclusion in any application to be submitted by the Secretary for licensing of such site as a repository;

(F) the views and comments of the Governor and legislature of any State, or the governing body of any affected Indian tribe, as determined by the Secretary, together with the response of the Secretary to such views;

(G) such other information as the Secretary considers appropriate; and

$(\mathrm{H})$ any impact report submitted under section 116(c)(2)(B) by the State of Nevada.

(2)(A) If, after recommendation by the Secretary, the President considers the Yucca Mountain site qualified for application for a construction authorization for a repository, the President shall submit a recommendation of such site to Congress.

(B) The President shall submit with such recommendation a copy of the statement for such site prepared by the Secretary under paragraph (1). 
Construction authorization applications.
(3)(A) The President may not recommend the approval of Yucca Mountain site unless the Secretary has recommended to the President under paragraph (1) approval of such site and has submitted to the President a statement for such site as required under such paragraph.

(B) No recommendation of a site by the President under this subsection shall require the preparation of an environmental impact statement under section 102(2)(C) of the National Environmental Policy Act of 1969 (42 U.S.C. 4332(2)(C), or to require any environmental review under subparagraph $(E)$ or $(F)$ of section 102(2) of such Act.

(b) Submission Of Application.-If the President recommends to the Congress the Yucca Mountain site under subsection (a) and the site designation is permitted to take effect under section 115 , the Secretary shall submit to the Commission an application for a construction authorization for a repository at such site not later than 90 days after the date on which the recommendation of the site designation is effective under such section and shall provide to the Governor and legislature of the State of Nevada a copy of such application.

(c) Status Report On Application.-Not later than 1 year after the date on which an application for a construction authorization is submitted under subsection (b), and annually thereafter until the date on which such authorization is granted, the Commission shall submit a report to the Congress describing the proceeding undertaken through the date of such report with regard to such application, including a description of-

(1) any major unresolved safety issues, and the explanation of the Secretary with respect to design and operation plans for resolving such issues;

(2) any matters of contention regarding such application; and

(3) any Commission actions regarding the granting of denial of such authorization.

(d) Commission Action-The Commission shall consider an application for a construction authorization for all or part of a repository in accordance with the laws applicable to such applications, except that the Commission shall issue a final decision approving or disapproving the issuance of a construction authorization not later that the expiration of 3 years after the date of the submission of such application, except that the Commission may extend such deadlines by not more than 12 months if, not less than 30 days before such deadlines, the Commission complies with the reporting requirements established in subsection (e)(2). The Commission decision approving the first such application shall prohibit the emplacement in the first repository of a quantity of spent fuel containing in excess of 70,000 metric tons of heavy metal or a quantity of solidified high-level radioactive waste resulting from the reprocessing of such a quantity of spent fuel until such time as a second repository is in operation. In the event that a monitored retrievable storage facility, approved pursuant to subtitle $C$ of this Act, shall be located, or is planned to be located, within 50 miles of the first repository, then the Commission decision approving the first such application shall prohibit the emplacement of a quality of spent fuel containing in excess of 70,000 metric tons of heavy metal or a quantity of solidified high-level radioactive waste resulting from the reprocessing of spent fuel in both the reposi- 
Report submittal to Secretary and Congress.

Report response, filing with Congress.

tory and monitored retrievable storage facility until such time as a second repository is in operation.

(e) Protect Decision Schedule.-(1) The Secretary shall prepare and update, as appropriate, in cooperation with all affected Federal agencies, a project decision schedule that portrays the optimum way to attain the operation of the repository within the time periods specified in this subtitle. Such schedule shall include a description of objectives and a sequence of deadlines for all Federal agencies required to take action, including an identification of the activities in which a delay in the start, or completion, of such activities will cause a delay in beginning repository operation.

(2) Any Federal agency that determines that it cannot comply with any deadline in the project decision schedule, or fails to so comply, shall submit to the Secretary and to the Congress a written report explaining the reason for its failure or expected failure to meet such deadlines, the reason why such agency could not reach an agreement with the Secretary, the estimated time for completion of the activity or activities involved, the associated effect on its other deadlines in the project decision schedule, and any recommendations it may have or actions it intends to take regarding any improvements in its operation or organization, or changes to its statutory directives or authority, so that it will be able to mitigate the delay involved. The Secretary, within 30 days after receiving any such report, shall file with the Congress his response to such report, including the reasons why the Secretary could not amend the project decision schedule to accommodate the Federal agency involved.

(f) Environmental Impact Statement.-(1) Any recommendation made by the Secretary under this section shall be considered a major Federal action significantly affecting the quality of the human environment for purposes of the National Environmental Policy Act of 1969 (42 U.S.C. 4321 et seq.). A final environmental impact statement prepared by the Secretary under such Act shall accompany any recommendation to the President to approve a site for a repository.

(2) With respect to the requirements imposed by the National Environmental Policy Act of 1969 (42 U.S.C. 4321 et seq.), compliance with the procedures and requirements of this Act shall be deemed adequate consideration of the need for a repository, the time of the initial availability of a repository, and all alternatives to the isolation of high-level radioactive waste and spent nuclear fuel in a repository.

(3) For purposes of complying with the requirements of the $\mathrm{Na}$ tional Environmental Policy Act of 1969 (42 U.S.C. 4321 et seq.) and this section, the Secretary need not consider alternative sites to the Yucca Mountain site for the repository to be developed under this subtitle.

(4) Any environmental impact statement prepared in connection with a repository proposed to be constructed by the Secretary under this subtitle shall, to the ex tent practicable, be adopted by the Commission in connection with the issuance by the Commission of a construction authorization and license for such repository. To the 
42 USC 10135.

extent such statement is adopted by the Commission, such adoption shall be deemed to also satisfy the responsibilities of the Commission under the National Environmental Policy Act of 1969 (42 U.S.C. 4321 et seq.) and no further consideration shall be required, except that nothing in this subsection shall affect any independent responsibilities of the Commission to protect the public health under the Atomic Energy Act of 1954 (42 U.S.C. 2011 et seq.).

(5) Nothing in this Act shall be construed to amend or otherwise detract from the licensing requirements of the Nuclear Regulatory Commission established in title II of the Energy Reorganization Act of 1974 (42 U.S.C. 5841 et seq.).

(6) In any such statement prepared with respect to the repository to be constructed under this subtitle, the Nuclear Regulatory Commission need not consider the need for a repository, the time of initial availability of a repository, alternate sites to the Yucca Mountain site, or nongeologic alternatives to such site. ${ }^{4}$

\section{REVIEW OF REPOSITORY SITE SELECTION}

Sec. 115. (a) Definition.-For purposes of this section, the term "resolution of repository siting approval" means a joint resolution of the Congress, the matter after the resolving clause of which is as follows: "That there hereby is approved the site at ... for a repository, with respect to which a notice of disapproval was submitted by ... on ...". The first blank space in such resolution shall be filled with the name of the geographic location of the proposed site of the repository to which such resolution pertains; the second blank space in such resolution shall be filled with the designation of the State Governor and legislature or Indian tribe governing body submitting the notice of disapproval to which such resolution pertains; and the last blank space in such resolution shall be filled with the date of such submission.

(b) State Or Indian Tribe Petitions. - The designation of a site as suitable for application for a construction authorization for a repository shall be effective at the end of the 60 -day period beginning on the date that the President recommend such site to the Congress under section 114, unless the Government and legislature of the State in which such site is located, or the governing body of an Indian tribe on whose reservation such site is located, as the case may be, has submitted to the Congress a notice of disapproval under section 116 or 118 . If any such

Notice of disapproval, submittal to Congress. notice of disapproval has been submitted, the designation of such site shall not be effective except as provided under subsection (c).

(c) Congressional Review Of Petitions. - If any notice of disapproval of a repository site designation has been submitted to the Congress under section 116 or 118 after a recommendation for approval of such site is made by the President under section 114, such site shall be disapproved unless, during the first period of 90 calendar days of continuous session of the Congress after the date of the receipt by the Congress of such notice of disapproval, the Congress passes a resolution of repository siting approval in accordance with this subsection approving such site, and such resolution thereafter becomes law.

${ }^{4}$ Public Law 100-203 (101 Stat. 1330) (1987) sec. 5011, amended Sec. 114. 
Introduction of resolution.

Committee recommendations.

Discharge of committee. (d) Procedures Applicable To The Senate.-(1) The provisions of this subsection are enacted by the Congress-

(A) as an exercise of the rulemaking power of the Senate, and as such they are deemed a part of the rules of the Senate, but applicable only with respect to the procedure to be followed in the Senate in the case of resolutions of repository siting approval, and such provisions supersede other rules of the Senate only to the extent that they are inconsistent with such other rules; and

(B) with full recognition of the constitutional right of the Senate to change the rules (so far as relating to the procedure of the Senate) at any time, in the same, manner and to the same extent as in the case of any other rule of the Senate.

(2)(A) Not later than the first day of session following the day on which any notice of disapproval of a repository site selection is submitted to the Congress under section 116 or 118, a resolution of repository siting approval shall be introduced (by request) in the Senate by the chairman of the committee to which such notice of disapproval is referred, or by a Member of Members of the Senate designated by such chairman.

(B) Upon introduction, a resolution of repository siting approval shall be referred to the appropriate committee or committees of the Senate by the President of the Senate, and all such resolutions with respect to the same repository site shall be referred to the same committee or committees. Upon the expiration of 60 calendar days of continuous session after the introduction of the first resolution of repository siting approval with respect to any site, each committee to which such resolution was referred shall make its recommendations to the Senate.

(3) If any committee to which is referred a resolution of siting approval introduced under paragraph (2)(A), or, in the absence of such a resolution, any other resolution of siting approval introduced with respect to the site involved, has not reported such resolution at the end of 60 days of continuous session of Congress after introduction of such resolution, such committee shall be deemed to be discharged from further consideration of such resolution, and such resolution shall be placed on the appropriate calendar of the Senate.

(4)(A) When each committee to which a resolution of siting approval has been referred has reported, or has been deemed to be discharged from further consideration of, a resolution described in paragraph (3), it shall at any time thereafter be in order (even though a previous motion to the same effect has been disagreed to) for any Member of the Senate to move to proceed to the consideration of such resolution. Such motion shall be highly privilege and shall not be debatable. Such motion shall not be subject to amendment, to a motion to postpone, or to a motion to proceed to the consideration of other business. A motion to reconsider the vote by which such motion is agreed to or disagreed to shall not be in order. If a motion to proceed to the consideration of such resolution is agreed to, such resolution shall remain the unfurnished business of the Senate until disposed of. 
Debate.

Appeals.
(B) Debate on a resolution of siting approval, and on all debatable motions and appeals in connection with such resolution, shall be limited to not more than 10 hours, which shall be divided equally between Members favoring and Members opposing such resolution. A motion further to limit debate shall be in order and shall not be debatable. Such motion shall not be subject to amendment, to a motion to postpone, or to a motion to proceed to the consideration of other business, and a motion to recommit such resolution shall not be in order. A motion to reconsider the vote by which such resolution is agreed to or disagreed to shall not be in order.

(C) Immediately following the conclusion of the debate on a resolution of siting approval, and a single quorum call at the conclusion of such debate if requested in accordance with rules of the Senate, the vote on final approval of such resolution shall occur.

(D) Appeals from the decisions of the Chair relating to the application of the rules of the Senate to the procedure relating to a resolution of siting approval shall be decided without debate.

(5) If the Senate receives from the House a resolution of repository siting approval with respect to any site, then the following procedure shall apply:

(A) The resolution of the House with respect to such site shall not be referred to a committee.

(B) With respect to the resolution of the Senate with respect to such site-

(i) the procedure with respect to that or other resolutions of the Senate with respect to such site shall be the same as if no resolution from the House with respect to such site had been received; but

(ii) on any vote on final passage of a resolution of the Senate with respect to such site, a resolution from the House with respect to such site where the text is identical shall be automatically substituted for the resolution of the Senate.

(e) Procedures Applicable To The House Of Representatives. -

(1) The provisions of this section are enacted by the Congress(A) as an exercise of the rulemaking power of the House of Representatives, and as such they are deemed a part of the rules of the House, but applicable only with respect to the procedure to be followed in th House in the case of resolutions of repository siting approval, and such provisions supersede other rules of the House only to the extent that they are inconsistent with such other rules; and

(B) with full recognition of the constitutional right of the House to change the rules (so farr as relating to the procedure of the House) at any time, in the same manner and to the same extent as in the case of any other rule of the House.

(2) Resolutions of repository siting approval shall upon introduction be immediately referred by the Speaker of the House to the 
Discharge of committee.

Resolution, consideration and debate.

appropriate committee or committees of the House. Any such resolution received from the Senate shall be held at the Speaker's table.

(3) Upon the expiration of 60 days of continuous session after the introduction of the first resolution of repository siting approval with respect to any site, each committee to which such resolution was referred shall be discharged from further consideration of such resolution, and such resolution shall be referred to the appropriate calendar, unless such resolution or an identical resolution was previously reported by each committee to which it was referred.

(4) It shall be in order for the Speaker to recognize a Member favoring a resolution to call up a resolution of repository siting approval after it has been on the appropriate calendar for 5 legislative days. When any such resolution is called up, the House shall proceed to its immediate consideration and the Speaker shall recognize the Member calling up such resolution and a Member opposed to such resolution for 2 hours of debate in the House, to be equally divided and controlled by such Members. When such time has expired, the previous question shall be considered as ordered on the resolution to adoption without intervening motion. No amendment to any such resolution shall be in order, nor shall it be in order to move to reconsider the vote by which such resolution is agreed to or disagreed to.

(5) If the House receives from the Senate a resolution of repository siting approval with respect to any site, then the following procedure shall apply:

(A) The resolution of the Senate with respect to such site shall not be referred to a committee.

(B) With respect to the resolution of the House with respect to such site-

(i) the procedure with respect to that or other resolutions of the House with respect to such site shall be the same as if no resolution from the Senate with respect to such site had been received; but

(ii) on any vote on final passage of a resolution of the House with respect to such site, a resolution from the Senate with respect to such site where the text is identical shall be automatically substituted for the resolution of the House.

(f) Computation Of Days.-For purposes of this section-

(1) continuity of session of Congress is broken only by an adjournment sine die; and

(2) the days on which either House is not in session because of an adjournment of more than 3 days to a day certain are excluded in the computation of the 90-day period referred to in subsection (c) and the 60-day period referred to in subsections (d) and (e).

(g) Information Provided To Congress. - In considering any notice of disapproval submitted to the Congress under section 116 or 118, the Congress may obtain any comments of the Commission with respect to such notice of disapproval. The provision of such comments by the Commission shall not be construed as binding the Commission with respect 
to any licensing or authorization action concerning the repository involved.

\section{PARTICIPATION OF STATES}

42 USC 10136

Sec. 116. (a) Notification Of States And Affected Tribes. - The Secretary shall identify the States with one or more potentially acceptable sites for a repository within 90.days after the date of enactment of this Act. Within 90 days of such identification, the Secretary shall notify the Governor, the State legislature, and the tribal council of any affected

Potentially acceptable site.

Notice of disapproval, submittal to Congress.

Grants. Indian tribe in any State of the potentially acceptable sites within such State. For the purposes of this title, the term "potentially acceptable site" means any site at which, after geologic studies and field mapping but before detailed geologic data gathering, the Department undertakes preliminary drilling and geophysical testing for the definition of site location.

(b) State Participation In Repository Siting Decisions. - (1) Unless otherwise provided by State law, the Governor or legislature of each State shall have authority to submit a notice of disapproval to the Congress under paragraph (2). In any case in which State law provides for submission of any such notice of disapproval by any other person or entity, any reference in this subtitle to the Governor or legislature of such State shall be considered to refer instead to such other person or entity.

(2) Upon the submission by the President to the Congress of a recommendation of a site for a repository, the Governor or legislature of the State in which such site is located may disapprove the site designation and submit to the Congress a notice of disapproval. Such Governor or legislature may submit such a notice of disapproval to the Congress not later than the 60 days after the date that the President recommends such site to the Congress under section 114. A notice of disapproval shall be considered to be submitted to the Congress on the date of the transmittal of such notice of disapproval to the Speaker of the House and the President pro tempore of the Senate. Such notice of disapproval shall be accompanied by a statement of reasons explaining why such Governor or legislature disapproved the recommended repository site involved.

(3) The authority of the Governor or legislature of each State under this subsection shall not be applicable with respect to any site located on a reservation.

(c) Financial Assistance.-(1)(A) The Secretary shall make grants to the State of Nevada and any affected unit of local government for the purpose of participating in activities required by this section and section 117 or authorized by written agreement entered into pursuant to section 117(c). Any salary or travel expense that would ordinarily be incurred by such State or affected unit of local government, may not be considered eligible for funding under this paragraph.

(B) The Secretary shall make grants to the State of Nevada and any affected unit of local government for purposes of enabling such State or affected unit of local government-

(i) to review activities taken under this subtitle with respect to the Yucca Mountain site for purposes of deter- 
mining any potential economic, social, public health and safety, and environmental impacts of a repository on such State, or affected unit of local government and its residents;

(ii) to develop a request for impact assistance under paragraph (2);

(iii) to engage in any monitoring, test, or evaluation activities with respect to site characterization programs with regard to such site;

(iv) to provide information to Nevada residents regarding any activities of such State, the Secretary, or the Commission with respect to such site; and

(v) to request information from, and make comments and recommendations to, the Secretary regarding any activities taken under this subtitle with respect to such site.

(C) Any salary or travel expense that would ordinarily be incurred by the State of Nevada or any affected unit of local government may not be considered eligible for funding under this paragraph.

(2)(A)(i) The Secretary shall provide financial and technical assistance to the State of Nevada, and any affected unit of local government requesting such assistance.

(ii) Such assistance shall be designed to mitigate the impact on such State or affected unit of local government of the development of such repository and the characterization of such site.

(iii) Such assistance to such State or affected unit of local government of such State shall commence upon the initiation of site characterization activities.

(B) The State of Nevada and any affected unit of local government may request assistance under this subsection by preparing and submitting to the Secretary a report on the economic, social, public health and safety, and environmental impacts that are likely to result from site characterization activities at the Yucca Mountain site. Such report shall be submitted to the Secretary after the Secretary has submitted to the State a general plan for site characterization activities under section 113(b).

(C) As soon as practicable after the Secretary has submitted such site characterization plan, the Secretary shall seek to enter into a binding agreement with the State of Nevada setting forth-

(i) the amount of assistance to be provided under this subsection to such State or affected unit of local government; and

(ii) the procedures to be followed in providing such assistance.

(3)(A) In addition to financial assistance provided under paragraphs (1) and (2), the Secretary shall grant to the State of Nevada and any affected unit of local government an amount each fiscal year equal to the amount such State or affected unit of local gov- 
ernment, respectively, would receive if authorized to tax site characterization activities at such site, and the development and operation of such repository, as such State or affected unit of local government taxes the non-Federal real property and industrial activities occurring within such State or affected unit of local government.

(B) Such grants shall continue until such time as all such activities, development, and operation are terminated at each such site.

(4)(A) The State of Nevada or any affected unit of local government may not receive any grant under paragraph (1) after the expiration of the 1 year period following-

(i) the date on which the Secretary notifies the Governor and legislature of the State of Nevada of the termination of site characterization activities at the site in such State;

(ii) the date on which the Yucca Mountain site is disapproved under section 115; or

(iii) the date on which the Commission disapproves an application for a construction authorization for a repository at such site; whichever occurs first.

(B) The State of Nevada or any affected unit of local government may not receive any further assistance under paragraph (2) with respect to a site if repository construction activities or site characterization activities at such site are terminated by the Secretary or if such activities are permanently enjoined by any court.

(C) At the end of the 2-year period beginning on the effective date of any license to receive and possess for a repository in a State, no Federal funds, shall be made available to such State or affected unit of local government under paragraph (1) or (2), except for-

(i) such funds as may be necessary to support activities related to any other repository located in, or proposed to be located in, such State, and for which a license to receive and possess has not been in effect for more than 1 year;

(ii) such funds as may be necessary to support State activities pursuant to agreements or contracts for impact assistance entered into, under paragraph (2), by such State with the Secretary during such 2-year period; and

(iii) such funds as may be provided under an agreement entered into under title $\mathrm{IV}$.

(5) Financial assistance authorized in this subsection shall be made out of amounts held in the Waste Fund.

(6) No State, other than the State of Nevada, may receive financial assistance under this subsection after the date of the enactment of the Nuclear Waste Policy Amendments Act 1987.5

(d) Additional Notification And Consultation.-Whenever the Secretary is required under any provision of this Act to notify or consult with the governing body of an affected Indian tribe where a site is located, the

SPublic Law 100-203 (101 Stat. 1330) (1987) Sec. 5032, amended Sec. 116(c). 
Secretary shall also notify or consult with, as the case may be, the Governor of the State in which such reservation is located.

\section{CONSULTATION WITH STATES AND AFFECTED INDIAN TRIBES}

42 USC 10137. Sec. 117. (a) Provision Of Information. - (1) The Secretary, the Commission, and other agencies involved in the construction, operation, or regulation of any aspect of a repository in a State shall provide to the Governor and legislature of such State, and to the governing body of any affected Indian tribe, timely and complete information regarding determinations or plans made with respect to the site characterization siting, development, design, licensing, construction, operation, regulation, or decommissioning of such repository.

Information request, response.

(2) Upon written request for such information by the Governor or legislature of such State, or by the governing body of any affected Indian tribe, as the case may be, the Secretary shall provide a written response to such request within 30 days of the receipt of such request. Such response shall provide the information requested or, in the alternative, the reasons why the information cannot be so provided. If the Secretary fails to so respond within such 30 days, the Governor or legislature of such State, or the governing body of any affected Indian tribe, as the case may be, may transmit a formal written objection to such failure to respond to the President. If the President or Secretary fails to respond to such written request within 30 days of the receipt by the President of such formal written objection, the Secretary shall immediately suspend all activities in such State authorized by this subtitle, and shall not renew such activities until the Governor or legislature of such State, or the governing body of any affected Indian tribe, as the case may be, has received the written response to such written request required by this subsection.

(b) Consultation And Cooperation.-In performing any study of an area within a State for the purpose of determining the suitability of such area for a repository pursuant to section 112(c), and in subsequently developing and loading any repository within such State, the Secretary shall consult and cooperate with the Governor and legislature of such State and the governing body of any affected Indian tribe in an effort to resolve the concerns of such State and any affected Indian tribe regarding the public health and safety, environmental, and economic impacts of any such repository. In carrying out his duties under this subtitle, the Secretary shall take such concerns into account to the maximum extent feasible and as specified in written agreements entered into under subsection (c).

(c) Written Agreement.-Not later than 60 days after (1) the approval of a site for site characterization for such a repository under section 112 (c), or (2) the written request of the State or Indian tribe in any affected State notified under section 116(a) to the Secretary, whichever, first occurs, the Secretary shall seek to enter into a binding written agreement, and shall begin negotiations, with such State and, where appropriate, to enter into a separate binding agreement with the governing body of any affected Indian tribe, setting forth (but not limited to) the procedures under which the requirements of subsections (a) and (b), and 
Report to

Congress.

Report, review and comments.
Transportation of radioactive waste and spent nuclear fuel, State notification. the provisions of such written agreement, shall be carried out. Any such written agreement shall not affect the authority of the Commission under existing law. Each such written agreement shall, to the maximum extent feasible, to completed no later than 6 months after such notification. If such written agreement is not completed within such period, the Secretary shall report to the Congress in writing within 30 days on the status of negotiation to develop such agreement and the reasons why such agreement has not been completed. Prior to submission of such report to the Congress, the Secretary shall transmit such report to the Governor of such State or the governing body of such affected Indian tribe, as the case may be, for their review and comments. Such comments shall be included in such report prior to submission to the Congress. Such written agreement shall specify procedures-

(1) by which such State or governing body of an affected Indian tribe, as the case may be, may study, determine, comment on, and make recommendations with regard to the possible public health and safety, environmental, social, and economic impacts of any such repository;

(2) by which the Secretary shall consider and respond to comments and recommendations made by such State or governing body of an affected Indian tribe, including the period in which the Secretary shall so respond;

(3) by which the Secretary and such State or governing body of an affected Indian tribe may review or modify the agreement periodically;

(4) by which such State or governing body of an affected Indian tribe is to submit an impact report and request for impact assistance under section $116(\mathrm{c})$ or section $118(\mathrm{~b})$, as the case may be;

(5) by which the Secretary shall assist such State, and the units of general local government in the vicinity of the repository site, in resolving the offsite concerns of such State and units of general local government, including, but not limited to, questions of State liability arising from accidents, necessary road upgrading and access to the site, ongoing emergency preparedness and emergency response, monitoring of transportation of high-level radioactive waste and spent nuclear fuel through such State, conduct of baseline health studies of inhabitants in neighboring communities near the repository site and reasonable periodic monitoring thereafter, and monitoring of the repository site upon any decommissioning and decontamination;

(6) by which the Secretary shall consult and cooperate with such State on a regular, ongoing basis and provide for an orderly process and timely schedule for State review and evaluation, including identification in the agreement of key events, milestones, and decision points in the activities of the Secretary at the potential repository site;

(7) by which the Secretary shall notify such State prior to the transportation of any high-level radioactive waste and spent nuclear fuel into such State for disposal at the repository site;

(8) by which such State may conduct reasonable independent monitoring and testing of activities on the repository site, except 
Monitoring and testing.

Notice of disapproval, submittal to Congress. 42 USC 10138.

Grants. that such monitoring and testing shall not unreasonably interfere with or delay onsite activities;

(9) for sharing, in accordance with applicable law, of all technical and licensing information, the utilization of available expertise, the facilitating of permit procedures, joint project review, and the formation of joint surveillance and monitoring arrangements to carry out applicable Federal and State laws;

(10) for public notification of the procedures specified under the preceding paragraphs; and

(11) for resolving objections of a State and affected Indian tribes at any stage of the planning, siting, development, construction, operation, or closure of such a facility within such State through negotiation, arbitration, or other appropriate mechanisms.

(d) On-site Representative. - The Secretary shall offer to any State, Indian tribe or unit of local government within whose jurisdiction a site for a repository or monitored retrievable storage facility is located under this title an opportunity to designate a representative to conduct on-site oversight activities at such site. Reasonable expenses of such representatives shall be paid out of the Waste Fund. 6

\section{PARTICIPATION OF INDIAN TRIBES}

Sec. 118. (a) Participation Of Indian Tribes In Repository Siting Decisions.-Upon the submission by the President to the Congress of a recommendation of a site for a repository located on the reservation of an affected Indian tribe, the governing body of such Indian tribe may disapprove the site designation and submit to the Congress a notice of disapproval. The governing body of such Indian tribe may submit such a notice of disapproval to the Congress not later than the 60 days after the date that the President recommends such site to the Congress under section 114. A notice of disapproval shall be considered to be submitted to the Congress on the date of the transmittal of such notice of disapproval to the Speaker of the House and the President pro tempore of the Senate. Such notice of disapproval shall be accompanied by a statement of reasons explaining why the governing body of such Indian tribe disapproved the recommended repository site involved.

(b) Financial Assistance.-(1) The Secretary shall make grants to each affected tribe notified under section 116(a) for the purpose of participating in activities required by section 117 or authorized by written agreement entered into pursuant to section 117(c). Any salary or travel expense that would ordinarily be incurred by such tribe, may not be considered eligible for funding under this paragraph.

(2) (A) The Secretary shall make grants to each affected Indian tribe where a candidate site for a repository is approved under section 112(c). Such grants may be made to each such Indian tribe only for purposes of enabling such Indian tribe-

(i) to review activities taken under this subtitle with respect to such site for purposes of determining any potential economic, social, public health and safety, and environmental impacts of such repository on the reservation and its residents;

6Public Law 100-203 (101 Stat. 1330) (1987) Sec. 5011, added Sec. 117 (d). 
Report submittal.

(ii) to develop a request for impact assistance under paragraph (2);

(iii) to engage in any monitoring, testing, or evaluation activities with respect to site characterization programs with regard to such site;

(iv) to provide information to the residents of its reservation regarding any activities of such Indian tribe, the Secretary, or the Commission with respect to such site; and

(v) to request information from, and make comments and recommendations to, the Secretary regarding any activities taken under this subtitle with respect to such site. (B) The amount of funds provided to any affected Indian tribe under this paragraph in any fiscal year may not exceed 100 percent of the costs incurred by such Indian tribe with respect to the activities described in clauses (i) through (v) of subparagraph (A). Any salary or travel expense that would ordinarily be incurred by such Indian tribe may not be considered eligible for funding under this paragraph.

(3) (A) The Secretary shall provide financial and technical assistance to any affected Indian tribe requesting such assistance and where there is a site with respect to which the Commission has authorized construction of a repository. Such assistance shall be designed to miligate the impact on such Indian tribe of the development of such repository. Such assistance to such Indian tribe shall commence within 6 months following the granting by the Commission of a construction authorization for such repository and following the initiation of construction activities at such site.

(B) Any affected Indian tribe desiring assistance under this paragraph shall prepare and submit to the Secretary a report on any economic, social, public health and safety, and environmental impacts that are likely as a result of the development of a repository at a site on the reservation of such Indian tribe. Such report shall be submitted to the Secretary following the completion of site characterization activities at such site and before the recommendation of such site to the President by the Secretary for application for a construction authorization for a repository. As soon as practicable following the granting of a construction authorization for such repository, the Secretary shall seek to enter into a binding agreement with the Indian tribe involved setting forth the amount of assistance to be provided to such Indian tribe under this paragraph and the procedures to be followed in providing such assistance.

(4) The Secretary shall grant to each affected Indian tribe wherea site for a repository is approved under section 112(c) an amount each fiscal year equal to the amount such Indian tribe would receive were it authorized to tax site characterization activities at such site, and the development and operation of such repository, as such Indian tribe taxes the other commercial activities occurring on such reservation. Such grants shall continue until such time as all such activities, development, and operation are terminated at such site. 
Grants, limitation.

Funding.

Post, p. 2257.

42 USC 10139

(5) An affected Indian tribe may not receive any grant under paragraph (1) after the expiration of the 1-year period following(i) the date on which the Secretary notifies such Indian tribe of the termination of site characterization activities at the candidate site involved on the reservation of such Indian tribe;

(ii) the date on which such site is disapproved under section 115;

(iii) the date on which the Commission disapproves an application for a construction authorization for a repository at such site;

(iv) the date of the enactment of the Nuclear Waste Policy Amendments Acts of 1987;

whichever occurs first, unless there is another candidate site on the reservation of such Indian tribe that is approved under section 112(c) and with respect to which the actions described in clauses (i), (ii), and (iii) have not been taken.

(B) An affected Indian tribe may not receive any further assistance under paragraph (2) with respect to a site if repository construction activities at such site are terminated by the Secretary or if such activities are permanently enjoined by any court.

(C) At the end of the 2-year period beginning on the effective date of any license to receive and possess for a repository at a site on the reservation of an affected Indian tribe, no Federal funds shall be made available under paragraph (1) or (2) to such Indian tribe, except for-

(i) such funds as may be necessary to support activities of such Indian tribe related to any other repository where a license to receive and possess has not been in effect for more than 1 year; and

(ii) such funds as may be necessary to support activities of such Indian tribe pursuant to agreements or contracts for impact assistance entered into, under paragraph (2), by such Indian tribe with the Secretary during such 2-year period.

(6) Financial assistance authorized in this subsection shall be made out of amounts held in the Nuclear Waste Fund established in section 302.

\section{JUDICIAL REVIEW OF AGENCY ACTIONS}

Sec. 119. (a) Jurisdiction Of United States Courts Of Appeals.-(1) Except for review in the Supreme Court of the United States courts of appeals shall have original and exclusive jurisdiction over any civil action-

(A) for review of any final decision or action of the Secretary, the President, or the Commission under this subtitle;

(B) alleging the failure of the Secretary, the President, or the Commission to make any decision, or take any action, required under this subtitle;

${ }^{7}$ Public Law 100-203 (101 Stat. 1330) (1987) Sec. 5033, amended Sec. 118(b)(5)(ii) and (iv). 
Post, p. 2245.

42 USC 10140.

42 USC 10141.
(C) challenging the constitutionality of any decision made, or action taken, under any provision of this subtitle;

(D) for review of any environmental impact statement prepared pursuant to the National Environmental Policy Act of 1969 (42 U.S.C. 4321 et seq.) with respect to any action under this subtitle, or as required under section 135(c) (1), or alleging a failure to prepare such statement with respect to any such action;

(E) for review of any environmental assessment prepared under section 112(b) (1) or 135(c) (2); or

(F) for review of any research and development activity under title II.

(2) The venue of any proceeding under this section shall be in the judicial circuit in which the petitioner involved resided or has its principle office, or in the United States Court of Appeals for the District of Columbia.

(c) Deadline For Commencing Action.-A civil action for judicial review described under subsection (a)(1) may be brought not later than the 180 th day after the date of the decision or action or failure to act involved, as the case may be, except that if a party shows that he did not know of the decision or action complained of (or of the failure to act), and that a reasonable person acting under the circumstances would not have known, such party may bring a civil action not later than the 180th day after the date such party acquired actual or constructive knowledge of such decision, action, or failure to act.

\section{EXPEDITED AUTHORIZATIONS}

Sec. 120. (a) Issuance Of Authorization.-(1) To the extent that the taking of any action related to the site characterization of a site or the construction or initial operation of a repository under this subtitle requires a certificate, right-of-way, permit, lease, or other authorization from a Federal agency or officer, such agency or officer shall issue or grant any such authorization at the earliest practicable date, to the extent permitted by the applicable provisions of law administered by such agency or officer. All actions of a Federal agency or officer with respect to consideration of applications or requests for the issuance or grant of any such authorization shall be expedited, and any such application or request shall take precedence over any similar applications or requests not related to such repositories.

(2) The provisions of paragraph (1) shall not apply to any certificate, right-of-way, permit, lease, or other authorization issued or granted by, or requested from, the Commission.

(b) Terms Of Authorizations.-Any authorization issued or granted pursuant to subsection (a) shall include such terms and conditions as may be required by law, and may include terms and conditions permitted by law.

\section{CERTAIN STANDARDS AND CRITERIA}

Sec. 121. (a) Environmental Protection Agency Standards. - Not later than 1 year after the date of the enactment of this Act, the Administrator, pursuant to authority under other provisions of law, shall, by rule, promulgate generally applicable standards for protection of the general 
environment from offsite releases from radioactive material in repositories.

(b) Commission Requirements And Criteria.-(1) (A) Not later than January 1, 1984, the Commission, pursuant to authority under other provisions of law, shall, by rule promulgate technical requirements and criteria that it will apply, under the Atomic Energy Act of 1954 (42 U.S.C. 2011 et seq.) and the Energy Reorganization Act of 1974 (42 U.S.C. 5801 et seq.), in approving or disapproving.-

(i) applications for authorization to construct repositories;

(ii) applications for licenses to receive and possess spent nuclear fuel and high-level radioactive waste in such repositories; and

(iii) applications for authorization for closure and decommissioning of such repositories.

(B) Such criteria shall provide for the use of a system of multiple barriers in the design of the repository and shall include such restrictions on the retrievability of the solidified high-level radioactive waste and spent fuel emplaced in the repository as the Commission deems appropriate.

(C) Such requirements and criteria shall not be inconsistent with any comparable standards promulgated by the Administrator under subsection (a).*

(2) For purposes of this Act, nothing in this section shall be constructed to prohibit the Commission from promulgating requirements and criteria under paragraph (1) before the Administrator promulgates standards under subsection (a). If the Administrator promulgates standards under subsection (a) after requirements and criteria are promulgated by the Commission under paragraph (1), such requirements and criteria shall be revised by the Commission if necessary to comply with paragraph (1) (C).

(c) Environmental Impact Statements.-The promulgation of standards or criteria in accordance with the provisions of this section shall not require the preparation of an environmental impact statement under section 102(2)(C) of the National Environmental Policy Act of 1969 (42 U.S.C. 4332(2)(C)), or to require any environmental review under subparagraph (E) or (F) of section 102(2) of such Act.

42 USC 10142.

DISPOSAL OF SPENT NUCLEAR FUEL

Sec. 122. Notwithstanding any other provision of this subtitle, any repository constructed on a site approved under this subtitle shall be designed and constructed to permit the retrieval of any spent nuclear fuel placed in such repository, during an appropriate period of operation of the facility, for any reason pertaining to the public health and safety, or the environment, or for the purpose of permitting the recovery of the economically valuable contents of such spent fuel. The Secretary shall specify the appropriate period of retrievability with respect to any repository at the time of design of such repository, and such aspect of such repository shall be subject to approval or disapproval by the Commission

-See Public Law 102-486 (106Stat. 2922); Sec. 801(b) for Nuclear Regulatory Commission Requirements and Criteria. 
as part of the construction authorization process under subsections(b) through (d) of section 114 .

TITLE TO MATERIAL

42 USC 10143. Sec. 123. Delivery, and acceptance by the Secretary, of any high-level radioactive waste or spent nuclear fuel for a repository constructed under this subtitle shall constitute a transfer to the Secretary of title to such waste or spent fuel.

CONSIDERATION OF EFFECT OF ACQUISITION OF WATER RIGHTS

42 USC 10144. Sec. 124. The Secretary shall give full consideration to whether the development, construction, and operation of a repository may require any purchase or other acquisition of water rights that will have a significant adverse effect on the present or future development of the area in which such repository is located. The Secretary shall mitigate any such adverse effects to the maximum extent practicable.

TERMINATION OF CERTAIN PROVISIONS

42 USC 10145. Sec.125. Sections 119 and 120 shall cease to have effect at such time as a repository developed under this subtitle is licensed to receive and possess high-level radioactive waste and spent nuclear fuel.

\section{SUBTITLE B-INTERIM STORAGE PROGRAM}

\section{FINDINGS AND PURPOSES}

42 USC 10151.

Sec. 131. (a) Findings. - The congress finds that-

(1) the persons owning and operating civilian nuclear power reactors have the primary responsibility for providing interim storage of spent nuclear fuel from such reactors by maximizing, to the extent practical, the effective use of existing storage facilities at the site of each civilian nuclear power reactor, and by adding new onsite storage capacity in a timely manner where practical;

(2) the Federal Government has the responsibility to encourage and expedite the effective use of existing storage facilities and the addition of needed new storage capacity at the site of each civilian nuclear power reactor; and

(3) the Federal Government has the responsibility to provide, in accordance with the provisions of this subtitle, not more than 1,900 metric tons of capacity for interim storage of spent nuclear fuel for civilian nuclear power reactors that cannot reasonably provide adequate storage capacity at the sites of such reactors when needed to assure the continued, orderly operation of such reactors.

(b) Purposes. - The purposes of this subtitle are-

(1) to provide for the utilization of available spent nuclear fuel pools at the site of each civilian nuclear power reactor to the extent practical and the addition of new spent nuclear fuel storage capacity where practical at the site of such reactor; and

(2) to provide, in accordance with the provisions of this subtitle, for the establishment of a federally owned and operated system for the interim storage of spent nuclear fuel at one or more facilities owned by the Federal Government with not more than 1,900 metric tons of capacity to prevent disruptions in the orderly operation of any civilian nuclear power reactor that cannot reasonably provide adequate spent nuclear fuel storage capacity at the site of such reactor when needed. 
42 USC 10152.

AVAILABLE CAPACITY FOR INTERIM STORAGE OF SPENT NUCLEAR FUEL

Sec. 132. The Secretary, the Commission, and other authorized Federal officials shall each take such actions as such official considers necessary to encourage and expedite the effective use of available storage and necessary additional storage, at the site of each civilian nuclear power reactor consistent with-

(1) the protection of the public health and safety, and the environment;

(2) economic considerations;

(3) continued operation of such reactor;

(4) any applicable provisions of law; and

(5) the views of the population surrounding such reactor.

\section{INTERIM AT REACTOR STORAGE}

Licensing procedures. 42 USC 10153.

42 USC 10154.

Summary submittal of facts, data and arguments.

Sec. 133. The Commission shall, by rule, establish procedures for the licensing of any technology approved by the Commission under section 219 (a) for use at the site of any civilian nuclear power reactor. The establishment of such procedures shall not preclude the licensing, under any applicable procedures or rules of the Commission in effect prior to such establishments, of any technology for the storage of civilian spent nuclear fuel at the site of any civilian nuclear power reactor.

\section{LICENSING OF FACILITY EXPANSIONS AND TRANSSHIPMENTS}

Sec. 134. (a) Oral Argument. - In any Commission hearing under section 189 of the Atomic Energy Act of 1954 (42 U.S.C. 2239) on an application for a license, or for an amendment to an existing license, filed after the date of the enactment of this Act, to expand the spent nuclear fuel storage capacity at the site of a civilian nuclear power reactor, through the use of high-density fuel storage racks, fuel rod compaction, the transshipment of spent nuclear fuel to another civilian nuclear power reactor within the same utility system, the construction of additional spent nuclear fuel pool capacity or dry storage capacity, or by other means, the Commission shall, at the request of any party, provide an opportunity for oral argument with respect to any matter which the Commission determines to be in controversy among the parties. The oral arguments shall preceded by such discovery procedures as the rules of the Commission shall provide. The Commission shall require each party, including the Commission staff, to submit in written form, at the time of the oral argument, a summary of the facts, data, and arguments upon which such party proposes to rely that are known at such time to such party. Only facts and data in the form of sworn testimony or written submission may be relied upon by the parties during oral arguments. Of the material that may be submitted by the parties during oral arguments, the Commission shall only consider those facts and data that are submitted in the form of sworn testimony or written submission.

(b) Adjudicatory Hearing. - (1) At the conclusion of any oral argument under subsection (a), the Commission shall designate any disputed questions of fact, together with any remaining questions of law, for resolution in an adjudicatory hearing only if it determines that-

(A) there is a genuine and substantial dispute of fact which can only be resolved with sufficient accuracy by the introduction of evidence in an adjudicatory hearing; and 
(B) the decision of the Commission is likely to depend in whole or in part on the resolution of such dispute.

(2) In making a determination under this subsection, the Commission-

(A) shall designate in writing the specific facts that are in genuine and substantial dispute, the reason why the decision of the agency is likely to depend on the resolution of such facts, and the reason why an adjudicatory hearing is likely to resolve the dispute; and

(B) shall not consider-

(i) any issue relating to the design, construction, or operation of any civilian nuclear power reactor already licensed to operate at such site, or any civilian nuclear power reactor for which a construction permit has been granted at such site, unless the Commission determines that any such issue substantially affects the design, construction, or operation of the facility or activity for which such license application, authorization, or amendment is being considered; or

(ii) any siting or design issue fully considered and decided by the Commission in connection with the issuance of a construction permit or operating license for a civilian nuclear power reactor at such site, unless (I) such issue results from any revision of siting or design criteria by the Commission following such decision; and (II) the Commission determines that such issue substantially affects the design, construction, or operation of the facility or activity for which such license application, authorization, or amendment is being considered.

(3) The provisions of paragraph (2)(B) shall apply only with respect to licenses, authorizations, or amendments to licenses or authorizations, applied for under the Atomic Energy Act of 1954 (42 U.S.C. 2011 et seq.) before December 31, 2005.

(4) The provisions of this section shall not apply to the first application for a license or license amendment received by the Commission to expand onsite spent fuel storage capacity by the use of a new technology not previously approved for use at any nuclear power plant by the Commission.

(c) Judicial Review.-No court shall hold unlawful or set aside a decision of the Commission in any proceeding described in subsection (a) because of a failure by the Commission to use a particular procedure pursuant to this section unless-

(1) an objection to the procedure used was presented to the Commission in a timely fashion or there are extraordinary circumstances that excuse the failure to present a timely objection; and

(2) the court finds that such failure has precluded a fair consideration and informed resolution of a significant issue of the proceeding taken as a whole.

STORAGE OF SPENT NUCLEAR FUEL

42 USC 10155. Sec. 135 (a) Storage Capacity. -(1) Subject to section 8, the Secretary 
shall provide, in accordance with paragraph (5), not more than 1,900 metric tons of capacity for the storage of spent nuclear fuel from civilian nuclear power reactors. Such storage capacity shall be provided through any one or more of the following methods, used in any combination determined by the Secretary to be appropriate:

(A) use of available capacity at one or more facilities owned by the Federal Government on the date of the enactment of this Act, including the modification and expansion of any such facilities, if the Commission determines that such use will adequately protect the public health and safety, except that such use shall not-

(i) render such facilities subject to licensing under the Atomic Energy Act of 1954 (42 U.S.C. 2011 et seq.) or the Energy Reorganization Act of 1974 (42 U.S.C. 5801 et. seq.); or

(ii) except as provided in subsection (c) require the preparation of an environmental impact statement under section 102(2)(C) of the National Environmental Policy Act of 1969 (42 U.S.C. 4332(2)(C)), such facility is already being used, or has previously been used, for such storage or for any similar purpose.

(B) acquisition of any modular or mobile spent nuclear fuel storage equipment, including spent nuclear fuel storage casks, and provision of such equipment, to any person generating or holding title to spent nuclear fuel, at the site of any civilian nuclear power reactor operated by such person or at any site owned by the Federal Government on the date of enactment of this Act;

(C) construction of storage capacity at any site of a civilian nuclear power reactor.

(2) Storage capacity authorized by paragraph (1) shall not be provided at any Federal or non-Federal site within which there is a candidate site for a repository. The restriction in the preceding sentence shall only apply until such time as the Secretary decides that such candidate site is no longer a candidate site under consideration for development as a repository.

(3) In selecting methods of providing storage capacity under paragraph (1), the Secretary shall consider the timeliness of the availability of each such method and shall seek to minimize the transportation of spent nuclear fuel, the public health and safety impacts, and the costs of providing such storage capacity.

(4) In providing storage capacity through any method described in paragraph (1), the Secretary shall comply with any applicable requirements for licensing or authorization of such method, except as provided in paragraph (1) (A) (i).

(5) The Secretary shall ensure that storage capacity is made available under paragraph (1) when needed, as determined on the basis of the storage needs specified in contracts entered into under section 136(a), and shall accept upon request any spent nuclear fuel as covered under such contracts. 
(b) Contracts.-(1) Subject to the capacity limitation established in subsections (a) (1) and (d), the Secretary shall offer to enter into, and may enter into contracts under section 136(a) with any person generating or owning spent nuclear fuel for purposes of providing storage capacity for such spent fuel under this section only if the Commission determines that-

(A) adequate storage capacity to ensure the continued orderly operation of the civilian nuclear power reactor at which such spent nuclear fuel is generated cannot reasonably be provided by the person owning and operating such reactor at such site, or at the site, of any other civilian nuclear power reactor operated by such person, and such capacity cannot be made available in a timely manner through any method described in subparagraph (B); and

(B) such person is diligently pursuing licensed alternatives to the use of Federal storage capacity for the storage of spent nuclear fuel expected to be generated by such person in the future, including-

(i) expansion of storage facilities at the site of any civilian nuclear power reactor operated by such person;

(ii) construction of new or additional storage facilities at the site of any civilian nuclear power reactor operated by such person;

(iii) acquisition of modular or mobile spent nuclear fuel storage equipment, including spent nuclear fuel storage casks, for use at the site of any civilian nuclear power reactor operated by such person; and

(iv) transshipment to another civilian nuclear power reactor owned by such person.

(2) In making the determination described in paragraph (1) (A), the Commission shall ensure maintenance of a full core reserve storage capability at the site of the civilian nuclear power reactor involved unless the Commission determines that maintenance of such capability is not necessary for the continued orderly operation of such reactor.

(3) The Commission shall complete the determinations required in paragraph (1) with respect to any request for storage capacity not later than 6 months after receipt of such request by the Commission.

(c) Environmental Review.-(1) The provision of 300 or more metric tons of storage capacity at any one Federal site under subsection (a)(1)(A) shall be considered to be a major Federal action requiring preparation of an environmental impact statement under section 102(2)(C) of the National Environmental Policy Act of 1969 (42 U.S.C. $4332(2)(\mathrm{C}))$.

Public availability.
(2) (A) The Secretary shall prepare, and make available to the public, an environmental assessment of the probable impacts of any provision of less than 300 metric tons of storage capacity at any one Federal site under subsection (a)(1)(A) that requires the modi- 
Judicial review.

5 USC 701 et. seq.

Investigation. fication or expansion of any facility at the site, and a discussion of alternative activities that may be undertaken to avoid such impacts. Such environmental assessment shall include-

(i) an estimate of the amount of storage capacity to be made available at such site;

(ii) an evaluation as to whether the facilities to be used at such site are suitable for the provision of such storage capacity;

(iii) a description of activities planned by the Secretary with respect to the modification or expansion of the facilities to be used at such site;

(iv) an evaluation of the effects of the provision of such storage capacity at such site on the public health and safety, and the environment;

(v) a reasonable comparative evaluation of current information with respect to such site and facilities and other sites and facilities available for the provision of such storage capacity;

(vi) a description of any other sites and facilities that have been considered by the Secretary for the provision of such storage capacity; and

(vii) an assessment of the regional and local impacts of providing such storage capacity at such site, including the impacts on transportation.

(B) The issuance of any environmental assessment under this paragraph shall be considered to be final agency action subject to judicial review in accordance with the provisions of chapter 7 of title 5, United States Code. Such judicial review shall be limited to the sufficiency of such assessment with respect to the items described in clauses (i) through (vii) of subparagraph (A).

(3) Judicial review of any environmental impact statement or environmental assessment prepared pursuant to this subsection shall be conducted in accordance with the provisions of section 119.

(d) Review Of Sites And State Participation.-(1) In carrying out the provisions of this subtitle with regard to any interim storage of spent fuel from civilian nuclear power reactors which the Secretary is authorized by section 135 to provide, the Secretary shall, as soon as practicable, notify, in writing, the Governor and the State legislature of any State and the Tribal Council of any affected Indian tribe in such State in which is located a potentially acceptable site or facility for such interim storage of spent fuel of his intention to investigate that site or facility.

(2) During the course of investigation of such site or facility, the Secretary shall keep the Governor, State legislature, and affected Tribal Council currently informed of the progress of the work, and results of the investigation. At the time of selection by the Secretary of any site or existing facility, but prior to undertaking any sitespecific work or alterations, the Secretary shall promptly notify the Governor, the legislature, and any affected Tribal Council in writing of such selection and subject to the provisions of paragraph (6) of this subsection, shall promptly enter into negotiations with such State and affected Tribal Council to establish a cooperative agree- 
Guidelines.

Cooperative agreement.

"Process of consultation and cooperation."

Report to Congress. ment under which such State and Council shall have the right to participate in a process of consultation and cooperation, based on public health and safety and environmental concerns, in all stages of the planning, development, modification, expansion, operation, and closure of storage capacity at a site or facility within such State for the interim storage of spent fuel from civilian nuclear power reactors. Public participation in the negotiation of such an agreement shall be provided for and encouraged by the Secretary, the State, and the affected Tribal Council. The Secretary, in cooperation with the State and Indian tribes, shall develop and publish minimum guidelines for public participation in such negotiations, but the adequacy of such guidelines or any failure to comply with such guidelines shall not be a basis for judicial review.

(3) The cooperative agreement shall include, but need not be limited to, the sharing in accordance with applicable law of all technical and licensing information, the utilization of available expertise, the facilitating of permitting procedures, joint project review, and the formulation of joint surveillance and monitoring arrangements to carry out applicable Federal and State laws. The cooperative agreement also shall include a detailed plan or schedule of milestones, decision points and opportunities for State or eligible Tribal Council review and objection. Such cooperative agreement shall provide procedures for negotiating and resolving objections of the State and affected Tribal Council in any stage of planning, development, modification, expansion, operation, or closure of storage capacity at a site or facility within such State. The terms of any cooperative agreement shall not affect the authority of the Nuclear Regulatory Commission under existing law.

(4) For the purpose of this subsection, "process of consultation and cooperation" means a methodology by which the Secretary $(A)$ keeps the State and eligible Tribal Council fully and currently informed about the aspects of the project related to any potential impact on the public health and safety and environment; (B) solicits, receives, and evaluates concerns and objections of such State and Council with regard to such aspects of the project on an ongoing basis; and $(C)$ works diligently and cooperatively to resolve, through arbitration or other appropriate mechanisms, such concerns and objections. The process of consultation and cooperation shall not include the grant of a right to any State or Tribal Council to exercise an absolute veto of any aspect of the planning, development, modification, expansion, or operation of the project.

(5) The Secretary and the State and affected Tribal Council shall seek to conclude the agreement required by paragraph (2) as soon as practicable, but not later than 180 daysfollowing the date of notification of the selection under paragraph (2). The Secretary shall periodically report to the Congress thereafter on the status of the agreements approved under paragraph (3). Any report to the Congress on the status of negotiations of such agreement by the Secretary shall be accompanied by comments solicited by the Secretary from the State and eligible Tribal Council. 
Notice of disapproval, submittal to Congress.

Ante, p. 2217, "Resolution."

(6) (A) Upon deciding to provide an aggregate of 300 or more metric tons of storage capacity under subsection (a)(1) at any one site, the Secretary shall notify the Governor and legislature of the State where such site is located, or the governing body of the Indian tribe in whose reservation such site is located, as the case may be, of such decision. During the 60-day period following receipt of notification by the Secretary of his decision to provide an aggregate of 300 or more metric tons of storage capacity at any one site, the Governor or legislature of the State in which such site is located, or the governing body of the affected Indian tribe where such site is located, as the case may be, may disapprove the provision of 300 or more metric tons of storage capacity at the site involved and submit to the Congress a notice of such disapproval. A notice of disapproval shall be considered to be submitted to the Congress on the date of the transmittal of such notice of disapproval to the Speaker of the House and

(B) Unless otherwise provided by State law, the Governor or legislature of each State shall have authority to submit a notice of disapproval to the Congress under subparagraph (A). In any case in which State law provides for submission of any such notice of disapproval by any other person or entity, any reference in this subtitle to the Governor or legislature of such State shall be considered to refer instead to such other person or entity.

(C) The authority of the Governor and legislature of each State under this paragraph shall not be applicable with respect to any site located on a reservation.

(D) If any notice of disapproval is submitted to the Congress under subparagraph (A), the proposed provision of 300 or more metric tons of storage capacity at the site involved shall be disapproved unless, during the first period of 90 calendar days of continuous session of the Congress following the date of the receipt by the Congress of such notice of disapproval, the Congress passes a resolution approving such proposed provision of storage capacity in accordance with the procedures established in this paragraph and subsections (d) through (f) of section 115 and such resolution thereafter becomes law. For purposes of this paragraph, the term "resolution" means a joint resolution of either House of the Congress, the matter after the resolving clause of which is as follows: "That there hereby is approved the provision of 300 or more metric tons of spent nuclear fuel storage capacity at the site located at

submitted by with respect to which a notice of disapproval was The first blank space in such resolution shall be filled with the geographic location of the site involved; the second blank space in such resolution shall be filled with the designation of the State Governor and legislature or affected Indian tribe governing body submitting the notice of disapproval involved; and the last blank space in such resolution shall befilled with the date of submission of such notice of disapproval. 
"Affected Tribal Council."

5 USC 533
(E) For purposes of the consideration of any resolution described in subparagraph (D), each reference in subsections (d) and (e) of section 115 to a resolution of repository siting approval shall be considered to refer to the resolution described in such subparagraph.

(7) As used in this section, the term "affected Tribal Council" means the governing body of any Indian tribe within whose reservation boundaries there is located a potentially acceptable site for interim storage capacity of spent nuclear fuel from civilian nuclear power reactors, or within whose boundaries a site for such capacity is selected by the Secretary, or whose federally defined possessory or usage rights to other lands outside of the reservation's boundaries arising out of congressionally ratified treaties, as determined by the Secretary of the Interior pursuant to a petition filed with him by the appropriate governmental officials of such tribe, may be substantially and adversely affected by the establishment of any such storage capacity.

(e) Limitations.-Any spent nuclear fuel stored under this section shall be removed from the storage site or facility involved as soon as practicable, but in any event not later than 3 years following the date on which a repository or monitored retrievable storage facility developed under this Act is available for disposal of such spent nuclear fuel.

(f) Report. - The Secretary shall annually prepare and submit to the Congress a report on any plans of the Secretary for providing storage capacity under this section. Such report shall include a description of the specific manner of providing such storage selected by the Secretary, if any. The Secretary shall prepare and submit the first such report not later than 1 year after the date of the enactment of this Act.

(g) Criteria For Determining Adequacy Of Available Storage Capacity.- Not later than 90 days after the date of the enactment of this Act, the Commission pursuant to section 553 of the Administrative Procedures Act, shall propose, by rule, procedures and criteria for making the determination required by subsection (b) that a person owning and operating a civilian nuclear power reactor cannot reasonably provide adequate spent nuclear fuel storage capacity at the civilian nuclear power reactor site when needed to ensure the continued orderly operation of such reactor. Such criteria shall ensure the maintenance of a full core reserve storage capability at the site of such reactor unless the Commission determines that maintenance of such capability is not necessary for the continued orderly operation of such reactor. Such criteria shall identify the feasibility of reasonably providing such adequate spent nuclear fuel storage capacity, taking into account economic, technical, regulatory, and public health and safety factors, through the use of highdensity fuel storage racks, fuel rod compaction, transshipment of spent nuclear fuel to another civilian nuclear power reactor within the same utility system, construction of additional spent nuclear fuel pool capacity, or such other technologies as may be approved by the Commission.

(h) Application.- Notwithstanding any other provision of law, nothing in this Act shall be construed to encourage, authorize, or require the private or Federal use, purchase, lease, or other acquisition of any storage facility located away from the site of any civilian nuclear power reactor 
and not owned by the Federal Government on the date of the enactment of this Act.

(i) Coordination with Research and Development Program.-To the extent available, and consistent with the provisions of this section, the Secretary shall provide spent nuclear fuel for the research and development program authorized in section 217 from spent nuclear fuel received by the Secretary for storage under this section. Such spent nuclear fuel shall not be subject to the provisions of subsection (e).

42 USC 10156.

\section{INTERIM STORAGE FUND}

Sec. 136. (a) Contracts.-(1) During the period following the date of the enactment of this Act, but not later than January 1, 1990, the Secretary is authorized to enter into contracts with persons who generate or own spent nuclear fuel resulting from civilian nuclear activities for the storage of such spent nuclear fuel in any storage capacity provided under this subtitle: Provided, however, That the Secretary shall not enter into contracts for spent nuclear fuel in amounts in excess of the available storage capacity specified in section 135(a). Those contracts shall provide that the Federal Government will (1) take title at the civilian nuclear power reactor site, to such amounts of spent nuclear fuel from the civilian nuclear power reactor as the Commission determines cannot be stored onsite, (2) transport the spent nuclear fuel to a federally owned and operated interim away-from-reactor storage facility, and (3) store such fuel in the facility pending further processing, storage, or disposal. Each such contract shall (A) provide for payment to the Secretary of fees determined in accordance with the provisions of this section; and (B) specify the amount of storage capacity to be provided for the person involved.

Sturty, report to Congress.

Pebrication in Federal Register.

Fees

(2) The Secretary shall undertake a study and, not later than 180 days after the date of the enactment of this Act, submit to the Congress a report, establishing payment charges that shall be calculated on an annual basis, commencing on or before January 1, 1984. Such payment charges and the calculation thereof shall be published in the Federal Register, and shall become effective not less than 30 days after publication. Each payment charge published in the Federal Register under this paragraph shall remain effective for a period of 12 months from the effective date as the charge for the cost of the interim storage of any spent nuclear fuel. The report of the Secretary shall specify the method and manner of collection (including the rates and manner of payment) and any legislative recommendations determined by the Secretary to be appropriate.

(3) Fees for storage under this subtitle shall be established on a nondiscriminatory basis. The fees to be paid by each person entering into a contract with the Secretary under this subsection shall be based upon an estimate of the pro rata costs of storage and related activities under this subtitle with respect to such person, including the acquisition, construction, operation, and maintenance of any facilities under this subtitle.

(4) The Secretary shall establish in writing criteria setting forth the terms and conditions under which such storage services shall be made available. 
(5) Except as provided in section 137, nothing in this or any other Act requires the Secretary, in carrying out the responsibilities of this section, to obtain a license or permit to possess or own spent nuclear fuel.

(b) Limitation. - No spent nuclear fuel generated or owned by any department of the United States referred to in section 101 or 102 of title 5, United States Code, may be stored by the Secretary in any storage capacity provided under this subtitle unless such department transfers to the Secretary, for deposit in the Interim Storage Fund, amounts equivalent to the fees that would be paid to the Secretary under the contracts referred to in this section if such spent nuclear fuel were generated by any other person.

(c) Establishment of Interim Storage Fund.-There hereby is established in the Treasury of the United States a separate fund, to be know as the Interim Storage Fund. The Storage Fund shall consist of-

(1) all receipts, proceeds, and recoveries realized by the Secretary under subsections (a), (b), and (e), which shall be deposited in the Storage Fund immediately upon their realization;

(2) any appropriations made by the Congress to the Storage Fund; and

(3) any unexpended balances available on the date of the enactment of this Act for functions or activities necessary or incident to the interim storage of civilian spent nuclear fuel, which shall automatically be transferred to the Storage Fund on such date.

(d) Use of Storage Fund.-The Secretary may make expenditures from the Storage Fund, subject to subsection (e), for any purpose necessary or appropriate to the conduct of the functions and activities of the Secretary, or the provision or anticipated provision of services, under this subtitle, including-

(1) the identification, development, licensing, construction, operation, decommissioning, and post-decommissioning maintenance and monitoring of any interim storage facility provided under this subtitle;

(2) the administrative cost of the interim storage program;

(3) the costs associated with acquisition, design, modification, replacement, operation, and construction of facilities at an interim storage site, consistent with the restrictions in section 135;

(4) the cost of transportation of spent nuclear fuel; and

(5). impact assistance as described in subsection (e).

Payments.

(e) Impact Assistance.-(1) Beginning the first fiscal year which commences after the date of the enactment of this Act, the Secretary shall make annual impact assistance payments to a State or appropriate unit of local government, or both, in order to mitigate social or economic impacts occasioned by the establishment and subsequent operation of any interim storage capacity within the jurisdictional boundaries of such government or governments and authorized under this subtitle: Provided, however, That such impact assistance payments shall not exceed (A) ten percentum of the costs incurred in paragraphs (1) and (2), or (B) \$15 per kilogram of spent fuel, whichever is less:

(2) Payments made available to States and units of local government pursuant to this section shall be- 
Regulations.

"Unit of local government."

Report to Congress.

Budget submittal.

Ante, p. 907.
(A) allocated in a fair and equitable manner with a priority to those States or units of local government suffering the most severe impacts; and

(B) utilized by States or units of local governments only for (i) planning, (ii) construction and maintenance of public services, (iii) provision of public services related to the providing of such interim storage authorized under this title, and (iv) compensation for loss of taxable property equivalent to that if the storage had been provided under private ownership.

(3) Such payments shall be subject to such terms and conditions as the Secretary determines necessary to ensure that the purposes of this subsection shall be achieved. The Secretary shall issue such regulations as may be necessary to carry out the provisions of this subsection.

(4) Payments under this subsection shall be made available solely from the fees determined under subsection (a).

(5) The Secretary is authorized to consult with States and appropriate units of local government in advance of commencement of establishment of storage capacity authorized under this subtitle in an effort to determine the level of the payment such government would be eligible to receive pursuant to this subsection.

(6) As used in this subsection, the term "unit of local government" means a county, parish, township, municipality, and shall include a borough existing in the State of Alaska on the date of the enactment of this subsection, and any other unit of government below the State level which is a unit of general government as determined by the Secretary.

(f) Administration of Storage Fund. - (1) The Secretary of the Treasury shall hold the Storage Fund and, after consultation with the Secretary, annually report to the Congress on the financial condition and operations of the Storage Fund during the preceding fiscal year.

(2) The Secretary shall submit the budget of the Storage Fund to the Office of Management and Budget triennially along with the budget of the Department of Energy submitted at such time in accordance with chapter 11 of title 31, United States Code. The budget of the Storage Fund shall consist of estimates made by the Secretary of expenditures from the Storage Fund and other relevant financial matters for the succeeding 3 fiscal years, and shall be included in the Budget of the United States Government. The Secretary may make expenditures from the Storage Fund, subject to appropriations which shall remain available until expended. Appropriations shall be subject to triennial authorization.

(3) If the Secretary determines that the Storage Fund contains at any time amounts in excess of current needs, the Secretary may request the Secretary of the Treasury to invest such amounts, or any portion of such amounts as the Secretary determines to be appropriate, in obligations of the United States-

(A) having maturities determined by the Secretary of the Treasury to be appropriate to the needs of the Storage Fund; and 
Ante, p. 927.

Ante, p. 927.

Interest

payments.

Deferral.
(B) bearing interest at rates determined to be appropriate by the Secretary of the Treasury, taking into consideration the current average market yield on outstanding marketable obligations of the United States with remaining periods to maturity comparable to the maturities of such investments, except that the interest rate on such investments shall not exceed the average interest rate applicable to existing borrowings.

(4) Receipts, proceeds, and recoveries realized by the Secretary under this section, and expenditures of amounts from the Storage Fund, shall be exempt from annual apportionment under the provisions of subchapter $\Pi$ of chapter 15 of title 31, United States Code.

(5) If at any time the moneys available in the Storage Fund are insufficient to enable the Secretary to discharge his responsibilities under this subtitle, the Secretary shall issue to the Secretary of the Treasury obligations in such forms and denominations, bearing such maturities, and subject to such terms and conditions as may be agreed to by the Secretary and the Secretary of the Treasury. The total of such obligations shall not exceed amounts provided in appropriation Acts. Redemption of such obligations shall be made by the Secretary from moneys available in the Storage Fund. Such obligations shall bear interest at a rate determined by the Secretary of the Treasury, which shall be not less than a rate determined by taking into consideration the average market yield on outstanding marketable obligations of the United States of comparable maturities during the month preceding the issuance of the obligations under this paragraph. The Secretary of the Treasury shall purchase any issued obligations, and for such purpose the Secretary of the Treasury is authorized to use as a public debt transaction the proceeds from the sale of any securities issued under chapter 31 of title 31, United States Code, and the purposes for which securities may be issued under such Act are extended to include any purchase of such obligations. The Secretary of the Treasury may at any time sell any of the obligations acquired by him under this paragraph. All redemptions, purchases, and sales by the Secretary of the Treasury of obligations under this paragraph shall be treated as public debt transactions of the United States.

(6) Any appropriations made available to the Storage Fund for any purpose described in subsection (d) shall be repaid into the general fund of the Treasury, together with interest from the date of availability of the appropriations until the date of repayment. Such interest shall be paid on the cumulative amount of appropriations available to the Storage Fund, less the average undisbursed cash balance in the Storage Fund account during the fiscal year involved. The rate of such interest shall be determined by the Secretary of the Treasury takking into consideration the average market yield during the month preceding each fiscal year on outstanding marketable obligations of the United States of comparable maturity. Interest payments may be deferred with the approval of the Secretary of the Treasury, but any interest payments so deferred shall themselves bear interest. 
Sec. 137. (a) Transportation.-(1) Transportation of spent nuclear fuel under section 136(a) shall be subject to licensing and regulation by the Commission and by the Secretary of Transportation as provided for transportation of commercial spent nuclear fuel under existing law.

(2) The Secretary, in providing for the transportation of spent nuclear fuel under this Act, shall utilize by contract private industry to the fullest extent possible in each aspect of such transportation. The Secretary shall use direct Federal services for such transportation only upon a determination of the Secretary of Transportation, in consultation with the Secretary, that private industry is unable or unwilling to provide such transportation services at reasonable cost.

\section{SUBTITLE C-MONITORED RETRIEVABLE STORAGE}

Sec. 141. (a) Findings.-The Congress finds that-

(1) long-term storage of high-level radioactive waste or spent nuclear fuel in monitored retrievable storage facilities is an option for providing safe and reliable management of such waste or spent fuel;

(2) the executive branch and the Congress should proceed as expeditiously as possible to consider fully a proposal for construction of one or more monitored retrievable storage facilities to provide such long-term storage;

(3) the Federal Government has the responsibility to ensure that site-specific designs for such facilities are available as provided in this section;

(4) the generators and owners of the high-level radioactive waste and spent nuclear fuel to be stored in such facilities have the responsibility to pay the costs of the long-term storage of such waste and spent fuel; and

(5) disposal of high-level radioactive waste and spent nuclear fuel in a repository developed under this Act should proceed regardless of any construction of a monitored retrievable storage facility pursuant to this section.

(b) Submission of Proposal by Secretary.-(1) On or before June 1, 1985, the Secretary shall complete a detailed study of the need for and feasibility of, and shall submit to the Congress a proposal for, the construction of one or more monitored retrievable storage facilities for high-level radioactive waste and spent nuclear fuel. Each such facility shall be designed-

(A) to accommodate spent nuclear fuel and high-level radioactive waste resulting from civilian nuclear activities;

(B) to permit continuous monitoring, management, and maintenance of such spent fuel and waste for the foreseeable future;

(C) to provide for the ready retrieval of such spent fuel and waste for further processing or disposal; and

(D) to safely store such spent fuel and waste as long as may be necessary by maintaining such facility through appropriate means, including any required replacement of such facility. 
Consultations.

Environmental assessment.

Submittal to Congress.
(2) Such proposal shall include-

(A) the establishment of a Federal program for the siting, development, construction, and operation of facilities capable of safely storing high-level radioactive waste and spent nuclear fuel, which facilities are to be licensed by the Commission;

(B) a plan for the funding of the construction and operation of such facilities, which plan shall provide that the costs of such activities shall be borne by the generators and owners of the high-level radioactive waste and spent nuclear fuel to be stored in such facilities;

(C) site-specific designs, specifications, and cost estimates sufficient to (i) solicit bids for the construction of the first such facility; (ii) support congressional authorization of the construction of such facility; and (iii) enable completion and operation of such facility as soon as practicable following congressional authorization of such facility; and

(D) a plan for integrating facilities constructed pursuant to this section with other storage and disposal facilities authorized in this Act.

(3) In formulating such proposal, the Secretary shall consult with the Commission and the Administrator, and shall submit their comments on such proposal to the Congress at the time such proposal is submitted.

(4) The proposal shall include, for the first such facility, at least 3 alternative sites and at least 5 alternative combinations of such proposed sites and facility designs consistent with the criteria of paragraph (b) (1). The Secretary shall recommend the combination among the alternatives that the Secretary deems preferable. The environmental assessment under subsection (c) shall include a full analysis of the relative advantages and disadvantages of all 5 such alternative combinations of proposed sites and proposed facility designs.

(c) Environmental Impact Statements.-(1) Preparation and submission to the Congress of the proposal required in this section shall not require the preparation of an environmental impact statement under section 102 (2) (C) of the National Environmental Policy Act of 1969 (42 U.S.C. 4332(2)(C)). The Secretary shall prepare, in accordance with regulations issued by the Secretary implementing such Act, an environmental assessment with respect to such proposal. Such environmental assessment shall be based upon available information regarding alternative technologies for the storage of spent nuclear fuel and highlevel radioactive waste. The Secretary shall submit such environmental assessment to the Congress at the time such proposal is submitted.

(2) If the Congress by law, after review of the proposal submitted by the Secretary under subsection (b), specifically authorizes construction of a monitored retrievable storage facility, the requirements of the National Environmental Policy Act of 1969 (42 U.S.C. 4321 et seq.) shall apply with respect to construction of such facility, except that any environmental impact statement prepared with respect to such facility shall not be required to consider the need for 
such facility or any alternative to the design criteria for such facility set forth in subsection (b) (1).

(d) Licensing.-Any facility authorized pursuant to this section shall be subject to licensing under section 202(3)) of the Energy Reorganization Act of 1974 (42 U.S.C. 5842(3). In reviewing the application filed by the Secretary for licensing of the first such facility, the Commission may not consider the need for such facility or any alternative to the design criteria for such facility set forth in subsection (b) (1).

(e) Clarification.-Nothing in this section limits the consideration of alternative facility designs consistent with the criteria of paragraph (b) (1) in any environmental impact statement, or in any licensing procedure of the Commission, with respect to any monitored, retrievable facility authorized pursuant to this section.

Payments.

(f) Impact Assistance.-(1) Upon receipt by the Secretary of congressional authorization to construct a facility described in subsection (b), the Secretary shall commence making annual impact aid payments to appropriate units of general local government in order to migrate any social or economic impacts resulting from the construction and subsequent operation of any such facility within the jurisdictional boundaries of any such unit.

(2) payments made available to units of general local government under this subsection shall be-

(A) allocated in a fair and equitable manner, with priority given to units of general local government determined by the Secretary to be most severely affected; and

(B) utilized by units of general local government only for planning, construction, maintenance, and provision of public services related to the siting of such facility.

(3) Such payments shall be subject to such terms and conditions

Regulations.

Consultations. as the Secretary determines are necessary to ensure achievement of the purposes of this subsection. The Secretary shall issue such regulations as may be necessary to carry out the provisions of this subsection.

(4) Such payments shall be made available entirely from funds held in the Nuclear Waste Fund established in section 302 (c) and shall be available only to the extent provided in advance in appropriation Acts.

(5) The Secretary may consult with appropriate units of general local government in advance of commencement of construction of any such facility in an effort to determine the level of payments each such unit is eligible to receive under this subsection.

(g) Limitation.-No monitored retrievable storage facility development pursuant to this section may be constructed in any State in which there is located any site approved for site characterization under section

Ante, p. 2208. 112. The restriction in the preceding sentence shall only apply until such time as the Secretary decides that such candidate site is no longer a candidate site under consideration for development as a repository. Such restriction shall continue to apply to any site selected for construction as a repository.

(h) Participation of States and Indian Tribes.-Any facility authorized pursuant to this section shall be subject to the provisions of sections 115 , 
USC 10162.

116 (a), 116 (b), 116 (d), 117, and 118. For purposes of carrying out the provisions of this subsection, any reference in sections 115 through 118 to a repository shall be considered to refer to a monitored retrievable storage facility.

AUTHORIZATION OF MONITORED RETRIEVABLE STORAGE

Sec. 142. (a) Nullification of Oak Ridge Sitting Proposal.-The proposal the Secretary (EC-1022, 100th Congress) to locate a monitored retrievable storage facility at a site on the Clinch River in the Roane County portion of Oak Ridge, Tennessee, with alternative sites on the Oak Ridge Reservation of the Department of Energy and on the former site of a proposed nuclear powerplant in Hartsville, Tennessee, is annulled and revoked. In carrying out the provisions of sections 144 and 145 , the Secretary shall make no presumption or preference to such sites by reason of their previous selection.

(b) Authorization.-The Secretary is authorized to site, construct, and operate one monitored retrievable storage facility subject to the conditions described in sections 143 through 149.

\section{MONITORED RETRIEVABLE STORAGE COMMISSION}

USC 10163. Sec. 143. (a) Establishment.-(1)(A)There is established a Monitored Retrievable Storage Review Commission (hereinafter in this section referred to as the 'MRS Commission'), that shall consist of 3 members who shall be appointed by and serve at the pleasure of the President pro tempore of the Senate and the Speaker of the House of Representatives.

(B) ${ }^{75}$ Members of the MRS Commission shall be appointed not later than 30 days after the date of the enactment of the Nuclear Waste Policy Amendments Act of 1987 from among persons who as a result of training, experience and attainments are exceptionally well qualified to evaluate the need for a monitored retrievable storage facility as a part of the Nation's nuclear waste management system.

Reports.

(C) The MRS Commission shall prepare a report on the need for a monitored retrievable storage facility as a part of a national nuclear waste management system that achieves the purposes of this Act. In preparing the report under this subparagraph, the MRS Commission shall-

(i) review the status and adequacy of the Secretary's evaluation of the systems advantages and disadvantages of bringing such a facility into the national nuclear waste disposal system;

(ii) obtain comment and available data on monitored retrievable storage from affected parties, including States containing potentially acceptable sites;

(iii) evaluate the utility of a monitored retrievable storage facility from a technical perspective; and

(iv) make a recommendation to Congress as to whether such a facility should be included in the national nuclear waste management system in order to achieve the purposes of this Act, including meeting needs for packaging and handling of spent nuclear fuel, improving the flexibility of the repository development schedule, and providing 
temporary storage of spent nuclear fuel accepted for disposal.

(2) In preparing the report and making its recommendation under paragraph (1) the MRS Commission shall compare such a facility to the alternative of at-reactor storage of spent nuclear fuel prior to disposal of such fuel in a repository under this Act. Such comparison shall take into consideration the impact on-

(A) repository design and construction;

(B) waste package design, fabrication and standardization;

(C) waste preparation;

(D) waste transportation systems;

(E) the reliability of the national system for the disposal of radioactive waste;

(F) the ability of the Secretary to fulfill contractual commitments of the Department under this Act to accept spent nuclear fuel for disposal; and

(G) economic factors, including the impact on the costs likely to be imposed on ratepayers of the Nation's electric utilities for temporary at-reactor storage of spent nuclear fuel prior to final disposal in a repository, as well as the costs likely to be imposed on ratepayers of the Nation's electric utilities in building and operating such a facility.

Reports.

(3) The report under this subsection, together with the recommendation of the MRS Commission, shall be transmitted to Congress on November $1,1989.8$

(4) (A) (i) Each member of the MRS Commission shall be paid at the rate provided for level $\mathrm{III}$ of the Executive Schedule for each day (including travel time) such member is engaged in the work of the MRS Commission, and shall receive travel expenses, including per diem in lieu of subsistence in the same manner as is permitted under sections 5702 and 5703 of title 5, United States Code.

(ii) The MRS Commission may appoint and fix compensation, not to exceed the rate of basic pay payable for GS-18 of the General Schedule, for such staff as may be necessary to carry out its functions.

(B) (i) The MRS Commission may hold hearings, sit and act at such times and places, take such testimony and receive such evidence as the MRS Commission considers appropriate. Any member of the MRS Commission may administer oaths or affirmations to witnesses appearing before the MRS Commission.

(ii) The MRS Commission may request any Executive agency, including the Department, to furnish such assistance or information, including records, data, files, or documents, as the Commission considers necessary to carry out its functions. Unless prohibited by law, such agency shall promptly furnish such assistance or information.

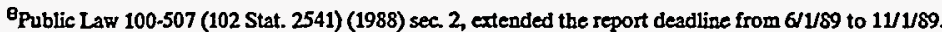


42 USC 10164.

(iii) To the extent permitted by law, the Administrator of the General Services Administration shall, upon request of the MRS Commission, provide the MRS Commission with necessary administrative services, facilities, and support on a reimbursable basis.

(iv) The MRS Commission may procure temporary and intermittent services from experts and consultants to the same extent as is authorized by section 3109 (b) of title 5 , United States Code, at rates and under such rules as the MRS Commission considers reasonable.

(C) The MRS Commission shall cease to exist 60 days after the submission to Congress of the report required under this subsection.

\section{SURVEY}

Sec. 144. After the MRS Commission submits its report to the Congress under section 143, the Secretary may conduct a survey and evaluation of potentially suitable sites for a monitored retrievable storage facility. In conducting such survey and evaluation, the Secretary shall consider the extent to which siting a monitored retrievable storage facility at each site surveyed would-

(1) enhance the reliability and flexibility of the system for the disposal of spent nuclear fuel and high-level radioactive waste established under this Act;

(2) minimize the impacts of transportation and handling of such fuel and waste;

(3) provide for public confidence in the ability of such system to safely dispose of the fuel and waste;

(4) impose minimal adverse effects on the local community and the local environment;

(5) provide a high probability that the facility will meet applicable environmental, health, and safety requirements in a timely fashion;

(6) provide such other benefits to the system for the disposal of spent nuclear fuel and high-level radioactive waste as the Secretary deems appropriate; and

(7) unduly burden a State in which significant volumes of highlevel radioactive waste resulting from atomic energy defense activities are stored.

42 USC 10165.

\section{SITE SELECTION}

Sec. 145. (a) General.-The Secretary may select the site evaluated under section 144 that the Secretary determines on the basis of available information to be the most suitable for a monitored retrievable storage facility that is an integral part of the system for the disposal of spent nuclear fuel and high-level radioactive waste established under this Act.

(b) Limitation.-The Secretary may not select a site under subsection (a) until the Secretary recommends to the President the approval of a site for development as a repository under section 114 (a).

(c) Site Specific Activities. - The Secretary may conduct such site specific activities at each site surveyed under section 144 as he determines 
may be necessary to support an application to the Commission for a license to construct a monitored retrievable storage facility at such site.

(d) Environmental Assessment.-Site specific activities and selection of a site under this section shall not require the preparation of an environmental impact statement under section 102(2)(C) of the National Environmental Policy Act of 1969 (42 U. S. C. 4332(2)(C)). The Secretary shall prepare an environmental assessment with respect to such selection in accordance with regulations issued by the Secretary implementing such Act. Such environmental assessment shall be based upon available information regarding alternative technologies for the storage of spent nuclear fuel and high-level radioactive waste. The Secretary shall submit such environmental assessment to the Congress at the time such site is selected.

(e) Notification Before Selection.-(1) At least 6 months before selecting a site under subsection (a), the Secretary shall notify the Governor and legislature of the State in which such site is located, or the governing body of the affected Indian tribe where such site is located, as the case may be, of such potential selection and the basis for such selection.

(2) Before selecting any site under subsection (a), the Secretary shall hold at least one public hearing in the vicinity of such site to solicit any recommendations of interested parties with respect to issues raised by the selection of such site.

(f) Notification of Selection.-The Secretary shall promptly notify Congress and the appropriate State or Indian tribe of the selection under subsection (a).

(g) Limitation.-No monitored retrievable storage facility authorized pursuant to section 142 (b) may be constructed in the State of Nevada.

\section{USC 10166.}

\section{NOTICE OF DISAPPROVAL}

Sec. 146. (a) In General.-The selection of a site under section 145 shall be effective at the end of the period of 60 calendar days beginning on the date of notification under such subsection, unless the governing body of the Indian tribe on whose reservation such site is located, or, if the site is not on a reservation, the Governor and the legislature of the State in which the site is located, has submitted to Congress a notice of disapproval with respect to such site. If any such notice of disapproval has been submitted under this subsection, the selection of the site under section 145 shall not be effective except as provided under section 115(c).

(b) References.-For purposes of carrying out the provisions of this subsection, references in section 115 (c) to a repository shall be considered to refer to a monitored retrievable storage facility and references to a notice of disapproval of a repository site designation under section 116 (b) or 118 (a) shall be considered to refer to a notice of disapproval under this section.

\section{BENEFITS AGREEMENT}

42 USC 10167.

Sec. 147. Once selection of a site for a monitored retrievable storage facility is made by the Secretary under section 145 , the Indian tribe on whose reservation the site is located, or, in the case that the site is not located on a reservation, the State in which the site is located, shall be 
eligible to enter into a benefits agreement with the Secretary under section 170.

\section{CONSTRUCTION AUTHORIZATION}

42 USC 10168.

Sec. 148 (a) Environmental Impact Statement.-(1) Once the selection of a site is effective under section 146, the requirements of the $\mathrm{Na}$ tional Environmental Policy Act of 1969 (42 U. S. C. 4321 et seq.) shall apply with respect to construction of a monitored retrievable storage facility, except that any environmental impact statement prepared with respect to such facility shall not be required to consider the need for such facility or any alternative to the design criteria for such facility set forth in section 141 (b) (1).

(2) Nothing in this section shall be construed to limit the consideration of alternative facility designs consistent with the criteria described in section 141 (b) (1) in any environmental impact statement, or in any licensing procedure of the Commission, with respect to any monitored retrievable storage facility authorized under section 142 (b).

(b) Application For Construction License.-Once the selection of a site for a monitored retrievable storage facility is effective under section 146 , the Secretary may submit an application to the Commission for a license to construct such a facility as part of an integrated nuclear waste management system and in accordance with the provisions of this section and applicable agreements under this Act affecting such facility.

(c) Licensing. - Any monitored retrievable storage facility authorized pursuant to section 142 (b) shall be subject to licensing under section 202(3) of the Energy Reorganization Act of 1974 (42 U. S. C. 5842(3)). In reviewing the application filed by the Secretary for licensing of such facility, the Commission may not consider the need for such facility or any alternative to the design criteria for such facility set forth in section 141 (b) (1).

(d) Licensing Conditions. - Any license issued by the Commission for a monitored retrievable storage facility under this section shall provide that-

(1) construction of such facility may not begin until the Commission has issued a license for the construction of a repository under section 115 (d);

(2) construction of such facility or acceptance of spent nuclear fuel or high-level radioactive waste shall be prohibited during such time as the repository license is revoked by the Commission or construction of the repository ceases;

(3) the quantity of spent nuclear fuel or high-level radioactive waste at the site of such facility at any one time may not exceed 10,000 metric tons of heavy metal until a repository under this Act first accepts spent nuclear fuel or solidified high-level radioactive waste; and

(4) the quantity of spent nuclear fuel or high-level radioactive waste at the site of the facility at any one time may not exceed 15,000 metric tons of heavy metal. 
42 USC 10169.

FINANCIAL ASSISTANCE

Sec. 149. The provisions of section 116 (c) or 118 (b) with respect to grants, technical assistance, and other financial assistance shall apply to the State, to affected Indian tribes and to affected units of local government in the case of a monitored retrievable storage facility in the same manner as for a repository. ${ }^{9}$

\section{SUBTITLE D-LOW-LEVEL RADIOACTIVE WASTE}

\section{FINANCIAL ARRANGEMENTS FOR LOW-LEVEL RADIOACTIVE WASTE SITE} CLOSURE

42 USC 10171. Sec. 151. (a) Financial Arrangements. - (1)The Commission shall establish by rule, regulation, or order, after public notice, and in accordance with section 181 of the Atomic Energy Act of 1954 (42 U. S. C. 2231), such standards and instructions as the Commission may deem necessary or desirable to ensure in the case of each license for the disposal of low-level radioactive waste that an adequate bond, surety, or other financial arrangement (as determined by the Commission) will be provided by a licensee to permit completion of all requirements established by the Commission for the decontamination, decommissioning, site closure, and reclamation of sites, structures, and equipment used in conjunction with such low-level radioactive waste. Such financial arrangements shall be provided and approved by the Commission, or, in the case of sites within the boundaries of any agreement State under section 274 of the Atomic Energy Act of 1954 (42 U. S. C. 2021), by the appropriate State or State entity, prior to issuance of licenses for low-level radioactive waste disposal or, in the case of licenses in effect on the date of the enactment of this Act, prior to termination of such licenses.

(2) If the Commission determines that any long-term maintenance or monitoring, or both, will be necessary at a site described in paragraph (1), the Commission shall ensure before termination of the license involved that the licensee has made available such bonding, surety, or other financial arrangements as may be necessary to ensure that any necessary long-term maintenance or monitoring needed for such site will be carried out by the person having title and custody for such site following license ternination.

(b)Title And Custody.-(1) The Secretary shall have authority to assume title and custody of low-level radioactive waste and the land on which such waste is disposed of, upon request of the owner of such waste and land and following termination of the license issued by the Commission for such disposal, if the Commission determines that-

(A) the requirements of the Commission for site closure, decommissioning, and decontamination have been met by the licensee involved and that such licensee is in compliance with the provisions of subsection (a);

(B) such title and custody will be transferred to the Secretary without cost to the Federal Government; and

(C) Federal ownership and management of such site is necessary or desirable in order to protect the public health and safety, and the environment.

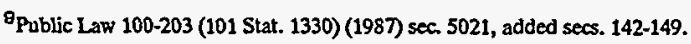


(2) If the Secretary assumes title and custody of any such waste and land under this subsection, the Secretary shall maintain such waste and land in a manner that will protect the public health and safety, and the environment.

(c) Special Sites.-If the low-level radioactive waste involved is the result of a licensed activity to recover zirconium, hafnium, and rare earths from source material, the Secretary, upon request of the owner of the site involved, shall assume title and custody of such waste and the land on which it is disposed when such site has been decontaminated and stabilized in accordance with the requirements established by the Commission and when such owner has made adequate financial arrangements approved by the Commission for the long-term maintenance and monitoring of such site.

\section{SUBTITLE E-REDIRECTION OF THE NUCLEAR WASTE PROGRAM}

\section{SELECTION OF YUCCA MOUNTAIN SITE}

Sec. 160. (a) In General.-(1) The Secretary shall provide for an orderly phase-out of site specific activities at all candidate sites other than the Yucca Mountain site.

(2) The Secretary shall terminate all site specific activities (other than reclamation activities) at all candidate sites, other than the Yucca Mountain site, within 90 days after the date of enactment of the Nuclear Waste Policy Amendments Act of 1987.

(b) Effective on the date of the enactment of the Nuclear Waste Policy Amendments Act of 1987, the State of Nevada shall be eligible to enter into a benefits agreement with the Secretary under section $170 .{ }^{10}$

\section{SITING A SECOND REPOSITORY}

Sec.161. (a) Congressional Action Required.-The Secretary may not conduct site-specific activities with respect to a second repository unless Congress has specifically authorized and appropriated funds for such activities.

(b) Report.-The Secretary shall report to the President and to Congress on or after January 1, 2007, but not later than January 1, 2010, on the need for a second repository.

(c) Termination of Granite Research.-Not later than 6 months after the date of the enactment of the Nuclear Waste Policy Amendments Act of 1987, the Secretary shall phase out in an orderly manner funding for all research programs in existence on such date of enactment designed to evaluate the suitability of crystalline rock as a potential repository host medium.

(d) Additional Siting Criteria. - In the event that the Secretary at any time after such date of enactment considers any sites in crystalline rock for characterization or selection as a repository, the Secretary shall consider (as a supplement to the siting guidelines under section 112) such potentially disqualifying factors as-

(1) seasonal increases in population;

(2) proximity to public drinking water supplies, including those of metropolitan areas; and

\footnotetext{
${ }^{10}$ Public Law 100-203 (101 Stat. 1330) (1987) sec. 5011, added new Subtitle E.
} 
(3) the impact that characterization or siting decisions would have on lands owned or placed in trust by the United States for Indian tribes. ${ }^{11}$

\section{SUBTITLE F- BENEFITS}

42 USC 10173.

\section{BENEFTTS AGREEMENTS}

Sec. 170. (a) In General.- (1) The Secretary may enter into a benefits agreement with the State of Nevada concerning a repository or with a State or an Indian tribe concerning a monitored retrievable storage facility for the acceptance of high-level radioactive waste or spent nuclear fuel in that State or on the reservation of that tribe, as appropriate.

(2) The State or Indian tribe may enter into such an agreement only if the State Attorney General or the appropriate governing authority of the Indian tribe or the Secretary of the Interior, in the absence of an appropriate governing authority, as appropriate, certifies to the satisfaction of the Secretary that the laws of the State or Indian tribe provide adequate authority for that entity to enter into the benefits agreement.

(3) Any benefits agreement with a State under this section shall be negotiated in consultation with affected units of local government in such State.

(4) Benefits and payments under this subtitle may be made available only in accordance with a benefits agreement under this section.

(b) Amendment.-A benefits agreement entered into under subsection (a) may be amended only by the mutual consent of the parties to the agreement and terminated only in accordance with section 173 .

(c) Agreement With Nevada.-The Secretary shall offer to enter into a benefits agreement with the Governor of Nevada. Any benefits agreement with a State under this subsection shall be negotiated in consultation with any affected units of local government in such State.

(d) Monitored Retrievable Storage. - The Secretary shall offer to enter into a benefits agreement relating to a monitored retrievable storage facility with the governing body of the Indian tribe on whose reservation the site for such facility is located, or, if the site is not located on a reservation, with the Governor of the State in which the site is located and in consultation with affected units of local government in such State.

(e) Limitation.-Only one benefits agreement for a repository and only one benefits agreement for a monitored retrievable storage facility may be in effect at any one time.

(f) Judicial Review.-Decisions of the Secretary under this section are not subject to judicial review.

42 USC 10173a.

\section{CONTENT OF AGREEMENTS}

Sec. 171. (a) In General.-(1) In addition to the benefits to which a State, an affected unit of local government or Indian tribe is entitled under title I, the Secretary shall make payments to a State or Indian tribe that is a party to a benefits agreement under section 170 in accordance with the following schedule:

\footnotetext{
${ }^{11}$ Public Law 100-203 (101 Stat. 1330) (1987) sec. 5012, amended Subtitle E by adding sec. 161.
} 


\section{Event MRS Repository}

(A) Annual payments prior to first spent fuel receipt ................... 5 10

(B) Upon first spent fuel receipt $\ldots \ldots \ldots \ldots \ldots 10 \quad 20$

(C) Annual payments after the first spent fuel receipt until closure of the facility $\ldots \ldots \ldots \ldots \ldots \ldots \ldots \ldots, 10$

20

(2) For purposes of this section, the term-

(A) 'MRS' means a monitored retrievable storage facility,

(B) 'spent fuel' means high-level radioactive waste or spent nuclear fuel, and

(C) 'first spent fuel receipt' does not include receipt of spent fuel or high-level radioactive waste for purposes of testing or operational demonstration.

(3) Annual payments prior to first spent fuel receipt under paragraph (1)(A) shall be made on the date of execution of the benefits agreement and thereafter on the anniversary date of such execution. Annual payments after the first spent fuel receipt until closure of the facility under paragraph (1)(C) shall be made on the anniversary date of such first spent fuel receipt.

(4) If the first spent fuel payment under paragraph (1)(B) is made within six months after the last annual payment prior to the receipt of spent fuel under paragraph (1)(A), such first spent fuel payment under paragraph (1)(B) shall be reduced by an amount equal to one-twelfth of such annual payment under paragraph (1)(A) for each full month less than six that has not elapsed since the last annual payment under paragraph (1)(A).

(5) Notwithstanding paragraph (1), (2), or (3), no payment under this section may be made before January 1,1989 , and any payment due under this title before January 1, 1989, shall be made on or after such date.

(6) Except as provided in paragraph (7), the Secretary may not restrict the purposes for which the payments under this section may be used.

(7) (A) Any State receiving a payment under this section shall transfer an amount equal to not less than one-third of the amount of such payment to affected units of local government of such State.

(B) A plan for this transfer and appropriate allocation of such portion among such governments shall be included in the benefits agreement under section 170 covering such payments.

(C) In the event of a dispute concerning such plan, the Secre-

tary shall resolve such dispute, consistent with this Act and applicable State law.

(b) Contents. - A benefits agreement under section 170 shall provide that-

(1) a Review Panel be established in accordance with section 172; 
(2) the State or Indian tribe that is party to such agreement waive its rights under title I to disapprove the recommendation of a site for a repository;

(3) the parties to the agreement shall share with one another information relevant to the licensing process for the repository of monitored retrievable storage facility, as it becomes available;

(4) the State or Indian tribe that is party to such agreement par: ticipate in the design of the repository or monitored retrievable storage facility and in the preparation of documents required under law or regulation governing the effects of the facility on the public health and safety; and

(5) the State or Indian tribe waive its rights, if any, to impact assistance under sections $116(\mathrm{c})(1)(\mathrm{B})(\mathrm{ii}), 116(\mathrm{c})(2), 118(\mathrm{~b})(2)(\mathrm{A})(\mathrm{ii})$, and $118(\mathrm{~b})(3)$.

(c) The Secretary shall make payments to the States or affected Indian tribes under a benefits agreement under this section from the Waste Fund. The signature of the Secretary on a valid benefits agreement under section 170 shall constitute a commitment by the United States to make payments in accordance with such agreement.

\section{REVIEW PANEL}

42 USC 10173b.

Sec. 172. (a) In General.- The Review Panel required to be established by section 171(b)(1) of this Act shall consist of a Chairman selected by the Secretary in consultation with the Governor of the State or governing body of the Indian tribe, as appropriate, that is party to such agreement and 6 other members as follows:

(1) 2 members selected by the Governor of such State or governing body of such Indian tribe;

(2) 2 members selected by units of local government affected by the repository or monitored retrievable storage facility;

(3) 1 member to represent persons making payments into the Waste Fund, to be selected by the Secretary; and

(4) 1 member to represent other public interests, to be selected by the Secretary.

(b) Terms.-(1) The members of the Review Panel shall serve for terms of 4 years each.

(2) Members of the Review Panel who are not full-time employees of the Federal Government, shall receive a per diem compensation for each day spent conducting work of the Review Panel, including their necessary travel or other expenses while engaged in the work of the Review Panel.

(3) Expenses of the Panel shall be paid by the Secretary from the Waste Fund.

(c) Duties.-The Review Panel shall-

(1) advise the Secretary on matters relating to the proposed repository or monitored retrievable storage facility, including issues relating to design, construction, operation, and decommissioning of the facility;

(2) evaluate performance of the repository or monitored retrievable storage facility, as it considers appropriate;

(3) recommend corrective actions to the Secretary; 
42 USC $10173 c$

(4) assist in the presentation of State or affected Indian tribe and local perspectives to the Secretary; and

(5) participate in the planning for and the review of preoperational data on environmental, demographic, and socioeconomic conditions of the site and the local community.

(d) Information.-The Secretary shall promptly make available promptly any information in the Secretary's possession requested by the Panel or its Chairman.

(e) Federal Advisory Committee Act.-The requirements of the Federal Advisory Committee Act shall not apply to a Review Panel established under this title.

\section{TERMINATION}

Sec. 173. (a) In General. - The Secretary may terminate a benefits agreement under this title if-

(1) the site under consideration is disqualified for its failure to comply with guidelines and technical requirements established by the Secretary in accordance with this Act; or

(2) the Secretary determines that the Commission cannot license the facility within a reasonable time.

(b) Termination By State Or Indian Tribe.-A State or Indian tribe may terminate a benefits agreement under this title only if the Secretary disqualifies the site under consideration for its failure to comply with technical requirements established by the Secretary in accordance with this Act or the Secretary determines that the Commission cannot license the facility within a reasonable time.

(c) Decisions Of The Secretary.-Decisions of the Secretary under this section shall be in writing, shall be available to Congress and the public, and are not subject to judicial review.

\section{SUBTITLE G-OTHER BENEFITS}

\section{CONSIDERATION IN SITING FACILITIES}

42 USC 10174.

Sec. 174. The Secretary, in siting Federal research projects, shall give special consideration to proposals from States where a repository is located.

\section{REPORT}

42 USC 10174a. Sec. 175. (a) In General.-Within one year of the date of the enactment of the Nuclear Waste Policy Amendments Act of 1987, the Secretary shall report to Congress on the potential impacts of locating a repository at the Yucca Mountain site, including the recommendations of the Secretary for mitigation of such impacts and a statement of which impacts should be dealt with by the Federal Government, which should be dealt with by the State with State resources, including the benefits payments under section 171, and which should be a joint Federal-State responsibility. The report under this subsection shall include the analysis of the Secretary of the authorities available to mitigate these impacts and the appropriate sources of funds for such mitigation.

(b) Impacts To Be Considered.- Potential impacts to be addressed in the report under this subsection (a) shall include impacts on-

(1) education, including facilities and personnel for elementary and secondary schools, community colleges, vocational and technical schools and universities; 
(2) public health, including the facilities and personnel for treatment and distribution of water, the treatment of sewage, the control of pests and the disposal of solid waste;

(3) law enforcement, including facilities and personnel for the courts, police and sheriff's departments, district attorneys and public defenders and prisons;

(4) fire protection, including personnel, the construction of fire stations, and the acquisition of equipment;

(5) medical care, including emergency services and hospitals;

(6) cultural and recreational needs, including facilities and personnel for libraries and museums and the acquisition and expansion of parks;

(7) distribution of public lands to allow for the timely expansion of existing, or creation of new, communities and the construction of necessary residential and commercial facilities;

(8) vocational training and employment services;

(9) social services, including public assistance programs, vocational and physical rehabilitation programs, mental health services, and programs relating to the abuse of alcohol and controlled substances;

(10) transportation, including any roads, terminals, airports, bridges, or railways associated with the facility and the repair and maintenance of roads, terminals, airports, bridges, or railways damaged as a result of the construction, operation, and closure of the facility;

(11) equipment and training for State and local personnel in the management of accidents involving high-level radioactive waste;

(12) availability of energy;

(13) tourism and economic development, including the potential loss of revenue and future economic growth; and

(14) other needs of the State and local governments that would not have arisen but for the characterization of the site and the construction, operation, and eventual closure of the repository facility. 12

\section{SUBTITLE H-TRANSPORTATION} TRANSPORTATION

42 USC 10175. Sec. 180 (a) No spent nuclear fuel or high-level radioactive waste may be transported by or for the Secretary under subtitle A or under subtitle C except in packages that have been certified for such purpose by the Commission.

(b) The Secretary shall abide by regulations of the Commission regarding advance notification of State and local governments prior to transportation of spent nuclear fuel or high-level radioactive waste under subtitle $A$ or under subtitle $C$.

(c) The Secretary shall provide technical assistance and funds to States for training for public safety officials of appropriate units of local government and Indian tribes through whose jurisdiction the Secretary plans to transport spent nuclear fuel or high-level radioactive waste under subtitle $A$ or under subtitle $C$. Training shall cover procedures re-

${ }^{12}$ Public Law 100-203 (101 Stat. 1330) (1987), sec. 5031, amended Title I by adding Subtitles F and G. 
quired for safe routine transportation of these materials, as well as procedures for dealing with emergency response situations. The Waste Fund shall be the source of funds for work carried out under this subsection. ${ }^{13}$

\section{TITLE II-RESEARCH, DEVELOPMENT, AND DEMONSTRATION REGARDING DISPOSAL OF HIGH-LEVEL RADIOACTIVE WASTE AND SPENT NUCLEAR FUEL}

42 USC 10191

42 USC 10192 Ante, p. 2205.

42 USC 10193

\section{PURPOSE}

Sec. 211. It is the purpose of this title-

(1) to provide direction to the Secretary with respect to the disposal of high-level radioactive waste and spent nuclear fuel;

(2) to authorize the Secretary, pursuant to this title(A) to provide for the construction, operation, and maintenance of a deep geologic test and evaluation facility; and

(B) to provide for a focused and integrated high-level radioactive waste and spent nuclear fuel research and development program, including the development of a test and evaluation facility to carry out research and provide an integrated demonstration of the technology for deep geologic disposal of highlevel radioactive waste, and the development of the facilities to demonstrate dry storage of spent nuclear fuel; and

(3) to provide for an improved cooperative role between the Federal Government and States, affected Indian tribes, and units of general local government in the siting of a test and evaluation facility.

\section{APPLICABILITY}

Sec. 212. The provisions of this title are subject to section 8 and shall not apply to facilities that are used for the disposal of high-level radioactive waste, low-level radioactive waste, transuranic waste, or spent nuclear fuel resulting from atomic energy defense activities.

\section{IDENTIFICATION OF SITES}

Sec. 213. (a) Guidelines. - Not later than 6 months after the date of the enactment of this Act and notwithstanding the failure of other agencies to promulgate standards pursuant to applicable law, the Secretary, in consultation with the Commission, the Director of the Geological Survey, the Administrator, the Council on Environmental Quality, and such other Federal agencies as the Secretary considers appropriate, is authorized to issue, pursuant to section 553 of title 5, United States Code, general guidelines for the selection of a site for a test and evaluation facility. Under such guidelines the Secretary shall specify factors that qualify or disqualify a site for development as a test and evaluation facility, including factors pertaining to the location of valuable natural resources, hydrogeophysics, seismic activity, and atomic energy defense activities, proximity to water supplies, proximity to populations, the effect upon the rights of users of water, and proximity to components of the National Park System, the National Wildlife Refuge System, the National Wild and Scenic Rivers System, the National Wilderness Preservation System, or National Forest Lands. Such guidelines shall require

${ }^{13}$ Public law 100-203 (101 Stat. 1330) (1987), sec. 5061, amended Title I by adding Subtitle H. 
Environmental assessment.

the Secretary to consider the various geologic media in which the site for a test and evaluation facility may be located and, to the extent practicable, to identify sites in different geologic media. The Secretary shall use guidelines established under this subsection in considering and selecting sites under this title.

(b) Site Identification By The Secretary.-(1) Not later than 1 year after the date of the enactment of this Act, and following promulgation of guidelines under subsection (a), the Secretary is authorized to identify 3 or more sites, at least 2 of which shall be in different geologic media in the continental United States, and at least.1 of which shall be in media other than salt. Subject to Commission requirements, the Secretary shall give preference to sites for the test and evaluation facility in media possessing geochemical characteristics that retard aqueous transport of radionucleides in order to provide a greater possible protection of public health and safety as operating experience is gained at the test and operation facility, and with the exception of the primary areas under review by the Secretary on the date of the enactment of this Act for the location of a test and evaluation facility or repository, all sites identified under this subsection shall be more than 15 statute miles from towns having a population of greater than 1000 persons as determined by the most recent census unless such sites contain high-level radioactive waste prior to identification under this title. Each identification of a site shall be supported by an environmental assessment, which shall include a detailed statement of the basis for such identification and of the probable impacts of the siting research activities planned for such site, and a discussible impacts of the siting research activities planned for such site, and a discussion of alternative activities relating to siting research that may be undertaken to avoid such impacts. Such environmental assessment shall include-

(A) an evaluation by the Secretary as to whether such site is suitable for siting research under the guidelines established under subsection (a);

(B) an evaluation by the Secretary of the effects of the siting research activities at such site on the public health and safety and the environment;

(C) a reasonable comparative evaluation by the Secretary of such site with other sites and locations that have been considered;

(D) a description of the decision process by which such site was recommended; and

(E) an assessment of the regional and local impacts of locating the proposed test and evaluation facility at such site.

(2) When the Secretary identifies a site, the Secretary shall as soon as possible notify the Governor of the State in which such site is located, or the governing body of the affected Indian tribe where such site is located, of such identification and the basis of such identification. Additional sites for the location of the test and evaluation facility authorized in section 302(d) may be identified after such 1 year period, following the same procedure as if such sites had been identified within such period. 
42 USC 10194.

SITING RESEARCH AND RELATED ACTIVITIES

Sec. 214. (a) In General.-Not later than 30 months after the date on which the Secretary completes the identification of sites under section 213 , the Secretary is authorized to complete sufficient evaluation of 3 sites to select a site for expanded siting research activities and for other activities under section 218 . The Secretary is authorized to conduct such preconstruction activities relative to such site selection for the test and evaluation facility as he deems appropriate. Additional sites for the location of the test and evaluation facility authorized in section 302(d) may be evaluated after such 30-month period, following the same procedures as if such sites were to be evaluated within such period.

(b) Public Meetings And Environmental Assessment.-Not later than 6 months after the date on which the Secretary completes the identification of sites under section 213 , and before beginning siting research activities, the Secretary shall hold at least 1 public meeting in the vicinity of each site to inform the residents of the area of the activities to be conducted at such site and to receive their views.

(c) Restrictions. - Except as provided in section 218 with respect to a test and evaluation facility, in conducting siting research activities pursuant to subsection (a)-

(1) the Secretary shall use the minimum quantity of high-level radioactive waste or other radioactive materials, if any, necessary to achieve the test or research objectives;

(2) the Secretary shall ensure that any radioactive material used or placed on a site shall be fully retrievable; and

(3) upon termination of siting research activities at a site for any reason, the Secretary shall remove any radioactive material at or in the site as promptly as practicable.

(d) Title To Material. - The Secretary may take title, in the name of the Federal Government, to the high-level radioactive waste spent nuclear fuel, or other radioactive material emplaced in a test and evaluation facility. If the Secretary takes title to any such material, the Secretary shall enter into the appropriate financial arrangements described in subsection (a) or (b) of section 302 for the disposal of such material.

TEST AND EVALUATION FACILITY SITING REVIEW AND REPORTS

42 USC 10195.

Sec. 215. (a) Consultation And Cooperation.-The Governor of a State, or the governing body of an affected Indian tribe, notified of a site identification under section 213 shall have the right to participate in a process of consultation and cooperation as soon as the site involved has been identified pursuant to such section and throughout the life of the test and evaluation facility. For purposes of this section, the term "process of consultation and cooperation" means a methodology-

"Process of consultation and cooperation."

(1) by which the Secretary-

(A) keeps the Governor or governing body involved fully and currently informed about any potential economic or public health and safety impacts in all stages of the siting, development, construction, and operation of a test and evaluation facility;

(B) solicits, receives, and evaluates concerns and objections of such Governor or governing body with regard to such test and evaluation facility on an ongoing basis; and 
(C) works diligently and cooperatively to resolve such concerns and objections; and

(2) by which the State or affected Indian tribe involved can exercise reasonable independent monitoring and testing of onsite activities related to all stages of the siting, development, construction and operation of the test and evaluation facility, except that any such monitoring and testing shall not unreasonably interfere with onsite activities.

(b) Written Agreements.-The Secretary shall enter into written agreements with the Governor of the State in which an identified site is located or with the governing body of any affected Indian tribe where an identified site is located in order to expedite the consultation and cooperation process. Any such written agreement shall specify-

(1) procedures by which such Governor or governing body may study, determine, comment on, and make recommendations with regard to the possible health, safety, and economic impacts of the test and evaluation facility;

(2) procedures by which the Secretary shall consider and respond to comments and recommendations made by such Governor or governing body, including the period in which the Secretary shall so respond;

(3) the documents the Department is to submit to such Governor or governing body, the timing for such submissions, the timing for such Governor or governing body to identify public health and safety concerns and the process to be followed to try to eliminate those concerns;

(4) procedures by which the Secretary and either such Governor or governing body may review or modify the agreement periodically; and

(5) procedures for public notification of the procedures specified under subparagraphs $(A)$ through (D).

(c) Limitation.-Except as specifically provided in this section, nothing in this title is intended to grant any State or affected Indian tribe any authority with respect to the siting, development, or loading of the test and evaluation facility.

\section{FEDERAL AGENCY ACTIONS}

42 USC 10196.

Sec. 216. (a) Cooperation And Coordination.-Federal agencies shall assist the Secretary by cooperating and coordinating with the Secretary in the preparation of any necessary reports under this title and the mission plan under section 301.

(b) Environmental Review.-(1) No action of the Secretary or any other Federal agency required by this title or section 301 with respect to a test and evaluation facility to be taken prior to the initiation of onsite construction of a test and evaluation facility shall require the preparation of an environmental impact statement under section 102(2)(C) of the Environmental Policy Act of 1969 (42 U.S.C.: 4332(2)(C)), or to require the preparation of environmental reports, except as otherwise specifically provided for in this title.

(2) The Secretary and the heads of all other Federal agencies shall, to the maximum extent possible, avoid duplication of efforts in the preparation of reports under the National Environmental Policy Act of 1969 (42 U. S. C. 4321 et seq.). 

RADIOACTIVE WASTE

42 USC 10197.

Sec. 217. (a) Purpose. - Not later than 64 months after the date of the enactment of this Act, the Secretary is authorized to, to the extent practicable, begin at a site evaluated under section 214, as part of and as an extension of siting research activities of such site under such section, the mining and construction of a test and evaluation facility. Prior to the mining and construction of such facility, the Secretary shall prepare an environmental assessment. the purpose of such facility shall be-

Environmental assessment.
Testing.
(1) to supplement and focus the repository site characterization process;

(2) to provide the conditions under which known technological components can be integrated to demonstrate a functioning repository-like system;

(3) to provide a means of identifying, evaluating, and resolving potential repository licensing issues that could not be resolved during the siting research program conducted under section 212;

(4) to validate, under actual conditions, the scientific models used in the design of a repository;

(5) to refine the design and engineering of repository components and systems and to confirm the predicted behavior of such components and systems;

(6) to supplement the siting data, the genericand specific geological characteristics developed under section 214 relating to isolating disposal materials in the physical environment of a repository;

(7) to evaluate the design concepts for packaging, handling, and emplacement of high-level radioactive waste and spent nuclear fuel at the design rate; and

(8) to establish operating capability without exposing workers to excessive radiation.

(b) Design. - The Secretary shall design each test and evaluation facility-

(1) to be capable of receiving not more than 100 full-sized canisters of solidified high-level radioactive waste (which canisters shall not exceed an aggregate weight of 100 metric tons), except that spent nuclear fuel may be used instead of such waste if such waste cannot be obtained under reasonable conditions;

(2) to permit full retrieval of solidified high-level radioactive waste, or other radioactive material used by the Secretary for testing, upon completion of the technology demonstration activities; and

(3) based upon the principle that the high-level radioactive waste, spent nuclear fuel, or other radioactive material involved shall be isolated from the biosphere iri such a way that the initial isolation is provided by engineered barriers functioning as a system with the geologic environment.

(c) Operation.-(1) Not later than 88 months after the date of the enactment of this Act, the Secretary shall begin an in situ testing program at the test and evaluation facility in accordance with the mission plan developed under section 301, for purposes of- 
(A) conducting in situ tests of bore hole sealing, geologic media fracture sealing, and room closure to establish the techniques and performance for isolation of high-level radioactive waste, spent nuclear fuel, or other radioactive materials from the biosphere;

(B) conducting in situ tests with radioactive sources and materials to evaluate and improve reliable models for radionuclide mitigation, absorption, and containment within the engineered barriers and geologic media involved, if the Secretary finds there is reasonable assurance that such radioactive sources and materials will not threaten the use of such site as a repository;

(C) conducting in situ tests to evaluate and improve models for ground water or brine flow through fractured geologic media;

(D) conducting in situ tests under conditions representing the real time and the accelerated time behavior of the engineered barriers within the geologic environment involved;

$(E)$ conducting in situ tests to evaluate the effects of heat and pressure on the geologic media involved on the hydrology of the surrounding area and on the integrity of the disposal packages;

(F) conducting in situ tests under both normal and abnormal repository conditions to establish safe design limits for disposal packages and to determine the effects of the gross release of radionuclides into surroundings, and the effects of various credible failure modes, including-

(i) seismic events leading to the coupling of aquifers through the test and evaluation facility;

(ii) thermal pulses significantly greater than the maximum calculated; and

(iii) human intrusion creating a direct pathway to the biosphere; and

(G) conducting such other research and development activities as the Secretary considers appropriate, including such activities necessary, to obtain the use of high-level radioactive waste, spent nuclear fuel, or other radioactive materials (such as any highly radioactive material from the Three Mile Island nuclear powerplant or from the West Valley Demonstration Project) for test and evaluation purposes, if such other activities are reasonably necessary to support the repository program and if there is reasonable assurance that the radioactive sources involved will not threaten the use of such site as a repository.

(2) The in situ testing authorized in this subsection shall be designed to ensure that the suitability of the site involved for licensing by the Commission as a repository will not be adversely affected. (d) Use Of Existing Department Facilities.-During the conducting of siting research activities under section 214 and for such period thereafter as the Secretary considers appropriate, the Secretary shall use Department facilities owned by the Federal Government on the date of the enactment of this Act for the conducting of generically applicable test regarding packaging, handling, and emplacement technology for solidi- 
fied high-level radioactive waste and spent nuclear fuel from civilian nuclear activities.

(e) Engineered Barriers. - The system of engineered barriers and selected geology used in a test and evaluation facility shall have a design life at least as long as that which the Commission requires by regulations issued under this Act, or under the Atomic Energy Act of 1954 (42 U.S. C. 2011 et seq.), for repositories.

(f) Role Of Commission.-(1)(A) Not later than 1 year after the date of the enactment of this Act, the Secretary and the Commission shall reach a written understanding establishing the procedures for review, consultation, and coordination in the planning, construction, and operation of the test and evaluation facility under this section. Such understanding shall establish a schedule, consistent with the deadlines set forth in this subtitle, for submission by the Secretary of, and review by the Commission of and necessary action on-

(i) the mission plan prepared under section 301; and

(ii) such reports and other information as the Commission may reasonably require to evaluate any health and safety impacts of the test and evaluation facility.

(B) Such understanding shall also establish the conditions under which the Commission may have access to the test and evaluation facility for the purpose of assessing any public health and safety concerns that it may have. No shafts may be excavated for the test and evaluation until the Secretary and the Commission enter into such understanding.

(2) Subject to section 305 , the test and evaluation facility, and the facilities authorized in section 217 , shall be constructed and operated as research, development, and demonstration facilities, and shall not be subject to licensing under section 202 of the Energy Reorganization Act of 1974 (42 U. S. C. 5842).

(3)(A) The Commission shall carry out a continuing analysis of the activities undertaken under this section to evaluate the adequacy of the consideration of public health and safety issues.

(B) The Commission shall report to the President, the Secretary, and the Congress as the Commission considers appropriate with respect to the conduct of activities under this section.

(g) Environmental Review.- The Secretary shall prepare an environmental impact statement under section 102(2)(C) of the National Environmental Policy Act of 1969 (42 U.S. C. 4332)(2)(C) prior to conducting tests with radioactive materials at the test and evaluation facility. Such environmental impact statement shall incorporate, to the extent practicable, the environmental assessment prepared under section 217(a). Nothing in this subsection may be construed to limit siting research activities conducted under section 214 . This subsection shall apply only to activities performed exclusively for a test and evaluation facility.

(h) Limitations. - (1) If the test and evaluation facility is not located at the site of a repository, the Secretary shall obtain the concurrence of the Commission with respect to the decontamination and decommissioning of such facility.

(2) If the test and evaluation facility is not located at a candidate site or repository site, the Secretary shall conduct only the portion 
Terminations.

of the in situ testing program required in subsection (c) determined by the Secretary to be useful in carrying out the purposes of this act.

(3) The operation of the test and evaluation facility shall terminate not later than-

(A) 5 years after the date on which the initial repository begins operation; or

(B) at such time as the Secretary determines that the continued operation of a test and evaluation facility is not necessary for research, development, and demonstration purposes; whichever occurs sooner.

(4) Notwithstanding any other provisions of this subsection, as soon as practicable following any determination by the Secretary, with the concurrence of the Commission, that the test and evaluation facility is unsuitable for continued operation, the Secretary shall take such actions as are necessary to remove from such site any radioactive material placed on such site as a result of testing and evaluation activities conducted under this section. Such requirement may be waived if the Secretary, with the concurrence of the Commission, finds that short-term testing and evaluation activities using radioactive material will not endanger the public health and safety.

42 USC 10198. Sec.218. (a) Demonstration And Cooperative Programs. - The Secretary shall establish a demonstration program, in cooperation with the private sector, for the dry storage of spent nuclear fuel at civilian nuclear power reactor sites, with the objective of establishing one or more technologies that the Commission may, by rule, approve for use at the sites of civilian nuclear power reactors without, to the maximum extent practicable, the need for additional site-specific approvals by the Commission. Not later than 1 year after the date of the enactment of this Act, the Secretary shall select at least 1 , but not more than 3 , sites evaluated under section 214 at such power reactors. In selecting such site or sites, the Secretary shall give preference to civilian nuclear power reactors that will soon have a shortage of interim storage capacity for spent nuclear fuel. Subject to reaching agreement as provided in subsection (b), the Secretary shall undertake activities to assist such power reactors with demonstration projects at such sites, which may use one of the following types of alternate storage technologies; spent nuclear fuel storage casks, caissons, or silos. The Secretary shall also undertake a cooperative program with civilian nuclear power reactors to encourage the development of the technology for spent nuclear fuel rod consolidation in existing power reactor water storage basins.

(b) Cooperative Agreements. - To carry out the programs described in subsection (a), the Secretary shall enter into a cooperative agreement with each utility involved that specifies, at a minimum, that-

(1) such utility shall select the alternate storage technique to be used, make the land and spent nuclear fuel available for the dry storage demonstration, submit and provide site-specific documentation for a license application to the Commission, obtain a license relating to the facility involved, construct such facility, operate 
Report to congressional committees. such facility after licensing, pay the costs required to construct such facility, and pay all costs associated with the operation and maintenance of such facility;

(2) the Secretary shall provide, on a cost-sharing basis, consultative and technical assistance, including design support and generic licensing documentation, to assist such utility in obtaining the construction authorization and appropriate license from the Commission; and

(3) the Secretary shall provide generic research and development of alternative spent nuclear fuel storage techniques to enhance utility-provided, at-reactor storage capabilities, if authorized in any other provision of this act or in any other provision of law.

(c) Dry Storage Research And Development.-(1) The consultative and technical assistance referred to in subsection (b)(2) may include, but shall not be limited to, the establishment of a research and development program for the dry storage of not more than 300 metric tons of spent nuclear fuel at facilities owned by the Federal Government on the date of the enactment of this Act. The purpose of such program shall be to collect necessary data to assist the utilities involved in the licensing process.

(2) To the extent available, and consistent with the provisions of section 135, the Secretary shall provide spent nuclear fuel for the research and development program authorized in this subsection from spent nuclear fuel received by the Secretary for storage under section 135 . Such spent nuclear fuel shall not be subject to the provisions of section $135(\mathrm{e})$.

(d) Funding.- The total contribution from the Secretary from Federal funds and the use of Federal facilities or services shall not exceed 25 percent of the total costs of the demonstration program authorized in subsection (a), as estimated by the Secretary. All remaining costs of such program shall be paid by the utilities involved or shall be provided by the Secretary from the Interim Storage Fund established in section 136.

(e) Relation To Spent Nuclear Fuel Storage Program.-The spent nuclear fuel storage program authorized in section 135 shall not be construed to authorize the use of research development or demonstration facilities owned by the Department unless-

(1) a period of 30 calendar days (not including any day in which either House of Congress is not in session because of adjournment of more than 3 calendar days to a day certain) has passed after the Secretary has transmitted to the Committee on Science and Technology of the House of Representatives and the Committee on Energy and Natural Resources of the Senate a written report containing a full and complete statement concerning (A) the facility involved; (B) any necessary modifications; (C) the cost thereof; and (D) the impact on the authorized research and development program; or

(2) each such committee, before the expiration of such period, has transmitted to the Secretary a written notice to the effect that such committee has no objection to the proposed use of such facility. 
PAYMENTS TO STATES AND INDIAN TRIBES

42 USC $10199 . \quad$ Sec. 219. (a) Payments. - Subject to subsection (b), the Secretary shall make payments to each State or affected Indian tribe that has entered into an agreement pursuant to section 215 . The Secretary shall pay an amount equal to 100 percent of the expenses incurred by such State or Indian tribe in engaging in any monitoring, testing, evaluation, or other consultation and cooperation activity under section 215 with respect to any site. The amount paid by the Secretary under this paragraph shall not exceed $\$ 3,000,000$ per year from the date on which the site involved was identified to the date on which the decontamination and decommission of the facility is complete pursuant to section 217(h). Any such payment may only be made to a State in which a potential site for a test and evaluation facility has been identified under section 213 , or to an affected Indian tribe where the potential site has been identified under such section.

(b) Limitation.-The Secretary shall make any payment to a State under subsection (a) only if such State agrees to provide, to each unit of general local government within the jurisdictional boundaries of which the potential site or effectively selected site involved is located, at least one-tenth of the payments made by the Secretary to such State under such subsection. A State or affected Indian tribe receiving any payment under subsection (a) shall otherwise have discretion to use such payment for whatever purpose it deems necessary, including the State or tribal activities pursuant to agreements entered into in accordance with section 215. Annual payments shall be prorated on a 365-day basis to the specified dates.

Report to

Congress.

42 USC 10200.

42 USC 10201.

Ante, p. 2227.

42 USC 10202.

42 USC 10203

Joint notice,

\section{STUDY OF RESEARCH AND DEVELOPMENT NEEDS FOR MONITORED} RETRIEVABLE STORAGE PROPOSAL

Sec. 220. Not later than 6 months after the date of the enactment of this Act, the Secretary shall submit to the Congress a report describing the research and development activities the Secretary considers necessary to develop the proposal required in section 141(b) with respect to a monitored retrievable storage facility.

\section{JUDICIAL REVIEW}

Sec. 221. Judicial review of research and development activities under this shall be in accordance with the provisions of section 119.

Sec. 222. Research on Alternatives for the Permanent Disposal of High-Level Radioactive Waste.-The Secretary shall continue and accelerate a program of research, development, and investigation of alternative means and technologies for the permanent disposal of high-level radioactive waste from civilian nuclear activities and Federal research and development activities except that funding shall be made from amounts appropriated to the Secretary for purposes of carrying out this section. Such program shall include examinations of various waste disposal options.

TECHNICAL ASSISTANCE TO NON-NUCLEAR WEAPON STATES IN THE FIELD OF SPENT FUEL STORAGE AND DISPOSAI

Sec. 223. (a) It shall be the policy of the United States to cooperate with and provide technical assistance to non-nuclear weapon states in the field of spent fuel storage and disposal.

(b)(1) Within 90 days of enactment of this Act, the Secretary and the 
publication in Federal Register.

Joint notice, reissuance.

Expressions of interest.

"Non-nuclear weapon state."

Reports. 42 USC 10204.
Commission shall publish a joint notice in the Federal Register stating that the United States is prepared to cooperate with and provide technical assistance to non-nuclear weapon states in the fields of at-reactor spent fuel storage; away-from-reactor spent fuel storage; monitored, retrievable spent fuel storage; geologic disposal of spent fuel; and the health, safety, and environmental regulation of such activities. The notice shall summarize the resources that can be made available for international cooperation and assistance in these fields through existing programs of the Department and the Commission, including the availability of: (i) data from past or ongoing research and development projects; (ii) consultations with expert Department or Commission personnel or contractors; and (iii) liaison with private business entities and organizations working in these fields.

(2) The joint notice described in the preceding subparagraph shall be updated and reissued annually for 5 succeeding years.

(c) Following publication of the annual joint notice referred to in paragraph (2), the Secretary of State shall inform the governments of nonnuclear weapon states and, as feasible, the organizations operating nuclear powerplants in such states, that the United States is prepared to cooperate with and provide technical assistance to non-nuclear weapon states in the fields of spent fuel storage and disposal, as set forth in the joint notice. The Secretary of State shall also solicit expressions of interest from non-nuclear weapon state governments and non-nuclear weapon state nuclear power reactor operators concerning their participation in expanded United States cooperation and technical assistance programs in these fields. The Secretary of State shall transmit any such expressions of interest to the Department and the Commission.

(d) With his budget presentation materials for the Department and the Commission for fiscal years 1984 through 1989, the President shall include funding requests for an expanded program of cooperation and technical assistance with non-nuclear weapon states in the fields of spent fuel storage and disposal as appropriate in light of expressions of interest in such cooperation and assistance on the part of non-nuclear weapon state governments and non-nuclear weapon state nuclear power reactor operators.

(e) For the purposes of this subsection, the term "non-nuclear weapon state" shall have the same meaning as that set forth in article IX of the Treaty on the Non-Proliferation of Nuclear Weapons (21 U.S.C. 438).

(f) Nothing in this subsection shall authorize the Department of Commission to take any action not authorized under existing law.

\section{SUBSEABED DISPOSAL}

Sec. 224. (a) Study. - Within 270 days after the date of the enactment of the Nuclear Waste Policy Amendments Act of 1987, the Secretary shall report to Congress on subseabed disposal of spent nuclear fuel and high-level radioactive waste. The report under this subsection shall include-

(1) an assessment of the current state of knowledge of subseabed disposal as an alternative technology for disposal of spent nuclear fuel and high-level radioactive waste;

(2) an estimate of the costs of subseabed disposal; 
(3) an analysis of institutional factors associated with subseabed disposal, including international aspects of a decision of the United States to proceed with subseabed disposal as an option for nuclear waste management;

(4) a full discussion of the environmental and public health and safety aspects of subseabed disposal;

(5) recommendations on alternative ways to structure an effort in research, development, and demonstration with respect to subseabed disposal; and

(6) the recommendations of the Secretary with respect to research, development and demonstration in subseabed disposal of spent nuclear fuel and high-level radioactive waste.

Establishment.

(b) Office Of Subseabed Disposal Research.-(1) There is hereby established an Office of Subseabed Disposal Research within the Office of Energy Research of the Department of Energy. The Office shall be headed by the Director, who shall be a member of the Senior Executive Service appointed by the Director of the Office of Energy Research, and compensated at a rate determined by applicable law.

(2) The Director of the Office of Subseabed Disposal Research shall be responsible for carrying out research, development, and demonstration activities on all aspects of subseabed disposal of high-level radioactive waste and spent nuclear fuel, subject to the general supervision of the Secretary. The Director of the Office shall be directly responsible to the Director of the Office of Energy Research, and the first such Director shall be appointed within 30 days of the date of enactment of the Nuclear Waste Policy Amendments Act of 1987.

Grants.

Contracts.

Reports.

(3) In carrying out his responsibilities under this Act, the Secretary may make grants to, or enter into contracts with, the Subseabed Consortium described in subsection (d) of this section, and other persons.

(4) (A) Within 60 days of the date of enactment of the Nuclear Waste Policy Amendments Act of 1987, the Secretary shall establish a university-based Subseabed Consortium involving leading oceanographic universities and institutions, national laboratories, and other organizations to investigate the technical and institutional feasibility of subseabed disposal.

(B) The Subseabed Consortium shall develop a research plan and budget to achieve the following objectives by 1995:

(i) demonstrate the capacity to identify and characterize potential subseabed disposal sites;

(ii) develop conceptual designs for a subseabed disposal system, including estimated costs and institutional requirements; and

(iii) identify and assess the potential impacts of subseabed disposal on the human and marine environment.

(C) In 1990, and again in 1995, the Subseabed Consortium shall report to Congress on the progress being made in achieving the objectives of paragraph (2). 
Reports.

42 USC 10221,

(5) The Director of the Office of Subseabed Disposal Research shall annually prepare and submit a report to the Congress on the activities and expenditures of the Office. ${ }^{14}$

\section{TITLE III-OTHER PROVISIONS RELATING TO RADIOACTIVE}

\section{WASTE}

\section{MISSION PLAN}

Sec. 301. (a) CONTENTS OF MISSION PLAN.-The Secretary shall prepare a comprehensive report, to be known as the mission plan, which shall provide an informational basis sufficient to permit informed decisions to be made in carrying out the repository program and the research, development, and demonstration programs required under this Act. The mission plan shall include-

(1) an identification of the primary scientific, engineering, and technical information, including any necessary demonstration of engineering or systems integration, with respect to the siting and construction of a test and evaluation facility and repositories;

(2) an identification of any information described in paragraph (1) that is not available because of any unresolved scientific, engineering, or technical questions, or undemonstrated engineering or systems integration, a schedule including specific major milestones for the research, development, and technology demonstration program required under this Act and any additional activities to be undertaken to provide such information, a schedule for the activities necessary to achieve important programmatic milestones, and an estimate of the costs required to carry out such research, development and demonstration programs;

(3) an evaluation of financial, political, legal, or institutional problems that may impede the implementation of this Act, the plans of the Secretary to resolve such problems, and recommendations for any necessary legislation to resolve such problems;

(4) any comments of the Secretary with respect to the purpose and program of the test and evaluation facility;

(5) a discussion of the significant results of research and development programs conducted and the implications for each of the different geologic media under consideration for the siting of repositories, and, on the basis of such information, a comparison of the advantages and disadvantages associated with the use of such media for repository sites;

(6) the guidelines issued under section 112(a);

(7) a description of known sites at which site characterization activities should be undertaken, a description of such siting characterization activities, including the extent of planned excavations, plans for onsite testing with radioactive or nonradioactive material, plans for any investigations activities which may affect the capability of any such site to isolate high-level radioactive waste or spent nuclear fuel, plans to control any adverse, safety-related impacts from such site characterization activities, and plans for the decon-

14 Public Law 100-203 (101 Stat. 1330) (1987) Sec. 5063, amended Title II by adding Sec. 224. 
tamination and decommissioning of such site if it is determined unsuitable for licensing as a repository;

(8) an identification of the process for solidifying high-level radioactive waste or packaging spent nuclear fuel, including a summary and analysis of the data to support the selection of the solidification process and packaging techniques, an analysis of the requirements for the number of solidification packaging facilities needed, a description of the state of the art for the materials proposed to be used in packaging such waste or spent fuel and the availability of such materials including impacts on strategic supplies and any requirements for new or reactivated facilities to produce any such materials needed, and a description of a plan, and the schedule for implementing such plan, for an aggressive research and development program to provide when needed a high-integrity disposal package at a reasonable price;

(9) an estimate of (A) the total repository capacity required to safely accommodate the disposal of all high-level radioactive waste and spent nuclear fuel expected to be generated through December 31,2020, in the event that no commercial reprocessing of spent nuclear fuel occurs, as well as the repository capacity that will be required if such reprocessing does occur; (B) the number and type of repositories required to be constructed to provide such disposal capacity; (C) a schedule for the construction of such repositories; and (D) an estimate of the period during which each repository listed in such schedule will be accepting high-level radioactive waste or spent nuclear fuel for disposal;

(10) an estimate, on an annual basis, of the costs required (A) to construct and operate the repositories anticipated to be needed under paragraph (9) based on each of the assumptions referred to in such paragraph; (B) to construct and operate a test and evaluation facility, or any other facilities, other than repositories described in subparagraph (A), determined to be necessary; and (C) to carry out any other activities under this Act; and

(11) an identification of the possible adverse economic and other impacts to the State or Indian tribe involved that may arise from the development of a test and evaluation facility or repository at a site.

(b) Submission Of Mission Plan.-(1) Not later than 15 months after the date of the enactment of this Act, the Secretary shall submit a draft mission plan to the States, the affected Indian tribes, the Commission, and other Government agencies as the Secretary deems appropriate for their comments.

Publication in Federal Register. Public inspection and agency comments.

(2) In preparing any comments on the mission plan, such agencies shall specify with precision any objections that they may have. Upon submission of the mission plan to such agencies, the Secretary shall publish a notice in the Federal Register of the submission of the mission plan and of its availability for public inspection, and, upon receipt of any comments of such agencies respecting the mission plan, the Secretary shall publish a notice in the Federal Register of the receipt of comments and of the availability of the comments for public inspection. If the Secretary does 
Plan submittal to congressional committees.

42 USC 10222.

Fees.

Fees.

Ante, p. 2229.

Collection and payment procedures. Review. not revise the mission plan to meet objections specified in such comments, the Secretary shall publish in the Federal Register a detailed statement for not so revising the mission plan.

(3) The Secretary, after reviewing any other comments made by such agencies and revising the mission plan to the extent that the Secretary may consider to be appropriate, shall submit the mission plan to the appropriate committees of the Congress not later than 17 months after the date of the enactment of this Act. The mission plan shall be used by the Secretary at the end of the first period of 30 calendar days (not including any day on which either House of Congress is not in session because of adjournment of more than 3 calendar days to a day certain) following receipt of the mission plan by the Congress.

\section{NUCLEAR WASTE FUND}

Sec. 302. (a) Contracts. - (1) In the performance of his functions under this Act, the Secretary is authorized to enter into contracts with any person who generates or holds title to high-level radioactive waste, or spent nuclear fuel, of domestic origin for the acceptance of title, subsequent transportation, and disposal of such waste or spent fuel. Such contracts shall provide for payment to the Secretary of fees pursuant to paragraphs (2) and (3) sufficient to offset expenditures in subsection (d).

(2) For electricity generated by a civilian nuclear power reactor and sold on or after the date 90 days after the date of enactment of this Act, the fee under paragraph (1) shall be equal to $1.0 \mathrm{mil}$ per kilowatt-hour.

(3) For spent nuclear fuel, or solidified high-level radioactive waste derived from spent nuclear fuel, which fuel was used to generate electricity in a civilian nuclear power reactor prior to the application of the fee under paragraph (2) to such reactor, the Secretary shall, not later than 90 days after the date of enactment of this Act, establish a 1 time fee per kilogram of heavy metal in spent nuclear fuel, or in solidified high-level radioactive waste. Such fee shall be in amount equivalent to an average charge of $1.0 \mathrm{mil}$ per kilowatt-hour for electricity generated by such spent nuclear fuel, or such solidified high-level waste derived therefrom, to be collected from any person delivering such spent nuclear fuel or high-level waste, pursuant to section 123, to the Federal Government. Such fee shall be paid to the Treasury of the United States and shall be deposited in the separate fund established by subsection (c) $126(\mathrm{~b})$. In paying such a fee, the person delivering spent fuel, or solidified high-level radioactive wastes derived therefrom, to the Federal Government shall have no further financial obligation to the Federal Government for the long-term storage and permanent disposal of such spent fuel, or the solidified high-level radioactive waste derived therefrom.

(4) Not later than 180 days after the date of enactment of this Act, the Secretary shall establish procedures for the collection and payment of the fees established by paragraph (2) and paragraph (3). The Secretary shall annually review the amount of the fees established by paragraphs (2) and (3) above to evaluate whether col- 
Transmittal to Congress.

42 USC 6421.
Disposal services, terms and conditions. License renewal or issuance.

lection of the fee will provide sufficient revenues to offset the costs as defined in subsection (d) herein. In the event the Secretary determines that either insufficient or excess revenues are being collected, in order to recover the costs incurred by the Federal Government that are specified in subsection (d), the Secretary shall propose an adjustment to the fee to insure full cost recovery.

The Secretary shall immediately transmit this proposal for such an adjustment to Congress. The adjusted fee proposed by the Secretary shall be effective after a period of 90 days of continuous session have elapsed following the receipt of such transmittal unless during such 90-day period either House of Congress adopts a resolution disapproving the Secretary's proposed adjustment in accordance with the procedures set forth for congressional review of an energy action under section 551 of the Energy Policy and Conservation Act.

(5) Contracts entered into under this section shall provide that(A) following commencement of operation of a repository, the Secretary shall take title to the high-level radioactive waste or spent nuclear fuel involved as expeditiously as practicable upon the request of the generator or owner of such waste or spent fuel; and

(B) in return for the payment of fees established by this section, the Secretary, beginning not later than January 31, 1998, will dispose of the high-level radioactive waste or spent nuclear fuel involved as provided in this subtitle.

(6) The Secretary shall establish in writing criteria setting forth the terms and conditions under which such disposal services shall be made available.

(b) Advance Contracting Requirement.-(1) (A) The Commission shall not issue or renew a license to any person to use a utilization or production facility under the authority of section 103 or 104 of the Atomic Energy Act of 1954 (42 USC 2133, 2134) unless-

(i) such person has entered into a contract with the Secretary under this section; or

(ii) the Secretary affirms in writing that such person is actively and in good faith negotiating with the Secretary for a contract under this section.

(B) The Commission, as it deems necessary or appropriate, may require as a precondition to the issuance or renewal of a license under section 103 or 104 of the Atomic Energy Act of 1954 (42 U. S. C. 2133,2134 ) that the applicant for such license shall have entered into an agreement with the Secretary for the disposal of high-level radioactive waste and spent nuclear fuel that may result from the use of such license.

(2) Except as provided in paragraph (1), no spent nuclear fuel or high-level radioactive waste generated or owned by any person (other than a department of the United States referred to in section 101 or 102 of title 5, United States Code) may be disposed of by the Secretary in any repository constructed under this Act unless the generator or owner of such spent fuel or waste has entered into a contract with the Secretary under this section by not later than- 
Disposal of radioactive waste or spent nuclear fuel.

Ante, pp. 2206, 2245.
(A) June 30, 1983; or

(B) the date on which such generator or owner commences generation of, or takes title to, such spent fuel or waste; whichever occurs later.

(3) The rights and duties of a party to a contract entered into under this section may be assignable with transfer of title to the spent nuclear fuel or high-level radioactive waste involved.

(4) No high-level radioactive waste or spent nuclear fuel generated or owned by any department of the United States referred to in section 101 or 102 of title 5, United States Code, may be disposed of by the Secretary in any repository constructed under this Act unless such department transfers to the Secretary, for deposit in the Nuclear Waste Fund, amounts equivalent to the fees that would be paid to the Secretary under the contracts referred to in this section if such waste or spent fuel were generated by any other person.

(c) Establishment Of Nuclear Waste Fund.-There hereby is established in the Treasury of the United States a separate fund, to be known as the Nuclear Waste Fund. The Waste Fund shall consist of-

(1) all receipts, proceeds, and recoveries realized by the Secretary under subsections (a), (b), and (e), which shall be deposited in the Waste Fund immediately upon their realization;

(2) any appropriations made by the Congress to the Waste Fund; and

(3) any unexpended balances available on the date of the enactment of this Act for functions or activities necessary or incident to the disposal of civilian high-level radioactive waste or civilian spent nuclear fuel, which shall automatically be transferred to the Waste Fund on such date.

(d) Use Of Waste Fund. - The Secretary may make expenditures from the Waste Fund, subject to subsection (e), only for purposes of radioactive waste disposal activities under titles I and II, including -

(1) the identification, development, licensing, construction, operation, decommissioning, and post-decommissioning maintenance and monitoring of any repository, monitored retrievable storage facility or test evaluation facility constructed under this Act;

(2) the conducting of nongeneric research, development, and demonstration activities under this Act;

(3) the administrative cost of the radioactive waste disposal program;

(4) any costs that may be incurred by the Secretary in connection with the transportation, treating, or packaging of spent nuclear fuel or high-level radioactive waste to be disposed of in a repository, to be stored in a monitored, retrievable storage site or to be used in a test and evaluation facility;

(5) the costs associated with acquisition, design, modification, replacement, operation and construction of facilities at a repository site, a monitored, retrievable storage site or a test and evaluation facility site and necessary or incident to such repository, monitored, retrievable storage facility or test and evaluation facility; and 
Ante, pp. 2220, 2225, 2253.

Report to Congress.

Budget submittal.

Ante, p. 907.

Ante, p. 927.
(6) the provision of assistance to States, units of general local government, and Indian tribes under sections 116, 118 and 219.

No amount may be expended by the Secretary under this subtitle for the construction or expansion of any facility unless such construction or expansion is expressly authorized by this or subsequent legislation. The Secretary hereby is authorized to construct one repository and one test and evaluation facility.

(e) Administration Of Waste Fund.-(1) The Secretary of the Treasury shall hold the Waste Fund and, after consultation with the Secretary, annually report to the Congress on the financial condition and operations of the Waste Fund during the preceding fiscal year.

(2) The Secretary shall submit the budget of the Waste Fund to the Office of Management and Budget triennially along with the budget of the Department of Energy submitted at such time in accordance with chapter II of title 31, United States Code. The budget of the Waste Fund shall consist of the estimates made by the Secretary of expenditures from the Waste Fund and other relevant financial matters for the succeeding 3 fiscal years, and shall be included in the Budget of the United States Government. The Secretary may make expenditures from the Waste Fund, subject to appropriations which shall remain available until expended. Appropriations shall be subject to triennial authorization.

(3) If the Secretary determines that the Waste Fund contains at any time amounts in excess of current needs, the Secretary may request the Secretary of the Treasury to invest such amounts, or any portion of such amounts as the Secretary determines to be appropriate, in obligations of the United States-

(A) having maturities determined by the Secretary of the Treasury to be appropriate to the needs of the Waste Fund; and

(B) bearing interest at rates determined to be appropriate by the Secretary of the Treasury, taking into consideration the current average market yield on outstanding marketable obligations of the United States with remaining periods to maturity comparable to the maturities of such investments, except that the interest rate on such investments shall not exceed the average interest rate applicable to existing borrowings.

(4) Receipts, proceeds, and recoveries realized by the Secretary under this section, and expenditures of amounts from the Waste Fund, shall be exempt from annual apportionment under the provisions of subchapter II of chapter 15 of title 31, United States Code.

(5) If at any time the moneys available in the Waste Fund are insufficient to enable the Secretary to discharge his responsibilities under this subtitle, the Secretary shall issue to the Secretary of the Treasury obligations in such forms and denominations, bearing such maturities, and subject to such terms and conditions as may be agreed to by the Secretary and the Secretary of the Treasury. A total of such obligations shall not exceed amounts provided in appropriation Acts. Redemption of such obligations shall be made by the Secretary from moneys available in the Waste Fund. Such obligations shall bear interest at a rate determined by the Secretary of the Treasury, which shall be not less than a rate determined by taking into consideration the average market yield on out- 
Ante, p. 937.

Interest

payments.

Deferral.

Study.

42 USC 10223.

Report to

Congress.

42 USC 10224. standing marketable obligations of the United States of comparable maturities during the month preceding the issuance of the obligations under this paragraph. The Secretary of the Treasury shall purchase any issued obligations, and for such purpose the Secretary of the Treasury is authorized to use as a public debt transactions the

proceeds from the sale of any securities issued under chapter 31 of title 31, United States Code, and the purposes for which securities may be issued under such Act are extended to include any purchase of such obligations. The Secretary of the Treasury may at any time sell any of the obligations acquired by him under this paragraph. All redemptions, purchases, and sales by the Secretary of the Treasury of obligations under this paragraph shall be treated as public debt transactions of the United States.

(6) Any appropriations made available to the Waste Fund for any purpose described in subsection (d) shall be repaid into the general fund of the Treasury, together with interest from the date of availability of the appropriations until the date of repayment. Such interest shall be paid on the cumulative amount of appropriations available to the Waste Fund, less the average undisbursed cash balance in the Waste Fund account during the fiscal year involved. The rate of such interest shall be determined by the Secretary of Treasury taking into consideration the average market yield during the month preceding each fiscal year on outstanding marketable obligations of the United States of comparable maturity. Interest payments may be deferred with the approval of the Secretary of the Treasury, but any interest payments so deferred shall themselves bear interest.

\section{ALTERNATIVE MEANS OF FINANCING}

Sec. 303. The Secretary shall undertake a study with respect to alternative approaches to managing the construction and operation of all civilian radioactive waste management facilities, including the feasibility of establishing a private corporation for such purposes. In conducting such study, the Secretary shall consult with the Director of the Office of Management and Budget, the Chairman of the Commission, and such other Federal agency representatives as may be appropriate. Such study shall be completed, and a report containing the results of such study shall be submitted to the Congress, within 1 year after the date of the enactment of this Act.

\section{OFFICE OF CIVILIAN RADIOACTIVE WASTE MANAGEMENT}

Sec. 304. (a) Establishment.-There hereby is established within the Department of Energy an Office of Civilian Radioactive Waste Management. The Office shall be headed by a Director, who shall be appointed by the President, by and with the advice and consent of the Senate, and who shall be compensated at the rate payable for level IV of the Executive Schedule under section 5315 of title 5, United States Code.

(b) Functions Of Director.-The Director of the Office shall be responsible for carrying out the functions of the Secretary under this Act, subject to the general supervision of the Secretary. The Director of the Office shall be directly responsible to the Secretary. 
Report to Congress.

42 USC 10225.

Ante, p. 2206.

Ante, p. 2217.

Regulations or guidance.

42 USC 10226.

Report to

Congress. (c) Annual Report To Congress.- The Director of the Office shall annually prepare and submit to the Congress a comprehensive report on the activities and expenditures of the Office.

(d) Annual Audit By Comptroller General.-The Comptroller General of the United States shall annually make an audit of the Office, in accordance with such regulations as the Comptroller General may prescribe. The Comptroller General shall have access to such books, records, accounts, and other materials of the Office as the Comptroller General determines to be necessary for the preparation of such audit. The Comptroller General shall submit to the Congress a report on the results of each audit conducted under this section.

\section{LOCATION OF TEST AND EVALUATION FACILITY}

Sec.305. (a) Report To Congress. - Not later than 1 year after the date of the enactment of this Act, the Secretary shall transmit to the Congress a report setting forth whether the Secretary plans to locate the test and evaluation facility at the site of a repository.

(b) Procedures. - (1) If the test and evaluation facility is to be located at any candidate site or repository site (A) site selection and development of such facility shall be conducted in accordance with the procedures and requirements established in title I with respect to the site selection and development of repositories; and (B) the Secretary may not commence construction of any surface facility for such tests and evaluation facility prior to issuance by the Commission of a construction authorization for a repository at the site involved.

(2) No test and evaluation facility may be converted into a repository unless site selection and development of such facility was conducted in accordance with the procedures and requirements established in title I with respect to the site selection and development of repositories.

(3) The Secretary may not commence construction of a test and evaluation facility at a candidate site or site recommended as the location for a repository prior to the date on which the designation of such site is effective under section 115 .

\section{NUCLEAR REGULATORY COMMISSION TRAINING AUTHORIZATION}

Sec. 306. Nuclear Regulatory Commission Training Authorization. - The Nuclear Regulatory Commission is authorized and directed to promulgate regulations, or other appropriate Commission regulatory guidance, for the training and qualifications of civilian nuclear powerplant operators, supervisors, technicians and other appropriate operating personnel. Such regulations or guidance shall establish simulator training requirements for applicants for civilian nuclear powerplant operator licenses and for operator requalification programs; requirements governing NRC administration of requalification examinations; requirements for operating tests at civilian nuclear powerplant simulators, and instructional requirements for civilian nuclear powerplant licensee personnel training programs. Such regulations or other regulatory guidance shall be promulgated by the Commission within the 12-month period following enactment of this Act, and the Commission within the 12-month period following enactment of this Act shall submit a report to Congress setting forth the actions the Commission has taken with respect to fulfilling its obligations under this section. 


\section{TITLE IV-NUCLEAR WASTE NEGOTIATOR}

42 USC 10241. Sec. 401. For purposes of this title, the term 'State' means each of the several States and the District of Columbia. 16

THE OFFICE OF THE NUCLEAR WASTE NEGOTIATOR

42 USC 10242

Sec. 402 (a) Establishment.-There is established the Office of the Nuclear Waste Negotiator that shall be an independent establishment in the executive branch. ${ }^{15}$

President of U.S. $\quad$ (b) The Nuclear Waste Negotiator.-(1) The Office shall be headed by a Nuclear Waste Negotiator who shall be appointed by the President, by and with the advice and consent of the Senate. The Negotiator shall hold office at the pleasure of the President, and shall be compensated at the rate provided for level III of the Executive Schedule in section 5314 of title 5, United States Code.

(2) The Negotiator shall attempt to find a state or Indian tribe willing to host a repository or monitored retrievable storage facility at a technically qualified site on reasonable terms and shall negotiate with any State or Indian tribe which expresses an interest in hosting a repository or monitored retrievable storage facility.

\section{DUTIES OF THE NEGOTIATOR}

42 USC 10243.

Sec. 403. (a) Negotiations With Potential Hosts.-(1) The Negotiator shall-

(A) seek to enter into negotiations on behalf of the United States, with-

(i) the Governor of any State in which a potential site is located; and

(ii) the governing body of any Indian tribe on whose reservation a potential site is located; and

(B) attempt to reach a proposed agreement between the United States and any such State or Indian tribe specifying the terms and conditions under which such State or tribe would agree to host a repository of monitored retrievable storage facility within such State or reservation.

(2) In any case in which State law authorizes any person or entity other than the Governor to negotiate a proposed agreement under this section on behalf of the State, any reference in this title to the Governor shall be considered to refer instead to such other person or entity.

(b) Consultation With Affected States, Subdivisions Of States, And Tribes.-In addition to entering into negotiations under subsection (a), the Negotiator shall consult with any State, affected unit of local government, or any Indian tribe that the Negotiator determines may be affected by the siting of a repository or monitored retrievable storage facility and may include in any proposed agreement such terms and conditions relating to the interest of such States, affected units of local government, or Indian tribes as the Negotiator determines to be reasonable and appropriate.

\footnotetext{
${ }^{16}$ Public Law 102-486 (102 Stat 2923); Oct. 24, 1992.

${ }^{15}$ Public Law 100-507 (102 Stat 2541) (1988) Sec. 1 amended Sec. 402(a).
} 
(c) Consultation With Other Federal Agencies. - The Negotiator may solicit and consider the comments of the Secretary, the Nuclear Regulatory Commission, or any other Federal agency on the suitability of any potential site for site characterization. Nothing in this subsection shall be construed to require the Secretary, the Nuclear Regulatory Commission, or any other Federal agency to make a finding that any such site is suitable for site characterization.

(d) Proposed Agreement.-(1) The Negotiator shall submit to the Congress any proposed agreement between the United States and a State or Indian tribe negotiated under subsection (a) and an environmental assessment prepared under section 404(a) for the site concerned.

(2) Any such proposed agreement shall contain such terms and conditions (including such financial and institutional arrangements) as the Negotiator and the host State or Indian tribe determine to be reasonable and appropriate and shall contain such provisions as are necessary to preserve any right to participation or compensation of such State, affected unit of local government, or Indian tribe under sections 116(c), 117, and 118(b).

(3) (A) No proposed agreement entered into under this section shall have legal effect unless enacted into Federal law.

(B) A State or Indian tribe shall enter into an agreement under this Section in accordance with the laws of such State or tribe. Nothing in this section may be construed to prohibit the disapproval of a proposed agreement between a State and the United States under this section by a referendum or an act of the legislature of such State.

(4) Notwithstanding any proposed agreement under this section, the Secretary may construct a repository or monitored retrievable storage facility at a site agreed to under this title only if authorized by the Nuclear Regulatory Commission in accordance with the Atomic Energy Act of 1954 (42 U.S.C. 2012 et seq.), title II of the Energy Reorganization Act of 1982 (42 U.S.C. 5841 et seq.) and any other law applicable to authorization of such construction.

42 USC 10244.

\section{ENVIRONMENTAL ASSESSMENT OF SITES}

Sec. 404. (a) In General.- Upon the request of the Negotiator, the Secretary shall prepare an environmental assessment of any site that is the subject of negotiations under section 403(a).

(b) Contents. - (1) Each environmental assessment prepared for a repository site shall include a detailed statement of the probable impacts of characterizing such site and the construction and operation of a repository at such site.

(2) Each environmental assessment prepared for a monitored retrievable storage facility site shall include a detailed statement of the probable impacts of construction and operation of such a facility at such site.

(c) Judicial Review.-The issuance of an environmental assessment under subsection (a) shall be considered to be a final agency action subject to judicial review in accordance with the provisions of chapter 7 of title 5, United States Code, section 119. 
(d) Public Hearings. - (1) In preparing an environmental assessment for any repository or monitored retrievable storage facility site, the Secretary shall hold public hearings in the vicinity of such site to inform the residents of the area in which such site is located that such site is being considered and to receive their comments.

(2) At such hearings, the Secretary shall solicit and receive any recommendations of such residents with respect to issues that should be addressed in the environmental assessment required under subsection (a) and the site characterization plan described in section 113 (b) (1).

(e) Public Availability.-Each environmental assessment prepared under subsection (a) shall be made available to the public.

(f) Evaluation Of Sites.-(1) In preparing an environmental assessment under subsection (a), the Secretary shall use available geophysical, geologic, geochemical and hydrologic, and other information and shall not conduct any preliminary borings or excavations at any site that is the subject of such assessment unless-

(A) such preliminary boring or excavation activities were in progress on or before the date of the enactment of the Nuclear Waste Policy Amendments Act of 1987; or

(B) the Secretary certifies that, in the absence of preliminary borings or excavations, adequate information will not be available to satisfy the requirements of this Act or any other law.

(2) No preliminary boring or excavation conducted under this section shall exceed a diameter of 40 inches.

42 USC 10245.

\section{SITE CHARACTERIZATION; LICENSING}

Sec. 405. (a) Site Characterization.-Upon enactment of legislation to implement an agreement to site a repository negotiated under section 403(a), the Secretary shall conduct appropriate site characterization activities for the site that is the subject of such agreement subject to the conditions and terms of such agreement. Any such site characterization activities shall be conducted in accordance with section 113, except that references in such section to the Yucca Mountain site and the State of Nevada shall be deemed to refer to the site that is the subject of the agreement and the State of Indian tribe entering into the agreement.

(b) Licensing.-(1) Upon completion of site characterization activities carried out under subsection (a), the Secretary shall submit to the $\mathrm{Nu}$ clear Regulatory Commission an application for construction authorization for a repository at such site.

(2) The Nuclear Regulatory Commission shall consider an application for a construction authorization for a repository or monitored retrievable storage facility in accordance with the laws applicable to such applications, except that the Nuclear Regulatory Commission shall issue a final decision approving or disapproving the issuance of a construction authorization not later than 3 years after the date of the submission of such application.

\section{MONITORED RETRIEVABLE STORAGE}

42 USC 10246.

Sec. 406. (a) Construction And Operation. - Upon enactment of legislation to implement an agreement negotiated under section 403(a) to site a monitored retrievable storage facility, the Secretary shall con- 
Grants.

struct and operate such facility as part of an integrated nuclear waste management system in accordance with the terms and conditions of such agreement.

(b) Financial Assistance.-The Secretary may make grants to any State, Indian tribe, or affected unit of local government to assess the feasibility of siting a monitored retrievable storage facility under this section at a site under the jurisdiction of such State, tribe, or affected unit of local government.

\section{ENVIRONMENTAL, IMPACT STATEMENT}

42 USC 10247. Sec.407. (a)In General.-Issuance of a construction authorization for a repository or monitored retrievable storage facility under section 405 (b) shall be considered a major Federal action significantly affecting the quality of the human environment for purposes of the National Environmental Policy Act of 1969 (42 U.S.C. 4321 et seq.)

(b) Preparation.- A final environmental impact statement shall be prepared by the Secretary under such Act and shall accompany any application to the Nuclear Regulatory Commission for a construction authorization.

(c) Adoption.-(1) Any such environmental impact statement shall, to the extent practicable, be adopted by the Nuclear Regulatory Commission, in accordance with section 1506.3 of title 40 , Code of Federal Regulations, in connection with the issuance by the Nuclear Regulatory Commission of a construction authorization and license for such repository or monitored retrievable storage facility.

(2) (A) In any such statement prepared with respect to a repository to be constructed under this title at the Yucca Mountain site, the Nuclear Regulatory Commission need not consider the need for a repository, the time of initial availability of a repository, alternate sites to the Yucca Mountain site, or nongeologic alternatives to such site.

(B) In any such statement prepared with respect to a repository to be constructed under this title at a site other than the Yucca Mountain site, the Nuclear Regulatory Commission need not consider the need for a repository, the time of initial availability of a repository, or nongeologic alternatives to such site but shall consider the Yucca Mountain site as alternative to such site in the preparation of such statement.

42 USC 10248.

\section{ADMINISTRATIVE POWERS OF THE NEGOTIATOR}

Sec. 408. In carrying out his functions under this title, the Negotiator may-

(1) appoint such officers and employees as he determines to be necessary and prescribe their duties;

(2) obtain services as authorized by section 3109 of title 5 , United States Code, at rates not to exceed the rate prescribed for grade GS-18 of the General Schedule by section 5332 of title 5, United States Code;

(3) promulgate such rules and regulations as may be necessary to carry out such functions;

(4) utilize the services, personnel, and facilities of other Federal agencies (subject to the consent of the head of any such agency); 
Contracts.

42 USC 10249.

42 USC 10250.

42 USC 10251.

2 USC 10261.

2 USC 10262.

President of U.S.
(5) for purposes of performing administrative functions under this title, and to the extent funds are appropriated, enter into and perform such contracts, leases, cooperative agreements, or other transactions as may be necessary and on such terms as the Negotiator determines to be appropriate, with any agency or instrumentality of the United States, or with any public or private person or entity;

(6) accept voluntary and uncompensated services, notwithstanding the provisions of section 1342 of title 31, United States Code;

(7) adopt an official seal, which shall be judicially noticed;

(8) use the United States mails in the same manner and under the same conditions as other departments and agencies of the United States;

(9) hold such hearings as are necessary to determine the views of interested parties and the general public; and

(10) appoint advisory committees under the Federal Advisory Committee Act (5 U.S.C. App.)

\section{COOPERATION OF OTHER DEPARTMENTS AND AGENCIES}

Sec. 409. Each department, agency, and instrumentality of the United States, including any independent agency, may furnish the Negotiator such information as he determines to be necessary to carry out his functions under this title.

\section{TERMINATION OF THE OFFICE}

Sec. 410. The Office shall cease to exist not later than 30 days after the date 7 years after the date of the enactment of the Nuclear Waste Policy Amendments Act of 1987.17

\section{AUTHORIZATION OF APPROPRIATIONS}

Sec. 411. Notwithstanding subsection (d) of section 302, and subject to subsection (e) of such section, there are authorized to be appropriated for expenditures from amounts in the Waste Fund established in subsection (c) of such section, such sums as may be necessary to carry out the provisions of this title. ${ }^{18}$

\section{TITLE V-NUCLEAR WASTE TECHNICAL REVIEW BOARD} DEFINITIONS

Sec. 501. As used in this title:

(1) The term 'Chairman' means the Chairman of the Nuclear Waste Technical Review Board.

(2) The term 'Board' means the Nuclear Waste Technical Review Board established under section 502.

NUCLEAR WASTE TECHNICAL REVIEW BOARD

Sec. 502. (a) Establishment.-There is established a Nuclear Waste Technical Review Board that shall be an independent establishment within the executive branch.

(b) Members. - (1) The Board shall consist of 11 members who shall be appointed by the President not later than 90 days after the date of the

${ }^{17}$ Public Law 102-486 (106 Stat. 2923).

${ }^{10}$ Public Law 100-203 (101 Stat. 1330) (1987) Sec. 5041, added Title IV. 
President of U.S.

enactment of the Nuclear Waste Policy Amendments Act of 1987 from among persons nominated by the National Academy of Sciences in accordance with paragraph (3).

(2) The President shall designate a member of the Board to serve as chairman.

(3) (A) The National Academy of Sciences shall, not later than 90 days after the date of the enactment of the Nuclear Waste Policy Amendments Act of 1987, nominate not less than 22 persons for appointment to the Board from among persons who meet the qualifications described in subparagraph (C).

(B) The National Academy of Sciences shall nominate not less than 2 persons to fill any vacancy on the Board from among persons who meet the qualifications described in subparagraph (C).

(C) (i) Each person nominated for appointment to the Board shall be-

(I) eminent in a field of science or engineering, including environmental sciences; and

(II) selected solely on the basis of established records of distinguished service.

(ii) The membership of the Board shall be representative of the broad range of scientific and engineering disciplines related to activities under this title.

(iii) No person shall be nominated for appointment to the Board who is an employee of-

(I) the Department of Energy;

(II) a national laboratory under contract with the Department of Energy; or

(III) an entity performing high-level radioactive waste or spent nuclear fuel activities under contract with the Department of Energy.

(4) Any vacancy on the Board shall be filled by the nomination and appointment process described in paragraphs (1) and (3).

(5) Members of the Board shall be appointed for terms of 4 years, each such term to commence 120 days after the date of enactment of the Nuclear Waste Policy Amendments Act of 1987, except that of the 11 members first appointed to the Board, 5 shall serve for 2 years and 6 shall serve for 4 years, to be designated by the President at the time of appointment.

42 USC 10263.

\section{FUNCTIONS}

Sec. 503. The Board shall evaluate the technical and scientific validity of activities undertaken by the Secretary after the date of the enactment of the Nuclear Waste Policy Amendments Act of 1987, including-

(1) site characterization activities; and

(2) activities relating to the packaging or transportation of highlevel radioactive waste or spent nuclear fuel.

42 USC 10264.

INVESTIGATORY POWERS

Sec. 504. (a) Hearings. - Upon request of the Chairman or a majority of the members of the Board, the Board may hold such hearings, sit and act at such times and places, take such testimony, and receive such evi- 
42 USC 10265.

dence, as the Board considers appropriate. Any member of the Board may administer oaths or affirmations to witnesses appearing before the Board.

(b) Production Of Documents.-(1) Upon the request of the Chairman or a majority of the members of the Board, and subject to existing law, the Secretary (or any contractor of the Secretary) shall provide the Board with such records, files, papers, data, or information as may be necessary to respond to any inquiry of the Board under this title.

(2) Subject to existing law, information obtainable under paragraph (1) shall not be limited to final work products of the Secretary, but shall include drafts of such products and documentation of work in progress.

\section{COMPENSATION OF MEMBERS}

Sec. 505. (a) In General. - Each member of the Board shall be paid at the rate of pay payable for level III of the Executive Schedule for each day (including travel time) such member is engaged in the work of the Board.

(b) Travel Expenses.-Each member of the Board may receive travel expenses, including per diem in lieu of subsistence, in the same manner as is permitted under sections 5702 and 5703 of title 5, United States Code.

STAFF

42 USC 10266.

Sec. 506. (a) Clerical Staff.-(1) Subject to paragraph (2), the Chairman may appoint and fix the compensation of such clerical staff as may be necessary to discharge the responsibilities of the Board.

(2) Clerical staff shall be appointed subject to the provisions of title 5, United States Code, governing appointments in the competitive service, and shall be paid in accordance with the provisions of chapter 51 and subchapter $\mathrm{III}$ of chapter 53 of such title relating to classification and General Schedule pay rates.

(b) Professional Staff.-(1) Subject to paragraphs (2) and (3), the Chairman may appoint and fix the compensation of such professional staff as may be necessary to discharge the responsibilities of the Board.

(2) Not more than 10 professional staff members may be appointed under this subsection.

(3) Professional staff members may be appointed without regard to the provisions of title 5, United States Code, governing appointments in the competitive service,and may be paid without regard to the provisions of chapter 51 and subchapter III of chapter 53 of such title relating to classification and General Schedule pay rates, except that no individual so appointed may receive pay in excess of the annual rate of basic pay payable of GS-18 of the General Schedule.

42 USC 10267. Sec. 507. (a) General Services.-To the extent permitted by law and requested by the Chairman, the Administrator of General Services shall provide the Board with necessary administrative services facilities, and support on a reimbursable basis.

(b) Accounting, Research, And Technology Assessment Services. - The Comptroller General, the Librarian of Congress, and the Di- 
rector of the Office of Technology Assessment shall, to the extent permitted by law and subject to the availability of funds, provide the Board with such facilities, support, funds and services, including staff, as may be necessary for the effective performance of the functions of the Board.

(c) Additional Support.-Upon the request of the Chairman, the Board may secure directly from the head of any department or agency of the United States information necessary to enable it to carry out this title.

(d) Mails.-The Board may use the United States mails in the same manner and under the same conditions as other departments and agencies of the United States.

(e) Experts And Consultants.-Subject to such rules as may be prescribed by the Board, the Chairman may procure temporary and intermittent services under section 3109(b) of title 5 of the United States Code, but at rates for individuals not to exceed the daily equivalent of the maximum annual rate of basic pay payable for GS-18 of the General Schedule.

42 USC 10268.

\section{REPORT}

Sec. 508. The Board shall report not less than 2 times peryear to Congress and the Secretary its findings, conclusions, and recommendations. The first such report shall be submitted not later than 12 months after the date of the enactment of the Nuclear Waste Policy Amendments Act of 1987.

\section{AUTHORIZATION OF APPROPRIATIONS}

42 USC 10269. Sec. 509. Notwithstanding subsection (d) of section 302, and subject to subsection (e) of such section, there are authorized to be appropriated for expenditures from amounts in the Waste Fund established in subsection (c) of such section such sums as may be necessary to carry out the provisions of this title.

\section{TERMINATION OF THE BOARD}

42 USC 10270. Sec. 510. The Board shall cease to exist not later than 1 year after the date on which the Secretary begins disposal of high-level radioactive waste or spent nuclear fuel in a repository. ${ }^{17}$

\footnotetext{
17Public Law 100-203 (101 Stat. 1330) (1987) Sec. 5051, added Tille V.
} 


\section{OMNIBUS BUDGET RECONCILIATION ACT OF 1987}

Public Law 100-203

(101 Stat. 1330-251)

\section{TABLE OF CONTENTS}

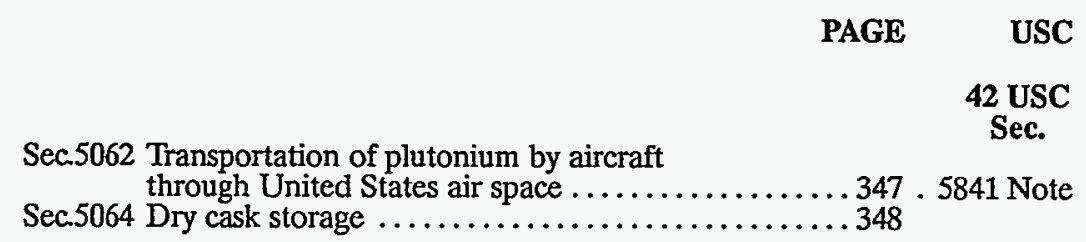


42 USC 5841 note.

\author{
Sec. 5062. Transportation Of Plutonium By Aircraft Through United \\ States Air Space. -
}

(a) In General.-Notwithstanding any other provision of law, no form of plutonium may be transported by aircraft through the air space of the United States from a foreign nation to a foreign nation unless the $\mathrm{Nu}$ clear Regulatory Commission has certified to Congress that the container in which such plutonium is transported is safe, as determined in accordance with subsection (b), the second undesignated paragraph under section 201 of Public Law 94-79 (89 Stat. 413; 42 U.S.C. 5841 note), and all other applicable laws.

(b) Responsibilities Of The Nuclear Regulatory Commission.-

(1) Determination Of Safety.-The Nuclear Regulatory Commission shall determine whether the container referred to in subsection (a) is safe for use in the transportation of plutonium by aircraft and transmit to Congress a certification for the purposes of such subsection in the case of each container determined to be safe.

(2) Testing.-In order to make a determination with respect to a container under paragraph (1), the Nuclear Regulatory Commission shall-

(A) require an actual drop test from maximum cruising altitude of a full-scale sample of such container loaded with test materials; and

(B) require an actual crash test of a cargo aircraft fully loaded with full-scale samples of such container loaded with test material unless the Commission determines, after consultation with an independent scientific review panel, that the stresses on the container produced by other tests used in developing the container exceed the stresses which would occur during a worst case plutonium air shipment accident.

(3) Limitation.-The Nuclear Regulatory Commission may not certify under this section that a container is safe for use in the transportation of plutonium by aircraft if the container ruptured or released its contents during testing conducted in accordance with paragraph (2).

(4) Evaluation.-The Nuclear Regulatory Commission shall evaluate the container certification required by title $I I$ of the Energy Reorganization Act of 1974 (42 U.S.C. 5841 et seq.) and subsection (a) in accordance with the National Environmental Policy Act of 1969 (83 Stat. 852; 42 U.S.C. 4321 et. seq.) and all other applicable law.

(c) Content Of Certification.-A certification referred to in subsection (a) with respect to a container shall include-

(1) the determination of the Nuclear Regulatory Commission as to the safety of such container;

(2) a statement that the requirements of subsection (b)(2) were satisfied in the testing of such container; and 
(3) a statement that the container did not rupture or release its contents into the environment during testing.

(d) Design Of Testing Procedures.-The tests required by subsection (b) shall be designed by the Nuclear Regulatory Commission to replicate actual worst case transportation conditions to the maximum extent practicable. In designing such tests, the Commission shall provide for public notice of the proposed test procedures, provide a reasonable opportunity for public comment on such procedures, and consider such comments, if any.

(e) Testing Results: Reports And Public Disclosure.-The Nuclear Regulatory Commission shall transmit to congress a report on the results of each test conducted under this section and shall make such results available to the public.

President of U.S. (f) Alternative Routes And Means Of Transportation.-With respect to any shipments of plutonium from a foreign nation to a foreign nation which are subject to United States consent rights contained in an Agreement for Peaceful Nuclear Cooperation, the President is authorized to make every effort to pursue and conclude arrangements for alternative routes and means of transportation, including sea shipment. All such arrangements shall be subject to stringent physical security conditions, and other conditions designed to protect the public health and safety, and provisions of this section, and all other applicable laws.

(g) Inapplicability To Medical Devices. - Subsections (a) through (e) shall not apply with respect to plutonium in any form contained in a medical device designed for individual human application.

(h) Inapplicability To Military Uses. - Subsections (a) through (e) shall not apply to plutonium in the form of nuclear weapons nor to other shipments of plutonium determined by the Department of Energy to be directly connected with the United States national security or defense programs.

(i) Inapplicability To Previously Certified Containers.-This section shall not apply to any containers for the shipment of plutonium previously certified as safe by the Nuclear Regulatory Commission under Public Law 94-79 (89 Stat. 413; 42 U.S.C. 5841 note).

(j) Payment Of Costs. All costs incurred by the Nuclear Regulatory Commission associated with the testing program required by this section, and administrative costs related thereto, shall be reimbursed to the Nuclear Regulatory Commission by any foreign country receiving plutonium shipped through United States airspace in containers specified by the Commission. ${ }^{18}$

Sec. 5064. Dry Cask Storage.-

(a) Study.-During the period between the date of the enactment of the Nuclear Waste Policy Amendment Act of 1987 and October 1, 1988, the Secretary of Energy (hereinafter in this section referred to as the "Secretary") shall conduct a study and evaluation of the use of dry cask storage technology at the sites of civilian nuclear power reactors for the temporary storage of spent nuclear fuel until such time as a permanent geologic repository has been constructed and licensed by the Nuclear

${ }^{18}$ Public Law 100-203 (101 Stint. 1330) (1987) Sec. 5062, is not part of the Nuclear Waste Policy act as amended. 
Regulatory Commission (hereinafter in this section referred to as the "Commission" and is capable of receiving spent nuclear fuel. The Secretary shall report to Congress of the study under this paragraph by October 1, 1988.

(b) Contents Of Study. - In conducting the study under paragraph (1) the Secretary shall-

(1) consider the costs of dry cask storage technology, the extent to which dry cask storage on the site of civilian nuclear power reactors will affect human health and the environment, the extent to which the storage on the sites of civilian nuclear power reactors affects the costs and risk of transporting spent nuclear fuel to a central facility such as a monitored retrievable storage facility, and any other factors the Secretary considers appropriate;

(2) consider the extent to which amounts in the Nuclear Waste Fund established in section 302(c) of the Nuclear Waste Policy Act of 1982 (42 USC 10222(c)) can be used, and should be used, to provide funds to construct, operate, maintain, and safeguard spent nuclear fuel in dry cask storage at the sites for civilian nuclear power reactors;

(3) consult with the Commission and include the views of the Commission in the report under paragraph (1); and

(4) solicit the views of State and local governments and the public. 19

\footnotetext{
10Public Law 100-203 (101 Stat. 1330) (1987) Sec. 5064, is not part of the Nuclear Waste Policy act as amended.
} 


\title{
URANIUM MILL TAILINGS RADIATION CONTROL ACT OF 1978,
} AS AMENDED

Public Law 95-604 [H.R. 13650]

(92 Stat. 3021)

An Act

SHORT TITLE AND TABLE OF CONTENTS

TABLE OF CONTENTS

\author{
PAGE USC \\ 42 USC \\ Sec. \\ Sec. 1. Short title and table of contents. ..............350 ... 7901 \\ Sec. 2. Findings and purposes. ......................
}

TITLE I - REMEDIAL ACTION PROGRAM

Sec. 101 Definitions. .................................... 7911

Sec. 102. Destination of processing sites. ................352 ..... 7912

Sec. 103. State cooperative agreements. .......................... 7913

Sec. 104 Acquisition and disposition of land

and materials. ................................ 79514

Sec 105. Indian tribe cooperative agreements. ......................... 75815

Sec.106. Acquisition of lands by Secretary. .............. 359 ..... 7916

Sec.107. Financial assistance. .............................. 79917

Sec.108. Remedial action. ......................................... 79018

Sec.109. Rules. .............................. $361 \ldots \ldots .7919$

Sec.110. Enforcement........................................... $761 \ldots 20$

Sec.111. Public participation. ................................ 7921

Sec.112. Termination; authorization. ...................362 .... 7922

Sec.113. Limitation. ...........................362 .... 7923

Sec.114. Reports to Congress. .............................. $762 \ldots 24$

Sec.115. Active operations: liability for remedial action. . ............................ 363 . 7925

TITLE II - URANIUM MILL TAILINGS LICENSING AND REGULATIONS

Sec. 201. Definition. ...................................... 2014

Sec. 202. Custody of disposal site. ..................364 .... 2111

Sec. 203. Authority to establish certain

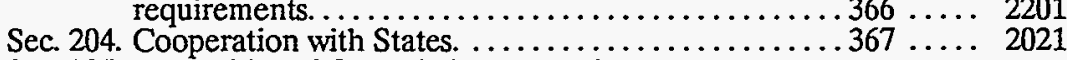

Sec. 205. Authorities of Commission respecting certain byproduct material. .................370 ... 2111

Sec. 206. Authority of Environmental Protection Agency respecting certain byproduct material. ................................371 .... 2021

Sec. 207. Authorization of appropriations for grants. ....................................... 2021

Sec. 208. Effective date. ................................... 2014

Sec. 209. Consolidation of licenses and procedures............................... 2113

TITLE III - STUDY AND DESIGNATION OF TWO MILL TAILING SITES IN NEW MEXICO

Sec. 301. Study. ................................. $373 \ldots \ldots .7941$

Sec. 302. Designation by Secretary. .......................... 3744942 


\section{URANIUM MILL TAILINGS RADIATION CONTROL ACT OF 1978, AS AMENDED}

42 USC 7901.

\section{FINDINGS AND PURPOSES}

Sec. 2. (a) The Congress finds that uranium mill tailings located at active and inactive mill operations may pose a potential and significant radiation health hazard to the public, and that the protection of the public health, safety, and welfare and the regulation of interstate commerce require that every reasonable effort be made to provide for the stabilization, disposal, and control in a safe and environmentally sound manner of such tailings in order to prevent or minimize radon diffusion into the environment and to prevent or minimize other environmental hazards from such tailings.

(b) The purposes of this Act are to provide-

(1) in cooperation with the interested States, Indian tribes, and the persons who own or control inactive mill tailings sites, a program of assessment and remedial action at such sites, including, where appropriate, the reprocessing of tailings to extract residual uranium and other mineral values where practicable, in order to stabilize and control such tailings in a safe and environmentally sound manner and to minimize or eliminate radiation health hazards to the public, and

(2) a program to regulate mill tailings during uranium or thorium ore processing at active mill operations and after termination of such operations in order to stabilize and control such tailings in a safe and environmentally sound manner and to minimize or eliminate radiation health hazards to the public.

\section{TITLE I-REMEDIAL ACTION PROGRAM}

42 USC 7911.

\section{DEFINITIONS}

Sec. 101. For purposes of this title-

(1) The term "Secretary" means the Secretary of Energy.

(2) The term "Commission" means the Nuclear Regulatory Commission.

(3) The term "Administrator" means the Administrator of the Environmental Protection Agency.

(4) The term "Indian tribe" means any tribe, band, clan, group, pueblo, or community of Indians recognized as eligible for services provided by the Secretary of the Interior to Indians.

(5) The term "person" means any individual association, partnership, corporation, firm, joint venture, trust, government entity, and any other entity, except that such term does not include any Indian or Indian tribe.

(6) The term "processing site" means-

(A) any site, including the mill, containing residual radioactive materials at which all or substantially all of the uranium was produced for sale to any Federal agency prior to January 1, 1971 under a contract with any Federal agency, except in the case of a site at or near Slick Rock, Colorado, unless- 
42 USC 2011

note.

42 USC 2021.

42 USC 7912. (i) such site was owned or controlled as of January 1, 1978 , or is thereafter owned or controlled by any Federal agency, or

(ii) a license (issued by the Commission or its predecessor agency under the Atomic Energy Act of 1954 or by a State as permitted under section 274 of such Act) for the production at such site of any uranium or thorium product derived from ores is in effect on January 1,1978 , or is issued or renewed after such date; and

(B) any other real property or improvement thereon which-

(i) is in the vicinity of such site, and

(ii) is determined by the Secretary, in consultation with the Commission, to be contaminated with residual radioactive materials derived from such site.

Any ownership or control of an area by a Federal agency which is acquired pursuant to a cooperative agreement under this title shall not be treated as ownership or control by such agency for purposes of subparagraph (A)(i). A license for the production of any uranium product from residual radioactive materials shall not be treated as a license for production from ores within the meaning of subparagraph (A)(ii) if such production is in accordance with section 108(b).

(7) The term "residual radioactive material" means-

(A) waste (which the Secretary determines to be radioactive) in the form of tailings resulting from the processing of ores for the extraction of uranium and other valuable constituents of the ores; and

(B) other waste (which the Secretary determines to be radioactive) at a processing site which relate to such processing, including any residual stock of unprocessed ores or low-grade materials.

(8) The term "tailings" means the remaining portion of a metalbearing ore after some or all of such metal, such as uranium, has been extracted.

(9) The term "Federal agency" includes any executive agency as defined in section 105 of title 5 of the United States Code.

(10) The term "United States" means the 48 contiguous States and Alaska, Hawaii, Puerto Rico, the District of Columbia, and the territories and possessions of the United States.

\section{DESIGNATION OF PROCESSING SITES}

Sec. 102 (a)(1) As soon as practicable, but no later than one year after enactment of this Act, the Secretary shall designate processing sites at or near the following locations:

Salt Lake City, Utah

Green River, Utah

Mexican Hat, Utah

Durango, Colorado

Grand Junction, Colorado

Rifle, Colorado (two sites)

Gunnison, Colorado

Naturita, Colorado 


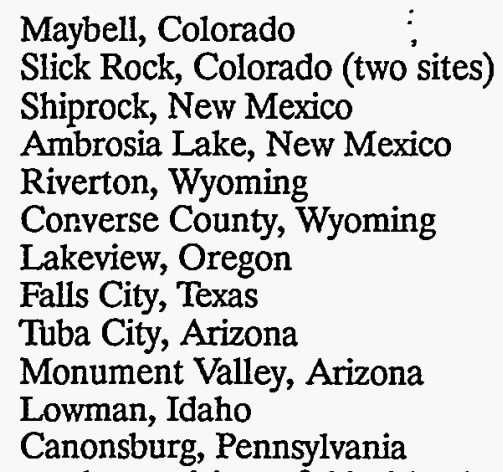

Remedial action.

86 Stat. 222.

Health hazard assessment.

Notification. Subject to the provisions of this title, the Secretary shall complete remedial action at the above listed sites before his authority terminates under this title. The Secretary shall within one year of the date of enactment of this Act also designate all other processing sites within the United States which he determines requires remedial action to carry out the purposes of this title. In making such designation, the Secretary shall consult with the Administrator, the Commission, and the affected States, and in the case of Indian lands, the appropriate Indian tribe and the Secretary of the Interior.

(2) As part of his designation under this subsection, the Secretary, in consultation with the Commission, shall determine the boundaries of each such site.

(3) No site or structure with respect to which remedial action is authorized under Public Law 92-314 in Grand Junction, Colorado, may be designated by the Secretary as a processing site under this section.

(b) Within one year from the date of the enactment of this Act, the Secretary shall assess the potential health hazard to the public from the residual radioactive materials at designated processing sites. Based upon such assessment,the secretary shall, within such one year period, establish priorities for carrying out remedial action at each such site. In establishing such priorities, the Secretary shall rely primarily on the advice of the Administrator.

(c) Within thirty days after making designations of processing sites and establishing the priorities for such sites under this section, the Secretary shall notify the Governor of each affected State, and where appropriate, the Indian tribes and the Secretary of the Interior.

(d) The designations made, and priorities established, by the Secretary under this section shall be final and not be subject to judicial review.

(e)(1) The designation of processing sites within one year after enactment under this section shall include, to the maximum extent practicable, the areas referred to in section 101(6)(B).

(2) Notwithstanding the one year limitation contained in this section, the Secretary may, after such one year period, include any areas described in section 101(6)(B) as part of a processing site designated under this section if he determines such inclusion to be appropriate to carry out the purposes of this title.

(3) The Secretary shall designate as a processing site within the meaning of section 101(6) any real property, or improvements 
42 USC 7911.

42 USC 7917.

42 USC 7913.

Terms and Conditions.

Written consent.

Waiver. thereon, in Edgemont, South Dakota, that-

" $(\mathrm{A})$ is in the vicinity of the Tennessee Valley Authority uranium mill site at Edgemont (but not including such site), and

"(B) is determined by the Secretary to be contaminated with residual radioactive materials.

In making the designation under this paragraph, the Secretary shall consult with the Administrator, the Commission and the State of South Dakota. The provisions of this title shall apply to the site so designated in the same manner and to the same extent as to the sites designated under subsection (a) except that, in applying such provisions to such site, any reference in this title to the date of enactment of this Act shall be treated as a reference to the date of the enactment of this paragraph and in determining the State share under section 107 of the costs of remedial action, there shall be credited to the State, expenditures made by the State prior to the date of the enactment of this paragraph which the Secretary determines would have been made by the State or the United States in carrying out the requirements of this title.".1

\section{STATE COOPERATIVE AGREEMENTS}

Sec. 103. (a) After notifying a State of the designation referred to in section 102 of this title, the Secretary subject to section 113, is authorized to enter into cooperative agreement with such State to perform remedial actions at each designated processing site in such State (other than a site location on Indian lands referred to in section 105). The Secretary shall, to the greatest extent practicable, enter into such agreements and carry out such remedial actions in accordance with the priorities established by him under section 102 . The Secretary shall commence preparations for cooperative agreements with respect to each designated processing site as promptly as practicable following the designation of each site.

(b) Each cooperative agreement under this section shall contain such terms and conditions as the Secretary deems appropriate and consistent with the purposes of this Act, including, but not limited to, a limitation on the use of Federal assistance to those costs which are directly required to complete the remedial action selected pursuant to section 108.

(c)(1) Except where the State is required to acquire the processing site as provided in subsection (a) of section 104, each cooperative agreement with a State under section 103 shall provide that the State shall obtain, in a form prescribed by the Secretary, written consent from any person holding any record interest in the designated processing site for the Secretary or any person designated by him to perform remedial action at such site.

(2) Such written consent shall include a waiver by each such person on behalf of himself, herself, his heirs, successors, and assigns-

(A) releasing the United States of any liability or claims thereof by such person, his heirs, successors, and assigns concerning such remedial action, and 
Post, p. 3039.

(B) holding the United States harmless against any claim by such person on behalf of himself, his heirs, successors, or assigns arising out of the performance of any remedial action.

(d) Each cooperative agreement under this section shall require the State to assure that the Secretary, the Commission, and the Administrator and their authorized representatives have a permanent right of entry at any time to inspect the processing site and the site provided pursuant to section 104(b)(1) in furtherance of the provisions of this title and to carry out such agreement and enforce this Act and any rules prescribed under this Act. Such right of entry under this section or section 106 into an area described in section 101(6)(B) shall terminate on completion of the remedial action, as determined by the Secretary.

(e) Each agreement under this section shall take effect only upon the concurrence of the Commission with the terms and conditions thereof.

(f) The Secretary may, in any cooperative agreement enter into this section or section 105, provide for reimbursement of the actual costs, as determined by the Secretary, of any remedial action performed with respect to so much of a designated processing site as is described in section 101(6)(B). Such reimbursement shall be made only to a property owner of record at the time such remedial action was undertaken and only with respect to costs incurred by such property owner. No such reimbursement may be made unless-

(1) such remedial action was completed prior to enactment of this Act, and unless the application for such reimburse was filed by such owner within one year after a agreement under this section or section 105 is approved by the Secretary and the Commission, and

(2) the Secretary is satisfied that such action adequately achieves the purposes of this Act with respect to the site concerned and is consistent with the standards established by the Administrator pursuant to section 275(a) of the Atomic Energy Act of 1954.

\section{ACQUISITION AND DISPOSITION OF LANDS AND MATERIALS}

42 USC 7914. Sec. 104. (a) Each cooperative agreement under section 103 shall require the State where determined appropriate by the Secretary with the concurrence of the Commission, to acquire any designated processing site, including where appropriate any interest therein. In determining whether to require the State to acquire a designated processing site or interest therein, consideration shall be given to the prevention of windfall profits.

Residual radioactive material, removal.

(b)(1) If the Secretary with the concurrence of the Commission determines that removal of residual radioactive material from a processing site is appropriate, the cooperative agreement shall provide that the State shall acquire land (including, where appropriate, any interest therein) to be used as a site for the permanent disposition and stabilization of such residual radioactive materials in a safe and environmentally sound manner.

(2) Acquisition by the State shall not be required under this subsection if a site located on land controlled by the Secretary or made available by the Secretary of the Interior pursuant to section $106(a)(2)$ is designated by the Secretary, with the concurrence of the Commission, of such disposition and stabilization. 
(c) No State shall be required under subsection (a) or (b) to acquire any real property or improvement outside the boundaries of-

(1) that portion of the processing site which is described in section $101(6)(\mathrm{A})$, and

(2) the site used for disposition of the residual radioactive materials.

(d) In the case of each processing site designated under this title other than a site designated on Indian land, the State shall take such action as may be necessary, and pursuant to regulations of the Secretary under this subsection, to assure that any person who purchases such a processing site after the removal of radioactive materials from such site shall be notified in any appropriate manner prior to such purchase, of the nature and extent of residual radioactive materials removed from site, including notice of the date when such action took place, and the condition of such site after such action. If the State is the owner if such site, the State

Notification.

Rules and regulations. shall so notify any prospective purchaser before entering into a contract, option or other arrangement to sell or otherwise dispose of such site. The Secretary shall issue appropriate rules and regulations to require notice in the local land records of the residual radioactive materials which were located at any processing site and notice of the nature and extent of residual radioactive materials removed from the site, including notice of the date when such action took place.

(e)(1) The terms and conditions of any cooperative agreement with a State under section 103 shall provide that in the case of any lands or interests therein acquired by the State pursuant to subsection (a), the State, with the concurrence of the Secretary and the Commission, may-

(A) sell such lands and interests,

(B) permanently retain such land and interests in lands (or donate such lands and interests therein to another governmental entity within such State) for permanent use by such State or entity solely for park, recreational, or other public purposes, or

(C) transfer such lands and interest to the United Sates as provided in subsection ( $f$ ).

No lands may be sold under subparagraph (A) without the consent of the Secretary and the Commission. No site may be sold under subparagraph (A) or retained under subparagraph (B) if such site is used for the disposition of residual radioactive materials.

(2) Before offering for sale any lands and interests therein which comprise a processing site, the State shall offer to sell such lands and interests at their fair market value to the person from whom the State acquired them.

(f)(1) Each agreement under section 103 shall provide that title to-

(A) the residual radioactive materials subject to the agreement, and

(B) any lands and interests therein which have been acquired by the State, under subsection (a) or (b), for the disposition of such materials, shall be transferred by the State to the Secretary when the Secretary (with the concurrence of the Commission) determines that remedial action is completed in accordance with the requirements imposed pursuant to this title. No 
Post, p. 3039.

Fair market value.

payment shall be made in connection with the transfer of such property from fund appropriated for purposes of this Act other than payments for any administrative and legal costs incurred in carrying out such transfer.

(2) Custody of any property transferred to the United States under this subsection shall be assumed by the Secretary or such Federal agency as the President may designate. Notwithstanding any other provision of law, upon completion of the remedial action program authorized by this title, such property and minerals shall be maintained pursuant to a license issued by the Commission in such manner as will protect the public health, safety, and the environment. The Commission may, pursuant to such license or by rule or order, require the Secretary or other Federal agency having custody of such property and minerals to undertake such monitoring, maintenance, and emergency measures necessary to protect public health and safety and other actions as the Commission deems necessary to comply with the standards of section 275(a) of the Atomic Energy Act of 1954. The Secretary or such other Federal agency is authorized to carry out maintenance, monitoring and emergency measures under this subsection, but shall take no other action pursuant to such license, rule or order with respect to such property and minerals unless expressly authorized by Congress after the date of enactment of this Act. The United States shall not transfer title to property or interest therein acquired under this subsection to any person or State, except as provided in subsection (h).

(g) Each agreement under section 103 which permits any sale described in subsection (e)(1)(A) shall provide for the prompt reimbursement to the Secretary form the proceeds of such sale. Such reimbursement shall be in an amount equal to the lesser of-

(1) that portion of the fair market value of the lands or interests therein which bears the same ratio to such fair market value as the Federal share of the costs of acquisition by the State to such lands or interest therein bears to the total cost of such acquisition, or

(2) the total amount paid by the Secretary with respect to such acquisition.

The fair market value of such lands or interest shall be determined by the Secretary as of the date of the sale by the State. Any amounts received by the Secretary under this title shall be deposited in the Treasury of the United States as miscellaneous receipts.

(h) No provision of any agreement under section 103 shall prohibit the Secretary of the Interior, with the concurrence of the Secretary of Energy and the Commission, from disposing of any subsurface mineral rights by sale or lease (in accordance with laws of the United States applicable to the sale, lease, or other disposal of such rights) which are associated with land on which residual radioactive materials are disposed and which are transferred to the United States as required under this section if the Secretary of the Interior takes such action as the Commission deems necessary pursuant to a license issued by the Commission to assure that the residual radioactive materials will not be disturbed by reason of any activity carried on following such disposition. If any such 
materials are disturbed by any such activity, the Secretary of the Interior shall insure, prior to the disposition of the minerals, that such materials will be restored to a safe and environmentally sound condition as determined by the Commission, and that the costs of such restoration will be borne by the person acquiring such rights from the Secretary of the Interior or from his successor or assign.

\section{INDIAN TRIBE COOPERATTVE AGREEMENTS}

42 USC 7915.

Terms and conditions.

Sec. 105. (a) After notifying the Indian tribe of the designation pursuant to section 102 of this title, the Secretary, in consultation with the Secretary of the Interior, is authorized to enter into a cooperative agreement, subject to section 113, with any Indian tribe to perform remedial action at a designated processing site located on land of such Indian tribe. The Secretary shall, to the greatest extent practicable, enter into such agreements and carry out such remedial actions in accordance with the priorities established by him under section 102 . In performing any remedial action under this section and in carrying out any continued monitoring or maintenance respecting residual radioactive materials associated with any site subject to a cooperative agreement under this section, the Secretary shall make full use of any qualified members of Indian tribes resident in the vicinity of any such site. Each such agreement shall contain such terms and conditions as the Secretary deems appropriate and consistent with the purpose of this Act. Such terms and conditions shall require the following:

(1) The Indian tribe and any person. holding any interest in such land shall execute a waiver $(A)$ releasing the United States of any liability or claim thereof by such tribe or person concerning such remedial action and $(B)$ holding the United States harmless against any claim arising out of the performance of any such remedial action.

(2) The remedial action shall be selected and performed in accordance with section 108 by the Secretary or such person as he may designate.

(3) The Secretary, the Commission, and the Administrator and their authorized representatives shall have a permanent right of entry at any time to inspect such processing site in furtherance of the provisions of this title, to carry out such agreement, and to enforce any rules prescribed under this Act.

Each agreement under this section shall take effect only upon concurrence of the Commission with the terms and conditions thereof.

(b) When the Secretary with the concurrence of the Commission determines removal of residual radioactive materials from a processing site on land described on subsection (a) to be appropriate, he shall provide, consistent with other applicable provisions of law, a site or sites for the permanent disposition and stabilization in a safe and environmentally sound manner of such residual radioactive materials. Such materials shall be transferred to the Secretary (without payment therefor by the Secretary) and permanently retained and maintained by the Secretary under the conditions established in a license issued by the commission, subject to section 104(f)(2) and (h). 


\section{USC 7916.}

Uranium Mill Tailings Remedial Action Amendments Act of 1988. 42 USC 7901 note. Public lands. State listing.

42 USC 7917.

\section{ACQUISITION OF LAND BY SECRETARY}

Sec. 106. Where necessary or appropriate in order to consolidate in a safe and environmentally sound manner the location of residual radioactive materials which are removed from processing sites under cooperative agreements under this title or where otherwise necessary for the permanent disposition and stabilization of such materials in such manner-

(1) the Secretary may acquire land and interest in land for such purposes by purchase, donation, or under any other authority of law or

(2) the Secretary of the Interior may transfer permanently to the Secretary to carry out the purposes of this Act, public lands under the jurisdiction of the Bureau of Land Management in the vicinity of processing sites in the following counties:

(A) Apache County in the State of Arizona;

(B) Mesa,Gunnison, Moffat, Montrose, Garfield, and San Miguel Counties in the State of Colorado;

(C) Boise County in the State of Idaho;

(D) Billings and Bowman Counties in the State of North Dakota;

(E) Grand and San Juan Counties in the State of Utah; and

(F) Converse and Frement Counties in the State of Wyoming;

(G) Any other county in the vicinity of a processing site, if no site in the county in which a processing site is located is suitable. Any permanent transfer of lands under the jurisdiction of the Bureau of Land Management by the Secretary of the Interior to the Secretary shall not take place until the Secretary complies with the requirements of the National Environmental Policy Act (42 U.S.C. 4321 et seq.) with respect to the selection of a site for the permanent disposition and stabilization of residual radioactive materials. Section 204 of the Federal Land Policy and Management Act (43 U.S.C. 1714) shall not apply to this transfer of jurisdiction. Prior to acquisition of land under paragraph (1) or (2) of this subsection in any State, the Secretary shall consult with the Governor of such State. No lands may be acquired under such paragraph (1) or (2) in any State in which there is no (1) processing site designated under this title or (2) active uranium mill operation, unless the Secretary has obtained the consent of the Governor of such State. No lands controlled by any Federal agency may be transferred to the Secretary to carry out the purposes of this Act without the Concurrence of the chief administrative officer of such agency. ${ }^{1}$

\section{FINANCIAL ASSISTANCE}

Sec. 107. (a) In the case of any designated processing site for which an agreement is executed with any State for remedial action at such site, the Secretary shall pay 90 per centum of the actual cost of such remedial action, including the actual costs of acquiring such site (and any interest therein) or any disposition site (and any interest therein pursuant to section 103 of this title, and the State shall pay the remainder of such costs from non-Federal funds. The Secretary shall not pay the administrative

\footnotetext{
${ }^{T}$ Public Law 100-616 (102 Stat. 3192) amended sec. 106.(2).
} 
costs incurred by any State to develop, prepare, and carry out any cooperative agreement executed with such State under this title, except the proportionate share of the administrative costs associated with the acquisition of lands and interests therein acquired by the State pursuant to this title.

(b) In the case of any designated processing site located on Indian lands, the Secretary shall pay the entire cost of such remedial action.

42 USC 7918.

\section{REMEDIAL ACTION}

Sec. 108. (a)(1) The Secretary or such person as he may designate shall select and perform remedial actions at designated processing sites and disposal sites in accordance with the general standards prescribed by the Administrator pursuant to section $275 \mathrm{a}$. of the Atomic Energy Act of

Post, p. 3039.

Ante, p. 2077; post, p. 2080.

Evaluation. 1954. The State shall participate fully in the selection and performance of a remedial action for which it pays part of the cost. Such remedial action shall be selected and performed with the concurrence of the Commission and in consultation, as appropriate, with the Indian tribe and the Secretary of the Interior.

(2) The Secretary shall use technology in performing such remedial action as will insure compliance with the general standards promulgated by the Administrator under section $275 \mathrm{a}$. of the Atomic Energy Act of 1954 and will assure the safe and environmentally sound stabilization of residual radioactive materials, consistent with existing law. ${ }^{2}$

(3) Notwithstanding paragraph (1) and (2) of this subsection, after October 31, 1982, if the Administrator has not promulgated standards under section 275a. of the Atomic Energy Act of 1954 in final form by such date, remedial action taken by the Secretary under this title shall comply with standards proposed by the Administrator under such section 275 a. until such time as the Administrator promulgates the standards in final form.". 3

(b) Prior to undertaking any remedial action at a designated site pursuant to this title, the Secretary shall request expressions of interest from private parties regarding the remilling of the residual radioactive materials at the site and, upon receipt of any expression of interest, the Secretary shall evaluate among other things the mineral concentration of the residual radioactive materials at each designated processing site to determine whether, as a part if any remedial action program, recovery of such minerals is practicable. The Secretary, with the concurrence of the Commission, may permit the recovery of such minerals, under such terms and conditions as he may prescribe to carry out the purposes of this title. No such recovery shall be permitted unless such recovery is consistent with remedial action. Any person permitted by the Secretary to recover such mineral shall pay to the Secretary a share of the net profits derived from such recovery, as determined by the Secretary. Such share shall not exceed the total amount paid by the Secretary for carrying out remedial action at such designated site. After payment of such share to the United States under this subsection, such person shall pay

\footnotetext{
2Public Law 97-415 (96 Stat. 2067)(1983 sec. 18 repealed second sentence of sea. 108(a)(2), which read, "No such remedial action may be undertaken under this section before the promulgation by the Administrator of such stap dards."

${ }^{3}$ Public Law 97-415 (96 Stat. 2067)(1983) sec. 18 added new paragraph (3) to sec. 108(a).
} 
to the State in which the residual radioactive materials are located a share of the net profits derived from such recovery, as determined by the Secretary. The person recovering such minerals shall bear all cost of such recovery. Any person carrying out mineral recovery activities under this paragraph shall be required to obtain any necessary license under

42 USC 2021. the Atomic Energy Act of 1954 or under State law as permitted under section 274 of such Act.

\section{USC 7919.}

42 USC 7920.

Notice, hearing opportunity.

5 USC 500

et seq.

Jurisdiction.

42 USC 7172.

42 USC 2011

note.

42 USC 7921

Sec. 109. The Secretary may prescribe such rules consistent with the purposes of this Act as he deems appropriate pursuant to title $V$ of the Department of Energy Organization Act.

\section{ENFORCEMENT}

Sec. 110. (a) (1) Any person who violates any provision of this title or any cooperative agreement entered into pursuant to this title or any rule prescribed under this Act concerning any designated processing site, disposition site, or remedial action shall be subject to an assessment by the Secretary of a civil penalty of not more than $\$ 1,000$ per day per violation. Such assessment shall be made by order after notice and an opportunity for a public hearing, pursuant to section 554 of title 5 , United States Code.

(2) Any person against whom a penalty is assessed under this section may, within sixty calendar days after the date of the order of the Secretary assessing such penalty, institute an action in the United States court of appeals for the appropriate judicial circuit for judicial review of such order in accordance with chapter 7 of title 5, United States Code. The court shall have jurisdiction to enter a judgment affirming, modifying, or setting aside in whole or in part, the order of the Secretary, or the court may remand the proceeding to the Secretary for such further action as the court may direct.

(3) If any person fails to pay an assessment of a civil penalty after it has become a final and unappealable order, the Secretary shall institute an action to recover the amount of such penalty in any appropriate district court of the United States. In such action, the validity and appropriateness of such final assessment order or judgment shall not be subject to review. Section 402(d) of the Department of Energy Organization Act shall not apply with respect to the functions of the Secretary under this section.

(4) No civil penalty may be assessed against the United States or any State or political subdivision of a State or any official or employee of the foregoing.

(5) Nothing in this section shall prevent the Secretary from enforcing any provision of this title or any cooperative agreement or any such rule by injunction or other equitable remedy.

(b) Subsection (a) shall not apply to any license requirement under the Atomic Energy Act of 1954. Such licensing requirements shall be forced by the Commission as provided in such Act.

\section{PUBLIC PARTICIPATION}

Sec. 111. In carrying out the provisions of this title, including the designation of processing sites, establishing priorities for such sites, the selec- 
Water.

42 USC 7922

42 USC 7923

42 USC 7924 tion of remedial actions, and the execution of cooperative agreements, the Secretary, the Administrator, and the Commission shall encourage public participation and, where appropriate, the Secretary shall hold public hearings relative to such matters in the State where processing sites and disposal sites are located.

\section{TERMINATION:AUTHORIZATION}

Sec. 112(a) The authority of the Secretary to perform remedial action under this title shall terminate on September 30, 1994, except that the authority of the Secretary to perform groundwater restoration activities under this title is without limitation. ${ }^{30}$

(b) The amounts authorized to be appropriated to carry out the purposes of this duty by the Secretary, the Administrator, the Commission, and the Secretary of the Interior shall not exceed such amounts as are established in annual authorization Acts for fiscal year 1979 and each fiscal year thereafter applicable to the Department of Energy. Any sums appropriated for the purposes of this title shall be available until expended.

\section{LIMITATION}

Sec. 113. The authority under this title to enter into contacts or other obligations requiring the United States to make outlays may be exercised only to the extent provided in advance in annual authorization and appropriation Acts.

\section{REPORTS TO CONGRESS}

Sec. 114. (a) Beginning on January 1, 1980, and each year thereafter until January 1, 1986, the Secretary shall submit a report to the Congress with respect to the status of the actions required to be taken by the Secretary, the Commission, the Secretary of the Interior, the Administrator, and the States and Indian tribes under this Act and any amendments to other laws made by this Act. Each report shall-

(1) include data on the actual and estimated costs of the program authorized by this title;

(2) described the extent of participation by the States and Indian tribe in this program;

(3) evaluate the effectiveness of remedial actions, and describe any problems associated with the performance of such actions; and

(4) contain such other information as may be appropriate. Such report shall be prepared in consultation with the Commission, the Secretary of the Interior, and the Administrator and shall contain their separate views, comments, and recommendations, if any. The Commission shall submit to the Secretary and Congress such portion of the report under this subsection as relates to the authorities of the Commission under title II of this Act.

(b) Not later than July 1,1979 , the Secretary shall provide a report to the Congress which identifies all sites located on public or acquired lands of the United States containing residual radioactive materials and other radioactive materials and other radioactive waste (other than waste resulting from the production of electric energy) and specifies which Federal agency has jurisdiction over such sites. The report shall include the identity of property and other structures in the vicinity of

${ }^{3}$ Public Law 100-616 (102 Stat. 3192)(1988), amended sec. 112 (a). 
such site that are contaminated or may be contaminated by such materials and actions planned or taken to remove such materials. The report shall describe in what manner such sites are adequately stabilized and otherwise controlled to prevent radon diffusion from such sites into the environment and other environmental harm. If any site is not so stabilized or controlled, the report shall describe the remedial actions planned for such site and the time frame for performing such actions. In preparing the reports under this section, the Secretary shall avoid duplication of previous or ongoing studies and shall utilize all information available from other departments and agencies of the United States respecting the subject matter of such report. Such agencies shall cooperate with the Secretary in the preparation of such report and furnish

Cooperation. such information as available to them and necessary for such reports.

(c) Not later than January 1, 1980, the Administrator, in consultation with the Commission, shall provide a report to the Congress which identifies the location and potential health, safety, and environmental hazards of uranium mine wastes together with recommendations, if any, for a program to eliminate these hazards.

(d) Copies of the reports required by this section to be submitted to the Congress shall be separately submitted to the Committees on Interior and Insular Affairs and on Interstate and Foreign Commerce of the House of Representatives and the Committee on Energy and Natural Resources of the Senate.

(e) The Commission, in cooperation with the Secretary, shall ensure that any relevant information, other than trade secrets and other proprietary information otherwise exempted from mandatory disclosure under any other provision of law, obtained from the conduct of each of the remedial actions authorized by this title and the subsequent perpetual care of those residual radioactive materials is documented systematically, and made publicly available conveniently for use.

\section{ACTIVE OPERATIONS: LIABILITY FOR REMEDIAL ACTION}

42 USC 7925.

Sec. 115. (a) No amount may be expended under this title with respect to any site licensed by the Commission under the Atomic Energy Act of 42 USC 2011 note. 1954 or by a State as permitted under section 274 of such Act at which production of any uranium product from ores (other than from residual radioactive materials) takes place.

(b) In the case of each processing site designated under this title, the

42 USC 2021 Study. Attorney General shall conduct a study to determine the identity and legal responsibility which any person (other than the United States, a State, or Indian tribe) who owned or operated or controlled (as determined by the Attorney General) such site before the date of the enactment of this Act may have under any law or rule of law for reclamation or other remedial action with respect to such site. The Attorney General shall publish the results of such study, and provide copies thereof to the Congress, as promptly as practicable following the date of the enactment of this Act. The Attorney General, based on such study, shall, to the extent he deems it appropriate and in the public interest, take such action under any provision of law in effect when uranium was produced at such site to require payment by such person of all or any part of the 
costs incurred by the United States for such remedial action for which he determines such person is liable.

\section{TITLE II-URANIUM MILL TAILINGS LICENSING AND REGULATION DEFINITION}

42 USC 2014

"Byproduct material."

42 USC 2111

et seg.

42 USC 2113.

42 USC 2002,

2111.

42 USC 2014.

42 USC 2014.

Rule, regulation or order.
Sec.201. Section 11e. of the Atomic Energy Act of 1954, is amended to read as follows:

"e. The term 'byproduct material' means (1) any radioactive material (except special nuclear material) yielded in or made radioactive by exposure to the radiation incident to the process of producing or utilizing special nuclear material, and (2) the tailings or wastes produced by the extraction or concentration of uranium or thorium from any ore processed primarily for its source material content."

\section{CUSTODY OF DISPOSAL SITE}

Sec. 202. (a) Chapter 8 Of the Atomic Energy Act of 1954, is amended by adding the following new section at the end thereof:

"Sec. 83. Ownership And Custody Of Certain By-product Material And Disposal Sites.-

"a. Any license issued or renewed after the effective date of this section under section 62 or section 81 for any activity which results in the production of any byproduct materials, as defined in section 11e. (2), shall contain such terms and conditions as the commission determines to be necessary to assure that, prior to termination of such license-

"(1) the licensee will comply with decontamination, decommissioning, and reclamation standards prescribed by the Commission for sites (A) at which ores were processed primarily for their source material content and $(B)$ at which such byproduct material is deposited, and

"(2) ownership of any byproduct material, as defined in section 11e. (2), which resulted from such licensed activity shall be transferred to (A) the United States or (B) in the State in which such activity occurred if such State exercises the option under subsection b. (1) to acquire land used for the disposal of byproduct material.

Any license in effect on the date of the enactment of this section shall either contain such terms and conditions on renewal thereof after the effective date of this section, or comply with paragraphs (1) and (2) upon the termination of such license, whichever first occurs.

"(b)(1)(A) The Commission shall require by rule, regulation, or order that prior to the termination of any license which is issued after the effective date of this section, title to the land, including any interests therein (other than land owned by the United States or by a State) which is used for the disposal of any byproduct material, as defined by section 11e. (2), pursuant to such license shall be transferred to-

"(A) the United States, or

"(B) the State in which such land is located, at the option of such State.

"(2) Unless the Commission determines prior to such termination that transfer of title to such land and such byproduct material is not necessary or desirable to protect the public health, safety, or welfare or to minimize or eliminate danger to life or property. Such 
determination shall be made in accordance with section 181 of this Act. Notwithstanding any other provision of law or any such determination, such property and materials shall be maintained pursuant to a license issued by the Commission pursuant to section 84(b) in such manner as will protect the public health, safety, and the environment.

"(B) If the Commission determines by order that use of the surface or subsurface estates, or both, of the land transferred to the United States or to a State under subparagraph (A) would not endanger the public health, safety, welfare, or environment, the Commission, pursuant to such regulations as it may prescribe, shall permit the use of the surface or subsurface estates, or both, of such land in a manner consistent with the provisions of this section. If the Commission permits such use of such land, it shall provide the person who transferred such land with the right of first refusal with respect to such use of such land.

"(2) If the transfer to the United States of title to such by-product material and such land is required under this section, the Secretary of Energy or any Federal agency designated by the President shall, follow the Commission's determination of compliance under subsection c., assume title and custody of such byproduct material and land transferred as provided in this subsection. Such Secretary or Federal agency shall mairtain such material and land in such manner as will protect the public health and safety and the environment. Such custody maybe transferred to another officer or instrumentality of the United States only upon approval of the President.

"(3) If transfer to a State of title to such byproduct material is required in accordance with this subsection, such State shall, following the Commission's determination of compliance under subsection d., assume title and custody of such byproduct material and land transferred as provided in this subsection. Such State shall maintain such material and land in such manner as will protect the public health, safety, and the environment.

42 USC 2092.

"(4) In the case of any such license under section 62, which was in effect on the effective date of this section, the Commission may require, before the termination of such license, such transfer of land and interests therein (as described in paragraph (1) of this subsection) to the United States or a State in which such land is located, at the option of such State, as may be necessary to protect the public health, wealth, and the environment from any effects associated with such byproduct material. In exercising the authority of this paragraph, the Commission shall take into consideration the status of the ownership of such land and interests therein and the ability of the licensee to transfer title and custody thereof to the United States or a State.

"(5) The Commission may, pursuant to a license, or by rule or order, require the Secretary or other Federal agency or State having custody of such property and materials to undertake such monitoring, maintenance, and emergency measures as are necessary to protect the public health and safety and such other actions as the 
Post, p. 3039.

42 USC 2014.

Effective date. 42 USC 2113 note.

42 USC 2201.

42 USC 2231.
Commission deems necessary to comply with the standards promulgated pursuant to section 84 of this Act. The Secretary or such other Federal agency is authorized to carry out maintenance, monitoring, and emergency measures, but shall take no other action pursuant to such license, rule or order, with respect to such property and materials unless expressly authorized by Congress after the date of enactment of this Act.

"(6) The transfer of title to land or byproduct materials, as defined in section $11 \mathrm{e}$. (2), to a State or the United States pursuant to this subsection shall not relieve any licensee of liability for any fraudulent or negligent acts done prior to such transfer.

"(7) Material and land transferred to the United States or a State in accordance with this subsection shall be transferred without cost to the United States or a State (other than administrative and legal costs incurred in carrying out such transfer). Subject to the provisions of paragraph (1)(B) of this subsection, the United States or a State shall not transfer title to material or property acquired under this subsection to any person, unless such transfer is in the same manner as provided under section 104(h) of the Uranium Mill Tailings Radiation Control Act of 1978.

"(8) The provisions of this subsection respecting transfer of title and custody to land shall not apply in the case of lands held in trust by the United States for any Indian tribe or lands owned by such Indian tribe subject to a restriction against alienation imposed by the United States. In the case of such lands which are used for the disposal of byproduct material, as defined in section $11 \mathrm{e}$. (2), the license shall be required to enter into such arrangements with the Commission as may be appropriate to assure the long-term maintenance and monitoring of such lands by the United States.

"c. Upon termination on any license to which this section applies, the Commission shall determine whether or not the licensee has complied with all applicable standards and requirements under such license.".

(b) this section shall be effective three years after the enactment of this Act.

(c) The table of contents for chapter 8 of the Atomic Energy Act of 1954 , is amended by inserting the following new item after the item relating to section 82:

"Sec. 83. Ownership and custody of certain byproduct material and disposal sites.".

\section{AUTHORITY TO ESTABLISH CERTAIN REQUIREMENTS}

Sec. 203. Section 161 of the Atomic Energy Act of 1954, is amended, by adding the following new subsection at the end thereof:

" $x$. Establish by rule, regulation, or order, after public notice, and in accordance with the requirements of section 181 of this Act, such standards and instructions as the Commission may deem necessary or desirable to ensure-

"(1) that an adequate bond, surety, or other financial arrangement (as determined by the Commission) will be provided before termination of any license for byproduct material as defined in 
42 USC 2014.

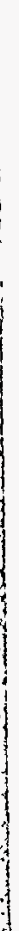

42 USC 2021.

42 USC 2021.

Review.

section 11 e. (2), by a licensee to permit the completion of all requirements established by the Commission for the decontamination, decommissioning, and reclamation of sites, structures, and equipment used in conjunction with byproduct material as so defined, and

"(2) that-

"(A) in the case of any such license issued or renewed after the date of the enactment of this subsection, the need for long term maintenance and monitoring of such sites, structures and equipment after termination of such license will be minimized and, to the maximum extent practicable, eliminated; and

"(B) in the case of each license for such material (whether in effect on the date of the enactment of this section or issued or renewed thereafter), if the Commission determines that any such long-term maintenance and monitoring is necessary, the licensee, before termination of any license for byproduct material as defined in section 11 e. (2), will make available such bonding, surety, or other financial arrangements as may be necessary to assure such long-term maintenance and monitoring. Such standards and instructions promulgated by the Commission, pursuant to this subsection shall take into account, as determined by the Commission, so as to avoid unnecessary duplication and expense, performance bonds or other financial arrangements which are required by other Federal agencies or State agencies and/or other local governing bodies for such decommissioning, decontamination, and reclamation and long-term maintenance and monitoring except that nothing in this paragraph shall be construed to require that the Commission accept such bonds or arrangements if the Commission determines that such bonds or arrangements are not adequate to carry out subparagraphs (1) and (2) of this subsection.".

\section{COOPERATION WITH STATES}

Sec. 204. (a) Section 274 b. of the Atomic Energy Act of 1954, is amended by adding "as defined in section 11 e. (1)" after the words " byproduct materials" in paragraph (1) by renumbering paragraphs (2) and (3) as paragraph (3) and (4); and by inserting the following new paragraph immediately after paragraph(1):

"(2) byproduct materials as defined in section 11 e. (2);".

(b) Section 274 d. (2) of such Act is amended by inserting the following before the word "compatible": "in accordance with the requirements of subsection 0 . and in all other respects".

"Agreement." (c) Section $274 \mathrm{n}$. of such Act is amended by adding the following new sentence at the end thereof:"As used in this section, the term "agreement' includes any amendment to any agreement.".

(d) Section $274 \mathrm{j}$. of such Act is amended-

(1) by inserting "all or part of" after "suspend";

(2) by inserting "(1)" after "finds that"; and

(3) by adding at the end before the period the following: “, or (2) the State has not complied with one or more of the requirements of this section. The Commission shall periodically review such agree- 
Ante, p. 3033.

Post, p. 3039.

ments and actions taken by the States under the agreements to ensure compliance with the provisions of this section.".

(e)(1) Section 274 of such Act is amended by adding the following new subsection at the end thereof:

" 0 . In the licensing and regulation of byproduct material, as defined in section 11 e. (2) of this Act, or of any activity which results in the production of byproduct material as so defined under an agreement entered into pursuant to subsection b., a State shall require-

"(1) compliance with the requirements of subsection b. of section 83 (respecting ownership of byproduct material and land), and

"(2) compliance with standards which shall be adopted by the State for the protection of the public health, safety, and the environment from hazards associated with such material which are equivalent, to the extent practicable, or more stringent than, standards adopted and enforced by the Commission for the same purpose, including requirements and standards promulgated by the Commission and the Administrator of the Environmental Protection Agency pursuant to section 83, 84, and 275, and

"(3) procedures which-

"(A) in the case of licenses, provide procedures under State law which include-

"(i) an opportunity, after public notice, for written comments and a public hearing, with a transcript,

"(ii) an opportunity for cross examination, and

"(iii) a written determination which is based upon findings included in such determination and upon the evidence presented during the public comment period and which is subject to judicial review;

"(B) in the case of rulemaking, provide an opportunity for public participation through written comments or a public hearing and provide for judicial review of the rule;

"(C) require for each license which has a significant impact on the human environment a written analysis (which shall be available to the public before the commencement of any such proceedings) of the impact of such licenses, including any activities conducted pursuant thereto, on the environment, which analysis shall include-

"(i) an assessment of the radiological and nonradiological impacts to the public health of the activities to be conducted pursuant to such license;

"(ii) an assessment of any impact on any waterway and groundwater resulting from such activities;

"(iii) consideration of alternatives, including alternative sites and engineering methods, to the activities to be conducted pursuant to such license; and

"(iv) consideration of the long-term impacts, including decommissioning, decontamination, and reclamation impacts, associated with activities to be conducted pursuant to such license, including the management of any byproduct material, as defined by section 11 e. (2); and 
“(D) prohibit any major construction activities with respect to such material prior to complying with the provisions of subparagraph (C).

If any State under such agreement imposes upon any licensee any requirement for the payment of funds to such State for the reclamation or long-term maintenance and monitoring of such material and if transfer to the United States of such material is required in accordance with Ante, p. 3033. section 83 b. of this Act, such agreement shall be amended by the Commission to provide that such State shall transfer to the United States upon termination of the license issued to such licensee the total amount collected by such State from such licensee for such purpose. If such payments are required, they must be sufficient to ensure compliance with

42 USC 2201. the standards established by the Commission pursuant to section $161 \mathrm{x}$. of this Act. No State shall be required under paragraph (3) to conduct proceedings concerning any license or regulation which would duplicate proceedings conducted by the Commission.".

92 Stat. 3037

42 USC 2021

note.

42 USC 2021.

"(2) The provisions of the amendment made by paragraph (1) of this subsection (which adds a new subsection o. to section 274 of the Atomic Energy Act of 1954) shall apply only to the maximum extent practicable during the three-year period beginning on the date of the enactment of this Act." 4

(f) Section $274 \mathrm{c}$. of such Act is amended by inserting the following new sentence after paragraph (4) thereof: "The Commission shall also retain authority under any such agreement to make a determination that all applicable standards and requirements have been met prior to termina-

42 USC 2014. 42 USC 2021 note.

tion of a license for byproduct material, as defined in section 11 e. (2).".

(g) Nothing in any amendment made by this section shall preclude any State from exercising any other authority permitted under the Atomic Energy Act of 1954 respecting any byproduct material, as defined in section 11 e. (2) of the Atomic Energy Act of 1954.

"(h)(1) During the three-year period beginning on the date of the enactment of this Act, notwithstanding any other provision of this title, any State may exercise any authority under State law (including author42 USC 2021. 92 Stat. 3033. 42 USC 2014.

92 Stat. 3036. 42 USC 204

92 STAT. 3039. ity exercised pursuant to an agreement entered into pursuant to section 274 of the Atomic Energy Act of 1954) respecting (A) byproduct material, as defined in section 11 e. (2) of the Atomic Energy Act of 1954, or (B) any activity which results in the production of byproduct material as so defined, in the same manner and to the same extent as permitted before the date of the enactment of this Act, except that such State authority shall be exercised in a manner which, to the extent practicable, is consistent with the requirements of section $274 \mathrm{o}$. of the Atomic Energy Act of 1954 (as added by section 204(e) of this Act). The Commission shall have the authority to ensure that such section $274 \mathrm{o}$. is implemented by any such State to the extent practicable during the three-year period beginning on the date of the enactment of this Act. Nothing in this section shall be construed to preclude the Commission or the Administrator of the Environmental Protection Agency from

${ }^{4}$ P.L. 96-106 (93 Stat. 800) (1979), sec. 22(d) amends sec. 204(e) by adding new paragraph (2) 

may be necessary to implement title I of this Act.". 5

(2) An agreement entered into with any State as permitted under section 274 of the Atomic Energy Act of 1954 with respect to byproduct material as defined in section 11 e. (2) of such Act, may be entered into at any time after the date of the enactment of this Act but no such agreement may take effect before the date three years after the date of the enactment of this Act.

42 USC 2021.

"(3) Notwithstanding any other provision of this title, where a State assumes or has assumed, pursuant to an agreement entered into under section 274b. of the Atomic Energy Act of 1954, author-

92 Stat. 3033.

42 USC 2014.

42 USC 2021

42 USC 2111

et seq.

42 USC 2114.

42 USC 2114 ity over any activity which results in the production of byproduct material, as defined in section $11 \mathrm{e}$. (2) of such Act, the Commission shall not, until the end of three-year period beginning on the date of the enactment of this Act, have licensing authority over such byproduct material produced in any activity covered by such agreement, unless the agreement is terminated, suspended, or amended to provide for such Federal licensing. If, at the end of such threeyear period, a State has not entered into such an agreement with respect to byproduct material, as defined in section $11 \mathrm{e}$. (2) of the Atomic Energy Act of 1954, the

Commission shall have authority over such byproduct material.". 6 Provided, however, That, in the case of a State which has exercised any authority under State law pursuant to an agreement entered into under section 274 of the Atomic Energy Act of 1954, the State authority over such byproduct material-may be terminated, and the Commission authority over such material may be exercised, only after compliance by the Commission with the same procedures as are applicable in the case of termination of agreements under section 274 j. of the Atomic Energy Act of 1954.".7

\section{AUTHORITIES OF COMMISSION RESPECTING CERTAIN BYPRODUCT} MATERIAL

Sec. 205. (a) Chapter 8 of the Atomic Energy Act of 1954, is amended by adding the following new section at the end thereof:

"Sec. 84, Authorities Of Commission Respecting Certain Byproduct Material.-

"a. The Commission shall insure that the management of any byproduct material, as defined in section $11 \mathrm{e}$. (2), is carried out in such manner as-

"(1) the Commission deems appropriate to protect the public health and safety and the environment from radiological and nonradiological hazards associated with the processing and with the possession and transfer of such material,

${ }^{6}$ P.L. 96-106 (93 Stat. 799)(1979), sec 22(b) amended sec. 204(b)(D) by substituting a complete new sec. 204(h)(1). Before amendment, sec. 204(h)(i) read as follows:

(h)(I) On or before the date three years after the date of the enactment of this Act, notwithstanding amy amendment made by this titls, any State may exercise any authority under State law respecting byproduct material as defined in section $11 \mathrm{e}$. (2) of the Atomic Energy Act of 1954, in the same manner, and to the same extent, as permitted before the enactnient of this Act.

${ }^{6}$ P.L. 96-106 (93 Stat. 799) (1979), sec. 22(a) added sec. 204(h)(93).

${ }^{7}$ Public Law $97-415$ (96 Stal. 2067) (1983), sec. 19 added this language. 
Infra.

42 USC 6091.

Rule, regulation or order.

42 USC 2111.

Civil penalty.

Ante, p. 3033.

42 USC 2282.

42 USC 2111

42 USC 2112 Supra.

42 USC 2021

42 USC 2022.

Rule.

“(2) conforms with applicable general standards promulgated by the Administrator of the Environmental Protection Agency under section 275 , and

"(3) conforms to general requirements established by the Commission, with the concurrence of the Administrator, which are, to the maximum extent practicable, at least comparable to requirements applicable to the possession, transfer, and disposal of similar hazardous material regulated by the Administrator under the Solid Waste Disposal Act, as amended.

"b. In carrying out its authority under this section, the Commission is authorized to-

"(1) by rule, regulation, or order require persons, officers, or instrumentalities exempted from licensing under section 81 of this Act to conduct monitoring, perform remedial work, and to comply with such other measures as it may deem necessary or desirable to protect health or to minimize danger to life or property, and in connection with the disposal or storage of such byproduct material; and

"(2) make such studies and inspections and to conduct such monitoring as may be necessary.

Any violation by any person other than the United States or any officer or employee of the United States or a State of any rule, regulation, or order or licensing provision, of the Commission established under this section or section 83 shall be subject to a civil penalty in the same manner and in the same amount as violations subject to a civil penalty under section 234. Nothing in this section affects any authority of the Commission under any other provision of this Act.".

(b) The first sentence of section 81 of the Atomic Energy Act of 1954, is amended to read as follows: "No person may transfer or receive in interstate commerce, manufacture, produce, transfer, acquire, own, possess, import, or export any byproduct material, except to the extent authorized by this section, section 82 or section $84 . "$.

(c) The table of content for such chapter 8 is amended by inserting the following new item after the item relating to section 83:

"Sec. 84. Authorities of Commission respecting certain byproduct material.".

\section{AUTHORITY OF ENVIRONMENTAL PROTECTION AGENCY RESPECTING CERTAIN BYPRODUCT MATERIAL}

Sec.206. (a) Chapter 19 of the Atomic Energy Act of 1954, is amended by inserting after section 274 the following new section:

"Sec. 275. Health And Environmental Standards For Uranium Mill Tailings.-

"a. As soon as practicable, but not later than one year after the date of enactment of this section, the Administrator of the Environmental Protection Agency (hereinafter referred to in this section as the Administrator') shall, by rule, promulgate standards of general application (including standards applicable to licenses under section 104(h) of the Uranium Mill Tailings Radiation Control Act of 1978)for the protection of the public health, safety, and the environment from radiological and nonradiological hazards associated with residual radioactive materials (as defined in section 101 of the Uranium Mill Tailings Radiation Con- 
42 USC 6901

note.

Rule.

42 USC 2014.

42 USC 2021.

Publication in

Federal

Register.

Notice, hearing opportunity.

Consultation.

Judicial

Review. trol Act of 1978) located at inactive uranium mill tailings sites and depository sites for such materials selected by the Secretary of Energy, pursuant to title I of the Uranium Mill Tailing Radiation Control Act of 1978. Standards promulgated pursuant to this subsection shall, to the maximum extent practicable, be consistent with the requirements of the Solid Waste Disposal Act, as amended. The Administrator may periodically revise any standard promulgated pursuant to this subsection.

"b. (1) As soon as practicable, but not later than eighteen months after the enactment of this section, the Administrator shall, by rule, promulgate standards of general application for the protection of the public health, safety, and the environment from radiological and nonradiological hazards associated with the processing and with the possession, transfer, and disposal of byproduct material, as defined in section $11 \mathrm{e}$. (2) of this Act, at sites at which ores are processed primarily for their source material content or which are used for the disposal of such byproduct material.

"(2) Such generally applicable standards promulgated pursuant to this subsection for nonradiological hazards shall provide for the protection of human health and the environment consistent with the standards required under subtitle $\mathrm{C}$ of the Solid Waste Disposal Act, as amended, which are applicable to such hazards: Provided, however, That no permit issued by the Administrator is required under this Act or the Solid Waste Disposal Act, as amended, for the processing, possession, transfer, or disposal of byproduct material, as defined in section 11 e. (2) of this Act. The Administrator may periodically revise any standard promulgated pursuant to this subsection. Within three years after such revision of any such standard, the Commission and any State permitted to exercise authority under section $274 \mathrm{~b}$. (2) shall apply such revised standard in the case of any license for byproduct material as defined in section $11 \mathrm{e}$. (2) or any revision thereof.

"c. (1) Before the promulgation of any rule pursuant to this section, the Administrator shall publish, the proposed rule in the Federal Register, together with a statement of the research, analysis, and other available information in support of such proposed rule, and provide a period of public comment of at least thirty days for written comments thereon and an opportunity, after such comment period and after public notice, for any interested person to present oral data, views, and arguments at a public hearing. There shall be a transcript of any such hearing. The Administrator shall consult with the Commission and the Secretary of Energy before promulgation of any such rule.

“(2) Judicial review of any rule promulgated under this section may be obtained by any interested person only upon such person filing a petition for review within sixty days after such promulgation in the United States court of appeals for the Federal judicial circuit in which such person resides or has his principal place of business. A copy of the petition shall be forthwith transmitted by the clerk of court to the Administrator. The Administrator thereupon shall file in the court the written submissions to, and transcript of, the written or oral proceedings on which such rule was based as provided in 
5 USC 701

et seq.

42 USC 2021.

42 USC 2014.

42 USC 7401

note.

33 USC 1251

note.

42 USC 2018

et seq.

42 USC 2014

note.

42 USC 2113

note.

42 USC 2011

note.

42 USC 7941.

42 USC 2021 section 2112 of title 28, United States Code. The court shall have jurisdiction to review the rule in accordance with chapter 7 of title 5, United States Code, and to grant appropriate relief as provided in such chapter. The judgment of the court affirming, modifying, or setting aside, in whole or in part, any such rule shall be final, subject to judicial review by the Supreme Court of the United States upon certiorari or certification as provided in section 1254 of title 28, United States Code.

"(3) Any rule promulgated under this section shall not take effect earlier than sixty calendar days after such promulgation.

"d. Implementation and enforcement of the standards promulgated pursuant to subsection $b$. of this section shall be the responsibility of the Commission in the conduct of its licensing activities under this Act. States exercising authority pursuant to section $274 \mathrm{~b}$. (2) of this Act shall implement and enforce such standards in accordance with subsection 0 . of such section.

"e. Nothing in this Act applicable to byproduct material, as defined in section 11 e. (92) of this Act, shall affect the authority of the Administrator under the Clean Air Act of 1970, as amended, or the Federal Water Pollution Control Act, as amended.".

(b) The table of contents for chapter 19 of the Atomic Energy Act is amended by inserting the following new item after the item relating to section 274:

"Sec. 275. Health and environmental standards for uranium tailings.". AUTHORIZATION OF APPROPRIATION FOR GRANTS

Sec. 207. There is hereby authorized to be appropriated for fiscal year 1980 to the Nuclear Regulatory Commission not to exceed $\$ 500,000$ to be used for making grants to States which have entered into agreements with the Commission under section 274 of the Atomic Energy Act of 1954 , to aid in the development of State regulatory programs under such section which implement the provisions of this Act.

\section{EFFECTIVE DATE}

Sec. 208. Except as otherwise provided in this title the amendments made by this title shall take effect on the date of the enactment of this Act.

\section{CONSOLIDATION OF LICENSES AND PROCEDURES}

Sec. 209. The Regulatory Commission shall consolidate, to the maximum extent practicable, licenses and licensing procedures under amendments made by this title with licenses and licensing procedures under other authorities contained in the Atomic Energy Act of 1954.

\section{TITLE III-STUDY AND DESIGNATION OF TWO MILL TAILINGS SITES IN NEW MEXICO}

\section{STUDY}

Sec. 301. The Commission, in consultation with the Attorney General and the Attorney General of the State of New Mexico, shall conduct a study to determine the extent and adequacy of the authority of the Commission and the State of New Mexico to require, under the Atomic Energy Act of 1954 (as amended by title II of this Act) or under State authority as permitted under section 274 of such Act or under other pro- 
Report to Congress.

42 USC 7942

Submittal to congressional committees. vision of law, the owners of the following active uranium mill sites to undertake appropriate action to regulate and control all residual radioactive materials at such sites to protect public health, safety, and the environment: the former Homestake-New Mexico Partners site near Milan, New Mexico, and the Anaconda carbonate process tailing site near Bluewater, New Mexico. Such study shall be completed and a report thereof submitted to the Congress and to the Secretary within one year after enactment of this Act, together with such recommendations as may be appropriate. If the Commission determines that such authority is not adequate to regulate and control such materials at such sites in the manner provided in the first sentence of this section, the Commission shall include in the report a statement of the basis for such determination. Nothing in this Act shall be construed to prevent or delay action by a State as permitted under section 274 of the Atomic Energy Act of 1954 or under any other provision of law or by the Commission to regulate such residual radioactive materials at such sites prior to completion of such study.

\section{DESIGNATION BX SECRETARY}

Sec. 302. (a) Within ninety days from the date of his receipt of the report and recommendations submitted by the Commission under section 301 , notwithstanding the limitations contained in section 301, notwithstanding the limitations contained in section 101(6)(A) and in section 115(a), if the Commission determines, based on such study, that such sites cannot be regulated and controlled by the State or the Commission in the manner described in section 301, the Secretary may designate either or both of the sites referred to in section 301 as a processing site for purposes of title I. Following such designation, the Secretary may enter into cooperative agreements with New Mexico to perform remedial action pursuant to such title concerning only the residual radioactive materials at such site resulting from uranium produced for sale to a Federal agency prior to January 1, 1971, under contract with such agency. Any such designation shall be submitted by the Secretary, together with his estimate of the cost of carrying out such remedial action at the designated site, to the Committee on Interior and Insular Affairs and the Committee on Interstate and Foreign Commerce of the House of Representatives and to the Committee on Energy and Natural Resources of the Senate.

(b)(1) No designation under subsection (a) shall take effect before the expiration of one hundred and twenty calendar days (not including any day in which either House of Congress is not in session because of an adjournment of more than three calendar days to a day certain or an adjournment sine die) after receipt by such Committees of such designation.

(c) Except as otherwise specifically provided in subsection (a), any remedial action under title I with respect to any sites designated under this title shall be subject to the provisions of title I (including the authorization of appropriations referred to in section 112(b)).

Approved November 8, 1978. 
NUCLEAR REGULATORY COMMISSION ANNUAL CHARGES

PAGE 42 USC

Sec.6101.NRC User Fees.

Sec.

$376 \ldots 2214$. 


\section{OMNIBUS BUDGET RECONCILIATION ACT OF 1990}

Public Law 101-508-NOV. 5, 1990

104 Stat. 1388

\section{TITLE VI \\ ENERGY AND ENVIRONMENTAL PROGRAMS}

Subtitle B-NRC User Fees and Annual Charges

42 USC 2214

42 USC 2214

SEC. 6101. NRC USER FEES AND ANNUAL CHARGES

(a) ANNUAL ASSESSMENT.-

(1) IN GENERAL.-Except as provided in paragraph (3), the Nuclear Regulatory Commission (in this section referred to as the "Commission") shall annually assess and collect such fees and charges as are described in subsections (b) and (c).

(2) FIRST ASSESSMENT.-The first assessment of fees under subsection (b) and annual charges under subsection (c) shall be made not later than September 30, 1991.

(3) LAST ASSESSMENT OF ANNUAL CHARGES.-The last assessment of annual charges under subsection (c) shall be made not later than September 30, 1998.

(b) FEES FOR SERVICE OR THING OF VALUE.-Pursuant to section 9701 of title 31, United States Code, any person who receives a service or thing of value from the Commission shall pay fees to cover the Commission's costs in providing any such service or thing of value.

(c) ANNUAL CHARGES.-

(1) PERSONS SUBJECT TO CHARGE.-Except as provided in paragraph (4), any licensee of the Commission may be required to pay, in addition to the fees set forth in subsection (b), an annual charge.

(2) AGGREGATE AMOUNT OF CHARGES.-The aggregate amount of the annual charge collected from all licensees shall equal an amount that approximates 100 percent of the budget authority of the Commission in the fiscal year in which such charge is collected, less any amount appropriated to the Commission from the Nuclear Waste Fund and the amount of fees collected under subsection (b) in such fiscal year.

(3) AMOUNT PER LICENSEE.-The Commission shall establish, by rule, a schedule of charges fairly and equitably allocating the aggregate amount of charges described in paragraph (2)among licensees. To the maximum extent practicable, the charges shall have a reasonable relationship to the cost of providing regulatory services and may be based on the allocation of the Commission's resources among licensees or classes of licensees.

(4) EXEMPTION.-

(A) IN GENERAL. - Paragraph (1) shall not apply to the holder of any license for a federally owned research reactor used primarily for educational training and academic research purposes. 
(B) RESEARCH REACTOR.-For purposes of subparagraph $(A)$, the term 'research reactor' means a nuclear reactor that-

(i) is licensed by the Nuclear Regulatory Commission under section $104 \mathrm{c}$. of the Atomic Energy Act of 1954 (42 U.S.C. 2134(c)) for operation at a thermal power level of 10 megawatts or less; and

(ii) if so licensed for operation at a thermal power level of more than 1 megawatt, does not contain-

(I) a circulating loop through the core in which the licensee conducts fuel experiments;

(II) a liquid fuel loading; or

(III) an experimental facility in the core in excess of 16 square inches in cross-section.

(d) DEFINITION.-As used in this section, the term "Nuclear Waste Fund" means the fund established pursuant to section 302(c) of the Nuclear Waste Policy Act of 1982 (42 U.S.C. 10222(c)).

42 USC 2213

(e) CONFORMING AMENDMENT TO COBRA.-Paragraph(1)(a) of section 7601 of the Consolidated Omnibus Budget Reconciliation

Act of 1985 (Public Law 99-272) is amended by striking "except that for fiscal year of 1990 such maximum amount shall be estimated to be equal to 45 percent of the costs incurred by the Commission for fiscal year 1990" and inserting "except as otherwise provided by law".1

${ }^{1}$ Under P.L 99-272, NRC was required to collect user fees totalling 33\% of its budget on a fiscal yeare basis.

Under P.L. 100-203, NRC was required to collect user fees totalling 45\% of its budget for FY88\&89. This amended P.L. 99-272.

P.L. 102-486, Title XXIX, $\$ 2983($ a), 106 Stat. 3125, Oat. 24, 1992.

P.L. 103-66, Title VI, \& 7001, 107 Stat. 401, Aug. 10, 1993 
NRC AUTHORIZATION ACTS

PAGE USC

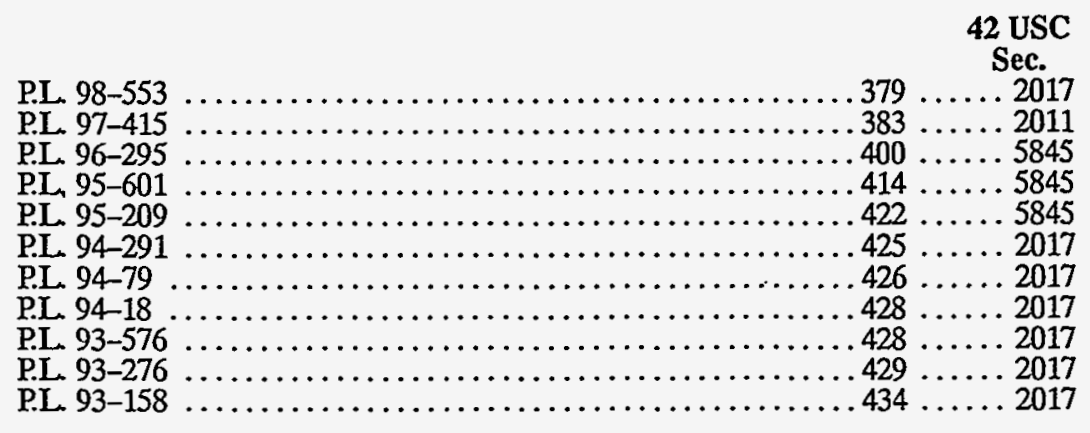


NRC AUTHORIZATION ACT FOR FISCAL YEAR 1984-1985

Public Law 98-553

98 Stat. 2825

\section{An Act}

October 30, 1984 [S. 1291]

42 USC 2017. 42 USC 5875.

Grants.

To authorize appropriations to the Nuclear Regulatory Commission in accordance with section 261 of the Atomic Energy Act of 1954, and section 305 of the Energy Reorganization Act of 1974.

Be it enacted by the Senate and House of Representatives of the United States of America in Congress assembled,

\section{TITLE I- AUTHORIZATION OF APPROPRIATIONS FOR FISCAL YEARS 1984 AND 1985}

Sec. 101. There are hereby authorized to be appropriated to the Nuclear Regulatory Commission in accordance with the provisions of section 261 of the Atomic Energy Act of 1954 and section 305 of the Energy Reorganization Act of 1974, for the fiscal years 1984 and 1985 to remain available until expended, $\$ 466,800,000$ for fiscal year 1984 and $\$ 460,000,000$ for fiscal year 1985 .

Sec. 102. (a) The sums authorized to be appropriated in this Act for fiscal years 1984 and 1985 shall be allocated as follows:

. (1) not more than $\$ 91,490,000$ for fiscal year 1984 and $\$ 87,140,000$ for fiscal year 1985, may be used for "Nuclear Reactor Regulation", of which an amount not be exceed $\$ 1,000,000$ is authorized each such fiscal year to be used to accelerate the effort in gas-cooled thermal reactor preapplication review;

"(2) not more than $\$ 70,910,000$ for fiscal year 1984 and $\$ 74,770,000$ for fiscal year 1985 , may be used for "Inspection and Enforcement";

"(3) not more than $\$ 36,280,000$ for fiscal year 1984 and $\$ 35,710,000$ for fiscal year 1985 , may be used for "Nuclear Material Safety and Safeguards";

"(4) not more than $\$ 199,740,000$ for fiscal year 1984 and $\$ 193,290,000$ for fiscal year 1985 , may be used for "Nuclear Regulatory Research", of which an amount not to exceed $\$ 2,600,000$ is authorized each such fiscal year to be used to accelerate the effort in gas-cooled thermal reactor safety research;

"(5) not more than $\$ 27,520,000$ for fiscal year 1984 and $\$ 27,470,000$ for fiscal year 1985 , may be used for "Program Technical Support";

"(6) not more than $\$ 40,860,000$ for fiscal year 1984 and $\$ 41,620,000$ for fiscal year 1985 , may be used for "Program Direction and Administration".

(b) The Nuclear Regulatory Commission may use not more than 1 per centum of the amounts authorized to be appropriated under paragraph 102(a)(4) to exercise its authority under section 31 a. of the Atomic Energy Act of 1954 (42 U.S.C. 2051(a)) to enter into grants and cooperative agreements with universities pursuant to such paragraph. Grants made by the Commission shall be made in accordance with the Federal Grant and Cooperative Agreement Act of 1977 (41 U.S.C. 501 et seq.) and other applicable law. 
31 USC 3302.

Report.

Prohibition. (c) Any amount appropriated for a fiscal year to the Nuclear Regulatory Commission pursuant to any paragraph of subsection 102(a) for purposes of the program referred to in such paragraph, may be reallocated by the Commission for use in a program referred to in any other paragraph of such subsection, or for use in any other activity within a program, except that the amount available from appropriations for such fiscal year for use in any program or specified activity may not, as a result of reallocations made under this subsection, be increased or reduced by more than $\$ 500,000$ unless-

(1) a period of thirty calendar days (excluding any day in which either House of Congress is not in session because of an adjournment of more than three calendar days to a day certain or an adjournment sine die) passes after the receipt, by the Committee on Energy and Commerce and the Committee on Interior and Insular Affairs of the House of Representatives and the Committee on Environment and Public Works of the Senate, of notice submitted by the Commission containing a full and complete statement of the reallocation proposed to be made and the facts and circumstances relied upon in support of such proposed reallocation; or

(2) each such committee, before the expiration of such period, transmits to the Commission a written notification that such committee does not object to such proposed reallocation.

Sec. 103. Moneys received by the Nuclear Regulatory Commission for the cooperative nuclear research program and the material access authorization program may be retained and used for salaries and expenses associated with such programs, notwithstanding the provisions of section 3617 of the Revised Statutes (31 U.S.C. 484), and shall remain available until expended.

Sec 104. From amounts appropriated to the Nuclear Regulatory Commission pursuant to this title, the Commission may transfer to other agencies of the Federal Government sums for salaries and expenses for the performance by such agencies of activities for which such appropriations of the Commission are made. Any sums so transferred may be merged with the appropriation of the agency to which such sums are transferred.

Sec. 105. Notwithstanding any other provisions of this Act, no authority to make payments under this Act shall be effective except to such extent or in such amounts as are provided in advance in appropriation Acts.

Sec 106. (a) No funds authorized to be appropriated under this Act may be used to carry out any policy or program for the decentralization or regionalization of any Nuclear Regulatory Commission authorities regarding commercial nuclear powerplant licensing until sixty legislative days after the date on which the Commission submits to the Congress a report evaluating the effect of such policy or program on nuclear reactor safety: Provided, however, That the prohibition contained in this subsection shall not apply to any personnel assigned to the field, or to activities in which they were engaged, on or before September 22, 1983. The report shall include- 
(1) a detailed description of the authorities to be transferred, the reason for such transfer, and an assessment of the effect of such transfer on nuclear reactor safety;

(2) an analysis of all comments submitted to the Commission regarding the effect on nuclear reactor safety which would result from carrying out the policy or program proposed by the Commission; and

(3) an evaluation of the results, including the advantages and disadvantages, of the pilot program conducted under subsection (b). (b) Notwithstanding the prohibition contained in subsection (a), the Commission is authorized to conduct a pilot program for the purpose of evaluating the concept of delegating authority to regional offices for issuance of specific types of operating reactor licensing actions and for the purpose of addressing the issues identified in paragraphs (a)(1)-(3) of this section.

Sec. 107. (a) Of the amounts authorized to be appropriated under this Act for the fiscal years 1984 and 1985, such sums as may be necessary are authorized to be used by the Nuclear Regulatory Commission for-

(1) the acquisition (by purchase, lease, or otherwise) and installation of equipment to be used for the small test prototype nuclear data link program or for any other program for the collection and transmission to the Commission of data from licensed nuclear reactors during abnormal conditions at such reactors; and

(2) a full and complete analysis of-

(A) the appropriate role of the Commission during abnormal conditions at a nuclear reactor licensed by the Commission;

(B) the information which should be available to the Commission to enable the Commission to fulfill such role and to carry out other related functions;

(C) various alternative means of assuring that such information is available to the Commission in a timely manner; and

(D) any changes in existing Commission authority necessary to enhance the Commission response to abnormal conditions at a nuclear reactor licensed by the Commission:

Provided, however, That no funds shall be available under this Act for the acquisition and installation of any equipment for the collection and transmission to the Commission of data from licensed nuclear reactors during abnormal conditions at such reactors, or for the analysis of such equipment, unless such acquisition and analysis includes, as one of the alternatives considered, a fully automated electronic nuclear data link. The small test prototype referred to in paragraph (1) may be used by the Commission in carrying out the study and analysis under paragraph (2). Such analysis shall include a cost-benefit analysis of each alternative examined under subparagraph (C).

Sec. 108. Of the amounts authorized to be appropriated under this Act, the Nuclear Regulatory Commission may use such sums as may be necessary, in the absence of a State or local emergency preparedness plan which has been approved by the Federal Emergency Management Agency, to issue an operating license (including a temporary operating 42 USC 2242. license under section 192 of the Atomic Energy Act of 1954, as amended)for a nuclear power reactor, if it determines that there exists a 
42 USC 2133

42 USC 2134
State, local, or utility plan which provides reasonable assurance that public health and safety is not endangered by operation of the facility concerned.

Sec 109. Notwithstanding the second sentence of section $103 \mathrm{~d}$. and the second sentence of section $104 \mathrm{~d}$. of the Atomic Energy Act of 1954, as amended, the Nuclear Regulatory Commission is hereby authorized to transfer Facility Operating License numbered R-81 to a United States entity or corporation owned or controlled by a foreign corporation if the Commission-

(1) finds that such transfer would not be inimical to the common defense and security or to the health and safety of the public; and (2) includes in such license, as transferred, such conditions as the Commission deems necessary to ensure that such foreign corporation cannot direct the actions of the licensee in ways that would be inimical to the common defense and security or the health and safety of the public.

Approved October 30, 1984.

\footnotetext{
LEGISLATIVE HISTORY-S. 1291 (S. 2846) (H.R. 2510):

HOUSE REPORTS: No. 98-103,PT. 1 (Comm. on Interior and Insular Affairs) and Pt. 2 (Comm. on Energy and Commerce) both accompanying H.R. 2510

SENATE REPORTS: No. 98-118 (Comm. on Environment and Public Works); No. 98-546 (Comm. on Environment and Public Works); No. 98-579 (Comm. on Energy and Natural Resources) both accompanying $S .2846$. 
NRC AUTHORIZATION ACT FOR FISCAL YEAR 1982-1983

Public Law 97-415

96 Stat. 2067

\section{An Act}

Jan. 4, 1983

[H.R. 2330]

Nuclear

Regulatory

Commission.

Appropriations

To authorize appropriations to the Nuclear Regulatory Commission in accordance with section 261 of the Atomic Energy Act of 1954, as amended, and section 305 of the Energy Reorganization Act of 1974, as amended, and for other purposes.

Be it enacted by the Senate and House of Representatives of the United States of America in Congress assembled,

\section{AUTHORIZATION OF APPROPRIATIONS}

Section 1. (a) There are hereby authorized to be appropriated to the Nuclear Regulatory Commission in accordance with the provisions of section 261 of the Atomic Energy Act of 1954 (42 U.S.C. 2017) and section 305 of the Energy Reorganization Act of 1974 (42 U.S.C. 5875), for the fiscal years 1982 and 1983 to remain available until expended, $\$ 485,200,000$ for fiscal year 1982 and $\$ 513,100,000$ for fiscal year 1983 to be allocated as follows:

(1) Not more than $\$ 80,700,000$ for fiscal year 1982 and $\$ 77,000,000$ for fiscal year 1983 may be used for "Nuclear Reactor Regulation", of which an amount not to exceed $\$ 1,000,000$ is authorized each such fiscal year to be used to accelerate the effort in gas-cooled thermal reactor preapplication review, and an amount not to exceed $\$ 6,000,000$ is authorized each such fiscal year to be used for licensing review work for a fast breeder reactor plant project. In the event of a termination of such breeder reactor project, any unused amount appropriated pursuant to this paragraph for licensing review work for such project may be used only for safety technology activities.

(2) Not more than $\$ 62,900,000$ for fiscal year 1982 and $\$ 69,850,000$ for fiscal year 1983 may be used for "Inspection and Enforcement".

(3) Not more than $\$ 42,000,000$ for fiscal year 1982 and $\$ 47,059,600$ for fiscal year 1983 may be used for "Nuclear Material Safety and Safeguards".

(4) Not more than $\$ 240,300,000$ for fiscal year 1982 and $\$ 257,195,600$ for fiscal year 1983 may be used for "Nuclear Regulatory Research", of which-

(A) an amount not to exceed $\$ 3,500,000$ for fiscal year 1982 and $\$ 4,500,000$ for fiscal year 1983 is authorized to be used to accelerate the effort in gas-cooled thermal reactor safety research;

(B) an amount not to exceed $\$ 18,000,000$ is authorized each such fiscal year to be used for fast breeder reactor safety research; and

(C) an amount not to exceed $\$ 57,000,000$ is authorized for such two fiscal year period to be used for the Loss-of-Fluid Test Facility research program. 
Grants and cooperative agreements.

Reallocated funds.

Notification of congressional committees.

Ante, p. 948. 31 USC 3302
In the event of a termination of the fast breeder reactor plant project, any unused amount appropriated pursuant to this paragraph for fast breeder reactor safety research may be used generally for "Nuclear Regulatory Research".

(5) Not more than $\$ 21,900,000$ for fiscal year 1982 and $\$ 20,197,800$ for fiscal year 1983 may be used for "Program Technical Support".

(6) Not more than $\$ 37,400,000$ for fiscal year 1982 and $\$ 41,797,000$ for fiscal year 1983 may be used for "Program Direction and Administration."

(b) The Nuclear Regulatory Commission may use not more than 1 percent of the amounts authorized to be appropriated under subsection (a)(4) to exercise its authority under section 31 a. of the Atomic Energy Act of 1954 (42 U.S.C. 2051(a)) to enter into grants and cooperative agreements with universities pursuant to such section. Grants made by the Commission shall be made in accordance with the Federal Grant and Cooperative Agreement Act of 1977 (41 U.S.C. 501 et seq.) and other applicable law. In making such grants and entering into such cooperative agreements, the Commission shall endeavor to provide appropriate opportunities for universities in which the student body has historically been predominantly comprised of minority groups.

(c) Any amount appropriated for a fiscal year to the Nuclear Regulatory Commission pursuant to any paragraph of subsection (a) for purposes of the program office referred to in such paragraph, or any activity that is within such program office and is specified in such paragraph, may be reallocated by the Commission for use in a program office, except that the amount available from appropriations for such fiscal year for use in any program office or specified activity may not, as a result of reallocations made under this subsection, be increased or reduced by more than $\$ 500,000$ unless -

(1) a period of 30 calendar days (excluding any day in which either House of Congress is not in session because of an adjournment of more than 3 calendar days to a day certain or an adjournment sine die) passes after the receipt, by the Committee on Energy and Commerce and the Committee on Interior and Insular Affairs of the House of Representatives and the Committee on Environment and Public Works of the Senate, of notice submitted by the Commission containing a full and complete statement of the reallocation proposed to be made and the facts and circumstances relied upon in support of such proposed reallocation; or

(2) each such committee, before the expiration of such period, transmits to the Commission a written notification that such committee does not object to such proposed reallocation.

\section{AUTHORITY TO RETAIN CERTAIN AMOUNTS RECEIVED}

Sec. 2. Moneys received by the Nuclear Regulatory Commission for the cooperative nuclear research program and the material access authorization program may be retained and used for salaries and expenses associated with such programs, notwithstanding the provisions of section 3617 of the Revised Statutes (31 U.S.C. 484), and shall remain available until expended. 


\section{AUTHORITY TO TRANSFER CERTAIN AMOUNTS TO OTHER AGENCIES}

Sec. 3. From amounts appropriated to the Nuclear Regulatory Commission pursuant to section 1(a), the Commission may transfer to other agencies of the Federal Government sums for salaries and expenses for the performance by such agencies of activities for which such appropriations of the Commission are made. Any sums so transferred may be merged with the appropriation of the agency to which such sums are transferred.

\section{LIMITATION ON SPENDING AUTHORITY}

Sec. 4. Notwithstanding any other provision of this Act, no authority to make payments under this Act shall be effective except to such extent or in such amounts as are provided in advance in appropriation Acts.

\section{AUTHORITY TO ISSUE LICENSES IN ABSENCE OF EMERGENCY
PREPAREDNESS PLANS}

Sec.5. Of the amounts authorized to be appropriated under section 1 , the Nuclear Regulatory Commission may use such sums as may be necessary, in the absence of a State or local emergency preparedness plan which has been approved by the Federal Emergency Management Agency, to issue an operating license (including a temporary operating license under section 192 of the Atomic Energy Act of 1954, as amended by section 11 of this Act) for a nuclear power reactor, if it determines that there exists a State, local, or utility plan which provides reasonable assurance that public health and safety is not endangered by operation of the facility concerned.

\section{NUCLEAR SAFETY GOALS}

Sec. 6. Funds authorized to be appropriated under this Act shall be used by the Nuclear Regulatory Commission to expedite the establishment of safety goals for nuclear reactor regulation. The development of such safety goals, and any accompanying methodologies for the application of such safety goals, should be expedited to the maximum extent practicable to permit establishment of a safety goal by the Commission not later than December 31, 1982.

\section{LOSS-OF-FLUID TEST FACILITY}

Sec. 7. Of the amounts authorized to be used for the Loss-of-Fluid Test Facility in accordance with section 1(a)(4) for fiscal years 1982 and 1983, the Commission shall provide funding through contract with the organization responsible for the Loss-of-Fluid Test operations for a detailed technical review and analysis of research results obtained from the Loss-of-Fluid Test Facility research program. The contract shall provide funding for not more than twenty man-years in each of fiscal years 1982 and 1983 to conduct the technical review and analysis.

\section{NUCLEAR DATA LINK}

Sec. 8. (a) Of the amounts authorized to be appropriated under this Act for the fiscal years 1982 and 1983, not more than $\$ 200,000$ is authorized to be used by the Nuclear Regulatory Commission for-

(1) the acquisition (by purchase, lease, or otherwise) and installation of equipment to be used for the "small test prototype nuclear data link" program or for any other program for the collection and transmission to the Commission of data from licensed nuclear reactors during abnormal conditions at such reactors; and 
Study and analysis.

Report to Congress.

Commission action; notification of congressional committees.

42 USC 2011 note.
(2) the conduct of a full and complete study and analysis of(A) the appropriate role of the Commission during abnormal conditions at a nuclear reactor licensed by the Commission;

(B) the information which should be available to the Commission to enable the Commission to fulfill such role and to carry out other related functions;

(C) various alternative means of assuring that such information is available to the Commission in a timely manner; and

(D) any changes in existing Commission authority necessary to enhance the Commission response to abnormal conditions at a nuclear reactor licensed by the Commission.

The small test prototype referred to in paragraph (1) may be used by the Commission in carrying out the study and analysis under paragraph (2). Such analysis shall include a cost-benefit analysis of each alternative examined under subparagraph (C).

(b)(1) Upon completion of the study and analysis required under subsection (a)(2), the Commission shall submit to Congress a detailed report setting forth the results of such study and analysis.

(2) The Commission may not take any action with respect to any alternative described in subsection (a)(2)(C), unless a period of 60 calendar days (excluding any day in which either House of Congress is not in session because of an adjournment of more than 3 calendar days to a day certain or an adjournment sine die) passes after the receipt, by the Committee on Energy and Commerce and the Committee on Interior and Insular Affairs of the House of Representatives and the Committee on Environment and Public Works of the Senate, of notice submitted by the Commission containing a full and complete statement of the action proposed to be taken and the facts and circumstances relied upon in support of such proposed action.

\section{INTERIM CONSOLIDATION OF OFFICES}

Sec. 9. (a) Of the amounts authorized to be appropriated pursuant to paragraph 6 of section 1(a), such sums as may be necessary shall be available for interim consolidation of Nuclear Regulatory Commission headquarters staff offices.

(b) No amount authorized to be appropriated under this Act may be used, in connection with the interim consolidation of Nuclear Regulatory Commission offices, to relocate the offices of members of the Commission outside the District of Columbia.

\section{THREE MILE ISLAND}

Sec. 10. (a) No part of the funds authorized to be appropriated under this Act may be used to provide assistance to the General Public Utilities Corporation for purposes of the decontamination, cleanup, repair, or rehabilitation of facilities at Three Mile Island Unit 2.

(b) The prohibition contained in subsection (a) shall not relate to the responsibilities of the Nuclear Regulatory Commission for monitoring or inspection of the decontamination, cleanup, repair, or rehabilitation activities at Three Mile Island and such prohibition shall not apply to the use of funds by the Nuclear Regulatory Commission to carry out regulatory functions of the Commission under the Atomic Energy Act of 1954 with respect to the facilities at Three Mile Island. 
42 USC 5877

note.

42 USC 2133, 2134.

Post, p. 2073

Initial petition.

Affidavits

Publication in Federal (c) The Nuclear Regulatory Commission shall include in its annual report to the Congress under section 307(c) of the Energy Reorganization Act of 1974 (42 U.S.C. 5877(c)) as a separate chapter a description of the collaborative efforts undertaken, or proposed to be undertaken, by the Commission and the Department of Energy with respect to the decontamination, cleanup, repair, or rehabilitation of facilities at Three Mile Island Unit 2.

(d) No funds authorized to be appropriated under this Act may be used by the Commission to approve any willful release of "accidentgenerated water", as defined by the Commission in NUREG-0683 ("Final Programmatic Environmental Impact Statement" p. 1-23), from Three Mile Island Unit 2 into the Susquehanna River or its watershed.

\section{TEMPORARY OPERATING LICENSES}

Sec. 11. Section 192 of the Atomic Energy Act of 1954 (42 U.S.C. 2242) is amended to read as follows:

"SEC. 192. TEMPORARY OPERATING LICENSE.-

"a. In any proceeding upon an application for an operating license for a utilization facility required to be licensed under section 103 or $104 \mathrm{~b}$. of this Act, in which a hearing is otherwise required pursuant to section 189 a., the applicant may petition the Commission for a temporary operating license for such facility authorizing fuel loading, testing, and operation at a specific power level to be determined by the Commission, pending final action by the Commission on the application. The initial petition for a temporary operating license for each such facility, and any temporary operating license issued for such facility based upon the initial petition, shall be limited to power levels not to exceed 5 percent of rated full thermal power. Following issuance by the Commission of the temporary operating license for each such facility, the licensee may file petitions with the Commission to amend the license to allow facility operation in staged increases at specific power levels, to be determined by the Commission, exceeding 5 percent of rated full thermal power. The initial petition for a temporary operating license for each such facility may be filed at any time after the filing of: (1) the report of the Advisory Committee on Reactor Safeguards required by section 192 b.; (2) the filing of the initial Safety Evaluation Report by the Nuclear Regulatory Commission staff and the Nuclear Regulatory Commission staff's first supplement to the report prepared in response to the report of the Advisory Committee on Reactor Safeguards for the facility; (3) the Nuclear Regulatory Commission staff's final detailed statement on the environmental impact of the facility prepared pursuant to section 102(2)(C) of the National Environmental Policy Act of 1969 (42 U.S.C. 4332(2)(C)); and (4) a State, local, or utility emergency preparedness plan for the facility. Petitions for the issuance of a temporary operating license, or for an amendment to such a license allowing operation at a specific power level greater than that authorized in the initial temporary operating license, shall be accompanied by an affidavit or affidavits setting forth the specific facts upon which the petitioner relies to justify issuance of the temporary operating license or the amendment thereto. The Commission shall publish notice of each such petition in the Federal Register 
and in such trade or news publications as the Commission deems appropriate to give reasonable notice to persons who might have a potential interest in the grant of such temporary operating license or amendment thereto. Any person may file affidavits or statements in support of, or in opposition to, the petition within thirty days after the publication of such notice in the Federal Register.

"b. With respect to any petition filed pursuant to subsection a. of this section, the Commission may issue a temporary operating license, or amend the license to authorize temporary operation at each specific power level greater than that authorized in the initial temporary operating license, as determined by the Commission, upon finding that-

"(1) in all respects other than the conduct or completion of any required hearing, the requirements of law are met;

"(2) in accordance with such requirements, there is reasonable assurance that operation of the facility during the period of the temporary operating license in accordance with its terms and conditions will provide adequate protection to the public health and safety and the environment during the period of temporary operation; and

"(3) denial of such temporary operating license will result in delay between the date on which construction of the facility is sufficiently completed, in the judgment of the Commission, to permit issuance of the temporary operating license, and the date when such facility would otherwise receive a final operating license pursuant to this Act.

The temporary operating license shall become effective upon issuance and shall contain such terms and conditions as the Commission may deem necessary, including the duration of the license and any provision

Final order, transmittal to congressional committees.

Judicial review.

28 USC 2341 et seq.

Post, p. 2073

Hearing. for the extension thereof. Any final order authorizing the issuance or amendment of any temporary operating license pursuant to this section shall recite with specificity the facts and reasons justifying the findings under this subsection, and shall be transmitted upon such issuance to the Committees on Interior and Insular Affairs and Energy and commerce of the House of Representatives and the Committee on Environment and Public Works of the Senate. The final order of the Commission with respect to the issuance or amendment of a temporary operating license shall be subject to judicial review pursuant to chapter 158 of title 28, United States Code. The requirements of section $189 \mathrm{a}$. of this Act with respect to the issuance or amendment of facility licenses shall not apply to the issuance or amendment of a temporary operating license under this section.

"c. Any hearing on the application for the final operating license for a facility required pursuant to section $189 \mathrm{a}$. shall be concluded as promptly as practicable. The Commission shall suspend the temporary operating license if it finds that the applicant is not prosecuting the application for the final operating license with due diligence. Issuance of a temporary operating license under subsection $b$. of this section shall be without prejudice to the right of any party to raise any issue in a hearing required pursuant to section 189 a.; and failure to assert any ground for denial or limitation of a temporary operating license shall not bar the assertion of 
Infra.

Expiration date.

Notice of publication.

Regulations establishing standards, criteria, and procedures.

42 USC 2239 such ground in connection with the issuance of a subsequent final operating license. Any party to a hearing required pursuant to section 189 a. on the final operating license for a facility for which a temporary operating license has been issued under subsection $b$., and any member of the Atomic Safety and Licensing Board conducting such hearing, shall promptly notify the Commission of any information indicating that the terms and conditions of the temporary operating license are not being met, or that such terms and conditions are not sufficient to comply with the provisions of paragraph (2) of subsection $b$.

"d. The Commission is authorized and directed to adopt such administrative remedies as the Commission deems appropriate to minimize the need for issuance of temporary operating licenses pursuant to this section.

"e. The authority to issue new temporary operating licenses under this section shall expire on December 31, 1983.”.

\section{OPERATING UICENSE AMENDMENT HEARINGS}

Sec. 12. (a) Section 189 a. of the Atomic Energy Act of 1954 (42 U.S.C. 2239(a)) is amended-

(1) by inserting "(1)" after the subsection designation; and

(2) by adding at the end thereof the following new paragraph:

"(2)(A) The Commission may issue and make immediately effective any amendment to an operating license, upon a determination by the Commission that such amendment involves no significant hazards consideration, notwithstanding the pendency before the Commission of a request for a hearing from any person. Such amendment may be issued and made immediately effective in advance of the holding and completion of any required hearing. In determining under this section whether such amendment involves no significant hazards consideration, the Commission shall consult with the State in which the facility involved is located. In all other respects such amendment shall meet the requirements of this Act.

"(B) The Commission shall periodically (but not less frequently than once every thirty days) publish notice of any amendments issued, or proposed to be issued, as provided in subparagraph (A). Each such notice shall include all amendments issued, or proposed to be issued, since the date of publication of the last such periodic notice. Such notice shall, with respect to each amendment or proposed amendment (i) identify the facility involved; and (ii) provide a brief description of such amendment. Nothing in this subsection shall be construed to delay the effective date of any amendment.

"(C) The Commission shall, during the ninety-day period following the effective date of this paragraph, promulgate regulations establishing (i) standards for determining whether any amendment to an operating license involves no significant hazards consideration; (ii) criteria for providing or, in emergency situations, dispensing with prior notice and reasonable opportunity for public comment on any such determination, which criteria shall take into account the exigency of the need for the amendment involved; and (iii) procedures for consultation on any such determination with the State in which the facility involved is located.".

(b) The authority of the Nuclear Regulatory Commission, under the 
note.

Resident inspector program. 42 USC 5841 note.

Commercial nuclear powerplant construction, study.

"Independent inspector." provisions of the amendment made by subsection (a), to issue and to make immediately effective any amendment to an operating license shall take effect upon the promulgation by the Commission of the regulations required in such provisions.

\section{QUALITY ASSURANCE}

Sec. 13. (a) The Nuclear Regulatory Commission is authorized and directed to implement and accelerate the resident inspector program so as to assure the assignment of at least one resident inspector by the end of fiscal year 1982 at each site at which a commercial nuclear powerplant is under construction and construction is more than 15 percent complete. At each such site at which construction is not more than 15 percent complete, the Commission shall provide that such inspection personnel as the Commission deems appropriate shall be physically present at the site at such times following issuance of the construction permit as may be necessary in the judgment of the Commission.

(b) The Commission shall conduct a study of existing and alternative programs for improving quality assurance and quality control in the construction of commercial nuclear powerplants. In conducting the study, the Commission shall obtain the comments of the public, licensees of nuclear powerplants, the Advisory Committee on Reactor Safeguards, and organizations comprised of professionals having expertise in appropriate fields. The study shall include an analysis of the following:

(1) providing a basis for quality assurance and quality control, inspection, and enforcement actions through the adoption of an approach which is more prescriptive than that currently in practice for defining principal architectural and engineering criteria for the construction of commercial nuclear powerplants;

(2) conditioning the issuance of construction permits for commercial nuclear powerplants on a demonstration by the licensee that the licensee is capable of independently managing the effective performance of all quality assurance and quality control responsibilities for the powerplant;

(3) evaluations, inspections, or audits of commercial nuclear powerplant construction by organizations comprised of professionals having expertise in appropriate fields which evaluations, inspections, or audits are more effective than those under current practice;

(4) improvement of the Commission's organization, methods, and programs for quality assurance development, review, and inspection; and

(5) conditioning the issuance of construction permits for commercial nuclear powerplants on the permittee entering into contracts or other arrangements with an independent inspector to audit the quality assurance program to verify quality assurance performance.

For purposes of paragraph (5), the term "independent inspector" means a person or other entity having no responsibility for the design or construction of the plant involved. The study shall also include an analysis of quality assurance and quality control programs at representative sites at 
which such programs are operating satisfactorily and an assessment of the reasons therefor.

(c) For purposes of-

(1) determining the best means of assuring that commercial nu-

42 USC 2011

note.

Pilot program.

Study results, submittal to

Congress.

42 USC 2014. 42 USC 2133, 2134. clear powerplants are constructed in accordance with the applicable safety requirements in effect pursuant to the Atomic Energy Act of 1954; and

(2) assessing the feasibility and benefits of the various means listed in subsection (b);

the Commission shall undertake a pilot program to review and evaluate programs that include one or more of the alternative concepts identified in subsection (b) for the purposes of assessing the feasibility and benefits of their implementation. The pilot program shall include programs that use independent inspectors for auditing quality assurance responsibilities of the licensee for the construction of commercial nuclear powerplants, as described in paragraph (5) of subsection (b). The pilot program shall include at least three sites at which commercial nuclear powerplants are under construction. The Commission shall select at least one site at which quality assurance and quality control programs have operated satisfactorily, and at least two sites with remedial programs underway at which major construction, quality assurance, or quality control deficiencies (or any combination thereof) have been identified in the past. The Commission may require any changes in existing quality assurance and quality control organizations and relationships that may be necessary at the selected sites to implement the pilot program.

(d) Not later than fifteen months after the date of the enactment of this Act, the Commission shall complete the study required under subsection (b) and submit to the United States Senate and House of representatives a report setting forth the results of the study. The report shall include a brief summary of the information received from the public and from other persons referred to in subsection (b) and a statement of the Commission's response to the significant comments received. The report shall also set forth in analysis of the results of the pilot program required under subsection (c). The report shall be accompanied by the recommendations of the Commission, including any legislative recommendations, and a description of any administrative actions that the Commission has undertaken or intends to undertake, for improving quality assurance and quality control programs that are applicable during the construction of nuclear powerplants.

\section{LIMITATION ON USE OF SPECIAL NUCLEAR MATERIAL}

Sec. 14. Section 57 of the Atomic Energy Act of 1954 (42 U.S.C. 2077) is amended by adding at the end thereof the following new subsection:

"e. Special nuclear material, as defined in section 11, produced in facilities licensed under section 103 or 104 may not be transferred, reprocessed, used, or otherwise made available by any instrumentality of the United States or any other person for nuclear explosive purposes."

\section{RESIDENT INSPECTORS}

Sec. 15. Of the amounts authorized to be appropriated under section 1, the Nuclear Regulatory Commission shall use such sums as may be necessary to conduct a study of the financial hardships incurred by 
Report to

Congress.

Penalties.

95 Stat. 1169.

Judicial review.

Quarterly report. resident inspectors as a result of (1) regulations of the Commission requiring resident inspectors to relocate periodically from one duty station to another; and (2) the requirements of the Commission respecting the domicile of resident inspectors and respecting travel between their domicile and duty station in such manner as to avoid the appearance of a conflict of interest. Not later than 90 days after the date of the enactment of this Act, the Commission shall submit to the Congress a report setting forth the findings of the Commission as a result of such study, together with a legislative proposal (including any supporting data or information) relating to any assistance for resident inspectors determined by the Commission to be appropriate.

\section{SABOTAGE OF NUCLEAR FACILITIES OR FUEL}

Sec. 16. Section 236 of the Atomic Energy Act of 1954 (42 U.S.C. 2284) is amended to read as follows:

"SEC. 236. SABOTAGE OF NUCLEAR FACILITIES OR FUEL.-

"a. Any person who intentionally and willfully destroys or causes physical damage to, or who intentionally and willfully attempts to destroy or cause physical damage to-

"(1) any production facility or utilization facility licensed under this Act;

"(2) any nuclear waste storage facility licensed under this Act; or

"(3) any nuclear fuel for such a utilization facility, or any spent nuclear fuel from such a facility;

shall be fined not more than $\$ 10,000$ or imprisoned for not more than ten years, or both.

"b. Any person who intentionally and willfully causes or attempts to cause an interruption of normal operation of any such facility through the unauthorized use of or tampering with the machinery, components, or controls of any such facility, shall be fined not more than $\$ 10,000$ or imprisoned for not more than ten years, or both.".

\section{DEPARTMENT OF ENERGY INFORMATION}

Sec. 17. (a) Section 148 a. (1) of the Atomic Energy Act of 1954 (42 U.S.C. 2168(a)(1)) is amended by inserting after "Secretary')" the following: ", with respect to atomic energy defense programs,".

(b) Section 148 of the Atomic Energy Act of 1954 (42 U.S.C. 2168) is amended by adding at the end thereof the following new subsections:

"d. Any determination by the Secretary concerning the applicability of this section shall be subject to judicial review pursuant to section 552(a)(4)(B) of title 5, United States Code.

"e. The Secretary shall prepare on a quarterly basis a report to be made available upon the request of any interested person, detailing the Secretary's application during that period of each regulation or order prescribed or issued under this section. In particular, such report shall"(1) identify any information protected from disclosure pursuant to such regulation or order;

"(2) specifically state the Secretary's justification for determining that unauthorized dissemination of the information protected from disclosure under such regulation or order could reasonably be expected to have a significant adverse effect on the health and safety of the public or the common defense and security by significantly 
increasing the likelihood of illegal production of nuclear weapons, or theft, diversion, or sabotage of nuclear materials, equipment, or facilities, as specified under subsection a.; and

"(3) provide justification that the Secretary has applied such regulation or order so as to protect from disclosure only the minimum amount of information necessary to protect the health and safety of the public or the common defense and security.".

42 USC 2022.

STANDARDS AND REQUIREMENTS UNDER SECTION 275

42 USC 7911.

Promulgation authority.

42 USC 2014.

Uranium mill licensing requirement

Sec. 18. (a) Section 275 of the Atomic Energy Act of 1954 is amended-

(1) by striking in subsection a. "one year after the date of enactment of this section" and substituting "October 1, 1982" and by adding the following at the end thereof: "After October 1, 1982, if the Administrator has not promulgated standards in final form under this subsection, any action of the Secretary of Energy under title I of the Uranium Mill tailings Radiation Control Act of 1978 which is required to comply with, or be taken in accordance with, the standards proposed by the Administrator under this subsection until such time as the Administrator promulgates such standards in final form.";

(2) by striking in subsection b. (1) "eighteen months after the enactment of this section, the Administrator shall, by rule, promulgate" and inserting in lieu thereof the following: "October 31, 1982, the Administrator shall, by rule, propose, and within 11 months thereafter promulgate in final form,";

(3) by adding the following at the end of subsection b. (1): "If the Administrator fails to promulgate standards in final form under this subsection by October 1, 1983, the authority of the Administrator to promulgate such standards shall terminate, and the Commission may take actions under this Act without regard to any provision of this Act requiring such actions to comply with, or be taken in accordance with, standards promulgated by the Administrator. In any such case, the Commission shall promulgate, and from time to time revise, any such standards of general application which the Commission deems necessary to carry out its responsibilities in the conduct of its licensing activities under this Act. Requirements established by the Commission under this Act with respect to byproduct material as defined in section $11 \mathrm{e}$. (2) shall conform to such standards. Any requirements adopted by the Commission respecting such byproduct material before promulgation by the Commission of such standards shall $\mathrm{b}$ amended as the Commission deems necessary to conform to such standards in the same manner as provided in subsection $f$. (3). Nothing in this subsection shall be construed to prohibit or suspend the implementation or enforcement by the Commission of any requirement of the Commission respecting byproduct material as defined in section $11 \mathrm{e}$. (2) pending promulgation by the Commission of any such standard of general application.";

(4) by adding the following new subsection at the end thereof:

"f. (1) Prior to January 1, 1983, the Commission shall not implement or enforce the provisions of the Uranium Mill Licensing Requirements 
regulations.

Implementation and enforcement.

Review, public comment, and suspension.

42 USC 2114.

Remedial action 42 USC 7918.

Ante, p. 2077; Post, p. 2080.

42 USC 2021. published as final rules at 45 Federal Register 65521 to 65538 on October 3, 1980 (hereinafter referred to as the 'October 3 regulations'). After December 31,1982 , the Commission is authorized to implement and enforce the provisions of such October 3 regulations (and any subsequent modifications or additions to such regulations which may be adopted by the Commission), except as otherwise provided in paragraphs (2) and (3) of this subsection.

"(2) Following the proposal by the Administrator of standards under subsection b., the Commission shall review the October 3 regulations, and, not later than 90 days after the date of such proposal, suspend implementation and enforcement of any provision of such regulations which the Commission determines after notice and opportunity for public comment to require a major action or major commitment by licensees which would be unnecessary if-

"(A) the standards proposed by the Administrator are promulgated in final form without modification, and

"(B) the Commission's requirements are modified to conform to such standards.

Such suspension shall terminate on the earlier of April 1, 1984 or the date on which the Commission amends the October 3 regulations to conform to final standards promulgated by the Administrator under subsection b. During the period of such suspension, the Commission shall continue to regulate byproduct material (as defined in section $11 \mathrm{e}$. (2)) under this Act on a licensee-by-licensee basis as the Commission deems necessary to protect public health, safety, and the environment.

"(3) Not later than 6 months after the date on which the Administrator promulgates final standards pursuant to subsection $b$. of this section, the Commission shall, after notice and opportunity for public comment, amend the October 3 regulations, and adopt such modifications, as the Commission deems necessary to conform to such final standards of the Administrator.

"(4) Nothing in this subsection may be construed as affecting the authority or responsibility of the Commission under section 84 to promulgate regulations to protect the public health and safety and the environment."

(b)(1) Section 108(a) of the Uranium Mill Tailings Radiation Control Act of 1978 is amended by adding the following new paragraph at the end thereof:

“(3) Notwithstanding paragraphs (1) and (2) of this subsection, after October 31, 1982, if the Administrator has not promulgated standards under section 275 a. of the Atomic Energy Act of 1954 in final form by such date, remedial action taken by the Secretary under this title shall comply with the standards proposed by the Administrator under such section 275a. until such time as the Administrator promulgates the standards in final form.".

(2) The second sentence of section 108(a)(2) of the Uranium Mill tailings Radiation Control Act of 1978 is repealed.

\section{AGREEMENT STATES}

Sec. 19. (a) Section 2740 of the Atomic Energy Act of 1954 is amended by adding the following at the end thereof: "In adopting requirements 
42 USC 2014.

pursuant to paragraph (2) of this subsection with respect to sites at which ores are processed primarily for their source material content or which are used for the disposal of byproduct material as defined in section $11 \mathrm{e}$. (2), the State may adopt alternatives (including, where appropriate, sitespecific alternatives) to the requirements adopted and enforced by the Commission for the same purpose if, after notice and opportunity for public hearing, the Commission determines that such alternatives will achieve a level of stabilization and containment of the sites concerned, and a level of protection for public health, safety, and the environment from radiological and nonradiological hazards associated with such sites, which is equivalent to, to the extent practicable, or more stringent than the level which would be achieved by standards and requirements adopted and enforced by the Commission for the same purpose and any final standards promulgated by the Administrator of the Environmental Protection Agency in accordance with section 275. Such alternative 42 USC 2022. State requirements may take into account local or regional conditions, including geology, topography, hydrology and meteorology.".

(b) Section 204(h)(3) of the Uranium Mill Tailings Radiation Control 42 USC 2021. Act of 1978 is amended by inserting the following before the period at note.

42 USC 2021. the end thereof: ".: Provided, however, That, in the case of a State which has exercised any authority under State law pursuant to an agreement entered into under section 274 of the Atomic Energy Act of 1954, the State authority over such byproduct material may be terminated, and the Commission authority over such material may be exercised, only after compliance by the Commission with the same procedures as are applicable in the case of termination of agreements under section $274 \mathrm{j}$. of the Atomic Energy Act of 1954.".

Alternative proposals by licensees. 42 USC 2114.

\section{AMENDMENT TO SECTION 84}

Sec. 20. Section 84 of the Atomic Energy Act of 1954 is amended by adding the following at the end thereof:

"c. In the case of sites at which ores are processed primarily for their source material content or which are used for the disposal of byproduct material as defined in section 11 e. (2), a licensee may propose alterna42 USC 2014. tives to specific requirements adopted and enforced by the Commission under this Act. Such alternative proposals may take into account local or regional conditions, including geology, topography, hydrology and meteorology. The Commission may treat such alternatives as satisfying Commission requirements if the Commission determines that such alternatives will achieve a level of stabilization and containment of the sites concerned, and a level of protection for public health, safety, and the environment from radiological and nonradiological hazards associated with such sites, which is equivalent to, to the extent practicable, or more stringent than the level which would be achieved by standards and requirements adopted and enforced by the Commission for the same purpose and any final standards promulgated by the Administrator of

42 USC 2022. the Environmental Protection Agency in accordance with section 275.".

\section{EDGEMONT}

Sec. 21. Section 102(e) of the Uranium Mill Tailings Radiation Con42 USC 7912. trol Act of 1978 is amended by adding the following at the end thereof: 

ing of section 101(6) any real property, or improvements thereon, in Edgemont, South Dakota, that-

"(A) is in the vicinity of the Tennessee Valley Authority uranium mill site at Edgemont (but not including such site), and

" $(B)$ is determined by the Secretary to be contaminated with residual radioactive materials.

In making the designation under this paragraph, the Secretary shall consult with the Administrator, the Commission and the State of South Dakota. The provisions of this title shall apply to the site so designated in the same manner and to the same extent as to the sites designated under subsection (a) except that, in applying such provisions to such site, any reference in this title to the date of the enactment of this Act shall be treated as a reference to the date of the enactment of this paragraph and

42 USC 7917. in determining the State share under section 107 of the costs of remedial action, there shall be credited to the State, expenditures made by the State prior to the date of the enactment of this paragraph which the Secretary determines would have been made by the State or the United States in carrying out the requirements of this title.".

\section{ADDITIONAL AMENDMENTS TO SECTIONS 84 AND 275}

42 USC 2114.

Sec. 22. (a) Section 84 a. (1) of the Atomic Energy Act of 1954 isamended by inserting before the comma at the end thereof the following: ", taking into account the risk to the public health, safety, and the environment, with due consideration of the economic costs and such other factors as the Commission determines to be appropriate,".

Ante, p. 2077.

(b) Section 275 of the Atomic Energy Act of 1954 is amended-

(1) in subsection a., by inserting after the second sentence there of the following new sentence: "In establishing such standards, the Administrator shall consider the risk to the public health, safety, and the environment, the environmental and economic costs of applying such standards, and such other factors as the Administrator determines to be appropriate."; and

(2) by adding at the end of subsection b. (1) the following new sentence: "In establishing such standards, the Administrator shall consider the risk to the public health, safety, and the environment, the environmental and economic costs of applying such standards, and such other factors as the Administrator determines to be appropriate.".

\section{URANIUM SUPPLY}

Comprehensive industry review, submittal to Congress. 42 USC $2210 b$ note.

Sec. 23. (a)(1) Not later than 12 months after the date of enactment of this section, the President shall prepare and submit to the Congress a comprehensive review of the status of the domestic uranium mining and milling industry. This review shall be made available to the appropriate committees of the United States Senate and the House of Representatives.

(2) The Comprehensive review prepared for submission under paragraph (1) shall include-

(A) projections of uranium requirements and inventories of domestic utilities; 
(B) present and future projected uranium production by the domestic mining and milling industry;

(C) the present and future probable penetration of the domestic market by foreign imports;

(D) the size of domestic and foreign ore reserves;

(E) present and projected domestic uranium exploration expenditures and plans;

(F) present and projected employment and capital investment in the uranium industry;

(G) an estimate of the level of domestic uranium production necessary to ensure the viable existence of a domestic uranium industry and protection of national security interests'

$(H)$ an estimate of the percentage of domestic uranium demand which must be met by domestic uranium production through the year 2000 in order to ensure the level of domestic production estimated to be necessary under subparagraph $(G)$;

(I) a projection of domestic uranium production and uranium price levels which will be in effect both under current policy and in the event that foreign import restrictions were enacted by Congress in order to guarantee domestic production at the level estimated to be necessary under subparagraph (G);

(J) the anticipated effect of spent nuclearfuel reprocessing on the demand for uranium; and

(K) other information relevant to the consideration of restrictions on the importation of source material and special nuclear material from foreign sources.

Report to

Congress and

President.

42 USC $2210 \mathrm{~b}$.

42 USC 2231.

Regulations.

Proprietary information, disclosure.

Criteria

(b)(1) Chapter 14 of the Atomic Energy Act of 1954 is amended by adding the following new section at the end thereof:

"SEC. 170B. URANIUM SUPPLY.-

"a. The Secretary of Energy shall monitor and for the years 1983 to 1992 report annually to the Congress and to the President a determination of the viability of the domestic uranium mining and milling industry and shall establish by rule,after public notice and in accordance with the requirements of section 181 of this Act, within 9 months of enactment of this section, specific criteria which shall be assessed in the annual reports on the domestic uranium industry's viability. The Secretary of Energy is authorized to issue regulations providing for the collection of such information as the Secretary of Energy deems necessary to carry out the monitoring and reporting requirements of this section.

"b. Upon a satisfactory showing to the Secretary of Energy by any person that any information, or portion thereof obtained under this section, would, if made public, divulge proprietary information of such person, the Secretary shall not disclose such information and disclosure thereof shall be punishable under section 1905 of title 18, United States Code.

"c. The criteria referred to in subsection a. shall also include, but not be limited to-

“(1) an assessment of whether executed contracts or options for source material or special nuclear material will result in greater than $37^{1 / 2}$ percent of actual or projected domestic uranium requirements for any two-consecutive-year period being supplied by source material or special nuclear material from foreign sources; 
Imported material, impact on domestic industry and national security.

Investigations.
“(2) projections of uranium requirements and inventories of domestic utilities for a 10 year period;

"(3) present and probable future use of the domestic market by foreign imports;

"(4) whether domestic economic reserves can supply all future needs for a future 10 year period;

"(5) present and projected domestic uranium exploration expenditures and plans;

"(6) present and projected employment and capital investment in the uranium industry;

"(7) the level of domestic uranium production capacity sufficient to meet projected domestic nuclear power needs for a 10 year period; and

"(8) a projection of domestic uranium production and uranium price levels which will be in effect under various assumptions with respect to imports.

"d. The Secretary or Energy, at any time, may determine on the basis of the monitoring and annual reports required under this section that source material or special nuclear material from foreign sources is being imported in such increased quantities as to be a substantial cause of serious injury, or threat thereof, to the United States uranium mining and milling industry. Based on that determination, the United States Trade Representative shall request that the United States International Trade Commission initiate an investigation under section 201 of the Trade Act of 1974 (19 U.S.C. 2251).

"e. (1) If, during the period 1982 to 1992, the Secretary of Energy determines that executed contracts or options for source material or special nuclear material from foreign sources for use in utilization facilities within or under the jurisdiction of the United States represent greater than $371 / 2$ percent of actual or projected domestic uranium requirements for any two-consecutive-year period, or if the Secretary of Energy shall request the Secretary of Commerce to initiate under section 232 of the Trade Expansion Act of 1962 (19 U.S.C. 1862) an investigation to determine the effects on the national security of imports of source material and special nuclear material. The Secretary of Energy shall cooperate fully with the Secretary of Commerce in carrying out such an investigation and shall make available to the Secretary of Commerce he findings that lead to this request an such other information that will assist the Secretary of Commerce in the conduct of the investigation.

"(2) The Secretary of Commerce shall, in the conduct of any investigation requested by the Secretary of Energy pursuant to this section, take into account any information made available by the Secretary of Energy, including information regarding the impact on national security of projected or executed contracts or options for source material or special nuclear material from foreign sources or whether domestic production capacity is sufficient to supply projected national security requirements.

"(3) No sooner than 3 years following completion of any investigation by the Secretary of Commerce under paragraph (1), if no recommendation has been made pursuant to to such study for trade adjustments to assist or protect domestic uranium production, the Secretary of Energy 
may initiate a request for another such investigation by the Secretary of Commerce.".

Approved January 4, 1983. 


\section{NRC AUTHORIZATION ACT FOR FISCAL YEAR 1980}

Public Law 96-295

94 Stat. 780

Nuclear

Regulatory

Commission.

Appropriation authorization.

To authorize appropriations to the Nuclear Regulatory Commission in accordance with section 261 of the Atomic Energy Act of 1954, as amended, and section 305 of the Energy Reorganization Act of 1974, as amended, and for other purposes.

Be it enacted by the Senate and House of Representatives of the United States of America in Congress assembled,

\section{TITLE I-AUTHORIZATION OF APPROPRIATIONS FOR FISCAL YEAR 1980}

Sec. 101. (a) There is hereby authorized to be appropriated to the Nuclear Regulatory Commission in accordance with the provisions of section 261 of the Atomic Energy Act of 1954 (42 U.S.C. 2017) and section 305 of the Energy Reorganization Act of 1974 (42 U.S.C. 5875), for the fiscal year 1980 , the sum of $\$ 426,821,000$, to remain available until expended. Of such total amount authorized to be appropriated:

(1) not more than $\$ 66,510,000$, may be used for "Nuclear Reactor Regulation", of which an amount not to exceed $\$ 1,000,000$ is authorized to accelerate the effort in gas-cooled thermal reactor preapplication review;

(2) not more than $\$ 42,440,000$, may be used for "Inspection and Enforcement"; of the total amount appropriated for this purpose $\$ 4,684,000$ shall be available for support for 146 additional inspectors for the Resident Inspector program;

(3) not more than $\$ 15,953,000$, may be used for "Standards Development";

(4) not more than $\$ 32,380,000$, may be used for "Nuclear Material Safety and Safeguards"; of the total amount appropriated for this purpose-

(A) not less than $\$ 60,000$ shall be available only for the employment by the Commission of two qualified individuals to be assigned by the Commission for implementation of the United States International Atomic Energy Agency Safeguards Treaty, following ratification of such treaty by the United States Senate;

(B) not less than $\$ 180,000$ and six additional positions shall be included in the Division of Safeguards for the regulatory improvements of material control and accounting safeguards and the development of improved regulatory requirements for safeguarding the transportation of spent fuel; and

(C) not less than $\$ 9,675,000$ shall be available for Nuclear Waste Disposal and Management activities, including support for five additional positions in the Division of Waste Management for implementation of the Uranium Mill Tailings Radiation Control Act of 1978 (Public Law 95-604; 42 U.S.C. 7901 and following); 
(5) not more than $\$ 213,005,000$, may be used for "Nuclear Regulatory Research", of which-

(A) an amount not to exceed $\$ 3,700,000$ shall be available to accelerate the effort in gas-cooled thermal reactor safety research;

(B) an amount not to exceed $\$ 4,400,000$ shall be available for implementation of the Improved Safety Systems Research plan required by section 205(f) of the Energy Reorganization Act of 1974.

(C) an amount not to exceed $\$ 6,700,000$ shall be available for Nuclear Waste Research activities;

(6) not more than $\$ 18,125,000$, may be used for "Program Technical Support"; of the total amount appropriated for this purpose, $\$ 4,238,000$ shall be available to the Office of State Programs, including support for eight additional positions for training and assistance to State and local governments in radiological emergency response planning and operations and for review of State plans; and

(7) not more than $\$ 38,408,000$ may be used for "Program Direction and Administration"; of the total amount appropriated for this purpose, $\$ 400,000$ shall be available for support of eight additional positions in the Division of contracts, Office of Administration.

(b) No amount appropriated to the Nuclear Regulatory Commission pursuant to subsection (a) may be used for any purpose in excess of the amount expressly authorized to be appropriated therefore by paragraphs (1) through (7) of such subsection if such excess amount is greater than $\$ 500,000$, nor may the amount available from any appropriation for any purpose specified in such paragraphs be reduced by more than $\$ 500,000$, unless-

(1) a period of 45 calendar days (not including any day in which either House of Congress is not in session because of an adjournment of more than 3 calendar days to a day certain or an adjournment sine die) has passed after the receipt by the Committee on Interstate and Foreign Commerce and the Committee on Interior and Insular Affairs of the House of representatives and the Committee on Environment and Public works of the Senate of notice given by the Commission containing a full and complete statement of the action proposed to be taken and the facts and circumstances relied upon in support of such proposed action, or

(2) each such Committee has, before the expiration of such period, transmitted to the Commission a written notification that there is no objection to the proposed action.

(c) No amount authorized to appropriated by this Act may be used by the Nuclear Regulatory Commission to enter into any contract providing funds in excess of $\$ 50,000$ encompassing research, study, or technical assistance on domestic safeguards matters except as directed by the Commission, by majority vote, following receipt by the Commission of a recommendation from the Executive Director for Operations supporting the need for such contract.

(d) No amount authorized to be appropriated by this Act may be used by the Nuclear Regulatory Commission to- 
Transfers of sums.
(1) place any new work or substantial modification to existing work with another Federal agency, or

(2) contract for research services or modify such contract in an amount greater than $\$ 500,000$ unless such placement of work, contract or modification is approved by a Senior Contract Review Board, to be appointed by the Commission within sixty days of the date of enactment of this Act. Such Board shall be accountable to and under the direction of the Commission. If the amount of such placement, contract, or modification is $\$ 1,000,000$ or more, approval thereof shall be by majority vote of the Commission. Prior to affording any approval in accordance with the subsection, the reviewing body designated hereunder shall determine that the placement, contract, or modification contains a detailed description of work to be performed, and that alternative methods of obtaining performance including competitive procurement have been considered.

Sec. 102. During the fiscal year 1980 , moneys received by the Nuclear Regulatory Commission for the cooperative nuclear research programs may be retained and used for salaries and expenses associated with those programs, notwithstanding the provisions of section 3617 of the Revised Statutes (31 U.S.C. 484). Such moneys shall remain available until expended.

Sec. 103. During the fiscal year 1980, transfers of sums from salaries and expenses of the Nuclear Regulatory Commission may be made to other agencies of the United States Government for the performance of the work for which the appropriation is made, and in such cases of the sums to transferred may be merged with the appropriation to which transferred.

Sec. 104. Notwithstanding any other provision of this Act, no authority to make payments hereunder shall be effective except to such extent or in such amounts as are provided in advance in appropriation Acts.

Sec. 105. No amount authorized to be appropriated pursuant to this Act may be used to grant any license, permit or other authorization, or permission to any person for the transportation to, or the interim, long-term, or permanent storage of, spent nuclear fuel or high-level radioactive waste on any territory or insular possession of the United States or the Trust Territory of the Pacific Islands unless-

(1) the President submits to the Congress a report on the transfer at least $\mathbf{3 0}$ days before such transfer and on a day during which-

(A) both Houses of the Congress are in session, or

(B) either or both Houses are not in session because of an adjournment of three days or less to a day certain; or

(2) the President determines that an emergency situation exists with respect to such transfer and that it is in the national interest to make such transfer and the President notifies the Speaker of the House of Representatives and the President of the Senate as soon as possible of such transfer.

The provisions of this section shall not apply to the cleanup and rehabilitation of Bikini and Eniwetok Atolls.

Sec. 106. Of the amounts authorized to be appropriated pursuant to this Act, the Nuclear Regulatory Commission is authorized and directed 
42 USC 2133, 2134.

Regulations.

Notice and hearing. "Utilization facility." 42 USC 2133, 2134.

"Accidental release."

Information and recommendations. to use such sums as may be necessary to develop a plan for agency response to accidents at a utilization facility licensed under section 103 or section 104(b) of the Atomic Energy Act of 1954. The plan required to be developed by this section shall be forwarded to the Congress on or before September 30, 1980.

Sec. 107. No funds appropriated pursuant to this Act may be used for the purpose of providing for the licensing or approval of any disposal of nuclear wastes in the oceans.

Sec. 108. (a) Of the amounts authorized to be appropriated pursuant to this Act, the Nuclear Regulatory Commission is authorized and directed to use such sums as may be necessary to develop and promulgate regulations establishing demographic requirements for the siting of utilization facilities. Such regulations shall be promulgated by the Commission after notice and opportunity for hearing in accordance with section 553 of title 5 of the United States Code. For purposes of this section, the term "utilization facility" means a facility licensed under section 103 or 104(b) of the Atomic Energy Act of 1954.

(b) The regulations promulgated pursuant to this section shall provide that no construction permit may be issued for a utilization facility to which this section applies after the date of such promulgation unless the facility complies with the requirements set forth in such regulations, except that regulations promulgated under this section shall not apply to any facility for which an application for a construction permit was filed on or before October 1,1979 .

(c) The regulations promulgated pursuant to this section shall specify demographic criteria for facility siting, including maximum population density and population distribution for zones surrounding the facility without regard to any design, engineering, or other differences among such facilities.

(d) The regulations promulgated pursuant to this section shall take into account the feasibility of all actions outside the facility which may be necessary to protect public health and safety in the event of any accidental release of radioactive material from the facility which may endanger public health or safety. For purposes of this subsection, the term "accidental release" includes, but is not limited to, each potential accidental release of radioactive material which is required by the Commission to be taken into account for purposes of facility design.

(e) The Commission shall provide information and recommendations to State and local land use planning authorities having jurisdiction over the zones established under the regulations promulgated pursuant to this section and over areas beyond the zones which may be affected by a radiological emergency. The information and recommendations provided under this subsection shall be designed to assist such authorities in making State and local land use decisions which may affect emergency planning in relation to utilization facilities.

(f) Nothing in this section shall be construed to provide that the Commission shall have any authority to preempt any State requirement relating to land use or respecting the siting of any utilization facility, except that no State or local land use or facility siting requirement relating to the same aspect of facility siting as a requirement established pursuant to this section shall have any force and effort unless such State 
"Utilization facility."

42 USC 2133, 2134.

Rules. or local requirement is identical to, or more stringent than, the requirement promulgated pursuant to this section.

Sec. 109. (a) Funds authorized to be appropriated pursuant to this Act may be used by the Nuclear Regulatory Commission to conduct proceedings, and take other actions, with respect to the issuance of an operating license for a utilization facility only if the Commission determines that -

(1) there exists a State or local emergency preparedness plan which-

(A) provides for responding to accidents at the facility concerned, and

(B) as it applies to the facility concerned only, complies with the Commission's guidelines for such plans, or

(2) in the absence of a plan which satisfies the requirements of paragraph (1), there exists a State, local, or utility plan which provides reasonable assurance that public health and safety is not endangered by operation of the facility concerned.

A determination by the Commission under paragraph (1) may be made only in consultation with the Director of the Federal Emergency Management Agency. If, in any proceeding for the issuance of an operating license for a utilization facility to which this subsection applies, the Commission determines that there exists a reasonable assurance that public health and safety is endangered by operation of the facility, the Commission shall identify the risk to public health and safety and provide the applicant with a detailed statement of the reasons for such determination. For purposes of this section, the term "utilization facility" means a facility required to be licensed under section 103 or 104(b) of the Atomic Energy Act of 1954.

(b) Of the amounts authorized to be appropriated under section 101(a), such sums as may be necessary shall be used by the Nuclear Regulatory Commission to-

(1) establish by rule-

(A) standards for State radiological emergency response plans, developed in consultation with the Director of the Federal Emergency Management Agency, and other appropriate agencies, which provide for the response to a radiological emergency involving any utilization facility,

(B) a requirement that-

(i) the Commission will issue operating licenses for utilization facilities only if the Commission determines that(I) there exists a State or local radiological emergency response plan which provides for responding to any radiological emergency at the facility concerned and which complies with the Commission's standards for such plans under subparagraph (A), or

(II) in the absence of a plan which satisfies the requirements of subclause (I), there exists a State, local, or utility plan which provides reasonable assurance that public health and safety is not endangered by operation of the facility concerned, and 
Review of plans.

\section{Report to} congressional committees.

42 USC 2133, 2134. (ii) any determination by the Commission under subclause (I) may be made only in consultation with the Director of the Federal Emergency Management Agency and other appropriate agencies, and

(C) a mechanism to encourage and assist States to comply as expeditiously as practicable with the standards promulgated under subparagraph (A) of this paragraph,

(2) review all plans and other preparations respecting such an emergency which have been made by each State in which there is located a utilization facility or in which construction of such a facility has been commenced and by each State which may be affected (as determined by the Commission) by any such emergency,

(3) assess the adequacy of the plans and other preparations reviewed under paragraph (2) and the ability of the States involved to carry out emergency evacuations during an emergency referred to in paragraph (1) and submit a report of such assessment to the appropriate committees of the Congress within 6 months of the date of the enactment of this Act.

(4) identify which, if any, of the States described in paragraph (2) do not have adequate plans and preparations for such an emergency and notify the Governor and other appropriate authorities in each such State of the respects in which such plans and preparations, if any, do not conform to the guidelines promulgated under paragraph (1), and

(5) submit a report to Congress containing $(A)$ the results of its actions under preceding paragraphs and $(B)$ its recommendations respecting any additional Federal statutory authority which the Commission deems necessary to provide that adequate plans and preparations for such radiological emergencies are in effect for each State described in paragraph (2).

(c) In carrying out its review and assessment under subsection (b)(2) and (3) and in submitting its report under subsection (a)(5), the Commission shall include a review and assessment, with respect to each utilization facility and each site for which a construction permit has been issued for such a facility, of the emergency response capability of State and local authorities and of the owner or operator (or proposed owner or operator) of such facility. Such review and assessment shall include a determination by the Commission of the maximum zone in the vicinity of each such facility for which evacuation of individuals is feasible at various different times corresponding to the representative warning times for various different types of accidents.

Sec. 110. (a) Of the amounts authorized to be appropriated pursuant to section 101(a), such sums as may be necessary shall be used by the Nuclear Regulatory Commission to develop, submit to the Congress, and implement, as soon as practicable after notice and opportunity for public comment, a comprehensive plan for the systematic safety evaluation of all currently operating utilization facilities required to be licensed under section 103 or section 104(b) of the Atomic Energy Act of 1954.

(b) The plan referred to in subsection (a) shall include- 
(1) the identification of each current rule and regulation compliance with which the Commission specifically determines to be of particular significance to the protection of the public health and safety;

(2) a determination by the Commission of the extent to which each operating facility complies with each rule and regulation identified under paragraph (2) of this subsection, including an indication of where such compliance was achieved by use of Division 1 regulatory guides and staff technical positions and where compliance was achieved by equivalent means;

(3) a list of the generic safety issues set forth in NUREG 0410 (including categories A, B, C, and D) for which technical solutions have been developed;

(4) a determination by the Commission of which technical solutions for generic safety issues identified in paragraph (3) of this subsection should be incorporated into the Commission's rules and regulations; and

(5) a schedule for developing a technical solution to those generic safety issues listed in NUREG 0410 which have not yet been technically resolved.

(c) Not later than 90 days from the date of enactment of this Act, the Commission shall report to the Congress on the status of efforts to carry out subsection (a).

\section{TITLE II-AMENDMENTS TO THE ATOMIC ENERGY ACT OF 1954}

42 USC 2133.

42 USC 2134.

42 USC 2237.

42 USC 2283.

42 USC 2133, 2134.
Sec. 201. (a) Section 103 of the Atomic Energy Act of 1954 is amended by adding at the end thereof the following new subsection:

"f. Each license issued for a utilization facility under this section or section $104 \mathrm{~b}$. shall require as a condition thereof that in case of any accident which could result in an unplanned release of quantities of fission products in excess of allowable limits for normal operation established by the Commission, the licensee shall immediately so notify the Commission. Violation of the condition prescribed by this subsection may, in the Commission's discretion, constitute grounds for license revocation. In accordance with section 187 of this Act, the Commission shall promptly amend each license for a utilization facility issued under this section or section $104 \mathrm{~b}$. which is in effect on the date of enactment of this subsection to include the provisions required under this subsection.".

Sec. 202 (a) Chapter 18 of the Atomic Energy Act of 1954 is amended by adding the following new section at the end thereof: "Sec. 235. Protection of Nuclear Inspectors.-

"a. Whoever kills any person who performs any inspections which"(1) are related to any activity or facility licensed by the Commission, and

"(2) are carried out to satisfy requirements under this Act or under any other Federal law governing the safety of utilization facilities required to be licensed under section 103 or $104 \mathrm{~b}$, or the safety of radioactive materials, 
shall be punished as provided under sections 1111 and 1112 of title 18 , United States Code. The preceding sentence shall be applicable only if such person is killed while engaged in the performance of such inspection duties or on account of the performance. of such duties.

"b. Whoever forcibly assaults, resists, opposes, impedes, intimidates, or interferes with any person who performs inspections as described under subsection a. of this section, while such person is engaged in such inspection duties or on account of the performance of such duties, shall be punished as provided under section 111 of title 18, United States Code.".

(b) The table of contents for chapter 18 of the Atomic Energy Act of 1954 is amended by adding the following new item at the end thereof:

"Sec. 235. Protection of nuclear inspectors.".

42 USC 2273. Sec. 203. Section 223 of the Atomic Energy Act of 1954 is amended by striking out "Whoever" and substituting:

"a. Whoever"

and by adding at the end thereof the following:

'b. Any individual director, officer, or employee of a firm constructing, or supplying the components of any utilization facility required to be licensed under section 103 or $104 \mathrm{~b}$. of this Act who by act or omission, in connection with such construction or supply, knowingly and willfully violates or causes to be violated, any section of this Act, any rule, regulation, or order issued thereunder, or any license condition, which violation results, or if undetected could have resulted, in a significant impairment of a basic component of such a facility shall, upon conviction, be subject to a fine of not more than $\$ 25,000$ for each day of violation, or to imprisonment not to exceed two years, or both. If the conviction is for a violation committed after a first conviction under this

"Basic component."

42 USC 2133, 2134.

42 USC 2284. subsection, punishment shall be a fine of not more than $\$ 50,000$ per day of violation, or imprisonment for not more than two years, or both. For the purposes of this subsection, the term 'basic component' means a facility structure, system, component or part thereof necessary toassure-

"(1) the integrity of the reactor coolant pressure boundary,

"(2) the capability to shut-down the facility and maintain it in a safe shut-down condition, or

"(3) the capability to prevent or mitigate the consequences of accidents which could result in an unplanned offsite release of quantities of fission products in excess of the limits established by the Commission.

The provisions of this subsection shall be prominently posted at each site where a utilization facility required to be licensed under section 103 or $104 \mathrm{~b}$. of this Act is under construction and on the premises of each plant where components for such a facility are fabricated.".

Sec. 204. (a) The Atomic Energy Act of 1954 is amended by adding the following new section after section 234:

"Sec. 236. Sabotage of Nuclear Facilities or Fuel.-

Any person who intentionally and willfully destroys or causes physical damage to, or who intentionally and willfully attempts to destroy or cause physical damage to-

"(1) any production facility or utilization facility licensed under this Act, 
42 USC 2021.

42 USC 2282

42 USC 2167.

Regulations.

"(2) any nuclear waste storage facility licensed under this Act,

"(3) any nuclear fuel for such a utilization facility, or any spent nuclear fuel from such a facility,

shall be fined not more than $\$ 10,000$ or imprisoned for not more than ten years, or both.".

(b) The table of contents for such Act is amended by inserting the following new item after the item relating to section 234:

"Sec. 236. Sabotage of nuclear facilities or fuel.".

Sec. 205. Section $274 \mathrm{j}$. of the Atomic Energy Act of 1954 is amended by inserting "(1)" after " $\mathrm{j}$." and by adding the following at the end thereof:

"(2) The Commission, upon its own motion or upon request of the Governor of any State, may, after notifying the Governor, temporarily suspend all or part of its agreement with the State without notice or hearing if, in the judgment of the Commission:

"(A) an emergency situation exists with respect to any material covered by such an agreement creating danger which requires immediate action to protect the health or safety of persons either within or outside the State, and

"(B) the State has failed to take steps necessary to contain or eliminate the cause of the danger within a reasonable time after the situation arose.

A temporary suspension under this paragraph shall remain in effect only for such time as the emergency situation exists and shall authorize the Commission to exercise its authority only to the extent necessary to contain or eliminate the danger.".

Sec. 206. The first sentence of section $234 \mathrm{a}$. of the Atomic Energy Act of 1954 is amended by striking all that follows "exceed" the first time it appears and inserting in lieu thereof the following: " $\$ 100,000$ for each such violation.".

Sec. 207 (a)(1) The Atomic Energy Act of 1954 is amended by inserting the following new section immediately after section 146:

"Sec. 147. Safeguards Information.-

"a. In addition to any other authority or requirement regarding protection from disclosure of information, and subject to subsection (b)(3) of section 552 of title 5 of the United States Code, the Commission shall prescribe such regulations, after notice and opportunity for public comment, or issue such orders, as necessary to prohibit the unauthorized disclosure of safeguards information which specifically identifies a licensee's or applicant's detailed-

"(1) control and accounting procedures or security measures (including security plans, procedures, and equipment) for the physical protection of special nuclear material, by whomever possessed, whether in transit or at fixed sites, in quantities determined by the Commission to be significant to the public health and safety or the common defense and security;

"(2) security measures (including security plans, procedures, and equipment) for the physical protection of source material or byproduct material, by whomever possessed, whether in transit or at fixed sites, in quantities determined by the Commission to be sig- 
nificant to the public health and safety or the common defense and security; or

"(3) security measures (including security plans, procedures, and equipment) for the physical protection of and the location of certain plant equipment vital to the safety of production or utilization facilities involving nuclear materials covered by paragraphs (1) and (2)

if the unauthorized disclosure of such information could reasonably be expected to have a significant adverse effect on the health and safety of the public or the common defense and security by significantly increasing the likelihood of theft, diversion, or sabotage of such material or such facility. The Commission shall exercise the authority of this subsection-

"(A) so as to apply the minimum restrictions needed to protect the health and safety of the public or the common defense and security, and

"(B) upon a determination that the unauthorized disclosure of such information could reasonably be expected to have a significant adverse effect on the health and safety of the public or the common defense and security by significantly increasing the likelihood of theft, diversion, or sabotage of such material or such facility.

Nothing in this Act shall authorize the Commission to prohibit the public disclosure of information pertaining to the routes and quantities of shipments of source material, by-product material, high-level nuclear waste, or irradiated nuclear reactor fuel. Any person, whether or not a licensee of the Commission, who violates any regulation adopted under

42 USC 2282. this section shall be subject to the civil monetary penalties of section 234 of this Act. Nothing in this section shall be construed to authorize the withholding of information from the duly authorized committees of the Congress.

42 USC 2273. "b. For the purposes of section 223 of this Act, any regulations or orders prescribed or issued by the Commission under this section shall also be deemed to be prescribed or issued under section $161 \mathrm{~b}$. of this Act.

"c. Any determination by the Commission concerning the applicability of this section shall be subject to judicial review pursuant to subsection (a)(4)(B) of section 552 of title 5 of the United States Code.

"d. Upon prescribing or issuing any regulation or order under subsection a. of this section, the Commission shall submit to Congress a report that:

"(1) specifically identifies the type of information the Commission intends to protect from disclosure under the regulation or order;

"(2) specifically states the Commission's justification for determining that unauthorized disclosure of the information to be protected from disclosure under the regulation or order could reasonably be expected to have a significant adverse effect on the health and safety of the public or the common defense and security by significantly increasing the likelihood of theft, diversion, or sabotage of such material or such facility, as specified under subsection (a) of this section; and 
42 USC 2231.

"(3) provides justification, including proposed alternative regulations or orders, that the regulation or order applies only the minimum restrictions needed to protect the health and safety of the public or the common defense and security.

"e. In addition to the reports required under subsection d. of this section, the Commission shall submit to Congress on a quarterly basis a report detailing the Commission's application during that period of every regulation or order prescribed or issued under this section. In particular, the report shall:

"(1) identify any information protected from disclosure pursuant to such regulation or order;

"(2) specifically state the Commission's justification for determining that unauthorized disclosure of the information protected from disclosure under such regulation or order could reasonably be expected to have a significant adverse effect on the health and safety of the public or the common defense and security by significantly increasing the likelihood of theft, diversion or sabotage of such material or such facility, as specified under subsection a. of this section; and

"(3) provide justification that the Commission has applied such regulation or order so as to protect from disclosure only the minimum amount of information necessary to protect the health and safety of the public or the common defense and security.".

(2) The table of contents for such Act is amended by inserting the following new item after the item relating to section 146:

"Sec. 147. Safeguards Information.".

(b) Section 181 of the Atomic Energy Act of 1954 is amended-

(1) by striking out "or defense information" the first time it appears and substituting ",defense information, or safeguards information protected from disclosure under the authority of section 147"; and

(2) by striking out "or defense information" in each other place it appears in such section and substituting ", defense information, or such safeguards information,".

\section{TITLE III - OTHER PROVISIONS}

Regulations. 42 USC 5841 note.

"State."

Sec. 301. (a) The Nuclear Regulatory Commission, within 90 days of enactment of this Act, shall promulgate regulations providing for timely notification to the Governor of any State prior to the transport of nuclear waste, including spent nuclear fuel, to, through, or across the boundaries of such State. Such notification requirement shall not apply to nuclear waste in such quantities and of such types as the Commission specifically determines do not pose a potentially significant hazard to the health and safety of the public.

(b) As used in this section, the term "State" includes the several States of the Union, the District of Columbia, the Commonwealth of Puerto Rico, the Virgin Islands, Guam, American Samoa, the Trust Territory of the Pacific Islands, and the Commonwealth of the Northern Mariana Islands.

Contract Sec. 302. The Nuclear Regulatory Commission is authorized and 
authorization.

Report.

42 USC 2016 note.

42 USC 2016.

National

Contingency

Plan, publication.

42 USC 2133, 2134. 42 USC 5842 note

Study, transmittal to Congress.

Investigation and study. directed to enter into a contract for an independent review of the Commission's management structure, processes, procedures, and operations. The review shall include an assessment of the effectiveness of all levels of agency management in carrying out the Commission's statutory responsibilities, in developing and implementing policies and programs, and in using the personnel and funding available to it. The contract shall provide for submission of a report of the findings and recommendations of the review to the Commission not later than one year from the date of enactment of this Act, and the Commission shall promptly transmit such report to the Congress.

Sec. 303. The Nuclear Regulatory Commission shall include in its annual report to Congress under section 251 of the Atomic Energy Act of 1954 a statement of -

(1) the direct and indirect costs to the Commission for the issuance of any license or permit and for the inspection of any facility; and

(2) the fees paid to the Commission for the issuance of any license or permit and for the inspection of any facility.

Sec. 304. On or before September 30, 1980, the President shall prepare and publish a National Contingency Plan to provide for expeditious, efficient, and coordinated action by appropriate Federal agencies to protect the public health and safety in the case of accidents at any utilization facility licensed under section 103 or 104 b. of the Atomic Energy Act of 1954.

Sec. 305. (a) As expeditiously as practicable, the Nuclear Regulatory Commission shall establish a mechanism for instantaneous and uninterrupted verbal communication between each utilization facility licensed to operate under section 103 or section $104 \mathrm{~b}$. of the Atomic Energy Act of 1954 on the date of enactment of this Act, or thereafter, and

(1) Commission headquarters, and

(2) the appropriate Commission regional office.

(b) Within ninety days after the date of the enactment of this Act, the Commission shall prepare and transmit to the Congress a study of alternate plans for instantaneous and otherwise timely transmission to the Commission of data indicating the status of principal system parameters at utilization facilities licensed to operate under section 103 or section $104 \mathrm{~b}$. of the Atomic Energy Act of 1954. For each alternative, the study shall present procedures for transmitting and analyzing such data and a Commission statement regarding the advantages, disadvantages and desirability.

Sec. 306. (a) The Nuclear Regulatory Commission is authorized and directed to undertake a comprehensive investigation and study of the impediments to expeditious and reliable communication among Commission headquarters, the Commission regional office, Commission representatives at the facility site, senior management officials and operator personnel of the licensee, and the Governor of Pennsylvania and other State officials, in the thirty day period immediately following the accident of March 28,1979, at unit two of the Three Mile Island Nuclear Station in Pennsylvania. Such investigation and study shall include, but not be limited to, a determination of the need for improved communica- 
Report to Congress

42 USC 2133 , 2134

Plan, development. 42 USC 2137, note.

42 USC 2137.

Plan, transmittal to Congress. tions procedures and the need for advanced communications technology.

(b) The Commission shall report to the Congress by September 30, 1980 , on the findings of the investigation and study required by subsection (a), including recommendations on administrative or legislative measures necessary to facilitate expeditious and reliable communications in case of an accident which could result in an unplanned release of quantities of fission products in excess of the allowable limits for normal operation established by the Commission at a utilization facility licensed under section 103 or $104 \mathrm{~b}$. of the Atomic Energy Act of 1954. The Commission shall implement, as soon as practicable, each such recommendation not requiring legislative enactment, and shall incorporate the recommendation in the plan for agency response promulgated pursuant to section 304 of this Act.

Sec.307. (a) The Commission is authorized and directed to prepare a plan for improving the technical capability of licensee personnel to safely operate utilization facilities licensed under section 103 or $104 \mathrm{~b}$. of the Atomic Energy Act of 1954. In proposing such plan, the Commission shall consider the feasibility of requiring standard mandatory training programs for nuclear facility operators, including classroom study, apprenticeships at the facility, and emergency simulator training. Such plan shall include specific criteria for more intensive training and retraining of operator personnel licensed under section 107 of the Atomic Energy Act of 1954, and for the licensing of such personnel, to assure-

(1) conformity with all conditions and requirements of the operating license;

(2) early identification of accidents, events, or event sequences which may significantly increase the likelihood of an accident; and

(3) effective response to any such event or sequence. Such plan shall include provision for Commission review and approval of the qualifications of personnel conducting any required training and retraining program. The plan shall also include requirements for the renewal of operator licenses including, to the extent practicable, requirements that the operator-

(A) has been actively and extensively engaged in the duties listed in such license,

(B) has discharged such duties safely to the satisfaction of the Commission,

(C) is capable of continuing such duties, and

(D) has participated in a requalification training program. Such plan shall include criteria for suspending or revoking operator licenses. In addition, the Commission shall also consider the feasibility of requiring such licensed operator to pass a requalification test every six months including-

(i) written questions, and

(ii) emergency simulator exams.

The Commission shall transmit to the Congress the plan required by this subsection within six months after the date of the enactment o this Act, and shall implement as expeditiously as practicable each element thereof not requiring legislative enactment. 
Study.

(b) The Nuclear Regulatory Commission is authorized and directed to undertake a study of the feasibility and value of licensing, under section 42 USC 2137. 107 of the Atomic Energy Act of 1954, plant managers of utilization facilies and senior licensee officers responsible for operation of such Report to facilities. The Commission shall report to the Congress within six Congress. months of the date of enactment of this Act on the findings and recommendations of the study required by this subsection, and shall expeditiously implement each such recommendation not requiring legislative enactment.

Sec. 308. (a) In the conduct of the study required by section 5(d) of the

42 USC 2051

note. Nuclear Regulatory Commission Authorization Act for Fiscal Year 1979 (Public Law 95-601), the Nuclear Regulatory Commission and the Environmental Protection Agency, in consultation with the Secretary of Health and Human Services, shall evaluate the feasibility of epidemiological research on the health effects of low-level ionizing radiation exposure to licensee, contractor, and subcontractor employees as a result of-

(1) the accident of March 28, 1979, at unit two of the Three Mile Island Nuclear Station in Pennsylvania;

(2) efforts to stabilize such facility or reduce or prevent radioactive unplanned offsite releases in excess of allowable limits for normal operation established by the Commission; or

(3) efforts to decontaminate, decommission, or repair such facility.

42 USC 2051

The report required by such section 5(d) shall include the results of the evaluation required under this subsection.

note.

(b) Section 5(d) of the Nuclear Regulatory Commission Authorization Act for Fiscal Year 1979 (Public Law 95-601), is amended by striking "September 30, 1979" and inserting in lieu thereof "September 30, 1980".

Approved June 30, 1980. 
NRC AUTHORIZATION ACT FOR FISCAL YEAR 1979

Public Law 95-601

92 Stat. 2947

\begin{abstract}
Nuclear Regulatory Commission. Appropriation authorization, 1978.
\end{abstract}

42 USC 5845

Safeguard research contracts; limitation.

\section{An Act}

To authorize appropriations to the Nuclear Regulatory Commission for fiscal year 1979, and for other purposes.

\section{Be it enacted by the Senate and House of Representatives of the United States of America in Congress assembled,}

Section 1. (a) There is hereby authorized to be appropriated to the Nuclear Regulatory Commission in accordance with the provisions of section 261 of the Atomic Energy Act of 1954, as amended (42 U.S.C. 2017), and section 305 of the Energy Reorganization Act of 1974, as amended (42 U.S.C. 5875), for the fiscal year 1979, to remain available until expended $\$ 333,007,000$. Of such total amount authorized to be appropriated:

(1) Not more than $\$ 47,162,000$ may be used for "Nuclear Reactor Regulation"; of the total amount appropriated for this purpose, $\$ 2,080,000$ shall be available for Advanced Reactors;

(2) Not more than $\$ 38,760,000$ may be used for "Inspection and Enforcement";

(3) Not more than $\$ 14,945,000$ may be used for "Standards Development"; of the total amount appropriated for this purpose, $\$ 650,000$ shall be available for Low-Level Radiation activities, including those described in section 5 of this Act;

(4) Not more than $\$ 27,240,000$ may be used for "Nuclear Material Safety and Safeguards"; of the total amount appropriated for this purpose, $\$ 8,127,000$ shall be available for Nuclear Waste Disposal and Management activities;

(5) Not more than $\$ 163,470,000$ may be used for "Nuclear Regulatory Research"; of the total amount appropriated for this purpose, $\$ 1,500,000$ shall be available for the implementation of the Improved Safety Systems Research plan required by section 205(f) of the Energy Reorganization Act of 1974, as amended, $\$ 4,448,000$ shall be available for Nuclear Waste research activities, and $\$ 18,333,000$ shall be available for Advanced Reactor Research, including an authorization of $\$ 3,900,000$ to accelerate the effort in gas-cooled thermal reactor safety research.

(6) Not more than $\$ 13,480,000$ may be used for "Program Technical Support";

(7) Not more than $\$ 27,950,000$ may be used for "Program Direction and Administration"; of the total amount appropriated for this purpose, $\$ 225,000$ shall be available for equal employment opportunity activities, including support of four positions in the Office of Equal Employment Opportunity.

(b)(1) Not more than $\$ 14,285,000$ of the aggregate amount authorized to be appropriated under paragraphs (1) through (7) of subsection (a) may be used for contracts encompassing research, studies, and technical assistance on domestic safeguards matters. 
(2) Of the aggregate amount authorized to be appropriated under paragraphs (1) through (7) of subsection (a), $\$ 1,000,000$ shall be available for studies and analysis of alternative fuel cycles (including studies and analysis relating to licensing and safety, safeguards, and environmental aspects).

(c)(1) No amount appropriated pursuant to subsection (a)for purposes of subparagraphs (1) through (7) of such subsection, may be used for any function of the Commission in excess of the amount expressly authorized to be appropriated for functions referred to in such paragraphs, if such excess amount is in excess of $\$ 500,000$, nor may the amount available from any appropriation for any function referred to in subparagraphs be reduced by more than $\$ 500,000$ unless

(i) a period of thirty calendar days (not including any day in which either House of Congress is not in session because of an adjournment of more than three calendar days to a day certain or an adjournment sine die) has passed after the receipt by the Committee on Interstate and Foreign Commerce and the Committee on Interior and Insular Affairs of the House of Representatives and the Committee on Environment and Public Works of the Senate of notice given by the Commission containing a full and complete statement of the action proposed to be taken and the facts and circumstances relied upon in support of such proposed action, or

(ii) each such committee before the expiration of such period has transmitted to the Commission, written notice stating in substance that such committee has no objection to the proposed action.

(2) Of the amounts authorized to be appropriated for the purposes set forth in paragraphs (1) through (7) of subsection (a) of this section, the amounts available for Advanced Reactors, Low-Level Radiation, Nuclear Waste Disposal and Management, Improved Safety Systems, Research, and Nuclear Waste Research, or that specified in subsection (b)(2) of this section for Alternative Fuel Cycle activities shall not be reprogrammed, unless-

(i) a period of ninety calendar days (not including any day in which either House of Congress is not in session because of an adjournment of more than three calendar days to a day certain or an adjournment sine die) has passed after the receipt by the Committee on Interior and Insular Affairs and the Committee on Interstate and Foreign Commerce of the House of representatives and the Committee on Environment and Public Works of the Senate of notice given by the Commission containing a full and complete statement of the action proposed to be taken and the facts and circumstances relied upon in support of such proposed action, or

(ii) each such committee before the expiration of such period has transmitted to the Commission, written notice stating in substance that such committee has no objection to the proposed action. 
Safeguard research contracts, limitation.

Funds, transfers.

42 USC 5849

Equal employment opportunity, report.

Radiation, health effects studies, consultation. 42 USC 2051 note.

Memorandum, submittal to Congress.

Reports to Congress, consultations. (d) No amount authorized to be appropriated by this Act may be used by the Commission to enter into any contract, providing funds in excess of $\$ 20,000$ encompassing research, study, or technical assistance on domestic safeguards matters except as directed by the Commission, by majority vote, following receipt by the Commission of a recommendation from the Executive Director for Operations supporting the need for such contract.

Sec. 2. Moneys received by the Commission for the cooperative nuclear research programs may be retained and used for salaries and expenses associated with those programs, notwithstanding the provisions of section 3617 of the Revised Statutes (31 U.S.C. 484), and shall remain available until expended.

Sec. 3. Transfers of sums from salaries and expenses may be made to other agencies of the Government for the performance of the work for which the appropriation is made, and in such cases the sums so transferred may be merged with the appropriation to which transferred.

Sec. 4. (a) Subsection (b) of section 209 of the Energy Reorganization Act of 1974, as amended, is amended by adding at the end thereof the following sentence: "Notwithstanding the preceding sentence, each such director shall keep the Executive Director fully and currently informed concerning the content of all such direct communications with the Commission."

(b) Section 209 of the Energy Reorganization Act of 1974, as amended, is amended by adding a new subsection (c) to read as follows and redesignating existing subsection (c) accordingly:

“(c) The Executive Director shall report to the Commission at semiannual public meetings on the problems, progress, and status of the Commission's equal employment opportunity efforts.".

Sec. 5. (a) The Commission and the Environmental Protection Agency in consultation with the Secretary of Health, Education, and Welfare, are authorized and directed to conduct preliminary planning and design studies for epidemiological research on the health effects of low-level ionizing radiation. In the conduct of such studies, the Commission and the Environmental Protection Agency shall consult with appropriate scientific organizations and Federal and State agencies.

(b) Within thirty days after the date of enactment of this section, the Commission and the Environmental Protection Agency shall submit to the Congress a memorandum of understanding to delineate their responsibilities in the conduct of the planning studies authorized by subsection (a) of this section.

(c) On or before April 1, 1979, the Commission and the Environmental Protection Agency shall submit a report to the Congress containing an assessment of the capabilities and research needs of such agencies in the area of health effects of low-level ionizing radiation.

(d) On or before September 30,1979, the Commission and the Environmental Protection Agency, in consultation with the Secretary of Health, Education, and Welfare, shall submit a report to the Congress which includes a study of options for Federal epidemiological research on the health effects of low-level ionizing radiations, with evaluations of 
Cooperation.

Copies.

Annual status report.

Report to Congress.

Review, 42 USC 5841 note.

Report to Congress.

Disclosure rules. 42 USC 2210a.

the feasibility of such options. Such report shall be consistent with the findings of the assessment required by subsection (c) of this section.

(e) In carrying out the activities specified in subsections (c) and (d) such agencies shall:

(i) cooperate with appropriate scientific organizations and agencies involved in related research, and

(ii) furnish copies of the reports required by those subsections to the organizations and agencies referred to in subsection (e)(i).

Sec. 6. Section 209 of the Energy Reorganization Act of 1974 is amended by adding the following new subsection at the end thereof:

“(d) The Executive Director shall prepare and forward to the Commission an annual report (for the fiscal year 1978 and each succeeding fiscal year) on the status of the Commission's programs concerning domestic safeguards matters including an assessment of the effectiveness and adequacy of safeguards at facilities and activities licensed by the Commission. The Commission shall forward to the Congress a report under this section prior to February 1,1979 , as a separate document, and prior to February 1 of each succeeding year as a separate chapter of the Commission's annual report (required under section 307(c) of the Energy Reorganization Act of 1974) following the fiscal year to which such report applies.".

Sec. 7. The Commission is authorized and directed to undertake a comprehensive review of the existing process for selection and training of members of the Atomic Safety and Licensing Boards, including, but not limited to, the selection criteria, including qualifications, the selection procedures, and the training programs for Board members. The Commission shall report to the Congress on the findings of such review by January 1, 1979, and shall revise such selection and training process as appropriate, based on such findings.

Sec. 8 (a) Chapter 14 of the Atomic Energy Act of 1954 is amended by adding the following new section at the end thereof:

"Sec. 170A. Conflicts of Interest Relating to Contracts and Other Arrangements.-

"a. The Commission shall, by rule, require any person proposing to enter into a contract, agreement, or other arrangement, whether by competitive bid or negotiation, under this Act or any other law administered by it for the conduct of research, development, evaluation activities, or for technical and management support services, to provide the Commission, prior to entering into any such contract, agreement, or arrangement, with all relevant information, as determined by the Commission, bearing on whether that person has a possible conflict of interest with respect to-

"(1) being able to render impartial, technically sound, or objective assistance or advice in light of other activities or relationships with other persons, or

"(2) being given an unfair competitive advantage. Such person shall insure, in accordance with regulations prescribed by the Commission, compliance with this section by any subcontractor (other than a supply subcontractor) of such person in the case of any subcontract for more than $\$ 10,000$. 
Publication.

Monitoring and assistance, reports to Congress. 42 USC 2153 note.

42 USC 5851.

42 USC 2011 note. "b. The Commission shall not enter into any such contract agreement or arrangement unless it finds, after evaluating all information provided under subsection a. and any other information otherwise available to the Commission that-

"(1) it is unlikely that a conflict of interest would exist, or

"(2) such conflict has been avoided after appropriate conditions have been included in such contract, agreement, or arrangement; except that if the Commission determines that such conflict of interest exists and that such conflict of interest cannot be avoided by including appropriate conditions therein, the Commission may enter into such contract, agreement, or arrangement, if the Commission determines that it is in the best interests of the United States to do so and includes appropriate conditions in such contract, agreement, or arrangement to mitigate such conflict.

"c. The Commission shall publish rules for the implementation of this section, in accordance with section 553 of title 5, United States Code (without regard to subsection (a)(2) thereof) as soon as practicable after the date of the enactment of this section, but in no event later than 120 days after such date.".

(b) The table of contents for such chapter 14 is amended by adding the following new item at the end thereof:

Sec. 170A. Conflicts of interest relating to contracts and other arrangements.".

Sec. 9. The Commission shall monitor and assist, as requested, the International Fuel Cycle Evaluation and the studies and evaluations of the various nuclear fuel cycle systems by the Department of Energy in progress as of the date of enactment, and report to the Congress semiannually through calendar year 1980 and annually through calendar year 1982 on the status of domestic and international evaluations of nuclear fuel cycle systems. This report shall include, but not be limited to, a summary of the information developed by and available to the Commission on the health, safety and safeguards implications of the leading fuel cycle technologies.

Sec. 10. Title II of the Energy Reorganization Act of 1974, as amended, is amended by adding at the end thereof a new section to read as follows:

\section{"EMPLOYEE PROTECTION}

Sec. 210. (a) No employer, including a Commission licensee, an applicant for a Commission license, or a contractor or a subcontractor of a Commission licensee or applicant, may discharge any employee or otherwise discriminate against any employee with respect to his compensation, terms, conditions, or privileges of employment because the employee (or any person acting pursuant to a request of the employee)-

"(1) commenced, caused to be commenced, or is about to commence or cause to be commenced a proceeding under this Act or the Atomic Energy Act of 1954, as amended, or a proceeding for the administration or enforcement of any requirement imposed under this act or the Atomic Energy Act of 1954, as amended;

"(2) testified or is about to testify in any such proceeding or;

"(3) assisted or participated or is about to assist or participate in any manner in such a proceeding or in any other manner in such a 
Complaint, filing and notification.

Investigation and notification.

Order.

Notice and hearing. Settlement.

Relief.

Review.

5 U.S.C. 701 et seq. proceeding or in any other action to carry out the purposes of this Act or the Atomic Energy Act of 1954, as amended.

"(b)(1) Any employee who believes that he has been discharged or otherwise discriminated against by any person in violation of subsection (a) may, within thirty days after such violation occurs, file (or have any person file on his behalf) a complaint with the Secretary of Labor (hereinafter in this subsection referred to as the 'Secretary') alleging such discharge or discrimination. Upon receipt of such a complaint, the Secretary shall notify the person named in the complaint of the filing of the complaint and the Commission.

"(2)(A) Upon receipt of a complaint filed under paragraph (1), the Secretary shall conduct an investigation of the violation alleged in the complaint. Within thirty days of the receipt of such complaint, the Secretary shall complete such investigation and shall notify in wirting the complainant (any any person acting in his behalf) and the person alleged to have committed such violation of the results of the investigation conducted pursuant to this subparagraph. Within ninety days of the receipt of such complaint the Secretary shall, unless the proceeding on the complaint is terminated by the Secretary on the basis of a settlement entered into by the Secretary and the person alleged to have committed such violation, issue an order either providing the relief prescribed by subparagraph (B) or denying the complaint. An order of the Secretary shall be made on the record after notice and opportunity for public hearing. The Secretary may not enter into a settlement terminating a proceeding on a complaint without the participation and consent of the complainant.

"(B) If, in response to a complaint filed under paragraph (1), the Secretary determines that a violation of subsection (a) has occurred, the Secretary shall order the person who committed such violation to (i) take affirmative action to abate the violation, and (ii) reinstate the complainant to his former position together with the compensation (including back pay), terms, conditions, and privileges of his employment, and the Secretary may order such person to provide compensatory damages to the complainant. If an order is issued under this paragraph, the Secretary, at the request of the complainant shall assess against the person against whom the order is issued a sum equal to the aggregate amount of all costs and expenses (including attorneys' and expert witness fees) reasonably incurred, as determined by the Secretary, by the complainant for, or in connection with, the bringing of the complaint upon which the order was issued.

“(c)(1) Any person adversely affected or aggrieved by an order issued under subsection (b) may obtain review of the order in the United States court of appeals for the circuit in which the violation, with respect to which order was issued, allegedly occurred. The petition for review must be filed within sixty days from the issuance of the Secretary's order.

Review shall conform to chapter 7 of title 5 of the United States Code. The commencement of proceedings under this subparagraph shall not, unless ordered by the court, operate as a stay of the Secretary's order. 
Jurisdiction.

Litigative costs.

42 USC 2011

note.

Report to

Congress.

42 USC 2205a.

Authority extention, study.

42 USC 5842 note Cooperation.

Report to Congress.
"(2) An order of the Secretary with respect to which review could have been obtained under paragraph (1) shall not be subject to judicial review in any criminal or other civil proceeding.

“(d) Whenever a person has failed to comply with an order issued under subsection (b)(2), the Secretary may file a civil action in the United States district court for the district in which the violation was found to occur to enforce such order. In actions brought under this subsection, the district courts shall have jurisdiction to grant all appropriate relief, including, but not limited to, injunctive relief, compensatory, and exemplary damages.

"(e)(1) Any person on whose, behalf an order was issued under paragraph (2) of subsection (b) may commence a civil action against the person to whom such order was issued to require compliance with such order. The appropriate United States district court shall have jurisdiction, without regard to the amount in controversy or the citizenship of the parties, to enforce such order.

"(2) The court, in issuing any final order under this subsection, may award costs of litigation (including reasonable attorney and expert witness fees) to any party whenever the court determines such award is appropriate.

"(f) Any nondiscretionary duty imposed by this section shall be enforceable in a mandamus proceeding brought under section 1361 of title 28 of the United States Code.

"(g) Subsection (a) shall not apply with respect to any employee who, acting without direction from his or her employer (or the employer's agent), deliberately causes a violation of any requirements of this Act or of the Atomic Energy Act of 1954, as amended.".

Sec. 11. The Conmission shall report to the Congress on January 1, 1979, and annually thereafter on the use of contractors, consultants, and the National Laboratories by the Commission. Such report shall include, for each contract issued, in progress or completed during fiscal year 1978, information on the bidding procedure, nature of the work, amount and duration of the contract, progress of work, relation to previous contracts, and the relation between the amount of the contract and the amount actually spent.

Sec. 12. (a) The Commission, in cooperation with the Department of Energy, is authorized and directed to conduct a study of extending the Commission's licensing or regulatory authority to include categories of existing and future Federal radioactive waste storage and disposal activities not presently subject to such authority.

(b) Each Federal agency, subject to the provisions of existing law, shall cooperate with the Commission in the conduct of the study. Such cooperation shall include providing access to existing facilities and sites and providing any information needed to conduct the study which the agency may have or be reasonably able to acquire.

(c) On or before March 1, 1979, the Commission shall submit a report to the Congress containing the results of the study, the Report shall include a complete listing and inventory of all radioactive waste storage and disposal activities now being conducted or planned by Federal agencies. 
Waste storage or disposal facility planning, notification. 42 USC 2021a.

State participation, report.

Submittal with legislative recommendations to Congress
Sec. 13. Notwithstanding any other provision of this Act, no authority to make payments under this Act shall be effective except to such extent or in such amounts as are provided in advance in appropriation Acts.

Sec. 14. (a) Any person, agency, or other entity proposing to develop a storage or disposal facility, including a test disposal facility, for highlevel radioactive wastes, non-high-level radioactive wastes including transuranium contaminated wastes, or irradiated nuclear reactor fuel, shall notify the Commission as early as possible after the commencement of planning for a particular proposed facility. The Commission shall in turn notify the Governor and the State legislature of the State of proposed sites whenever the Commission has knowledge of such proposal.

(b) The Commission is authorized and directed to prepare a report on means for improving the opportunities for State participation in the process for siting, licensing, and developing nuclear waste storage or disposal facilities. Such report shall include detailed consideration of a program to provide grants through the Commission to any State, and the advisability of such a program, for the purpose of conducting an independent State review of any proposal to develop a nuclear waste storage or disposal facility identified in subsection (a) within such State. On or before March 1, 1979, the Commission shall submit the report to the Congress including recommendations for improving the opportunities for State participation together with any necessary legislative proposals.

Approved November 6, 1978. 
NRC AUTHORIZATION ACT FOR FISCAL YEAR 1978

Public Law 95-209

91 Stat. 1481

\section{An Act}

To authorize appropriations for Nuclear Regulatory Commission for the fiscal year 1978, and for other purposes.

Nuclear

Regulatory

Commission.

Appropriation authorization, 1978.

Reallocation.

Safeguard research contract statement publication.
Be it enacted by the Senate and House of Representatives of the United States of America in Congress assembled,

\section{AUTHORIZATION}

Section 1. (a) There is authorized to be appropriated to the Nuclear Regulatory Commission (hereafter in this act referred to as the "Commission") to carry out its functions and authorities under the Atomic Energy Act of 1954 (42 U.S.C. 2017) and the Energy Reorganization Act of 1974 (42 U.S.C. 5875) for the fiscal year 1978 to remain available until expended $\$ 297,740,000$ to be allocated as follows:

(1) For "Nuclear Reactor Regulation", not more than $\$ 41,480,000$;

(2) For "Standards Development", not more than $\$ 12,130,000$;

(3) For "Inspection and Enforcement", not more than $\$ 33,050,000$;

(4) For "Nuclear Materials Safety and Safeguards", not more than $\$ 22,090,000$;

(5) For "Nuclear Regulatory Research", \$148,900,000;

(6) For "Program Technical Support", 10,180,000; of which an amount not to exceed $\$ 600,000$ is authorized for a fellowship program pursuant to section 5 of this Act.

(7) For "Program Direction and Administration", not more than $\$ 29,910,000$.

(b) Of the total amount authorized under section 1(a), the Commissioners may, by majority vote, reallocate among program activities specified in subsection (a) or pursuant to the authority granted in subsection (d) an amount not exceeding $\$ 10,000,000$ except that the amount transferred from any of the major program activities specified in subsection (a) shall not exceed 15 per centum of the amount so specified. Prior to any reallocation of an amount in accordance with the provisions of this subsection, where such amount is in excess of $\$ 500,000$, the Commission shall inform the appropriate congressional committees. Such reallocation may be made notwithstanding the limitations of subsection (a).

(c) No amount authorized to be appropriated for contracts for research, studies, and technical assistance on domestic safeguard matters under subsection (a) including any amount reallocated under subsection (b) may be used for such contracts and no amount authorized to be a propriated under this subsection may be used by the Office of Nuclear Regulatory Research for such contracts until a statement supporting the need for such research, study, or technical assistance has been prepared and published by the Commission. 
Quarterly report to Congress. 42 USC 5841.

42 USC 2000e.

42 USC 5850.

Submittal to Congress. Progress reports.

Long-term plan development. 42 USC 5845. (d) No amount authorized to be appropriated for contracts for regulatory research related to advanced reactor safety under this Act may be used for such contracts except as directed by the Commission, following consideration by the Commission of any recommendation that may be made by the ACRS regarding the proposed research.

(e) In the event that the license application is withdrawn or funding for the continuation of the Clinch River Breeder Reactor project is not authorized or appropriated, the total authorization in subsection (a) shall be reduced by $\$ 2,700,000$.

(f) In the event that further construction of the facility at Barnwell, South Carolina, for the purpose of providing plutonium to be used as fuel is canceled or deferred, the total authorization in subsection (a) shall be reduced by $\$ 2,100,000$.

\section{COMMISSION PERSONNEL}

Sec. 2. Section 201 of title II of the Energy Reorganization Act of 1974 is amended by adding the following new subsection at the end thereof:

"(h) The Commission shall prepare and submit to the Congress a quarterly report which documents, for grades GS-11 or above:

"(1) the number of minority and women candidates hired, by grade level;

"(2) the number of minority and women employees promoted, by grade level;

"(3) the procedures followed by the Commission in preparing job descriptions, informing potential applicants, and selecting from candidates the persons to be employed in positions at grade GS-11 or above; and

"(4) other steps taken to meet provisions of the Equal Employment Act.

The first quarterly report shall be submitted to the Congress not later than January 31, 1978, and subsequent reports shall be submitted prior to the end of one calendar month after the end of each calendar quarter thereafter.".

\section{UNRESOLVED SAFETY ISSUES}

Sec. 3. Title II of the Energy Reorganization Act of 1974, is amended by adding the following new section at the end thereof:

\section{"UNRESOLVED SAFETY ISSUES PLAN}

"Sec. 210. The Commission shall develop a plan providing for the specification and analysis of unresolved safety issues relating to nuclear reactors and shall take such action as may be necessary to implement corrective measures with respect to such issues. Such plan shall be submitted to the Congress on or before January 1, 1978 and progress reports shall be included in the annual report of the Commission thereafter.".

\section{IMPROVED SAFETY SYSTEMS RESEARCH}

Sec. 4. (a) Section 205 of the Energy Reorganization Act of 1974 is amended by adding the following new subsection at the end thereof:

"(f) The Commission shall develop a long-term plan for projects for the development of new or improved safety systems for nuclear power plants.". 
Annual report to Congress. 42 USC 2039.

Establishment. 42 USC 2040.

Guidelines. 42 USC 2201 note.

Salaries and expenses.

\section{REACTOR SAFETY RESEARCH STUDY}

Sec. 5. Section 29 of the Atomic Energy Act of 1954 is amended by adding the following at the end thereof: "In addition to its other duties under this section, the committee, making use of all available sources, shall undertake a study of reactor safety research and prepare and submit annually to the Congress a report containing the results of such study. The first such report shall be submitted to the Congress not later than December 31, 1977.

\section{ACRS FELLOWSHIP PROGRAM}

Sec. 6. To assist the Advisory Committee on Reactor Safeguards in carrying out its function, the committee shall establish a fellowship program under which persons having appropriate engineering or scientific expertise are assigned particular tasks relating to the functions of the committee. Such fellowship shall be for 2-year periods and the recipients of such fellowships shall be selected pursuant to such criteria as may be established by the committee.

\section{ORGANIZATIONAL CONFLICTS OF INTEREST}

Sec. 7. The Commission shall by December 31, 1977, promulgate guidelines to be applied by the Commission in determining whether an organization proposing to enter into a contractual arrangement with the Commission has a conflict of interest which might impair the contractor's judgment or otherwise give the contractor an unfair competitive advantage.

\section{COOPERATIVE RESEARCH FUNDING}

Sec. 8. Moneys received by the Commission for the cooperative nuclear safety research programs may be retained and used for salaries and expenses associated with those programs, notwithstanding the provisions of section 3617 of the Revised Statutes (31 U.S.C. 484), and shall remain available until expended. Funds may be obligated for purposes stated in this section only to the extent provided in appropriation Acts.

\section{TRANSFER OF FUNDS}

Sec. 9. Transfers of sums from salaries and expenses may be made to other agencies of the Government for the performance of the work for which the appropriation is made, and in such cases the sums so transferred may be merged with the appropriations to which transferred.

\section{APPROPRIATIONS}

Sec. 10. Notwithstanding any other provision of this Act, no authority to make payments under this Act shall be effective except to such extent or in such amounts as are provided in advance in appropriations Acts. Approved December 13, 1977. 
Nuclear Regulatory Commission. Appropriation authorization. 42 USC 2017. 42 USC 5875.

Moneys for research programs, use.

Transfer of sums.

89 Stat. 413.

\section{An Act}

To authorize appropriations to the Nuclear Regulatory Commission in accordance with section 261 of the Atomic Energy Act of 1954, as amended, and section 305 of the Energy Reorganization Act of 1974, as amended, and for other purposes.

Be it enacted by the Senate and House of Representatives of the United States of America in Congress assembled,

Sec. 101. There is hereby authorized to be appropriated to the Nuclear Regulatory Commission in accordance with the provisions of section 261 of the Atomic Energy Act of 1954, as amended, and section 305 of the Energy Reorganization Act of 1974, as amended; for salaries and expenses, $\$ 274,300,000$ to remain available until expended.

Sec. 102. Moneys received by the Commission for the cooperative nuclear safety research programs may be retained and used for salaries and expenses associated with those programs, notwithstanding the provisions of section 3617 of the Revised Statutes (31 U.S.C. 484), and shall remain available until expended. Funds may be obligated for purposes stated in this section only to the extent provided in appropriation Acts.

Sec. 103. Transfers of sums from salaries and expenses may be made to other agencies of the Government for the performance of the work for which the appropriation is made, and in such cases the sums so transferred may be merged with the appropriation to which transferred.

\section{AMENDMENTS TO PRIOR YEAR ACT}

Sec. 104. (a) Title I of Public Law 94-79 is amended by adding section 102 to read as follows: "Moneys received by the Commission for the cooperative nuclear research program may be retained and used for salaries and expenses associated with that program, notwithstanding the provisions of section 3617 of the Revised Statutes (31 U.S.C 484), and shall remain available until expended. Funds may be obligated for purposes stated in this section only to the extent provided in appropriation Acts.".

(b) Section 101 of Public Law 94-79 is amended by adding the phase "and shall remain available until expended" after the words "September 30, 1976". 


\section{An Act}

To authorize appropriations to the Nuclear Regulatory Commission in accordance with section 261 of the Atomic Energy Act of 1954, as amended, and section 305 of the Energy Reorganization Act of 1974, and for other purposes.

Be it enacted by the Senate and House of Representatives of the United States of America in Congress assembled,

Nuclear

Regulatory Commission. Appropriation authorization. 42 USC 2017 42 USC 5875

42 USC 5841

Commission chairman, functions.

42 USC 5801 note.

\section{TITLE I}

Sec. 101. There is authorized to be appropriated to the Nuclear Regulatory Commission to carry out the provisions of section 261 of the Atomic Energy Act of 1954, as amended, and section 305 of the Energy Reorganization Act of 1974: \$222,935,000 for fiscal year 1976 and $\$ 52,750,000$ for the period from July 1, 1976 through September 30, 1976 and shall remain available until expended. ${ }^{3}$

Sec. 102. Moneys received by the Commission for the cooperative nuclear research program may be retained and used for salaries and expenses associated with that program, notwithstanding the provisions of section 3617 of the Revised Statutes (31 U.S.C. 484), and shall remain available until expended. Funds may be obligated for purposes stated in this section only to the extent provided in appropriations Acts.".4

\section{TITLE II}

Sec. 201. Section 201(a) of the Energy Reorganization Act of 1974 is amended-

(1) by inserting "(1)" immediately after "Sec. 201.(a)"; and

"(2) The Chairman of the Commission shall be the principal executive officer of the Commission, and he shall exercise all of the executive and administrative functions of the Commission, including functions of the Commission with respect to (a) the appointment and supervision of personnel employed under the commission (other than personnel employed regularly and full time in the immediate offices of commissioners other than the Chairman, and except as otherwise provided in the Energy Reorganization Act of 1974), (b) the distribution of business among such personnel and among administrative units of the Commission, and (c) the use and expenditure of funds.

"(3) In carrying out any of his functions under the provisions of this section the Chairman shall be governed by general policies of the Commission and by such regulatory decisions, findings, and determinations as the Commission may by law be authorized to make.

"(4) The appointment by the Chairman of the heads of major administrative units under the Commission shall be subject to the approval of the Commission.

${ }^{3}$ Public Law 94-291 (90 STAT. 523) (1976) sec. 104(b) amended sec. 101 by adding the phrase "and shall remain available until expended " after "September 30, 1976".

${ }^{4}$ Public Law 94-291 (90 STAT. 523) (1976) sec. 104(a) added sec. 102. 
Plutonium shipments, restrictions, 42 USC 5841 note.

Term of office. 42 USC 5841

“(5) There are hereby reserved to the Commission its functions with respect to revising budget estimates and with respect to determining upon the distribution of appropriated funds according to major programs and purposes.",

The Nuclear Regulatory Commission shall not license any shipments by air transport of plutonium in any form, whether exports, imports or domestic shipments: Provided, however, That any plutonium in any form contained in a medical device designed for individual human application is not subject to this restriction. This restriction shall be in force until the Nuclear Regulatory Commission has certified to the Joint Committee on Atomic Energy of the Congress that a safe container has been developed and tested which will not rupture under crash and blasttesting equivalent to the crash and explosion of a high-flying aircraft.

Sec. 202. Subsection 201(c) of the Energy Reorganization Act of 1974 is amended by deleting the period at the end of the subsection and adding the following text: "; and except that any member appointed to fill a vacancy occurring prior to the expiration of the term for which his predecessor was appointed, shall be appointed for the remainder of such term.".

Sec. 203. Section 201(c) is amended to include the following: "For the purpose of determining the expiration date of the terms of office of the five members first appointed to the Nuclear Regulatory Commission, each such term shall be deemed to have begun July 1, 1975.”.

4Public Law 94-291 (90 STAT.523)(1976) sec. 104(a) added sec. 102. 
NRC FISCAL YEAR 1975 SUPPLEMENTAL AUTHORIZATION ACT

Public Law 94-18

89 Stat. 80

\section{An Act}

To authorize supplemental appropriations to the Nuclear Regulatory Commission for fiscal year 1975.

Be it enacted by the Senate and House of Representatives of the United States of America in Congress assembled,

Nuclear

Regulatory

Commission

Appropriation

Authorization.

42 USC 2017.

42 USC 5875.

Atomic Energy

Commission.

Appropriation

increase.

Ante, p. 116.

Safeguards program.

88 Stat. 1878.
That there is authorized to be appropriated to the Nuclear Regulatory Commission to carry out the provisions of section 261 of the Atomic Energy Act of 1954, as amended, and section 305 of the Energy Reorganization Act of 1974, \$50,200,000 for fiscal year 1975.

\section{AEC FISCAL YEAR 1975 SUPPLEMENTAL AUTHORIZATION ACT}

Public Law 93-576

88 Stat. 1878

\section{An Act}

To amend Public Law 93-276 to increase the authorization for appropriations to the Atomic Energy Commission in accordance with section 261 of the Atomic Energy Act of 1954, as amended, and for other purposes.

Be it enacted by the Senate and House of Representatives of the United States of America in Congress assembled,

That section 101(a) of Public Law 93-276 is hereby amended by striking therefrom the figure " $\$ 2,551,533,000$ " and substituting the figure “\$2,580,733,000".

Sec. 2. Section 101(b) of Public Law 93-276 is hereby amended by striking from subsection (11) capital equipment the figure $\$ 208,850,000$ " and substituting the figure " $\$ 224,900,000$ ".

Sec. 3. From the increase of the sums authorized to be appropriated by this Act $\$ 23,000,000$ shall be allotted to, and made available only for the Safeguards Program, with regard to the safeguarding of special nuclear materials from diversion from its intended uses, and for research and development of safeguards techniques and related activities involved in handling nuclear material.

Approved December 31, 1974. 
AEC AUTHORIZATION ACT FOR FISCAL YEAR 1975

Public Law 93-276

77 Stat. 88

\section{An Act}

To authorize appropriations to the Atomic Energy Commission in accordance with section 261 of the Atomic Energy Act of 1954, as amended, and for other purposes.

$B e$ it enacted by the Senate and House of Representatives of the United States of America in Congress assembled,

Atomic Energy Commission. Appropriation authorization. 77 Stat. 88 442 USC 2017

88 Stat. 115 88 Stat. 116

Sec. 101. There is hereby authorized to be appropriated to the Atomic Energy Commission in accordance with the provisions of section 261 of the Atomic Energy Act of 1954, as amended:

(a) For “Operating expenses", \$2,580,733,000' not to exceed $\$ 132,200,000$ in operating costs for the high energy physics program category.

(b) For "Plant and capital equipment", including construction, acquisition, or modification of facilities, including land acquisition; and acquisition and fabrication of capital equipment not related to construction, a sum of dollars equal to the total of the following:

(1) NUCLEAR MATERIALS.-

Project 75-1a, additional facilities, high-level waste handling and storage, Savannah River, South Carolina, $\$ 30,000,000$.

Project 75-1-b, replacement ventilation air filter, $\mathrm{H}$ chemical separations area, Savannah River, South Carolina, $\$ 6,000,000$.

Project 75-1-c, new waste calcining facility, Idaho Chemical Processing Plant, National Reactor Testing Station, Idaho, $\$ 20,000,000$.

Project 75-1-d, waste management effluent control, Richland, Washington, $\$ 3,500,000$.

Project 75-1-e, retooling of component preparation laboratories, multiple sites, $\$ 4,500,000$.

Project 75-1-f, atmospheric pollution control facilities, stoker fired boilers, Savannah River, South Carolina, $\$ 7,500,000$.

(2) NUCLEAR MATERIALS.-

Project 75-2-a, additional cooling tower capacity, gaseous diffusion plant, Portsmouth, Ohio, $\$ 2,200,000$.

(3) WEAPONS. -

Project 75-3-a, weapons production, development, and test installations, $\$ 10,000,000$.

Project 75-3-b, high energy laser facility, Los Alamos Scientific Laboratory, New Mexico, \$22,600,000.

Project 75-3-c, TRIDENT production facilities, various locations, $\$ 22,200,000$.

Project 75-3-d, consolidation of final assembly plants, Pantex, Amarillo, Texas, $\$ 4,500,000$.

Project 75-3-e, addition to building 350 for safeguards analytical laboratory, Argonne National Laboratory, Illinois, \$3,500,000.

'Public Law 93-576 (88 Stat. 1878) (1974), sec. 1, increased this figure from the previously authorized $\$ 2,551,533,000$. 
88 Stat. 116 88 Stat. 117

(4) WEAPONS.-

Project 75-4-a, technical support relocation, Los Alamos Scientific Laboratory, New Mexico, \$2,800,000.

(5) CIVILIAN REACTOR RESEARCH AND DEVELOPMENT.-

Project 75-5-a, transient test facility, Santa Susana, California, $\$ 4,000,000$.

Project 75-5-b, advanced test reactor control system upgrading,

National Reactor Testing Station, Idaho, $\$ 2,400,000$.

Project 75-5-c, test reactor area water recycle and pollution control facilities, National Reactor Testing Station, Idaho, $\$ 1,000,000$.

Project 75-5-d, modifications to reactors, $\$ 4,000,000$.

Project 75-5-e, high temperature gas reactor fuel re-processing facility, National Reactor Testing Station, Idaho, $\$ 10,100,000$.

Project 75-5-f, high temperature gas reactor fuel refabrication pilot plant, Oak Ridge National Laboratory, Tennessee, $\$ 3,000,000$.

Project 75-5-g, molten salt breeder reactor (preliminary planning preparatory to possible future demonstration project), $\$ 1,500,000$.

(6) PHYSICAL RESEARCH.-

Project 75-6-a, accelerator and reactor improvements and modifications, $\$ 3,000,000$.

Project 75-6-b, heavy ion research facilities, various locations, $\$ 19,200,000$.

Project 75-6-c, positron-electron joint project, Lawrence Berkeley Laboratory and Stanford Linear Accelerator Center, $\$ 900,000$.

(7) BIOMEDICAL AND ENVIRONMENTAL RESEARCH AND SAFETY.-

Project 75-7-a, upgrading of laboratory facilities, Oak Ridge National Laboratory, Tennessee, $\$ 2,100,000$.

Project 75-7-b, environmental research laboratory, Savannah River, South Carolina, $\$ 2,000,000$.

Project 75-7-c, intermediate-level waste management facilities,

Oak Ridge National Laboratory, Tennessee, \$9,500,000.

Project 75-7-d, modifications and additions to biomedical and environmental research facilities, $\$ 2,850,000$.

(8) BIOMEDICAL AND ENVIRONMENTAL RESEARCH AND SAFETY.-

Project 75-8-a, environmental sciences laboratory, Oak Ridge National Laboratory, Tennessee, $\$ 8,800,000$.

(9) GENERAL PLANT PROJECTS.-\$55,650,000.

(10) CONSTRUCTION PLANNING AND DESIGN.$\$ 2,000,000$.

(11) CAPTTAL EQUIPMENT.-Acquisition and fabrication of capital equipment not related to construction, $\$ 224,900,000.2$

(12) REACTOR SAFETY RESEARCH.-

Project 75-12-a, reactor safety facilities modifications, $\$ 1,000,000$. (13) APPLIED ENERGY TECHNOLOGY.Project 75-13-a, hydrothermal pilot plant, $\$ 1,000,000$.

${ }^{2}$ Public Law 93.576 (88 Stat. 1878) (1978) (1974), sec. 2, increased this figure from the previously authorized $\$ 208,850,000$. 
Sec. 102. Limitations. - (a) The Commission is authorized to start any project set forth in subsection 101(b)(1), (3), (5), (6), (7), (12), and (13) only if the currently estimated cost of that project does not exceed by more than 25 per centum the estimated cost set forth for that project.

(b) The Commission is authorized to start any project set forth in subsection 101(b) (2), (4), (8), and (10) only if the currently estimated cost of that project does not exceed by more than 10 per centum the estimated cost set forth for that project.

(c) The Commission is authorized to start any project under subsection 101(b)(9) only if it is in accordance with the following:

(1) The maximum currently estimated cost of any project shall be $\$ 500,000$ and the maximum currently estimated cost of any building included in such project shall be $\$ 100,000$ : Provided, That the building cost limitation may be exceeded if the Commission determines that it is necessary in the interest of efficiency and economy.

(2) The total cost of all projects undertaken under subsection 101(b)(9) shall not exceed the estimated cost set forth in that subsection by more than 10 per centum.

(d) The total cost of any project undertaken under subsection 101(b) (1), (3), (5), (6), (7), (12), and (13) shall not exceed the estimated cost set forth for that project by more than 25 per centum, unless and until

77 Stat. 88

42 USC 2017.

88 Stat. 118

77 Stat. 88

42 USC 2017.

Construction

design

services.

69 Stat. 471

Transfer of sums.

Transfer of amounts. additional appropriations are authorized under section 261 of the Atomic Energy Act of 1954, as amended, provided that this subsection will not apply to any project with an estimated cost less than $\$ 5,000,000$.

(e) The total cost of any project undertaken under subsection 101(b) (2), (4), (8), (9), and (10) shall not exceed the estimated cost set forth for that project by more than 10 per centum, unless and until additional appropriations are authorized under section 261 of the Atomic Energy Act of 1954, as amended, provided that this subsection will not apply to any project with an estimated cost less than $\$ 5,000,000$.

Sec. 103. The Commission is authorized to perform construction design services for any Commission construction project whenever (1) such construction project has been included in a proposed authorization bill transmitted to the Congress by the Commission, and (2) the Commission determines that the project is of such urgency that construction of the project should be initiated promptly upon enactment of legislation appropriating funds for its construction.

Sec. 104. Any moneys received by the Commission (except sums received from the disposal of property under the Atomic Energy Community Act of 1955, as amended (42 U.S.C. 2301)), may be retained by the Commission and credited to its "Operating expenses" appropriation notwithstanding the provisions of section 3617 of the Revised Statutes (31 U.S.C. 484).

Sec. 105. Transfers of sums from the "Operating expenses" appropriation may be made to to other agencies of the Government for the performance of the work for which the appropriation is made, and in such cases the sums so transferred may be merged with the appropriation to which transferred.

Sec. 106. When so specified in an appropriation Act, transfers of amounts between "Operating expenses" and "Plant and capital equipment" may be made as provided in such appropriation Act. 
80 Stat. 162;

81 Stat. 126.

87 Stat. 145.

84 Stat. 300; 87 Stat. 145.

31 USC 665.

86 Stat. 223.

88 Stat 119. 87 Stat. 143.

83 Stat. 46; 86 Stat. 225.

85 Stat. 304.
Sec. 107. AMENDMENT OF PRIOR YEAR ACTS.-(a) Section 101 of Public Law 89-428, as amended, if further amended by striking from subsection (b)(3) project 67-3-a, fast flux test facility, the figure " $\$ 87,500,000$ ", and substituting therefor the figure " $\$ 420,000,000 "$.

(b) Section 101 of Public Law 91-273, as amended, is further amended by striking from subsection (b)(1), project 71-1-f, process equipment modifications, gaseous diffusion plants, the figure " $\$ 172,100,000$ " and substituting therefor the figure " $\$ 295,100,000$ ".

(c) Section 106 of Public Law 91-273, as amended, is further amended by striking from subsection (a) the figure " $\$ 2,000,000$ " and substituting therefor the figure " $3,000,000$ ", and by adding thereto the following new subsection (c):

"(c) The Commission is hereby authorized to agree, by modification to the definitive cooperative arrangement reflecting such changes therein as it deems appropriate for such purpose, to the following: (1) to execute and deliver to the other parties to the AEC definitive contract, the special undertaking of indemnification specified in said contract, which undertakings shall be subject to availability of appropriations to the Atomic Energy Commission (or any other Federal agency to which the Commission's pertinent functions might be transferred at some future time) and to the provisions of section 3679 of the Revised Statutes, as amended; and (2) to acquire ownership and custody of the property constituting the Liquid Metal Fast Breeder Reactor powerplant or parts thereof, and to use, decommission, and dispose of said property, as provided for in the AEC definitive contract."

(d) Section 101 of Public Law 92-314, as amended, is amended by striking from subsection (b)(4), project 73-4-b, land acquisition, Rocky Flats, Colorado, the figure " $\$ 8,000,000$ " and substituting therefor the figure $\$ 11,400,000 "$ ".

(e) Section 101 of Public Law 93-60 is amended by (1) striking from subsection (b)(1), project 74-1-a, additional facilities, high level waste storage, Savannah River, South Carolina, the figure " $\$ 14,000,000$ " and substituting therefor the figure " $\$ 17,500,000 "$ ", (2) striking from subsection (b)(1), project 74-1-g, cascade uprating program, gaseous diffusion plants, the words "(partial AE and limited component procurement only)" and further striking the figure " $\$ 6,000,000$ " and substituting therefore the figure " $\$ 183,100,000$ ", and (3) striking from subsection (b)(2), project 74-2-d, national security and resources study center, the words "(AE only), site undesignated" and substituting therefor the words "Los Alamos Scientific Laboratory, New Mexico" and further striking the figure " $\$ 350,000$ " and substituting therefor the figure " $\$ 4,600,000$ ".

Sec. 108. RESCISSION.-(a) Public Law 91-44, as amended, is further amended by rescinding therefrom authorization for a project, except for funds heretofore obligated, as follows:

Project 70-1-b, bedrock waste storage (AE and site selection drilling only), Savannah River, South Carolina, $\$ 4,300,000$.

(b) Public Law 92-84, as amended, is further amended by rescinding therefrom authorization for a project, except for funds heretofore obligated, as follows: 
Project 72-3-b, national radioactive waste repository, site undetermined, $\$ 3,500,000$.

86 Stat. 224.

(c) Public Law 92-314, as amended, is further amended by rescinding therefrom authorization for a project, except for funds heretofore obligated, as follows:

Project 73-6-c, accelerator improvements, Cambridge Electron Accelerator, Massachusetts, $\$ 75,000$.

\section{TITLE II}

69 Stat. 947. 42 USC 2187.

Sec. 201. Section 157b.(3) of the Atomic Energy Act of 1954, as amended, is amended by striking out "upon the recommendation of" and inserting in lieu thereof "after consultation with".

Approved May 10, 1974. 


\section{NRC AUTHORIZATION ACTS}

\section{Public Law 93-158}

87 Stat. 627

\section{An Act}

To amend Public Law 93-60 to increase the authorization for appropriations to the Atomic Energy Commission in accordance with section 261 of the Atomic Energy Act of 1954, as amended, and for other purposes.

Be it enacted by the Senate and House of Representatives of the United States of America in Congress assembled,

That section 101(a) of Public Law 93-60 is hereby amended by striking therefrom the figure " $\$ 1,740,750,000$ " and substituting the figure "\$1,751,450,000".

Sec. 2. Section 101(b) of Public Law 93-60 is hereby amended by adding to subsection (b)(1) the following words: "Project 74-1-i, additional waste concentration and salt cake storage facilities, Richland, Washington, $\$ 30,000,000 . ”$

Approved November 26, 1973. 


\section{INSPECTOR GENERAL ACT OF 1978, AS AMENDED}

\section{Public Law 95-452}

Sec. 1. Short Title. .......................... $436 \ldots \ldots$ app

Sec. 3. Appointment of Inspector General. .................... app.

Sec. 4. Duties and Responsibilities. ...............437 ..... app.

Sec. 5 Semiannual Reports. . . . . . . . . . . . . . $438 \ldots \ldots$ app.

Sec. 6. Authority of Inspector General. ..............442 .... app.

Sec. 7. Complaints by Employees. ................444 ..... app.

Sec. 8. Additional Provisions with Respect

to the Inspector General. . ............... $444 \ldots \ldots$ app

Sec. 8A. Special Provisions Relating to the

Agency for International Development. . . . . . . . . 446 app.

Sec. 8B. Special Provisions Concerning the

Nuclear Regulatory Commission. ............ 447 .... app.

Sec. 8C. Special Provisions Concerning the

Department of the Treasury. .................... app.

Sec. 8D. Special Provisions Concerning

the Department of Justice. . . . . . . . . . .

Sec. 8E. Requirements for Federal Entities

and Designated Federal Entities. ............. $451 \ldots \ldots$ app.

Sec. 8F. Rule of Construction of Special

Provisions. .........................455 ..... app.

Sec. 9. Transfer of Functions. $\ldots \ldots \ldots \ldots \ldots \ldots \ldots \ldots \ldots 455 \ldots \ldots$ app.

Sec. 10. Conforming and Technical

Amendments.

$457 \ldots$.... app.

Sec. 11. Definitions. ..................... $457 \ldots \ldots$ app.

Sec. 12. Effective Date. .................... $458 \ldots \ldots$ app. 
Government organization and employees.

5 USC app.

Sec. 1. SHORT TITLE

Sec. 2. PURPOSE AND ESTABLISHMENT OF OFFICES OF INSPECTOR GENERAL: DEPARTMENTS AND AGENCIES INVOLVED

In order to create independent and objective units-

(1) to conduct and supervise audits and investigations relating to the programs and operations of the establishments listed in section 11(2).

(2) to provide leadership and coordination and recommend policies for activities designed (A) to promote economy, efficiency, and effectiveness in the administration of, and (B) to prevent and detect fraud and abuse in, such programs and operations; and

(3) to provide a means for keeping the head of the establishment and the Congress fully and currently informed about problems and deficiencies relating to the administration of such programs and operations and the necessity for and progress of corrective action; there is hereby established in each of such establishments an Office of Inspector General.

Sec. 3. APPOINTMENT OF INSPECTOR GENERAL. SUPERVISION: REMOVAL: POLITICAL ACTIVITIES: APPOINTMENT OF ASSISTANT INSPECTOR GENERAL FOR AUDITING AND ASSISTANT INSPECTOR GENERAL FOR INVESTIGATIONS

(a) There shall be at the head of each Office an Inspector General who shall be appointed by the President, by and with the advice and consent of the Senate, without regard to political affiliation and solely on the basis of integrity and demonstrated ability in accounting, auditing, financial analysis, law, management analysis, public administration, or investigations. Each Inspector General shall report to and be under the general supervision of the head of the establishment involved or, to the extent such authority is delegated, the officer next in rank below such head, but shall not report to, or be subject to supervision by, any other officer of such establishment. Neither the head of the establishment nor the officer next in rank below such head shall prevent or prohibit the Inspector General from initiating,carrying out, or completing any audit or investigation, or from issuing any subpoena during the course of any audit or investigation.

(b) An Inspector General may be removed from office by the President. The President shall communicate the reasons for any such removal to both Houses of Congress.

(c) For the purposes of section 7324 of title 5, United States Code, no Inspector General shall be considered to be an employee who determines policies to be pursued by the United States in the nationwide administration of Federal laws.

(d) Each Inspector General shall, in accordance with applicable laws and regulations governing the civil service- 
(1) appoint an Assistant Inspector General for Auditing who shall have the responsibility for supervising the performance of auditing activities relating to programs and operations of the establishment, and

(2) appoint an Assistant Inspector General for Investigations who shall have the responsibility for supervising the performance of investigative activities relating to such programs and operations.

Sec. 4. DUTIES AND RESPONSIBILITIES. REPORT OF CRIMINAL VIOLATIONS TO ATTORNEY GENERAL.

(a) It shall be the duty and responsibility of each Inspector General, with respect to the establishment within which his Office is established-

(1) to provide policy direction for and to conduct, supervise, and coordinate audits and investigations relating to the programs and operations of such establishment;

(2) to review existing and proposed legislation and regulations relating to programs and operations of such establishment and to make recommendations in the semiannual reports required by section 5(a) concerning the impact of such legislation or regulation on the economy and efficiency in the administration of programs and operations administered or financed by such establishment or the prevention and detection of fraud and abuse in such programs and operations;

(3) to recommend policies for, and to conduct, supervise, or coordinate other activities carried out or financed by such establishment for the purpose of promoting economy and efficiency in the administration of, or preventing and detecting fraud and abuse in, its programs and operations;

(4) to recommend policies for, and to conduct, supervise, or coordinate relationships between such establishment and other Federal agencies, State and local governmental agencies, and nongovernment entities with respect to (A) all matters relating to the prevention and detection of fraud and abuse in, programs and operations administered or financed by such establishment, or (B) the identification and prosecution of participants in such fraud or abuse; and

(5) to keep the head of such establishment and the Congress fully and currently informed, by means of the reports required by section 5 and otherwise, concerning fraud and other serious problems, abuses, and deficiencies relating to the administration of programs and operations administered or financed by such establishment, to recommend corrective action concerning such problems, abuses, and deficiencies, and to report on the progress made in implementing such corrective action.

"(b)(1) in carrying out the responsibilities specified in subsection (a)(1), each Inspector General shall-

(A) comply with standards established by the Comptroller General of the United States for audits of Federal establishments, organizations, programs, activities, and functions; 
(B) establish guidelines for determining when it shall be appropriate to use non-Federal auditors; and

(C) take appropriate steps to assure that any work performed by non-Federal auditors complies with the standards established by the Comptroller General as described in paragraph (1).

“(2) For purposes of determining compliance with paragraph (1)(A) with respect to whether internal quality controls are in place and operating and whether established audit standards, policies, and procedures are being followed by Offices of Inspector General of establishments defined under section 11(2), Offices of Inspector General of designated Federal entities defined under section $8 \mathrm{E}(\mathrm{a})(2)$, and any audit office established within a Federal entity defined under section $8 \mathrm{E}(\mathrm{a})(1)$, reviews shall be performed exclusively by an audit entity in the Federal Government, including the General Accounting Office or the Office of Inspector General of each establishment defined under section 11(2), or the Office of Inspector General of each designed Federal entity defined under section $8 \mathrm{E}(\mathrm{a})(2)$.

"(c) In carrying out the duties and responsibilities established under this Act, each Inspector General shall give particular regard to the activities of the Comptroller General of the United States with a view toward avoiding duplication and insuring effective coordination and cooperation.

"(d) In carrying out the duties and responsibilities established under this Act, each Inspector General shall report expeditiously to the Attorney General whenever the Inspector General has reasonable grounds to believe there has been a violation of Federal criminal law.

Sec. 5. SEMIANNUAL REPORTS: TRANSMITTAL TO CONGRESS: AVAILABILITY TO PUBLIC: IMMEDIATE REPORT.ON SERIOUS OR FLAGRANT PROBLEMS

"(a) Each Inspector General shall, not later than April 30 and October 31 of each year, prepare semiannual reports summarizing the activities of the Office during the immediately preceding six-month periods ending March 31 and September 30. Such reports shall include, but need not be limited to-

(1) a description of significant problems, abuses, and deficiencies relating to the administration of programs and operations of such establishment disclosed by such activities during the reporting period;

(2) a description of the recommendations for corrective action made by the Office during the reporting period with respect to significant problems, abuses, or deficiencies identified pursuant to paragraph (1);

(3) an identification of each significant recommendation described in previous semiannual reports on which corrective action has not been completed;

(4) a summary of matters referred to prosecutive authorities and the prosecutions and convictions which have resulted; 
(5) a summary of each report made to the head of the establishment under section $6(\mathrm{~b})(2)$ during the reporting period;

(6) a listing, subdivided according to subject matter, of each audit report issued by the Office during the reporting period and for each audit report, where applicable, the total dollar value of questioned costs (including a separate category for the dollar value of unsupported costs) and the dollar value of recommendations that funds be put to better use;

(7) a summary of each particularly significant report;

(8) statistical tables showing the total number of audit reports and the total dollar value of questioned costs (including a separate category for the dollar value of unsupported costs), for audit reports-

(A) for which no management decision had been made by the commencement of the reporting period;

(B) which were issued during the reporting period;

(C) for which a management decision was made during the reporting period, including-

(i) the dollar value of disallowed costs; and

(ii) the dollar value of costs not disallowed; and

(D) for which no management decision has been made by the end of the reporting period;

(9) statistical tables showing the total number of audit reports and the dollar value of recommendations that funds be put to better use by management, for audit reports-

(A) for which no management decision had been made by the commencement of the reporting period;

(B) which were issued during the reporting period;

(C) for which a management decision was made during the reporting period, including-

(i) the dollar value of recommendations that were agreed to by management; and

(ii) the dollar value of recommendations that were not agreed to by management; and

(D) for which no management decision has been made by the end of the reporting period;

(10) a summary of each audit report issued before the commencement of the reporting period for which no management decision has been made by the end of the reporting period (including the date and title of each such report), an explanation of the reasons such management decision has not been made, and a statement concerning the desired timetable for achieving a management decision on each such report;

(11) a description and explanation of the reasons for any significant revised management decision made during the reporting period; and

(12) information concerning any significant management decision with which the Inspector General is in disagreement;

“(b) Semiannual reports of each Inspector General shall be furnished to the head of the establishment involved not later than April 30 and October 31 of each year and shall be 
transmitted by such head to the appropriate committees or subcommittees of the Congress within thirty days after receipt of the report, together with a report by the head of the establishment containing-

(1) any comments such head determines appropriate;

(2) statistical tables showing the total number of audit reports and the dollar value of disallowed costs, for audit reports-

(A) for which final action had not been taken by the commencement of the reporting period;

(B) on which management decisions were made during the reporting period;

(C) for which final action was taken during the reporting period, including-

(i) the dollar value of disallowed costs that were recovered by management through collection, offset, property in lieu of cash, or otherwise; and

(ii) the dollar value of disallowed costs that were written off by management; and

(D) for which no final action has been taken by the end of the reporting period;

(3) statistical tables showing the total number of audit reports and the dollar value of recommendations that funds be put to better use by management agreed to in a management decision for audit reports-

(A) for which final action had not been taken by the commencement of the reporting period;

(B) on which management decisions were made during the reporting period;

(C) for which final action was taken during the reporting period, including-

(i) the dollar value of recommendations that were actually completed; and

(ii) the dollar value of recommendations that management has subsequently concluded should not or could not be implemented or completed; and

(D) for which no final action has been taken by the end of the reporting period; and

(4) a statement with respect to audit reports on which management decisions have been made but final action has not been taken, other than audit reports on which a management decision was made within the preceding year, containing-

(A) a list of such audit reports and the date each such report was issued;

(B) the dollar value of disallowed costs for each report;

(C) the dollar value of recommendations that funds be put to better use agreed to by management for each report; and

(D) an explanation of the reasons final action has not been taken with respect to each such audit report, except that such statement may exclude such audit reports that are under formal administrative or judicial appeal or upon which management 
of an establishment has agreed to pursue a legislative solution, but shall identify the number of reports in each category so excluded.

(c) Within sixty days of the transmission of the semiannual reports of each Inspector General to the Congress, the head of each establishment shall make copies of such report available to the public upon request and at a reasonable cost.

Within 60 days after the transmission of the semiannual report of each establishment head to the Congress, the head of each establishment shall make copies of such report available to the public upon request and at a reasonable cost.

(d) Each Inspector General shall report immediately to the head of the establishment involved whenever the Inspector General becomes aware of particularly serious or flagrant problems, abuses, or deficiencies relating to the administration of programs and operations of such establishment. The head of the establishment shall transmit any such report to the appropriate committees or subcommittees of Congress within seven calendar days, together with a report by the head of the establishment containing any comments such head deems appropriate.

(e)(1) Except to the extent and in the manner provided under section 6103(f) of the Internal Revenue Code of 1986, nothing in this section shall be construed to authorize the public disclosure of information which is-

(A) specifically prohibited from disclosure by any other provision of law;

(B) specifically required by Executive order to be protected from disclosure in the interest of national defense or national security or in the conduct of foreign affairs; or

(C) a part of an ongoing criminal investigation.

(2) Notwithstanding paragraph (1)(C), any report under this section may be disclosed to the public in a form which includes information with respect to a part of an ongoing criminal investigation if such information has been included in a public record.

(3) Nothing in this section or in any other provision of this Act shall be construed to authorize or permit the withholding of information from the Congress, or from any committee or subcommittee thereof.

(f)As used in this section-

(1) the term 'questioned cost' means a cost that is questioned by the Office because of-

(A) an alleged violation of a provision of a law, regulation, contract, grant, cooperative agreement, or other agreement or document governing the expenditure of funds;

(B) a finding that, at the time of the audit, such cost is not supported by adequate documentation; or

(C) a finding that the expenditure of funds for the intended purpose is unnecessary or unreasonable; 
(2) the term 'unsupported cost' means a cost that is questioned by the Office because the Office found that, at the time of the audit, such cost is not supported by adequate documentation;

(3) the term 'disallowed cost' means a questioned cost that management, in a management decision, has sustained or agreed should not be charged to the Government;

(4) the term 'recommendation that funds be put to better use' means a recommendation by the Office that funds could be used more efficiently if management of an establishment took actions to implement and complete the recommendation, including-

(A) reductions in outlays;

(B) deobligation of funds from programs or operations;

(C) withdrawal of interest subsidy costs on loans or loan guarantees, insurance, or bonds;

(D) costs not incurred by implementing recommended improvements related to the operations of the establishment, a contractor grantee;

(E) avoidance of unnecessary expenditures noted in preaward reviews of contract or grant agreements; or

(F) any other savings which are specifically identified;

(5) the terms 'management decision' means the evaluation by the management of an establishment of the findings and recommendations included in an audit report and the issuance of a final decision by management concerning its response to such findings and recommendations, including actions concluded to be necessary; and

(6) the term 'final actions' means-

(A) the completion of all actions that the management of an establishment has concluded, in its management decision, are necessary with respect to the findings and recommendations included in an audit report; and

(B) in the event that the management of an establishment concludes no action is necessary, final action occurs when a management decision has been made.

Sec. 6. AUTHORITY OF INSPECTOR GENERAL; INFORMATION AND ASSISTANCE FROM FEDERAL AGENCIES, UNREASONABLE REFUSAL, OFFICE SPACE AND EQUIPMENT

(a) In addition to the authority otherwise provided by this Act, each Inspector General, in carrying out the provisions of this Act, is authorized-

(1) to have access to all records, reports, audits, reviews, documents, papers, recommendations, or other material available to the applicable establishment which relate to programs and operations with respect to which that Inspector General has responsibilities under this Act;

(2) to make such investigations and reports relating to the administration of the programs and operations of the applicable establishment as are in the judgment of the Inspector General, necessary or desirable;

(3) to request such information or assistance as may be necessary for carrying out the duties and responsibilities provided by this Act 
from any Federal, State, or local governmental agency or unit thereof;

(4) to require by subpoena the production of all information, documents, reports, answers, records, accounts, papers, and other data and documentary evidence necessary in the performance of the functions assigned by this Act, which subpoena, in the case of contumacy or refusal to obey, shall be enforceable by order of any appropriate United States district court: Provided, That procedures other than subpoenas shall be used by the Inspector General to obtain documents and information from Federal agencies;

(5) to administer to or take from any person an oath, affirmation, or affidavit, whenever necessary in the performance of the functions assigned by this Act, which oath, affirmation, or affidavit when administered or taken by or before an employee of an Office of Inspector General designated by the Inspector General shall have the same force and effect as if administered or taken by or before an officer having a seal;

(6) to have direct and prompt access to the head of the establishment involved when necessary for any purpose pertaining to the performance of functions and responsibilities under this Act;

(7) to select, appoint, and employ such officers and employees as may be necessary for carrying out the functions, powers, and duties of the Office subject to the provisions of title 5, United States Code, governing appointments in the competitive service, and the provisions of chapter 51 and subchapter III of chapter 53 of such title relating to classification and General Schedule pay rates;

(8) to obtain services as authorized by section 3109 of title 5 , United States Code, at daily rates not to exceed the equivalent rate prescribed for grade GS-18 of the General Schedule by section 5332 of title 5, United States Code; and

(9) to the extent and in such amounts as may be provided in advance by appropriations Acts, to enter into contracts and other arrangements for audits, studies, analyses, and other services with public agencies and with private persons, and to make such payments as may be necessary to carry out the provisions of this Act.

(b)(1) Upon request of an Inspector General for information or assistance under subsection (a)(3), the head of any Federal agency involved shall, insofar as is practicable and not in contravention of any existing statutory restriction or regulation of the Federal agency from which the information is requested, furnish to such Inspector General, or to an authorized designee, such information or assistance.

(2) Whenever information or assistance requested under subsection (a)(1) or (a)(3) is, in the judgment of an Inspector General, unreasonably refused or not provided, the Inspector General shall report the circumstances to the head of the establishment involved without delay.

(c) Each head of an establishment shall provide the Office within such establishment with appropriate and adequate office space at central and field office locations of such establishment, together with such equipment, office supplies, and 
communications facilities and services as may be necessary for the operation of such offices, and shall provide necessary maintenance services for such offices and the equipment and facilities located therein.

(d) For purposes of the provisions of title 5, United States Code, governing the Senior Executive Service, any reference in such provisions to the 'appointing authority' for a member of the Senior Executive Service or for a Senior Executive Service position shall, if such member or position is or would be within the Office of an Inspector General, be deemed to be a reference to such Inspector General.

Sec 7. COMPLAINTS BY EMPLOYEES. DISCLOSURE OF IDENTITY; REPRISALS

(a) The Inspector General may receive and investigate complaints or information from an employee of the establishment concerning the possible existence of an activity constituting a violation of law, rules, or regulations, or mismanagement, gross waste of funds, abuse of authority or a substantial and specific danger to the public health and safety.

(b) The Inspector General shall not, after receipt of a complaint or information from an employee, disclose the identity of the employee without the consent of the employee, unless the Inspector General determines such disclosure is unavoidable during the course of the investigation.

(c) Any employee who has authority to take, direct others to take, recommend, or approve any personnel action, shall not with respect to such authority, take or threaten to take any actions against any employee as a reprisal for making a complaint or disclosing information to an Inspector General, unless the complaint was made for the information disclosed with the knowledge that it was false or with willful disregard for its truth or falsity.

Sec. 8. ADDITIONAL PROVISIONS WITH RESPECT TO THE INSPECTOR GENERAL OF THE DEPARTMENT OF DEFENSE

(a) No member of the Armed Forces, active or reserve, shall be appointed Inspector General of the Department of Defense.

(b) (1) Notwithstanding the last two sentences of section 3(a), the Inspector General shall be under the authority, direction, and control of the Secretary of Defense with respect to audits or investigations, or the issuance of subpoenas, which require access to information concerning -

(A) sensitive operational plans;

(B) intelligence matters;

(C) counterintelligence matters;

(D) ongoing criminal investigations by other administrative units of the Department of Defense related to national security; or

(E) other matters the disclosure of which would constitute a serious threat to national security.

(2) With respect to the information described in paragraph (1) the Secretary of Defense may prohibit the Inspector General from in- 
itiating, carrying out, or completing any audit or investigation, or from issuing any subpoena, after the Inspector General has decided to initiate, carry out or complete such audit or investigation or to issue such subpoena, if the Secretary determines that such prohibition is necessary to preserve the national security interests of the United States.

(3) If the Secretary of Defense exercises any power under paragraph (1) or (2), the Inspector General shall submit a statement concerning such exercise within thirty days to the Committees on Armed Services and Governmental Affairs of the Senate and the Committees on Armed Services and Government Operations of the House of Representatives and to other appropriate committees or subcommittees of the Congress.

(4) The Secretary shall, within thirty days after submission of a statement under paragraph (3), transmit a statement of the reasons for the exercise of power under paragraph (1) and (2) to the Committees on Armed Services and Governmental Affairs of the Senate and the Committees on Armed Services and Government Operations of the House of Representatives and to other appropriate committees or subcommittees.

(c) In addition to the other duties and responsibilities speci-

fied in this Act, the Inspector General of the Department of

Defense shall-

(1) be the principal adviser to the Secretary of Defense for matters relating to the prevention and detection of fraud, waste, and abuse in the programs and operations of the Department;

(2) initiate, conduct, and supervise such audits and investigations in the Department of Defense (including the military departments) as the Inspector General considers appropriate;

(3) provide policy direction for audits and investigations relating to fraud, waste, and abuse and program effectiveness;

(4) investigate fraud, waste, and abuse uncovered as a result of other contract and internal audits, as the Inspector General considers appropriate;

(5) develop policy, monitor and evaluate program performance, and provide guidance with respect to all Department activities relating to criminal investigation programs;

(6) monitor and evaluate the adherence of Department auditors to internal audit, contract audit, and internal review principles, policies, and procedures;

(7) develop policy, evaluate program performance, and monitor actions taken by all components of the Department in response to contract audits, internal audits, internal review reports, and audits conducted by the Comptroller General of the United States;

(8) request assistance as needed from other audit, inspection, and investigative units of the Department of Defense (including military departments); and

(9) give particular regard to the activities of the internal audit, inspection, and investigative units of the military departments with a view toward avoiding duplication and insuring effective coordination and cooperation. 
(d) Notwithstanding section 4(d), the Inspector General of the Department of Defense shall expeditiously report suspected or alleged violations of chapter 47 of title 10, United States Code (Uniform Code of Military Justice), to the Secretary of the military department concerned or the Secretary of Defense.

(e) For the purposes of section 7, a member of the Armed Forces shall be deemed to be an employee of the Department of Defense, except that, when the Coast Guard operates as a service of another department or agency of the Federal Government, a member of the Coast Guard shall be deemed to be an employee of such department or agency.

(f)(1) Each semiannual report prepared by the Inspector General of the Department of Defense under section 5(a) shall include information concerning the numbers and types of contract audits conducted by the Department during the reporting period. Each such report shall be transmitted by the Secretary of Defense to the Committees on Armed Services and Governmental Affairs of the Senate and the Committees on Armed Services and Governmental Operations of the House of Representatives and to other appropriate committees or subcommittees of the Congress.

(2) Any report required to be transmitted by the Secretary of Defense to the appropriate committees or subcommittees of the congress under section 5(d) shall also be transmitted within the sevenday period specified in such section, to the Committees on Armed Services and Governmental Affairs of the Senate and the Committees on Armed Services and Government Operations of the House of Representatives.

(g) The provisions of section 1385 of title 18, United States Code, shall not apply to audits and investigations conducted by, under the direction of, or at the request of the Inspector General of the Department of Defense to carry out the purposes of this Act.

Sec. 8A. SPECIAL PROVISIONS RELATING TO THE AGENCY FOR INTERNATIONAL DEVELOPMENT

(a) In addition to the other duties and responsibilities specified in this Act, the Inspector General of the Agency for International Development-

(1) shall supervise, direct, and control all security activities relating to the programs and operations of that Agency, subject to the supervision of the Administrator of that Agency; and

(2) to the extent requested by the Director of the United States International Development Cooperation Agency (after consultation with the Administrator of the Agency for International Development), shall supervise, direct, and control all audit, investigative and security activities relating to programs and operations within the United States International Development Cooperation Agency.

(b) In addition to the Assistant Inspector Generals provided for in section 3(d) of this Act, the Inspector General of the 
Agency for International Development shall, in accordance with applicable laws and regulations governing the civil service, appoint an Assistant Inspector General for Security who shall have the responsibility for supervising the performance of security activities relating to programs and operations of the Agency for International Development.

(c) The semiannual reports required to be submitted to the Administrator of the Agency for International Development pursuant to section 5(b) of this Act shall also be submitted to the Director of the United States International Development Cooperation Agency.

(d) In addition to the officers and employees provided for in section 6(a) (6) of this Act, members of the Foreign Service may, at the request of the Inspector General of the Agency for International Development, be assigned as employees of the Inspector General. Members of the Foreign Service so assigned shall be responsible solely to the Inspector General, and the Inspector General (or his or her designee) shall prepare the performance evaluation reports for such members.

(e) In establishing and staffing field offices pursuant to section 6(c) of this Act, the Administrator of the Agency for International Development shall not be bound by overseas personnel ceilings established under the monitoring Overseas Direct Employment policy.

(f) The reference in section 7(a) of this Act to an employee of the Establishment shall, with respect to the Inspector General of the Agency for International Development, be construed to include an employee of or under the United States International Development Cooperation Agency.

(g) The Inspector General of the Agency for International Development shall be in addition to the officers provided for in section 624(a) of the Foreign Assistance Act of 1961 [22 U.S.C. 2384(a)].

(h) As used in this Act, the term "Agency for International Development" includes any successor agency primarily responsible for administering part I of the Foreign Assistance Act of 1961 [22 U.S.C. 2151 et seq.].

Sec. 8B. SPECIAL PROVISIONS CONCERNING THE NUCLEAR REGULATORY COMMISSION

(a) The Chairman of the Commission may delegate the authority specified in the second sentence of section 3(a) to another member of the Nuclear Regulatory Commission, but shall not delegate such authority to any other officer or employee of the Commission.

(b) Notwithstanding sections $6(a)(7)$ and (8), the Inspector General of the Nuclear Regulatory Commission is authorized to select, appoint, and employ such officers and employees as may be necessary for carrying out the functions, powers and duties of the Office of Inspector General and to obtain the temporary or intermittent services of experts or consultants or an organization thereof, subject to the applicable laws and 
regulations that govern such selections, appointments and employment, and the obtaining of such services, within the Nuclear Regulatory Commission.

Sec. 8C. SPECIAL PROVISIONS CONCERNING THE DEPARTMENT OF THE TREASURY

(a)(1) Notwithstanding the last two sentences of section 3(a), the Inspector General shall be under the authority, direction, and control of the Secretary of the Treasury with respect to audits or investigation, or the issuance of subpoenas, which require access to sensitive information concerning-

(A) ongoing criminal investigations or proceedings;

(B) undercover operations;

(C) the identity of confidential sources, including protected witnesses;

(D) deliberations and decisions on policy matters, including documented information used as a basis for making policy decisions, the disclosure of which could reasonably be expected to have a significant influence on the economy or market behavior;

$(E)$ intelligence or counterintelligence matters; or

(F) other matters the disclosure of which would constitute a serious threat to national security or to the protection of any person or property authorized protection by section 3056 of title 18, United States Code, section 202 of title 3, United States Code, or any provision of the Presidential Protection Assistance Act of 1976 (18 U.S.C 3056 note; Public Law 94-524),

(2) With respect to the information described under paragraph (1), the Secretary of the Treasury may prohibit the Inspector General from carrying out or completing any audit or investigation, or from issuing any subpoena, after such Inspector General has decided to initiate, carry out, or complete such audit or investigation or to issue such subpoena, if the Secretary determines that such prohibition is necessary to prevent the disclosure of any information described under paragraph (1) or to prevent significant impairment to the national interests of the United States.

(3) If the Secretary of the Treasury exercise any power under paragraph (1) or (2), the Secretary of the Treasury shall notify the Inspector General in writing stating the reasons for such exercise. Within 30 days after receipt of any such notice, the Inspector General shall transmit a copy of such notice to the Committees on Governmental Affairs and Finance of the Senate and the Committees on Government Operations and Ways and Means of the House of Representatives, and to other appropriate committees or subcommittees of the Congress.

(b) In carrying out the duties and responsibilities specified in this Act, the Inspector General of the Department of Treasury shall have oversight responsibility for the internal investigations performed by the Office of Internal Affairs of the Bureau of Alcohol, Tobacco and Firearms, the Office of Internal Affairs of the United States Customs Service, and the Office of 
Inspections of the United States Secret Service, and the internal audits and internal investigations performed by the Office of Assistant Commissioner (Inspection) of the Internal Revenue Service. The head of each such office shall promptly report to the Inspector General the significant activities being carried out by such office.

(c) Notwithstanding subsection (b), the Inspector General may initiate, conduct and supervise such audits and investigations in the Department of the Treasury (including the bureaus and services referred to in subsection (b) as the Inspector General considers appropriate.

(d) If the Inspector General initiates an audit or investigation under subsection (c) concerning a bureau or service referred to in subsection (b), the Inspector General may provide the head of the office of such bureau or service referred to in subsection (b) with written notice that the Inspector General has initiated such an audit or investigation. If the Inspector General issues a notice under the preceding sentence, no other audit or investigation shall be initiated into the matter under audit or investigation by the Inspector General and any other audit or investigation of such matter shall cease.

(e)(1) The Inspector General shall have access to returns and return information, as defined in section 6103(b) of the Internal Revenue Code of 1986, only in accordance with the provisions of section 6103 of such Code and this Act.

(2) Access by the Inspector General to returns and return information under section 6103(h)(1) of such Code shall be subject to the following additional requirements:

(A) In order to maintain internal controls over access to returns and return information, the Inspector General, or in the absence of the Inspector General, the Acting Inspector General, The Deputy Inspector General, the Assistant Inspector General for Audits, or the Assistant Inspector General for Investigations, shall provide to the Assistant Commissioner (Inspection) of the Internal Revenue Service written notice of the Inspector General's intent to access returns and return information. If the Inspector General determines that the Inspection Service of the Internal Revenue Service should notbe made aware of a notice of access to returns and return information, such notice shall be provided to the Senior Deputy Commission of Internal Revenue.

(B) Such notice shall clearly indicate the specific returns or return information being accessed, contain a certification by the Inspector General, or in the absence of the Inspector General, the Acting Inspector General, the Deputy Inspector General, the Assistant Inspector General for Audits, or the Assistant Inspector General for Investigations, that the returns or return information being accessed are needed for a purpose described under section 6103(h)(1) of the Internal Revenue Code of 1986, and 
identify those employees of the Office of Inspector General of the Department of Treasury who may receive such returns or return information.

(C) The Internal Revenue Service shall maintain the same system of standardized records or accounts of all requests from the Inspector General for inspection or disclosure of returns and return information (including the reasons for and dates of such requests), and of returns and return information inspected or disclosed pursuant to such requests, as described under section $6103(\mathrm{p})(3)(\mathrm{A})$ of the Internal Revenue Code of 1986 . Such system of standardized records or accountings shall also be available for examination in the same manner as provided under section 6103(p)(3) of the Internal Revenue Code of 1986.

(D) The Inspector General shall be subject to the same safeguards and conditions for receiving returns and return information as are described under section 6103(p)(4) of the Internal Revenue Code of 1986.

(f) An audit or investigation conducted by the Inspector General shall not affect a final decision of the Secretary of the Treasury or his delegate under section 6404 of the Internal Revenue Code of 1986.

(g) Notwithstanding section 4(d), in matters involving chapter 75 of the Internal Revenue Code of 1986, the Inspector General shall report expeditiously to the Attorney General only offenses under section 7214 of such Code, unless the Inspector General obtains the consent of the Commissioner of Internal Revenue to exercise additional reporting authority with respect to such chapter.

(h) Any report required to be transmitted by the Secretary of the Treasury to the appropriate committees or subcommittees of the Congress under section 5(d) shall also be transmitted, within the seven-day period specified under such section, to the Committees on Governmental Affairs and Finance of the Senate and the Committees on Government Operations and Ways and Means of the House of Representatives.

Sec. 8D. SPECIAL PROVISIONS CONCERNING THE DEPARTMENT OF JUSTICE

(a)(1) Notwithstanding the last two sentences of section 3(a), the Inspector General shall be under the authority, direction, and control of the Attorney General with respect to audits or investigations, or the issuance of subpoenas, which require access to sensitive information concerning-

(A) ongoing civil or criminal investigations or proceedings;

(B) undercover operations;

(C) the identity of confidential sources, including protected witnesses;

(D) intelligence or counterintelligence matters; or

(E) other matters the disclosure of which would constitute a serious threat to national security. 
(2) With respect to the information described under paragraph (1), the Attorney General may prohibit the Inspector General from carrying out or completing any audit or investigation, or from issuing any subpoena, after such Inspector General has decided to initiate, carry out, or complete such audit or investigation or to issue such subpoena, if the Attorney General determines that such prohibition is necessary to prevent the disclosure of any information described under paragraph (1) or to prevent the significant impairment to the national interests of the United States.

(3) If the Attorney General exercises any power under paragraph (1) or (2), the Attorney General shall notify the Inspector General in writing stating the reasons for such exercise. Within 30 days after receipt of any such notice, the Inspector General shall transmit a copy of such notice to the Committees on Governmental Affairs and Judiciary of the Senate and the Committees on Government Operations and Judiciary of the House of Representatives, and to other appropriate committees or subcommittees of the Congress.

(b) In carrying out the duties and responsibilities specified in

this Act, the Inspector General of the Department of Justice-

(1) may initiate, conduct and supervise such audits and investigations in the Department of Justice as the Inspector General considers appropriate;

(2) shall give particular regard to the activities of the Counsel, Office of Professional Responsibility of the Department and the audit, internal investigative, and inspection units outside the Office of Inspector General with a view toward avoiding duplication and insuring effective coordination and cooperation; and

(3) shall refer to the Counsel, Office of Professional Responsibility of the Department for investigation, information or allegations relating to the conduct of an officer or employee of the Department of Justice employed in an attorney, criminal investigation of law, regulation, or order of the Department or any other applicable standard of conduct, except that no such referral shall be made if the officer or employee is employed in the Office of Professional Responsibility of the Department.

(c) Any report required to be transmitted by the Attorney General to the appropriate committees or subcommittees of the Congress under section 5(d) shall also be transmitted, within the seven-day period specified under such section, to the Committees on the Judiciary and Governmental Affairs of the Senate and the Committees on the Judiciary and Government Operations of the House of Representatives.

Sec. 8E. REQUIREMENTS FOR FEDERAL ENTITIES AND DESIGNATED FEDERAL ENTITIES

(a) Notwithstanding section 11 of this Act, as used in this section-

(1) the term 'Federal entity' means any Government corporation (within the meaning of section 103(1) of title 5, United States Code), any Government controlled corporation (within the meaning of section 103(2) of such title), or any other entity in the Execu- 
tive branch of the Government, or any independent regulatory agency, but does not include-

(A) an establishment (as defined under section 11(2) of this Act) or part of an establishment;

(B) a designated Federal entity (as defined under paragraph (2) of this subsection) or part of a designated Federal entity;

(C) the Executive Office of the President;

(D) the Central Intelligence Agency;

(E) the General Accounting Office; or

(F) any entity in the judicial or legislative branches of the Government, including the Administrative Office of the United States Courts and the Architect of the Capitol and any activities under the direction of the Architect of the Capitol;

(2) the term 'designated Federal entity' means ACTION, Amtrak, the Appalachian Regional Commission, the Board of Governors of the Federal Reserve System, the Board for International Broadcasting, the Commodity Futures Trading Commission, the Consumer Product Safety Commission, the Corporation for Public Broadcasting, the Equal Employment Opportunity Commission, the Farm Credit Administration, the Federal Communications Commission, the Federal Deposit Insurance Corporation, the Federal Election Commission, the Federal Home Loan Bank Board, the Federal Labor Relations Authority, the Federal Maritime Commission, the Federal Trade Commission, the Interstate Commerce Commission, the Legal Services Corporation, the National Archives and Records Administration, the National Credit Union Administration, the National Endowment for the Arts, the National Endowment for the Humanities, the National Labor Relations Board, the National Science Foundation, the Panama Canal Commission, the Peace Corps, the Pension Benefit Guaranty Corporation, the Securities and Exchange Commission, the Smithsonian Institution, the Tennessee Valley Authority, the United States International Trade Commission, and the United States Postal Service;

(3) the term 'head of the Federal entity, means any person or persons designated by statute as the head of a Federal entity, and if no such designation exists, the chief policymaking officer or board of a Federal entity as identified in the list published pursuant to subsection $(h)(1)$ of this section;

(4) the term 'head of the designated Federal entity' means any person or persons designated by statute as the head of a designated Federal entity and if no such designation exists, the chief policymaking officer or board of a designated Federal entity as identified in the list published pursuant to subsection $(h)(1)$ of this section, except that with respect to the National Science Foundation, such term means the National Science Board;

(5) the term 'Office of Inspector General' means an Office of Inspector General of a designated Federal entity; and 
(6) the term 'Inspector General' means an Inspector General of a designated Federal entity.

(b) No later than 180 days after the date of the enactment of this section, there shall be established and maintained in each designated Federal entity an Office of Inspector General. The head of the designated Federal entity shall transfer to such office the offices, units, or other components, and the functions, powers, or duties thereof, that such head determines are properly related to the functions of the Office of Inspector.General and would, if so transferred, further the purposes of this section. There shall not be transferred to such office any program operating responsibilities.

(c) Except as provided under subsection ( $f$ ) of this section, the Inspector General shall be appointed by the head of the designated Federal entity in accordance with the applicable laws and regulations governing appointments within the designated Federal entity.

(d) Each Inspector General shall report to and be under the general supervision of the head of the designated Federal entity, but shall not report to, or be subject to supervision by, any other officer or employee of such designated Federal entity. The head of the designated Federal entity shall not prevent or prohibit the Inspector General from initiating, carrying out, or completing any audit or investigation, or from issuing any subpoena during the course of any audit or investigation.

(e) If an Inspector General is removed from office or is transferred to another position or location within a designated Federal entity, the head of the designated Federal entity shall promptly communicate in writing the reasons for any such removal or transfer to both Houses of the Congress.

(f)(1) The Chief Postal Inspector of the United States Postal Service shall also hold the position of Inspector General of the United States Postal Service, and for purposes of this section, shall report to, and be under the general supervision of, the Postmaster General of the United States Postal Service. The Postmaster General, in consultation with the Governors of the United States Postal Service, shall appoint the Chief Postal Inspector. The Postmaster General, with the concurrence of the Governors of the United States Postal Service, shall have power to remove the Chief Postal Inspector or transfer the Chief Postal Inspector to another position or location within the United States Postal Service. If the Chief Postal Inspector is removed or transferred in accordance with this subsection, the Postmaster General shall promptly notify both Houses of the Congress in writing of the reasons for such removal or transfer.

(2) For purposes of paragraph (1), the term "Governors" has the same meaning as such term is defined under section 102(3) of title 39, United States Code.

(g)(1) Sections 4, 5, 6 (other than subsections (a)(7) and (a)(8) thereof), and 7 of this Act shall apply to each Inspector General and Office of Inspector General of a designated Federal entity 
and such sections shall be applied to each designated Federal entity and head of the designated Federal entity (as defined under subsection (1) by substituting-

(A) "designated Federal entity" for "establishment"; and

(B) "head of the designated Federal entity" for "head of the establishment".

(2) In addition to the other authorities specified in this Act, an Inspector General is authorized to select, appoint, and employ such officers and employees as may be necessary for carrying out the functions, powers, and duties of the Office of Inspector General and to obtain the temporary or intermittent services of experts or consultants or an organization thereof, subject to the applicable laws and regulations that govern such selections, appointments, and employment, and the obtaining of such services, within the designated Federal entity.

(3) Notwithstanding the last sentence of subsection (d) of this section, the provisions of subsection (a) of section $8 \mathrm{C}$ (other than then provisions of subparagraphs (A), (B), (C), and (E) of subsection (a)(1) shall apply to the Inspector General of the Board of Governors of the Federal Reserve System and the Chairman of the Board of Governors of the Federal Reserve System in the same manner as such provisions apply to the Inspector General of the Department of the Treasury and the Secretary of the Treasury, respectively.

(h)(1) No later than April 30, 1989 and annually thereafter, the Director of the Office of Management and: Budget, after consultation with the Comptroller General of the United States, shall publish in the Federal Register a list of the Federal entities and designated Federal entities and the head of each such entity (as defined under subsection (a) of this section).

(2) Beginning on October 31, 1989, and on October 31 of each succeeding calendar year, the head of each Federal entity (as defined under subsection (a) of this section) shall prepare and transmit to the Director of the Office of Management and Budget and to each House of the Congress a report which-

(A) states whether there has been established in the Federal entity an office that meets the requirements of this section;

(B) specifies the actions taken by the Federal entity otherwise to ensure that audits are conducted of its programs and operations in accordance with the standards for audit of governmental organizations, programs, activities, and functions issued by the Comptroller General of the United States, and includes a list of each audit report completed by a Federal or non-Federal auditor during the reporting period and a summary of any particularly significant findings; and

(C) summarizes any matters relating to the personnel, programs, and operations of the Federal entity referred to prosecutive authorities, including a summary description of any preliminary investigation conducted by or at the re- 
quest of the Federal entity concerning these matters, and the prosecutions and convictions which have resulted.

Sec. 8F. RULE OF CONSTRUCTION OF SPECIAL PROVISIONS Sec. 8f. The special provisions under section $8,8 \mathrm{~A}, 8 \mathrm{~B}, 8 \mathrm{C}$, or $8 \mathrm{D}$ of this Act relate only to the establishment named in such section and no inference shall be drawn from the presence or absence of a provision in any such section with respect to an establishment not named in such section or with respect to a designated Federal entity as defined under section $8 \mathrm{E}(\mathrm{a})$.

Sec. 9. TRANSFER OF FUNCTIONS

(a) There shall be transferred-

(1) to the Office of Inspector General-

(A) of the Department of Agriculture, the offices of that department referred to as the "Office of Investigation" and the "Office of Audit";

(B) of the Department of Commerce, the offices of that department referred to as the "Office of Audits" and the "Investigations and Inspections Staff" and that portion of the office referred to as the "Office of Investigations and Security" which has responsibility for investigation of alleged criminal violations and program abuse;

(C) of the Department of Defense, the offices of that department referred to as the "Defense Audit Service" and the "Office of Inspector General, Defense Logistics Agency", and that portion of the office of that department referred to as the "Defense Investigative Service" which has responsibility for the investigation of alleged criminal violations;

(D) of the Department of Education, all functions of the Inspector General of Health, Education, and Welfare or of the Office of Inspector General of Health, Education, and Welfare relating to functions transferred by section 301 of the Department of Education Organization Act [20 U.SC. 3441];

(E) of the Department of Energy, the Office of Inspector General (as established by section 208 of the Department of Energy Organization Act);

(F) of the Department of Health and Human Services, the Office of Inspector General (as established by title II of Public Law 94-505);

(G) of the Department of Housing and Urban Development, the office of that department referred to as the "Office of Inspector General";

$(\mathrm{H})$ of the Department of the Interior, the office of that department referred to as the "Office of Audit and Investigations";

(I) of the Department of Justice, the offices of that Department referred to as (i) the "Audit Staff, Justice Management Division", (ii) the "Policy and Procedures Branch, Office of the Comptroller, Immigration and Naturalization Service", the "Office of Professional Re- 
sponsibility, Immigration and Naturalization Service", and the "Office of Program Inspections, Immigration and Naturalization Service", (iii) the "Office of Internal Inspection, United States Marshals Service", (iv) the "Financial Audit Section, Office of Financial Management, Bureau of Prisons" and the "Office of Inspections, Bureau of Prisons", and (v) from the Drug Enforcement Administration, that portion of the "Office of Inspections" which is engaged in internal audit activities, and that portion of the "Office of Planning and Evaluation" which is engaged in program review activities;

(J) of the Department of Labor, the office of that department referred to as the "Office of Special Investigations"

(K) of the Department of Transportation, the offices of that department referred to as the "Office of Investigations and Security" and the "Office of Audit" of the Department, the "Offices of Investigations and Security, Federal Aviation Administration", and "External Audit Divisions, Federal Aviation Administration", the "Investigations Division and the External Audit Division of the Office of Program Review and Investigation, Federal Highway Administration", and the "Office of Program Audits, Urban Mass Transportation Administration";

(L) of the Department of the Treasury, the office of that department referred to as the "Office of Inspector General", and, notwithstanding any other provision of law, that portion of each of the offices of that department referred to as the "Office of Internal Affairs, Bureau of $\mathrm{Al}$ cohol, Tobacco, and Firearms", the "Office of Internal Affairs, United States Customs Service", and the "Office of Inspections, United States Secret Service", which is engaged in internal audit activities;

(M) of the Environmental Protection Agency, the offices of that agency referred to as the "Office of Audit" and the "Security and Inspection Division";

$(\mathrm{N})$ of the Federal Emergency Management Agency, the office of that agency referred to as the "Office of Inspector General";

(O) of the General Services Administration, the offices of that agency referred to as the "Office of Audits" and the "Office of Investigations";

$(\mathrm{P})$ of the National Aeronautics and Space Administration, the offices of that agency referred to as the "Management Audit Office" and the "Office of Inspections and Security";

(Q) of the Nuclear Regulatory Commission, the office of that commission referred to as the "Office of Inspector and Auditor";

(R) of the Office of Personnel Management, the offices of that agency referred to as the "Office of Inspector General", the "Insurance Audits Division, Retirement and In- 
surance Group", and the "Analysis and Evaluation Division, Administration Group";

(S) of the Railroad Retirement Board, the Office of Inspector General (as established by section 23 of the Railroad Retirement Act of 1974);

(T) of the Small Business Administration, the office of that agency referred to as the "Office of Audits and Investigations";

(U) of the Veteran's Administration, the offices of that agency referred to as the "Office of Audits" and the "Office of Investigations"; and

(2) such other offices or agencies, of functions, powers, or duties thereof, as the head of the establishment involved may determine are properly related to the functions of the Office and would, if so transferred, further the purposes of this Act, except that there shall not be transferred to an Inspector General under paragraph (2) program operating responsibilities.

(b) The personnel, assets, liabilities, contracts, property, records, and unexpended balances of appropriations, authorizations, allocations, and other funds employed, held, used, arising from, available or to be made available, of any office or agency the functions, powers, and duties of which are transferred under subsection (a) are hereby transferred to the applicable Office of Inspector General.

(c) Personnel transferred pursuant to subsection (b) shall be transferred in accordance with applicable laws and regulations relating to the transfer of functions except that the classification and compensation of such personnel shall not be reduced for one year after such transfer.

(d) In any case where all the functions, powers, and duties of any office or agency are transferred pursuant to this subsection, such office or agency shall lapse. Any person who, on the effective date of this Act [Oct. 1, 1971], held a position compensated in accordance with the General Schedule, and who, without a break in service, is appointed in an Office of Inspector General to a position having duties comparable to those performed immediately preceding such appointment shall continue to be compensated in the new position at not less than the rate provided for the previous position, for the duration of service in the new position.

Sec. 10. CONFORMING AND TECHNICAL AMENDMENTS

[Section amended sections 5315 and 5316 of Title 5, Government Organization and Employees, and section 3522 of Title 42, The Public Health and Welfare, which amendments have been executed to text.]

Sec. 11. DEFINITIONS

As used in this Act-

(1) the term 'head of the establishment' means the Secretary of Agriculture, Commerce, Defense, Education, Energy, Health and Human Services, Housing and Urban Development, the Interior, Labor, State, Transportation, or the Treasury; the Attorney General; the Administrator of the Agency for International Development, Environmental Protection, General Services, National Aeronautics and Space, Small Business, or Veterans' Affairs; the Director of the Federal Emergency 
Management Agency, the Office of Personnel Management or the United States Information Agency; the Chairman of the Nuclear Regulatory Commission or the Railroad Retirement Board; as the case may be;

(2) the term 'establishment' means the Department of Agriculture, Commerce, Defense, Education, Energy, Health and Human Services, Housing and Urban Development, the Interior, Justice, Labor, State, Transportation, or the Treasury; the Agency for International Development, the Environmental Protection Agency, the Federal Emergency Management Agency, the General Services Administration, the National Aeronautics and Space Administration, the Nuclear Regulatory Commission, the Office of Personnel Management, the Railroad Retirement Board, the Small Business Administration, the United States Information Agency, or the Veterans' Administration; as the case may be;

(3) the term "Inspector General" means the Inspector General of an establishment;

(4) the term "Office" means the Office of Inspector General of an establishment; and

(5) the term "Federal agency" means an agency as defined in section 552(e) of title 5 (including an establishment as defined in paragraph (2)), United States Code, but shall not be construed to include the General Accounting Office.

Sec. 12. EFFECTIVE DATE

The [original] provisions of this Act and the amendments [to other laws] made by this Act [see section 10 of this Act] shall take effect October 1, 1978.

\section{PERTINENT PORTIONS OF INSPECTOR GENERAL ACT AMENDMENT \\ of 1988 which did not amend Inspector General Act of 1978.}

\section{UNIFORM SALARIES FOR INSPECTORS GENERAL.}

(a) UNIFORM SALARIES.-Section 5315 of title 5, United States Code, is amended by adding at the end thereof the following new paragraphs

"Inspector General, Department of Commerce.

"Inspector General, Department of the Interior.

"Inspector General, Department of Justice.

"Inspector General, Department of the Treasury.

"Inspector General, Agency for International Development.

"Inspector General, Environmental Protection Agency.

"Inspector General, Federal Emergency Management Agency.

"Inspector General, General Services Administrator.

"Inspector General, National Aeronautics and Space Administration.

"Inspector General, Nuclear Regulatory Commission.

"Inspector General, Office of Personnel Management.

"Inspector General, Railroad Retirement Board.

"Inspector General, Small Business Administration.". 


\section{APPROPRIATION ACCOUUNTS.}

Section 1105(a)(25) of title 31, United States code, is amended to read as follows:

(a) During the first 15 days of each regular session of Congress, the President shall submit a budget of the United States Government for the following fiscal year. Each budget shall include a budget message and summary and supporting information. The President shall include in each budget the following:

(25) a separate appropriation account for appropriations for each Office of Inspector General of an establishment defined under section 11(2) of the Inspector General Act of 1978.

\section{PAYMENT AUTHORITY SUBJECT TO APPROPRIATIONS.}

Any authority to make payments under this title (Inspector General Act Amendments) shall be effective only to such extent as provided in appropriations Acts.

\section{EFFECTIVE DATE.}

This title and the amendments made by this title shall take effect 180 days after the date of the enactment of this title, except that section 5(a)(6) through (12) of the Inspector General Act of 1978 (as amended by section 106(a) of this title) and section (5)(b)(1) through (4) of the Inspector General Act of 1978 (as amended by section 106(b) of this title) shall take effect 1 year after the date of the enactment of this title. 


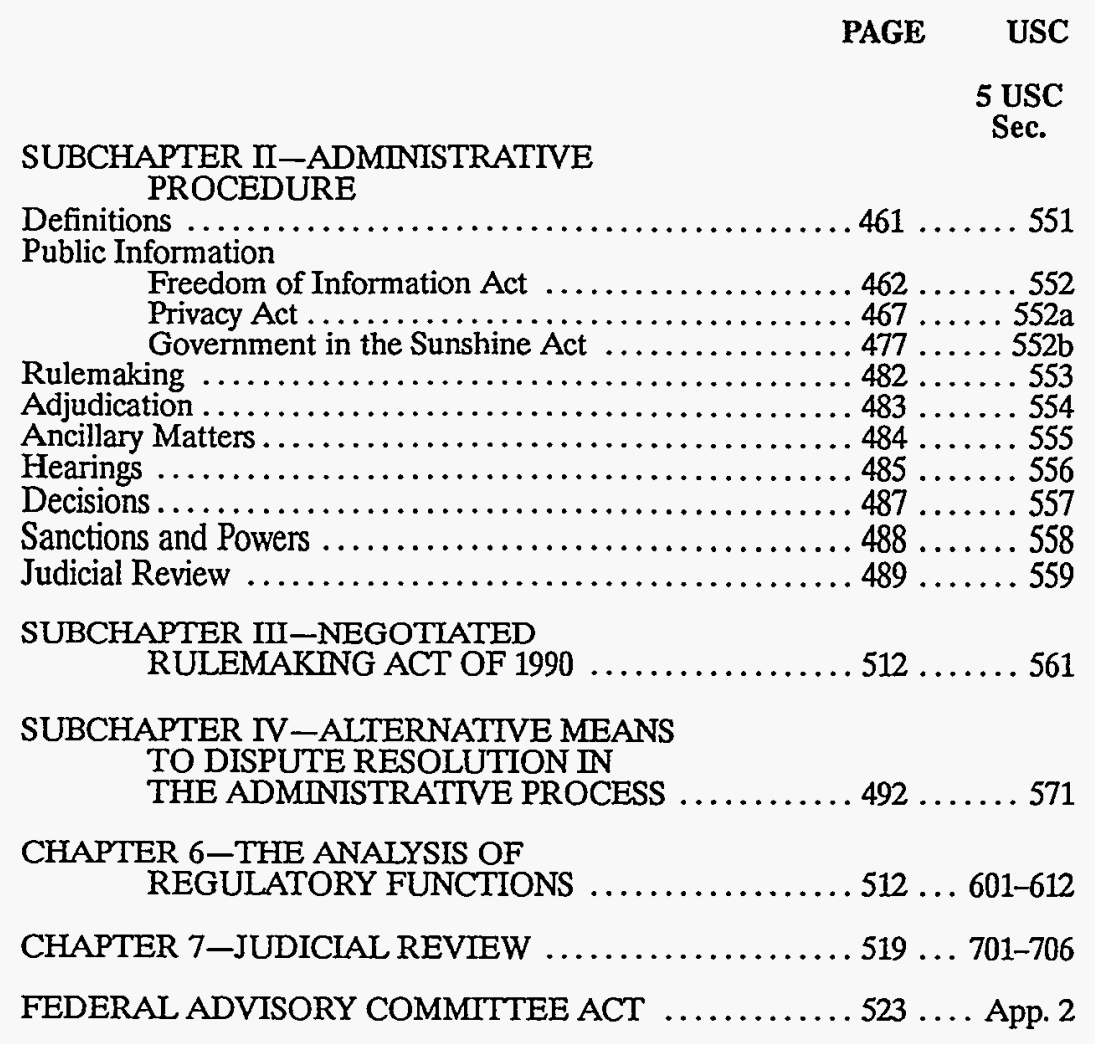




\section{SECTIONS OF TITLE 5 UNITED STATES CODE}

\section{SUBCHAPTER II-ADMINISTRATIVE PROCEDURES SECTIONS 551.559;}

Sec. 551. Definitions.

For the purpose of this subchapter-

(1) "agency" means each authority of the Government of the United States, whether or not it is within or subject to review by another agency, but does not include-

(A) the Congress;

(B) the courts of the United States;

(C) the governments of the territories or possessions of the United States;

(D) the Government of the District of Columbia;

or except as to the requirements of section 552 of this title

(E) agencies composed of representatives of the parties or of representatives of organizations of the parties to the disputes determined by them;

(F) courts martial and military commissions;

(G) military authority exercised in the field in time of war or in occupied territory; or

(H) functions conferred by sections $1738,1739,1743$, and 1744 of title 12; chapter 2 of title 41 ; subchapter $\Pi$ of chapter 471 of title 49; or sections ${ }^{1} 1884,1891-1902$, and former section 1641(b)(2), of title 50, appendix;

(2) "person" includes an individual, partnership, corporation, association, or public or private organization other than a agency;

(3) "party" includes a person or agency named or admitted as a party, or properly seeking and entitled as of right to be admitted as a party, in an agency proceeding, and a person or agency admitted by an agency as a party for limited purposes;

(4) "rule" means the whole or a part of an agency statement of general or particular applicability and future effect designed to implement, interpret, or prescribe law or policy or describing the organization, procedure, or practice requirements of an agency and includes the approval or prescription for the future of rates, wages, corporate or financial structures or reorganizations thereof, prices, facilities, appliances, services or allowances therefor or of valuations, costs, or accounting, or practices bearing on any of the foregoing;

(5) “rule making" means agency process for formulating, amending, or repealing a rule;

(6)"order" means the whole or part of a final disposition whether affirmative, negative, injunctive, or declaratory in form, of an agency in a matter other than rule making but including licensing;

(7) "adjudication" means agency process for the formulation of an order;

'PublicLaw 103-272 (108 Stat. 1373)struck"sections 1622" and added "subchapter II of chapter 471 of title 49, or sections." 
(8) "license" includes the whole or a part of an agency permit, certificate, approval, registration, charter, membership, statutory exemption or other form of permission;

(9) "licensing" includes agency process respecting the grant, renewal, denial, revocation, suspension, annulment, withdrawal, limitation, amendments, modification, or conditioning of a license;

(10) "sanction" includes the whole or a part of an agency-

(A) prohibition requirement, limitations, or other condition af-

fecting the freedom of a person;

(B) withholding of relief;

(C) imposition of penalty or fine;

(D) destruction, taking, seizure, or withholding of property;

(E) Assessment of damages, reimbursement, restitution, compensation, costs, charges, or fees;

(F) requirement, revocation, or suspension of a license; or

(G) taking other compulsory or restrictive action;

(11) "relief" includes the whole or a part of an agency-

(A) grant of money, assistance, license, authority, exemption, exception, privilege, or remedy;

(B) recognition of a claim, right, immunity, privilege, exemption, or exception,; or

(C) taking of other action on the application or petition of, and beneficial to, a person;

(12) "agency proceedings" means an agency process as defined by paragraphs (5), (7), and (9) of this section;

(13) "agency action" includes the whole or a part of an agency rule, order, license, sanction, relief, or the equivalent or denial thereof, or failure to act; and

(14) "ex parte communication" means an oral or written communication not on the public record with respect to which reasonable prior notice to all parties is not given, but it shall not include requests for status reports on any matter or proceeding covered by this subchapter; (Pub. L. 89-554, Sept. 6, 1966, 80 Stat. 381; amended Pub. L. 94-409, Sept 13, 1976, 90 Stat. 1247.)

Sec. 552. Public Information, Agency Rules, Opinions, Orders, Records, and Proceeding.

(a) Each agency shall make available to the public information as follows;

(1) Each agency shall separately state and currently publish in the Federal Register for the guidance of the public-

(A) descriptions of its central and field organization and the established places at which, the employees (and in the case of a uniformed service, the members) from whom, and the methods whereby, the public may obtain information, make submittals or requests, or obtain decisions;

(B) statements of the general course and method by which its functions are channeled and determined, including the nature and requirements of all formal and informal procedures available; 
(C) rules of procedure, descriptions of forms available or the places at which forms may be obtained, and instructions as to the scope and contents of all papers, reports, or examinations;

(D) substantive rules of general applicability adopted as authorized by law, and statements of general policy or interpretations of general applicability formulated and adopted by the agency; and

(E) each amendment, revision, or repeal of the foregoing.

Except to the extent that a person has actual and timely notice of the terms thereof, a person may not in any manner be required to resort to, or be adversely affected by, a matter required to be published in the Federal Register and not so published. For the purpose of this paragraph, matter reasonably available to the class of persons affected thereby is deemed published in the Federal Register when incorporated by reference therein with the approval of the Director of the Federal Register.

(2)Each agency, in accordance with published rules, shall make available for public inspection and copying-

(A) final opinions, including concurring and dissenting opinions, as well as orders, made in the adjudication of cases;

(B) those statements of policy and interpretations which have been adopted by the agency and are not published in the Federal Register; and

(C) administrative staff manuals and instructions to staff that affect a member of the public;

unless the materials are promptly published and copies offered for sale. To the extent required to prevent a clearly unwarranted invasion of personal privacy, and agency may delete identifying details when it make available or publishes an opinion, statement of policy, interpretation, or staff manual or instruction. However, in each case the justification for the deletion shall be explained fully in writing. Each agency shall also maintain and make available for public inspection and copying current indexes providing identifying information for the public as to any matter issued, adopted, or promulgated after July 4, 1967, and required by this paragraph tobe made available or published. Each agency shall promptly publish, quarterly or more frequently, and distribute (by sale or otherwise) copies of each index or supplements thereto unless it determines by order published in the Federal Register that the publications would be unnecessary and impracticable, in which case the agency shall nonetheless provide copies of such index on request at a cost not to exceed the direct cost of duplication. A final order, opinion, statement of policy interpretation, or staff manual or instruction that affects a member of the public may be relied on, used, or cited as precedent by an agency against a party other than an agency only if-

(i) it has been indexed and either made available published as provided by this paragraph; or

(ii) the party has actual and timely notice of the terms thereof.

(3) Except with respect to the records made available under paragraphs (1) and (2) of this subsection, each agency, upon any request 
for records which (A) reasonably describes such records and $(B)$ is made in accordance with published rules stating the time, place, fees (if any), and procedures to be followed, shall make the records promptly available to any person.

(4)(A) In order to carry out the provisions of this section, each agency shall promulgate regulations, pursuant to notice and receipt of public comments, specifying a uniform schedule of fees applicable to all constituent units of such agency. Such fees shall be limited to reasonable standard charges for document search and duplication and provide for recovery of only the direct costs of such search and duplication. Documents shall be furnished without charge or at a reduced charge where the agency determines that waiver or reduction of the fee is in the public interest because furnishing the information can be considered as primarily benefiting the general public.

(B) On complaint, the district court of the United States in the district in which the complainant resides, or has his principal place of business, or in which the agency records are situated, or in the District of Columbia, has jurisdiction to enjoin the agency from withholding agency records and to order the production of any agency records improperly withheld from the complainant. In such a case the court shall determine the matter de novo, and may examine the contents of such agency records in camera to determine whether such records or any part thereof shall be withheld under any of the exemptions set forth in subsection (b) of this section, and the burden is on the agency to sustain its action.

(C) Notwithstanding any other provision of law, the defendant shall serve an answer or otherwise plead to any complaint made under this subsection within thirty days after service upon the defendant of the pleading in which such complaint is made, unless the court otherwise directs for good cause shown.

(D) Repealed. Public Law 98-620, Title IV, § 402(2), Nov. 8, 1984, 98 Stat. 3357.

(E) The court may assess against the United States reasonable attorney fees and other litigation costs reasonably incurred in any case under this section in which the complainant has substantially prevailed.

(F) Whenever the court orders the production of any agency records improperly withheld from the complainant and assesses against the United States reasonable attomey fees and other litigation costs, and the court additionally issues a written finding that the circumstances surrounding the withholding raise questions whether agency personnel acting arbitrarily or capriciously with respect to the withholding, the Special Counsel shall promptly initiate a proceeding to determine whether disciplinary action is warranted against the officer or employee who was primarily responsible for the withholding. The Special Counsel, after investigation and consideration of the evidence submitted, shall submit his findings and recommendations to the administrative authority of the agency concerned and shall send copies of the findings and recommendations to the officer or employee of his representative. 
The administrative authority shall take the corrective action that the Special Counsel recommends.

(G) In the event of noncompliance with the order of the court, the district court may punish for contempt the responsible employee, and in the case of a uniformed service, the responsible member.

(5) Each agency having more than one member shall maintain and make available for public inspection a record of the final votes of each member in every agency proceeding.

(6)(A) Each agency, upon any request for records made under paragraph (1), (2), or (3) of this subsection shall-

(i) determine within ten days (excepting Saturdays, Sundays, and legal public holidays) after the receipt of any such request whether to comply with such request and shall immediately notify the person making such request of such determination and the reasons therefor, and of the right of such person to appeal to the head of the agency any adverse determination; and

(ii) make a determination with respect to any appeal within twenty days (excepting Saturdays, Sundays and legal public holidays) after the receipt of such appeal. If on appeal the denial of the request for records is in whole or in part upheld, the agency shall notify the person making such request of the provisions for judicial review of that determination under paragraph (4) of this subsection.

(B) In unusual circumstances as specified in this subparagraph, the time limits prescribed in either clause (i) or clause(ii) of subparagraph (A) may be extended by written notice to the person making such request settling forth the reasons for such extension and the date on which a determination is expected to be dispatched. No such notice shall specify a date that would result in an extension for more than ten working days. As used in this subparagraph, "unusual circumstances" means, but only to the extent reasonable necessary to the proper processing of the particular request-

(i) the need to search for and collect the requested records from field facilities or other establishment that are separate from the office processing the request;

(ii) the need to search for, collect, and appropriately examine a voluminous amount of separate and distinct records which are demanded in a single request; or

(iii) the need for consultation, which shall be conducted with all practicable speed, with another agency having a substantial interest in the determination of the request or among two or more components of the agency having substantial subject-matter interest therein.

(C) Any person making a request to any agency for records under paragraph (1), (2), or (3) of this subsection shall be deemed to have exhausted his administrative remedies with respect to such request if the agency fails to comply with the applicable time limit provisions of this paragraph. If the Government can show exceptional circumstances exist and that the agency is exercising due diligence 
in responding to the request, the court may retain jurisdiction and allow the agency additional time to complete its review of the records. Upon any determination by an agency to comply with a request for records, the records shall be made promptly available to such person making such request. Any notification of denial of any request for records under this subsection shall set forth the names and titles or positions of each person responsible for the denial of such request.

(b) This section does not apply to matters that are-

(1)(A) specifically authorized under criteria established by an Executive order to be kept secret in the interest of national defense or foreign policy and (B) are in fact properly classified pursuant to such Executive order;

(2) related solely to the internal personnel rules and practices of an agency;

(3) specifically exempted from disclosure by statute (other than section $552 \mathrm{~b}$ of this title), provided that such statute (A) requires that the matters be withheld from the public in such a manner as to leave no discretion on the issue, or (B) establishes particular criteria for withholding or refers to particular types of matters to be withheld;

(4) trade secrets and commercial or financial information obtained from a person and privileged or confidential;

(5) inter-agency or intra-agency memorandums or letters which would not be available by law to a party other than an agency in litigation with the agency;

(6) personnel and medical files and similar files the disclosure of which would constitute a clearly unwarranted invasion of personal privacy;

(7) investigatory records compiled for law enforcement purposes, but only to the extent that the production of such records would (A) interfere with enforcement proceedings, (B) deprive a person of a right to a fair trial or an impartial adjudication, (C) constitute an unwarranted invasion of personal privacy, (D) disclose the identity of a confidential source and, in the case of a record compiled by a criminal law enforcement authority in the course of a criminal investigation, or by an agency conducting a lawful national security intelligence investigation, confidential information furnished only by the confidential source, $(E)$ disclose investigative techniques and procedures, or (F) endanger the life or physical safety of law enforcement personnel;

(8) contained in or related to examination, operating, or condition reports prepared by, on behalf of, or for the use of an agency responsible for the regulation or supervision of financial institutions; or

(9) geological and geophysical information and data, including maps, concerning wells.

Any reasonably segregable portion of a record shall be provided to any person requesting such record after deletion of the portions which are exempt under this subsection. 
(c) This section does not authorize withholding of information or limit the availability of records to the public, except as specifically stated in this section. This section is not authority to withhold information from Congress.

(d) On or before March 1 of each calendar year, each agency shall submit a report covering the preceding calendar year to the Speaker of the House of Representatives and President of the Senate for referral to the appropriate committee of the Congress. The report shall include-

(1) the number of determinations made by such agency not to comply with requests for records made to such agency under subsection (a) and the reasons for each such determination;

(2) the number of appeals made by persons under subsection (a)(6), result of such appeals, and the reason for the action upon each appeal that results in a denial of information;

(3) the names and titles or positions of each person responsible for the denial of records requested under this section, and the number of instances of participation for each;

(4) the results of each proceeding conducted pursuant to subsection $(\mathrm{a})(4)(\mathrm{F})$, including a report of the disciplinary action taken against the officer or employee who was primarily responsible for improperly withholding records or an explanation of why disciplinary action was not taken;

(5) a copy of every rule made by such agency regarding this section;

(6) a copy of the fee schedule and the total amount of fees collected by the agency for making records available under this section; and

(7) such other information as indicates efforts to administer fully this section.

The Attorney General shall submit an annual report on or before March 1 of each calendar year which shall include for the prior calendar year a listing of the number of cases arising under this section, the exemption involved in each case, the disposition of such case, and the cost, fees, and penalties assessed under subsections $(a)(4)(E),(F)$ and $(G)$. Such report shall also include a description of the efforts undertaken by the Department of Justice to encourage agency compliance with this section.

(e) For purposes of this section, the term "agency" as defined in section 551(1) of this title includes any executive department, military department, Government corporation. Government controlled corporation, or other establishment in the executive branch of the Government (including the Executive Office of the President), or any independent regulatory agency. (Pub. L. 89-554, Sept. 6, 1966, 80 Stat. 383; amended Pub. L. 90-23, §1, June 6, 1967, 81 Stat. 54; Pub. L. 93-502, §§1-3, Nov. 21, 1974, 88 Stat. 1561-1564; Pub. L. 94-409, Sept. 13, 1976, 90 Stat. 1247; amended Pub. L. 95-454, Oct. 13, 1978, 92 Stat. 1225.)

Sec. 552a. Records Maintained On Individuals.

(a) DEFINITIONS.-For purposes of this section-

(1) the term "agency" means agency as defined in section 552(e) of this title; 
(2) the term "individual" means a citizen of the United States or an alien lawfully admitted for permanent residence;

(3) the term "maintain" includes maintain, collect, use, or disseminate;

(4) the term "record" means any item, collection, or grouping of information about an individual that is maintained by an agency, including, but not limited to, his education, financial transactions, medical history, and criminal or employment history and that contains his name, or the identifying number, symbol, or other identifying particular assigned to the individual, such as a finger or voice print or a photograph;

(5) the term "system of records" means a group of any records under the control of any agency from which information is retrieved by the name of the individual or by some identifying number, symbol, or other identifying particular assigned to the individual;

(6) the term "statistical record" means a record in a system of records maintained for statistical research or reporting purposes only and not used in whole or in part in making any determination about an identifiable individual, except as provided by section 8 of title 13; and

(7) the term "routine use" means, with respect to the disclosure of a record, the use of such record for a purpose which is compatible with the purpose for which it was collected.

(b) CONDITIONS OF DISCLOSURE-No agency shall disclose any record which is contained in a system of records by any means of communication to any person, or to another agency, except pursuant to a written request by, or with the prior written consent of, the individual to whom the record pertains, unless disclosure of the record would be-

(1) to those officers and employees of the agency which maintains the record who have a need for the record in the performance of their duties;

(2) required under section 552 of this title;

(3) for a routine us as defined in subsection (a)(7) of this section and described under subsection (e)(4)(D) of this section;

(4) to the Bureau of the Census for purposes of planning or carrying out a census or survey or related activity pursuant to the provisions of title13;

(5) to a recipient who has provided the agency with advance adequate written assurance that the record will be used solely as a statistical research or reporting record, and the record is to be transferred in a form that is not individually identifiable;

(6) to the National Archives of the United States as a record which has sufficient historical or other value to warrant its continued preservation by the United States Government, or for evaluation by the Administrator of General Services or his designee to determine whether the record has such value;

(7) to another agency or to an instrumentality of any governmental jurisdiction within or under the control of the United States for a civil or criminal law enforcement activity if the activity is authorized by law, and if the head of the agency or instrumentality has 
made a written request to the agency which maintains the record specifying the particular portion desired and law enforcement activity for which the record is sought;

(8) to a person pursuant to a showing of compelling circumstances affecting the health or safety of an individual if upon such disclosure notification is transmitted to the last known address of such individual;

(9) to either House of Congress, or, to the extent of matter within its jurisdiction, any committee or subcommittee thereof, any joint committee of Congress or subcommittee of any such joint committee;

(10) to the Comptroller General, or any of his authorized representatives, in the course of the performance of the duties of the General Accounting Office;

(11) pursuant to the order of a court of competent jurisdiction; or

(12) to a consumer reporting agency in accordance with section 3711(f) of title 31 .

(c) ACCOUNTING OF CERTAIN DISCLOSURES.-Each agency, with respect to each system of records under its control, shall-

(1) except for disclosures made under subsections (b)(1) or (b)(2) of this section, keep an accurate accounting of-

(A) the date, nature, and purpose of each disclosure of a record to any person or to another agency made under subsection (b) of this section; and

(B) the name and address of the person or agency to whom the disclosure is made;

(2) retain the accounting made under paragraph (1) of this subsection for at least five years or the life of the record, whichever is longer, after the disclosure for which the accounting is made;

(3) except for disclosures made under subsection (b)(7) of this section, make the accounting made under paragraph (1) of this subsection available to the individual named in the record at his request; and

(4) inform any person or other about any correction or notation of dispute made by the agency in accordance with subsection (d) of this section of any record that has been disclosed to the person or agency if an accounting of the disclosure was made.

(d) ACCESS TO RECORDS.-Each agency that maintains a system of records shall-

(1) upon request by any individual to gain access to his record or any information pertaining to him which is contained in the system, permit him and upon his request, a person of his own choosing to accompany him, to review the record and have a copy made of all or any portion thereof in a form comprehensible to him, except that the agency may require the individual to furnish a written statement authorizing discussion of that individual's record in the accompanying person's presence;

(2) permit the individual to request amendment of a record pertaining to him and- 
(A) not later than 10 days (excluding Saturdays, Sundays, and legal public holidays) after the date of receipt of such request, acknowledge in writing such receipt; and-

(B) promptly, either-

(i) make any correction of any portion thereof which the individual believes is not accurate, relevant, timely, or complete; or

(ii) inform the individual of its refusal to amend the record in accordance with his request, the reason for the refusal, the procedures established by the agency for the individual to request a review of that refusal by the head of the agency or an officer designated by the head of the agency, and the name and business address of that official;

(3) permit the individual who disagrees with the refusal of the agency to amend his record to request a review of such refusal, and not later than 30 days (excluding Saturdays, Sundays, and legal public holidays) from the date on which the individual requests such review, complete such review and make a final determination unless, for good cause shown, the head of the agency extends such 30-day period; and, if after his review, the reviewing official also refuses to amend the record in accordance with the request, permit the individual to file with the agency a concise statement setting forth the reasons for his disagreement with the refusal of the agency, and notify the individual of the provisions for judicial review of the reviewing official's determination under subsection $(\mathrm{g})(1)(\mathrm{A})$ of this section;

(4) in any disclosure, containing information about which the individual has filed a statement of disagreement, occurring after the filing of the statement under paragraph (3) of this subsection, clearly note any portion of the record which is disputed and provide copies of the statement and, if the agency deems it appropriate, copies of a concise statement of the reasons of the agency for not making the amendments requested, to persons or other agencies to whom the disputed record has been disclosed; and

(5) nothing in this section shall allow an individual access to any information compiled in reasonable anticipation of a civil action or proceeding.

(e) AGENCY REQUIREMENTS.-Each agency that maintains a system of records shall-

(1) maintain in its records only such information about an individual as is relevant and necessary to accomplish a purpose of the agency required to be accomplished by statute or by executive order of the President;

(2) collect information to the greatest extent practicable directly from the subject individual when the information may result in adverse determinations about an individual's rights, benefits, and privileges under Federal programs;

(3) inform each individual whom it asks to supply information, on the form which it uses to collect the information or on a separate form that can be retained by the individual- 
(A) the authority (whether granted by statue, or by executive order of the President) which authorizes the solicitation of the information and whether disclosure of such information is mandatory or voluntary;

(B) the principal purpose or purposes for which the information is intended to be used;

(C) the routine uses which may be made of the information, as published pursuant to paragraph (4)(D) of this subsection; and

(D) the effects on him, if any, of not providing all or any part of the requested information;

(4) subject to the provisions of paragraph (11) of this subsection, publish in the Federal Register upon establishment or revision a notice of the existence and character of the system of records, which notice shall include-

(A) the name and location of the system;

(B) the categories of individuals on whom records are maintained in the system;

(C) the categories of records maintained in the system;

(D) each routine use of the records contained in the system, including the categories of users and the purpose of such use;

(E) the policies and practices of the agency regarding storage, retrievability, access controls, retention, and disposal of the records;

(F) the title and business address of the agency official who is responsible for the system of records;

$(G)$ the agency procedures whereby an individual can be notified at his request if the system of records contains a record pertaining to him;

$(\mathrm{H})$ the agency procedures whereby an individual can be notified at his request how he can gain access to any record pertaining to him contained in the system of records, and how he can contest its content; and

(I) the categories of sources of records in the system;

(5) maintain all records which are used by the agency in making any determination about any individual with such accuracy, relevance, timeless, and completeness as is reasonably necessary to assure fairness to the individual in the determination;

(6) prior to disseminating any record about an individual to any person other than an agency, unless the dissemination is made pursuant to subsection (b)(2) of this section, make reasonable efforts to assure that such records are accurate, complete, timely, and relevant for agency purposes;

(7) maintain no record describing how any individual exercises rights guaranteed by the First Amendment unless expressly authorized by statute or by the individual about whom the record is maintained or unless pertinent to and within the scope of an authorized law enforcement activity;

(8) make reasonable efforts to serve notice on an individual when any record on such individual is made available to any person under compulsory legal process when such process becomes a matter of public record; 
(9) establish rules of conduct for persons involved in the design, development, operation, or maintenance of any system of records, or in maintaining any record, and instruct each such person with respect to such rules and the requirements of this section, including any other rules and procedures adopted pursuant to this section and the penalties for noncompliance;

(10) establish appropriate administrative, technical, and physical safeguards to insure the security and confidentiality of records and to protect against any anticipated threats or hazards to their security or integrity which could result in substantial harm, embarrassment, inconvenience, or unfairness to any individual on whom information is maintained; and

(11) at least 30 days prior to publication of information under paragraph (4)(D) of this subsection, publish in the Federal Register notice of any new use or intended use of the information in the system, and provide an opportunity for interested persons to submit written data, views, or arguments to the agency.

(f) AGENCY RULES. - In order to carry out the provisions of this section, each agency that maintains a system of records shall promulgate rules, in accordance with the requirement (including general notice) of section 553 of this title, which shall-

(1) establish procedures whereby an individual can be notified in response to his request if any system of records named by the individual contains a record pertaining to him;

(2) define reasonable times, places, and requirements for identifying an individual who requests his record or information pertaining to him before the agency shall make the record or information available to the individual;

(3) establish procedures for the disclosure to an individual upon his request of his record or information pertaining to him, including special procedures, if deemed necessary, for the disclosure to an individual of medical records, including psychological records pertaining to him;

(4) establish procedures for reviewing a request from an individual concerning the amendment to any record or information pertaining to the individual, for making a determination on the request, for an appeal within the agency of an initial adverse agency determination, and for whatever additional means may be necessary for each individual to be able to exercise fully his rights under this section; and

(5) establish fees to be charged, if any, to any individual for making copies of his record, excluding the cost of any search for and review of the record.

The Office of the Federal Register shall annually compile and publish the rules promulgated under this subsection and agency notices published under subsection (e)(4) of this section in a form available to the public at low cost.

(g)(1) CIVIL REMEDIES. - Whenever any agency-

(A) makes a determination under subsection (a)(3) of this section not to amend an individual's record in accordance with his request, or fails to make such review in conformity with that subsection; 
(B) refuses to comply with an individual request under subsection (d)(1) of this section;

(C) fails to maintain any record concerning any individual with such accuracy, relevance, timeliness, and completeness as is necessary to assure fairness in any determination relating to the qualification, character, rights, or opportunities of, or benefits to the individual that may be made on the basis of such record, and consequently a determination is made which is adverse to the individual; or

(D) fails to comply with any other provisions of this section, or any rule promulgated thereunder, in such a way as to have an adverse effect on an individual,

the individual may bring a civil action against the agency, and the district courts of the United States shall have jurisdiction in the matters under the provisions of this subsection.

(2)(A) In any suit brought under the provisions of subsection (g)(1)(A) of this section, the court may order the agency to amend the individual's record in accordance with his request or in such other way as the court may direct. In such case the court shall determine the matter de novo.

(B) The court may assess against the United States reasonable attorney fees and other litigation costs reasonably incurred in any case under this paragraph in which the complainant has substantially prevailed.

(3)(A) In any suit brought under the provisions of subsection (g)(1)(B) of this section, the court may enjoin the agency from withholding the records and order the production to the complainant of any agency records improperly withheld from him. In such a case the court shall determine the matter de novo, and may examine the contents of any agency records in camera to determine whether the records or any portion there of may be withheld under any of the exemptions set forth in subsection (k) of this section, and the burden is on the agency to sustain its action.

(B) The court may assess against the United States reasonable attorney fees and other litigation costs reasonably incurred in any case under this paragraph in which the complainant has substantially prevailed.

(4) In any suit brought under the provisions of subsection $(\mathrm{g})(1)(\mathrm{C})$ or (D) of this section in which the court determines that the agency acted in a manner which was intentional or willful, the United States shall be liable to the individual in an amount equal to the sum of-

(A) actual damages sustained by the individual as a result of the refusal or failure, but in no case shall a person entitled to recovery receive less than the sum of $\$ 1,000$; and

(B) the costs of the action together with reasonable attorney fees as determined by the court.

(5) An action to enforce any liability created under this section may be brought in the district court of the United States in the district in which the complainant resides, or has his principal place of business, or in which the agency records are situated, or in the District of Columbia, without regard to the amount in controversy, within two years from the date on which the cause of action arises, except that where an agency has materially and willfully misrepresented any information required under this section to be disclosed to an individual and the information so mis- 
represented is material to establishment of the liability of the agency to the individual under this section, the action may be brought at any time within two years after discovery by the individual of the misrepresentation. Nothing in this section shall be construed to authorize any civil action by reason of any injury sustained as the result of a disclosure of a record prior to September 27, 1975.

(h) RIGHTS OF LEGAL GUARDIANS.-For the purpose of this section, the parent of any minor, or the legal guardian of any individual who has been declared to be incompetent due to physical or mental incapacity or age by a court of competent jurisdiction, may act on behalf of the individual.

(i)(1) CRIMINAL PENALTIES. - Any officer or employee of an agency, who by virtue of his employment or official position, has possession of, or access to, agency records which contain individually identifiable information the disclosure of which is prohibited by this section or by rules or regulations established thereunder, and who knowing that disclosure of the specific material is so prohibited, willfully discloses the material in any manner to any person or agency not entitled to receive it, shall be guilty of a misdemeanor and fined not more than $\$ 5,000$.

(2) Any officer or employee of any agency who willfully maintains a system of records without meeting the notice requirements of subsection (e)(4) of this section shall be guilty of a misdemeanor or fined not more than $\$ 5,000$.

(3) Any person who knowingly and willfully requests or obtains any record concerning an individual from an agency under false pretenses shall be guilty of a misdemeanor and fined not more than $\$ 5,000$.

(j) GENERAL EXEMPTIONS. - The head of any agency may promulgate rules, in accordance with the requirements (including general notice) of sections 553 (b) (1), (2) and (3), (c), and (e) of this title, to exempt any system of records within the agency from any part of this section except subsections (b), (c) (1) and (2), (e) (4) (A) through (F), (e) (6), (7), (9), (10) and (11), and (i) if the system of records is-

(1) maintained by the Central Intelligence Agency; or

(2) maintained by an agency or component thereof which performs as its principal function any activity pertaining to the enforcement of criminal laws, including police efforts to prevent, control, or reduce crime or to apprehend criminals, and the activities of prosecutors, courts, correctional, probation, pardon, or parole authorities, and which consists of $(\mathrm{A})$ information compiled for the purpose of identifying individual criminal offenders and alleged offenders and consisting only of identifying data and notations of arrests, the nature and disposition of criminal charges, sentencing, confinement, release, and parole and probation status; (B) information compiled for the purpose of a criminal investigation, including reports of informants and investigators, and associated with an identifiable individual; or (C) reports identifiable to an individual compiled at any stage of the process of enforcement of the criminal laws from arrest or indictment through release from supervision.

At the time rules are adopted under this subsection, the agency shall include in the statement required under section 553(c) of this title, the rea- 
sons why the system of records is to be exempted from a provision of this section.

(k) SPECIFIC EXEMPTIONS.-The head of any agency may promulgate rules, in accordance with the requirements (including general notice) of sections 553(b) (1), (2), and (3), (c), and (e) of this title, to exempt any system of records within the agency from subsections (c) (3), (d), (e) $(1),(e)(4)(G),(H)$, and (I) and (f) of this section if the system of records is-

(1) subject to the provisions of section 552(b) (1) of this title;

(2) investigatory material compiled for law enforcement purposes, other than material within the scope of subsection (j)(2) of this section: Provided, however, That if any individual is denied any right, privilege, or benefit that he would otherwise be entitled by Federal law, or for which he would otherwise be eligible, as a result of the maintenance of such material, such material shall be provided to such individual, except to the extent that the disclosure of such material would reveal the identity of a source who furnished information to the Government under an express promise that the identity of the source would be held in confidence, or, prior to the effective date of this section, under an implied promise that the identity of the source would be held in confidence;

(3) maintained in connection with providing protective services to the President of the United States or other individuals pursuant to section 3056 of title 18;

(4) required by statute to be maintained and used solely as statistical records;

(5) investigatory material compiled solely for the purpose of determination suitability, eligibility, or qualifications for Federal civilian employment, military service, Federal contracts, or access to classified information, but only to the extent that the disclosure of such material would reveal the identity of a source who furnished information to the Government under an express promise that the identity of the source would be held in confidence, or, prior to the effective date of this section, under an implied promise that the identity of the source would be held in confidence;

(6) testing or examination material used solely to determine individual qualifications for appointment or promotion in the Federal service the disclosure of which would compromise the objectivity or fairness of the testing or examination process; or

(7) evaluation material used to determine potential for promotion in the armed services, but only to the extent that the disclosure of such material would reveal the identity of a source who furnished information to the Government under an express promise that the identity of the source would be held in confidence, or, prior to the effective date of this section, under an implied promise that the identity of the source would be held in confidence.

At the time rules are adopted under this subsection, the agency shall include in the statement required under section 553(c) of this title the reasons why the system of records is to be exempted from a provision of this section. 
(1)(1) ARCHIVAL RECORDS.-Each agency record which is accepted by the Administrator of General Services for storage, processing, and servicing in accordance with section 3103 of title 44 shall, for the purposes of this section, be considered to be maintained by the agency which deposited the record and shall be subject to the provisions of this section. The Administrator of General Services shall not disclose the record except to the agency which maintains the record, or under rules established by that agency which are not inconsistent with the provisions of this section.

(2) Each agency record pertaining to an identifiable individual which was transferred to the National Archives of the United States as a record which has sufficient historical or other value to warrant its continued preservation by the United States Government, prior to the effective date of this section, shall, for the purposes of this section, be considered to be maintained by the National Archives and shall not be subject to the provisions of this section, except that a statement generally describing such records (modeled after the requirement relating to records subject to subsections (e)(4)(A) through (G) of this section) shall be published in the Federal Register.

(3) Each agency record pertaining to an identifiable individual which is transferred to the National Archives of the United States as a record which has sufficient historical or other value to warrant its continued preservation by the United States Government, on or after the effective date of this section, shall, for the purposes of this section, be considered to be maintained by the National Archives and shall be exempt from the requirements of this section except subsections (e)(4)(A) through(G) and $(e)(9)$ of this section.

$(m)(1)$ GOVERNMENT CONTRACTORS. - When an agency provides by a contract for the operation by or on behalf of the agency of a system of records to accomplish an agency function, the agency shall, consistent with its authority, cause the requirements of this section to be applied to such system. For purposes of subsection (i) of this section any such contractor and any employee of such contractor, if such contract is agreed to on or after the effective date of this section, shall be considered to be an employee of an agency.

(2) A consumer reporting agency to which a record is disclosed under section 371(f) of title 31 shall not be considered a contractor for the purposes of this section,

(n) MAILING LISTS.-An individual's name and address may not be sold or rented by an agency unless such action is specifically authorized by law. This provision shall not be construed to require the withholding of names and addresses otherwise permitted to be made public.

(o) REPORTING NEW SYSTEM.-Each agency shall provide adequate advance notice to Congress and the Office of Management and Budget of any proposal to establish or alter any system of records in order to permit an evaluation of the probable or potential effect to such proposal on the privacy and other personal or property rights of individuals or the disclosure of information relating to such individuals, and its effect on the preservation of the constitutional principles of federalism and separation of powers. 
(p) ANNUAL REPORT.-The President shall annually submit to the Speaker of the House of Representatives and the President pro tempore of the Senate a report-

(1) describing the actions of the Director of the Office of Management and Budget pursuant to section 6 of the Privacy Act of 1974 during the preceding year;

(2) describing the exercise of individual rights of access and amendment under this section during such year;

(3) identifying changes in or additions to systems of record;

(4) containing such other information concerning administration of this section as may be necessary or useful to the Congress in reviewing the effectiveness of this section in carrying out the purposes of the Privacy Act of 1974.

(q) EFFORT OF OTHER LAWS.-No agency shall rely on any exemption contained in section 552 of this title to with hold from an individual any record which is otherwise accessible to such individual under the provisions of this section. (Pub. L. 93-479, Sec. 3, Dec. 31, 1974, 88 Stat. 1897, amended Pub. L. 94-183, Sec. 2(2), Dec. 31, 1975, 89 Stat.1057; Pub. L. 97-365, OCT. 25, 1982, 96 STAT. 1749; PUB. L. 97-452, Jan. 3, 1983, 96 Stat. 2478; Pub. L. 97-375, Dec. 21, 1982, 96 Stat. 1821.)

Sec. 552b. Open Meetings.

(a) For purposes of this section-

(1) the term "agency" means any agency, as defined in section 552(e) of this title, headed by a collegial body composed of two or more individual members, a majority of whom are appointed to such position by the President with the advice and consent of the Senate, and any subdivision thereof authorized to act on behalf of the agency;

(2) the term "meeting" means the deliberations of at least the number of individual agency members required to take action on behalf of the agency where such deliberations determine or result in the joint conduct or disposition of official agency business, but does not include deliberation required or permitted by subsection (d) or (e); and

(3) the term "members" means an individual who belongs to a collegial body heading an agency.

(b) Members shall not jointly conduct or dispose of agency business other than in accordance with this section. Except as provided in subsection (c), every portion of every meeting of an agency shall be open to public observation.

(c) Except in a case where the agency finds that the public interest requires otherwise, the second sentence of subsection (b) shall not apply any portion of any agency meeting, and the requirements of subsections (d) and (e) shall not apply to any information pertaining to such meeting otherwise required by this section to be disclosed to the public, where the agency properly determines that such portion or portions of its meeting or the disclosure of such information is likely to-

(1) disclose matters that are (A) specifically authorized under criteria established by an Executive Order to be kept secret in the in- 
terest of national defense or foreign policy and $(B)$ in fact properly classified pursuant to such Executive Order;

(2) relate solely to the internal personnel rules an practices of an agency;

(3) disclose matters specifically exempted from disclosure by statute (other than section 552, of this title), provided that such statute (A) requires that the matters be withheld from the public in such a manner as to leave no discretion on the issue, or

(B) establishes particular criteria for withholding or refers to particular types of matters to be withheld;

(4) disclose trade secrets and commercial or financial information obtained from a person and privileged or confidential;

(5) involve accusing any person of a crime, or formally censuring any person;

(6) disclose information of a personal nature where disclosure would constitute a clearly unwarranted invasion of personal privacy;

(7) disclose investigatory records compiled for law enforcement purposes, or information which if written would be contained in such records, but only to the extent that the production of such records or information would (A) interfere with enforcement proceedings, (B) deprive a person of a right to a fair trial or an impartial adjudication, (C) constitute an unwarranted invasion of personal privacy, (D) disclose the identity of a confidential source and, in the case of a record compiled by criminal law enforcement authority in the course of a criminal investigation, or by an agency conducting a lawful national security intelligence investigation, confidential information furnished only by the confidential source, (E) disclose investigative techniques and procedures, or $(F)$ endanger the life or physical safety of law enforcement personnel;

(8) disclose information contained in or related to examination, operating, or condition reports prepared by, on behalf of, or for the use of an agency responsible for the regulation or supervision of financial institutions;

(9) disclose information the premature disclosure of which would-

(A) in the case of an agency which regulates currencies, securities, commodities, or financial institutions, be likely to (i) lead to significant financial speculation in currencies, securities, or commodities, or (ii) significantly endanger the stability of any financial institution; or

(B) in the case of any agency, be likely to significantly frustrate implementation of a proposed agency action,

except that subparagraph (B) shall not apply in any instance where the agency has already disclosed to the public the content or nature of its proposed action, or where the agency is required by law to make such disclosure on its own initiative prior to taking final agency action on such proposal; or

(10) specifically concern the agency's issuance of a subpena, or the agency's participation in a civil action or proceeding, an action in a foreign court or internecine tribunal, or an arbitration, or the 
initiation, conduct, or disposition by the agency of a particular case of formal agency adjudication pursuant to the procedures in section 554 of this title or otherwise involving a determination on the record after opportunity for a hearing.

(d)(1) Action under subsection (c) shall be taken only when a majority of the entire membership of the agency (as defined in subsection (a)(1)) votes to take such action. A separate vote of the agency members shall be taken with respect to each agency meeting a portion or portions of which are proposed to be closed to the public pursuant to subsection (c), or with respect to any information which is proposed to be withheld under subsection (c). A single vote may be taken with respect to a series of meetings, a portion or portions of which are proposed to be closed to the public, or with respect to any information concerning such series of meetings, so long as each meeting in such series involves the same particular matters and is scheduled to be held no more than thirty days after the initial meeting in such series. The vote of each agency member participating in such vote shall be recorded and no proxies shall be allowed.

(2) Whenever any person whose interests may be directly affected by a portion of a meeting requests that the agency close such portion to the public for any of the reasons referred to in paragraph (5), (6), or (7) of subsection (c), the agency, upon request of any one of its members, shall vote by recorded vote whether to close such meeting.

(3) Within one day of any vote taken pursuant to paragraph (1) or (2), the agency shall make publicly available a written copy of such vote reflecting the vote of each member on the question. If a portion of a meeting is to be closed to the public, the agency shall, within one day of the vote taken pursuant to paragraph (1) or (2) of this subsection, make publicly available a full written explanation of its action closing the portion together with a list of all persons expected to attend the meeting and their affiliation.

(4) Any agency, a majority of whose meetings may properly be closed to the public pursuant to paragraph (4), (8), (9)(A), or (10) of subsection (c), or any combination thereof, may provide by regulation for the closing of such meetings or portions thereof in the event that a majority of the members of the agency votes by recorded vote at the beginning of such meeting, or portion thereof, to close the exempt portion or portions of the meeting, and a copy of such vote, reflecting the vote of each member on the question, is made available to the public. The provisions of paragraphs (1), (2), and (3) of this subsection and subsections (e) shall not apply to any portion of a meeting to which such regulations apply: Provided, That the agency shall, except to the extent that such information is exempt from disclosure under the provisions of subsection (c), provide the public with public announcement of the time, place, and subject matter of the meeting and of each portion thereof at the earliest practicable time.

(e)(1) In the case of each meeting, the agency shall make public announcement, at least one week before the meeting, of the time, place, and subject matter of the meeting, whether it is to be open or closed to the public, and the name and phone number of the official designated by the agency to respond to requests for information about the meeting. Such announcement shall be made unless a majority of the members of 
the agency determines by a recorded vote that agency business requires that such meeting be called at an earlier date, in which case the agency shall make public announcement of the time, place, and subject matter of such meeting, and whether open or closed to the public at the earliest practicable time.

(2) The time or place of a meeting maybe changed following the public announcement required by paragraph (1) only if the agency publicly announces such change at the earliest practicable time. The subject matter of a meeting, or the determination of the agency to open or close a meeting, or portion of a meeting, to the public, may be changed following the public announcement required by this subsection only if (A) a majority of the entire membership of the agency determines by a recorded vote that agency business so requires and that no earlier announcement of the chance was possible, and (B) the agency publicly announces such change and the vote of each member upon such change at the earliest practicable time.

(3) Immediately following each public announcement required by this subsection, notice of the time, place, and subject matter of a meeting, whether the meeting is open or closed, any change in one of the preceding, and the name and phone number of the official designated by the agency to respond to requests for information about the meeting, shall also be submitted for publication in the Federal Register.

(f)(1) For every meeting closed pursuant to paragraphs (1) through (10) of subsection (c), the General Counsel or chief legal officer of the agency shall publicly certify that, in his or her opinion, the meeting may be closed to the public and shall state each relevant exemptive provision. A copy of such certification, together with a statement from the presiding officer of the meeting setting forth the time and place of the meeting, and the persons present, shall be retained by the agency. The agency shall maintain a complete transcript or electronic recording adequate to record fully the proceedings of each meeting, or portion of a meeting, closed to the public, except that in the case of a meeting, or portion of a meeting, closed to the public pursuant to paragraph (8), (9)(A), or (10) of subsection (c), the agency shall maintain either such a transcript or recording, or a set of minutes. Such minutes shall fully and clearly describe all matters discussed and shall provide a full and accurate summary of any actions taken, and the reasons therefor, including a description of each of the views expressed on any item and the record of any rollcall vote (reflecting the vote of each member on the question). All documents considered in connection with any action shall be identified in such minutes.

(2) The agency shall make promptly available to the public, in a place easily accessible to the public, the transcript, electronic recording, or minutes (as required by paragraph (1)) of the discussion of any item on the agenda, or of any item of the testimony of any witness received at the meeting, except for such item or items of such discussion or testimony as the agency determines to contain information which may be withheld under subsection (c). Copies of such transcript, or minutes, or a transcription of such recording disclosing the identity of each speaker, shall be furnished to any person at the actual cost of duplication or transcription. The agency shall maintain a complete verbatim copy of the tran- 
script, a complete copy of the minutes, or a complete electronic recording of each meeting, or portion of a meeting, closed to the public, for a period of at least two years after such meeting, or until one year after the conclusion of any agency proceeding with respect to which the meeting or portion was held, whichever occurs later.

(g) Each agency subject to the requirements of this section shall, within 180 days after the date of enactment of this section, following consultation with the Office of the Chairman of the Administrative Conference of the United States and published notice in the Federal Register of at least thirty days and an opportunity for written comments by any person, promulgate regulations to implement the requirements of subsections (b) through ( $f$ ) of this section. Any person may bring a proceeding in the United States District Court for the District of Columbia to require an agency to promulgate such regulations if such agency has not promulgated such regulations within the time period specified herein. Subject to any limitations of time provided by law, any person may bring a proceeding in the United States Court of Appeals for the District of Columbia to set aside agency regulations issued pursuant to this subsection that are not in accord with the requirements of subsections (b) through ( $f$ ) of this section and to require the promulgation of regulations that are in accord with such subsections.

(h) (1) The district courts of the United States shall have jurisdiction to enforce the requirements of subsections (b) through ( $f$ ) of this section by declaratory judgment, injunctive relief, or other relief as may be appropriate. Such actions may be brought by any person against an agency prior to, or within sixty days after, the meeting out of which the violation of this section arises, except that if public announcement of such meeting is not initially provided by the agency in accordance with the requirements of this section, such action may be instituted pursuant to this section at any time prior to sixty days after any public announcement of such meeting. Such actions may be brought in the district court of the United States for the district in which the agency meeting is held or in which the agency in question has its headquarters, or in the District Court for the District of Columbia. In such actions a defendant shall serve his answer within thirty days after the service of the complaint. The burden is on the defendant to sustain his action. In deciding such cases the court may examine in camera any portion of the transcript, electronic recording, or minutes of a meeting closed to the public, and may take such additional evidence as it deems necessary. The court, having due regard for orderly administration and the public interest, as well as the interests of the parties, may grant such equitable relief as it deems appropriate, including granting an injunction against future violations of this section or ordering the agency to make available to the public such portion of the transcript, recording, or minutes of a meeting as is not authorized to be withheld under subsection (c) of this section.

(2) Any Federal court otherwise authorized by law to review agency action may, at the application of any person properly participating in the proceeding pursuant to other applicable law, inquire into violations by the agency of the requirements of this section and afford such relief as it deems appropriate. Nothing in this section authorizes any Federal court having jurisdiction solely on the basis of paragraph (1) to set aside, en- 
join, or invalidate any agency action (other than an action to close a meeting or to withhold information under this section) taken or discussed at any agency meeting out of which the violation of this section arose.

(i) The court may assess against any party reasonable attorney fees and other litigation costs reasonably incurred by any other party who substantially prevails in any action brought in accordance with the provisions of subsections (g) or (h) of this section, except that costs may be assessed against the plaintiff only where the court finds that the suit was initiated by the plaintiff primarily for frivolous or dilatory purposes. In the case of assessment of costs against an agency, the costs may be assessed by the court against the United States.

(j) Each agency subject to the requirements of this section shall annually report to Congress regarding its compliance with such requirements, including a tabulation of the total number of agency meetings open to the public, the total number of meetings closed to the public, the reasons for closing such meetings, and a description of any litigation brought against the agency under this section, including any costs assessed against the agency in such litigation (whether or not paid by the agency).

(k) Nothing herein expands or limits the present rights of any person under section 552 of this title, except that the exemptions set forth in subsection (c) of this section shall govern in the case of any request made pursuant to section 552 to copy or inspect the transcripts, recordings, or minutes described in subsection (f) of this section. The requirements of chapter 33 of title 44, United States Code, shall not apply to the transcripts, recordings, and minutes described in subsection ( $f$ ) of this section.

(1) This section does not constitute authority to withhold any information from Congress, and does not authorize the closing of any agency meeting or portion thereof required by any other provision of law to be open.

(m) Nothing in this section authorizes any agency to withhold from any individual any record, including transcripts, recordings, or minutes required by this section, which is otherwise accessible to such individual under section 552a of this title. (Pub. L. 94-409, Sec. 3(a), Sept. 13, 1976, 90 Stat. 1241.)

Sec. 553. Rulemaking.

(a) This section applies, according to the provisions thereof, except to the extent that there is involved-

(1) a military or foreign affairs function of the United States; or

(2) a matter relating to agency management or personnel or to public property, loans, grants, benefits, or contracts.

(b) General notice of proposed rule making shall be published in the Federal Register, unless persons subject thereto are named and either personally served or otherwise have actual notice thereof in accordance with law. The notice shall include-

(1) a statement of the time, place, and nature of public rule making proceedings; 
(2) reference to the legal authority under which the rule is proposed; and

(3) either the terms or substance of the proposed rule or a description of the subjects and issues involved.

Except when notice or hearing is required by statute, this subsection does not apply-

(A) to interpretative rules, general statements of policy, or rules of agency organization, procedure, or practice; or

(B) when the agency for good cause finds (and incorporates the finding and a brief statement of reasons therefor in the rules issued) that notice and public procedure thereon are impracticable, unnecessary, or contrary to the public interest.

(c) After notice required by this section, the agency shall give interested persons an opportunity to participate in the rule making through submission of written data, views, or arguments with or without opportunity for oral presentation. After consideration of the relevant matter presented, the agency shall incorporate in the rules adopted a concise general statement of their basis and purpose. When rules are required by statute to be made on the record after opportunity for an agency hearing, sections 556 and 557 of this title apply instead of this subsection.

(d) The required publication or service of a substantive rule shall be made not less than 30 days before its effective date, except-

(1) a substantive rule which grants or recognizes an exemption or relieves a restriction;

(2) interpretative rules and statements of policy; or

(3) as otherwise provided by the agency for good cause found and published with the rule.

(e) Each agency shall give an interested person the right to petition for the issuance, amendment, or repeal of a rule. (Pub. L. 89-554, Sept. 6, 1966, 80 Stat. 383.)

Sec. 554. Adjudications

(a) This section applies, according to the provisions thereof, in every case of adjudication required by statute to be determined on the record after opportunity for an agency hearing, except to the extent that there is involved-

(1) a matter subject to a subsequent trial of the law and the facts de novo in a court;

(2) the selection or tenure of an employee, except an administrative law judge appointed under section 3105 of this title;

(3) proceedings in which decisions rest solely on inspections, tests, or elections;

(4) the conduct of military or foreign affairs functions;

(5) cases in which an agency is acting as an agent for a court; or

(6) the certification of worker representatives.

(b) Persons entitled to notice of an agency hearing shall be timely informed of-

(1) the time, place, and nature of the hearing;

(2) the legal authority and jurisdiction under which the hearing is

to be held; and

(3) the matters of fact and law asserted. 
When private persons are the moving parties, other parties to the proceeding shall give prompt notice of issues controverted in fact or law; and in other instances agencies may by rule require responsive pleading. In fixing the time and place for hearings, due regard shall be had for the convenience and necessity of the parties or their representatives.

(c) The agency shall give all interested parties opportunity for-

(1) the submission and consideration of facts, arguments, offers of settlement, or proposals of adjustment when time, the nature of the proceeding, and the public interest permit; and

(2) to the extent that the parties are unable so to determine a controversy by consent, hearing and decision on notice and in accordance with sections 556 and 557 of this title.

(d) The employee who presides at the reception of evidence pursuant to section 556 of this title shall make the recommended decision or initial decision required by section 557 of this title, unless he becomes unable to the agency. Except to the extent required for the disposition of ex parte matters as authorized by law, such an employee may not-

(1) consult a person or party on a fact in issue, unless on notice and opportunity for all parties to participate; or

(2) be responsible to or subject to the supervision or direction of an employee or agent engaged in the performance of investigative or prosecuting functions for an agency.

An employee or agent engaged in the performance of investigative or prosecuting functions for an agency in a case may not, in that or a factually related case, participate or advise in the decision, recommended decision, or agency review pursuant to section 557 of this title, except as witness or counsel in public proceedings. This subsection does not apply-

(A) in determining applications for initial licenses;

(B) to proceedings involving the validity or application of rates,

facilities, or practices of public utilities or carriers; or

(C) to the agency or a member or members of the body comprising the agency.

(e) The agency, with like effect as in the case of other orders, and in its sound discretion, may issue a declaratory order to terminate a controversy or remove uncertainty. (Pub. L. 89-554, Sept. 6, 1966, 80 Stat. 384; amended Publ. L. 95-251, Mar. 27, 1978, 92 Stat. 183.)

Sec. 555. Ancillary Matters.

(a) This section applies, according to the provisions thereof, except as otherwise provided by this subchapter.

(b) A person compelled to appear in person before an agency or representative thereof is entitled to be accompanied, represented, and advised by counsel or, if permitted by the agency, by other qualified representative. A party is entitled to appear in person or by or with counsel or other duly qualified representative in an agency proceeding. So far as the orderly conduct of public business permits, an interested person may appear before an agency or its responsible employees for the presentation, adjustment, or determination of an issue, request, or controversy in a proceeding, whether interlocutory, summary, or otherwise, or in connection with an agency function. With due regard for the convenience 
and necessity of the parties or their representatives and within a reasonable time, each agency shall proceed to conclude a matter presented to it. This subsection does not grant or deny a person who is not a lawyer the right to appear for or represent others before an agency or in an agency proceeding.

(c) Process, requirement of a report, inspection, or other investigative act or demand may not be issued, made, or enforced except as authorized by law. A person compelled to submit data or evidence is entitled to retain or, on payment of lawfully prescribed to submit data or evidence is entitled to retain or, on payment of lawfully prescribed costs, procure a copy or transcript thereof, except that in a nonpublic investigatory proceeding the witness may for good cause be limited to inspection of the official transcript of his testimony.

(d) Agency subpoenas authorized by law shall be issued to a party on request and, when required by rules of procedure on a statement or showing of general relevance and reasonable scope of the evidence sought. On contest, the court shall sustain the subpena or similar process or demand to the extent that it is found to be in accordance with law. In a proceeding for enforcement, the court shall issue an order requiring the appearance of the witness or the production of the evidence or data within a reasonable time under penalty of punishment for contempt in case of contumacious failure to comply.

(e) Prompt notice shall be given of the denial in whole or in part of a written application, petition, or other request of an interested person made in connection with any agency proceedings. Except in affirming a prior denial or when the denial is self-explanatory, the notice shall be accompanied by a brief statement of the grounds for denial. (Pub. L. 89-554, Sept. 6, 1966, 80 Stat. 385.)

Sec. 556. Hearings; Presiding Employees; Powers and Duties; Burden of Proof; Evidence; Record as Basis of Decision.

(a) This section applies, according to the provisions thereof, to hearings required by section 553 or 554 of this title to be conducted in accordance with this section.

(b) There shall preside at the taking of evidence-

(1) the agency;

(2) one or more members of the body which comprises the agency; or

(3) one or more administrative law judges appointed under section 3105 of this title.

This subchapter does not supersede the conduct of specified classes of proceedings, in whole or in part, by or before boards or other employees specially provided for by or designated under statute. The functions of presiding employees and of employees participating in decisions in accordance with section 557 of this title shall be conducted in an impartial manner. A presiding or participating employee may at any time disqualify himself. On the filing in good faith of a timely and sufficient affidavit of personal bias or other disqualification of a presiding or participating employee, the agency shall determine the matter as a part of the record and decision in the case. 
(c) Subject to published rules of the agency and within its powers, employees presiding at hearings may-

(1) administer oaths and affirmations;

(2) issue subpoenas authorized by law;

(3) rule on offers of proof and receive relevant evidence;

(4) take depositions or have depositions taken when the ends of justice would be served;

(5) regulate the course of the hearing;

(6) hold conferences for the settlement of simplification of the issues by consent of the parties; or by the use of alternative means of dispute resolution as provided in subchapter IV of this chapter;

(7) inform the parties as to the availaility of one or more alternative means of dispute resolution, and encourage use of such methods;

(8) require the attendance at any conference held pursuant to paragrtaph (6) of at least one representative of each party who has authority to negotiate concerning resolution of issues in controversy. 1

(9) dispose of procedural requests or similar matters;

(10) make or recommend decisions in accordance with section 557 of this title; and

(11) take other action authorized by agency rule consistent with this subchapter.

(d) Except as otherwise provided by statute, the proponents of a rule or order has the burden of proof. Any oral or documentary evidence may be received, but the agency as a matter of policy shall provide for the exclusion of irrelevant, immaterial, or unduly repetitious evidence. A sanction may not be imposed or rule or order issued except on consideration of the whole record or those parts thereof cited by a party and supported by and in accordance with the reliable, probative, and substantial evidence. The agency may, to the extent consistent with the interests of justice and the policy of the underlying statutes administered by the agency, consider a violation of section 557(d) of this title sufficient grounds for a decision adverse to a party who has knowingly committed such violation or knowingly caused such violation to occur. A party is entitled to present his case or defense by oral or documentary evidence, to submit rebuttal evidence, and to conduct such cross-examination as may be required for a full and true disclosure of the facts. In rule making or determining claims for money or benefits or applications for initial licenses an agency may, when a party will not be prejudiced thereby, adopt procedures for the submission of all or part of the evidence in written form.

(e) The transcript of testimony and exhibits, together with all papers and requests filed in the proceedings, constitutes the exclusive record for decision in accordance with section 557 of this title and, on payment of lawfully prescribed costs, shall be made available to the parties. When an agency decision rests on official notice of a material fact not appearing in the evidence in the record, a party is entitled, on timely request, to an opportunity to show the contrary. (Pub. L. 89-554, Sept. 6,

'P.L. 101-552 (104 Stat. 2736), November 15, 1990 changed (c)(6) and added new (7) and (8). 
1966, 80 Stat. 386; amended Pub. L. 94-409, Sept. 13, 1976, 90 Stat. 1247; Pub. L. 95-251, Mar. 27, 1978, 92 Stat. 183.)

Sec. 557. Initial Decisions; Conclusiveness; Review by Agency; Submissions by Parties; Contents of Decisions; Record.

(a) This section applies, according to the provisions thereof, when a hearing is required to be conducted in accordance with section 556 of this title.

(b) When the agency did not preside at the reception of the evidence, the presiding employee or, in cases not subject to section 554(d) of this title, an employee qualified to preside at hearings pursuant to section 556 of this title, shall initially decide the case unless the agency requires, either in specific cases or by general rule, the entire record to be certified to it for decision. When the presiding employee makes an initial decision, that decision then becomes the decision of the agency without further proceedings unless there is an appeal to, or review on motion of, the agency within time provided by rule. On appeal from or review of the initial decision, the agency has all the powers which it would have in making the initial decision except as it may limit the issues on notice or by rule. When the agency makes the decision without having presided at the reception of the evidence, the presiding employee or an employee qualified to preside at hearings pursuant to section 556 of this title shall first recommend a decision, except that in rule making or determining applications for initial licenses-

(1) instead thereof the agency may issue a tentative decision or one of its responsible employees may recommend a decision; or

(2) this procedure may be omitted in a case in which the agency finds on the record that due and timely execution of its functions imperatively and unavoidably so requires.

(c) Before a recommended, initial, or tentative decision, or a decision on agency review of the decision of subordinate employees, the parties are entitled to a reasonable opportunity to submit for the consideration of the employees participating in the decisions-

(1) proposed findings and conclusions; or

(2) exceptions to the decisions or recommended decisions of subordinate employees or to tentative agency decisions; and

(3) supporting reasons for the exception of proposed findings or conclusions.

The record shall show the ruling on each finding, conclusion, or exception presented. All decisions, including initial, recommended, and tentative decisions, are a part of the record and shall include a statement of-

(A) findings and conclusions and the reasons or basis therefor, on all the material issues of fact, law, or discretion presented on the record; and

(B) the appropriate rule, order, sanction, relief, or denial thereof.

(d)(1) In an agency proceeding which is subject to subsection (a) of this section, except to the extent required for the disposition of ex parte matters as authorized by law-

(A) no interested person outside the agency shall make or knowingly cause to be made to any member of the body comprising the 
agency, administrative law judge, or other employee who is or may reasonably be expected to be involved in the decisional process of the proceeding, an ex parte communication relevant to the merits of the proceeding;

(B) no member of the body comprising the agency, administrative law judge, or other employee who is or may reasonably be expected to be involved in the decisional process of the proceeding, shall make or knowingly cause to be made to any interested person outside the agency an ex parte communication relevant to the merits of the proceeding;

(C) a member of the body comprising the agency, administrative law judge, or other employee who is or may reasonably be expected to be involved in the decisional process of such proceeding who receives, or who makes or knowingly causes to be made, a communication prohibited by this subsection shall place on the public record of the proceeding:

(i) all such written communications;

(ii) memoranda stating the substance of all such oral communications; and

(iii) all written responses, and memoranda stating the substance of all oral responses, to the materials described in clauses (i) and (ii) of this subparagraph;

(D) upon receipt of a communication knowingly made or knowingly caused to be made by a party in violation of this subsection, the agency, administrative law judge, or other employee presiding at the hearing may, to the extent consistent with the interests of justice and the policy of the underlying statutes, require the party to show cause why his claim or interest in the proceedings should not be dismissed, denied, disregarded, or otherwise adversely affected on account of such violation; and

(E) the prohibitions of this subsection shall apply beginning at such time as the agency may designate, but in no case shall they begin to apply later than the time at which a proceeding is noticed for hearing unless the person responsible for the communication has knowledge that is will be noticed, in which case the prohibitions shall apply beginning at the time of his acquisition of such knowledge.

(2) This subsection does not constitute authority to withhold information from Congress. (Pub. L. 89-554, Sept. 6, 1966, 80 Stat. 837; amended Pub. L. 94-409, Sept. 13, 1976, 90 Stat. 1246.)

Sec. 558. Imposition of Sanctions; Determination of Applications For Licenses; Suspension, Revocation, and Expiration of Licenses.

(a) This section applies, according to the provisions thereof, to the exercise of a power or authority.

(b) A sanction may not be imposed or a substantive rule or order issued except within jurisdiction delegated to the agency and as authorized by law.

(c) When application is made for a license required by law, the agency, with due regard for the rights and privileges of all the interested parties or adversely affected persons and within a reasonable time, shall set and 
complete proceedings required to be conducted in accordance with sections 556 and 557 of this title or other proceedings required by law and shall make its decision. Except in cases of willfulness or those in which public health, interest, or safety requires otherwise, the withdrawal, suspension, revocation, or annulment of a license is lawful only if, before the institution of agency proceedings therefor, the licensee has been given-

(1) notice by the agency in writing of the facts or conduct which may warrant the action; and

(2) opportunity to demonstrate or achieve compliance with all lawful requirements.

When the licensee has made timely and sufficient application for a renewal or a new license in accordance with agency rules, a license with reference to an activity of a continuing nature does not expire until the application has been finally determined by the agency. (Pub. L. 89-554, Sept. 6, 1966, 80 Stat. 388.)

Sec. 559. Effect on Other Laws; Effect of Subsequent Statute.

This subchapter, chapter 7, and sections $1305,3105,3344,4301(2)(E)$, 5372 , and 7521 of this title, and the provisions of section 5335(a)(B) of this title that relate to administrative law judges, do not limit or repeal additional requirements imposed by statute or otherwise recognized by law. Except as otherwise required by law, requirements or privileges relating to evidence or procedure apply equally to agencies and persons. Each agency is granted the authority necessary to comply with the requirements of this subchapter through the issuance of rules or otherwise. Subsequent statute may not be held to supersede or modify this subchapter, chapter 7 , sections $1305,3105,3344,4301(2)(E), 5372$, or 7521 of this title, or the provisions of section 5335(a)(B) of this title that relate to administrative law judges, except to the extent that it does so expressly. (Pub L. 89-554, Sept. 6, 1966, 80 Stat. 388; amended Pub. L. 90-623,\$ 1(1), Oct 22, 1968, 82 Stat. 1312; Pub. L. 95-251, Mar. 27, 1978, 92 Stat. 183; Pub. L. 95-454, Oct. 13, 1978, 92 Stat. 1221.) 
ADMINISTRATIVE DISPUTE RESOLUTION ACT

Public Law 101-552

November 15, 1990

\section{An Act}

Nov. 15, 1990 To authorize and encourage Federal agencies to use mediation,

[H.R. 2497] conciliation, arbitration, and other techniques for the prompt and informal resolution of disputes, and for other purposes.

Administrative

Dispute

Resolution Act.

5 USC 571 note.

5 USC 571 note.

$B e$ it enacted by the Senate and House of Representatives of the United States of America in Congress assembled,

\section{SECTION 1. SHORT TITLE*}

This Act may be cited as the "Administrative Dispute Resolution Act." SEC. 2. FINDINGS.

The Congress finds that-

(1) administrative procedure, as embodied in chapter 5 of title 5 , United States Code, and other statutes, is intended to offer a prompt, expert, and inexpensive means of resolving disputes as an alternative to litigation in the Federal courts;

(2) administrative proceedings have become increasingly formal, costly, and lengthy resulting in unnecessary expenditures of time and in a decreased likelihood of achieving consensual resolution of disputes;

(3) alternative means of dispute resolution have been used in the private sector for many years and, in appropriate circumstances, have yielded decisions that are faster, less expensive, and less contentious;

(4) such alternative means can lead to more creative, efficient, and sensible outcomes;

(5) such alternative means may be used advantageously in a wide variety of administrative programs;

(6) explicit authorization of the use of well-tested dispute resolution techniques will eliminate ambiguity of agency authority under existing law;

(7) Federal agencies may not only receive the benefit of techniques that were developed in the private sector, but may also take the lead in the further development and refinement of such techniques; and

(8) the availability of a wide range of dispute resolution procedures, and an increased understanding of the most effective use of such procedures, will enhance the operation of the Government and better serve the public.

5 USC 571 note. SEC. 3. PROMOTION OF ALTERNATIVE MEANS OF DISPUTE RESOLUTION

(a) PROMULGATION OF AGENCY POLICY.-Each agency shall adopt a policy that addresses the use of alternative means of dispute

- When originally enacted, this law was codified at 5 USC 581, note. P.L. 102-354 (106 Stat 943) redesignated section numbers and U.S. Code cites and made minor amendments to the act. 
resolution and case management. In developing such a policy, each agency shall-

(1) consult with the Administrative Conference of the United States and the Federal Mediation and Conciliation Service; and

(2) examine alternative means of resolving disputes in connection with-

(A) formal and informal adjudications;

(B) rulemakings;

(C) enforcement actions;

(D) issuing and revoking licenses or permits;

(E) contract administration;

(F) litigation brought by or against the agency; and

(G) other agency actions.

(b) DISPUTE RESOLUTION SPECIALISTS.-The head of each agency shall designate a senior official to be the dispute resolution specialist of the agency. Such official shall be responsible for the implementation of-

(1) the provisions of this Act and the amendments made by this Act; and

(2) the agency policy developed under subsection (a).

(c) TRAINING.-Each agency shall provide for training on a regular basis for the dispute resolution specialist of the agency and other employees involved in implementing the policy of the agency developed under subsection (a). Such training should encompass the theory and practice of negotiation, mediation, arbitration, or related techniques. The dispute resolution specialist shall periodically recommend to the agency head agency employees who would benefit from similar training.

(d) PROCEDURES FOR GRANTS AND CONTRACTS.-

(1) Each agency shall review each of its standard agreements for contracts, grants, and other assistance and shall determine whether to amend any such standard agreements to authorize and encourage the use of alternative means of dispute resolution.

(2)(A) Within 1 year after the date of the enactment of this Act, the Federal Acquisition Regulation shall be amended, as necessary, to carry out this Act ad the amendments made by this Act.

(B) For purposes of this section, the term "Federal Acquisition Regulation" means the single system of Government-wide procurement regulation referred to in section 6(a) of the Office of Federal Procurement Policy Act (41 U.S.C. 405(a)).

SEC. 4. ADMINISTRATIVE PROCEDURES.

(a) ADMINISTRATIVE HEARINGS.-Section 556(c) of title 5, United States Code, is amended-

(1) in paragraph (6) by inserting before the semicolon at the end thereof the following: "or by the use of alternative means of dispute resolution as provided in subchapter IV of this chapter"; and

(2) by redesignating paragraphs (7) through (9) as paragraphs (9) through (11), respectively, and inserting after paragraph (6) the following new paragraphs: 
"(7) inform the parties as to the availability of one or more alternative means of dispute resolution, and encourage use of such methods;

"(8) require the attendance at any conference held pursuant to paragraph (6) of at least one representative of each party who has authority to negotiate concerning resolution of issues in controversy;".

(b) ALTERNATIVE MEANS OF DISPUTE RESOLUTION.Chapter 5 of title 5, United States Code, is amended by adding at the end the following new subchapter:

"SUBCHAPTER IV-ALTERNATTVE MEANS OF DISPUTE RESOLUTION IN THE ADMINISTRATIVE PROCESS

\section{“\$571. Definitions}

"For the purposes of this subchapter, the termtitle;

“(1) 'agency' has the same meaning as in section 551(1) of this

“(2) 'administrative program' includes a Federal function which involves protection of the public interest and the determination of rights, privileges, and obligations of private persons through rule making, adjudication, licensing, or investigation, as those terms are used in subchapter II of this chapter;

"(3) 'alternative means of dispute resolution' means any procedure that is used, in lieu of an adjudication as defined in section 551(7) of this title, to resolve issues in controversy, including but not limited to, settlement negotiations, conciliation, facilitation, mediation, factfinding, minitrials, and arbitration, or any combination thereof;

(4) 'award' means any decision by an arbitrator resolving the issues in controversy;

"(5) 'dispute resolution communication' means any oral or written communication prepared for the purposes of a dispute reso- lution proceeding, including any memoranda, notes or work product of the neutral, parties or nonparty participant; except that a written agreement to enter into a dispute resolution proceeding, or final written agreement or arbitral award reached as a result of a dispute resolution proceeding, is not a dispute resolution communication;

"(6) 'dispute resolution proceeding' means any process in which an alternative means of dispute resolution is used to resolve an issue in controversy in which a neutral is appointed and specified parties participate;

"(7) 'in confidence' means, with respect to information, that the information is provided-

"(A) with the expressed intent of the source that it not be disclosed; or

"(B) under circumstances that would create the reasonable expectation on behalf of the source that the information will not be disclosed;

"(8) 'issue in controversy' means an issue which is material to a decision concerning an administrative program of an agency, and 
with which there is disagreement between the agency and persons who would be substantially affected by the decision but shall not extend to matters specified under the provisions of sections 2302 and 7121(c) of title 5;

"(9)'neutral' means an individual who, with respect to an issue in controversy, functions specifically to aid the parties in resolving the controversy;

"(10) 'party' means-

"(A) for a proceeding with named parties, the same as in section 551(3) of this title; and

"(B) for a proceeding without named parties, a person who will be significantly affected by the decision in the proceeding and who participates in the proceeding;

“(11) 'person' has the same meaning as in section 551(2) of this title; and

“(12) 'roster' means a list of persons qualified to provide services as neutrals.

5 USC 572

\section{“§ 572. General authority}

"(a) An agency may use a dispute resolution proceeding for the resolution of an issue in controversy that relates to an administrative program, if the parties agree to such proceeding.

"(b) An agency shall consider not using a dispute resolution proceeding if-

"(1) a definitive or authoritative resolution of the matter is required for precedential value, and such a proceeding is not likely to be accepted generally as an authoritative precedent;

"(2) the matter involves or may bear upon significant questions of Government policy that require additional procedures before a final resolution may be made, and such a proceeding would not likely serve to develop a recommended policy for the agency;

"(3) maintaining established policies is of special importance, so that variations among individual decisions are not increased and such a proceeding would not likely reach consistent results among individual decisions;

"(4) the matter significantly affects persons or organizations who are not parties to the proceeding;

"(5) a full public record of the proceeding is important, and a dispute resolution proceeding cannot provide such a record; and

"(6) the agency must maintain continuing jurisdiction over the matter with authority to alter the disposition of the matter in the light of changed circumstances, and a dispute resolution proceeding would interfere with the agency's fulfilling that requirement.

“(c) Alternative means of dispute resolution authorized under this subchapter are voluntary procedures which supplement rather than limit other available agency dispute resolution techniques.

\section{"§ 573. Neutrals}

5 USC 573

"(a) A neutral may be a permanent or temporary officer or employee of the Federal Government or any other individual who is acceptable to the parties to a dispute resolution proceeding. A neutral shall have no 
official, financial, or personal conflict of interest with respect to the issues in controversy, unless such interest is fully disclosed in writing to all parties and all parties agree that the neutral may serve.

"(b) A neutral who serves as a conciliator, facilitator, or mediator serves at the will of the parties.

"(c) In consultation with the Federal Mediation and Conciliation Service, other appropriate Federal agencies, and professional organi-zations experienced in matters concerning dispute resolution, the Administrative Conference of the United States shall-

"(1) establish standards for neutrals (including experience, training, affiliations, diligence, actual or potential conflicts of interest, and other qualifications) to which agencies may refer,

"(2) maintain a roster of individuals who meet such standards and are otherwise qualified to act as neutrals, which shall be made available upon request;

"(3) enter into contracts for the services of neutrals that may be used by agencies on an elective basis in dispute resolution proceedings; and

"(4) develop procedures that permit agencies to obtain the services of neutrals on an expedited basis.

"(d) An agency may use the services of one or more employees of other agencies to serve as neutrals in dispute resolution proceedings. The agencies may enter into an interagency agreement that provides for the reimbursement by the user agency or the parties of the full or partial cost of the services of such an employee.

"(e) Any agency may enter into a contract with any person on a roster established under subsection (c)(2) or a roster maintained by other public or private organizations, or individual for services as a neutral, or for training in connection with alternative means of dispute resolution. The parties in a dispute resolution proceeding shall agree on compensation for the neutral that is fair and reasonable to the Government.

“\$ 574. Confidentiality

"(a) Except as provided in subsections (d) and (e), a neutral in a dispute resolution proceeding shall not voluntarily disclose or through discovery or compulsory process be required to disclose any information concerning any dispute resolution communication or any communication provided in confidence to the neutral, unless-

"(1) all parties to the dispute resolution proceeding and the neutral consent in writing, and, if the dispute resolution communi-cation was provided by a nonparty participant, that participant also consents in writing;

"(2) the dispute resolution communication has already been made public;

"(3) the dispute resolution communication is required by statute to be made public, but a neutral should make such communication public only if no other person is reasonably available to disclose the communication; or

"(4) a court determines that such testimony or disclosure is necessary to-

"(A) prevent a manifest injustice; 
"(B) help establish a violation of law; or

“(C) prevent harm to the public health or safety,

of sufficient magnitude in the particular case to outweigh the integrity of dispute resolution proceedings in general by reducing the confidence of parties in future cases that their communications will remain confidential.

"(b) A party to a dispute resolution proceeding shall not voluntarily disclose or through discovery or compulsory process be required to disclose any information concerning any dispute resolution communication, unless-

"(1) the communication was prepared by the party seeking disclosure;

"(2) all parties to the dispute resolution proceeding consent in writing;

"(3) the dispute resolution communication has already been made public;

"(4) the dispute resolution communication is required by statute to be made public;

"(5) a court determines that such testimony or disclosure is necessary to-

"(A) prevent a manifest injustice;

"(B) help establish a violation of law; or

"(C) prevent harm to the public health and safety, of sufficient magnitude in the particular case to outweigh the integrity of dispute resolution proceedings in general by reducing the confidence of parties in future cases that their communications will remain confidential;

"(6) the dispute resolution communication is relevant to determining the existence or meaning of an agreement or award that resulted from the dispute resolution proceeding or to the enforcement of such an agreement or award; or

"(7) the dispute resolution communication was provided to or was available to all parties to the dispute resolution proceeding.

"(c) Any dispute resolution communication that is disclosed in violation of subsection (a) or (b), shall not be admissible in any proceeding relating to the issues in controversy with respect to which the communication was made.

"(d) The parties may agree to alternative confidential procedures for disclosures by a neutral. Upon such agreement the parties shall inform the neutral before the commencement of the dispute resolution proceeding of any modifications to the provisions of subsection (a) that will govern the confidentiality of the dispute resolution proceeding. If the parties do not so inform the neutral, subsection (a) shall apply.

"(e) If a demand for disclosure, by way of discovery request or other legal process, is made upon a neutral regarding a dispute resolution communication, the neutral-shall make reasonable efforts to notify the parties and any affected nonparty participants of the demand. Any party or affected nonparty participant who receives such notice and within 15 calendar days does not offer to defend a refusal of the neutral to disclose the requested information shall have waived any objection to such disclosure. 
"(f) Nothing in this section shall prevent the discovery or admissibility of any evidence that is otherwise discoverable, merely because the evidence was presented in the course of a dispute resolution proceeding.

" (g) Subsections (a) and (b) shall have no effect on the information and data that are necessary to document an agreement reached or order issued pursuant to a dispute resolution proceeding.

"(h) Subsections (a) and (b) shall not prevent the gathering of information for research or educational purposes, in cooperation with other agencies, governmental entities, or dispute resolution programs, so long as the parties and the specific issues in controversy are not identifiable. "(i) Subsections (a) and (b) shall not prevent use of a dispute resolution communication to resolve a dispute between the neutral in a dispute resolution proceeding and a party to or participant in such proceeding, so long as such dispute resolution communication is disclosed only to the extent necessary to resolve such dispute.

"(j) This section shall not be considered a statute specifically exempting disclosure under section 552(b)(3) of this title.

\section{" $§ 575$. Authorization of arbitration}

“(a)(1) Arbitration may be used as an alternative means of dispute resolution whenever all parties consent. Consent may be obtained either before or after an issue in controversy has arisen. A part may agree to-

"(A) submit only certain issues in controversy to arbitration; or

"(B) arbitration on the condition that the award must be within a range of possible outcomes.

"(2) Any arbitration agreement that sets forth the subject matter submitted to the arbitrator shall be in writing.

"(3) An agency may not require any person to consent to arbitration as a condition of entering into a contract or obtaining a benefit.

"(b) An officer or employee of an agency may offer to use arbitration for the resolution of issues in controversy, if such officer or employee-

"(1) has authority to enter into a settlement concerning the matter; or

"(2) is otherwise specifically authorized by the agency to consent to the use of arbitration.

\section{“§ 576. Enforcement of arbitration agreements}

"An agreement to arbitrate a matter to which this subchapter applies is enforceable pursuant to section 4 of title 9 , and no action brought to enforce such an agreement shall be dismissed nor shall relief therein be denied on the grounds that it is against the United States or that the United States is an indispensable party.

\section{“§ 577. Arbitrators}

“(a) The parties to an arbitration proceeding shall be entitled to participate in the selection of the arbitrator.

"(b) The arbitrator shall be a neutral who meets the criteria of section 573 of this title.

“§ 578. Authority of the arbitrator 
"An arbitrator to whom a dispute is referred under this subchapter may-

“(1) regulate the course of and conduct arbitral hearings;

"(2) administer oaths and affirmations;

"(3) compel the attendance of witnesses and production of evidence at the hearing under the provisions of section 7 of title 9 only to the extent the agency involved is otherwise authorized by law to do so; and

"(4) make awards.

\section{“§ 579. Arbitration proceedings}

"(a) The arbitrator shall set a time and place for the hearing on the dispute and shall notify the parties not less than 5 days before the hear-

Records. ing.

(b) Any party wishing a record of the hearing shall-

"(1) be responsible for the preparation of such record;

"(2) notify the other parties and the arbitrator of the preparation of such record;

"(3) furnish copies to all identified parties and the arbitrator; and

"(4) pay all costs for such record, unless the parties agree otherwise or the arbitrator determines that the costs should be apportioned.

“(c)(1) The parties to the arbitration are entitled to be heard, to present evidence material to the controversy, and to cross-examine witnesses appearing at the hearing.

"(2) The arbitrator may, with the consent of the parties, conduct all or part of the hearing by telephone, television, computer, or other electronic means, if each party has an opportunity to participate.

"(3) The hearing shall be conducted expeditiously and in an informal manner.

"(4) The arbitrator may receive any oral or documentary evidence, except that irrelevant, immaterial, unduly repetitious, or privileged evidence may be excluded by the arbitrator.

"(5) The arbitrator shall interpret and apply relevant statutory and regulatory requirements, legal precedents, and policy directives.

"(d) No interested person shall make or knowingly cause to be made to the arbitrator an unauthorized ex parte communication relevant to the merits of the proceeding, unless the parties agree otherwise. If a communication is made in violation of this subsection, the arbitrator shall ensure that a memorandum of the communication is prepared and made a part of the record, and that an opportunity for rebuttal is allowed. Upon receipt of a communication made in violation of this subsection, the arbitrator may, to the extent consistent with the interests of justice and the policies underlying this subchapter, require the offending party to show cause why the claim of such party should not be resolved against such party as a result of the improper conduct.

"(e) The arbitrator shall make the award within 30 days after the close of the hearing, or the date of the filing of any briefs authorized by the arbitrator, whichever date is later, unless-

"(1) the parties agree to some other time limit; or 
"(2) the agency provides by rule for some other time limit.

\section{“§ 580. Arbitration awards}

"(a)(1) Unless the agency provides otherwise by rule, the award in an arbitration proceeding under this subchapter shall include a brief, informal discussion of the factual and legal basis for the award, but formal findings of fact or conclusions of law shall not be required.

"(2) The prevailing parties shall file the award with all relevant agencies, along with proof of service on all parties.

"(b) The award in an arbitration proceeding shall become final 30 days after it is served on all parties. Any agency that is a party to the proceeding may extend this 30-day period for an additional 30 -day period by serving a notice of such extension on all other parties before the end of the first 30-day period.

"(c) The head of any agency that is a party to an arbitration proceeding conducted under this subchapter is authorized to terminate the arbitration proceeding or vacate any award issued pursuant to the proceeding before the award becomes final by serving on all other parties a written notice to that effect, in which case the award shall be null and void. Notice shall be provided to all parties to the arbitration proceeding of any request by a party, nonparty participant or other person that the agency head terminate the arbitration proceeding or vacate the award. An employee or agent engaged in the performance of investigative or prosecuting functions for an agency may not, in that or a factually related case, advise in a decision under this subsection to terminate an arbitration proceeding or to vacate an arbitral award, except as witness or counsel in public proceedings.

"(d) A final award is binding on the parties to the arbitration proceeding, and may be enforced pursuant to section 9 through 13 of title 9 . No action brought to enforce such an award shall be dismissed not shall relief therein be denied on the grounds that it is against the United States or that the United States is an indispensable party.

"(e) An award entered under this subchapter in an arbitration proceeding may not serve as an estoppel in any other proceeding for any issue that was resolved in the proceeding. Such an award also may not be used as precedent or otherwise be considered in any factually unrelated proceeding, whether conducted under this subchapter, by an agency, or in a court, or in any other arbitration proceeding.

"(f) An arbitral award that is vacated under subsection (c) shall not be admissible in any proceeding relating to the issues in controversy with respect to which the award was made.

"(g) If an agency head vacates an award under subsection (c), a party to the arbitration (other than the United States) may within 30 days of such action petition the agency head for an award of attorney fees and expenses (as defined in section 504(b)(1)(A) of this title) incurred in connection with the arbitration proceeding. The agency head shall award the petitioning party those fees and expenses that would not have been incurred in the absence of such arbitration proceeding, unless the agency head or his or her designee finds that special circumstances make such an award unjust. The procedures for reviewing applications for 
awards shall, where appropriate, be consistent with those set forth in subsection (a)(2) and (3) of section 504 of this title. Such fees and expenses shall be paid from the funds of the agency that vacated the award.

\section{"§ 581. Judicial Review}

“(a) Notwithstanding any other provision of law, any person adversely affected or aggrieved by an award made in an arbitration proceeding conducted under this subchapter may bring an action for review of such award only pursuant to the provisions of sections 9 through 13 of title 9 .

“(b)(1) A decision by an agency to use or not to use a dispute resolution proceeding under this subchapter shall be committed to the discretion of the agency and shall not be subject to judicial review, except that arbitration shall be subject to judicial review under section 10(b) of title 9 .

"(2) A decision by the head of an agency under section 580 to terminate an arbitration proceeding or vacate an arbitral award shall be committed to the discretion of the agency and shall not be subject to judicial review.

\section{"§ 582. Compilation of information}

"The Chairman of the Administrative Conference of the United States shall compile and maintain data on the use of alternative means of dispute resolution in conducting agency proceedings. Agencies shall, upon the request of the Chairman of the Administrative Conference of the United States, supply such information as is required to enable the Chairman to comply with this section.

\section{“§ 583. Support services}

"For the purposes of this subchapter, an agency may use (with or without reimbursement) the services and facilities of other Federal agencies, public and private organizations and agencies, and individuals, with the consent of such agencies, organizations, and individuals. An agency may accept voluntary and uncompensated services for purposes of this subchapter without regard to the provisions of section 1342 of title 31."

(c) TECHNICAL AMENDMENT.-The table of sections at the beginning of chapter 5 of title 5 , United States Code, is amended by adding at the end thereof the following:

\section{"SUBCHAPTER IV-ALTERNATTVE MEANS OF DISPUTE RESOLUTION IN THE ADMINISTRATIVE PROCESS}

"571. Definitions.

"572. General authority.

"573. Neutrals.

"574. Confidentiality.

"575. Authorization of arbitration.

“576. Enforcement of arbitration agreements.

“577. Arbitrators.

"578. Authority of the arbitrator.

"579. Arbitration proceedings.

"580. Arbitration awards.

"581. Judicial review.

"582. Compilation of information. 


\section{SEC. 5. JUDICIAL REVIEW OF ARBITRATION AWARDS.}

Section 10 of title 9, United States Code, is amended-

(1) by redesignating subsections (a) through (e) as paragraphs (1) through (5), respectively;

(2) by striking out "In either" and inserting in lieu thereof "(a) In any"; and

(3) by adding at the end thereof the following:

"(b) The United States district court for the district wherein an award was made that was issued pursuant to section 590 of title 5 may make an order vacating the award upon the application of a person, other than a party to the arbitration, who is adversely affected or aggrieved by the award, if the use of arbitration or the award is clearly inconsistent with the factors set forth in section 582 of title $5 . "$

\section{SEC. 6. GOVERNMENT CONTRACT CLAIMS.}

(a) ALTERNATIVE MEANS OF DISPUTE RESOLUTION.-Section 6 of the Contract Disputes Act of 1978 (41 U.S.C. 606) is amended by adding at the end the following new subsections:

"(d) Notwithstanding any other provision of this Act, a contractor and a contracting officer may use any alternative means of dispute resolution under subchapter IV of chapter 5 of title 5 , United States Code, or other mutually agreeable procedures, for resolving claims. In a case in which such alternative means of dispute resolution or other mutually agreeable procedures are used, the contractor shall certify that the claim is made in good faith, that the supporting data are accurate and complete to the best of his or her knowledge and belief, and that the amount requested accurately reflects the contract adjustment for which the contractor believes the Government is liable. All provisions of subchapter IV of chapter 5 of title 5, United States Code, shall apply to such alternative means of dispute resolution.

"(e) The authority of agencies to engage in alternative means of dispute resolution proceedings under subsection (d) shall cease to be effective on October 1, 1995, except that such authority shall continue in effect with respect to then pending dispute resolution proceedings which, in the judgment of the agencies that are parties to such proceedings, require such continuation, until such proceedings terminate.".

(b) JUDICIAL REVIEW OF ARBITRAL AWARDS.-Section 8(g) of the Contract Disputes Act of 1978 (41 U.S.C. 607(g)) is amended by adding at the end the following new paragraph:

"(3) An award by an arbitrator under this Act shall be reviewed pursuant to sections 9 through 13 of title 9, United States Code, except that the court may set aside or limit any award that is found to violate limitations imposed by Federal statue.".

\section{SEC. 7. FEDERAL MEDIATION AND CONCILIATION SERVICE}

Section 203 of the Labor Management Relations Act, 1947 (29 U.S.C. 173 ) is amended by adding at the end the following new subsection: 
"(f) The Service may make its services available to Federal agencies to aid in the resolution of disputes under the provisions of subchapter IV of chapter 5 of title 5, United States Code. Functions performed by the Service may include assisting parties to disputes related to administrative programs, training persons in skills and procedures employed in alternative means of dispute resolution, and furnishing officers and employees of the Service to act as neutrals. Only officers and employees who are qualified in accordance with section 583 of title 5, United States Code, may be assigned to act as neutrals. The Service shall consult with the Administrative Conference of the United States and other agencies in maintaining rosters of neutrals and arbitrators, and to adopt such procedures and rules as are necessary to carry out the services authorized in this subsection.".

\section{SEC. 8. GOVERNMENT TORT AND OTHER CLAIMS.}

(a) FEDERAL TORT CLAIMS.-Section 2672 of title 28, United States Code, is amended by adding at the end of the first paragraph the following: "Notwithstanding the proviso contained in the preceding sentence, any award, compromise, or settlement may be effected without the prior written approval of the Attorney General or his or her designee, to the extent that the Attorney General delegates to the head of the agency the authority to make such award, compromise, or settlement. Such delegations may not exceed the authority delegated by the Attorney General to the United States attorneys to settle claims for money damages against the United States. Each Federal agency may use arbitration, or other alternative means of dispute resolution under the provisions of subchapter IV of chapter 5 of title 5 , to settle any tort claim against the United States, to the extent of the agency's authority to award, compromise, or settle such claim without the prior written approval of the Attorney General or his or her designee.".

(b) CLAIMS OF THE GOVERNMENT.-Section 3711(a)(2) of title 31 , United States Code, is amended by striking out " $\$ 20,000$ (excluding interest)" and inserting in lieu thereof " $\$ 100,000$ (excluding interest) or such higher amount as the Attorney General may from time to time prescribe".

5 USC 571,

\section{SEC. 9. USE OF NONATTORNEYS.}

note.

(a) REPRESENTATION OF PARTIES.-Each agency, in developing a policy on the use of alternative means of dispute resolution under this Act, shall develop a policy with regard to the representation by persons other than attorneys of parties in alternative dispute resolution proceedings and shall identify any of its administrative programs with numerous claims or disputes before the agency and determine-

(1) the extent to which individuals are represented or assisted by attorneys or by persons who are not attorneys; and

(2) whether the subject areas of the applicable proceedings or the procedures are so complex or specialized that only attorneys may adequately provide such representation or assistance. 
5 USC 571, note.

5 USC 571, note. (b) REPRESENTATION AND ASSISTANCE BY NONATTORNEYS. - A person who is not an attorney may provide representation or assistance to any individual in a claim or dispute with an agency, if-

(1) such claim or dispute concerns an administrative program identified under subsection (a);

(2) such agency determines that the proceeding or procedure does not necessitate representation or assistance by an attorney under subsection (a)(2); and

(3) such person meets any requirement of the agency to provide representation or assistance in such a claim or dispute.

(c) DISQUALIFICATION OF REPRESENTATION OR ASSISTANCE.-Any agency that adopts regulations under subchapter IV of chapter 5 of title 5, United States Code, to permit representation or assistance by persons who are not attorneys shall review the rules of practice before such agency to-

(1) ensure that any rules pertaining to disqualification of attorneys from practicing before the agency shall also apply, as appropriate, to other persons who provide representation or assistance; and

(2) establish effective agency procedures for enforcing such rules of practice and for receiving complaints from affected persons.

\section{SEC. 10. DEFINITIONS.}

As used in this Act, the terms "agency", "administrative program", and "alternative means of dispute resolution" have the meanings given such terms in section 581 of title 5, United States Code, as added by section 4(b) of this Act.

\section{SEC. 11. SUNSET PROVISION.}

The authority of agencies to use dispute resolution proceedings under this Act and the amendments made by this Act shall terminate on October 1,1995 , except that such authority shall continue in effect with respect to then pending proceedings which, in the judgment of the agencies that are parties to the dispute resolution proceedings, require such continuation, until such proceedings terminate. 
Public Law 101-648

104 Stat. 4969

\section{An Act}

Nov. 29, 1990

[S. 303]

Negotiated

Rulemaking Act of 1990.

5 USC 561

5 USC 561

To establish a framework for the conduct of negotiated rulemaking by Federal agencies.

Be it enacted by the Senate and House of Representatives of the United States of America in Congress assembled,

SECTION 1. SHORT TITLE

This Act may be cited as the "Negotiated Rulemaking Act of 1990".

SEC. 2. FINDINGS.

The Congress makes the following findings:

(1) Government regulation has increased substantially since the enactment of the Administrative Procedure Act.

(2) Agencies currently use rulemaking procedures that may discourage the affected parties from meeting and communicating with each other, and may cause parties with different interests to assume conflicting and antagonistic positions and to engage in expensive and time-consuming litigation over agency rules.

(3) Adversarial rulemaking deprives the affected parties and the public of the benefits of face-to-face negotiations and co-operation in developing and reaching agreement on a rule. It also deprives them of the benefits of shared information, knowledge, expertise, and technical abilities possessed by the affected parties.

(4) Negotiated rulemaking, in which the parties who will be significantly affected by a rule participate in the development of the rule, can provide significant advantages over adversarial rulemaking.

(5) Negotiated rulemaking can increase the acceptability and improve the substance of rules, making it less likely that the affected parties will resist enforcement or challenge such rules in court. It may also shorten the amount of time needed to issue final rules.

(6) Agencies have the authority to establish negotiated rule making committees under the laws establishing such agencies and their activities and under the Federal Advisory Committee Act (5U.S.C. App.). Several agencies have successfully used negotiated rulemaking. The process has not been widely used by other agencies, however, in part because such agencies are unfamiliar with the process or uncertain as to the authority for such rulemaking.

SEC. 3. NEGOTIATED RULEMAKING PROCEDURE.

(a) IN GENERAL.-Chapter 5 of title 5, United States Code, is amended by adding at the end the following new subchapter: 


\section{"SUBCHAPTER IV-NEGOTIATED RULEMAKING PROCEDURE}

5 USC 561

5 USC 562

5 USC 563

\section{“\$561. Purpose}

"The purpose of this subchapter is to establish a framework for the conduct of negotiated rulemaking, consistent with section 553 of this title, to encourage agencies to use the process when it enhances the informal rulemaking process. Nothing in this subchapter should be construed as an attempt to limit innovation and experimentation with the negotiated rulemaking process or with other innovative rulemaking procedures otherwise authorized by law.

"§562. Definitions

"For the purposes of this subchapter, the term-

"(1) 'agency' has the same meaning as in section 551(1) of this title;

“(2) 'consensus' means unanimous concurrence among the interests represented on a negotiated rulemaking committee established under this subchapter, unless such committee-

"(A) agrees to define such term to mean a general but not unanimous concurrence; or

"(B) agrees upon another specified definition;

“(3) 'convener' means a person who impartially assists an agency in determining whether establishment of a negotiated rulemaking committee is feasible and appropriate in a particular rulemaking;

"(4) 'facilitator' means a person who impartially aids in the discussions and negotiations among the members of a negotiated rulemaking committee to develop a proposed rule; “(5) 'interest' means, with respect to an issue or matter, multiple parties which have a similar point of view or which are likely to be affected in a similar manner;

"(6) 'negotiated rulemaking' means rulemaking through the use of a negotiated rulemaking committee;

“(7) 'negotiated rulemaking committee' or 'committee' means an advisory committee established by an agency in accordance with this subchapter and the Federal Advisory Committee Act to consider and discuss issues for the purpose of reaching a consensus in the development of a proposed rule;

"(8) 'party' has the same meaning as in section 551(3) of this title;

"(9) 'person' has the same meaning as in section 551(2) of this title;

"(10) 'rule' has the same meaning as in section 551(4) of this title; and

"(11) 'rulemaking' means 'rulemaking' as that term is defined in section 551(5) of this title.

\section{“\$563. Determination of need for negotiated rulemaking committee}

“(a) DETERMINATION OF NEED BY THE AGENCY.-An agency may establish a negotiated rulemaking committee to negotiate and develop a proposed rule, if the head of the agency determines that the use of the negotiated rulemaking procedure is in the public interest. In making such a determination, the head of the agency shall consider whether-

"(1) there is a need for a rule;

"(2) there are a limited number of identifiable interests that will be significantly affected by the rule; 
"(3) there is a reasonable likelihood that a committee can be convened with a balanced representation of persons who-

"(A) can adequately represent the interests identified under paragraph (2); and

"(B) are willing to negotiate in good faith to reach a consensus on the proposed rule;

"(4) there is a reasonable likelihood that a committee will reach a consensus on the proposed rule within a fixed period of time;

"(5) the negotiated rulemaking procedure will not unreasonably delay" the notice of proposed rulemaking and the issuance of the final rule;

"(6) the agency has adequate resources and is willing to commit such resources, including technical assistance, to the committee; and

"(7) the agency, to the maximum extent possible consistent with the legal obligations of the agency, will use the consensus of the committee with respect to the proposed rule as the basis for the rule proposed by the agency for notice and comment.

"(b) USE OF CONVENERS.-

“(1) PURPOSES OF CONVENERS.-An agency may use the services of a convener to assist the agency in-

"(A) identifying person who will be significantly affected by a proposed rule, including residents of rural areas; and

"(B) conducting discussions with such persons to identify the issues of concern to such persons, and to ascertain whether the establishment of a negotiated rulemaking committee is feasible and appropriate in the particular rulemaking.

Reports.

“(2) DUTIES OF CONVENERS.-The convener shall report findings and may make recommendations to the agency. Upon request of the agency, the convener shall ascertain the names of persons who are willing and qualified to represent interests that will be significantly affected by the proposed rule, including residents of rural areas. The report and any recommendations of the convener shall be made available to the public upon request.

\section{“§ 564. Publication of notice; applications for membership on committees}

5 USC 564

“(a) PUBLICATION OF NOTICE.-If, after considering the report of a convener or conducting its own assessment, an agency decides to establish a negotiated rulemaking committee, the agency shall publish in the Federal Register and, as appropriate, in trade or other specialized publications, a notice which shall include-

"(1) an announcement that the agency intends to establish a negotiated rulemaking committee to negotiate and develop a proposed rule;

"(2) a description of the subject and scope of the rule to be developed, and the issues to be considered;

"(3) a list of the interests which are likely to be significantly affected by the rule;

"(4) a list of the persons proposed to represent such interests and the person or persons proposed to represent the agency; 
“(5) a proposed agenda and schedule for completing the work of the committee, including a target date for publication by the agency of a proposed rule for notice and comment;

"(6) a description of administrative support for the committee to be provided by the agency, including technical assistance;

"(7) a solicitation for comments on the proposal to establish the committee, and the proposed membership of the negotiated rulemaking committee; and

"(8) an explanation of how a person may apply or nominate another person for membership on the committee, as provided under subsection (b).

“(b) APPLICATTONS FOR MEMBERSHIP OR COMMITTE.-Persons who will be significantly affected by a proposed rule and who believe that their interests will not be adequately represented by any person specified in a notice under subsection (a)(4) may apply for, or nominate another person for, membership on the negotiated rulemaking committee to represent such interests with respect to the proposed rule. Each application or nomination shall include-

"(1) the name of the applicant or nominee and a description of the interests such person shall represent;

"(2) evidence that the applicant or nominee is authorized to represent parties related to the interests the person proposes to represent;

"(3) a written commitment that the applicant or nominee shall actively participate in good faith in the development of the rule under consideration; and

"(4) the reasons that the persons specified in the notice under subsection (a)(4) do not adequately represent the interests of the person submitting the application or nomination.

“(c) PERIOD FOR SUBMISSION OF COMMENTS AND AP-

PLICATIONS. - The agency shall provide for a period of at least 30 calendar days for the submission of comments and applications under this section.

“§ 565. Establishment of committee

“(a) ESTABLISHMENT.-

"(1) DETERMINATION TO ESTABLISH COMMITTEE.-If after considering comments and applications submitted under section 564, the agency determines that a negotiated rulemaking committee can adequately represent the interests that will be significantly affected by a proposed rule and that it is feasible and appropriate in the particular rulemaking, the agency may establish a negotiated rulemaking committee. In establishing and administering such a committee, the agency shall comply with the Federal Advisory Committee Act with respect to such committee, except as otherwise provided in this subchapter.

"(2) DETERMINATION NOT TO ESTABLISH COMMITTEE.-If after considering such comments and applications, the agency decides not to establish a negotiated rulemaking commit- 
tee, the agency shall promptly publish notice of such decision and the reasons therefor in the Federal Register and, as appropriate, in trade or other specialized publications, a copy of which shall be sent to any person who applied for, or nominated another person for membership on the negotiating rulemaking committee to represent such interests with respect to the proposed rule.

"(b) MEMBERSHIP.-The agency shall limit membership on a negotiated rulemaking committee to 25 members, unless the agency head determines that a greater number of members is necessary for the functioning of the committee or to achieve balanced membership. Each committee shall include at least one person representing the agency.

"(c) ADMINISTRATIVE SUPPORT.-The agency shall provide appropriate administrative support to the negotiated rulemaking committee, including technical assistance.

\section{“§ 566. Conduct of committee activity}

“(a) DUTIES OF COMMITTEE.-Each negotiated rulemaking committee established under this subchapter shall consider the matter proposed by the agency for consideration and shall attempt to reach a consensus concerning a proposed rule with respect to such matter and any other matter the committee determines is relevant to the proposed rule.

“(b) REPRESENTATIVES OF AGENCY ON COMMITTEE.-The person or persons representing the agency on a negotiated rulemaking committee shall participate in the deliberations and activities of the committee with the same rights and responsibilities as other members of the committee, and shall be authorized to fully represent the agency in the discussions and negotiations of the committee.

“(c) SELECTING FACILITATOR.-Notwithstanding section 10(e) of the Federal Advisory Committee Act, an agency may nominate either a person from the Federal Government or a person from outside the Federal Government to serve as a facilitator for the negotiations of the committee, subject to the approval of the committee by consensus. If the committee does not approve the nominee of the agency for facilitator, the agency shall submit a substitute nomination. If a committee does not approve any nominee of the agency for facilitator, the committee shall select by consensus a person to serve as facilitator. A person designated to represent the agency in substantive issues may not serve as facilitator or otherwise chair the committee.

“(d) DUTIES OF FACILITATOR.-A facilitator approved or selected by a negotiated rulemaking committee shall-

"(1) chair the meetings of the committee in an impartial manner;

"(2) impartially assist the members of the committee in conducting discussions and negotiations; and

"(3) manage the keeping of minutes and records as required under section 10 (b) and (c) of the Federal Advisory Committee Act, except that any personal notes and materials of the facilitator or of the members of a committee shall not be subject to section 552 of this title. 
“(e) COMMITTEE PROCEDURES.-A negotiated rulemaking committee established under this subchapter may adopt procedures for the operation of the committee. No provision of section 553 of this title shall apply to the procedures of a negotiated rulemaking committee.

"(f) REPORT OF COMMTTEE.-If a committee reaches a consensus on a proposed rule, at the conclusion of negotiations the committee shall transmit to the agency that established the committee a report containing the proposed rule. If the committee does not reach a consensus on a proposed rule, the committee may transmit to the agency a report specifying any areas in which the committee reached a consensus. The committee may include in a report any other information, recommendations, or materials that the committee considers appropriate. Any committee member may include as an addendum to the report additional information, recommendations, or materials.

"(g) RECORDS OF COMMITTEE.-In addition to the report required by subsection ( $\mathrm{f}$ ), a committee shall submit to the agency the records required under section 10 (b) and (c) of the Federal Advisory Committee Act.

\section{“§ 567. Termination of committee}

"A negotiated rulemaking committee shall terminate upon promulgation of the final rule under consideration, unless the committee's charter contains an earlier termination date or the agency, after consulting the committee, or the committee itself specifies an earlier termination date.

“§ 568. Services, facilities, and payment of committee member expenses

“(a) SERVICES OF CONVENERS AND FACILITATORS.-

"(1) IN GENERAL. - An agency may employ or enter into contracts for the services of an individual or organization to serve as a convener or facilitator for a negotiated rulemaking committee under this subchapter, or may use the services of a Government employee to act as a convener or a facilitator for such a committee.

“(2) DETERMINATION OF CONFLICTING INTERESTS. An agency shall determine whether a person under consideration to serve as a convener or facilitator of a committee under paragraph (1) has any financial or other interest that would preclude such person from serving in an impartial and independent manner.

"(b) SERVICES AND FACILITIES OF OTHER ENTTTIES.For purposes of this subchapter, an agency may use the services and facilities of other Federal agencies and public and private agencies and instrumentalities with the consent of such agencies and instrumentalities, and with or without reimbursement to such agencies and instrumentalities, and may accept voluntary and uncompensated services without regard to the pro visions of section 1342 of title 31. The Federal Mediation and Conciliation Service may provide services and facilities, with or without reimbursement, to assist 
agencies under this subchapter, including furnishing conveners, facilitators, and training in negotiated rulemaking.

“(c) EXPENSES OF COMMTTTEE MEMBERS.-Members of a negotiated rulemaking committee shall be responsible for their own expenses of participation in such committee, except that an agency may, in accordance with section 7(d) of the Federal Advisory Committee Act, pay for a member's reasonable travel and per diem expenses, expenses to obtain technical assistance, and a reasonable rate of compensation, if-

“(1) such member certifies a lack of adequate financial resources to participate in the committee; and

"(2) the agency determines that such member's participation in the committee is necessary to assure an adequate representation of the member's interest.

“(d) STATUS OF MEMBER AS FEDERAL EMPLOYEE.-A member's receipt of funds under this section or section 569 shall not conclusively deter mine for purposes of sections 202 through 209 of title 18 whether that member is an employee of the United States Government.

“§ 569. Role of the Administrative Conference of the United States and other entities

“(a) CONSULTATION BY AGENCIES.-An agency may consult with the Administrative Conference of the United States or other public or private individuals or organizations for information and assistance in forming a negotiated rulemaking committee and conducting negotiations on a proposed rule.

"(b) ROSTER OF POTENTIAL CONVENERS AND FACILITATORS.-The Administrative Conference of the United States, in consultation with the Federal Mediation and Conciliation Service, shall maintain a roster of individuals who have acted as or are interested in serving as conveners or facilitators in negotiated rulemaking proceedings. The roster shall include individuals from government agencies and private groups, and shall be made available upon request. Agencies may also use rosters maintained by other public or private individuals or organizations.

“(c) PROCEDURES TO OBTAIN CONVENERS AND FACILITATORS.-

"(1) PROCEDURES. - The Administrative Conference of the United States shall develop procedures which permit agencies to obtain the services of conveners and facilitators on an expedited basis.

“(2) PAYMENT FOR SERVICES. - Payment for the services of conveners or facilitators shall be made by the agency using the services, unless the Chairman of the Administrative Conference agrees to pay for such services under subsection (f).

“(d) COMPILATION OF DATA ON NEGOTIATED RULEMAKING; REPORT TO CONGRESS.

"(1) COMPILATION OF DATA.-The Administrative Conference of the United States shall compile and maintain data related 
to negotiated rulemaking and shall act as a clearinghouse to assist agencies and parties participating in negotiated rulemaking proceedings.

"(2) SUBMISSION OF INFORMATION BY AGENCIES.Each agency engaged in negotiated rulemaking shall provide to the Administrative Conference of the United States a copy of any reports submitted to the agency by negotiated rulemaking committees under section 566 and such additional information as necessary to enable the Administrative Conference of the United States to comply with this subsection.

"(3) REPORTS TO CONGRESS. - The Administrative Conference of the United States shall review and analyze the reports and information received under this subsection and shall transmit a biennial report to the Committee on Governmental Affairs of the Senate and the appropriate committees of the House of Representatives that-

“(A) provides recommendations for effective use by agencies of negotiated rulemaking; and

"(B) describes the nature and amounts of expenditures made by the Administrative Conference of the United States to accomplish the purposes of this subchapter.

"(e) TRAINING IN NEGOTIATED RULEMAKING.-The Administrative Conference of the United States is authorized to provide training in negotiated rulemaking techniques and procedures for personnel of the Federal Government either on a reimbursable or nonreimbursable basis. Such training may be extended to private individuals on a reimbursable basis.

"(f) PAYMENT OF EXPENSES OF AGENCIES. - The Chairman of the Administrative Conference of the United States is authorized to pay, upon request of an agency, all or part of the expenses of establishing a negotiated rulemaking committee and conducting a negotiated rulemaking. Such expenses may include, but are not limited to-

"(1) the costs of conveners and facilitators;

"(2) the expenses of committee members determined by the agency to be eligible for assistance under section 568(c); and

"(3) training costs. Determinations with respect to payments under this section shall be at the discretion of such Chairman in furthering the use by Federal agencies of negotiated rulemaking.

“(g) USE OF FUNDS OFTHE CONFERENCE.-The Administrative Conference of the United States may apply funds received under section 595(c)(12) of this title to carry out the purposes of this subchapter.

\section{“§ 570. Judicial review}

"Any agency action relating to establishing, assisting, or terminating a negotiated rulemaking committee under this subchapter shall not be subject to judicial review. Nothing in this section shall bar judicial review of a rule if such judicial review is otherwise provided by law. A rule which 
is the product of negotiated rulemaking and is subject to judicial review shall not be accorded any greater deference by a court than a rule which is the product of other rulemaking procedures.". (b) The table of sections at the beginning of chapter 5 of title 5 , United States Code, is amended by adding at the end the following:

\section{"SUBCHAPTER III-NEGOTIATED RULEMAKING} PROCEDURE

"Sec. 561. Purpose.

"Sec. 562. Definitions.

"Sec. 563. Determination of need for negotiated rulemaking committee.

"Sec. 564. Publication of notice; applications for membership on committees.

"Sec. 565. Establishment of committee.

"Sec. 566. Conduct of committee activity.

"Sec. 567. Termination of committee.

"Sec. 568. Services, facilities, and payment of committee member expenses.

"Sec. 569. Role of the Administrative Conference of the United States and other entities.

"Sec. 570. Judicial review.".

\section{USC 561 note. SEC. 4. AUTHORIZATION OF APPROPRIATIONS.}

In order to carry out this Act and the amendments made by this Act, there are authorized to be appropriated to the Administrative Conference of the United States, in addition to amounts authorized by section 596 of title 5, United States Code, not in excess of $\$ 500,000$ for each of the fiscal years 1991, 1992, and 1993.

5 USC 561 note. SEC. 5. SUNSET AND SAVINGS PROVISIONS.

Subchapter III of chapter 5, United States Code, (enacted as subchapter IV of chapter 5 of title 5, United States Code, by section 3 of this Act and redesignated as subchapter $\Pi$ of such chapter 5 by section (3)(a) of the Administrative Procedure Technical Amendments Act of 1991); and that portion of the table of sections at the beginning of chapter 5 of title 5, United States Code, relating to subchapter III, are repealed, effective 6 years after the date of the enactment of this Act, except that the provisions of such subchapter shall continue to apply after the date of the repeal with respect to then pending negotiated rulemaking proceedings initiated before the date of repeal which, in the judgment of the agencies which are convening or have convened such proceedings, require such continuation, until such negotiated rulemaking proceedings terminate pursuant to such subchapter. 


\section{CHAPTER 6 - THE ANALYSIS OF REGULATORY FUNCTIONS}

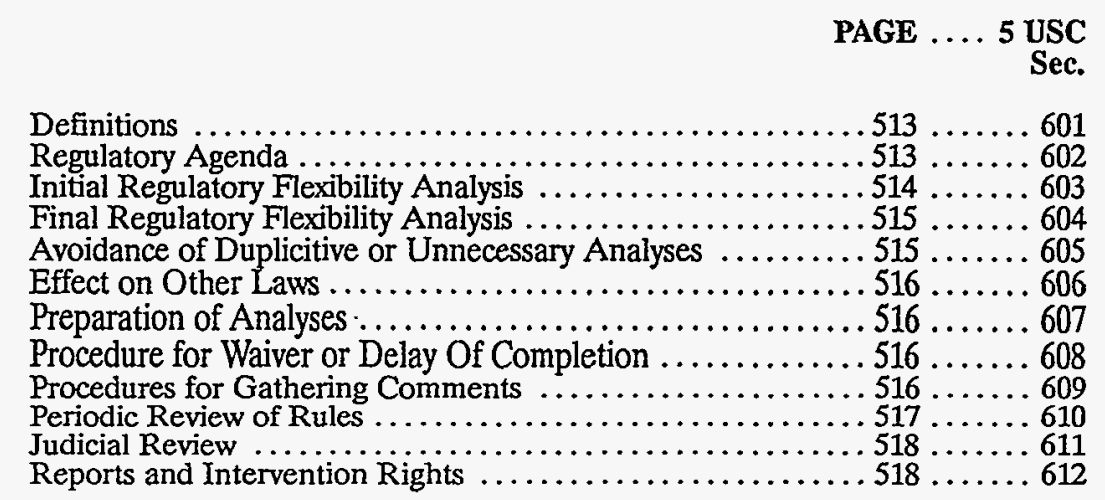




\section{CHAPTER 6-THE ANALYSIS OF REGULATORY FUNCTIONS}

Sec. 601. Definitions.

For purposes of this chapter-

(1) the term "agency" means an agency as defined in section 551 of this title;

(2) The term "rule" means any rule for which the agency publishes a general notice of proposed rulemaking pursuant to section 553(b) of this title, or any other law, including any rule of general applicability governing Federal grants to State and local governments for which the agency provides an opportunity for notice and public comment, except that the term "rule" does not include a rule of particular applicability relating to rates, wages, corporate or financial structures or reorganizations thereof, prices, facilities, appliances, services, or allowances therefor or to valuations, costs or accounting, or practices relating to such rates, wages, structures, prices, appliances, services, or allowances;

(3) the term "small business" has the same meaning as the term "small business concern" under section 3 of the Small Business Act, unless an agency, after consultation with the Office of Advocacy of the Small Business Administration and after opportunity for public comment, establishes one or more definitions of such term which are appropriate to the activities of the agency and publishes such definitions(s) in the Federal Register;

(4) the term "small organization" means any not-for-profit enterprise which is independently owned and operated and is not dominant in its field, unless an agency establishes, after opportunity for public comment, one or more definitions of such term which are appropriate to the activities of the agency and publishes such definition(s) in the Federal Register;

(5) the term "small governmental jurisdiction" means governments of cities, counties, towns, townships, villages, school districts, or special districts, with a population of less than fifty thousand, unless an agency establishes, after opportunity for public comment, one or more definitions of such term which are appropriate to the activities of the agency and which are based on such factors as location in rural or sparsely populated areas or limited revenues due to the population of such jurisdiction, and publishes definition(s) in the Federal Register; and

(6) the term "small entity" shall have the same meaning as the terms "small business," "small organization" and "small governmental jurisdiction" defined in paragraphs (3), (4) and (5) of this section.

(Added Pub. L. 96-354, Sept. 19, 1980, 94 Stat. 1165.)

Sec. 602. Regulatory Agenda.

(a) During the months of October and April of each year, each agency shall publish in the Federal Register a regulatory flexibility agenda which shall contain -

(1) a brief description of the subject area of any rule which the agency expects to proposed or promulgate which is likely to have a 
significant economic impact on a substantial number of small entities;

(2) a summary of the nature of any such rule under consideration for each subject area listed in the agenda pursuant to paragraph (1), the objectives and legal basis for the issuance of the rule, and an approximate schedule for completing action on any rule for which the agency has issued a general notice of proposed rulemaking, and

(3) the name and telephone number of an agency official knowledgeable concerning the items listed in paragraph (1).

(b) Each regulatory flexibility agenda shall be transmitted to the Chief Counsel for Advocacy of the Small Business Administration for comment, if any.

(c) Each agency shall endeavor to provide notice of each regulatory flexibility agenda to small entities or their representatives through direct notification or publication of the agenda in publications likely to be obtained by such small entities and shall invite comments upon each subject area on the agenda.

(d) Nothing in this section precludes an agency from considering or acting on any matter not included in a regulatory flexibility agenda, or requires an agency to consider or act on any matter listed in such agenda. (Added Pub. L. 96-354, Sept. 19, 1980, 94 Stat. 1166.)

\section{Sec. 603. Initial Regulatory Flexibility Analysis.}

(a) Whenever an agency is required by section 553 of this title, or any other law, to publish general notice of proposed rulemaking for any proposed rule, the agency shall prepare and make available for public comment an initial regulatory flexibility analysis. Such analysis shall describe the impact of the proposed rule on small entities. The initial regulatory flexibility analysis or a summary shall be published in the Federal Register at the time of the publication of general notice of proposed rulemaking for the rule. The agency shall transmit a copy of the initial regulatory flexibility analysis to the Chief Counsel for Advocacy of the Small Business Administration.

(b) Each initial regulatory flexibility analysis required under this section shall contain -

(1) a description of the reasons why action by the agency is being considered;

(2) a succinct statement of the objectives, and legal basis for, the proposed rule;

(3) a description of and, where feasible, an estimate of the number of small entities to which the proposed rule will apply;

(4) a description of the projected reporting, recordkeeping and other compliance requirements of the proposed rule, including an estimate of the classes of small entities which will be subject to the requirement and the type of professional skills necessary for preparation of the report or record;

(5) an identification to the extent practicable, of all relevant Federal rules which may duplicate, overlap or conflict with the proposed rule.

(c) Each initial regulatory flexibility analysis shall also contain a description of any significant alternatives to the proposed rule which ac- 
complish the stated objectives of applicable statutes and which minimize any significant economic impact of the proposed rule on small entities. Consistent with the stated objectives of applicable statutes, the analysis shall discuss significant alternatives such as-

(1) the establishment of differing compliance or reporting requirements or timetables that take into account the resources available to small entities;

(2) the clarification, consolidation, or simplification of compliance and reporting requirements under the rule for such small entities;

(3) the use of performance rather than design standards; and

(4) an exemption from coverage of the rule, or any part thereof, for such small entities.

(Added Pub. L. 96-354, Sept. 19, 1980, 94 Stat. 1166.)

Sec. 604. Final Regulatory Flexibility Analysis.

(a) When an agency promulgates a final rule under section 553 of this title, after being required by that section or any other law to publish a general notice of proposed rulemaking, the agency shall prepare a final regulatory flexibility analysis. Each final regulatory flexibility analysis shall contain-

(1) a succinct statement of the need for, and the objectives of the rule;

(2) a summary of the issues raised by the public comments in response to the initial regulatory flexibility analysis, a summary of the assessment of the agency of such issues, and a statement of any changes made in the proposed rule as a result of such comments; and

(3) a description of each of the significant alternatives to the rule consistent with the stated objectives of applicable statutes and designed to minimize any significant economic impact of the rule on small entities which was considered by the agency, and a statement of the reasons why each one of such alternatives was rejected.

(b) The agency shall make copies of the final regulatory flexibility analysis available to members of the public and shall publish in the Federal Register at the time of publication of the final rule under section 553 of this title a statement describing how the public may obtain such copies. (Added Pub. L. 96-354, Sept. 19, 1980, 94 Stat. 1167.)

Sec. 605. Avoidance of Duplicative or Unnecessary Analyses.

(a) Any Federal agency may perform the analyses required by sections 602,603 , and 604 of this title in conjunction with or as a part of any other agenda or analysis required by any other law if such other analysis satisfies the provisions of such sections.

(b) Sections 603 and 604 of this title shall not apply to any proposed or final rule if the head of the agency certifies that the rule will not, if promulgated, have a significant economic impact on a substantial number of small entities. If the head of the agency makes a certification under the preceding sentence, the agency shall publish such certification in the Federal Register, at the time of publication of general notice of proposed rulemaking for the rule or at the time of publication of the final rule, along with a succinct statement explaining the reasons for such cer- 
tification, and provide such certification and statement to the Chief Counsel for Advocacy of the Small business Administration.

(c) In order to avoid duplicative action, an agency may consider a series of closely related rules as one rule for the purpose of sections 602,603 , and 610 of this title. (Added Pub. L. 96-354, Sept. 19, 1980,94 Stat. 1167.)

\section{Sec. 606. Effect on Other Law.}

The requirements of sections 603 and 604 of this title do not alter in any manner standards otherwise applicable by law to agency action. (Added Pub. L. 96-354, Sept. 19, 1980, 94 Stat. 1168.)

\section{Sec. 607. Preparation of Analyses.}

In complying with the provisions of sections 603 and 604 of this title, an agency may provide either a quantifiable or numerical description of the effects of a proposed rule or alternatives to the proposed rule, or more general descriptive statements if quantification is not practicable or reliable. (Added Pub. L. 96-354, Sept. 19, 1980, 94 Stat. 1168.)

Sec. 608. Procedure for Waiver or Delay of Completion.

(a) An agency head may waive or delay the completion of some or all of the requirements of section 603 of this title by publishing in the Federal Register, not later than the date of publication of the final rule, a written finding, with reasons therefor, that the final rule is being promulgated in response to an emergency that makes compliance or timely compliance with the provisions of section 603 of this title impracticable.

(b) Except as provided in section 605(b), an agency head may not waive the requirements of section 604 of this title. An agency head may delay the completion of the requirements of section 604 of this title for a period of not more than one hundred and eighty days after the date of publication in the Federal Register of a final rule by publishing in the Federal Register, not later than such date of publication, a written finding, with reasons therefor, that the final rule is being promulgated to response to an emergency that makes timely compliance with the provisions of section 604 of this title impracticable. If the agency has not prepared a final regulatory analysis pursuant to section 604 of this title within one hundred and eighty days from the date of publication of the final rule, such rule shall lapse and have no effect. Such rule shall not be repromulgated until a final regulatory flexibility analysis has been completed by the agency. (Added Pub. L. 96-354, Sept. 19, 1980, 94 Stat. 1168.)

\section{Sec. 609. Procedures for Gathering Comments.}

When any rule is promulgated which will have a significant economic impact on a substantial number of small entities, the head of the agency promulgating the rule or the official of the agency with statutory responsibility for the promulgation of the rule shall assure that small entities have been given an opportunity to participate in the rulemaking for the rule through techniques such as-

(1) the inclusion in an advanced notice of proposed rulemaking, if issued, of a statement that the proposed rule may have a significant economic effect on a substantial number of small entities; 
(2) the publication of general notice of proposed rulemaking in publications likely to be obtained by small entities;

(3) the direct notification of interested small entities;

(4) the conduct of open conferences or public hearings concerning the rule for small entities; and

(5) the adoption or modification of agency procedural rules to reduce the cost or complexity of participation in the rulemaking by small entities. (Added Pub. L. 96-354, Sept. 19, 1980, 94 Stat. 1168.)

\section{Sec. 610. Periodic Review of Rules.}

(a) Within one hundred and eighty days after the effective date of this chapter, each agency shall publish in the Federal Register a plan for the periodic review of the rules issued by the agency which have or will have a significant economic impact upon a substantial number of small entities. Such plan may be amended by the agency at any time by publishing the revision in the Federal Register. The purpose of the review shall be to determine whether such rules should be continued without change, or should be amended or rescinded, consistent with the stated objectives of applicable statutes, to minimize any significant economic impact of the rules upon a substantial number of such small entities. The plan shall provide for the review of all such agency rules existing on the effective date of this chapter within ten years of that date and for the review of such rules adopted after the effective date of this chapter within ten years of the publication of such rules as the final rule. If the head of the agency determines that completion of the review of existing rules is not feasible by the established date, he shall so certify in a statement pub- . lished in the Federal Register and may extend the completion date by one year at a time for a total of not more than five years.

(b) In reviewing rules to minimize any significant economic impact of the rule on a substantial number of small entities in a manner consistent with the stated objectives of applicable statutes, the agency shall consider the following factors-

(1) the continued need for the rule;

(2) the nature of complaints or comments received concerning the rule from the public;

(3) the complexity of the rule;

(4) the extent to which the rule overlaps, duplicates or conflicts with other federal rules, and, to the extent feasible, with State and local governmental rules; and

(5) the length of time since the rule has been evaluated or the degree to which technology, economic conditions, or other factors have changed in the area affected by the rule.

(c) Each year, each agency shall publish in the Federal Register a list of the rules which have a significant economic impact on a substantial number of small entities, which are to be reviewed pursuant to this section during the succeeding twelve months. The list shall include a brief description of each rule and the need for and legal basis of such rule and shall invite public comment upon the rule. (Added Pub. L. 96-354, Sept. 19, 1980, 94 Stat. 1168.) 
Sec. 611. Judicial Review.

(a) Except as otherwise provided in subsection (b), any determination by an agency concerning the applicability of any of the provisions of this chapter to any action of the agency shall not be subject to judicial review.

(b) Any regulatory flexibility analysis prepared under sections 603 and 604 of this title and the compliance or noncompliance of the agency with the provisions of this chapter shall not be subject to judicial review. When an action for judicial review of a rule is instituted, any regulatory flexibility analysis for such rule shall constitute part of the whole record of agency action in connection with the review.

(c) Nothing in this section bars judicial review of any other impact statement or similar analysis required by any other law if judicial review of such statement or analysis is otherwise provided by law. (Added Pub. L. 96-354, Sept. 19, 1980, 94 Stat. 1169.)

Sec. 612. Reports and Intervention Rights.

(a) The Chief Counsel for Advocacy of the Small Business Administration shall monitor agency compliance with this chapter and shall report at least annually thereon to the President and to the Committees on the Judiciary of the Senate and House of Representatives, the Select Committee on Small Business of the Senate, and the Committee on Small Business of the House of Representatives.

(b) The Chief Counsel for Advocacy of the Small Business Administration is authorized to appear as amicus curiae in any action brought in a court of the United States to review a rule. In any such action, the Chief counsel is authorized to present his views with respect to the effect of the rule on small entities.

(c) A court of the United States shall grant the application of the Chief Counsel for Advocacy of the Small Business Administration to appear in any such action for the purposes described in subsection (b). (Added Pub. L. 96-354, Sept. 19, 1980, 94 Stat. 1170.) 


\section{CHAPTER 7 - JUDICIAL REVIEW}

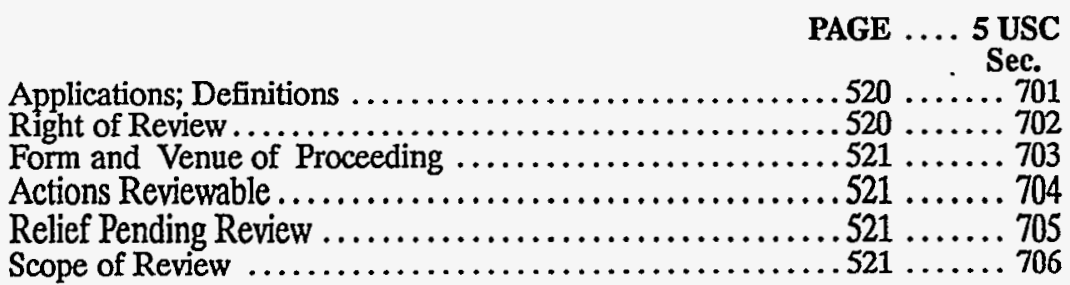




\section{CHAPTER 7-JUDICIAL REVIEW}

Sec. 701. Application; Definitions.

(a) This chapter applies, according to the provisions thereof, except to the extent that-

(1) statutes preclude judicial review; or

(2) agency action is committed to agency discretion by law.

(b) For the purpose of this chapter-

(1) "agency" means each authority of the Government of the United States, whether or not it is within or subject to review by another agency, but does not include-

(A) the Congress;

(B) the courts of the United States;

(C) the government of the territories or possessions of the United States;

(D) the government of the District of Columbia;

(E) agencies composed of representatives of the parties or of representatives of organizations of the parties to the disputes determined by them;

(F) courts martial and military commissions;

(G) military authority exercised in the field in time of war or in occupied territory; or

$(\mathrm{H})$ functions conferred by sections $1738,1739,1743$, and 1744 of title 12; chapter 2 of title 41 ; subchapter II of chapter 471 of title 49 ; or sections $11884,1891-1902$, and former section 1641(b)(2), of title 50, appendix; and

(2) "person", "rule", "order", "license", "sanction", "relief", and "agency action" have the meanings given them by section 551 of this title.

(Pub. L. 89-554, Sept. 6, 1966, 80 Stat. 392.)

Sec. 702. Right of Review.

A person suffering legal wrong because of agency action, or adversely affected or aggrieved by agency action within the meaning of a relevant statute, is entitled to judicial review thereof. An action in a court of the United States seeking relief other than money damages and stating a claim that an agency or an officer or employee thereof acted or failed to act in an official capacity or under color of legal authority shall not be dismissed nor relief therein be denied on the ground that it is against the United States or that the United States is an indispensable party. The United States may be named as a defendant in any such action, and judgment or decree may be entered against the United States: Provided, That any mandatory or injunctive decree shall specify the Federal officer or officers (by name or by title), and their successors in office, personally responsible for compliance. Nothing herein (1) affects other limitations on judicial review or the power or duty of the court to dismiss any action or deny relief on any other appropriate legal or equitable ground; or (2) confers authority to grant relief if any other statute that grants consent to suit expressly or impliedly forbids the relief which is sought.

'Public Law 103-272(108Stat. 1373 struck "sections 1622" andadded "subchapter II of chapter 471 of title 49; or sections." 
(Pub. L. 89-554, Sept. 6, 1966, 80 stat. 392; amended Pub. L. 94-574, Oct. 21, 1976, 90 stat. 2721.)

Sec. 703. Form and Venue of Proceeding.

The form of proceeding for judicial review is the special statutory review proceeding relevant to the subject matter in a court-specified by statute or, in the absence or inadequacy thereof, any applicable form of legal action, including actions for declaratory judgments or writs of prohibitory or mandatory injunction or habeas corpus, in a court of competent jurisdiction. If no special statutory review proceeding is applicable, the action for judicial review may be brought against the United States, the agency by its official title, or the appropriate officer. Except to the extent that prior, adequate, and exclusive opportunity for judicial review is provided by law, agency action is subject to judicial review in civil or criminal proceedings for judicial enforcement. (Pub. L. 89-554, Sept. 6, 1966, 80 stat. 392; amended Pub. L. 94-574, Oct. 21, 1976, 90 Stat. 2721.)

Sec. 704. Actions Reviewable.

Agency action made reviewable by statute and final agency action for which there is no other adequate remedy in a court are subject to judicial review. A preliminary, procedural, or intermediate agency action or ruling not directly reviewable is subject to review on the review of the final agency action. Except as otherwise expressly required by statute, agency action otherwise final is final for the purposes of this section whether or not there has been presented or determined an application for a declaratory order, for any form of reconsideration, or, unless the agency otherwise requires by rule and provides that the action meanwhile is inoperative, for an appeal to superior agency authority. (Pub. L. 89-554, Sept. 6, 1966, 80 stat. 392.)

Sec. 705. Relief Pending Review.

When an agency finds that justice so requires, it may postpone the effective date of action taken by it, pending judicial review. On such conditions as may be required and to the extent necessary to prevent irreparable injury, the reviewing court including the court to which a case may be taken on appeal from or on application for certiorari or other writ to a reviewing court, may issue all necessary and appropriate process to postpone the effective date of an agency action or to preserve status or rights pending conclusion of the review proceedings. (Pub. L. 89-554, Sept. 6, 1966, 80 stat. 393.)

Sec. 706. Scope of Review.

To the extent necessary to decision and when presented, the reviewing court shall decide all relevant questions of law, interpret constitutional and statutory provisions, and determine the meaning or applicability of the terms of an agency action. The reviewing court shall-

(1) compel agency action unlawfully withheld or unreasonably delayed; and

(2) hold unlawful and set aside agency action, findings, and conclusions found to be -

(A) arbitrary, capricious, and abuse of discretion, or otherwise not in accordance with law; 
(B) contrary to constitutional right, power, privilege, or immunity;

(C) in excess of statutory jurisdiction, authority, or limitations, or short of statutory right;

(D) without observance of procedure required by law;

(E) unsupported by substantial evidence in a case subject to sections 556 and 557 of this title or otherwise reviewed on the record of an agency hearing provided by statute; or

(F) unwarranted by the facts to the extent that the facts are subject to trial de novo by the reviewing court.

In making the foregoing determinations, the court shall review the whole record or those parts of it cited by a party, and due account shall be taken of the rule of prejudicial error. (Pub. L. 89-554, Sept. 6, 1966, 80 Stat. 393.) 


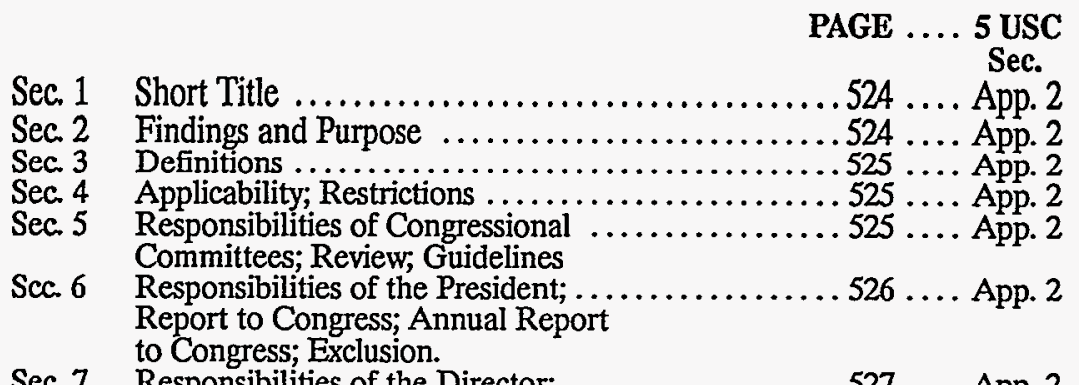

Sec. 7 Responsibilities of the Director;

Office of Management and Budget;

Committee Management Secretariat,

Establishment; Review; Recommendations

to President and Congress; Agency

Cooperation; Performance Guidelines;

Uniform Pay Guidelines; Travel Expenses;

Expense Recommendations.

Sec. 8 Responsibilities of Agency Heads; $\ldots \ldots \ldots \ldots \ldots \ldots 528 \ldots$... App. 2

Advisory Committee Management

Officer, Designation.

Sec. 9 Establishment and Purpose of

529 .... App. 2

Advisory Committees; Publication in

Federal Register;Charter; Filing; Contents;

Sec. 10 Advisory Committee Procedures

529 .... App. 2

Meetings; Notice; Publication in

Federal Register; Regulations; Minutes;

Certification; Annual Report; Federal

Officer or Employee, Attendance.

Sec. 11 Availability of Transcripts; "agency proceeding". ....530 ... App. 2

Sec. 12 Fiscal and Administrative Provisions; record-

keeping; Audit; Agency Support Services.

530 .... App. 2

Sec. 13 Responsibilities of Library of Congress;

reports and background papers; Depository. ....... 530 ... App. 2

Sec. 14 Termination of Advisory Committees; Renewal;

Sec. 15 Effective Date.

$531 \ldots$ App. 2 


\section{TITLE 5 USC-APPENDIX 2}

\section{FEDERAL ADVISORY COMMITTEE ACT}

\section{Public Law 92-463}

Sec.

1. Short title.

2. Findings and purpose.

3. Definitions.

4. Applicability; restrictions.

5. Responsibilities of Congressional committees; review; guidelines.

6. Responsibilities of the President; report to Congress; annual report to Congress; exclusion.

7. Responsibilities of the Director, Office of Management and Budget; Committee Management Secretariat, establishment; review; recommendations to President and Congress; agency cooperation; performance guidelines; uniform pay guidelines; travel expenses; expense recommendations.

8. Responsibilities of agency heads; Advisory Committee Management Officer, designation.
Sec.

9. Establishment and purpose of advisory committees; publication in Federal Register; charter, filing; contents; copy.

10. Advisory committee procedures; meetings; notice, publication in Federal Register; regulations; minutes; certification; annual report; Federal officer or employee, attendance.

11. Availability of transcripts; "agency proceeding".

12. Fiscal and administrative provisions; record-keeping; audit; agency support services.

13. Responsibilities of Library of Congress; reports and background papers; depository.

14. Termination of advisory committees; renewal; continuation.

15. Effective date.

Sec. 1. Short Title.

This Act may be cited as the "Federal Advisory Committee Act".

Sec. 2. Findings and Purpose.

(a) The Congress finds that there are numerous committees, boards, commissions, councils, and similar groups which have been established to advise officers and agencies in the executive branch of the Federal Government and that they are frequently a useful and beneficial means of furnishing expert advice, ideas, and diverse opinions to the Federal Government.

(b) The Congress further finds and declares that-

(1) the need for many existing advisory committees has not been adequately reviewed;

(2) new advisory committees should be established only when they are determined to be essential and their number should be kept to the minimum necessary;

(3) advisory committees should be terminated when they are no longer carrying out the purposes for which they were established; 
(4) standards and uniform procedures should govern the establishment, operation, administration, and duration of advisory committees;

(5) the Congress and the public should be kept informed with respect to the number, purpose, membership, activities, and cost of advisory committees; and

(6) the function of advisory committees should be advisory only, and that all matters under their consideration should be determined, in accordance with law, by the official, agency, or officer involved.

Sec. 3. Definitions.

For the purpose of this Act-

(1) The term "Director" means the Director of the Office of Management and Budget.

(2) The term "advisory committee" means any committee, board, commission, council, conference, panel, task force, or other similar group, or any subcommittee or other subgroup thereof (hereafter in this paragraph referred to as "committee"), which is-

(A) established by statute or reorganization plan, or

(B) established or utilized by the President, or

(C) established or utilized by one or more agencies, in the interest of obtaining advice or recommendations for the President or one or more agencies or officers of the Federal Government, except that such term excludes (i) the Advisory Commission on Intergovernmental Relations, (ii) the Commission on Government Procurement, and (iii) any committee which is composed wholly of full-time officers or employees of the Federal Government.

(3) The term "agency" has the same meaning as in section 551 (1) of Title 5.

(4) The term "Presidential advisory committee" means an advisory committee which advises the President.

Sec. 4. Applicability; Restrictions.

(a) The provisions of this Act or of any rule, order, or regulation promulgated under this Act shall apply to each advisory committee except to the extent that any Act of Congress establishing any such advisory committee specifically provides otherwise.

(b) Nothing in this Act shall be construed to apply to any advisory committee established or utilized by-

(1) the Central Intelligence Agency; or

(2) The Federal Reserve System.

(c) Nothing in this Act shall be construed to apply to any local civic group whose primary function is that of rendering a public service with respect to a Federal program, or any State or local committee, council, board, commission, or similar group established to advise or make recommendations to State or local officials or agencies.

Sec. 5. Responsibilities of Congressional Committees; Review; Guidelines. 
(a) In the exercise of its legislative review function, each standing committee of the Senate and the House of Representatives shall make a continuing review of the activities of each advisory committee under its jurisdiction to determine whether such advisory committee should be abolished or merged with any other advisory committee, whether the responsibilities of such advisory committee should be revised, and whether such advisory committee performs a necessary function not already being performed. Each such standing committee shall take appropriate action to obtain the enactment of legislation necessary to carry out the purpose of this subsection.

(b) In considering legislation establishing, or authorizing the establishment of any advisory committee, each standing committee of the Senate and of the House of Representatives shall determine, and report such determination to the Senate or to the House of Representatives, as the case may be, whether the functions of the proposed advisory committee are being or could be performed by one or more agencies or by an advisory committee already in existence, or by enlarging the mandate of an existing advisory committee. Any such legislation shall-

(1) contain a clearly defined purpose for the advisory committee;

(2) require the membership of the advisory committee to be fairly balanced in terms of the points of view represented and the functions to be performed by the advisory committee;

(3) contain appropriate provisions to assure that the advice and recommendations of the advisory committee will not be inappropriately influenced by the appointing authority or by any special interest, but will instead be the result of the advisory committee's independent judgment;

(4) contain provisions dealing with authorization of appropriations, the date for submission of reports (if any), the duration of the advisory committee, and the publication of reports and other materials, to the extent that the standing committee determines the provisions of section 10 of this Act to be inadequate; and

(5) contain provisions which will assure that the advisory committee will have adequate staff (either supplied by an agency or employed by it), will be provided adequate quarters, and will have funds available to meet its other necessary expenses.

(c) To the extent they are applicable, the guidelines set out in subsection (b) of this section shall be followed by the President, agency heads, or other Federal officials in creating an advisory committee.

Sec. 6. Responsibilities of the President; Report to Congress; Annual Report to Congress; Exclusion.

(a) The President may delegate responsibility for evaluating and taking action, where appropriate, with respect to all public recommendations made to him by Presidential advisory committees.

(b) Within one year after a Presidential advisory committee has submitted a public report to the President, the President or his delegate shall make a report to the Congress stating either his proposals for action or his reasons for inaction, with respect to the recommendations contained in the public report. 
(c) The President shall, not later than March 31 of each calendaryear (after the year in which this Act is enacted), make an annual report to the Congress on the activities, status, and changes in the composition of advisory committees in existence during the preceding calendar year. The report shall contain the name of every advisory committee, the date of and authority for its creation, its termination date or the date it is to make a report, its functions, a reference to the reports it has submitted, a statement of whether it is an ad hoc or continuing body, the dates of its meetings, the names and occupations of its current members, and the total estimated annual cost to the United States to fund, service, supply, and maintain such committee. Such report shall include a list of those advisory committees abolished by the President, and in the case of advisory committees established by statute, a list of those advisory committees which the President recommends be abolished together with his reasons therefor. The President shall exclude from this report any information which, in his judgment, should be withheld for reasons of national security, and he shall include in such report a statement that such information is excluded.

Sec. 7. Responsibilities of the Director, Office of Management and Budget; Committee Management Secretariat, Establishment; Review; Recommendations to President and Congress; Agency Cooperation; Performance Guidelines; Uniform Pay Guidelines; Travel Expenses; Expense Recommendations.

(a) The Director shall establish and maintain within the Office of Management and Budget a Committee Management Secretariat, which shall be responsible for all matters relating to advisory committees.

(b) The Director shall, immediately after October 6, 1972, institute a comprehensive review of the activities and responsibilities of each advisory committee to determine-

(1) whether such committee is carrying out its purpose;

(2) whether, consistent with the provisions of applicable statutes, the responsibilities assigned to it should be revised;

(3) whether it should be merged with other advisory committees; or

(4) whether it should be abolished.

The Director may from time to time request such information as he deems necessary to carry out his functions under this subsection. Upon the completion of the Director's review he shall make recommendations to the President and to either the agency head or the Congress with respect to action he believes should be taken. Thereafter, the Director shall carry out a similar review annually. Agency heads shall cooperate with the Director in making the reviews required by this subsection.

(c) The Director shall prescribe administrative guidelines and management controls applicable to advisory committees, and to the maximum extent feasible, provide advice, assistance, and guidance to advisory committees to improve their performance. In carrying out his functions under this subsection, the Director shall consider the recommendations of each agency head with respect to means of improving the performance of advisory committees whose duties are related to such agency. 
(d)(1) The Director, after study and consultation with the Civil Service Commission, shall establish guidelines with respect to uniform fair rates of pay for comparable services of members, staffs, and consultants of advisory committees in a manner which gives appropriate recognition to the responsibilities and qualifications required and other relevant factors. Such regulations shall provide that -

(A) no member of any advisory committee or of the staff of any advisory committee shall receive compensation at a rate in excess of the rate specified for GS-18 of the General Schedule under section 5332 of Title 5 ;

(B) such members, while engaged in the performance of their duties away from their homes or regular places of business, may be allowed travel expenses, including per diem in lieu of subsistence, as authorized by section 5703 of Title 5 , for persons employed intermittently in the Government service; and

(C) such members-

(i) who are blind or deaf or who otherwise qualify as handicapped individuals (within the meaning of section 501 of the Rehabilitation Act of 1973 (29 U.S.C. 794)), and

(ii) who do not otherwise qualify for assistance under section 3102 of Title 5 , by reason of being an employee of an agency (within the meaning of section 3102 (a)(1) of such Title 5),

(2) Nothing in this subsection shall prevent-

(A) an individual who (without regard to his service with an advisory committee) is a full-time employee of the United States; or

(B) an individual who immediately before his service with an advisory committee was such an employee,

from receiving compensation at the rate at which he otherwise would be compensated (or was compensated) as a full-time employee of the United States.

(e) The Director shall include in budget recommendations a summary of the amounts he deems necessary for the expenses of advisory committees, including the expenses for publication of reports where appropriate.

As amended Pub. L. 96-523, §2, Dec. 12, 1980, 94 Stat. 3040.

References in Text. Section 501 of the Rehabilitation Act of 1973, referred to in subsec. (d)(1)(C)(i), is classified to section 791 of Title 29, Labor, rather than to section 794 of Title 29 as shown in text.

1980.Amendment. Subsec. (d)(1). Pub. L. 96-523 added subpar. (C).

Effective Date of 1980 Amendment. Amendment by Pub. L. 96-523 effective sixty days after Dec. 12, 1980, see section 3 of Pub. L. 96-523, set out as a note under section 3102 of this title.

Legislative History. For legislative history and purpose of Pub. L. 96-523, see 1980 U.S. Code Cong. and Adm. News, p. 6530.

Sec. 8. Responsibilities of Agency Heads; Advisory Committee Management Officer, Designation.

(a) Each agency head shall establish uniform administrative guidelines and management controls for advisory committees established by that agency, which shall be consistent with directives of the Director un- 
der section 7 and section 10. Each agency shall maintain systematic information on the nature, functions, and operations of each advisory committee within its jurisdiction.

(b) The head of each agency which has an advisory committee shall designate an Advisory Committee Management Officer who shall-

(1) exercise control and supervision over the establishment, procedures, and accomplishments of advisory committees established by that agency;

(2) assemble and maintain the reports, records, and other papers of any such committee during its existence; and

(3) carry out, on behalf of that agency, the provisions of section 552 of Title 5, with respect to such reports, records, and other papers.

Sec. 9. Establishment and Purpose of Advisory Committees; Publication in Federal Register; Charter; Filing; Contents; Copy.

(a) No advisory committee shall be established unless such establishment is -

(1) specifically authorized by statute or by the President; or

(2) determined as a matter of formal record, by the head of the agency involved after consultation with the Director, with timely notice published in the Federal Register, to be in the public interest in connection with the performance of duties imposed on that agency by law.

Sec. 10. Advisory Committee Procedures; Meetings; Notice, Publication in Federal Register; Regulations; Minutes; Certification; Annual Report; Federal Officer or Employee; Attendance.

(a)(1) Each advisory committee meeting shall be open to the public.

(2) Except when the President determines otherwise for reasons of national security, timely notice of each such meeting shall be published in the Federal Register, and the Director shall prescribe regulations to provide for other types of public notice to insure that all interested persons are notified of such meeting prior thereto.

(3) Interested persons shall be permitted to attend, appear before, or file statements with any advisory committee, subject to such reasonable rules or regulations as the Director may prescribe.

(b) Subject to section 552 of Title 5 , the records, reports, transcripts, minutes, appendixes, working papers, drafts, studies, agenda, or other documents which were made available to or prepared for or by each advisory committee shall be available for public inspection and copying at a single location in the offices of the advisory committee or the agency to which the advisory committee reports until the advisory committee ceases to exist.

(c) Detailed minutes of each meeting of each advisory committee shall be kept and shall contain a record of the persons present, a complete and accurate description of matters discussed and conclusions reached, and copies of all reports received, issued, or approved by the advisory committee. The accuracy of all minutes shall be certified to by the chairman of the advisory committee.

(d) Subsections (a)(1) and (a)(3) of this section shall not apply to any portion of an advisory committee meeting where the President, or the 
head of the agency to which the advisory committee reports, determines that such portion of such meeting may be closed to the public in accordance with subsection (c) of section $552 \mathrm{~b}$ of Title 5. Any such determination shall be in writing and shall contain the reasons for such determination. If such a determination is made, the advisory committee shall issue a report at least annually setting forth a summary of its activities and such related matters as would be informative to the public consistent with the policy of section 552(b) of Title 5 .

(e) There shall be designated an officer or employee of the Federal Government to chair or attend each meeting of each advisory committee. The officer or employee or designated is authorized, whenever he determines it to be in the public interest, to adjourn any such meeting. No advisory committee shall conduct any meeting in the absence of that officer or employee.

(f) Advisory committees shall not hold any meetings except at the call of, or with the advance approval of, a designated officer or employee of the Federal Government, and in the case of advisory committees (other than Presidential advisory committees) with an agenda approved by such officer or employee.

As amended Pub. L. 94-409 §5(c), Sept. 13, 1976, 90 Stat. 1247.

Sec. 11. Availability of Transcripts: "Agency Proceeding"

(a) Except where prohibited by contractual agreements entered into prior to the effective date of this Act, agencies and advisory committees shall make available to any person, at actual cost of duplication, copies of transcripts of agency proceedings or advisory committee meetings.

(b) As used in this section "agency proceeding" means any proceeding as defined in section 551(12) of Title 5 .

Sec. 12. Fiscal and Administrative Provisions; Recordkeeping; Audit; Agency Support Services.

(a) Each agency shall keep records as will fully disclose the disposition of any funds which may be at the disposal of its advisory committees and the nature and extent of their activities. The General Services Administration, or such other agency as the President may designate, shall maintain financial records with respect to Presidential advisory committees. The Comptroller General of the United States, or any of his authorized representatives, shall have access, for the purpose of audit and examination, to any such records.

(b) Each agency shall be responsible for providing support services for each advisory committee established by or reporting to it unless the establishing authority provides otherwise. Where any such advisory committee reports to more than one agency, only one agency shall be responsible for support services at any one time. In the case of Presidential advisory committees, such services may be provided by the General Services Administration.

Sec. 13. Responsibilities of Library of Congress; Reports and Background Papers; Depository.

Subject to section 552 of Title 5, the Director shall provide for the filing with the Library of Congress of at least eight copies of each report made by every advisory committee and, where appropriate, background 
papers prepared by consultants. The Librarian of Congress shall establish a depository for such reports and papers where they shall be available to public inspection and use.

Sec. 14. Termination of Advisory Committees; Renewal; Continuation.

(a)(1) Each advisory committee which is in existence on the effective date of this Act shall terminate not later than the expiration of the twoyear period following such effective date unless-

(A) in the case of an advisory committee established by the President or an officer of the Federal Government, such advisory committee is renewed by the President or that officer by appropriate action prior to the expiration of such two-year period; or

(B) in the case of an advisory committee established by an Act of Congress, its duration is otherwise provided for by law.

(2) Each advisory committee established after such effectivedate shall terminate not later than the expiration of the two-yearperiod beginning on the date of its establishment unless-

(A) in the case of an advisory committee established by the President or an officer of the Federal Government such advisory committee is renewed by the President or such officer by appropriate action prior to the end of such period; or

(B) in the case of an advisory committee established by an Act of Congress, its duration is otherwise provided for by law.

(b)(1) Upon the renewal of any advisory committee, such advisory committee shall file a charter in accordance with section 9(c).

(2) Any advisory committee established by an Act of Congress shall file a charter in accordance with such section upon the expiration of each successive two-year period following the date of enactment of the Act establishing such advisory committee.

(3) No advisory committee required under this subsection to file a charter shall take any action (other than preparation and filing of such charter) prior to the date on which such charter is filed.

(c) Any advisory committee which is renewed by the President or any officer of the Federal Government may be continued only for successive two-year periods by appropriate action taken by the President or such officer prior to the date on which such advisory committee would otherwise terminate.

References in Text. Effective date of this Act, referred to in subsec. (a)(1), as meaning effective upon expiration of ninety days following enactment of Pub. L. 92-463 on Oct. 6, 1972, see section 15 of Pub. L. 92-463.

Sec. 15. Effective Date.

Except as provided in section 7(b), this Act shall become effective upon the expiration of ninety days following October 6, 1972. 


\begin{tabular}{|c|c|}
\hline $\begin{array}{l}\text { NAC FORM } 335 \\
(2-69) \text { U.S. NUCLEAR REGULATORY COMNISSTON } \\
\text { NFCM } 1102, \\
3201.3202\end{array}$ & $\begin{array}{l}\text { 1. REPOAT NUMBEBA } \\
\text { (Asslgnod by NRC, Add Vol. } \\
\text { Supp. Rev.; and Addendum Num- } \\
\text { bers, it any.) } \\
\text { NUREG-0980 } \\
\text { Vol. } 1 \text {, No. } 3\end{array}$ \\
\hline \multirow{3}{*}{$\begin{array}{l}\text { 2. TITLE AND SUBTTIE } \\
\text { Nuclear Regulatory Legislation } \\
\text { 103d Congress }\end{array}$} & 3. DATE REPOAT PURUSKED \\
\hline & \begin{tabular}{c|r} 
MONTH & YEAR \\
August & 1995
\end{tabular} \\
\hline & 4. FIN OR GRANT NUMBER \\
\hline 5. AUTHOR(S) & $\begin{array}{l}\text { 6. TrPE OF REPORT } \\
\text { Compilation of Nuclear } \\
\text { Legislation }\end{array}$ \\
\hline & $\begin{array}{l}\text { 7. PERIOD COVEREO (inclusiva Dates) } \\
\text { Through the } 103 \mathrm{~d} \\
\text { Congress; } 2 \mathrm{~d} \text { Session }\end{array}$ \\
\hline \multicolumn{2}{|c|}{$\begin{array}{l}\text { 8. PERFORMANG ORGMHZATON - NWME AND ADDRESS (II NRC, provide Division, Office or Region, U.S. Nuclear Regulatory Commission, and } \\
\text { maling addross; if contractor, provido name and mailing address.) }\end{array}$} \\
\hline \multicolumn{2}{|l|}{$\begin{array}{l}\text { Office of the General Counsel } \\
\text { U.S. Nuclear Regulatory Commission } \\
\text { Washington, D.C. 20555-0001 }\end{array}$} \\
\hline \multicolumn{2}{|c|}{$\begin{array}{l}\text { 9. SPONSOAING OAGANIZATION - NAME AND ADDRESS (It NRC, type "Same as above"; If contractor, provido NRC Divislon, Offico or Reglon. } \\
\text { U.s. Nuclear Regulatory Commission, and malling address.) } \\
\text { Same as } 8 \text {. above }\end{array}$} \\
\hline \multicolumn{2}{|l|}{ 10. SUPPLEMENTARY NOTES } \\
\hline \multicolumn{2}{|l|}{ 11. ABSTAACT (200 words or loss) } \\
\hline \multicolumn{2}{|c|}{$\begin{array}{l}\text { This document is a compilation of nuclear regulatory legislation and other relevant material } \\
\text { through the } 103 \mathrm{~d} \text { Congress, } 2 \mathrm{~d} \text { Session. This compilation has been prepared for use as a resource } \\
\text { document, which the NRC intends to update at the end of every Congress. }\end{array}$} \\
\hline \multicolumn{2}{|c|}{$\begin{array}{l}\text { The contents of NUREG-0980 include The Atomic Energy Act of 1954, as amended; Energy Re- } \\
\text { organization Act of 1974, as amended, Uranium Mill Tailings Radiation Control Act of 1978;Low- } \\
\text { Level Radioactive Waste Policy Act; Nuclear Waste Policy Act of 1982; and NRC Authorization } \\
\text { and Appropriations Acts. Other materials included are statutes and treaties on export licensing, } \\
\text { nuclear non-proliferation, and environmental protection. }\end{array}$} \\
\hline \multirow{4}{*}{$\begin{array}{l}\text { 12. KEY WORDS/DESCRIPTORS (LIst words or phrases that will assist resoarchers in locating the report.) } \\
\text { Nuclear Regulatory Legislation; Atomic Energy Act; Energy Reorganization } \\
\text { Act; Nuclear Waste Policy Act, NRC Authorization and Appropriations } \\
\text { Acts; Statutes, treaties, Agreements on Export Licensing and Nuclear Non- } \\
\text { Proliferation. }\end{array}$} & $\begin{array}{l}\text { 13. AVALABLTYY STATEMENT } \\
\text { Unlimited }\end{array}$ \\
\hline & $\begin{array}{l}\text { 14. SECUAMYY CLASSTICATON } \\
\text { (This Pase) } \\
\text { Unclassified } \\
\text { (This Report) }\end{array}$ \\
\hline & $\frac{\text { Unclassified }}{\text { 15. NUMBER OF PAGES }}$ \\
\hline & 16. PRICE \\
\hline
\end{tabular}

NAC FORM 335 (2-89) 